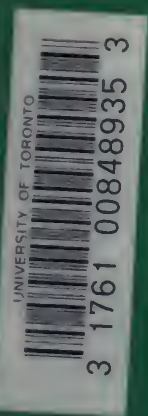








\title{
Syllabus der Pflanzenfamilien
}

\author{
Eine Übersicht
}

über das gesamte Pflanzensystem

mit Berücksichtigung der

\section{Medicinal- und Nutzpflanzen}

nebst einer Übersicht über die Florenreiche und Florengebiete der Erde

zum Gebrauch bei Vorlesungen und Studien

uber

specielle und medicinisch-pharmaceutische Botanik

von

Dr. Adolf Engler,

ord. Professor der Botanik und Director des botanischen Gartens und Museums zu Berlin

Dritte, umgearbeitete Auflage

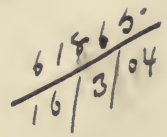

Berlin

Verlag von Gebrüder Borntraeger

SW 11 Dessauerstrasse 29 


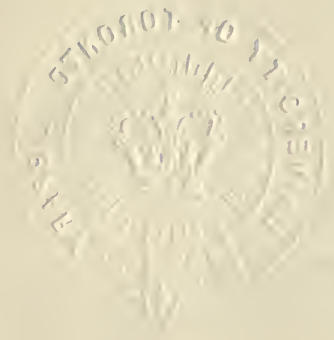

Alle Rechte, insbesondere das der Übersetzung, vom Verfasser und Verleger vorbehalten.

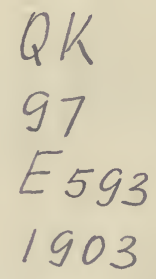




\section{Vor w o r t.}

Bei dem heutigen Umfang der speciellen Botanik, in welcher naturgemäss die niederen Pflanzen wegen ihrer Bedeutung für den Hanshalt der Natur und des Menschen die gleiche Beachtung wie die höheren Pflanzen beanspruchen, ist es in den Vorlesungen kaum noch möglich, alle Familien des Systems in gleicher Weise eingehend zu besprechen; es müssen notwendig, je nach der verfügbaren Zeit und je nach der Zusammensetzung des Auditoriums, einzelne Familien und Gruppen cursorisch, andere eingehender behandelt werden, ohne dass dabei der Zusammenhang des ganzen Pflanzensystems ausser Acht gelassen wird.

Dieser Zusammenhang der einzelnen Abteilungen des Pflanzenreiches unter einander wird aus einer knappen Übersicht, wie sie früher der Eichler'sche Syllabus bot, leicht ersichtlich, aber es macht sich auch oft ausserhalb der Vorlesungen, namentlich beim Studium im botanischen Garten und Laboratorium das Bedürfnis geltend, über die systematische Stellung einer Gattung Aufschluss zu erhalten; da ist es für den Studierenden oft genug wünschenswert, auch über die in der Heimat nicht vertretenen, in den Vorlesungen vielleicht nur kurz berührten Familien und Gruppen etwas mehr als eine knappe Blütenformel $\mathrm{zu}$ finden, eventuell auch einen Einblick in die Stufenfolge der in Betracht kommenden Familie zu gewinnen und die untersuchten Pflanzen in ihrem Zusammenhang mit dem ganzen Pflanzenreich zu erfassen.

Um den Studierenden von vornherein darauf aufmerksam zu machen, dass ein Teil des im Syllabus gebotenen Stoffes nur zum Zweck der vollständigen Ubersicht aufgeführt ist, ist das weniger Wichtige klein gedruckt. Für Specialvorlesungen dürften aber auch diese Abschnitte willkommen sein.

Dank der eifrigen Mitarbeiterschaft zahlreicher hervorragender Botaniker Deutschlands, Österreichs, der Schweiz, Dänemarks, Schwedens und Norwegens an dem umfassenden Werke „Die natürlichen Pflanzenfamilien * ist in den letzten Jahren die Systematik des Pflanzenreichs ganz erheblich gefördert worden; namentlich sind die Ansichten über die Verwandtschaftsverhältnisse der Familien unter einander und innerhalb derselben erheblich geklärt worden. Es ist daher selbstverständlich, dass der Syllabus in der Anordnung und der Charakterisierung der Familien sich, soviel es bei der knappen Fassung desselben möglich ist, an die in den "Pflanzenfamilien" 
gegebenen Bearbeitungen anschliesst. Bezüglich der in jenem Werk noch nicht vollständig behandelten Laubmoose bin ich Herrn Prof. Brotherus für Bearbeitung derselben zu grossem Dank verpflichtet. Die so lange Zeit aufrecht erhaltene Abteilung der Thallophyten habe ich jetzt als solche aufgelöst, indem ich die in derselben früher unterschiedenen Unterabteilungen $\mathrm{zu}$ Abteilungen erboben habe. Auch sonst habe ich neueren Forschungen möglichst Rechnung getragen und bin auch hier und da, wo es mir nötig erschien, von den »Pflanzenfamilien " abgewichen.

In der Anführung der Gattungen und Arten habe ich verschiedene Gesichtspunkte verfolgt. In erster Linie sollten alle wichtigen Medizinalund NutzpHanzen angeführt werden; die Namen derselben sind fett cursiv gedruckt; ich habe aber auch Namen von Gattungen, deren Arten morphologisch und biologisch interessant sind, in gleicher Weise hervorgehoben; denn ich möchte nicht die Auffassung unterstützen, als seien nur Medizinalund Nutzpflanzen von den Studierenden zu merken, die Kenntnis der nur wissenschaftlich interessanten Pflanzen aber überflüssig. Bei den niederen Pflanzen, für welche den meisten Studierenden Handbücher fehlen, habe ich auch Angaben über das Vorkommen beigefügt, ebenso bei denjenigen Angiospermen, welche nicht in Mitteleuropa vorkornmen; dagegen habe ich mit Rücksicht darauf, dass der Studierende in jeder Flora eines mitteleuropäischen Landes dic gewöhnlichen Arten citiert findet, von den in Mitteleuropa vorkommenden Gattungen die bemerkenswerten Arten nur dann angeführt, wenn dieselben Nutzpflanzen sind. In jeder guten Vorlesung über specielle Botanik wird ein grosser Teil der Demonstration gewidmet werden; ich hoffe, dass der Studierende durch den Syllabus in den Stand gresetzt wird, mehr Zeit auf das Analysieren und Zeichnen der ihm in die Hand gegebenen Objekte als auf das Nachschreiben zu verwenden, und dass er andererseits auch bei dem Studium im botanischen Garten, welches ganz besonders zu empfehlen ist, den Syllabus mit Erfolg benutzen wird.

Das System, welches ich dem Syllabus zu Grunde gelegt habe, ist im wesentlichen dasselbe, welches ich vor 16 Jahren in meinem »Führer durch den botanischen Garten zu Breslau * veröffentlicht habe; es weicht in einigen Punkten von dem des Eichler'schen Syllabus ab; es liegt aber auch ihm, sowie den Systemen von A. Braun und Eichler, das System von A. Brongniart zu Grunde. Dass früher als Unterabteilungen bezeichnete Gruppen zu Abteilungen erhoben wurden, hat in der bisherigen Reihenfolge nichts geändert, dagegen habe ich es vorgezogen, jetzt an die Phycomycetes zunächst die Hemiascomycetes und Ascomycetes anzuschliessen, dagegen die Basidiomycetes wegen der in neuerer Zeit von Iuël und Ruhland beobachteten Karyogamie an das Ende der Eumycetes zu setzen. Die Fungi imperfecti und Lichenes habe ich wegen ihrer starken verwandtschaftlichen Beziehungen zu den Ascomycetes zwischen diese und die Basidiomycetes eingescholen.

Der reifere Studierende wird danach streben, sich einen Einblick in die Stufenfolge der Pflanzenformen zu verschaffen; er soll das System nicht als eine von Autoritäten diktierte Einteilung des Pflanzenreiches hinnehmen, sondern er soll vor allem einsehen, warum die Pflanzen in der angegebenen 
Weise gruppiert werden. Aus diesem Grunde hahe ich in den schon der ersten Ausgabe des Syllabus beigegebenen »Principien der systematischen Anordnung « versucht, darzuthun, welche Gesichtspunkte für die Pflanzensystematik massgebend sind; und zwar habe ich hierbei vorzngsweise auf die Angiospermen Rücksicht genommen, da bei den viederen Pflanzen die systematische Anordnung an und für sich viel durchsichtiger ist und auch in allen botanischen Vorlesungen sowie in allen Handbüchern besprochen wird. Da die bisher separat verkäuflichen Abdrücke dieser "Principien etc. * schon seit einiger Zeit vergriffen sind, so habe ich dieselben in diese Ausgabe wieder aufgenommen und zugleich einige Paragraphen eingeschoben, die früher abgedruckten aber nur wenig verändert.

Für Erledigung der schwierigen Correctur sowie für Anfertigung des Registers bin ich Herrn Dr. Ruhland zu besonderem Dank verbunden.

Berlin, im Juli 1902.

A. Engler. 


\section{Principien der systematischen Anordnung.}

1. Das Streben der wissenschaftlichen Classification der Pflanzen oder der botanischen Systematik ist zunächst darauf gerichtet, die Pflanzenformen nach ihrer natürlichen Verwandtschaft in Gemeinschaften niederen und höheren Grades (in Arten, Gattungen, Familien, Familienreihen oder Ordnungen, Klassen, Abteilungen) zu gruppieren.

2. Die natürliche Verwandtschaft der pflanzlichen Organismen sowie der Organismen überhaupt ist unserer Erkenntniss in verschiedenem Grade zugänglich. Sie kann direkt und sicher erkannt werden durch Beobachtung der Entwicklungsgeschichte. In vielen Fällen zeigt schon die rohe Beobachtung von massenhaften Aussaaten solcher Pflanzen, bei denen eine Vermischung mit einer anderen Art ausgeschlossen war, dass äusserlich sehr verschiedene Formen denselben Ursprung haben können, so entstehen z. B. bei Aussaat von Nutzpflanzen und Gartenpflanzen neben Tausenden der Mutterpflanze ähnlichen Formen einige oder mehrere mit anders gestalteten Blättern, reicheren oder schwächer entwickelten Blütenständen, kleineren oder grösseren oder anders gefärbten Blüten. Noch offener tritt die Verwandtschaft äusserlich verschiedener Bildungen hervor, wenn auf demselben Stock verschieden gestaltete Blüten (Pelorien bei Scrophulariaceen und Labiaten, ungeschlechtliche Blüten neben geschlechtlichen, gefüllte neben ungefüllten) oder anders belaubte Sprosse (geschlitztblättrige neben ganzblättrigen bei unseren Laubbäumen, mit einfachen Blättern versehene neben solchen mit geteilten Blättern) auftreten und es gelingt, durch $\mathrm{Ab}$ leger oder Samen solche Abänderungen oder Variationen zu vermehren. Hierbei ist dann ferner zu beobachten, dass aus diesen Varietäten auch wieder die ursprünglichen Formen entstehen können, was als Rückschlag oder Atavismus bezeichnet wird. Noch auffallendere Erscheinungen, welche den Begriff der natürlichen Verwandtschaft illustrieren, zeigt die Entwicklungsgeschichte verschiedener niederer (Algen, Pilze) und höherer Pflanzen (Moose, Farne), bei denen aus verschiedenartigen Keimzellen dieselben Pflanzen wiederentstehen können und andererseits so verschiedene Generationen auftreten, dass man, bevor ihre Entwicklungsgeschichte bekannt war, sie als Vertreter verschiedener Gattungen oder noch höher stehender Pflanzensippen angesehen hat. Aus derartigen Beobachturgen und Betrachtungen ergiebt sich, dass in den äusserlich verschiedenen Keim. zellen derselben Pflanzen ein Teil der denselben zukommenden Eigenschaften bei gewissen Nachkommen in die Erscheinung tritt, bei anderen 
verborgen (latent) bleibt. Solche direkte Beobachtungen über natürliche Verwandtschaft lassen sich aber nur da machen, wo es sich um Sippen niederer Ordnung handelt, um Arten, Unterarten, Varietäten, Untervarietäten. Dagegen sind wir bei der Feststellung der Verwandtschaft höherer Sippen genötigt, auf indirektem Wege die natürliche Verwandtschaft zu ermitteln und dabei auch irrtümlichen Auffassungen ausgesetzt. Es hat die Erfahrung gelehrt, dass äusserlich oft sehr ähnliche Organismen nur eine geringe Verwandtschaft besitzen. Je weniger die äussere Gliederung eines Organismus vorgeschritten ist, eine desto grössere Beachtung muss seinem inneren Bau und den chemischen Eigenschaften seines Zellinhaltes zugewandt werden. So ist man zu der Erkenntnis gelangt, dass einzellige kugelige, also sehr ähnliche Organismen nicht bloss sehr verschiedenen Familien, sondern auch verschiedenen Klassen und Abteilungen angehören können. Vorhandensein oder Fehlen von Zellkernen, von Chromatophoren, die Fähigkeit, gewisse Elemente (Schwefel, Silicium) in grösserer Menge aufnehmen zu können, das Vorherrschen bestimmter Teilungsrichtungen sind Eigenschaften, welche bei diesen niederen Organismen besonders beachtet werden müssen. Thut man dies, so sieht man, dass durch solche herrschenden oder dominierenden Eigenschaften mit jenen äusserlich auf niederster Stufe (einzelne kugelige Zelle) stehenden. Pflanzen nicht selten andere in naher Beziehung stehen, welche eine weitergehende Gliederung und Arbeitsteilung zeigen. So gelangt man zur Feststellung von Verwandtschaftskreisen, deren systematischer Rang lediglich danach bestimmt wird, bis zu welchem Grade der Entwicklung ein durch gewisse Eigenschaften oder Dominanten charakterisierter Typus gelangen kann, welcher Progressionen er fähig ist. Wir erkennen hierbei, dass vielfach parallele Entwicklungen auftreten, und dass man sich hüten muss, die Parallelerscheinungen mit den eine Sippe charakterisierenden auf gleiche Stufe zu setzen. So wie man verschiedene Verwandtschaftsreihen, von einzelligen Organismen ausgehend, erkennen kann, so lehrt auch die Entwicklungs: geschichte eines jeden pflanzlichen und tierischen Organismus, dass, so weit er auch morphologisch vorgeschritten sein mag, seine Entwicklung von einer Zelle ausgeht. In dieser Entwicklung treten nicht selten Stadien auf, in denen der Organismus eine Form besitzt, welche an die Gestalt erinnert, die niedriger stehende Organismen überhaupt zu erreichen vermögen. Dies hat zu der Vorstellung geführt, dass die Ontogenie eines Organismus die Entwicklungsgeschichte, welche eine Sippe, ein Stamm, eine Phyle, von niederen Anfängen ausgehend in geologischen Zeiträumen durchgemacht habe, wiederhole, das heisst, dass die Ontogenie eines Organismus seiner Phylogenie entspreche. Gerade bei der Beurteilung dieser Verhältnisse muss man aber immer sich gegenwärtig halten, dass viele Stämme eine Parallelentwicklung aufweisen; man muss sich hüten, Analogieen für Beweise von Verwandtschaft zu halten. Alle diese Verhältnisse zeigen aber auch, dass für das Verständnis der Verwandtschaft und der systematischen Anordnung, insbesondere der Hauptstämme, die Kenntnis der Entwicklunggeschichte durchaus notwendig ist.

3. $\mathrm{Zu}$ einer Familie werden einerseits diejenigen Formen vereinigt, welche in allen wesentlichen Merkmalen des anatomischen Baues, der 
Blattstellung, des Blütenbaues, der Sporenbildung oder der Frucht- und Samenbildung eine augenfällige Übereinstimmung zeigen, wie z. B. die Bacteriaceen oder Stäbchenbacterien, die Lamellenschwämme oder Agaricaceen, die Armleuchtergewächse oder Characeen, die Polypodiaceen, die Gramineen, die Iridaceen, die Orchidaceen, die Cruciferen, die Umbelliferen, die Borraginaceen, die Labiaten, die Compositen, - anderseits diejenigen Formen, welche zwar unter einander in einzelnen der genannten Verhältnisse Verschiedenheiten zeigen, aber doch durch ein gemeinsames Merkmal, sei es der Zellbeschaffenheit, des anatomischen Baues, der Blüte oder Frucht, verbunden sind. Hierbei erscheint die Zusammengehörigkeit um so sicherer, je mehr die Verschiedenheiten schrittweise auftreten.

4. Die Aufstellung der Familie erfolgt also zunächst durch Erfahrung. Da aber die Verschiedenheiten nicht immer schrittweise, sondern auch sprungweise auftreten, einzelne Formen oft isoliert stehen oder noch häufiger nur wenige Formen eine engere Gemeinschaft bilden, so macht sich bei der Begrenzung der Familien auch vielfach das subjektive Ermessen der einzelnen Forscher geltend. So kommt es, dass nicht bloss zu verschiedenen Zeiten, je nach dem Grade der Erfahrung, sondern auch zu derselben Zeit die Familien in verschiedener Weise begrenzt wurden, je nachdem die Wertschätzung dieses oder jenes Merkmales mehr in den Vordergrund trat, und je nachdem man der Ansicht huldigte, dass jede Pflanzenform im natürlichen System unbedingt einer grösseren Pflanzengemeinschaft angeschlossen werden müsse. Es werden daher oft genug dieselben Formenkreise von den einen nur als Unterfamilien oder Gruppen, von den anderen als Familien bezeichnet.

5. Für die noch immer fortschreitende Entwicklung des natürlichen Systemes empfiehlt es sich, von allen sogenannten praktischen Rücksichten, welche Sache des künstlichen Systemes sind, Abstand zu nehmen und ohne Rücksicht auf den Umfang sowohl grosse Familien, wie z. B. die der Leguminosen (einschliessend Mimosoideae, Caesalpinioideae, Padilionatae) aufzustellen, wenn zwischen den verwandten Gruppen nur geringe graduelle Unterschierle auftreten, als auch kleine, ja selbst monotypische Familien zuzulassen, wenn ein Formenkreis in seinen Merkmalen isoliert dasteht.

6. Die Zusammenfassung der Familien zu Unterreihen, dieser zu Reihen und der Reihen zu Klassen erfolgt mit Rücksicht auf die mehreren Familien beziehungsweise mehreren Reihen gemeinsamen Merkmale; jedoch kommt es hierbei nicht selten vor, dass einzelne Gattungen das eine ganze Reihe oder Klasse charakterisierende Merkmal nicht besitzen, nichtsdestoweniger aber in der betreffenden Reihe oder Klasse belassen werden müssen, wenn sie in ihren übrigen Eigenschaften rnit den Gliedern einer dieser Reihe zuzurechnenden Familie übereinstimmen, was nicht verwundern kann, wenn man an die Thatsachen denkt, welche deutlich zeigen, dass oft durch viele Generationen hindurch einzelne Merkmale latent. bleiben könuen (vergl. § 2). Aus diesem Grunde stösst jeder Versuch, einen analytischen Schlüssel für das natürliche System auszuarbeiten, auf die grössten Schwierigkeiten; ja, es ist ein solcher Schlüssel korrekt nur dann herzustellen, wenn er für die Pflanzen eines Florengebietes bestimmt ist, dessen Arten alle dem Verfasser so bekannt sind, dass er bei dem Schlüssel auch die vorerwähnten Ausnahmen berücksichtigen kann. 
7. Die Erfahrung, dass einzelne Merkmale zur Charakterisierung grösserer Pflanzengemeinschaften verwendet werden können, andere nicht, führte zu der Annahme von wesentlichen und unwesentlichen Merknalen. Es hat sich jedoch herausgestellt, dass selbst sehr wesentliche Merkmale bei den durch sie charakterisierten Gruppen nicht immer constant auftreten; es hat sich ferner herausgestellt, dass viele Merkmale in der einen Pflanzen. gruppe wesentlich, in der anderen unwesentlich sind, so z. B. Art der Conidienbildung, Blütenfarbe, Secretzellen, Nebenblätter, Blattstellung, Ver• wachsung von Blumenblätterı etc.

8. An verschiedenen Pflanzengemeinschaften, sowohl der niederen wie der höheren Pflanzen, welche wir unzweifelhaft als natürliche Familien oder Familienreihen ansehen dürfen, lässt sich leicht zeigen, dass mehrere der von den Systematikern früher oder später sehr in den Vordergrund gestellten Merkmale zur Charakterisierung grösserer Gemeinschaften nicht geeignet sind. So hat man z. B. erkannt, dass die früher bei der Classificierung der als Thallophyten zusammengefassten Pflanzen so hoch gestellten Fortpflanzungsverhältnisse eine secundäre Rolle spielen, dass dagegen die Beschaffenheit der Vegetationsorgane, die Beschaffenheit des Zellinhaltes sich für grössere Gemeinschaften constant erweise. Ebenso hat man bei den Archegoniaten die Classificierung in Isospore und Heterospore nun in zweite Linie gestellt, nachdem man sich von der grösseren Constanz in der Entwicklung der Vegetationsorgane überzengt hat. Bei den Angiospermen lässt sich nachweisen, dass oft schon in einer und derselben Familie, ja selbst einer Gattung, die Formen der Blütenhülle, die Formen der Blütenaxe anftreten, nach denen frïher die Unterabteilungen der Monokotyledoneen und I)ikotyledoneen gebildet wurden. An anderen Familien (z. B. bei den Nymphaeaceen, Guttiferen) lässt sich der geringe Wert der sonst oft sehr wichtigen Stellungsverhältnisse der Blütenteile darthun, in wieder anderen, wie z. B. hei den Araceen, die geringe Bedeutung des in vielen Familien so constanten Nährgewebes. Dagegen erweisen sich in vielen Familien Sprossverhältnisse, Blattstellungsverhältnisse, Blattnervatur, die Beschaffenheit der Haare, der Bau und das Dickenwachstum der Leitbündel, die Art der Gefässperforation, die Beschaffenheit des mechanischen Gewehes, namentlich aber das Vorhandensein und die Entwicklung von Secretbehältern oft von grosser Constanz und somit von hohem, die Verwandtschaft darthuendem und zugleich diagnostischem Wert. Ander:eits sind aber auch in einzelnen Familien diese anatomischen Merkmale nicht constant; zur Charakterisierung von Reihen oder noch umfassenderen Gruppen sind sie meist nicht geeignet. Die grösseren Abteilungen der Angiospermen, der Monokotyledoneen und Dikotyledoneen werden stets nur durch die Beschaffenheit des Embryos und der Leitbündel auseinander gehalten werden können; für die Monokotyledoneen fehlt es vollständig an einem durchgreifenden Merkmale, nach welchem die Familienreihen sich in Gruppen verteilen liessen:- Bei den Dikotyledoneen aber ist man trot» der mehrfach vorkommenden Unbeständigkeit der Blütenhülle nicht in der Lage, die Berücksichtigung derselben für die Gruppierung der Familienreihen ganz ausser Acht zu lassen. Jedenfalls hat sie sich von höherem Wert erwiesen als die Blütenaxe. 
D. Die Aufgabe der wissenschaftlichen Systematik ist es aber nicht bloss, die durch gemeinsame Merkmale ausgezeichneten Formen zu Gruppen niederer oder höherer Ordnung zu vereinigen, sondern sie hat darnach zu streben, dass bei der Anordnung der Pflanzen die genetische Entwicklung oder wenigstens die morphologische Stufenfolge derselben zum Ausdruck kornmt.

10. Wären die Pflanzenformen in den Ablagerungen der vergangenen Erdperiode alle oder zum grossen Teil wohl erhalten, so dass man mit Zuverlässigkeit ihre Übereinstimmung mit den gegenwärtigen Formen feststellen könnte und auch einen Überblick über alle Formen bekäme, welche einmal existiert haben, so hätte man einen sicheren Anhalt. Da aber die niederen Pflanzen grösstenteils gar nicht und auch von den höheren Pflanzen nur ein ganz geringer Teil zur Erhaltung im fossilen Zustand befähigt sind, da ferner von den erhaltenen Formen gerade die Blütenteile, das Innere der Früchte und Samen sowie der anatomische Bau nur äusserst selten klarzustellen sind, so bietet die Pflanzenpaläontologie für die Aufstellung des Systems eine zwar nicht ganz von der Hand zu weisende, aber doch nur lïckenhafte Grundlage.

11. Wir sind daher darauf angewiesen, das System mit Rücksicht auf den anatomischen Bau und die äussere Gliederung der gegenwärtig existierenden Pflanzen und einer geringen Anzahl gut erhaltener fossiler Formen aufzustellen.

12. Es handelt sich hierbei um die Ermittelung der Stufenfolge, welche in der Entwicklung der einzelnen Organe stattgefunden hat, ferner um die Ermittelung der Merkmale, welche bei den unter verschiedenen Existenz. bedingungen lebenden Mitgliedern einer Familie gleich bleiben im Gegensatz zu denjenigen, welche die PHanze für besondere Existenzbedingungen befähigen. Mit der Kenntnis der früheren Existenzbedingungen der Pflanzen eines Typus ausgerüstet, vermöchte man wohl, aus der Art der Anpassungserscheinungen auch auf das Alter der Formen zu schliessen und danach wenigstens innerhalb der Familien eine phylogenetische Reihenfolge festzustellen. Wir kennen aber nicht die früheren Existenzbedingungen eines Typus, wir wissen $\mathrm{z}$. B. nicht, ob eine heute als Wasserpflanze existierende Art von Landpflanzen abstammt oder von Wasserpflanzen. Wir müssen uns demnach vorzugsweise von den schrittweise auftretenden Veränderungen leiten lassen, welche wir an den Formen eines Typus wahrnehmen, Erfahrungen darüber sammeln, ob dieselben Veränderungen häufiger auftreten, und in Erwägung ziehen, ob die Veränderungen derartige sind, dass dadurch die Existenzfähigkeit des Typus unter den ihn jetzt umgebenden Verhältnissen erhöht wird.

13. Sowohl die complicierteren Gestaltungen, welche aus einfacheren hervorgegangen sind, als auch die äusserlich einfacheren, welche durch gewisse Umstände, z. B. Parasitismus oder Trockenheit des Klimas dahin beeinflusst werden, dass die bei ihren Vorfahren weiter entwickelten Organe auf niederer Stufe stehen bleiben, sind spätere Bildungen und müssen im natürlichen System hinter denjenigen Formen folgen, welche noch nie eine höhere Stufe erreicht haben. So unbestreitbar dieser Satz an sich ist, so bereiten doch gerade viele einfach gebaute Formen grosse Schwierigkeiten, weil es nicht immer leicht, ja, manchmal absolut gar nicht 
zu entscheiden ist, ob eine einfach gebaute Form einen ursprünglichen Typus oder einen reducierten Typus repräsentiert. So kommt es, dass von den Botanikern in das Pflanzensystem oft genug eine sutjektive Meinung hineingelegt werden muss, und dass daher auch das natürliche Pflanzensystem jetzt zwar in seinen Grundzügen feststeht, im einzelnen aber noch immer mehrfachen Schwankungen unterworfen ist. Es ist noch zu bemerken, dass eine jede auf natürlichem Wege später entstandene, nicht individuelle, sondern erblich gewordene Bildung als Progression bezeichnet werden kann, auch wenn ihre Gestaltung in mancher Beziehung einen Rückschritt aufweist. So können bei Parasiten und Xerophyten die Blätter in ihrer Entwickelung sehr zurücktreten und bei manchen Saprophyten die Wurzeln ganz ausbleiben; nichtsdestoweniger nehmen sie phylogenetisch eine höhere Stufe ein, als die mit gleichen Blüten und Früchten versehenen PHlanzen, welche vollkommenere Blätter und Wurzeln besitzen; denn sie haben neue Wege der Gestaltung eingeschlagen, welche sie zu einer eigenartigen Existenz hefähigen.

14. Bei der Verfolgung der Progressionen ist immer festzuhalten, dass bei weitverbreiteten Formen dieselbe Progression mit geringen Variationen an verschiedenen Stellen eintreten kann. Es liegt. demnach die Gefahr nahe, dass man die auf der gleichen Progressionsstufe befind. lichen Formen ohne weiteres als nächst verwandt ansieht, während doch vielmehr eine reale Verwandtschaft zwischen den Formen besteht und bestanden hat, welche eine Progressionsreihe ausmachen. Man wird daher vorzugsweise auf diejenigen Merkmale zu achten haben, welche in den einzelnen Progressionsreihen sich gleich bleiben. Formen, welche hin. sichtlich des Blütenbanes Progressionen aufweisen, erweisen sich oft $\mathrm{zu}$ sammengehörig durch die gleichartige Beschaffenheit ihres anatomischen Baues - und Formen, welche hinsichtlich ihres ernährungsphysiologischen Verbaltens Progressionen zeigen, sind eng verbunden durch gleichartigen Bau ihrer Blüten und gleiche Stellungsverhältnisse ihrer Blattorgane. Früher stützte man sich bei der Umgrenzung der Verwandtschaftskreise fast ausschliesslich auf diese; aber es bietet hierbei auch eine wesentliche Stütze die Berücksichtigung der Anatomie und der geographischen Verbreitung. Es hat sich bei neueren Untersuchungen nunmehr schon sehr oft herausgestellt, dass der rote Faden zur Verbindung der inniger mit einander verwandten Formen gefunden wird, wenn man namentlich diejenigen anatomischen Verhältnisse berücksichtigt, welche nicht zu den äusseren Lebensverhältnissen in näherer Beziehung stehen. Ehenso führt die Berücksichtigung der geographischen Verbreitung zu wich. tigen .systematischen Resultaten, nanientlich daun, wenn es sich um Formen handelt, deren Verbreitungsmittel nur eine beschränkte Verbreitung zulassen und welche bei ihrer Organisation auf klimatische Hindernisse stossen. - Im folgenden werden die Progressionen, welche an den verschiedenen Teilen der Pflanze wahrgenommen werden, aufgefübrt.

15. In anatomischer Beziehung können - abgesehen von den bekannten, in dem folgenden System klar hervortretenden, einer speciellen Erläuterung kaum bedürfenden Stufen, die von den einzelligen, einzeln oder in Kolonien lebenden Pflanzen zu den aus Zellkomplexen bestehenden Zellen- uud Gefässpflanzen hinauf führen - nur noch wenige Stufen 
unterschieden werden. Dieselben beruhen nur noch auf einer weiter gehenden Differenzierung der Gewebe, auf einer weiter gehenden Verteilung der physiologischen Aufgaben auf verschiedene Zellen oder Zellkomplexe. Wenn die Trichome zu Secretionsorganen, zu Absorptionsorganen werden, wenn in Hautgewebe sich ein besonderes Wassergewehe absondert, wenn die sonst gleichnässig an der Stengeloberfläche-verteilten Spaltöffnungen nur in den Furchen des Stengels entwickelt werden, wenn das Assimilntionsgewebe sich lokalisiert, wenn im Grundgewebe Secrethehälter ent. wickelt werden, wenn dasselhe von Spicularzellen durchsetzt wird, wenn in den Leitbündeln das Cambium sich regeneriert, wenn im Grundgewebe ein Bündel erzeugendes Meristem auftritt, wenn an Embryonen sich Fortsätze bilden oder dieselben auf der Mutterpflanze sich kräftiger als gewöhnlich entwickeln, so sind dies alles Progressionen. Eine andere Frage aber ist dic, ob diese Progressionen einen systematischen Wert haben. Das gilt in erster Linie von solchen, welche eine Sippe charakterisieren, deren Glieder unter verschiedenen klimatischen Verhältnissen gedeihen, in zweiter Linie auch ron solchen Progressionen, welche bei einer zwar nur unter bestimmten klimatischen Verhältnissen gedeihenden, aber formenreichen Sippe constant auftreten. Viel häufiger als durch solche Progressionsmerkmale werden natürliche Sippen charakterisiert durch anatomische Merkmale, deren Verschiedenartigkeit nicht mit der Erfüllung anderer Aufgaben in Verbindung steht. Der Schutz, welchen dicht stehende Trichome jungen Organen gegen Transpiration gewälıren, bleibt derselbe, nıögen die Trichome einzellige, gegliederte oder Schuppenhare sein; ganze Sippen und Familien sind aber oft durch eine Form der Haare charakterisiert. Die Bedeutung der Schliesszellen der Spaltöffnungen ändert sich nicht mit den verschiedenen, bei einzelnen Sippen aber gleichartigen Teilungsvorgängen der jungen Oberhautzellen vor der Entwicklung der Spaltöffnungen. Die für einzelne Sippen charakteristische Verteilung der mechanischen Gewebselemente dient trotz ihrer Verschiedenheit dem gleichen Zweck und die mit bicollateralen Leitbündeln versehenen krautigen Pflanzen leben unter gleichen Verhältnissen, wie solche mit collateralen Bündeln. Auch ist kaum anzunehmen, dass es für die mit Secretbehältern versehenen Pflanzen von Bedeutung ist, ob dieselben bei gleichem Secret sich schizogen oder lysigen entwickeln.

16. In der Entwicklung der Sprosse bestehen zunächst Progressionen vom einfachen Spross zum Sprossverband, sodann von Sprossverband mit gleichartigen Sprossen zum Sprossverband mit verschiedenen Aufgaben dienenden Sprossen, vom Sprossverband mit entwickelten oberirdischen Internodien zum Sprossverhand mit unterirdisch gestauchten Internodien (Knolle oder Zwiebel), vom Spross mit assimilierenden Laubblätteln zum Spross mit vorzugsweise oder ausschliesslich assimilierendem Stamm. In vielen grossen Familien (Liliaceae, Araceae) können wir fast alle diese Progressionen der Sprossentwicklung in verschiedenen Gruppen verfolgen, sehen aber dabei anderseits die Blattstellung immer gleich (alterierend) bleiben. - Wenn in anderen Familien alternierende und echt quirlständige oder decussierte Stellung der Sprossblätter wahrgenommen wird, so ist die eine nicht als eine Progression von der andern her anzusehen. Wohl aber kann man von einer Progression sprechen, wenn bei einem Typus mit spiraliger Stellung der Blätter an einem unterwärts alternierende Blätter 
tragenden Spross die oberen zu einem Quirl zusammen treten und nunmehr die folgenden Blätter einen mit dem vorigen alternierenden Quirl bilden, wie dies z. B. bei der Liliacee Paris der Fall ist. An den Blättern -elbst köınen wir mannigfache Progressionen in der Gliederung und Verzweigung unterscheiden, die unendlich oft wiederkehren, aber auch nur bisweilen wie die vorher angedeuteten Progressionen in der Sprossentwicklung constant werden.

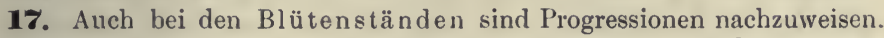
Zwar kunn man nicht den racemösen Typus höher stellen, als den cymösen oder umgekehrt, zumal sich auch beile von einer Urform, der Rispe, ableiten lassen; aber in beiden Fällen können mannigfache Complicationen eintreten, zunïchst dadurch, dass die Hauptaxen oder die Nebenaxen oder beide sich nicht strecken, dass anstatt des Längenwachstums in den Axen Breiten- oder Dickenwachstum eintritt, dass sich Dorsiventralität ausbildet, ferner darin, dass die Hochblätter der Blütenstände untereinander verwachsen, dass einzelne $\mathrm{Z}$ weige des Blïtenstandes steril werden und anderen Zwecken dienen, als den ursprïinglichen, dass endlich die einzelnen Teile des Blütenstandes verschiedene Blüten tragen. Die phylogenetisch am weitesten vorgeschrittenen Blütenstände sind diejenigen, welche so compliciert sind, dass sie einer Zwitterblüte entsprechen, wie z. B. die Blütenstände mancher Araceen und Euphorbiaceen.

18. Die mannigfachsten Progressionen finden sich bei den geschlechtlichen Fortpflanzungsorganen. Wiederholt sehen wir bei tiefer stehenden Abteilungen des Pflanzenreiches Isogamie in Heterogamie oder Oogamie übergehen, seltener Carposporenbildung auftreten. Die schönste Stufenfulge aher können wir bei den Archegoniaten und von denselben aufwärts in der Entwicklung der Sporophyten sowie der Prothallien verfolgen. Während bei den Sporophyten eine Progression von wenig gegliederten Körpern zu Kormophyten stattgefunden hat, macht sich bei den Prothallien die Progression darin geltend, dass die weiblichen massiger werden, wenige Archegonien entwickeln, bisweilen auch in den Sporen eingeschlossen bleiben, bei den männlichen aber immer weiter gehende Reduction bis an die Grenze der Möglichkeit. Schliesslich sehen wir die weiblichen Prothallien auch noch während der Befruchtung in der Spore eingeschlossen bleiben und in ihnen den Embryo.

19. In den Blüten kommt zunächst die Blütenaxe in Betracht. Da die Blüte ein Spross ist, so entsprechen die Blüten mit convexer Blütenaxe am meisten dem ursprünglichen Typus. Dagegen führen zu weiter vorgeschrittenen Stufen: a) intercalare Streckung einzelner Internodien zwischen einzelnen Formationen der Blüte; b) scheibenförmige Verbreiterung derselben, also die Entwicklung eines Discus und die Ausgliederung von Discuseffigurationen; c) schüssel- und becherförmige Gestaltung der Blütenaxe mit epigynischer Insertion. Die Stufen der Perigynie und Epigynie werden in den verschiedenen Verwandtschaftskreisen und oft auch in einem und demselben Verwandtschaftskreise $\mathrm{zu}$ verschiedenen Malen erreicht; anderseits giebt es viele Familien sowohl unter den Archichlamydeae, wie unter den Metachlamydeae oder Sympetalae, bei welchen namentlich die Epigynie constant geworden ist, und diese werden wir, so lange sich nicht ein innigerer Anschluss an Pflanzen mit flacher oder 
convexer Axe nachweisen lässt, an das Ende der genannten Sippen stellen, wenn die Versenkung des Gynaeceums in der Blütenaxe auch mit der Vereinigung der Carpelle zu einem unterständigen Fruchtknoten verbunden ist.

20. Da es Sippen mit durchgehend spiraliger Stellung der Laubblätter, anderseits solche mit durchgehend quirliger Stellung derselben giebt, so haben wir, wie schon unter 15 angedeutet wurde, keinen Grund, die Spiralstellung stets als die primäre, die Quirlstellung stets als die secundäre Stufe anzusehel. An und für sich sind beide Stellungen für die systematische Stufenfolge gleichwertig. Es werden aber in einem Formenkreis mit vorherrschend spiraliger Stellung der Blätter an den Laubsprossen und ebensolcher an den Blütensprossen die verwandten Formen mit Quirlstellung der Blütenteile als weiter vorgeschrittene anzusehen sein. Da ferner erfahrungsgemäss die quirlige Stellung der Blütenteile den Anstoss zu weiteren Complicationen, vor Allem zum consociierten Emporwachsen von Blütenteilen giebt, auch bei Quirlstellung Versenkung des Gynaeceums in die Axe, ferner Zygomorphie und Abort viel häufiger eintreten als bei Spiralstellung, so ist die quirlige Stellung meist als eine vorgeschrittene Stufe anzusehen.

21. Bezüglich der Zahl der Glieder einer Blüte kann man, abgeseben vou den später zu besprechenden Fällen im Androeceum und Gynaeceum kaum eine Stufenfolge aufstellen. Bei den Blüten mit spiraliger Anordnung der Blütenteile ist die Zahl der Glieder in den einzelnen Formationen bei ein und derselben Art recht wechselnd, zum Teil gewiss von der Stoffzufuhr abhängig; aber auch in quirligen Blüten treten Verschiedenheiten in der Zahl der Glieder auf, welche für sich allein nicht einen Fortschritt bezeichnen können. Wenn aus den Samen eines 3 gliederigen Lilium ein solches mit 2 gliederigen Blüten, wenn ferner aus dem Samen einer 4 gliederigen Paris eine solche mit 5 - oder 7 gliederigen Blüten hervorgeht, so kann hierbei von einer Progression nicht die Rede sein, weil bei den Nachkommen einer solchen Pflanze die Zahl der Glieder bald steigt, bald fällt. Wir haben daher auch keine Veranlassung, in Familien, bei denen Gattungen mit 2-, 3-, 4-, 5- und mehrgliederigen Blüten vorkommen, die eine höher als die andere zu stellen, so lange die Quirle unter sich gleichzählig sind. Dasselbe gilt auch hinsichtlich der Zahl der Quirle einer Formation; es giebt mehrere Arten, bei denen die einzelnen Individuen in ihrer Blüte bald 2, bald 3, bald 4 Quirle von Staubblättern oder Fruchtblättern entwickeln, bei denen also bald einmal die höhere, bald die geringere Zahl eine spätere Entwickelung repräsentiert. Aber es ist wohl $\mathrm{zu}$ beachten, dass diese Zahlenverhältnisse nur gleichgültig sind, so lange sie schwankend sind. Ist erst in einem Typus die Zahl der Quirle eine beschränkte geworden, dann tritt eine Steigerung äusserst selten ein und ist gewöhnlich auch mit Umgestaltung der Blütenformationen verbunden. Somit kann man immer den nicht fixierten Blütentypen diejenigen mit fixierter Quirlzahl als weiter vorgeschritten gegenüberstellen; jedoch ist es nicht immer notwendig, dass der Typus mit beschränkter Quirlzahl sich aus einem Typus mit unbeschränkter Zahl entwickelt hat. Die Blüten mit fixierter Quirlzahl sind auch diejenigen, bei denen nicht bloss die Arbeitsteilung der einzelnen Quirle, sondern auch der Glieder eines Quirls am meisten vorschreitet. 
22. Dafür, dass zygomorphe Blüten von aktinomorphen Blüten abzuleiten sind, finden sich so zahlreiche Belege, dass wir unbedenklich die zygomorphe Ausbildung als eine Progression gegenüber der aktinomorphen ansehen.

23. Unter den einzelnen Formationen der Blüte kommt zunächst die Blütenhülle in Betracht. Diejenigen Blüten, welche nur Sporangien tragende Blätter (d. h. nur Staubblätter und Fruchtblätter) besitzen, haben wir als auf der niedersten Stufe stehend anzusehen, sofern nicht irgend welche triftige Gründe vorliegen, den Abort einer Blütenhülle anzunehmen. Derartige typisch nackte Blïten heissen achlamydeisch. Als solche sind auch diejenigen zu bezeichnen, bei welchen Hochblätter in derselben Stellung wie am Grunde der vegetativen Sprosse den Schutz der jungen Sexualblätter übernehmen. Eine zweite Stufe ist diejenige, bei welcher die Sexualblätter von unter sich gleichartigen Blättern umhüllt sind, welchen entweder noch Vorblätter vorangehen, oder welche den Sexualblättern genähert und von dem Tragblatt durch ein Internodium getrennt sind, so dass sie mit den Sexualblättern zusammen ein Ganzes bilden. Sowohl unter den Monokotyledoneen wie unter den Dikotyledoneen finden sich mehrere Familien, bei denen durchweg die Blütenhülle diese Beschaffenheit zeigt; ausserordentlich gross ist die Zahl derjenigen Familien, von welchen noch einzelne Glieder der Familie diesen niederen Standpunkt der Blütenhülle aufweisen. Derartige Blütenhüllen nenne ich homoiochlamydeisch, sie sind einerseits haplochlamydeisch, wenn 1 Kreis von Blütenhüllblättern vorhanden ist, anderseits diplochlamydeisch, wenn, wie es sehr häufig der Fall ist, 2 Kreise von Blütenhüllblättern die Sexualorgane umgeben. Sie sind in ihrer Ausbildung bracteoid oder hochblattartig, wenn die Blütenhüllblätter den Hochblattcharakter behalten haben, oder petaloid, corollinisch, wenn sie nicht mehr grün, sondern weiss sind oder andere Färbungen zeigen. Während nun bei einem Teil der Angiospermen die ganze Blütenhülle corollinisch wurde, blieben bei anderen die äusseren Blätter hochblattartig und nur die inneren wurden corollinisch, die Blütenhülle wurde heterochlamydeisch. Hierbei ist jedoch zu berücksichtigen, dass eine heterochlamydeische Blütenhülle auch dadurch entstanden sein kann, dass die äusseren Staub. blätter einer haplochlamydeischen Blütenhülle zu Blumenblättern wurden. In jedem Falle steht eine solche heterochlamydeische Blütenhülle auf einer höheren Stufe als die vorher erwähnte. - Während bei einem Teil der Pflanzen die Blätter der Blütenhülle getrennt bleiben, sehen wir bei anderen dieselben vereint, consociiert, emporwachsen und ein Symphyllodium bilden. Ziemlich selten tritt dieser Fall bei homoiochlamydeischen bracteoiden Blütenhüllen ein, kommt aber doch vor; häufiger ist er bei homoiochlamydeischen corollischen Blütenhüllen und noch häufiger bei heterochlamydeischen Blütenhüllen. Auch diese Stufe wird oft in einer und derselben Familie, wie z. B. bei den Liliaceen, zu verschiedenen Malen erreicht. - Während in den besprochenen Fällen ein morphologischer Fortschritt sich in der weiteren Ausbildung der Blütenhülle bemerkbar macht, giebt es anderseits auch Fälle, wo in der Blütenhülle die Reduction Umgestaltungen herbeiführt, welche auch als Progressionen anzusehen sind. Diese Fälle sind für die phylogenetischen Anordnungsversuche schwierig, da es nicht immer leicht ist, $\mathrm{zu}$ entscheiden, ob Re- 
duction oder eine der ersten Stufen der Blütenhüllbildung vorliegt. Nur da, wo Übergangsglieder vorhanden sind, kann man sich für den einen oder andern Fall entscheiden. Wenn die Blüten durch Reduction ihre Blumenkrone verloren haben, so sind sie apetal (apopetal); halien sie ihre ganze Blütenhülle verloren, so heissen sie apochlamydeisch, im Gegensatz zu den achlamydeischen. In Allgemeinen ist man früher in der Annahme von Abort der Blumenblätter oder der Blütenhülle viel zu weit gegangen. Es ist namentlich unwahrscheinlich, dass ganz allgemein windblütige Pflanzen ohne Blütenhülle oder ohne Blumenblätter sich aus insektenblütigen mit Blütenhüllen entwickelt hätten.

24. Mit Ausnahme sehr weniger Fälle liegt bei den Angiospermen klar zu Tage, dass die Formen mit Zwitterblüten phylogenetisch älter sind, als die sonst sich gleich verhaltenden mit eingeschlechtlichen Blüten. Diese Progression tritt unendlich oft ein und ist zur Gruppenbildung kaum zu verwerten.

25. Bezüglich der Staubblätter ist zunächst klar, dass die der Gymnospermen mit nur auf der Unterseite entwickelten Mikrosporangien oder Pollensäcken den Sporophyllen der Pteridophyten näher stehen als die der Angiospermen, welche auf beiden Blattflächen Pollensäcke erzengen. Es verdient Beachtung, dass bei den Monokotyledoneen und bei einem Teil der Nymphaeaceen die Archisporzelle succesive in $2 \times 2$ Specialmutterzellen zerfällt, während hei allen übrigen Dikotyledoneen der Archisporkern durch wiederholte Teilung rasch 4 Zellkerne ergiebt, um welche erst die Membranen der Specialmutterzellen auftreten. Es dürfte dies Verhalten mit ein Grund dafür sein, die Monokotyledoneen vor den Dikotyledoneen aufzuführen. Progressionen in der Entwicklung der Antheren sind einmal die Querfächerung derselben, ferner die Vereinigung der Pollenzellen zu Pollengruppen, Massulis und Pollinarien, sodann die petaloide Ausbildung einzelner Staubblätter. In der Entwicklung der aus der Mikrosporen hervorgehenden Prothallien wird die Progression durch Reduktion derselben bezeichnet. Bei den Cycadales und Gingkoales besitzt dasselbe ausser der Spermotozoidenmutterzelle noch wenigstens 2 vegetative Zellen und echte Spermatozoiden treten in Aktion, bei den Coniferae und Taxaceae ist häufig nur eine vegetative Zelle vorhanden und die Spermakerne entbehren der Bewimperung, sind nicht mehr echte Spermatozoiden. Wenn in einzelnen Fällen das männliche Prothallium oder der Pollenschlauch sich im Nucellus verzweigt oder vom Chalazaende der Samenanlage zur Mikrophyle vordringt, wenn bei einzelnen Potamogetonaceen der Pollen in der Anthere noch fadenförmig entwickelt, so sind dies auch Progressionen; aber sie sind Anpassungserscheinungen ohne hohen systematischen Wert.

26. Für die Staubblätter gilt ferner dasselbe, was unter 18 über die Blüte im Allgemeinen und unter 20 über die Blütenhüllblätter gesagt wurde. Unter sonst gleichen Verhältnissen ist die cyklische Anordnung als eine Progression gegenüber der spiraligen anzusehen, ebenso die zygornorphe Ausbildung und der damit verbundene Abort einzelner Glieder gegenüber der aktinomorphen Ausbildung, die Consociation in mehrere oder ein Bündel gegenüber der freien Stellung. Desgleichen ist die Spaltung oder die Entwicklung von 2 bis mehr Staubblättern an Stelle eines einzigen als eine 
Progression anzusehen. W'as dagegen die Zahl der Staubblattquirle anbetrifft, so scheint kein Grund vorhanden zu sein, weshalb Formen mit 3 und mehr Quirlen phylogenetisch älter sein sollen als solche mit 2 und nur einem Quirl, wenn nicht gerade die Formen mit einem Staubblattquirl auch Staminodien besitzen, welche deutlich erkennen lassen, dass bei den Vorfahren noch ein Staubblattquirl vorhanden war, oder, wie bei den Iridaceen, die Stellungsverhältnisse des einen Staubblattkreises und bisweilen auftretende Rückschlagsbildungen darthun, dass ein Staubblattkreis nicht zur Ausgliederung gelangt ist. Blüten, die nur ein Staubblatt enthalten, lassen in den meisten Fällen sich als äusserst reducierte nachweisen. Dieselben Stufen, welche bei den Staubblättern unterschieden werden, kommen auch bei den Staminodien vor.

27. Die Fruchtblätter sind bei den Gymnospermen noch ohne empfängnisfähige Narbe, sie sind bei einem Teil derselben ausgebreitet und schliessen erst bei den Gnetaceen zu einem oben offenen Gehäuse zusanımen. Eine wesentliche Progression erfolgt bei den Angiospermen durch Entwicklung einer Narbe.

28. Das Gynaeceum oder der Complex der Fruchtblätter zeigt ähnliche Stufen wie das Androeceum. Die erste Stufe mit freien Carpellen (Apocarpie) ist besonders häufig bei Spiralstellung der Carpelle, eine Vereinigung der Carpelle unter einander tritt bei dieser Blattstellung verhältnismässig selten ein. Freie oder nur wenig vereinte Carpelle sind aber auch bei quirliger Anordnung derselben nicht selten. In sehr vielen Familien, bei denen vorzugsweise Syncarpie herrscht, finden sich doch noch einzelne Gattungen mit apocarpem Gynaeceum; nicht selten finden sich auch Formen, welche mit einem fertilen Carpell und einigen sterilen ausgestattet den Übergang zu wiederum auf einer höheren Stufe stehenden Gattungen mit nur einem einzigen freien Carpell vermitteln. Da die Blüten mit den Carpellen abschliessen, so sind bei quirliger Stellung dieselben einander immer so genähert, dass naturgemäss Syncarpie leicht eintreten muss. Der Apocarpie kommt diejenige Syncarpie am nächsten, bei welcher das Gynaeceum so viel Fächer enthält, als Carpelle an der Bildung des Gynaeceums beteiligt sind. Eine weitere Progression tritt ein, wenn in dem syncarpen Gynaeceum einzelne oder mehrere Fächer steril werden und schliesslich nur noch eines Samenanlagen enthält, während Griffel und Narben der Zahl der im Gynaeceum vereinigten Carpelle entsprechen. Dem gefächerten syncarpen Gynaeceum mit centralwinkelständigen Placenten steht das einfächerige syncarpe Gynaeceum mit parietalen Placenten gegenïher. Wenn in einem Verwandtschaftskreise nur parietale Placentation beobachtet wird, so ist es nicht gerade nötig, anzunehmen, dass diese Entwicklung des Gynaeceums als Progression aus dem gefächerten Gynaeceum hervorgegangen sei; denn sobald Syncarpie eintrat, konnte der eine der beiden Fälle, gefächertes Gynaeceum und ungefächertss Gynaeceum, entstehen, je nachdem die Fruchtblattränder sich mehr oder weniger nach innen krümmten. Dagegen steht offenbar in sehr vielen Fällen das einfächerige Gynaeceum mit grundständiger oder mit freier centraler Placenta zum gefächerten Gynaeceum in naher Beziehung, da in mehreren derartigen Fällen am Grunde des Fruchtknotens die Fruchtblattränder noch 
Scheidewände bilden, während in der oberen Region des Fruchtknotens die Carpellränder ohne Einwärtskrümmung verbunden sind. Ein in manchen Verwandtschaftskreisen auftretender Fortschritt ist der, dass die das Gynaeceum zusammensetzenden Carpelle sich entweder vom Rücken her zwischen den Samenanlagen einfalten oder dass im Innern zwischen denselben durch Wucherung der Fruchtknotenwandung sogenannte falsche Scheidewände gebildet werden. - Im Gynaeceum macht sich häufig bei nahe verwandten Formen unter sonst gleichen Verhältnissen in der Zahl der Samenanlagen eine Verschiedenheit geltend. Während bei der einen die Samenanlagen in unbestimmter Anzahl an beiden Carpellrändern auftreten, sehen wir, dass bei anderen die Zahl der Samenanlagen begrenzt ist und bei wieder anderen nur eine einzige auftritt. Wenn in in einem Verwandtschaftskreis sich stets nur eine Samenanlage findet, so ist kein zwingender Grund für die Annahme vorhanden, dass die Vorfahren in ihren Carpellen mehrere Samenanlagen entwickelt hätten. Wenn aber in einem Verwandtschaftskreis Formen auftreten, bei denen ein Teil der vorhandenen Samenanlagen nicht zur Samenreife gelangt und anderseits auch Formen mit nur einer Samenanlage existieren, so sind die letzteren als vorgeschrittene Bildungen anzusehen. Der Umstand, dass in vielen Fällen trotz der Entwicklung einer grösseren Anzahl von Samenanlagen nur wenige oder nur eine im Carpell oder im ganzen Gynaeceum zur Samenreife gelangt, beweist, dass entweder nicht ausreichend Pollen auf die Narbe gelangt oder einzelne Samenanlagen für die Befruchtung ungünstig gelegen sind; es wird also bei der Produktion der Samenanlagen unnütz Material verbraucht, und es ist als ein Fortschritt anzusehen, wenn nur eine Samenanlage entwickelt wird, die auch zum Samen reift.

29. Bezüglich der Samenanlage selbst ist es wahrscheinlich, dass ein Teil der nur ein Integument besitzenden Pflanzen (viele Gymnospermen) eine phylogenetisch ältere Stufe darstellt, als die zwei Integumente besitzenden; es ist aber anderseits auch wahrscheinlich, dass bei vielen Angiospermen die Formen mit nur einem Integument oder ohne jedes Integument in dieser Beziehung eine Reduction erfahren haben. Eine Entscheidung kann nur da getroffen werden, wo nahe verwandte Formen sich hinsichtlich der Integumente verschieden verhalten. Bemerkt sei noch, dass bei den Monokotyledoneen und bei Archichlamydeen Samenanlagen mit zwei Integumenten vorherrschen, bei den Metachlamydeen oder Sympetalen dagegen solche mit einem Integument. Wichtiger als das Verhalten der Integumente ist für die systematische Anordnung die Entwicklung der Nucellen. Bei den noch echte Spermatozoiden erzeugenden Cycadales und Gingkoales wird die dicke, die Makrospore oder den Embryosack bedeckende Gewebeschicht am Scheitel schleimig und gewährt ein gutes Substrat für die Keimung der Mikrosporen sowie für die Bewegung der Spermatozoiden zu den Eizellen. Ein Fortschritt zeigt sich bei den übrigen Gymnospermen darin, dass der Pollenschlauch das Scheitelgewebe des Nucellus durchbohrt und bis zur Eizelle vordringt. Bei den Angiospermen aber sehen wir einen weiteren Fortschritt in der Entwicklung einer empfängnisfähigen Narbe und in der Entwicklung von Papillen im Griffelkanal und Ovarium, welche den vorwärts wachsenden Pollenschlauch den Weg zur Samenanlage 
und dem am Scheitel ihres Nucellus gelegenen Sexualapparat erleichtern. Apogamie und Parthenogenesis sind gelegentlich auftretende Progressionen ohne systematische Bedeutung.

30. Die ausserordentliche Mannigfaltigkeit in der Fruchtbildung bietet lıäufig ein wertvolles Hilfsmittel zur Unterscheidung von Gruppen und Gattungen; aber ausser bei den oft sehr klar erkennbaren Reductionserscheinungen hat man kein Recht, die eine uder die andere Fruchtart, Kapsel, Nuss, Beere, Steinfrucht höher zu stellen; denn jede dieser Fruchtformen erweist sich unter Umständen als vorteilhaft für die Erhaltung der Art. Bei jeder der einzelnen Fruchtformen aber kann man leicht Steigerungen einzelner Eigenschaften nachweisen, die für die Verbreitungsfähigkeit und den Schutz der Samen von Vorteil sind; jecloch kehren diese Progressionen so oft wieder, dass sie bei der Charakterisierung grösserer Gruppen nur selten verwandt werden können.

31. Was von dem Pericarp der Früchte gilt, gilt auch von den Samenschalen. Dagegen ist als eine Progression die Entwicklung von Arillarbildungen aufzufassen, weil damit eine neue Eigenschaft geschaffen wird, die vielen Ptlanzen vorher abgegangen ist. Ebenso ist es phylogenetisch als ein Fortschritt zu bezeichnen, wenn das Nälırgewebe, sei es Endosperm oder Perisperm von dem Keimling im Samen aufgezehrt wird und der Keimling nach Sprengung der Samenschale sofort selbständig wird. Je weiter ferner die Blattentwicklung der Plumula im Samen gediehen ist, desto weiter ist die Pflanze vorgeschritten.

32. Beim Keimling selbst müssen typische Monokotyledonie und trpische Dikotyledonie als gleichwertig angesehen werden; die eine ist nicht von der andern abzuleiten. Dagegen sind vorgeschrittene Bildungen die knolligen Arten sonst zweikeimblättriger Familien, welche nur ein Keimblatt entwickeln, desgleichen die parisitären Formen, welche gar keine Keimblätter entwickeln.

33. Aus der vorausgegangenen Besprechung ergiebt sich, dass bis zu einem gewissen Grade in der verschiedenen Ausbildung der Blüten, Frïchte und Samen eine Stufenfolge existiert, welche der phylogenetischen Entwicklung entspricht. Das eingehendere Studium der Gattungen grösserer Pflanzenfamilien zeigt aber, dass dieselben häufig nach verschiedenen Richtungen hin vorgeschritten sind, dass ferner eine Gattung nach der einen Richtung vorschreiten, in anderen Merkmalen aber auf niedeser Stufe verharren kann, dass endlich ein und dieselbe Progression zu wiederholten Malen in verschiedenen engeren Formenkreisen eintreten konnte. So entstehen verschiedene Combinationen von Progressionen, welche die Anordnung oft erschweren. Bei dem leicht erklärlichen Streben, innerhalb einer Familie die Abstammungsfolge der Gattungen festzustellen, wird sehr oft übersehen, dass ein weitverbreiteter Typus an verschiedenen Stellen in verschiedener Weise variieren kann und die möglichen Abänderungen in mannigfacher Weise combiniert sein können. Die Aufgabe der heutigen, auf breiterer Grundlage beruhenden Systematik ist es, die Eigenschaften, welche sich trotz der mannigfachen Progressionen erhalten haben, aufzufinden. Diese Eigenschaften sind nicht selten anatomische; ferner geben namentlich die Stellung der Samenanlagen und der Embryo Anhaltspunkte. 
Die systematische Gliederung grosser Familien muss aber wenigstens die Hauptrichtungen, welche in der Entwicklung der Familie Platz gegriffen haben, erkennen lassen.

34. Wenn schon innerhalb einer Familie die Combination der Progressionen und die Wiederholung derselben Progressionen darthun, dass die lineare Anordnung nur teilweise der Entwicklung eines Typus entspricht, da dessen Glieder an verschiedenen Stellen oder auch in demselben Gebiet nach verschiedenen Richtungen hin sich verändert haben, so ist dasselbe noch mehr innerhalb der Familienreihen der Fall. Es können bei der einen Fámilie die weitestgehenden Progressionen nach einer Richtung hin stattgefunden haben, während bei einer phylogenetisch nahe verwandten mit ziemlich gleicher Ausgangsstufe die Progressionen sich mehr in einer anderen Richtung bewegten. Für die Zusammengehörigkeit der Familien zu einer Reihe kommen namentlich diese Ausgangsstufen in Betracht.

35. Hinsichtlich der Zusammenfassung der Reihen zu grösseren Abteilungen kann man doch nicht verkennen, dass bei den einen die Progression in der Entwicklung der Blütenhülle entweder ganz unterblieb oder wenigstens höhere Stufen nicht erreicht wurden, dass dagegen bei anderen die Entwicklung der Blütenhülle $\mathrm{zu}$ den höchsten Stufen vor. schreitet. Man hat vermutet, dass der Ursprung der zweiten Abteilung der Dikotyledoneen, welche wir als Sympetalae bezeichnen, nicht ein gemeinsamer sei, dass sie sich an verschiedene Reihen der hier als Archichlamydeae bezeichneten Dikotyledoneen anschliessen. Diese Möglichkeit ist nicht $z u$ bestreiten, da von den archichlamydeischen Familien nicht wenige einzelne Fälle von sympetaler Corollenbildung aufweisen. Indessen ist anderseits doch auch in Betracht zu ziehen, dass in den wenigen Familien der sympetalen Dikotyledoneen die einzelnen Familien unter einander in sehr enger Verwandtschaft stehen, so dass sie zum Teil schwer gegen einander abzugrenzen sind. Fs sind also die Reihen der Sympetalen natürliche. Es ist ferner zu berücksichtigen, dass wir bei nicht wenigen Familien der Sympetalen noch einzelne Gattungen mit choripetaler Blütenhülle finden, diese aber doch im sonstigen Bau sich nicht an bekannte Familien anschliessen. Es ist ferner zu beachten, dass bei den meisten Sympetalen das Androeceum auf einen Kreis beschränkt ist und mit Rücksicht hierauf der Anschluss auch nur an einige archichlamydee Familien stattfinden könnte. Trotzdem hat sich ein solcher bisher nicht ermitteln lassen. Es ist daher wahrscheinlich, dass die Sympetalen Typen darstellen, welche frühzeitig den Weg der Sympetalie eingeschlagen haben. Beachtung verdient auch der Umstand, dass bei dem grössten Teil der Sympetalen, namentlich denen der letzten Reihen die Samenanlagen durchweg mit nur einem Integument versehen sind, während bei den Archichlamydeae und den ersten Reihen der Sympetalen mit einem Integument versehene Samenanlagen seltener sind.

36. Innerhalb der Archichlamydeae und der Sympetalae sehen wir schliesslich die Versenkung des Gynaeceums in die Axe und die constante Reduction desselben eintreten, zu der sich bei den am höchsten stehenden Compositen auch Vereinigung der Staubblätter mit der Corolle und unter einander, endlich auch die zygomorphe Ausbildung der Corolle gesellt. 


\section{Grundzïge der älteren natürlichen Systeme.}

1. System von Antoine Laurent de Jussieu, publiciert 1789 in: Genera plantarum secundum ordines naturales disposita.

I. Acotyledones, Pflanzen ohne Keimblätter.

II. Monocotyledones, Pflanzen mit 1 Keimblatt.

1. Staubblätter unterweibig (hypogynisch).

2. Staubblätter umweibig (perigynisch).

3. Staubblätter oberweibig (epigynisch).

III. Dicotyledones, Pflanzen mit 2 Keimblättern.

1. A petalae, Kronenlose. a, b, c Staubblätter unterweibig etc. (wie bei II).

2. Monopetalae, mit (scheinbar) einblätriger Krone. $\mathrm{a}, \mathrm{b}$, c Krone unter-, um- oder oberweibig.

3. Polypetalae, mit mehreren (getrennten) Kronblättern. $a, b$, c Staubblatter unterweibig etc. (wie bei II).

4. Diclines irregulares, getrenntgeschlechtliche, meist kronenlose Pflanzen.

2. System von Auguste Pyramus de Candolle, publiciert 1813 in: Théorie élémentaire de la botanique, ou exposition des principes de la classification naturelle.

I. Vasculares, Pflanzen mit Gefässbündeln.

1. Exogenae. Gefässbündel auf dem Stammquerschnitt in einem, an Umfang wachsenden Kreis gestellt.

a) Diplochlamydeae, Kelch und Krone unterschieden.

๙) Thalamiflorae, Krone freiblättrig, unterständig.

ß) Calyciflorae, Krone um- oder oberständig.

7) Corolliflorae, Krone verwachsenblättrig, unterständig.

b) Monochlamydeae, Blütenhülle einfach.

2. Endogenae, Gefässbündel auf dem Stammquerschnitt zerstreut, die innersten die jüngsten (irrtümlich).

a) Phanerogamae, mit Blüten.

b) Cryptogamae, ohne Bluten.

II. Cellulares, Pflanzen ohne Gefässbündel, nur aus geschlossenen Zellen gebildet.

1. Foliaceae, mit Blättern.

2. Aphyllae, ohne Blätter. 
3. System von Stephan Endlicher, publiciert 1836-40 in: Genera , plantarum secundum ordines naturales disposita.

I. Thallophyta, kein Gegensatz von Stengel und Wurzel.

II. Cormophyta, Wurzel und Stengel differenziert

1. A crobrya, Stamm nur an der Spitze wachsend.

2. Amphibrya, Stamin nur am Umfang wachsend.

3. A cramphibrya, Stamm sowohl an der Spitze als am Umfang wachsend.

Diese Auffassungen der Wachstumsverhältnisse waren irrtümlich.

4. System von Adolphe Brongniart, publiciert 1843 in: Énumération des genres de plantes cultivées au Muséum d'histoire naturelle de Paris.

A. Cryptogamae, Pflanzen ohne Blüten.

a) Ampligenae, Blatt und Stengel noch nicht unterschieden.

b) Acrogenae, Blatt und Stengel unterschieden.

B. Phanerogamae, Pflanzen mit Blüten.

a) Monocotyledoneae, mit 1 Keimblatt.

'1. Albuminosae, mit Sameneiweiss.

2. Exalbuminosae, ohne Sameneiweiss.

b) Dicotyledoneae, mit 2 (oder mehreren) Keimblättern.

1. Angiospermae, mit geschlossenem Fruchtknoten.

a) Gamopetalae, Kronblätter verwachsen.

ß) Dialypetalae, Kronblätter frei (oder fehlend).

2. Gymnospermae, mit offenem Fruchtknoten.

5. System von Alexander Braun, publiciert 1864 in Ascherson's Flora der Provinz Brandenburg.

I. Bryophyta, Keimpflanzen.

1. Thallodea: Algen, Flechten, Pilze.

2. Thallophyllodea: Charen, Moose.

II. Cormophyta, Stockpflanzen.

1. Phyllopterides: Farne, Schachtelhalme.

2. Maschalopterides: Bärlappe.

3. Hydropterides: Wasserfarne.

III. Anthophyta, Blütenpflanzen.

A. Gymnospermae, Nacktsamige.

1. Frondosae: Cycadaceen.

2. Acerosae: Coniferen.

B. Angiospermae, Bedecktsamige.

1. Monocotyledones.

2. Dicotyledones.

a) Apetalae.

b) Sympetalae.

c) Eleutheropetalae. 
6. System von A. W. Eichler, publiciert 1883 in: Syllabus, 3. Aufl. und folgende.

\section{A. Cryptogamae.}

I. Abteil. Thallophyta.

I. Klasse. Algae.

I. Gruppe: Cyanophyceae.

II. 》 Diatomeae.

III. „ Chlorophyceae.

I. Reihe: Conjugatae.

II. Zoosporeae.

III. \$ Characeae.

IV. Gruppe: Phaeophyceae.

V. $\gg$ Rhodophyceae.

II. Klasse. Fungi.

I. Gruppe: Schizomycetes.

II. $\gg$ Eumycetes.

I. Reihe: Phycomycetes.

II. 》 Ustilagineae.

III. 》 Aecidiomycetes.

IV. 》 Ascomycetes.

V. Basidiomycetes.

III. Gruppe: Lichenes.

II. Abteil. Bryophyta.

I. Gruppe: Hepaticae.

II. 》 Musci.

III. Abteil. Pteridophyta.

I. Klasse: Equisetinae.

II. 》 Lycopodinae.

III. » Filicinae.

\section{B. Phanerogamae.}

I. Abteil. Gymnospermae.

II. \ Angiospermae.

I. Klasse: Monocotyleae.

I. Reihe: Liliiflorae.

II. „ Enantioblastae.
III. Reihe: Spadiciflorae.

IV. " Glumiflorae.

V. "Scitamineae.

VI. 》 Gynandrae.

VII. 》 Helobiae.

II. Klasse: Dicotyleae.

I. Unterkl. Choripetalae.

I. Reihe: Amentaceae.

II. "Urticinae.

III. » Polygoninae.

IV. » Centrospermae.

V. „ Polycarpicae.

VI. » Rhoeadinae.

VII. \ Cistiflorae.

VIII. " Columniferae.

IX., Gruinales.

X. 》 Terebinthinae.

XI. » Aesculinae.

XII. 》 Frangulinae.

XIII. » Tricoccae.

XIV. „ Umbelliflorae.

XV. „ Saxifraginae.

XVI. 》 Opuntiinae.

XVII. " Passiflorinae.

XVIII. 》 Myrtiflorae.

XIX. » Thymelinae.

XX. 》 Rosiflorae.

XXI. 》 Leguminosae.

Anhang: Hysterophyta.

II. Unterk]. Sympetalae.

I. Reihe: Bicornes.

$\begin{array}{rll}\text { II. } & \text { Primulinae. } \\ \text { III. } & \text { Diospyrinae. } \\ \text { IV. } & \text { Contortae. } \\ \text { V. } & \text { Tubiflorae. } \\ \text { VI. } & \text { Labiatiflorae. } \\ \text { VII. } & \text { Campanulinae. } \\ \text { VIII. } & \text { Rubinae. } \\ \text { IX. } & \text { Aggregatae. }\end{array}$




\section{Das in diesem Syllabus}

I. Abteilung.

PHYTOSARCODINA, MYXOTHALLOPHYTA, MYXOMYCETES.

Seite

1. Klasse Acrasiales . . . . 1

2. 》 Plasmodiophorales. . 1

3. 》 Myxogasteres . . . 1

1. Reihe Ectosporeae. . 2

2. Endosporeae . . 2

II. Abteilung.

SCHIZOPHYTA

1. Klasse Schizomycetes . . . 3

2 . Schizophyceae . . . 5

III. Abteilung.

FLAGELLATAE

1. Reihe Pantostomatinales 7

2. "Distomatinales. . 7

3. \Protomastigales . 7

4. \Chrysomonadales. 7

5. » Cryptomonadales. 7

6. ¿ Chloromonadales . 7

7. „ Euglenales . . . 7

IV. Abteilung.

DINOFLAGELLATAE

? Abteilung.

\section{SILICOFLAGELLATAE}

(s. Nachtrag.)

V. Abteilung.

ZYGOPHYCEAE . . . 8

1. Klasse Bacillariales . . . 9

2. $\gg$ Conjugatae . . . 10

VI. Abteilung.

CHLOROPHYCEAE ...11

1. Klasse Protococcales . . 11

2. \ Confervales . . . . 12

3. $\gg$ Siphoneae . . . . 13

VII. Abteilung.

CHARALES 15
VIII. Abteilung.

\section{PHAEOPHYCEAE}

1. Reihe Phaeospor

IX. Abteilung.

DICTYOTALES 18

X. Abteilung.

RHODOPHYCEAE $\quad 18$

1. Klasse Bangiales . . . 18

2. » Florideae . . . . . 19

1. Reihe Nemalionales . 20

2. „ Gigartinales : .21

3. \ Rhodymeniales . 21

4. » Cryptonemiales.23

XI. Abteilung.

\section{EUMYCETES}

(Fungi)

25

1. Klasse Phycomycetes . . . 25

1. Reihe Zygomycetes . .25

2. "Oomycetes . . . 26

2. Klasse Hemiascomycetes . . 28

Reihe Hemiascales . . . 28

3. Klasse Enascomycetes . . . 28

Reihe Euascales. . . . 29

Anhang zu Klasse 3 und 5 Fungi im. perfecti

Nebenklasse zu Klasse 3 u. 5 Lichenes 38

1. Reihe Ascolichenes . . 38

2. 》. Basidiolichenes. 42

4. Klasse Laboulbeniomycetes .42

Reihe Laboulbeniales . . 42

5. Klasse Basidiomycetes . . . 43

1. Unterkl. Hemibasidii . . 43

Reihe Hemibasidiales .43

2. Unterkl. Eubasidii . . . 44

1. Reihe Protobasidiomycetes . 44

2. $)$ Autobasidio. mycetes . . . 46

XII. Abteilung.

EMBRYOPHYTA ASIPHONOGAMA

(Archegoniatae) . . . 50

I. Unterabteil. BRYOPHYTA(Muscinei) 51

1. Klasse Hepaticae 
zu Grunde gelegte System.

1. Reihe Marchantiales Seit

1. Reihe Marchantiales. 51

3. 》 Jungermanniales:52

2. Klasse Musci . . . . . . 55

1. Unterkl. Sphagnales . . 55

2., Andreacales . .55

3. \$ Bryales . . 56

1. Reihe Acrocarpi . . . 56

2. \leurocarpi . . 60

II. Unterabteil. PTERIDOPHYTA . . 61

1. Klasse Fllicales . . . . . 62

1. Reihe Filicales lepto. sporangiatae. . 62

1. Unterr. Eufilicineae . . 62

z. Hydropteridineae 65

2. Reihe Marattiales . . 66

3. » Ophioglossales . 66

2. Klasse Sphenophyllales . . 67

3. , Equisetales . . . 67

1. Reihe Enequisetales. 67

2 》Calamariales . . 67

4. Klasse Lycopodiales . . . 67

1. Reihe Lycopodiales eli. gulatae . . . . 68

1. Unterr. Lycopodiineae . 68

2., Psilotineae . 68

2. Reihe Lycopodiales ligulatae... . 68

1. Unterr. Selaginellineae . 68

2 \epidophytineae- 68

3. „ Isoetinege . . 69

Anhang Cyeadofllices . . . . 69

\section{EMBRYOPHYTA SIPHONOGAMA}

XIII. Abteilung.

(Siphonogamen, Phanerogamen,

Endoprothalliaten, Samenpflanzen)

I. Unterabteil. GYMNOSPERMAE . . 70

1. Klasse Cycndales . . . . 71

2. "Bennettitales . . . 71

3. Cordaitales . . . 72

4. \ linkgoaleg . . . 72

5. , Coniferae . . . . 72

6. , inetales . . . . 75

II. Unterabteil. ANGiOSPERMAE . . 75
Seite

1. Klasse Monocotyledoneae . 76

1. Reihe Pandanales. . 77

2 Delobiae... . 78

3. „Triuridales. . 80

4. „ Glumiflorae . 81

5. „ Principes . . 84

6. \ynanthae . . 87

7. \$ Spathiflorae . 87

8. Farinosae . . 91

9. " Lilifflorae... 93

10. $\gg$ Scitamineae . . 101

11. 》 Microspernae . 102

2. Klasse Dicotyledoneae . . 106

1. Unterkl. Archichlamydeae 106

1. Reihe Verticillatae. .106

2. $\gg$ Piperales . . 107

3. Salicales . . 107

4. 》 Myricales... 108

5. Balanopsidales. 108

6. Leitneriales . 108

7. „Juglandales . . 108

8. " Fagales... 108

9. Urticales . . 109

10. „ Proteales . . 112

11. „Santalales. . 112

12. Aristolochiales. $\mathbf{1 1 5}$

13 "Polygonales. . 116

14. ॠ Centrospermae. 117

15. . Ranales... 122

16. Rhoeadales . . 198

1\%. Sarraceniales . 132

18. Rosales... 132

19. * Geraniales . 143

20. \Sapindales . . 151

21. Rhamnales . 155

22. \$ Malvales... 156

2.3. ¿ Parietales. . 159

24. * Opuntiales . 166

2.. " Myrtiflorae . . 167

26. Umbelliflorae . 171

2. Unterkl. Metachlamydeae Sympetalae . . 175

1. Reihe Ericales. . . 175

2. $\$$ Primulales . 177

3. . Ebenales . . 178

4. Contortae . . 180

5. "Tubiflorae . 184

6. Plantaginales .197

7. Rubiales . . 197

8. \Campaulatae. 200 


\section{Erklärung der Abkürzungen.}

1. Betreffend die Vegetationsorgane: Pfl. $=$ Pflanze, $\odot=$ einjährig, $4=$ ausdauernd, Kr. = Kraut, $\hbar=$ Holzgewächs, Str. = Strauch, B. = Blatt, opp. oder gegenst. = gegenständig, (9) = spiralig angeordnet.

2. Betreffend den Blütenstand: Invol. = Involucrum, Decksp. = Deckspelze oder Deckblatt, Vorb. = Vorblatt.

3. Betreffend die Blüte und Frucht:

Bl. = Blüte,

ఫ઼ $=$ zwitterig,

o = männlich,

$0=$ weiblich,

$0^{7}$ 우 $=$ eingeschlechtlich,

Blh. = Blütenhülle,

achlam. = achlamydeisch, oder ohne Blh.,

homoiochlam. = homoiochlamydeisch od. mit gleichartiger Blh.,

heterochlam. $=$ heterochlamydeisch oder mit Kelch und Blumenkrone,

haplochlam. = haplochlamydeisch od. mit einfacher Blh.,

diplochlam. = diplochlamydeisch od. mit doppelter Blh.,

$\phi=$ aktinomorph od. strablig,

$\%$ = zygomorph,

(9) = spiralig angeordnet,

$\mathrm{K} .=$ Kelchblätter,

(K.) $=$ Kelch,

$\mathrm{P} .=$ Blumenblätter,

$(\mathrm{P})=$. vereintblättrige Blumenkrone,

Blkr. = Blumenkrone,
Tep. = Tepalen einer homoiochlamydeischen Blh.,

Stb. = Staubblätter,

Stf. = Staubfäden,

A. = Antheren,

(Stb.) = Staubblätter vereint,

Std. = Staminodien,

Cp. = Carpelle,

(Cp.) = Carpelle vereint,

Gr. = Griffel,

$(\mathrm{Gr})=$. Griffel vereint,

N. = Narbe,

G. = Fruchtknoten,

G. = oberständiger Fruchtknoten,

$\overline{\overline{\mathrm{G}}}=$ unterständiger Fruchtknoten,

gef. = gefächert,

Plac. = Placenta,

Sa. = Samenanlage,

Integ. = Integument,

wandst. = wandständig,

grundst. = grundständig,

Fr. = Frucht,

$\mathrm{S}$. = Same,

E. = Embryo.

4. Betreffend die geographische Verbreitung:

trop. $=$ tropisch

palaeotrop. $=$ in den Tropen der alten

Welt,

subtrop. = subtropisch,

calid. = in warmen Ländern,

subcalid. = in ziemlich warmen Ländern,

temp. $=$ in den gemässigten Zonen,

nördl. temp. = in der nördlich gemässigten

Zone,

südl. temp. $=$ in der südlich gemässigten

Zone,

frigid. = in der kalten Zone,

- = auf der nördlichen Hemisphäre,

$\div=$ auf der südlichen Hemisphäre,

Eur. = Europa,
As. = Asien,

Afr. = Afrika,

Austr. = Australien,

Am. = Amerika,

atlant. oder atl. Nordam $=$ atlantisches Nordamerika, pacif. Am. = pacifisches Amerika, alp. = alpin, arkt. $=$ arktisch, medit. = im Mediterrangebiet,

Himal. $=$ im Hinılaya,

Ind. = Indien,

ind.-malay. $=\mathrm{im}$ indisch-malayischen Gebiet.

5. Sonstige Abkürzungen: $0=$ fehlend, $+=$ vorhanden, bisweilen auch $=$ und, $t=$ mehr oder weniger, $\infty=$ zahlreich, hfg. = häufig, lief. = liefert, off. = officinell, Var. = Varietăt, fg. = förmig. 


\section{Nachträge und Verbesserungen.}

S. 5 füge hinter der Familie Coccaceae ein:

Fam. Myxobacteriaceae. Zellen \pm stäbchenförmig ohne Geisseln, mit verschleimter Membran, sich langsam vorwärts bewegend, in Kolonieen (Pseudoplasmodien), welche zu sitzenden oder gestielten Cysten werden. Zellen bisweilen in 4-6 kugelige Sporen zerfallend. - Polyangium vitellinum (auf verrottetem Holz). - Chondromyces aurantiacus (auf afrikan. Antilopenmist). - Myxococcus.

S. 8 lies:

\section{DINOFLA GELIATAE anstatt DINOFLA GELLATA.}

S. 8 zwischen IV. und V. $\Lambda$ bteilung schalte ein:

\section{? Abteilung. SILICOFLAGELLATAE.}

Einzellige mit 1 oder 2 Geisseln, 1 Zellkern und gelbbraunen Chromatophoren versehene Organismen, deren Gehäuse aus Kieselstäben besteht. Verinehrung unbekannt.

Reihe SIPHONOTESTALES. Gehäuse aus hohlen Kieselstäben bestehend, ring-, hut- und pyramidenförmig.

Fam. Dictyochaceae. Zellen mit 1 Geissel. - Mesocena. - Dictyocha. - Distephanus. - Cannopilus. - Alle marin und fossil.

Reihe STEREOTESTALES. Gehäuse aus soliden Kieselstäben zusammengesetzt.

Fam. Ebriaceae. Zellen mit 2 Geisseln. - Ebria (Ostsee, Mittelmeer). Diese Abteilung ist vielleicht mit IV zu vereinigen.

S. 8 \%eile 7 von oben liess "Phacus" statt "Pharus".

S. 49 Zeile 18 von oben liess. „A. Mappa“ statt „bulbosa" und ebendort „in Kiefernwäldern" statt „Laubwäldern".

S. 60 sollten Zeile 11 und 12 folgendérmassen gedruckt werden:

2. Reihe PLEUROCARPI. Archegonien blattachselständig am Hauptstengel oder an den Ästen.

S. 69 '/eile 2 von unten liess .,Protoxylon statt "Poroxylon".

S. 99 Zeile 5 von oben liess "Eucharis" statt ,Eucharia".

S. 100 Zeile 9 von oben liess D. (Testudinaria) statt (D. Testudinario).

S. 105 Zeile 5 von unten liess „Bolbophyllum" statt „Bolphyllum".

S. 132 streiche Byblis bei den Droseraceae. 



\section{Abteilung. P H Y T O S A R C O D I N A, M Y X O TH A L L O P H Y TA, I YXOM Y CETE (Mycetozoa, Schleimpilze, Pilztiere).}

Chlorophyllfreie Organismen, deren Vegetationskörper, Plasmodium genannt, eine aus membranlosen Zellen bestehende Protoplasmamasse ist; Fortpflanzung ungeschlechtlich, durch Sporen, welche frei oder in geschlossenen Behältern entstehen; aus den keimenden Sporen treten Schwärmer (mit Geissel versehen) oder amöboide Protoplasmakörper aus, welche sich zu Plasmodien vereinigen.

\section{Kein Anschluss an höhere Pflanzen.}

1. Klasse ACRASIALES. Saprophyten. Keine Schwärmer, sondern amöboide Körper zum Plasmodium zusammentretend, aber nicht verschmelzend. Sporen in ballenartigen Anhäufungen, ohne Hülle.

Fam. Guttulinaceae. Fruchtkörper ungestielt. Amöboiden ohne Pseudopodien.

Fam. Dictyosteliaceae. Fruchtkörper deutlich gestielt. Amöboide Körper mit zahlreichen spitzen Pseudopodien. - Dictyostelium mucoroides häufig auf altem Mist, faulenden Stoffen, geronnener Milch.

2. Klasse PLASMODIOPHORALES. Parasiten in lebenden Pflanzenzellen. Sporen in Ballen die Nährzelle erfüllend.

Fam. Plasmodiophoraceae. - Plasmodiophora Brassicae erzeugt an den Wurzeln der Kohlgewächse den Kohlkropf oder die Kohlhernie.

3. Klasse MYXOGASTERES. Saprophyten. Aus den Sporen entstehen amöboide Schwärmer mit einer Geissel (Myxomonaden), welche sich durch fortgesetzte Zweiteilung vermehren. Die Myxomonaden werden nach dem Verschwinden der Geisseln zu kriechenden und durch Zwei. teilung sich ebenfalls vermehrenden amöboiden Körpern (Myxamoeben). Hierauf Verschmelzung der Myxamoeben zu Plasmodien, welche sich langsam fortbewegen und auch im Inneren Protoplasmaströmung zeigen, bei den Spumariaceae, Didymiaceae und Physaraceae reichlich kohlensauren Kalk, bei diesen und anderen auch Farbstoffe einlagern. Schliesslich entstehen aus den Plasmodien Fruchtkörper mit zahlreichen, mit einer Membran versehenen Sporen, welche in selteneren Fällen (Ectosporeae mit der

*) Diese Gruppe steht zu den echten Pilzen (Eumycetes) in gar keiner verwandt. schaftlichen Bezichung. Das Wort Pilze wird bald zur Bezeichnung eines physiologischen Begriffes, bald zur Bezeichnung eines systematischen Begriffes angewendet. Die einseitige Bertacksichtigung des physiologischen Verhaltens der Pilze ist die Veranlassung dafur gewesen, dass man drei ganz verschiedene Typen, die Myxomyceten, die Schizomyceten und die Eumyceten, in eine Abteilung zusammengefasst hat. 
Familie Ceratiomyxaceae) mittels eines Stielchens den mannigfach verbundenen Platten des Fruchtkörpers aufsitzen, meistens (Endosporeae mit den übrigen Familien) in dicken abgerundeten, sitzenden oder gestielten Fruchtkörpern (Sporangien) eingeschlossen sind. Stiel und Hülle (Peridie) der Fruchtkörper ohne zellige Structur. Häufig bilden zwischen den Sporen Fäden und dünne Röhren ein Capillitium. Höchst selten entstehen durch Vereinigung von Sporangien sogenannte Aethalien. Plasmodiocarpien sind Fruchtkörper von der gewundenen, aderigen oder netzförmigen Gestalt der Plasmodien. - Bisweilen Ruhezustände der Schwärmer: Microcysten; der jungen Plasmodien: Macrocysten; der erwachsenen Plasmodien: Sclerotien. (Etwa 400.)

\section{Reihe ECTOSPOREAE. (Siehe oben.)}

Fam. Ceratiomyxaceae. - Ceratiomyxa mucida und C. porioides entwickeln ihre Plasmodien in moderndem $\mathrm{Holz}$, die reifen Fruchtkörper bilden weisse orler gelbe schimmelartige Überzïge.

\section{Reihe ENDOSPOREAE. (Siehe oben.)}

a. Fruchtkörper ohne Capillitium.

\section{Fam. Liceaceae.}

Fam. Clathroptychiaceae.

Fam. Cribrariaceae. Peridien stellenweise verdickt, bei der Reife aus netzförmig verbundenen Leisten oder Platten bestehend. - Cribraria mit zahlreichen Arten auf Baumstïmpfen.

\section{b. Fruchtkörper mit Capillitium.}

a. Fruchtkörper ohne Kalkablagerungen.

I. Capillitium aus Röhren bestehend.

Fam. Trichiaceae. - Perichaena. - Arcyria (z. B. A. cinerea zwischen Moos auf moderndem Holz). - Lycogala epidendrum (Fruchtkörper 0,5-1,5 cm dicke Aethalien bildend). - Trichia mit vielen Arten, z. B. T. varia.

II. Capillitium aus soliden Strängen, Platten oder Fäden gebildet.

Fam. Reticulariaceae.

Fam. Stemonitaceae. Einzelsporangien mit schwarzviolettem Mittelsäulchen und Capillitium. - Stemonitis fusca häufig auf Holz, Rinde und Moos.

\section{Fam. Brefeldiacese.}

ß. Fruchtkörper mit Kalkablagerungen.

I. Im Capillitium keine amorphen Kalkausscheidungen.

Fam. Spumariaceae. Fruchtkörper mit langem Mittelsäulchen. - Spumaria alba, die unreifen, Aethalien bildenden Fruchtkörper als weisse, schleimige Massen Laub, Aestchen und lebende Pflanzen im Wald überziehend.

Fam. Didymiaceae. Fruchtkörper mit halbkugeligem oder scheibenförmigem Säulchen oder ganz ohne solches. - Didymium Serpula anf moderndem Laub, D. $f a$ rinaceum anf Rinde und Moos. - Chondrioderma difforme auf faulendem stroh, Laub, Stengeln etc. häufig.

II. Im Capillitium amorphe Kalkausscheidungen.

Fam. Physaraceae. - Leocarpus fragilis häufig an abgefallenen Zweigen, Moos, Gras etc. - Physarum cinereum u. a.; Fuligo septica mit lebhaft chromgelbem Plasmodium und Aethalien bildend, auf Lohe (Lohblüte), in Wäldern, auf Moos und Baumstümpfen. 


\section{Abteilung. S C H I Z O P II Y T A (Spaltpflanzen).}

Meist sehr kleine einzellige, niemals rein chlorophyllgrün, sonst aber oft mannigfach gefärbte Pflanzen, welche sich nur ungeschlechtlich (hauptsächlich durch Zweiteilung, Spaltung in der Mitte) vermehren, entweder einzeln leben oder verbunden bleibend fadenförmige oder scheibenförmige oder nach drei Richtungen ausgedehnte Kolonieen bilden. Normale Zellkerne nicht nachweisbar, dagegen bisweilen sogenannte Centralkörper. Chromatophoren ebenfalls selten; die Farbstoffe vielmehr gleichmässig im Inhalt verteilt oder an der Oberfläche. Fortpflanzung stets ungeschlechtlich, a) durch $\mathrm{Zweiteilung,} \mathrm{b)} \mathrm{durch} \mathrm{Dauerzellen}$ oder Cysten (auch kurzweg Sporen genannt, meist durch reichlicheren Inhalt und stärkere Membran ausgezeichnet), $\alpha$ ) Arthrosporen, durch Membranverdickung vegetativer Zellen entstehend, $\beta$ ) Endosporen oder Endogonidien, im Innern vegetativer Zellen entstehend.

\section{Kein direkter Anschluss an höhere Pflanzen.}

1. Klasse SCHIZOMYCETES (Bacteria, Bacterien). Zellinhalt häufig ganz farblos, seltener pfirsichblütrot oder chlorophyllgrün, ohne Chromatophoren, Membran meist aus Eiweisskörpern bestehend, bisweilen sehr stark aufquellend und schleinig werdend. Zellinhalt meist homogen. Einzelne vermöge der an ihren Enden oder an anderen Stellen der Oberfläche befindlichen Geisseln zeitweise sich lebhaft vorwärts bewegend, hierbei um ihre Achse rotierend.

Teils Aërobionten (bei Luftzutritt wachsend), teils facultative Anaërobionten (sowohl bei Luftzutritt, wie Luftabschluss vegetierend), teils obligatorische Anaërobionten (nur bei völliger Abwesenheit von Sauerstoff gedeihend).

Viele von grossem chemischen Einfluss auf das Substrat, zymogen; z. B. viele vergähren Zuckerarten und erzeugen Milchsäure, Buttersäure, Essigsäure, Kohlensäure, Alkohol, während andere Eiweiss zersetzen, daher von grosser Bedeutung für viele technische Processe. Andere, chromogene, erzeugen Farbstoffe in ihrer Umgebung; zahlreiche, auf und in lebenden Organismen vorkommende, sind pathogen, indem sie Verbindungen wie Ptomaïn, Toxalbumin, ausscheiden, welche auf den die Bacterien ernährenden Organismus schädlich wirken, daher ihre grosse Bedeutung als Erzeuger von Krankheiten, namentlich epidemischen. Wichtig auch ihr Einfluss auf die Beseitigung abgestorbener Tier- und Pflanzenkörper durch Zersetzung derselben in Kohlensäure, Ammoniak und Wasser.

Kulturen der Sch. auf Fleischwasserpeptongelatine, FleichwasserIgar, Blutserum, Milch, Bonillon, Pflanzenaufgüssen etc.; Plattenkultur, Strichkultur, Stichkultur.

1. Reihe EUBACTERIA. Zellen ohne Schwefel und Bakteriopurpurin.

Fam. Bacteriaceae (Stäbchenbacterien). Zellen cylindrisch, kurz oder lang, meist gerade, seltener leicht gebogen, vor der Teilung sich stets auf die doppelte Länge streckend. Nicht selten fadenförmige Kolonieen oder starke A ufquellung (ler Membran. Häufig Endosporen, von grosser Lebensdauer. 
A. Ohne Geisseln: Bacterium (200); a. aymogene und chromogene: $\boldsymbol{B}$. acidi lactici (Ursache des Gerinnens der Milch, der Milchsäuregährung in zuckerhaltigen Flüssigkeiten), $B$. aceticum (Essiggährung), $B$. chrysogloea. D. pathogene: B. murisepticum (Mäuse vertilgend) B. erysipelatos suum (Schweinerotlauf), B. Cuniculicida (Septikämie der Kaninchen), B. anthrucis (Milzbrandbacillus, Milzbrandbacterium 1876), B. Mallei (Rotzkrankheit der Pferde etc.), B. pmeumoniae (Lungenentzündung, croupöse Pneumonie); B. tuberculosis (Tuberculose), B. leprae (Lepra), B. influen:ce (Influenza), B. diphtheritidis.

B. Mit zerstreuten Geisseln an der Oberfläche: Bucillus; $\boldsymbol{\text { I. }}$ nicht pathogene: B. subtilis (Heubacillus), Endosporen (mit aequatorialem Riss bei der Keimung) bildend, B. megatherium, B. virens, B. amylobacter (= Clostridium butyrioum) erzeugt Buttersäure in kohlehydrathaltigen Flüssigkeiten und vermag auch Kasein zu lösen, $\boldsymbol{B}$. prodigriosus (Brot rotfärbend, Hostienpilz), B. vulgaris (Fäulniss in Eiweisskörpern hervorrufend; B. radicicola (Rhizobium leguminosarum) mit zahlreichen, die Wurzeln verschiedener Leguminosen bewolnenden und denselben angepassten Rassen, nach ihrem Absterben in den W'urzeln der Leg. gespeichert und den Boden mit Stickstoff anreichernd. b. pathogene: B. tetani (anaërob, Wundstarrkrampf), B. typh $\boldsymbol{i}$ (Unterleibstyphus) B. carbonis, (anaërob, erzeugt Rauschbrand bei Rindvieh, Schafen, Ziegen, welcher mit Erfolg durch Impfung bekämpft wird), B. oedematis (anaërob, Wundinfectionskrankheiten bei Tieren), B. suicida (Schweineseuche), B. typhi murium (epidemisch bei Feldmäusen).

C. mit polaren Geisseln: Pseudomonas; Ps. pyocyanea (blater Eiter), Ps. syncyanea (blawe Milch), Ps. putrida, häufig in Wässern, Ps. europaea (Erreger der Nitrification im Boden).

Fam. Spirillaceae (Schraubenbacterien). Halbkreisförmige bis schraubenförmig gewundene Zellen, ohne oder mit polaren Geisseln.

A. Zellen starr, nicht schlangenartig biegsam: Spirosoma nasale im Nasenschleim, ohne Geisseln. - Microspira (Vibrio) (30), mit meist einzelnen polaren Geisseln; M. comma (Cholerabacillus, Kommabacillus) Erreger der asiatischen Cholera, bildet auf Platten cultiviert seharf umrandete, glitzernde, höckerige Kolonieen), M. Finkleri und andere. - Spirillum (20), schraubig gewundene Stäbchen, mit Büscheln von Geisseln an beiden Polen: Sp. undula und Sp. volutums u. a. in faulendem Wasser, Sp. rufum, mit rötlichem Zellinhalt, blutrote Schleimüberzüge zwischen Algen bildend.

B. Zellen schlangenartig biegsam: Spirochaete (5), lange, einzellige Schraubenfäden, mit schlangenförmiger Bewegung; Sp. plicatilis in Sumpfwässern; Sp. Obermeieri, Erreger des Rückfalltyphus; $S p$. dentium im Zahnschleim.

Fam. Chlamydobacteriaceae. Fadenförmige, von \pm deutlich sichtbarer Scheide umgebene Kolonieen bildende Zellen, welche nur selten sich nach 3 Richtungen des Raumes teilen. Fortpflanzung durch Teilzellen (Conidien). - Phragmidiothrix. - Crenothrix (1) polyspora in Brunnen 
und Wasserleitungen. - Sphaerotilus (20) dichotomus auf Sumpfund Schmutzwässern Uberzüge bildend, Spl. natans in Fabrikwässern, Sph. (Actinomyces) bovis, Geschwülste im Körper von Tieren und Menschen erzeugend.

Fam. Coccaceae (Kugelbacterien). Zellen kugelig, vor der Teilung sich nicht in die Länge streckend. Zellteilung nach 1, 2 oder 3 Richtungen des Raumes. Frei oder in Kolonieen, ohne Geisseln und ohne Bewegung. Endosporen selten. - Streptococeus (incl. Lenconostoc und Torula) (20); St. erysipelatos bei Erysipel und anderen bösartigen Entzündungsprocessen, auch im Eiter; ebenso auch St. pyogenes; St. (IJeuconostoc) mesenterioides, Erzeuger der Dextrangährung in der Melasse der Zuckerfabriken. - Micrococcus (150); а. zymogene: M. ureae (Harngährung) M. acidi lactici (Milchsäuregährung); b. chromogene : $M$. aurantiacns, $M$. luteus, $M$. cinnaliareus; $c$. pathogene: $M$. gonorrhoeae, Erreger der Gonorrhoea, M. vacciniae, wirksamer Bestandteil der Pockenlymphe, $M$. variolue ovinae in der Lymphe der Schafpocken. - Sarcina (45); S. pulmonum im Sputum von Phthisikern, S. ventriculi im Mageninhalt von Magenkranken. - Planococcus. - Planosarcira.

2. Reihe THIOBACTERIA. Zellen mit Schwefeleinschlüssen, farblos oder durch Bakteriopurpurin rot oder violett.

Fam. Beggiatoaceae. Durch undulierende Membran bewegliche, fadenförmige Kolonieen ohne Scheide bildende Zellen, welche Schwefelkörnchen enthalten. - Beggiatoa (10) alba in Schwefelthermen und unreinem Wasser. - Thiothrix nivea in Schwefelquellen.

Fam. Rhodobacteriaceae. Zellinhalt durch Bacteriopurpurin rosa, rot oder violett gefärbt, mit Schwefelkörnchen. - Lamprocystis (5) roseopersicina in Sümpfen und Gräben. - Chromatium Okenii in sïmpfen, wie vorige mit Geisseln.

2. Klasse SCHIZOPHYCEAE (Cyanophyceae, Phycochromaceae, Spaltalgen). Die Zellen enthalten Phycocyan, welches mit Chlorophyll gemischt das Phycochrom (blau, blaugrün, violett, rötlich) bildet. Keine Sschwärmzellen.

Fam. Oscillatoriaceae (Jyngbyaceae). Scheibenförmige Zellen bilden einfache fadenförmige Kolonieen ohne Grenzzellen (nicht teilungsfähig, auch Heterocysten genannt) und ohne Haarspitze, meist mit Scheiden. In den Scheiden sondern sich bisweilen Hormogonien ab (Fadenstücke, welche sich in der Scheide bewegen und dann heraustreten). - Oscillatoria (Bewegung mit Drehung, viele (38) Arten in unreinen Wässern und Thermen). - Phormidium (50) (mit Hormogonien), P/l vulyare an schattigen und feuchten Orten. - Microcoleus (7) terrestris auf feuchter Erde. - Arthrospira (3) .Jenneri in schmutzigen Wässern. - Spirulina (9) versicolor im Brackwasser.

Fain. Scytonemataceae. Zellen in unecht verzweigten Fäden, da einzelne Fadenstiicke seitlich heraustreten und die Scheide durchbrechen. Keine Haarspitze. Grenzzellen, Dauerzellen. - Scytonema (24) myochrous 
und andere auf feuchten Felsen und Erde; Sc. Hofmannii in Gewächshäusern. - Tolypot/ırix (6) lanata an Wasserpflanzen und frei im Wasser.

Fam. Stigonemataceae (Sirosiphonaceae). Wie vorige, aber Zellteilung parallel der Längsaxe des Fadens, wodurch derselbe oft mehrreihig wird. - Stigonema (11) ocellatum u. a. auf feuchten Felsen und auf Moos, auch als Gonidie in Flechtenpilzen. - Hapalosiphon fontinalis an Wasserpflanzen.

Fam. Nostocaceae. Kugelige Zellen bilden unverzweigte Fäden ohne Haarspitze; Grenzzellen, Dauerzellen, Hormogonien. - Nostoc (29) Iinckia im Wasser, $N$. splacerioum im Wasser und auf feuchter Erde, $N$. commune auf feuchten Wiesen und Äckern; einzelne in Anthoceros, Blasia, Lemna, Gunnera, Flechtenpilzen. - Aurbciena (10) flos aquae in stehendem Wasser. - Aphaniamenon (2) flos aquae oft Teiche überziehend. Nodularia (4) häufig im Meer und Brackwasser. - Cylindrospermum (5) stagnale und andere auf nasser Erde, auch auf Blumentöpfen.

Fam. Rivulariaceae. Zellen in einfachen oder unecht rerzweigten Fäden mit haarförmiger Spitze mit Scheiden. Grenzzellen, Dauerzellen, Hormogonien. - Calothrix (23) pulvinata u. a. im Meere; C. parietina auf Steinen und $\mathrm{Holz}$ im Süsswasser. - Rivularia (18) pisum und $R$. natans in Teichen etc.; $R$. minutula an Wasserpflanzen, $R$. liaematites (Lager mit kohlensaurem Kalk incrustiert) an Wasserfällen.

Fam. Chroococcaceae. Zellindividuen rundlich, einzeln oder durch Gallertausscheidung zu (niemals fadenförmigen) Kolonieen verbunden, ohne Gegensatz von Basis und Spitze. Zellteilung in einer Richtung (G'loeothece - Aphanothece), nach zwei Richtungen (Merismopedia) und in drei Richtungen (Coelosphaerium - Clathrocystis aesuginosa - Gloeocopsa, Chroococcus, auch mit Flechtenpilzen symbiotisch). Bisweilen Dauerzellen.

Fam. Chamaesiphonaceae. Zellindividuen meist mit deutlichem Gegensatz von Basis und Spitze, einzeln oder kleine Kolonieen bildend. Endogonidien. - Chamaesiphon incrustans auf Wasserpflanzen.

\title{
III. Abteilung. F L A GE L L A T A E.
}

\author{
(Nach Dr. Senn.)
}

Einzellige mit Zellkern und scharf begrenztem Protoplasmakörper versehene Organismen, teils mit einfacher Hautschicht, teils mit differenzierter Plasmamembran, niemals mit Pseudopodien, während des grössten Teiles ihres Lebens beweglich, selten wimperlos, meist an Vorderende mit 1 oder mehreren Wimpern (Geisseln, Flagellen) und mit 1 oder 2 pulsierenden Vacuolen. Vermehrung ungeschlechtlich durch einfache Längsteilung, meist im geisseltragenden Zustande, bisweilen in der Ruhe. Viele für längere oder kürzere Zeit Dauercysten bildend. Ernährung tierisch, saprophytisch, parasitisch oder holophytisch. 


\section{Übergånge zn den Chlorophyceae und Phaeoplyceae.}

1. Reihe PANTOSTOMATINALES. Alle Stellen der Zelloberfläche können mit Hilfe von Pseudopodien feste Nahrung aufnehnen.

Fam. IIolomastlgaceae. - Multicilia im Süsswasser und marin.

Fam. Rhizomnstlgacene. - Mnstigamoeba in Süsswasser.

2. Reihe DISTOMATINALES. Aufnahme fester Nahrung nur an 2 bestimmten Stellen der Zelloberfläche. Vier bis viele parig angeorduete (ieisseln.

Fain. Distomataceae. - Megastoma entericum in Dünndarm von Menschen und anderen Säugetieren.

3. Reihe PROTOMASTIGALES. Aufnahme fester Nahrung nur an einer Mundstelle. 1-4, niemals paarige Geisseln, Vacuolen von einander unabhängig pulsierend. Niemals Plasmamembran. Farblos. Ernährung tierisch oder saprophytisch. Stoffwechselprodukt: fettes Öl.

Fam. Oicomonadaceae.

Fam. Bicoecaceae. - Biroeca im Süsswasser.

Fam. Craspedomonadaceae. - Protospongia im Süsswasser und marin. Diplosiga im Sïsswasser.

Fam. Phalansteriaceae.

Fan. Monadaecae. - Monas vivipara im Süsswasser.

Fam. Bodonaceae. - Bodo im Süsswasser, marin und parasitisch, im Darm von Vertebraten und Insekten.

Fam. Amphimonadaceae.

Fam. Trimastigaceae. - Costı necatrix, ektoparasitisch auf jungen Forellen, Epidemieen erzeugend.

Fam. Tetramitaceae. - Costiopsis Nitschei auf Goldfischen. Tetramitus, im Darm von Menschen, Schlangen und Insekten.

4. Reihe CHRYSOMONADALES. Wie Reihe 3, aber mit gelbbraunen ('hromatophoren. Stoffwechselprodukt: fettes Öl und Leukosin.

Fam. Chromulinaceae. Nit 1 Geissel. - Chromulina. - Chrysamoeba. - Hydrurns foetidus in Süsswasser. - Clirysopyxis.

Fam. Hymenomonadaceae. - Synura. Uroglena.

Fun. Ochromonadaceac. - Dinobryon sertularia im Süsswasser. - Epipyxis. -

5. Reihe CRYPTOMONADALES. Wie Reihe 3. Zellen farblos oder unit 1-2 Chromatophoren von verschiedener Färbung. Stoffivechselprodukt: stärke. Ernährung nie tierisch.

Fan. Cryptomonadaceae. - Cryptomonas im Süsswasser und marin.

6. Reihe CHLOROMONADALES. Mehrere contractile Vacuolen am I'orderende zu einem gemeinsam funktionierenden System vereinigt. Häufig grüne Chromatophoren in den nicht amöboiden, aber hïufig metabolischen Körper. Hautschicht glatt. Stoffivechselprodukt: fettes Öl.

Fam. Chloromonadaceae. - Vacuolaria. - Cliloramoeba im süisswasser. - Rhaplidomonus.

7. Reihe EUGLENALES. Wine nicht oder nur schwach contractile, in den Körper eingesenkte Hauptvacuole mit Ausfuhrkanal und mehrere 
sich darein ergiessende, pulsierende Nebenvacuolen. Deutliche, häufig gestreifte und resistente Plasmamembran. Stoffwechselprodukt: fettes Öl und Paramylon.

Fam. Euglenaceae. Radiär gebaut, frei rotierend schwimmend, mit grünen Chromatophoren und rotem Augenfleck. Ernährung nie tierisch. Euglena (18) im Süsswasser und marin; E. viridis, sanguinea (durch Lipochrom rot), oft massenhaft in Teichen. - Pharus pleuronectes. - Trachelomonas. Distigma.

Fam. Astasiaceae. Wie vorige, aher farblos. Saprophyten. - Astasia. -

Fam. Peranemataceae. Bilateral, meist mit kriechender Bewegung. Ernährung tierisch. - Peranema. - Heteronema acus im Süsswasser. - Euglenopsis. - Anisonema.

\section{Abteilung. D I N O F L A G L L A T A.}

(Peridiniales, Peridineae, Cilioflagellata.) [Nach Prof. Dr. Schütt.] Sehr klein, einzellig, bisweilen in kettenförmigen Kolonieen, meist mit panzerartiger, aus 2 oder mehr Tafeln zusammengesetzter Cellulosemembran. Tafeln in Schalen und Gürtel gegliedert. Panzerhälften nicht schachtelartig beweglich. Chromatophoren. Zweiteilung, bei welcher jede Tochterzelle eine Hälfte der Muttermembran erhält und eine andere neu ausscheidet. Bewegung durch 2 aus einem Membranspalt entspringende Geisseln, eine voranschreitende oder rückwärts gerichtete Längsgeissel und eine um den Körper quer herumgelegte Quergeissel. Sporen in Gallerthülle und Schwärmsporen. Meist marine Planktonpflanzen (Hochseepflanzen, am Meeresleuchten beteiligt).

Fam. Gymnodiniaceae. Zellen ohne Panzer mit Längs- und Querfurche. Pyrocystis (3) Lunula in allen Europa umgebenden Meeren.

Fam. Prorocentraceae. Zellen mit Panzer aus 2 Schalen, ohne Querfurche. - Exuviaella (3) marina. - Prorocentrum (4) micans.

Fam. Peridiniaceae. Zellen mit Panzer von mehr als 2 Platten. Quergeissel in Querfurche geborgen. Vermehrung ungeschlechtlich durch Zweiteilung. Schwärmsporenbildung verbunden mit Abwerfung des Panzers, mit oder ohne Gallerthüllenbildung. - Von Bedeutung für die Ernährung der Meerestiere. Wenige Arten im Süsswasser. - Ptychodiscus (1) Noctiluca. - Pyrophacus horologium. - Ceratium (40-50) tripos, besonder häufig in der Ostsee. - Peridinium (9) divergens.

\section{Anschluss an die Zygophyceae.}

\section{Abteilung. Z Y G O P H Y CEAE.}

Mit Membran Zellkern und Chromatophoren versehene einzellige Wasserpflanzen, welche sich durch Teilung in der Mitte und durch Conjugation vermehren. 


\section{Nach unten Anschlnss an die Dinoflagellata. Kein Anschluss an höher stehende Abteilungen.}

\section{Klasse BACILLARIALES. (Diatomeen.) [Nach Prof. Dr.} Schütt.] Sehr klein, einzellig, nicht reines Chlorophyll, sondern durch Diatomin gelb oder braun gefärbte Chromatophoren enthaltend, häufig lineare oder durch Verschiebung auch anders gestaltete, bisweilen auch gabelige Kolonieen bildend. Membran mit Kieseleinlagerung, aus zwei mittels der Gürtelbänder schachtelartig übereinander greifenden Panzerhälften bestehend; Gürteltafel oder Nebentafel ohne Sculptur; Schalentafeln (Hauptseiten) mannigfach mit nach aussen hervortretenden Leisten oder Knötchen, bisweilen mit Längsspalten, häufig mit areolären Liniensystemen. Mehrere mit 2 oder mehr spaltenartigen Membrandurchbrechungen (Naht, Raphe) und und mit Eigenbewegung durch ein aus der Raphe heraustretendes und strömendes Protoplasmaband. Teilung nur in einer Richtung, parallel zu den Hauptseiten; demzufolge allmäliche Abnahme der Grösse eines Teiles der Individuen. W'iederherstellung der ursprünglichen Grösse durch Auxosporenbildung. Dieselbe ist entweder eine Art Verjüngung, indem das Protoplasma eines Individuums wächst und sich mit einer neuen Membran umgiebt, oder indem das Protoplasma zweier Individuen zusammentritt, ohne zu verschmelzen, und zwei Auxosporen entstehen; oder die Auxosporenbildung ist eine Art Conjugation, bei welcher entweder nach Vereinigung des Inhaltes zweier Zellen 1-2 Auxosporen entstehen oder nach Teilung des Plasmas zweier gleich grosser Individuen die halben einander gegenüberliegenden Protoplasmakörper paar weise in Verbindung treten. Seltener Ruhesporen. - Im Süsswasser und Meer, oft massenhaft. - Bisweilen mächtige Ablagerungen abgestorbener B. (Kieselguhr).

Fam. Bacillariaceae. Charakter der Klasse.

A. Centricae. Schalen centrisch; Structur regellos, concentrisch oder radiär, nicht gefiedert. Keine Raphe oder Pseudoraphe. Querschnitt kreisförmig, polygnnal, elliptisch, selten schiffchenförmig oder unregelmässig. Chromatophoren meist klein und zahlreich.

Unterfam. Discoideae. Zellen discusartig, flache Scheiben, kurze Büchschen. Melosira (130) varians, sehr häufig im Süsswasser. - Sceletonema (10) costatum, häufig im Plankton der Ostsee. - Cuscinodiscus (330). - Aulacodiscus (119). - Auliscus (130) peruvianus im Peru-Guano.

Unterfam. Solenioideae. Zellen stabartig, mehrfach länger als dick, meist von kreisförmigem Querschnitt. - Rhizosolenia (34) setigera u. a. im Plankton.

Unterfam. Biddulphioideae. Zellen büchsenförmig, kürzer oder ein wenig länger als breit. Schalen mit meist 2, seltener mehr Polen; jeder Pol init Ecke und Buckel oder Horn. Querschnitt meist elliptisch. Schalen oft pseudozygomorph. - Bacteriastrum (5) varians in nordatlantischen Plankton. - Chaetoceras 46), viele Arten marin und im Plankton, - Triceratiun (455), marin und fossil. Hemiaulus (73), marin und fossil.

B. Pennatae. Schale nicht centrisch, zygomorph. Querschnitt meist schiffchen- oder stabförmig. Structur gefiedert. Fiedern in bestimmtem Winkel zur Raphe oder rapheähnlichen Sagittallinie. Active 
Bewegung in der Richtung der Raphe in Folge von Protoplasmaströmung in derselben.

Unterfam. Fragilarioideae. Schalen olıne Raphe, mit sagittaler linie, bisweilen mit Rapheanfang. - Tabellaria (35), im Sisswasser, marin oder fossil. Grammatophora (36) marinı, Kosmopolit. - Diatoma (7), im Süsswasser. Fragilaria (102), im Sïss- und Salzwasser, sowie fossil. - Syneirle (105), wie vorige. - Eunotia (60), im Süsswasser und fossil.

Unterfam. Acluanthoideae. Eine Schale mit echter Raphe, die andere mit Pseudoraphe. Zelle gekrïmmt oder geknickt. - Achnanthes (70 - Cocconeis (120). Beide marin und im Sitsswasser, letztere meist epiphytisch anf Algen.

Unterfam. Naviculoideae. Beide Schalen mit Raphe, letztere in der Sagittallinie. Schale ungekielt oder Kiel in der Sagittallinie. - Navicula (900 einschliess. lich Schizonema, Pinnularia etc.). - Pleurosigma (107), meist marin. - Gomphonema (66) mit gestielten Zellen. - Cymliella (64). - Amphora (220). - Epithemia (26). - Bucillaria (4) paradoxa in Siiss- und Salzwasser. - Nitzschia (180).

Unterfam. Surirelloideae. Beide sichalen mit Raphe; dieselbe versteckt in seitlichen Flügelkielen. - Surirella (194), im Süss- und Salzwasser. - Campylodiscus (112) meist marin.

2. Klasse CONJUGATAE. Chlorophyllgrüne Algen ohne Kieselsäureeinlagerung in der Membran. Zellen stets in der gleichen Richtung sich teilend, einzeln oder Faden bildend. Nie Schwärmer. Geschlechtliche Fortsetzung durch Vereinigung von Aplanogameten zu Zygosporen. Selten Akineten (dickwandige Dauerzellen) oder Aplanosporen (verjüngte Protoplasmakörper).

Fam. Desmidiaceae. Zellen meist durch eine Einschnürung in der Mitte in zwei symmetrische Hälften geteilt oder wenigstens mit symmetrisch verteiltem Inhalt; Chromatophoren mannigfach; Nembran aus zwei über einander greifenden Schalen bestehend; Individuen einzeln lebend oder Fäden bildend. Die aus der Zygospore hervorgehende Keimzelle nimint entweder die Gestalt der vegetativen Zellen an oder erzeugt durch Teilung 2, 4, 8 Individuen. - (Etwa 700) nur in süssem Wasser, namentlich in Torfsümpfen, an nassen Felswänden, zwischen Moos, auch in sonst reinem Quellwasser. - Penium, Closterium (95), Cosmurium (300), Staurastrum (250), Enastrum - in Kolonicen: Hyalotheca, Desmidium (15).

Fam. Zygnemataceae. Zellen eylindrisch und unverzweigte Fäden bildend. Chromatophoren mannigfach. Der gesammte Inhalt der copulierenden Zellen vereinigt sich zu einer Zygospore, welche bei der Keimung direct zu einen neuen Zellfaden auswächst. Auch Parthenogenesis. (100) in Süsswasser und Brackwasser. - Zygnemen (25), Sprirogyrol (70), Zygogonium (2).

Fam. Mesocarpaceae. Zellfáden wie bei voriger. Chromatophor eine axile Chlorophyllplatte. Nur ein Teil des Inhaltes der copulierenden Zellen vereinigt sich zu einer Zygospore, sonst wie vorige. Auch Parthenogenesis. - (32) im Sïsswasser und Brackwasser. - Mougeotia. 


\section{V1. Abteilung. CHLOR O P H Y CE A E.}

Chlorophyllgrüne Zellen mit ein oder mehreren Zellkernen, einzeln oder in Kolonieen oder zu mehrzelligen Individuen (Fäden, Flächen, Körpern) vereinigt. Meist ungeschlechtliche Fortpflanzung durch multilaterale Schwärmer, ausserdem Akineten (einzelne Zellen mit stark verdickter Wand), Aplanosporen (Zellen ohne Bewegung, welche sich mit einer neuen Membran umgeben). - Geschlechtliche Fortpflanzung durch Copulation schwärmender Gameten (Gametosporen oder (ramosporen) odervon Spermatozoiden und Oosphären (Oosporen); die Sporen entweder eine neue Pflanze erzeugend oder meistens erst schwärmer bildend.

Nach unten anschliessend an die Flagellata, nach oben Vorstufe für die niediren Embryophyten; aber nur bei Colcochaete die befruchtete Eizelle sich durch Teilung zu einem von der Mutterpflanze eingeschlosseneu Gewebekörper, einem Embryo, entwickelnd.

1. Klasse PROTOCOCCALES. Zellen mit einem, selten mehreren Zellkernen, einzeln lebend ohne Spitzenwachstum oder zu Kolonieen vereint, aber nicht eng unter einander verbunden, häufig in Gallerte eingelagert.

a. Vegetative Zellen activ beweglich.

Fam. Volvocaceae. Zellen mit zwei bis sechs Cilien, meist je ein Chromatophor enthaltend, einzeln schwärmend oder in beweglichen Kolonieen. Gametosporen und Oosporen. - (25) meist in Süsswasser, einige in Brackwasser.

A. Zellen einzeln. Gamosporen. Chlamydomonas (6) pulvisculus. - Spleciella (4) pluvialis in Wasseransammlungen; Sph. nivalis auf Schnee (beide durch Haematochrom blutrot).

B- Zellen in Kolonieen von bestimmter Form. - Tafeln: Gonium (2) pectorale. - Kugeln mit äquatorial geordneten Zellindividuen: Stephanosphaer (1) pluvialis. - Kugeln mit allseitig abstehenden Cilien: Pandorina (1) monum (Gametosporen), Eudorina (1) elegans und Tolvox (3) globator (Oosporen).

b. Vegetative Zellen nicht activ beweglich.

$\alpha$. Vegetative Zellteilungen vergrössern die Kolonieen.

Fam. Tetrasporaceae. Schwămer. Zellen an Gallertstielen oder in Gallertmassen von bestimmter Form, - (30) im silssen Wasser und auf feuchtem Boden. Tetraspora lubrica.

Fam. Chlorosphaeraceae. Wie vorige; aber Gallertmassen ohne bestimmte Form. - (5) im stissen Wasser oder in Wasserpflanzen. - Chlurosphaera Alismatis in toten Blättern von Alisma plantago.

Fam. Pleurococcaceae. Keine Schwärmer. Zellgestalten mannigfach. Vermehrung nur durch vegetative Teilungen. - (50) im süssen Wasser und auf feuchtem Substrat. - Pleurococcus (9) vulgaris namentlich auf Baumstämmen und an feuchten Mauern, auch mit vielen Flechten 
symbiotisch. - Scenedesmus (10) im Wasser. - Eremosphaera im Süsswasser.

$\beta$. Vegetative Zellteilungen fehlen.

Fam. Protococcaceae. Zellen meist einzeln, selten in Kolonieen von unbestimmter Form. Schwärmer mit 1-2 Cilien. Gametosporen. - (90) inn süssen Wasser oder auf feuchtem Substrat, wenige im Meerwasser. Chlorococcum (20) lnumicola auf feuchter Erde und an Baumstämmen, häufig mit Flechtenpilzen symbiotisch. - Chlorochytrium (8) in lebenden Wasserpflanzen. - Characium (35) auf Wasserpflanzen.

Fam. Hydrodictyaceae. Zellen zu bestimmt geformten Kolonieen vereinigt. Schwärmer mit zwei Cilien oder cilienlose Tochterzellen bilden innerhalb der Mutterzelle oder einer Gallerthülle Kolonieen von der Art der Mutterkolonie. Bei einigen Gametosporenbildung bekannt. - (36) im süssen Wasser. - Pedinstrum (25). - Tydrodictyon (1) reticulatum, Wassernetz.

2. Klasse CONFERVALES. Zellen mit einem oder mehreren Zell. kernen, einfache oder verzweigte Fäden, seltener ein- bis zweischichtige Fäden bildend.

A. Zellen mit nur je einem Zellkern.

a. Gametosporenbildung.

Fam. Ulvaceae. Thallus besteht aus einem oder zwei parenchyma. tischen Zellschichten, welche bisweilen eine hohle Röhre bilden. Ungeschlechtliche Schwärmer mit vier Cilien. Gameten mit 2 Cilien. - (70) im süssen Wasser und im Meer. - Monostroma (27) bullosum im süssen Wasser; M. Grevillei im Meer - Ulva (8) latissima und Enteromorpha (30) littoral.

Fam. Ulotrichaceae. In der Regel eine einfache unverzweigte Zellreihe, welche ausnahmsweise auch zu einer Zellfläche wird. Schwärmer mit einer oder vier Cilien. Akineten und Aplanosporen. Gameten mit zwei Cilien. - $(50-60)$ in süssen Wasser, Brackwasser und auf feuchtem Boden. - Ulothrix (5) zonata. - Hormidium (6) parietinum (in Prasiola crispa übergehend) auf feuchter Erde. - Conferva bombycina.

Fam. Chaetophoraceae. Eine verzweigte, aufrechte oder kriechende Zellreihe. Schwärmer mit zwei oder vier Cilien. Gameten mit zwei Cilien. - (116) meist in Süsswasser, einzelne auch auf Felsen und epiphytisch. - Stigeoclonium, Draparnaldia (10), Chaetophor' (10), meist im süssen Wasser. - Entoderma viridis auf Algen im Brackwasser. - Epicladia (1) Flustrae an Bryozoen. - Trentepohlia (30) iolithus auf Steinen (Veilchenstein); T. umbrinc auf Baumrinden und mit vielen Flechtenpilzen symbiotisch.

Fam. Mycoideaceae. Eine ein- oder mehrschichtige, regelmässige Zellscheibe. Schwärmer mit zwei oder vier Cilien, Gameten mit zwei Cilien. - (7) - Phycopeltis epiphyton, epiphytisch auf Blättern der Tanne, des Epheus und von Rubus. - My. coidea parasitica endophytisch zwischen Cuticula und Epidermiszellen auf Blattern von Treibhauspflanzen. 
b. Oosporenbildung.

Fam. Cylindrocapsaceae. Einreihige, unverzweigte Zellfaden. Die vegetativen Zellen erzeugen entweder einen grossen oder zwei bis vier kleinere Schwärmer mit z.wei Cilien. Antheridien erzeugen je zwei Spermatozoiden mit zwei Cilien, die Oogonien eine Oosphäre. - Auch Parthenogenesis. - 4 in süssem Wasser. Cylindrocapsu.

Fam. Oedogoniaceae. Ein verzweigter oder unverzweigter Zellfaden. l)ie vegetativen Zellen bilden je einen Schwärmer mit einem Kranz von Cilien. Antheridien erzeugen je eine oder zwei Spermatozoiden mit einem Kranz von Cilien, die Oogonien eine Oosphäre. Aus der Oospore entstehen bei der Keimung zunächst vier Schwärmsporen. - Zwergmännchen, aus kleinen Schwärmern entstanden, entwickeln sich entweder direct zu einem Antheridium oder einem ơ Pflänzchen mit einer oder einigen vegetativen Zellen und einem oder mehreren Antheridien. - (178) - Oedoyonium (138) curvum (nonöcisch), O. capillare (diöcisch). - Bulbochaete (40).

Fam. Coleochaetaceae. Auf Algen oder im Wasser befindlichen Gegenständen aufsitzend, aus dichotomisch verzweigten, oft pseudoparenchymatisch vereinigten Zellreihen bestehend. Schwärmer mit zwei Cilien einzeln in den vegetativen Zellen entstehend. Antheridien am Ende der Fäden je ein kugeliges Spermatozoid mit zwei Cilien erzeugend. Oogonien einzeln an Ende der Fäden flaschenförmig, mit einer Oosphäre. Nach der Befruchtung wachsen von der das Oogoniuın tragenden Zelle Fäden ans, welche sich an das Oogonium anlegen und dasselhe berinden. Dic keimende Oospore entwickelt eine kleine parenchymatische Schoibe, in deren Zellen je eine Schwärmspore entsteht. - Coleochaetc (6), im Süsswasser.

B. Zellen mit mehreren Zellkernen, einfache oder verzweigte Faden bildend, bei denen die Seitenzweige wie die Hauptaxen gebaut sind.

a. Gametosporenbildung.

Fam. Cladophoraceae. Fäden unverzweigt oder verzweigt, aufrecht. Schwärmer mit zwei oder vier Cilien. Ausserdem Akineten. Gameten mit zwei Cilien. - (300) im Süss- und Brackwasser. - Chaetomorpha linum. - Cladophore fracta; $\mathrm{Cl}$. Sauteri.

Fam. Gomontiaceae. Făden dorsiventral. Sporangien wachsen aus dem Mutterfarlen heraus und bilden Rhizoiden. In den Sporangien Schwärmer mit zwei Cilien oler Aplanosporen. - Gomontia polyrrhiza in alten Kalkschalen von Meeresmollusken.

b. Oosporeubildung.

Fam. Sphaeropleaceae. Fäden unverzweigt, freischwimmend, init langgestreckten vielkernigen Zellen, welche keine Schwärmer bildeu. Antheridien $\infty$ langgestreckte Spermatozoiden mit zwei Cilien erzeugend, Oogonien mit mehreren Oosphären, beide durch viele Poren sich öffnend. Lus der Oospore entstehen bei der Keimung direct 1-8 Schwärmer mit zwei Cilien. - Sphaeroplea (1) annulina im süssen Wasser.

3. Klasse SIPHONEAE. Zellen mit $\infty$ Zellkernen, mit Spitzenwachstum, einfach oder \pm verzweigt, selten im vegetativen $/ /$ ustande mit Querwänden. 
a. Thallus eine ungeteilte einfache oder verzweigte Zelle, deren Aeste von begrenztem Wachstum sind und daher auch als Blätter be. zeichnet werden, die aber nicht quirlig an der Hauptaxe stehen. Zellenäste nicht zu einem unechten Gewebe verflochten.

Fam. Botrydiaceae. Vegetativer Thallus einzellig, keulenförmig mit dünnerem, einfachem oder verzweigtem Wurzelende. Schwärmer mit einer oder zwei Cilien. Dauersporen - Aplanosporen - Hypnosporangien. Gameten mit zwei Cilien in Gametangien entstehend. - (7) - Codiolum (6) gregarium im Meerwasser. - Botrydium granulatum, herdenweise auf feuchtem Lehmboden.

Fam. Phyllosiphonaceac. Thallus einzellig mit $\infty$ gleichartigen, fadenförmigen ' weigen, parasitisch in Landpflanzen lebend. Nur Aplanosporen bekannt. - Phyllosiphon Arisari auf Arisarum in Südeuropa.

Fam. Bryopsidaceae. Vegetativer Thallus einzellig, reich verzweigt mit Rhizoiden, unbegrenzten und begrenzten Aesten ("Blätter»). In den begrenzten Aesten kleine braune $\precsim$ Gameten und grössere grüne $ᄋ \mathrm{Ga}$ meten, beide mit zwei Cilien. Schwärmer nicht bekannt. - (26) im Meer. - Bryopsis (25) plumosa schon in der Ostsee.

Fam. Vaucheriaceae. Vegetativer Thallus eine schlauchförmige, oft dichotomisch verzweigte Zelle, bisweilen mit Rhizoiden. Zellmembran nicht incrustirt. Schwärmer entstehen einzeln in den durch eine Querwand abgegrenzten Astspitzen. Aușserdem Akineten und Aplanosporen. Antheridien und Oogonien durch eine Querwand vom Thallus abgegrenzt; Antheridien $\infty$ Spermatozoiden mit zwei Cilien erzeugend; Oogonien nit einer Oosphäre. - (25) im Süsswasser und Brackwasser. - Vumcheria sessilis auf feuchtem Boden, $V$. dichotoma im Wasser.

Fam. Caulerpaceae. Vegetativer Thallus einzellig, in Wurzelschläuche, Stammschläuche und Blattschläuche gegliedert, mit den Zellraum durchsetzenden Cellulosebalken. Vermehrung durch Loslösung einzelner Thallusteile. - (77) in tropischen und subtropischen Meeren. - Caulerpa.

b. Thallus von bestimmter Gestalt, aus dicht verfilzten Zweigen ungeteilter oder mit Einschnürungen und Querwänden versehener Zellen gebildet, bisweilen ein pseudoparenchymatisches Gewebe bildend.

Fam. Codiaceae. Thallus wie oben angegeben, bisweilen mit Kalk incrustirt, Schwärmer in besonderen angeschwollenen Sporangienästen, mit zwei Cilien. - (68) in wärmeren Meeren. - Penicillus. - Halimeda. - Codium.

c. Thallus aus selten ungeteilten, meist eingeschuirten oder quergeteilten, verzweigten Zellen bestehend, im ersteren Fall die $Z$ weige quirlständig, von begrenztem Wachstum, verzweigt oder auch verwachsen.

Fam. Valoniaceae. Thallus eine blasen- oder fadenförmige, verzweigte Zelle, meist mit Querwänden an der Basis der Verweigungen, welche bisweilen zu einer blattartigen oder netzförmigen Scheibe verwachsen. Die vegetativen Zellen werden direct zu Zoosporangien. - (56) vorzugsweise in tropischen und subtropischen Meeren. - Valonia.

Fam. Dasycladaceae. Thallus eine axile lang gestreckte Zelle ohne Querwände, unten mit Rhizoiden, acropetal Quirle von gegliederten, einfachen und verzweigten Strahlen mit begrenztem Wachstum erzeugend. 
In den fertilen Strahlen entweder direct Gameten mit zwei Cilien entstehend oder Aplanosporen, welche später zu Gametangien werden. 22) in wärmeren Meeren. - Acetabulrovia (7) mecliterranea im Mittelnieer.

\section{Abteilung. CH A R A L E S.}

Sprossaxe in längere (berindete und unberindete) und kürzere Glieder (Knoten) gegliedert, an denen Quirle von einfachen oder ebenfalls quirlig verzweigten Strahlen ("Blätter") entstehen; in der Achscl eines Seitenstrahles entsteht ein dem Hauptspross ähnlicher Seitenspross. Internodialzellen mit zahlreichen durch Fragmentation sich vermehrenden Kernen in dem wandständigen, lebhaft strömenden Protoplasma und in Iängsreihen der Hautschicht des Protoplasma anliegenden unbeweglichen ovalen grünen Chromatophoren. An den Knoten stehen ferner die Antheridien und berindeten Eizellen. Antheridien aus acht Schildern bestehend, denen innen ein cylindrisches „Manubrium* mit 24 peitschenförmigen Fäden aufsitzt; jerler Faden mit 100-225 Gliederzellen, deren jede ein schraubenförmiges, mit zwei langen Cilien versehenes Spermatozoid erzeugt. Eizellen von fünf spiralig gewundenen Strahlen, berindet, welche oberhalb der Eizelle das sogenannte Krönchen bilden, zwischen dessen Spalten die Spermatozoiden zum Protoplasma der Eizelle vordringen. Aus der berindeten Oospore entsteht zunächst ein Vorkeim und an diesem Rhizoide sowie die geschlechtliche Pflanze. - Parthenogenesis. - Vegetative Verinehrung durch Wurzelknöllehen (einzellig, farblos, stärkereich), Stengelknöllchen oder Bulbillen (unterirdische Stengelknoten, reich an Stärke), nacktfüssige Zweige in den Strahlenachseln und Zweigvorkeime.

Sehr isoliert, kein directer Anschluss an die Chlorophycene, anf welche sie als nächsthöhere Stufe folgen müssen, und ebensowenig an die Bryophyten.

Fam. Characeae. (160) im Sïsswasser und Brackwasser.

§ Nitelleae. Krönchen der Fr. mit zweizelligen Hüllspitzen. - Nitella (77). - Tolypella (13).

§ Chareae. Krönchen der Fr. mit einzelligen Hüllspitzen. - Chara (67) foetida; Ch. fragilis. - Ch. crinita parthenogenetisch.

\section{Abteilung. P H A E O P H Y CE A E.}

Mehrzellige Wasserpflanzen, in deren braunen Chromatophoren das Chloroplyyll durch einen braunen Farbstoff (Phycophaein) verdeckt ist. Schwärmzellen (Zoosporen, Planogameten und Spermatozoiden) monosymmetrisch mit zwei seitlichen Cilien, von denen die eine bei der Bewegung vorwärts, die andere rückwärts gerichtet ist. Fortpflanzung ungeschlechtlich oder geschlechtlich. Niemals Tetragonidien. 


\section{Nach unten Anschlnss an die Flagellata. Kein Anschluss an höher stehende Abteilungen.}

1. Reihe PHAEOSPOREAE. Fortpflanzungsorgane aus oberflächlichen Teilen der Sprosse auswachsend oder durch Umbildung von Aussenzellen entstehend.

Fam. Ectocarpaceae. Sämmtliche Fortpflanzungszellen beweglich; schwärmende Gameten (Planogameten) in ein- oder mehrfächerigen Gametangien; auch die in den letzteren entstehenden von gleicher Grösse. Spross mannigfach; aber niemals mit Gliederung in wurzelartige und blattartige Teile.

$\S$ Sphacelarieae. Spross mehrreihig oder parenchymatisch, bisweilen nur eine Scheibe darstellend. Wachstum der Sprosse vermöge einer Scheitelzelle, die von, derselben abgegliederten Segmente in Gewebecylinder zerfallend. Sporangien auf kürzeren oder längeren Stielen. - (26) im Meer. - Sphacelaria (12) cirrhosa. - Chaetopteris - Cladostephus (3) verticillatus.

$\S$ Choristocarpeae. Verzweigte, mittels einer Scheitelzelle wachsende einreihige Fäden. Die von der Scheitelzelle abgegliederten Segmente nicht weiter geteilt. Sporangien an der Stelle von Auszweigungen des Thallus. - (4) im Meer und Süsswasser. - Pleurocladia (2) lacustris am Ufer von Landseen.

§ Ectocarpeae. Einfache oder verzweigte Zellfäden, welche einem kriechenden Zellfaden oder einer horizontal ausgebreiteten Zellscheibe entspringen, selten nur letzterer allein. Fäden durch intercalare Zellteilung sich verlängernd. Einfächerige Sporangien mit Zoosporen oder Aplanosporen und mehrfächerige Sporangien, meist Gametosporen, aber auch neutrale Schwärmer erzeugend. - (60-80) im Meer. - Pylayella littoralis - Ectocarpus confervoides und siliculosus, bei welchem von zahlreichen an einen weiblichen Gameten herantretenden und ebenso gestalteten männlichen Gameten nur einer mit ersterem copulirt.

$\S$ Myrionemeae. Thallus eine \pm kreisförmige, parenchymatische Zellscheibe, aus welcher verticale, unter sich freie oder verbundene, einfache oder verzweigte Zellreihen emporwachsen; Sporangien am Ende der Fäden oder an Stelle eines Fadens. - Ascocyclus und Myrionema auf Meerespflanzen. - Ralfsia verrucosa auf Steinen und $\mathrm{Holz}$ an den Meeresküsten. - Lithoderma fatiscens u. a. an Steinen und Schneckenhäusern im Meer und im Süsswasser.

§ Elachisteae. Spross vorzugsweise am Grunde wachsend, aus einem Büschel unten sich verzweigender Fäden bestehend. Sporangien einfächerig und vielfächerig, an der Stelle von Assimilationsfäden auftretend. - Im Meer auf Algen und Seegras. - Elachista fucicola. - Giraudia.

§ Encoelieae. Spross intercalar in die Länge wachsend, einfach oder-verzweigt. Sporangien aus Oberflächenzellen entstehend, einfächerig, seltener auch vielfächerig. - Meeresbewohner. - Encoelium echinatum. - Myriotrichia. - Phyllitis fascia in nördlichen Meeren und im Mittelmeer. - Scytosiplion lomentarius ebenso. Punctaria planiaginea, ebenso, aber nicht im Mittelmeer. - Desmotrichum, einige Arten auf Zostera-Blättern. - Striaria attenuata.

\& Chordeae. Spross langgestreckt, unverzweigt, im Querschnitt kreisförmig, hohl, intercalar wachsend, mit Ausnahme des untersten Teiles zuletzt von einer gleichförmigen Schicht einfächeriger Sporangien bedeckt, zwischen denen grosse sterile assimilirende Zellen stehen. - Chorda filum im nördlichen Eismeer und an den Kästen des nördlichen atlantischen Oceans. 
§ Dictyosiphoneae. Spross fadenförmig, vielästig, mittelst einer Scheitelzelle in clie Länge wachsend. Sporangien einfächerig, aus Oberflächenzellen hervorgehend. - In Meer. - Diclynsiphon foeniculaceus vom nördlichen Eismeer bis Frankreich.

§ Desmarestieae. Spross fadenförmig, fiederartig verzweigt, mit Fadenbüscheln an den Zweigspitzen, durch Teilungen an der Grenze zwischen der Fadenaxe und den Haarbüscheln wachsend (trichothallisch). Sporangien einfächerig. Im Meer. - Desmarestia.

$\S$ Chordarieae. Spross fadenförmig, verzweigt, am Ende wachsend, mit zahlreichen kurzen Gliederfäden an der Oberfläche. Sporangien entweder einfächerig, am Grunde der peripherischen Fäden oder vielfacherig, aus den unteren Gliedern der Fäden entstehend. - Im Meere. - Chordaria Alagelliformis in nördlichen Meeren. - Stilophorı rhizoides in der Küstenregion von Norwegen bis zum Mittelmeer.

Fam. Laminariaceae. Spross mannigfach gestaltet, gegliedert in wurzel-, stengel- und blätterartige Gebilde, intercalar wachsend, später mit localisirtern, intercalarem Vegetationspunkt. Nur einfächerige Sporangien in grossen fleckenförnigen Soris oder eine fast den ganzen Thallus beleckende Schicht bildend. - Hierher die grössten Meeresgewächse (50). - Alaria (18) esculenta (Nordsee, und Eismeer). - Laminaria (30) Cloustonii, L. ligitata, L. saccharina im nördlichen atlantischen Ucean, dienen zur Gewinnung von Jod und Mannit, sowie auch als Viehfutter und Düngungsmittel. Die "Stipites Jaminariae» von L. digitata werden in der Chirurgie verwendet. Einige zuckerhaltig, zur Syrupbereitung. - Tessonia (5) und Macrocystis (2) pyrifera (bis $300 \mathrm{~m}$ lang) in südlichen Neeren.

Fam. Cutleriaceae. Schwärmer (Gameten) der mehrfächerigen Sporangien verschieden, die $q$ Makrogameten) viel grösser als die ơ (Mikrogameten). Spross aufrecht oder horizontal, flach. Sporangien in Soris, die einfächerigen aus den Rindenzellen hervorwachsend, die vielfächerigen an gegliederten Nebenfäden, die die Mikrogameten enthaltenden kleiner, zahlreicher und mit kleineren Fächern. - Cutleria (2-3) multifida Zanardinia (1) auf Steinen im Meer.

Fam. Tilopteridaceae. Fortpflanzungszellen zweierlei Art, kleine hewegungsfähige und grosse, nicht activ bewegliche. Spross fadenförmig.

2. Reihe CYCLOSPOREAE. Keine ungeschlechtliche Fortpflanzung durch Schwärmsporen. Fortpillanzungsorgane, Antheridien und Oogonien im Innern von besonderen durch Neubildung unter der Sprossoberfläche entstehenden Behältern (Scaphidien, Conceptakeln).

Fam. Fucaceae. Spross parenchymatisch, verschieden gestaltet, oft reich gegliedert (Sargassum), viele mit Schwimmblasen. Ungeschlechtliche Fortpflanzung fehlt. Antheridien in grosser Zahl an reich verzweigten Sprossfäden, zahlreiche sehr kleine birnförmige, mit zwei seitlichen Cilien versehene Spermatozoiden enthaltend. Oogonien gross, auf kurzen Stielzellen, mit zwei, vier, acht Oosphaeren, welche aus dem Oogonium und dem Conceptaculum austreten und von den Spermatozoiden befruchtet werclen. Viele diöcisch. Oosporen nach Ausscheidung einer Membran sofort zu einer neuen Pflanze auswachsend. - Etwa $200 \mathrm{im}$ Meer. - Himant/ıalia (1) lorea (Nordsee) - Ascoplıyllum (1-2) nodosum (nördliche 
Meere, nicht in der Ostsee). - Fucus (16) vesiculosus und F. serratus (nördliche Meere, auch in der Ostsee), zur Gewinnung von Jod und Soda. - Cystoseira (60) (Mittelmeer, atlant. Ocean). - Saryassum (150) bacciferum u. a. (atlant. Ocean, Sargassomeer).

\section{Abteilung. D I C T Y O T' A L E S.}

Braune Algen. Sämmtliche Fortpflanzungszellen unbeweglich. Ungeschlechtliche Fortpflanzung durch Tetragonidien.

\section{Nach nnten Anschluss an die Flagellata, kein Anschluss an höher stehende} Abteilungen.

Fam. Dictyotaceae. Spross flach, olivenbraun, häutig mit Scheitelzellwachstum. Antheridien in Gruppen, zahlreiche bewegungslose Spermatien erzeugend. Oogonien mit je einer Oosphäre. Sporangien mit meist zwei oder vier unbeweglichen Gonidien (Tetragonidien). Meeresalgen. Dictyota (30) dichotoma (Nordsee und Mittelmeer). - Padina (8) pavonia (Mittelmeer). - Dictyopteris (13) polypodioides (Mittelmeer).

\section{Abteilung. R H O D O P H Y C E A E.}

(Wesentlich nach Schmitz.) Rosenrote bis violette Algen, in deren Chromatophoren das Chlorophyll durch einen rötlichen Farbstoff (Phy. coërythrin, Rhodophyll) verdeckt ist. Fortpflanzung ungeschlecht. lich oder geschlechtlich.

Sehr isoliert, kein direkter Anschluss an eine der niederen Abteilungen, höchstens durch Yermittlung der 1. Klasse Bangiales an die Schizophyta mit eigenartiger Entwicklnng nach oben. Das Produkt der Befruchtuug, der Gametophyt, im Gegensatz zu dem Gumetophyten der Embryophyten ein anf der Mutterpflanze vollständig entwickelter sprossender Körper, ein Gonimoblast.

1. Klasse BANGIALES. Spross fadenförmig, aus einer Zeilreihe, später aus mehreren Zellreihen bestehend oder blattartig. Geschlechtliche Fortpflanzung durch Copulation kleiner männlicher (Spermatien) und grösserer weiblicher Sexualzellen (Eizellen). Ungeschlechtliche Fortpflanzung durch Teilung einzelner Thalluszellen.

Fam. Bangiaceae. Spermatien in Mehrzahl aus einer Thalluszelle (durch wiederholte Teilung derselben), durch Verquellen der Zellmem. branen isolirt, meist farblos, membranlos, unbeweglich. Eizellen (meist) einzeln aus einer inhaltreichen Thalluszelle, häufig auswärts zu einem kurzen Fortsatz ausgestreckt, dauernd von Membran umgeben. Einzelne Spermatien, anscheinend passiv $\mathrm{zu}$ den Eizellen hinbewegt, verwachsen und copuliren mit diesen Eizellen. Befruchtete Eizellen in mehrere (häufig 8) Zellen zerteilt, die infolge Verquellens der Zellmembranen als nackte (erst später umwandete) Sporen frei werden; seltener die be- 
fruchtete Eizelle direkt zur Spore umgewandelt. - Ungeschlechtliche Fortpflanzung durch Teilung einzelner Thalluszellen, deren Teilzellen als nackte (erst später umwandete) Sporen (in verschiedener Weise) frei werden. - Geschlechtlich erzeugte und ungeschlechtliche Sporen häufig aufangs amöbenartig fortkriechend, später umwandet und (anscheinend) nur passiv fortbewegt. - Bangia im Neer, meist andern Algen aufsitzend, und im Süsswasser. - Porplıyra (20) leucosticta auf Steinen und grösseren Algen im Mittelmeer; $P$. laciniata in der Nord- und Ostsee.

Familien zweifelhafter Stellung, in einzelnen Merkrnalen an die Bangiales erinnernd:

Fam. Rhodochaetaceae, Meeresalgen.

Fam. Compsogonaceae, Süsswasseralgen wärıerer Länder.

2. Klasse FLORIDEAE. (Grossenteils nach Schmitz)*). Thallus vielzellig, sehr verschiedenartig gestaltet, aus getrennten oder (mehr oder minder dicht) congenital verwachsenen Zellen aufgebaut.

Geschlechtliche Fortpflanzung durch Antheridien und Carpogonien. Antheridien sehr verschiedenartig gestaltet, mit kleinen oberflächlich gelagerten Spermataingien, die je eine nackte (erst nachträglich umwandete) unbewegliche männliche Sexualzelle, Spermatium, liefern. Carpogonium einzellig, an der Spitze in ein langes dünnes, thallusauswärts vorgestrecktes Empfängnishaar, Trichogyn, ausgezogen, an einem kurzen (meist 3-4 zelligen, seltener längeren) Zellfaden, dessen $1-2$ oberste Gliederzellen vielfach eigenartig ausgebildet sind, endständig; Carpogon-Zellfäden an der Oberfläche oder im Innern des Thallus ausgebildet. Dazu kommen bei der Mehrzahl der Florideen noch eigenartig ausgestaltete Hülfszellen, Auxiliarzellen, im Innern des Thallus verstreut oder mit den Carpogon-Zellfäden (meist paarweise) zusammengeordnet und häufig mit diesen letzteren $\mathrm{zu}$ selbständig ausgegliederten Procarpien verbunden.

Befruchtung durch Copulation eines Carpogoniums und eines Spermatiums, das zuvor mit der vorgestreckten Spitze des Trichogyns verwachsen war. Infolge dieser Befruchtung gliedert sich der Bauchteil des Carpogoniums als befruchtete Eizelle von dem (nunmehr absterbenden) Trichogyn ab. Dann sprosst entweder aus der Fizelle eine Anzahl verzweigter Zellfäden hervor, die zu einem aufrechten, gerlrungenen oder ausgebreiteten Büschel sporenbildender Füden heranwachsen; oder aus der Eizelle wachsen mehrere (verzweigte oder unverzweigte) Zellfäden, sporogene Faden, hervor, die mit dell Auxiliarzellen fusioniren, olne dass eine Vereinigung der Zellkerne erfolgt und nachher Büschel sporenbildender Fäden entwickeln; oder endlich es copuliert die Eizelle mittels eines längeren oder kürzeren (zuweilen ganz kurzen) Fortsatzes mit einer Auxiliarzelle, unil hierauf wächst aus dieser Auxiliarzelle ein analoges Büschel sporenbildender Fäden hervor. Diese Büschel sporenbildender Fäden, die Gonimoblaste, bleiben bald einheitlich geschlossen, bald teilen sie sich in melırere kleinere, selbständig abgegrenzte Teilbüschel, Gonimoloben; in allen Fallen aber entwickeln sich zuletzt die Endzellen (und vielfach auch noch einzelne oder zahlreiche Gliederzellen) ihrer Fadenzweige zu unbeweglichen (zuweilen anfangs nackten und erst später umwandeten) Sporen, den Carposporen. In dieser Weise ausgebildet, zuweilen auch noch von be-

*) Da die in dieser Pflanzengruppe stattfindenden Fortpflanzungsverhaltnisse sich nicht mit wenig Worten beschreiben lassen, so wurde hier tiber die in dem Syllabus sonst angenommene knappe Darstellungsweise hinausgegangen. 
sonderen Fruchthtillen (aus sterilem Thallusgewebe) umschlossen, erscheinen dann diese Gonimoblaste bald dem Thallus aus ansitzend, bald dem Thallus eingelagert; in diesem letzteren Falle aber werden sie vielfach von den verdickten und local emporgewölbten (am Scheitel meist perforierten) Rindenschichten des Thallus fruchtwandartig überdeckt. - Diese Gonimoblaste heben sich nun entweder ohne weiteres an der Pflanze als selbständige Bildungen deutlich ab, oder es erscheinen die (nicht selten eigenartig ausgestalteten) Thallusabschnitte, denen die Gonimoblaste eingelagert sind, als deutlich abgesetzte selbständige Teile der ganzen Pflanze: in beiderlei Fällen werden diese selbständig abgegrenzteu Teile der Pflanze, in denen Carposporen ausgebildet werden, als Cystocarpien bezeichnet. Im einzelnen aher ist die Gestaltung dieser Cystocarpien äusserst mannigfaltig.

Ungeschlechtliche Fortpflanzung durch (früher oder später) umwandete, unbewegliche Sporen, die zu 4 (daher Tetrasporen), selten zu 1-2 oder in grösserer Anzabl in einem Sporangium ausgebildet werden. Sporangien dem Thallus aussen ansitzend oder der Thallus-Rinde (zuweilen auch lokalen Verdickungen der Thallus-Rinde [Nemathecien]) eingelagert. Tetrasporen innerhalb der Sporangien entweder gereiht oder paarig oder tetraedrisch angeordnet.

Die grosse Mehrzahl der Florideen ist ausschliesslich im Meere verbreitet; nur wenige Gattungen (Lemanea, Tuomeya, Batrachospermum, Thorea, Balbiania) gehören aus. schliesslich dem Süsswasser an; einige wenige Gattungen (Chantransia, Caloglossa, Bostrychia, Hildenbrandia) zählen Vertreter im Süsswasser und im Seewasser. Die Zahl der bisher bekannten Gattungen beträgt über 300 .

1. Reihe NEMALIONALES. Die befruchtete Eizelle selbst wächst zum Gonimoblasten aus. Gonimoblast ein aufrechtes, gedrungenes oder ein mehr oder weniger weit ausgebreitetes Zweigbüschel, dessen Zweiglein zuweilen mit benachbarten Thalluszellen oder mit besonders ausgeformten Auxiliarzellen fusioniren.

Fam. Lemaneaceae. Gonimoblast ein Büschel auseinander spreizender freier Zellfäden, die in Spalten des aufgelockerten Thallus sich ausbreiten und ihre Gliederzellen fast sämmtlich zu (gereihten) Sporen ausbilden. Lemanea (14) torulosa, I. fluviatilis in rasch fliessenden Bächen.

Fam. Helminthocladiaceae. Gonimoblast ein gedrungenes, gewölbtes Büschel verzweigter (freier oder von Gallerte mehr oder minder dicht zusammengehaltener) Zellfäden, die ihre Endzellen (seltener auch noch einzelne der obersten Gliederzellen) zu Sporen ausbilden. Gonimoblast dem Thallus aussen ansitzend oder eingesenkt, ohne besondere Fruchthülle, nur zuweilen von einigen Hüllfäden begleitet. Sporangien meist eiusporig. Batrachospermum (40) moniliforme u. a. in Bächen, Flüssen u.s. w. - Chantransia. - Nemalion (2) lubricum (Mittelmeer); N. multifidum (Nordsee). - Liagora viscida und $I$. distenta (Mittelmeer).

Fam. Thoreaceae. Thallus stielrund, 士 verzweigt, biegsam, ringsum dicht behaart, mit intensiv gefärbten, abstehenden Assimilationshaaren, im Inneren in Mark und Rinde differenzirt. Fortpflanzung 1. durch zerstreute ungeschlechtliche Monosporangien, die in grosser Zahl in der oberflächlichen Rindenschicht aus Endzellen kurzer Zweiglein der Rindenfäden gebildet werden; 2. durch Gonimoblasten, welche an einem aus locker verflochtenen Fäden bestehenden Prothallium entstehen. - Thorea (5-6) ramosissima in Flüssen und Seen Europas. 
Fam. Chactungiaceae. Gonimoblast ein gedrungenes, gewolbtes oder trug. dollig ausgebreitetes orler concav zusammengekrümmtes Büschel verzweigter Zellfäden, die ihre Endzellen zu Sporen ausbilden. Gonimoblast dem Thallus eingesenkt, stets von einer besonderen, meist derben Fruchthülle unschlossen. - Scinaiı furcelluta (Atlantischer Ocean, Mittelmeer). - Galaxaura (20). - Chaetangium (10).

Fam. Gelidiaceae. Gonimoblast ein Büschel weithin ausgezweigter Zellfäden, die häufig mit anstossenden (zuweilen als Auxiliarzellen besonders ausgeformten) Thalluszellen fusioniren; die Zweigspitzen dieser fertilen Zellfäden zu einem verschiedenartig ausgebreiteten Hymenium zusammengeordnet, an dem die Sporen einzeln (selten in kurze Ketten gereiht) endständig ausgebildet werden. - Wrangelia. - Gelidium cornerum u. a. A. (atlantischer Ocean, Mittelmeer u. s. w).

2. Reihe GIGARTINALES. Carpogon-Zellfäden und Auxiliarzellen paarweise zusammengelagert und meist zu selbständig ausgeformten Procarpien verbunden, seltener einzeln im Thallus verstreut. Die befruchtete Eizelle fusionirt mittels eines (meist ganz kurzen) Carpogonastes mit der Auxiliarzelle, und hierauf sprosst diese thalluseinwärts zum Gonimoblasten aus.

Fam. Acrotylaceae. - Wenige Arten an den Küsten von Südafrika und Australien.

Fam. Gigartinaceae. Gonimoblast ein Büschel reich verästelter Zellfäden, welche sich von der Auxiliarzelle aus thalluseinwärts in das angrenzende sterile Thallusgewebe hinein sehr reichlich verzweigen und hierdurch ein fast ordnungsloses Geflecht fertiler und steriler Zellfäden herstellen; im Innnern dieses Geflechtes bilden einzelne Gruppen reich verästelter fertiler Zweiglein ihre Endzellen oder zugleich auch die oberen Gliederzellen zu Sporen aus; diese Sporen zuletzt in einzelnen (meist ordnungslos zusammengehäuften) Gruppen dem Fruchtgeflechte eingelagert. Das ganze Fruchtgeflechte häufig von einer besonderen Fruchthülle eingeschlossen. Sporangien zumeist mit parig geordneten Tetrasporen. Chondrus (5) crispus und Gigartina (50) mamillosa (nördlicher Teil des atlantischen Oceans) liefern Carrageen. - Phyllophora (10) membranifolia und Brodiaei (nördl. Teil des atlant. Oceans, Nordsee, Ostsee). - Callophyllis.

Fam. Rhodophyllidaceae. Gonimoblast geteilt in mehrere oder zahlreiche, grössere oder kleinere, mehr oder minder deutlich gesonderte Gonimoloben, die von einer kleineren oder grösseren ízuweilen sehr grossen) Centralzelle (der thallusein. wärts ausgellehnten Auxiliarzelle) fast allseitig auseinanderstrahlen und sich, gesondert oder seitlich zusammengeschlossen, in das angrenzende sterile Thallusgewebe hinein ausstrecken; in diesen Gonimoloben bilden die lockerer oder dichter zusamnengeschlossenen Fadenzweiglein ausschliesslich die Endzellen oder zugleich auch die oberen (seltener fast sämmtliche) Gliederzellen zu Sporen aus. Sporan. gien fast stets mit gereihten Tetrasporen. - Cystoclonium purpurascens (Nordsee). Rhodophyllis' (15-20) bifida (Mittelmeer, atlantischer Ocean). - Eucheuma 10-15) spinosum u. a. A. (indischer Ocean) dient zur Bereitung von Agar-Agar.

3. Reihe RHODYMENIALES. Carpogon-Zellfäden und Mutterzellen der (meist erst nach der Befruchtung ausgegliederten) Auxiliarzellen paarweise zusammengelagert, häufig zu selbständig ausgeformten Procarpien verbunden. Die befruchtete Eizelle fusionirt mittels eines kurzen CarpogonFortsatzes mit der Auxiliarzelle, und hierauf sprosst diese Auxiliarzelle thallusauswärts zum Gonimoblasten aus. 
Fam. Sphaerococcaceae. Auxiliarzellen (resp. Mutterzellen der Auxiliarzellen) vor der Fusionirung nicht besonders ausgeformt. Gonimoblast dem Thallus eingelagert, im Inneren einer Fruchthöhlung, die auswärts von der emporgewölbten verdickten (am Scheitel perforirten) ThallusAussenrinde fruchtwandartig überwölbt wird, der Mitte der verdickten Grundfläche (Placenta) angeheftet, in die Fruchthöhlung meist frei emporragend. Gonimoblast ein aufrechtes, sehr reich verästeltes Zweigbüschel, dessen zahlreiche, aufwärts fächerförmig auseinanderfahrende Zweiglein seitlich dicht zusammenschliessen $\mathrm{zu}$ einem meist halbkugelig gewölbten Sporenträger; an der Oberfläche dieses Sporenträgers entstehen die Sporen einzeln oder zu kürzeren oder längeren Ketten gereiht aus den Spitzen der Büschelzweiglein. - Sphaerococcus (1) coronopifolius (Mittelmeer, atlantischer Ocean). - Gracilaria (50) lichenoides (indischer Ocean), „Ceylon-Moos", dient zur Bereitung einer Sorte von Agar-Agar; G., confervoides u. a. A. im Mittelmeer und im atlantischen Ocean.

Fam. Rhodymeniaceae. Mutterzellen der Auxiliarzellen vor der Fusionirung nicht besonders ausgeformt. Gonimoblast dem Thallus eingelagert, in Innern einer Fruchthőhlung, die auswärts von der emporgewölbten verdickten (ann Scheitel perforirten) Thallus-Aussenrinde fruchtwandartig äberwölbt wird, der Mitte der verdickten Grundfläche (Placenta) angeheftet, in die Fruchthöhlung frei emporragend. Gonimoblast aufrecht, in mehrere, succedan ausgebildete Gonimoloben, die fast sämmtliche Zellen zu Sporen ausbilden, geteilt. Sporangien fast stets mit paarig geordneten Tetrasporen. - Rhodymenia (10) palmata (Nordsee und nördlicher Teil des atlantischen Oceans). - Chrysymenia Uvaria (Mittelmeer). - Lomentaria articulala (Nordsee). - Chylocladia (10) kaliformis (Mittelmeer, atlantischer Ocean). Plocamium (20-30) coccineum (Mittelmeer, atlantischer Ocean u. s. w.).

Fan. Delesseriaceae. Thallus blattartig flach, mit einfacher horizontal ausgebreiteter Thallus-Mittelschicht. Procarpien der Thallus-Mittelschicht aufsitzend. Gonimoblast im Innern einer Fruchthölung, die auswärts von der emporgewölbten verdickten (am Scheitel perforirten) Thallus-Rinde fruchtwandartig überwölbt wird, der Mitte der meist nur schwach (placentaartig) verdickten Grundfläche, die durch die Thallus Mittelschicht gebildet wird, angeheftet, in die Fruchthöhlung frei emporragend. Gonimoblast aufrecht, meist nur undeutlich in mehrere, lockerer oder dichter geschlossene (nur zuweilen selbständiger abgegrenzte), simultan oder succedan ausgebildete Gonimoloben, die an den Spitzen der Büschelzweiglein die Sporen einzeln oder in kürzere (oder längere) Ketten gereiht ausbilden (nur zuweilen fast sämmtliche Zellen zu Sporen ausformen), geteilt. Sporangien mit tetraedrisch geordneten Tetrasporen. - Nilophyllum (50) punctatum (atlantischer Ocean, Mittelmeer). - Delesseria (50) sangwinea, D. sinuosa und $D$. alata in der Nordsee und den nördlichen Teilen des atlantischen Oceans.

Fam. Bonnemaisoniaceae. - Bonnemaisonia (1 an den südlichen und westlichen Küsten Europas).

Fam. Rhodomelaceae. Thallus-Sprosse mit (wenigstens anfangs) deutlich quergegliederter polysiphoner Achse, meist oberwärts (oder wenigstens nahe der fortwachsenden Spitze) mit (früher oder später hinfälligen) Haarblättern besetzt. Antheridien und Procarpien an (meist vereinfachten) Haarblättern ausgebildet, daher der Thallus-Oberfläche mittels besonderer Stielchen angeheftet, selten fast sitzend. Cystocarpien kurz gestielt, selten der Thallus-Oberfläche aufsitzend. Gonimoblast im Inneren eines (am Scheitel perforirten) Fruchtgehäuses, das durch ringwallartiges Emporwachsen der Hüllzellen des Procarpes gebildet wird, grundständig angeheftet, aufwärts frei emporragend. Gonimoblast ein reich verzweigtes, mehr oder 
weniger dicht geschlossenes, meist gedrunngenes Zweigbüschel, an dessen mehr oder weniger gewölbter Oberfläche die Endzellen der Zweiglein zu meist grossen eiförmigen oder keulenförmigen Sporen (selten zu kurzen Ketten von 2-3 kleineren gerundeten Sporen) heranreifen. Sporangien in den fertilen Sprossen (fast stets) aus oberseitigen Nebenzellen von Pericentralzellen der polysiphonen Achse hergestellt, mit tetraedrisch geordneten Tetrasporen. - Laurencia (50) obtusa (atlantischer Ocean, Mittelmeer). - Alsidium (2) helminthochorton (Mittelmeer) liefert (zusammen mit anderen kleinen Meeresalgen) das Helminthochorton oder corsicanische Wurmmoos. - Polysiphonia (5) in zahlreichen Arten durch alle Meere hin verbreitet. - Rhodomela (5) subfusca (Nordsee, nördlicher Teil des atlantischen Oceans). - Rytiphloea (1) tinctoria (Mittelmeer, atlantischer Ocean). - Dasya (30-40) elegans (Mittelmeer). Trichothamnion coccineum (Nordsee).

Fam. Ceramiaceae. Thallus feinfädig, aus freien, meist nackten oder rhizoid-berindeten (selten zellig-berindeten) Zellfäden aufgebaut. Procarpien clem Thallus aussen ansitzend. Gonimoblast ebenfalls dem Thallus aussen ansitzend, nackt oder von besonderen Hüllzweiglein umgeben. Gonimoblast aufrecht, in mehrere, dicht geschlossene, succedan ausgebildete Gonimoloben, die fast ihre sämmtlichen Zellen zu Sporen ausbilden, geteilt. Häufig je zwei Gonimoblaste zu einem einzelnen Cystocarp verbunden. Sporangien fast stets dem Thallus aussen ansitzend, mit meist tetraedrisch (seltener paarig) geordneten Tetrasporen. - Iejolisia (1, Mittelmeer). Griffithia (20-30). - Callithammion in zahlreichen Arten (C. corymbosum u. a.) durch alle Meere hin verbreitet. - Plumaria (6) elegans (Nordsee). - Plilota $(6-10)$ plumosa (nördlicher Teil des atlantischen Oceans). Cercamium (40) in zahlreichen Arten (C. rubrum u. a.) durch alle Meere hin verbreitet.

4. Reihe CRYPTONEMIALES. Carpogon-Zellfäden und Auxiliarzellen einzeln im Thallus verstreut. Die befruchtete Eizelle entsendet durch das Thallus-Gewebe hin mehr oder minder lange, häufig verzweigte Carpogonäste, deren Endzellen oder Gliederzellen mit einzelnen Auxiliarzellen fusioniren; hierauf sprossen diese einzellen Zellen (thallusauswärts oder thalluseinwärts) zu Gonimoblasten aus.

Fam. Glolosiphoniaceae. Auxiliarzellen aus Gliederzellen besonderer, secundär entwickelter Zellfäden hergestellt. Auxiliarzell-Zellfäden und Carpogon-Zellfäden mit einander zu verschiedenartig gestalteten Procarpien verbunden. Gonimoblast zumeist in mehrere dicht geschlossene, succedan ausgebildete Gonimoloben, die fast ihre sămmtlichen \%ellen zu Sporen ausbilden, geteilt, seltener zu einem einzelnen, dicht geschlossenen Z weigbuischel mit analoger Sporenhildung verwachsen. Gonimoblast dem Thallus-Gewebe eingelagert. - Gloiosiphonia (3). - Gloiopeltis (6) tenax (Chinesisches Meer) wird in China zur Bereitung eines zähen Leimes benutzt; $\boldsymbol{G l}$. coliformis, Gl. cervicornis (u. a. A. des chinesisch-japanischen Meeres) werden in Japan vielfach als Nahrungsmittel verwertet.

Fam. Grateloupiaceae. Auxiliarzellen aus Gliederzellen besonderer, secundär entwickelter, verzweigter Zellfäden hergestellt. Carpogon-Zellfäden ebenfalls secundar entwickelt und analog verzweigt. Auxiliarzell-Zellfäden und Carpogon-Zellfäden zu aufrechten flaschenförmigen Gehäusen mit grundständiger Auxiliarzelle resp. grundständigem Carpogonium gefornt. Gonimoblast in mehrere dicht ge- 
schlossene, succedan ausgebildete Gonimoloben, die fast ihre săınmtlichen Zellen zu Sporen ausbilden, geteilt. Gonimoblast dem Thallus-Gewehe eingelagert, nicht selten von dem mehr oder weniger vergrösserten Auxiliarzell-Gehäuse dauernd umschlossen. Sporangien mit paarig geordneten Tetrasporen. - Grateloupia $(30-40)$ filicina (Mittelmeer). Halymenia (10-20 in wärmeren Meeren).

Fam. Dumontiacene. Auxiliarzellen aus Gliederzellen hesonderer, secundür entwickelter, langer, meist gekrümmter Zellfäden hergestellt. Carpogon-Zellfäden ebenfalls secundär entwickelt, lang gestreckt und analog gekrümmt, zwischen die sehr zahlreichen Auxiliarzell-Zellfäden in geringerer Anzahl eingestreut. Gonimoblast nur unvollständig in mehrere, fast stets simultan ausgebildete und seitlich nur undeutlich gesonderte Gonimoloben, die fast ihre sämmtlichen Zellen zu Sporen aus. bilden, geteilt. Gonimoblast dem Thallus-Gewebe cingelagert. Sporangien mit paarig geordneten oder gereiluten Tetrasporen. - Dudresnaya (2) purpurifera (Mittelmeer); D. coccinea (Mittelmeer, atlantischer Ocean). - Dumontia (2) filiformis (Nordsee, atlantischer Ocean).

Fam. Nemastomaceae. Auxiliarzellen aus Gliederzellen unveränderter primärer Zellfäden hergestellt, meist zahlreich. Carpogon-Zellfäden kurz, unveränderten primären Thallus-Zellfäden seitlich ansitzend, meist vereinzelt. Gonimoblast zuweilen in mehrere dicht geschlossene, succedan ausgebildete Gonimoloben, die fast ihre sämmtlichen Zellen zu Sporen ausbilden, geteilt, meist zu einem einzelnen (mehr oder weniger regelmässig geformten) geschlossenen Zweigbüschel mit analoger Sporenbildung geformt. Gonimoblast dem Thallus-Gewebe eingelagert. Sporangien init meist paarig geordneten Tetrasporen. - Schizymenia (6-10) Dubyi (atlantischer Ocean, Mittelmeer). - Furcellaria (1) fastigiata (atlantischer Ocean, Nordsee, Ostsee).

Fam. Rhizophyllidaceae. In besonderen (meist nemathecienartig hervorgewachsenen) fertilen Abschnitten der Thallus-Rinde finden sich mehrere CarpogonZellfäden (meist verkürzte Thallus-Zellfäden) und zahlreichere Auxiliarzellen (Gliederzellen meist unveränderter Thallus-Zellfäden) vereinigt. In denselben nachträglich erstarkten fertilen Rindenabschnitte erscheinen später zahlreiche Gonimoblasten sorusartig (nahe zuweilen sehr nahe) zusammengerückt. Gonimoblaste in mehrere, fast stets simultan ausgebildete, mehr oder weniger dicht (zuweilen ganz dicht) seitlich zusammengeschlossene Gonimoloben, die fast ihre sämmtlichen Zellen zu Sporen ausbilden, geteilt. - Polyides (1) rotundus (atlantischer Ocean, Nordsee, Ostsee).

(Mittelmeer).

Fam. Squamariaceae. - Cruoria (3-4). - Peyssonellia (10-20) squamaria

Fam. Corallinaceae. Thallus dorsiventral oder radiär organisirt, meist mit (mehr oder weniger stark) verkalkten Zellmembranen. In besonders abgegrenzten Abschnitten der Thallusrinde finden sich mehrere (zum Teil rudimentäre) Carpogon-Zellfäden (eigenartig ausgebildete fertile Thallus-Zellfäden) und zahlreiche Auxiliarzellen (Gliederzellen dieser fertilen und der nächst angrenzenden, eigenartig ausgebildeten sterilen ThallusZellfäden) zu einem (meist von der Seite her ringwallartig überwölbten) Sorus dicht zusammengeordnet. Aus diesem Sorus entwickelt sich als Cystocarp ein (meist umwandetes) Syncarpium, indem infolge der Befruchtung eines Carpogoniums schliesslich sämmtliche (oder fast sämmtliche) Auxiliarzellen mit einander fusioniren und dann aus der Peripherie (selten auch aus der Mitte dieser scheibenförmigen grossen Copulationszelle ganz kleine Gonimoblaste in mehr oder minder grosser Anzahl hervorwachsen. Gonimoblaste kurze, basipetal heranreifende Ketten von Sporen. Sporangien mit gereihten Tetrasporen (seltener Disporen), in grösserer Anzahl $\mathrm{zu}$ besonderen (meist von einer Fruchtwand überdeckten) geschlossenen Gruppen (Sori) zusammengeordnet. - Melobesia (15-30) farinosa u. a. A. weit verbreitet im Meere. - Corallina (30-50) officinalis (atlan- 
tischer Ocean, Nordsee), C. mediterranea (Mittelmeer), C. mubens (Mittelmeer u. s. w.). - Lithothamnion (10-20) in wärmeren Meeren, $L$. fasciculatum (Mittelmeer und atlantischer Ocean).

Zweifelhafter Stellung: Hildenbrandia prototypus im nördlichen atlantischen Ocean; $H$. rivularis in Gebirgsbächen.

\section{Abteilung. E U II Y C E'T ES (Fumgi, echte Pilze).}

[Zum Teil nach Schroeter, Lindau, E. Fischer, Dietel, Hennings, Zah]. bruckner (Flechten), mit einigen Abänderungen.]

Ein- oder mehrzellige, niemals Chlorophyll führende, parasitische oder saprophytische Pflanzen mitechtem Spitzenwachstum. Mycelbildung fast allgemein. Geschlechtliche Fortpflanzung auf der niederen Stufe analog der der Zygophyceae, sodann der der Siphoneae, in der 3. und 4. Klasse an die der Florideae (X. Abt. 2. Klasse) erinnernd, in der 5. Klasse eine eigenartige Karyogamie. Ungeschlecht. liche Fortpflanzungnur in der ersten Reihe bisweilen noch durch Zoosporen, sonst nur durch abgeschnürte Zellen (Conidien, Sporen) oder durch unbewegliche endogene Sporen.

Nach unten Anschluss an die Siphoneae in der VI. Abteilung, mit reicher eigenartiger Entwlckelung nach oben, an keine hölıere Abteilung anschliessend.

1. Klasse PHYCOMYCETES. Der vegetative Spross meist einzellig; die Zelle häufig schlauchförmig und verzweigt. Fortpflanzung geschlechtlich durch Copulation oder durch Oosporenbildung.

1. Reihe ZYGOMYCETES. Mycel reich verzweigt. Ungeschlechtliche Fortpflanzung durch Endosporen oder Acroconidien, bisweilen auch durch Gemmen oder Cysten. Geschlechtliche Fortpflanzung durch Zygosporenbildung. - Saprophyten.

1. Unterreihe Mucorineas. Ungeschlechtliche Keimzellen in Sporangien erzeugte Conidien (Sporen) oder reducirte conidienartige Sporangien darstellend.

Fam. Mucoraceae. Sporangium mit Columella, vielsporig. Zygosporen zwischen den beiden Suspensoren gelagert, welche bis zuletzt einzellig bleiben.

§ Mucoreae. Sporangienhaut gleichmässig ausgebildet, zerfliessend oder zerbrechend, nicht cuticularisirt. - Mucor (50) mucedo auf Mist; M. racemosus auf Brot und pflanzlichen Substanzen als "Schimmel « verbreitet, in Glycose, auch in Rohrzucker Alkoholgährung erregend; $M$. stolonifer auf iaulenden Pflanzenresten etc. - Sporodinia (1) asperyillus (Zy. gospore Syzygites) auf fleischigen Hymenomyceten. - Pliycomyces (2) ritens in Ölmühlen, auf Ölkuchen, auf Brot etc, - Thannidium (10) elegans auf modernden Substanzen. 
§ Piloboleae. Sporangienhaut in der oberen Hälfte cuticularisirt, in der unteren Hälfte dünn. - Pilobolus (7) auf Mist von Pflanzenfressern.

Fam. Mortierellaceae. Sporangien ohne Columella. Sporangienträger häufig mit zahlreichen abstehenden Seitenästen. Zygosporen häufig von einer dicken Hülle eingeschlossen, welche durch zahlreiche verflochtene Fäden gebildet wird. - Mortierella (16) auf modernden Vegetabilien, besonders Hymenomyceten.

Fam. Choanephoraceae. - Choanephora (1) mit in lebenden Pflanzenteilen kriechendem Mycel, mit Conidienträgern und Sporangienträgern.

Fam. Chaetocladiaceae. Conidien (auf eine Spore reducirte Sporangien) an verzweigten Seitenästen. Zygosporen wie bei vorigen. - Chaetocladium (2) Jonesii und Ch. Brefeldii auf Mucor mucedo an Mist.

Fam. Piptocephalidaceae. Conidien reihenweise durch Quergliederung von strahlig angeordneten Ästen gebildet. Copulirende Myceläste aufsteigend; Zygospore an der Spitze der Copulationsäste, nachdem in jedem derselben eine Scheidewand gebildet wurde. - Piptocephalis (8) Freseniana auf Mucor mucedo an Pferdemist.

2. Unterreihe Entomophthorineae. Ungeschlechtliche Keimzellen einzelnstehende, am Ende eines Fruchtträgers abgeschntirte Conidien, welche bei der Reife abgeschleudert werden.

Fam. Entomophthoraceae. Mycel reich entwickelt, meist in lebenden Tieren, seltener auf Pflanzen oder saprophytisch. - Empusa (11) Muscae auf den Stubenfliegen, E. Aulicae auf Raupen. - Entomophthora (30) rimosa an Mücken, E. sphaerosperma an Raupen von Kohlweisslingen. - Basidiobolus (2) ranarum auf den Excrementen von Fröschen.

2. Reihe OOMYCETES. Mycel bisweilen nur schwach entwickelt. Ungeschlechtliche Fortpflanzung häufig durch Schwärmsporen oder durch Acroconidien. Geschlechtliche Fortpflanzung durch Oosporenbildung. Parasiten.

1. Unterreihe (Ordnung Chytridiineae. Mycel schwach oder fehlend. Spross zu einem einzelnen Sporangium oder durch Teilung sich zu einem Sporangiumsorus entwickelnd.

Fam. Olpidiaceae. Mycel oder Rhizoiden fehlend. Schwärmsporen in das Innere lebender Zellen eindringend. Die Schwärmspore entwickelt sich direct zu einem einfachen Sporangium oder zu einem Dauersporangium - Olpidium (25) endogenum und O. entoplytum in Algen; $O$. pendulum in Pollenzellen. - Ectrogella (1) Bacillariaceamum in verschiedenen Bacillariaceen.

Fam. Synchytriaceae. Durch Teilung des Fruchtkörpers entsteht ein Haufen oder Sorus oder eine Reihe von Schwärmsporangien. Sporangien im Innern von Pflanzen; auch Datersporangien, in denen wiederum Schwärmsporen entstehen. - Synchytrium (Pyenochytrium) (30) Anemones auf Anemone nemorosa, S. Mercurialis auf Mercurialis perennis, S. 
globosum auf verschiedenen Pflanzen, S. aurenum sehr verbreitet auf verschiedenen Pflanzen, besonders auf Isysimaclia nummularia.

Fam. Rhizidiaceae. Mycel auf ein einzelnes Sporangium beschränkt. Phlyctochytrium (5) Hydrodictyi auf Hydrodictyon - Rhizophidinom globosum auf verschiedenen Algen. - Chytridium (7) olla auf den Oogonien von Oedogonium.

Fam. Cladochytriaceae. Mycel weit verbreitet. Sporangien terminal oder intercalar. - Clıdochytrium (2) tenue im Gewebe von Acorus und Iris. - Physoderma in Parenchymzellen vieler Sumpfpflanzen.

Fam. Hyphochytriaceae.

Fam. Oochytriaceae. Spore durch Copulation zweier Sporangien gebildet. - Polyphagus (1) Euglenae auf Englena viridis. - Urophlyctis (4) pulposa in Chenopodiaceen.

2. Unterreihe (Ordung) Ancylistineae. Mycel schwach entwickelt. Fruchtkörper durch Querteilung in eine Kette von Zellen geteilt, welche sich teils zu Schwärmsporangien, teils zn Antheridien und Oogonien entwickeln.

Fam. Lagenidiacene. Fruchtkörper vollkommen in Sporangien oder Sexualzellen zerfallend. Mycel fehlend. - Lngenidium (5) Rabenhorstii in Spirogyra.

Fam. Ancylistacene. Fruchtkörper durch Querteilung in eine Kette von Zellen geteilt, welche sich teils zu Schwärmsporangien, teils zu Antheridien und Oogonien entwickeln. - Ancylistes (1) Closterii in Closterium-Arten.

3. Unterreihe (Ordnung) Saprolegniineae. Mycel entwickelt. Antheridien keine Spermatozoiden bildend, Befruchtungsschläuche in das Oogon treibend.

Fam. Saprolegniaceae. Mycel weit schlauchartig, nicht eingeschnürt, Zoosporangien cylindrisch. Oosporen ohne deutliche Befruchtung gebildet. Saprolegmia (11) monoica und S. ferax. - Achlya (13) prolifera auf ab. gestorbenen Insekten im Wasser, auch an Fischen. - Aphanomyces (4) an todten Insekten.

Fam. Leptomitaceae. Die Schläuche durch Einschnürungen in Glieder geteilt. Schwärmsporangien cylindrisch. - Leptomitus (1) lacters in Abwässern von Zucker-, Stiirke- und Spritfabriken, in fliessendem Wasser.

Fam. Pythiaceae. Mycel dünn, meist saprophytisch, seltener parasitisch, bisweilen auch im Wasser. Schwärmsporangien kugelig, wie die Oosporangien, vom Mycel streng geschieden. Auch Conidienbildung. Pythium (16) The Baryanum in den Kotyledonen von Keimlingen und in Prothallien; P. proliferum auf todten Insekten im Wasser.

4. Unterreihe (Ordnung) Monoblepharidineae. Mycel entwickelt. Antheridien bewegliche Spermatozoiden bildend, welche in das Oogon eindringen.

Fam. Monoblepharidaceae. - Monoblepharis (2) sphaerica auf abgestorbenen pflauzlichen und tierischen Geweben im Wasser.

5. Unterreilie (Ordnung) Peronosporineac. Conidientrăger vom Mycel nicht abgegrenzt, aërobiontisch, zahlreiche Conidien bildend. 
Fam. Albuginaceae. Conidienträger keulenförmig, unter der Oberhaut der Wirtpflanze, Conidien in Ketten abschnürend. - Albugo (12) candida auf Cruciferen, A. Tragopogonis und $A$. spinulosa auf Compositen.

Fam. Peronosporaceae. Parasiten in Landpflanzen. Mycel verzweigt. Conidienträger einzeln aus der Oberhaut hervortretend. Conidien einzeln abfallend. - Phytophthora (3) infestans, Ursache der Kartoffelkrankheit; $P$. Cactorum auf Keim- und Treibhauspflanzen. - Bremia Lactucae auf Compositen. - Peronospora (60) calotheca auf Rubiaceen; $P$. parasitica auf Cruciferen; $P$. Trifolionum auf Leguminosen; $P$. effiusa auf Chenopodiaceen. - Plasmopara (15) viticola auf Weinreben, aus Nordamerika stammend; $P$. nivea auf Umbelliferen.

2. Klasse HEMIASCOMYCETES. Mycel vielzellig. Sporangien (Schläuche, Asci) mit grösserer und unbestimmter Zahl von Sporen (Endogonidien).

\section{Reihe HEMIASCALES.}

Fam. Ascoideaceae. Reich verzweigtes und gegliedertes Mycel, dessen Äste einerseits Conidien, andererseits langgestreckte Sporangien mit zahlreichen sehr kleinen Sporen tragen. Die Sporangien öffnen sich durch Kappen und die nellgebildeten Sporangien wachsen in die Hällen der entleerten Sporangien hinein. Ascoidea (1) rubescens, auf umgehauenen Buchen im Saftfluss der verletzten Stellen.

Farn. Protomycetaceae. Mycel fadig, weit verzweigt, mit intercalarer (Protomyces) oder am Fnde (Endogone) entstehenden sehr grossen, ellipsoidischen oder kugeligen Sporangien, in denen nach längerer Ruhe sehr zahlreiche kleine Sporen entstehen, die hefeartig sprossen. - Prolomyces (4) macrosporus auf Umbelliferen, an Stengeln und Blattstielen dicke gelbe Schwielen bildend, Pr. pachydermus auf Taraxacum. Endogone (7).

Fam. Monascaceae. Sporangien mit \pm stark entwickelter Hülle von Mycelzweigen. - Monascus (3).

Fam. Saccharomycetaceae. Vegetative Zellen vereinzelt oder lose in 'Sprossverbänden. Schläuche den vegetativen Zellen fast gleich. Saccharomyces (40) cerevisiae (Bierhefe) in zahlreichen Varietäten, Zucker vergährend, Rohrzucker durch Invertin in Traubenzucker umsetzend, Bierwürze vergährend; S. ellipsoicleus (Weinhefe); S. Pasteurianus, in Bierwürze schwache Obergährung hervorrufend; S. conglomeratus auf faulenden Trauben; S. albicans (Soorpilz), auf Schleimhäuten, besonders der Mundschleimhaut von Menschen. S. mycoderma (Kahmpilz), auf Wein, Bier, sauren Gurken, Sauerkraut; S. apiculatus, Traubenzucker vergährend, wichtig bei der Bereitung von Obstweinen; S. kefyr, in den Kefyrkörnern zusammen mit Bacterienarten. - Bei Schizosaccharomyces wurde Copulation zweier Individuen beobachtet.

3. Klasse EUASCOMYCETES. Mycel vielzellig. Sporen in Sporangien (Schläuchen, Ascis) von begrenzter Zahl. Nach der Sporenbildung bleibt in der Ascis ein Teil des Plasmas als Epiplasma zurück. In sehr wenigen Fällen wurden Vorgänge beobachtet, welche als Sexualakte gedeutet werden, aber erst nach weiteren Beobachtungen sich vielleicht 
für eine Einteilung der Enasci werden verwerten lassen. Ausserdem häufig mannigfache Conidienbildungen, Pykniden (mit Stylosporen) und Spermogonien (mit Spermatien), alle keimend. Häufig Sclerotien.

\section{Reihe EUASCALES.}

1. Unterreihe (Ordnung) Protoascineae. Schläuche einzeln stehend, ganz isolirt, in verschiedener Höhe an den Mycelfäden.

Fam. Endomycetaceae. Vegetative Zellen ein fädiges Mycel bildend, Schläuche deutlich differenzirt, meist am Ende von Mycelästen. - Eremascus (1), ausgezeichnet durch Entwicklung eines Ascus an der Spitze zweier copulirender Äste. - Endomyces (5) Magnusii im gallertartigen, gährenden Schleimfluss der Eichen; $\boldsymbol{E}$. decipiens auf Armillavia mellea.

2. Unterreihe (Orduung) Protodiscineae. Schlauche neben einander stehend, ein unbegrenztes Hymenium bildend.

Fam. Exoascaceae. Mycel parasitisch. Glieder des Mycels bisweilen als Oidien sich loslösend. Schläuche unter sich frei. Auch Chlamydosporenbildung. Ascosporen häufig hefeartig sprossend. - Meist Parasiten auf chlorophyllhaltigen Pflanzenteilen. - Taphria (13) rlizoploora auf den Früchten von Populus-Arten. T. aurea auf den Blättern von Populus. Fxouscus (30) Cleformans verursacht die Kräuselkrankheit der Pfirsichblätter; E. Prumi, Ursache der Narrentaschenbildung von Prunus donestica und $P$. padis; E. Cerasi, Ursache der Hexenbesen der Kirschbäume, $E$. alnitorquis an den Schuppen der weiblichen Blütenstände von Alnus glutinosa, E. epiplyllus, Ursache der Hexenbesen von Alnus incana.

Fam. Ascocorticiaceae. Mycel saprophytisch. Fruchtträger häutig, flach aufsitzend, mit peripherischem Wachstum. Schläuche dicht, ein zusammenhängendes Hymenium bildend. - Ascororticium (1) allidum auf Rinde abgestorbener Kiefernstümpfe.

3. Unterreihe (Ordnung) Helvellinece. Ascusschicht von Anfang an und bei der Reife freiliegend.

Fam. Rhizinaceae. Fruchtkörper stiellos. - Rhizina (8) influta, häufig in Wäldern auf Brandstellen.

Fam. Geoglossaceae. Fruchtkörper gestielt, keulenförmig oder kopfförmig, Schläuche am Scheitel mit lochförmiger Mündung. - Geoglossum (20) liirsutum auf moorigen Wiesen; G. glabmum auf Grasplätzen. - Leotia (13) gelatinosa zwischen Gras und Moos.

Fam. Helvellaceae. Fruchtkörper gestielt, hutförmig. Schläuche mit Deckel aufspringend. - Morchella (23) esculenta (Speisemorchel) und I. conicr (Spitzmorchel) in Wäldern und Gebüschen, im Frühjahr beliebte Speisepilze. - Gyromitra (11) esculenta (Stockmorchel, Faltenmorchel, Lorchel) im Frühjahr besonders in Nadelwäldern, im frischen Zustand giftig, gekocht und getrocknet beliebter Speisepilz, da die in ihm enthaltene giftige Helvellasäure in heissem Wasser löslich ist und auch durch Trocknen schwindet. - Helvella (45) infula (Herbstmorchel), in Nadelwäldern in grosser Menge. - Verpa (12) bohemica in Laubwällern im Frühjahr. 
4. Unterreihe (Ordnung) Pezizineae. Fruchtschicht anfangs + vollkommen eingeschlossen, jedoch ohne feste Decke und sehr bald frei werdend. (Peridium oder Hiypothecium.)

Fam. Pyronemataceae. Fruchtkörper voln Anfang an offen, convex. Peridium fehlend oder sehr schwach. - Pyronema (20) omplialodes ( $P$. confluens), auf verlassenen Kohlenweilern, auf Lohe, Blumentöpfen etc., sehr interessant wegen der hier leicht zu beobachtenden Entwickelung der Fruchtkörper. Das keulenförmige Antheridium und das kugelige Oogonium sind vielkernig, dạs letztere besitzt einen durch eine Wand getrennten Conjugationsschlauch, in welchen zuerst die Antheridienkerne übertreten, um dann nach Verschwinden der trennenden Wand in das „Oogonium " einzudringen, und sich in demselben einzeln mit den Oogonkernen zu verbinden; dann entstehen an dem Oogon als Ausstïlpungen die ascogenen Hyphen; in welche die Copulationskerne einwandern. Schon vor diesen Vorgängen sind am Oogon und den benachbarten vegetativen Zellen Hyphen für das Hypothecium und die Paraphysen gebildet worden.

Fam. Pezizaceae. Fruchtkörper anfangs concav. Peridium fleischig. Schläuche bei der Reife über die Fruchtschicht nicht hervortretend. Lachnea (100) scutellata auf Erde, faulem Holz etc. - Peะiaa (150) vesiculosa auf Dunghaufen und Gartenerde, $P$. acetabulum in Wäldern, $P$. aurantia in feuchten Wäldern zwischen Moos. - Otidea leporina und O. onotica in Wäldern, am Boden zwischen Laub.

Fam. Ascobolaceae. Wie vorige; aber Schläuche bei der Reife hervortretend. Arten meist auf Mist, z. B. Ascobolus stercorarius.

Fam. Helotiaceae. Fruchtkörper mit Peridie, welche aus langgestreckten, parallel laufenden, pseudoparenchymatisch gefügten, hellen und dünnwandigen Hyphenzellen gebildet ist. - Sarcoscyplıa (20) coccineu auf faulenden Ästen. - Chlorosplenium (10) aemuginascens und Ch. aeruginosum auf faulem Holz, dasselbe durch den von den Hyphen abgesonderten Farbstoff grün färbend. - Sclerotinia (40) mit Sclerotien; Sc. urnula auf Preisselbeerpflanzen (mit Chlamydosporen); Sc. baccanum auf der Heidelbeere; Sc. Fuckeliana auf Weinblättern und Ranken (hierzu vielleicht als Conidienform Botrytis cinerea; Sc. sclerotiorum, häufig in feuchtem Boden auf den Wurzeln von Raps, Runkelrïben, Rettig, Bohnen, Hanf etc.; Sc. Trifoliorum auf Kleearten; Sc. bulborum auf Hyacinthenzwiebeln. - Dasyscypha (150) Willkommii, Ursache des Lärchenkrebs. Helotium (200) herbarum auf faulenden Kräuterstengeln. - Jachınım (150). - Coryne (10)'sar'coides auf faulendem Holz.

Fam. Mollisiaceae. Wie vorige; aber Peridie aus rundlichen oder eckigen, pseudoparenchymatisch gefügten, dick- und dunkelwandigen Zellen gebildet. - Mollisia (150) cinerea an nass liegenden Ästen. - Pseudopeziza (10) Trifolii auf Klee, sehr schädlich. - Orbilia (50) coccinella auf Holz, Flechten und Hutpilzen. - Calloria (10) fusarioides auf Nesseln.

Fam. Celidiaceae. Fruchtkörper leder-, horn- oder knorpelartig. Enden der Paraphysen ein Epithecium bildend. Peridien fehlend. Zum Teil mit Algen Flechten bildend. Auf Holz, Rinde und Flechten. 
Agyrium (10). - Celidium (2) stictamun auf der Fruchtscheibe der Flechte Sticta pulnonacea. - Mycarthonia.

An diese Familie schliessen sich unter den Flechten einige Gattungen der Graphidineae an; $\mathbf{2}$. B. Arthonia nnd Arthotelium (Graphidaceae).

Fam. Patellariaceae. Fruchtkörper von Anfang an frei, schüsseloder tellerförmig, mit leder- oder hornartiger Peridie. - Viele auf Flechten und auch Flechten bildend. - Biatorella (10). - Patellea. - Patinella (25). - Patellaria (30). - Karschia.

An diese Familie schliessen sich unter den Flechten mehrere Gattungen der Discocarpineae an, z. B. Biatoridium (Lecideaceae) an Biatorella, Lecidea an P'atellavia, Buellia (I'lysciaceae) an Karschia ; ferner auch Gattungen der Graphidineae: I'lacographa, Platygrapha, Dirina, Roccella.

Fam. Cenangiaceae. Fruchtkörper anfangs eingesenkt und von einer schwindenden Haut eingeschlossen, dann krug - oder becherförmig. Cenangiom (70) abietis auf Kiefern, bisweilen denselben wegen des die Zweige durchziehenden Mycels sehr schädlich. - Bulgaria polymorpha an gefällten Eichen und Buchen.

Fam. Cordieritidaceae. - Fain. Cyttariaceae.

5. Unterreihe (Ordnung) Protocaliciineae. Asci zur Zeit der Sporenreife verschwindend und die Sporen mit den meist verlängerten Paraphysen zu einer Masse (Mazaedium) verklebend.

Fam. Protocaliciaceae. Fruchtkörper anfangs krugförmig, sitzend oder lang gestielt. - Caliciopsis. - Mycocalicium parietinum an Holzplanken. - Mycoconiocybe, meist auf Baumrinden und parasitisch auf Flechten.

An diese Familie schliessen sich nnter den Flechten die Caliciaceae and durch lhre Vermittelung alle übrigen Coniocarpineae an.

6. Unterreihe (Ordnung) Phacidiineae. Fruchtschicht lange von einer festen Decke therzogen, welche erst bei der Fruchtreife zer. rissen wird. Fruchtkörper rundlich, meist sternförmig aufreissend.

Fam. Stictidaceae. Fruchtgehäuse fleischig weich, hell gefärbt. Scheibe von den Lappen des Gehäuses umgeben. - Stictis (70) radiatı an Laubhölzern und Stengeln.

An dlese Familie schliessen sich wahrscheinlich unter den Flechten die Xylographuceue aus der Unterreilie der Graphidineae an, möglicherweise auch elnige Discocurpineae.

Fam. Tryblidlaceae. Fruchtkörper lederig oder kohlig, schwarz, anfangs ein. gesenkt. Hypothecium dick.

Fam. Phacidiaceae. Fruchtkörper in das Substrat eingesenkt. Hypo. thecium dünn, wenig entwickelt. - Phacidium (70) abietinum auf Tannenblättern. - Rhytismu (22) acerinum auf den Blättern des Ahorns, Rh. salicinum auf Weidenblättern.

7. Unterreihe (Ordnung) Hysteriineae. Fruchtschicht wie bei vorigen; aber der Fruchtkorper meist lang gestreckt; die Decke durch Längsspalt sich öffnend.

Fam. Hypodermataceae. Gehäuse des eingesenkten Fruchtkörpers mit den bedeckenden Schichten verwachsen, häutig-lederig. - Hypodermu (30) commune, häufig an den Stengeln von Kräutern schwarze Flecken 
bildend. - Lophodermium (30) Pinastri auf den Blättern von Coniferen, die sogenannte »Schütte der Kiefer verursachend; L. nervisequium, Ursache des »Ritzenschorfs" der Weisstanne.

Fam. Dichaenaceae. - Fam. Ostropaceae.

Fam. Hysteriaceae. Fruchtkörper frei, mit schwarzem, kohligem Gehäuse. Fruchtscheibe rundlich oder linienförmig. - Hysterium (60) pulicare an alten Stümpfen und der Rinde von Laubhölzern.

An diese Familie .schliessen sich wahrscheinlich unter den Flechten die Gattung Graphis und Opegrapha (Graphidaceae) an.

8. Unterreihe (Ordnung) Tuberineae. Fruchtkörperunterirdisch, ziem lich gross, mit vielen unregelmässig gewundenen Kammern, deren Wände von dem Ascushymenium bekleidet sind. Asci mit 1-8 grossen Sporen. Mycel fadenförmig, den Wurzeln von Bäumen ansitzend und an denselben Mycorrhizen bildend. Conidien nicht bekannt.

Fam. Eutuberaceae. Fruchtkörper mit \pm hohlen Gängen, welche nach aussen münden oder sich in die pseudoparenchymatische Rinde des Fruchtkörpers fortsetzen, und deren Wandung vom Hymenium überzogen wird. - Genea (8) vermucosa unter Eichen, Buchen, Kastanien in Norditalien, Deutschland, Frankreich, England, - Tuber (35-55) aestivum (Speisetrüffel) in Laubwäldern von Norditalien, Frankreich, Deutschland, Böhmen und der Schweiz. T. brumale mit der Form melanosporum (Perigordtrüffel), sehr aromatisch, meist unter Eichen in Baden, im Elsass, Frankreich und Norditalien. T. magnatum, sehr geschätzt, in lehmigem Boden unter Weiden, Pappeln, Eichen in Norditalien und Frankreich.

Fam. Balsamiaceae. Fruchtkörper mit rings geschlossenen, nicht nach aussen mündenden hohlen Kammern, deren Wandung vom Hyme. mium überzogen ist. - Balsamia (4) vulgaris in Buchenwäldern oder unter Gras in Parkanlagen.

9. Unterreihe (Ordnung) Plectascineae. Fruchtk örper meist rundlich, mit steriler, fast immer mündungsloser Oberflächenschicht. Asci als Auszweigungen oder Glieder unregelmässig verästelter Hyphen entstehend, in grosser Zahl das Innere des Fruchtkörpers ausfüllend, in der Regel rundlich, mit 2-8 ein. oder mehrzelligen Sporen. Mycel wohlentwickelt. Conidien bei vielen bekannt.

Fam. Gymnoascaceae. Fruchtkörper mit einer aus locker verflochtenen Hyphen bestehenden Peridie. - Gymnoascus (5-7) Reesii, auf Mist. - Myxotrichum (2) churtarum auf faulendem Papier etc.

Fam. Aspergillaceae. Peridie dicht. Fruchtkörper klein, oberirdisch, ungestielt; Peridie sich meist nicht von selbst öffnend. - Aspergillus (7-10) herbariorum, kosmopolitisch; $A$. niger auf feucht liegenden Vegetabilien, auch im menschlichen $\mathrm{Ohr} ; \boldsymbol{A}$. oryzae, Diastasebildner bei der Darstellung der japanischen Soja-Sauce und bei der Bereitung von Reiswein (Saké); $A$. Wentii, in Java auf gekochten Sojabohnen auftretend und zur Darstellung von Sojasauce verwendet. A. fumigatus auf faulenden Pflanzenteilen, sowie pathogen in verschiedenen Organen (Trommelfell, Hornhaut, Lunge) des Menschen. - Penicillium (4) crustaceum 
(Pinselschimmel), kosmopolitisch. - Emericella (2) (Italien, Ostindien). Citromyces, in zuckerhaltigen Flüssigkeiten Citronensäure erzeugend.

Fam. Onygenaceae. Peridie des meist gestielten Fruchtkörpers bei der Reife ringförmig, lappig oder unregelmässig sich öffnend. - Onygena (6) equina an faulenden Hufen von Ein- und Zweihufern, sowie auf den Hörnern der letzteren.

Fam Trichocomaceae. - Trichocoma (2, tropisch).

Fam. Elaphomycetaceae. Peridie des ziemlich grossen, knollenförmigen, unterirdischen Fruchtkörpers gegen das Innere scharf abgegrenzt, sich nicht spontan öffnend. Sporenmasse bei Reife pulverig. - Elaphomyces (23) cervinus unter Kiefern und Fichten, seltener unter Eichen und Buchen.

Fam. Terfeziaceae. Peridie vom Innern des unterirdischen knollenförmigen Fruchtkörpers wenig abgegrenzt. Sporenmasse nicht pulverig. Terfeaia (16) leonis unter Cistaceen im Mittelmeergebiet. - Choiromyces (2) maeandriformis in Laub- und Nadelwäldern Mitteleuropas, Speisepilz, mit Tuber magnatum verwechselt.

\section{Fam. Myriangiaceae.}

10. Unterreibe (Ordnung) Pyrenomycetineae. Fruchtkörper rundlich mit dauernd geschlossener oder nur durch Verwitterung oder eine apicale Mündung sich öfnender Peridie. Schläuche büschelig gestellt und das Innere des Fıuchtkörpers als besonderer Kern a usfüllend.

Familiengruppe (Unterordnung) Perisporiaceales. Peridie kugelig, geschlossen bleibend oder aber nur in der oberen Hälfte ausgebildet und dann sich meist mit einem Loch öfnend.

Fam. Erysibaceae. Luftmycel weiss. Fruchtkörper \pm kugelig, mit Anhängsel, ohne Mündung oder am Scheitel unregelmässig zerfallend. Die erste Anlage des Peritheciums besteht aus einem Oogonium und einem Antheridium, dessen einer Zellkern sich mit dem einen des Oogoniums vereinigt. Während dasselbe von am Grunde entspringenden Hüllfäden eingeschlossen wird, entwickelt es sich durch Teilung zu einer Reihe von Zellen (Ascogon), deren eine (bei Sphaerotheca) entweder direct zum Ascus wird oder (bei Frysibe) mehrere ascogene Fäden entwickelt. Conidienform Oidium. Parasiten auf Pflanzen, auf denselben weissliche Uberzüge (Mehlthau) bildend. - Splicerotheca (14) pannosa auf Rose und Pfirsich; Sph. Humuli (Castagnei) auf Hopfen und vielen anderen Pflanzen. - Erysibe (20) graminis auf Gräsern; $E$. Martii und $E$. communis auf vielen Pflanzen. - Uncinula (20) spiralis (Oidium Tuckeri) auf dem Weinstock, Ursache des Beerenbruches; U. Aceris auf Ahorn. - Phyllactinia $(2-3)$ suffulta auf vielen Bäumen und Sträuchern.

Fam. Perisporiaceae. Luftmycel fehlend oder dunkelfarbig. Fruchtkörper ohne Anhängel. - Apiosporium (20) salicinum, schwarze Mycelflocken auf Weiden und Pappeln bildend; $A$. Tiliae auf Lindenästen.

\section{Fam. Microthyriaceae.}

Familiengruppe (Unterordnung) Hypocreaceales. Peridie kugelig oder ellipsoidisch, mit Mündung, weich, verschieden gefärbt; aber nie schwarz und hart. 
Fam. Hypocreaceae. Hypomyces, meist auf Hymenomyceten. - Melanospora (40) damnosa an Weizenhalmen. - Nectria (250) cinnabrrina, häufig auf dürren Ästen verschiedener Bäume und Sträucher; N. ditissima an vielen Laubbäumen Krebs erzeugend. - Gibberella (13) Sanbinetii, massenhaft auf grösseren Gräsern. - Hypocrea (110) rufa auf $\mathrm{Holz}$ und Rinde verschiedener Bäume; H. alutacea auf Clavaria-Arten. Polystigma (3) mubrum auf Blättern von Prunus domestica und $P$. spinosa. - Epichloë (9) typhina auf lebenden Grashalmen. - Claviceps (6) morpurea (hierzu Sclesotium clavus und Spharselia segetum) am Fruchtknoten verschiedener Gräser, besonders des Roggens (Secale cornutum, Mutterkorn). - Cordyceps entomorrliza auf abgestorbenen Insectenlarven; $C$. militaris, auf toten Schmetterlingsraupen und Puppen, in feuchter Walderde; C. oplioglossoides auf lebenden Elaphomyces-Arten in sandigen Wäldern.

Familiengruppe (Unterordnung) Dothideaceales. Peridie fehlend; der Fruchtkörper in einem Stroma gebildet und von de'ssen Gewebe nicht deutlich abgegrenzt.

Fam. Dothideaceae. Phyllachora (200) graminis auf lebenden und abgestorbenen Grasblättern. - Dotlidea (25) Sambuci auf dürren Ästen mehrerer Laubhölzer. - Rhopographus (6) Ptevidis auf dürren Blättern von Pteridium.

Familiengruppe(Unterordnung) Sphaeriaceales. Peridie lederartig, holzig oder kollig, von dem Stroma, wenn ein solches vorhanden, gesondert.

Fam. Sordariaceae. Mistbewohnend. Fruchtkörper meist in das Substrat eingesenkt, weich und mit dunkel gefärbten Sporen. - Sordaria (100) macrospor'a häufig auf Mist; $S$. fimicola auf Mist und faulenden Pflanzenteilen. - Sporormia.

Fam. Chaөtomiaceae. Fruchtkörper oberflächlich und frei, am oberflächlichen Mycel, sehr zerbrechlich, mit Haarschopf an der Münlung. Chatomium (60) chartarum auf moderndem Papier; andere auf Mist und faulenden Pflanzenteilen.

Fam. Sphaeriaceae. Fruchtkörper \pm frei oder höchstens an der Basis etwas eingesenkt, mit papillenförmiger Mündung. - Trichosphaeria (40) minima auf dürren Birkenästen; 7 . parasitica auf Blättern der Tannen und Fichten. - Herpotrichia (25) nigra auf Fichten und Krummholzkiefern im Hochgebirge. - Lasiosphaeria (40) Rhacodium auf faulendem Holz. - Rosellinia (170) pulveracea auf faulendem Holz, Ästen und Rinden; R. quereina, an den Wurzeln 1-3jähriger Eichen, die Pflanzen vernichtend. - Bertia (12) moriformis, auf dürren Ästen. - Melanomma (120) pulvis pyrius, bildet Überzüge an $\mathrm{Holz}$ und Rinden.

Fam. Ceratostomataceae. Peridie zart lederig, mit schnabelförmiger Mündung, bisweileu in der Jugend eingesenkt und erst später an die Oberfläche tretend. Cerutostomella (30) rostrata auf faulendem Holz; $C$. pilifera auf abgestorbenen Kieferstämmen. - Ceratosphaeria (15) aeruginosa auf faulendem Holz, welches gelb oder blau-grün gefärbt wird.

Fam. Curcurbitariaceae. Fruchtkörper in dichten Haufen oder Rasen dem ausgedehnten Stroma aufsitzend, nicht flaschenförmig und an der Spitze nicht trichterförmig. - Nitschkia (20) cupılaris auf dürren Ästen verschiedener Strüucher und Bäume. - Cucurbitaria (70). 


\section{Fam, Coryneliaceae.}

Fam. Amphisphaeriaceae. Fruchtkörper unten \pm eingesenkt und oben frei, derb, uhne Schnabel mit kreisrunder Mündung. - Amphisphaeria (100). - Trematosphaeria (50) mastoidea auf dürren Ästen verschiedener Bäume und Sträucher.

Fam. Lophiostomataceae. Wie vorige; aber mit zusammengedrückter von einer Längsspalte durchsetzter Mündung. - Lophiostoma (90) nucula an dicker Rinde, besonders von Weiden und Pappeln; L. compressum auf dürren Ästen und Holz.

Fam. Mycosphaerellaceae. Fruchtkörper in der obersten Substratschicht entstehend, später sich etwas hervorwölbend, mit häutig lederiger Peridie und ohne Paraphysen zwischen den Schläuchen. - Stigmatea (20) Robertiani auf Blättern von Geranium Robertianum. - Ascospora himantia auf dürren Stengeln von Umbelliferen. Pharcidia lichenum auf dem Thallus verschiedener Flechten - Tichothecium (13) pygmaeum auf Steinflechten. - Mycosphaerella filicum auf Blättern von Aspidium flix mas und $\boldsymbol{A}$ spinulosum, M. brassicicola auf lebenden Blättern von Brassica; $\boldsymbol{M}$. punctiformis auf den Blättern verschiedener Baume.

Fam. Pleosporaceae. Fruchtkörper in tieferen Gewebeschichten eingesenkt, nur mit der Mündung hervorragend, häutig oder lederartig, sonst wie vorige. Didymosphaeria conoidea auf dürren Kräuterstengeln. - Venturia chlorospora auf dürren Blättern verschiedener Bäume. - Leptosphaeria mit zahlreichen (500) Arten auf Grashalmen und auf Dikotylen. - I'leospora (200) Pteridis auf Pteridium aqu linum; Pl. vulguris und $\boldsymbol{P l}$. herbarum auf dürren Stengeln verschiedener Kräuter, namentlich letztere ausserordentlich verbreitet.

Fam. Massariaceae. Fruchtkörper wie bei vorigen; aber Peridie derb und immer bedeckt. - Massaria (60) auf dürren .̈̈sten.

Fam. Gnomoniaceae. Fruchtkörper eingesenkt bleibend, häutig, mit schnabelförmiger Mündung. - Gnomonia (60) auf dïrren Blättern; $G$. erythrostoma den Kirschbäumen gefährlich.

\section{Fam. Clypeosphaeriaceae.}

Fam. Valsaceae. Stroma ausgebreitet oder kegelförmig, meist ins Substrat eingesenkt oder hervorbrechend, die Fruchtkörper gleichmässig verteilt oder nur aın Grunde tragend. Kleinsporige Pykniden, zuweilen auch Conidienträger. Diaporthe (400). - Valsa (400), sehr häufig V. salicina und V. ambiens - Anthostoma.

Fam. Melanconidaceae. Stroma polster- oder kegelförmig, eingesenkt bleibend oder hervorbrechend, an seiner Basis die Fruchtkörper tragend. Grosssporige Conidienlager oder Pykniden, bisweilen auch Conidienträger. Ascosporen klein. Cryplospora (20). - Melanconis(15).

Fan. Diatrypaceae. Stroma ausgebreitet oder polsterförmig. Fruchtkörper eingesenkt. Kleinsporige Conidienlager von fleischiger Consistenz und lebhafter Färbung. - Calosphaeria (35) gregraria auf dürren Ästen vieler Bäume. - Diatrypella (40) verruciformis und Diatrype (70) stigma auf dürren Ästen verschiedener Bäume.

Fam. Melogrammataceae. Stroma polsterformig, hervorbrechend; im Inneren neben den Perithecien auch Conidien bildende Höhlungen ohne besonders differenzierte Wände. Ascosporen gross. - Melogramma (15). - Botryosphaeria (50).

Fam. Xylariaceae. Stroma oberflächlich, stark entwickelt, oft aufrecht, unmittelbar unter der Oberfläche in einer Schicht die Fruchtkörper tragend, in der Jugend mit Conidien bedeckt; meist auch freie Conidienträger. Ascosporen einzellig, schwarzbraun. - Nummularia (40) Bulliardii auf dicken Zweigen von Fagus. - Ustulina (9) vulgaris an alten Stämmen von Laubhölzern. - Hypoxylon (200) udum auf morschem, feuchtliegendem Holz; $H$. multiforme auf alten Baumstümpfen, besonders von Erlen und Birken; H. fuscum auf dürren Ästen. - Poronia (11) punctata auf altem Pferdemist. - Xylaria (200) Hypoxylon an alten Baum- 
stümpfen; $X$. digitata an altem, gezimmertem $\mathrm{Holz} ; \boldsymbol{X}$. polymorpha an alten Baumstümpfen.

An diese Familiengruppo der Sphaeriaceales schliessen sich unter den Flechten die Pyrenocarpineae an.

\section{Anhang zu Klasse 3 und 5. FUNGI IMPERFECTI. Unvollkommen bekannte Pilze.}

Pilze mit mehrzelligem Mycel, von denen weder Asci noch Basidien bekannt sind, welche aber zum Teil als Conidienformen von Ascomyceten anzusehen sind oder auch Mycelformen von unbekannter systematischer Stellung.

\section{A. Conidienformen.}

Reihe SPHAEROPSIDALES. Conidien in Pykniden oder kammerartigen Höhlıngen.

Fam. Sphaerioidaceae. Pykniden mit \pm kugeligem, lederigem, kohligem, schwarzem Gehäuse. - Pliyllosticta (800), Phoma (1100), auf Blättern zahlreicher Arten. - Sphaeropsis (180) auf Früchten und Rinden - Ascochyta (250) auf Blättern. - Diplodia (450) auf Blättern und Zweigen - Septoria (900) auf Früchten, Blättern etc. - Viele Arten dieser Gattungen Schädlinge von Kulturpflanzen.

Fam. Nectrioidaceae. Pykniden mit fleischigem oder wachsartigem, hellfarbigem Gehäuse und hyalinen Sporen.

Fam. Leptostromataceae. Pykniden mit schildförmigem, mündungslosem oder zweilippigem Gehäuse.

Fam. Excipulaceae. Pykniden mit schüssel-oder topfförmigem, anfangs fest geschlossenem, später weit geöffnetem Gehäuse.

Reihe MELANCONIALES. Conidien auf Conidienlagern, welche zuletzt ganz frei stehen.

Fam. Melanconiaceae. - Gloeosporinu (300) ampelophagum, der "schwarze Brenner des Weinstocks, auf Stengeln und Blättern desselben, sehr verderblich, G. Iindemutlianum auf Bohnen. - Melanconium (100) - Marssonia (60). - Septogloeum (23) - Conynentm - (70) Pestalozzia (170) funerea auf Coniferen und anderen Holzgewächsen, $P$. tumefaciens auf Coniferen, P. Hartigii auf Keimlingen.

Reihe HYPHOMYCETES. - Conidien an Conidienträgern gebildet, welche einzeln oder in Coremien zusammenstehen.

Fam. Mucedinaceae. Conidienträger von einander getrennt, ebenso die Hyphen, letztere bisweilen kurz und in Oidien zerfallend.

A. Micronomeae. Vegetative Hyphen kurz, fast wie Conidien aussehend oder gut entwickelt und dann die Conidienträger nur wenig vom Mycel differenziert.

a. Chromosporieae. Conidien nicht in Ketten, höchstens als Oidien reihenweise durch Zerfall von Hyphen gebildet, meist einzeln an Mycel. - 
Sachria auf Bierwürze. - Sarcinomyces. - Clıromosporium. - Opliocladium.

b. Oosporeae. Conidien an besonderen, aber einfachen Trägern, seltener reihenweise erzeugt. - Oospora (100) lactis, auf Käse, Milch, Würze; $O$. furfur, Ursache der Kleienflechte auf Brust und Hals; $O$. tonsurans, bei Glatzflechte auftretend; $O$. Schoenleinii, Ursache des Favus oder Kopfgrindes. - Momilia candida auf faulenden Früchten, Mist etc.; M. fructigena auf Früchten, Blättern und Ästen unserer Obstbäume.

B. Macronemeae. Vegetative Hyphen stets deutlich. Coni. dienträger scharf vom Mycel differenziert.

a. Cephalosporieae. Conidien einzeln, kopfig gehäuft.

b. Botrytideae. Conidienträger \pm reich verzweigt; aber nicht wirtelig. - Ovularia (70). - Sporotrichum (120). - Botrytis (150), B. Bassiana in den Raupen des Seidenspinners und anderer Falter die »Muscardine oder "Calcino" erzeugend; $\boldsymbol{B}$. parasitica auf Tulpen; $\boldsymbol{B}$. vulgaris und B. cinerea auf faulenden Pflanzenteilen verbreitet, das Mycel der letzteren Sclerotien bildend.

c. Verticillieae. Conidienträger mit wirteligen Verzweigungen Verticillium (50).

Fam. Dematiaceae. Hyphen dunkel oder schwarz, seltener blass. Conidien meist dunkel.

A. Amerosporeae. Mit einzelligen Conidien.

a. Micronemeae.

Toruleae. - Tomula (125).

b. Macronemeae.

Trichosporieae. Conidien einzeln endständig an verzweigten oder aufgeblasenen Conidienträgern. - Trichosporium (60), parasitisch und saprophytisch.

B. Didymosporeae. Mit 2-zelligen Conidien.

Fusicladium (32) dendriticum auf Äpfeln, andere auf Birnen und Kirschen. - Cladosporium (160) herbarum sehr verbreitet.

C. Phragmosporeae. Mit 3-mehrzelligen Conidien.

Helminthosporium (175) saprophytisch.

D. Dictyosporeae. Mit manerförmig geteilten Sporen. - Macrosporium (140) Solani, auf der Kartoffel.

E. Scolecosporeae. Mit wurmförmigen Sporen.

C'ercospora (500), viele auf Kulturpflanzen.

Fam. Stilbaceae. Hyphen und Conidienträeger zu einem Coremium verbunden. - Stilbella (100). - Isuria (100), teils auf Tieren parasitisch, teils auf Pflanzenteilen saprophytisch.

Fam. Tuberculariaceae. Hyphen und Conidienträger zu einem lagerartigen Polster verbunden. - Tubercularia. - Illosporium carneum auf Peltigera canina. - Fusarium (300), viele auf Kulturpflanzen, F. aquiductum in Wasserleitungsröhren nach Moschus riechend. 


\section{B. Mycelformen.}

Mycorrhiza, sehr feine gegliederte Mycelfäden, welche mit Wurzeln höherer Pflanzen in Symbiose leben. a) Endotrophische M., in den Zellen der Wurzelrinde oder ihrer Oberhaut lebend, in denselben Knäuel bildend und feine Fäden in den Humus entsendend, so bei Neottia, Monotropa, Corallior. rhiza. - b) Ektotrophische M., an der Oberfläche von Wurzeln eine dichte pseudoparenchymatische Schicht bildend, bei unsern waldbildenden Nadelhölzern, bei den Fagaceen, Salicaceen, Tilia, bei Ericaceen, überhaupt bei Bewohnern von Heiden, Mooren und Wiesen.

\section{Nebenklasse zu Klasse 3 und 5 LICHENES (FLECHTEN, FLECHTEN-} PILZE), Ascomyceten und Basidiomyceten, welche mit Sclizoplyyceae oder Clorophyceae, namentlich Protococcaceae und Pleurococcaceae derart in Symbiose leben, dass sie auf den Algen entweder nur parasitisch leben oder aber mit denselben eine innige Vereinigung, ein Consortium bilden, das eigenartige, bei den Pilzen nicht vorkommende Wachstumserscheinungen zeigt. Der durch die Symbiose gebildete Thallus ist in selteneren Fällen homoiomerisch, dann zugleich fast immer gallertartig, gelatinös, mit annähernd gleichmässiger Verteilung von Alge und Pilz, häufiger heteromerisch, mit Beschränkung der Alge auf eine Schicht (Gonidienschicht), welche zwischen Rindenschicht und Markschicht liegt. Thallus bisweilen unterrindig, hypophloeodisch, häufig krustig, laubig, strauchig. Die Algen (Gonidien) vermehren sich im Flechtenhallus nur vegetativ, ausserhalb desselben aber auch durch Schwärmsporen, sofern ihnen solche ẗberhaupt zukommen. Sehr verbreitet Vermehrung der Flechten durch Soredien, kurze Brutknöspchen, welche aus Pilzfäden und Algengonidien bestehen, seltener durch Hymenialgonidien, Vereinigungen von Algengonidien und Pilzsporen, die bei der grossen Mehrzahl der Flechten in Asci enthaltenden Fruchtkörpern (Apothecien) erzengt werden. Ascosporen in einem Schlauch 1 bis 32 oder mehr, einzellig oder septirt. Ausserdem Spermogonien mit keimfähigen Spermatien und Pykniden mit eingeschlossenen Conidien. - Eigenartige Produkte: Flechtensäuren und Flechtenfarbstoffe.

1. Reihe ASCOLICHENES. Ascomyceten, welche mit Algen in Symbiose leben. Reihenfolge der Familien nach Dr. Zahlbruckner.

1. Unterreihe Coniocarpineae. Protocaliciaceae in Symbiose mit Protococcaceae-und Trentepohlia-Gonidien. Fruchtkörperzuletzt \pm geöfnet, seltener mit einer schmalen Mündung. Paraphysen in ein \pm entwickeltes Capillitium sich fortsetzend. Sporen aus den bei der Reife dahinschwindenden Schläuchen entleert, den Hyphen des Capillitiums und der Unterlage des Fruchtkörpers lange anhängend. (Thallus krustig bis strauchig.)

Fam. Caliciaceae. Thallus meist krustig. Fruchtkörper kopfförmig, meist gestielt, selten sitzend, nach dem Absterben der älteren Schläuche reichlich neue erzeugend. - Sphinctrina parasitisch auf Flechten. - $C_{y}$. plelium, Coniocybe, Calicium auf Baumrinde.

Fam. Tylophoraceae. - Fam. Coniophyllaceae. 
Fam. Sphaerophoraceae. Thallus strauchig. Fruchtkörper anfangs in demselben eingeschlossen, dann denselben durchbrechend und sich unregelmässig öffnend. - Sphuerophorus coralloides im Hochgebirge auf Felsen und auf der Erde.

2. Unterreihe Graphidineae. Fruchtkörper langgestreckt, zygomorph oder unsymmetrisch, seltener kreisförmig. Paraphysen nicht in ein Capillitium abergehend. Stictidacene und Hysterineae, auch $P a$ tellariaceae in Symbiose mit Trentepohlia-Gonidien, seltener mit Protococcaceae-Gonidien.

Fam. Xylographaceae. Thallus meist in der Unterlage entwickelt (hypophloeodisch) mit Pleurococcus-Gonidien. - Xylogrupha an trockenem Holz.

Fam. Graphidaceae. Thallus krustig, mit Trentepolila-Gonidien. Opegropha varia und $O$. atra sehr verbreitet an Laubholzrinden. Grophis scripta sehr häufig an glätteren Baumrinden. - Arthonia an vielen Baumrinden.

Fam. Dirinaceae.

Fam. Roccellaceae. Thallus strauchig, mit Trentepollia-Gonidien. Fruchtkörper rundlich oder in die Länge gezogen. - Roccellı tinctoria auf Felsen an den Küsten der Kanaren und Azoren etc., ebenso R. fuciformis an den Küsten Westeuropas, geben Orseille und Lakmus.

\section{Fam. Rotulaceae.}

3. Unterreihe Discocarpineae. Patellariaceae und viele isoliert nicht bekannte discocarpe Pilze mit Protococcaceae oder Pleurococcaceae, oder Trentepohlia oder Schizophyceae. Fruchtkörper scheibenförmig, sonst wie vorige.

Fam. Lecanactidaceae. - Fam. Pilocarpaceae.

Fam. Chrysotrichaceae. - Fam. Thelotremataceae.

Fam. Gyalectaceae. Thallus mit Trentepohlia-Gonidien; Apothecium zumeist eingesenkt. - Gyalecta cupularis an Kalkfelseu. - Secoliga.

Fam. Diplochistaceae.

Fam. Coenogoniaceae. Thallus mit Cladophora-Gonidien. - Coenogonium.

Fam. Byssocaulaceae.

Fam. Lecideaceae. Thallus krustig, mit Pleurococcus-Gonidien; Apothecien von Anfang an rundlich, vom Thallus nicht herandet, dunkel und kohlig oder hell und weich. - Lecidea coarctata, sehr gemein auf Steinen; I. fusca häufig auf Moosen und nackter Erde; I. uliginosa auf feuchter Frde und faulendem Holz; L. sabuletorum anf Baumrinden, Steinen und über Moosen sehr häufig. - Catillaria. - Bacidia (incl. Bilimbia und Biatorina) auf Rinden, Holz und auf Erde. - Rhizocarpon yeogroplicum (Landkartenflechte) oft ganze Felsen mit weithin leuchtender gelbgrüner Kruste bekleidend. - Biatoridium und Jecidea stehen in Bezichung zu den Gattungen der Patellariaceae.

Fam. Psoraceae. Thallus schuppig-krustig, mit Pleurococcus-Gonidien. - Psora ostreatu an $\mathrm{Holz}, P_{s}$. luridn und $P_{s}$. decipiens auf kalkhaltigem Boden häufig. Toninia candida und T. vesicularis auf Erde.

Fam. Baeomycetaceae. Fruchtkörper \pm gestielt, mit heller Fruchtscheibe. - Icmadoplila aemuginosa an feuchter Erde, namentlich in Ge- 
birgen. - Baeomyces roseus auf trockenem Sand- und Heideboden. Sphyridium byssoides häufig an Waldwegen.

Fam. Collemataceae. Thallus homoiomerisch, gallertartig, mit Nostocoder Rivularia-Gonidien. Apothecien mit oder ohne eigenes Gehäuse. Plysma compactum auf trockenen, sandigen Stellen. - Collema, viele Arten auf Bäumen und Felsen. - Iseptogium. - Mallotium. - Porocyphus auf Felsblöcken. - Iichina (Rivularia-Gonidien) auf vom Meer überfluteten Felsen.

Fam. Pyrenopsidaceae. Wie vorige; aber mit Chroococcaceae-Gonidien, mit offenen und geschlossenen Apothecien. - Omphalaria. -- Synalissa. - Psurotrichia.

Fam. Ephebaceae. Thallus homoiomerisch, nicht gallertartig, mit Stigonema-Gonidien. - Ephebe pubescens an Felsen.

Fam. Pannariaceae. Thallus schuppig-krustig, heteromerisch, mit Phycochromaceae-Gonidien. - Pannuria.

Fam. Stictaceae. Thallus blattartig, heteromerisch, mit Haftfasern dem Substrat ansitzend, meist mit Plencrococcus- und Chlorococcum-Gonidien. Apothecien dem Thallus eingesenkt, schildförmig, mit deutlichem Rand. - Sticta pulmonaria an Laubholz, auch an Felsen, namentlich im Gebirge. - Lobaria. - Ricasolia.

Fam. Peltigeraceae. Thallus wie bei vorigen; aber Apothecien ohne deutlichen Rand. - Peltigera canina häufig an Waldrändern, auf Wiesen etc.; P. polydactyla nicht selten. - Solorina crocea im Gebirge, S. saccata auf feuchter Erde: - Neplirorna.

\section{Fam. Siphulastraceae.}

Fam. Pertusariaceae. Thallus krustig mit Protococeaceae-Gonidien und häufig mit Soredien; Apothecien punktförmig, selten scheibenartig erweitert; Sporen meist gross, mit dickem Exospor. - Pertusariı communis an den Rinden vieler Laubhölzer. - Ochrolechia tartare⿰ vorzugsweise an Steinen und Felsen; O. pallescens an Baumstämmen im Gebirge, zur Bereitung von Lakmus verwendet. - Pllyctis.

Fam. Lecanoraceae. Thallus krustig mit Protococcaceae-Gonidien. Apothecien dem Thallus eingesenkt mit Gonidien in ihrer nächsten Umgebung, ohne Rand. - Lecanora subfusca sehr verbreitet, namentlich an Laubbäumen und Holz; I. pallida ebenso; I. badia an Felsen und Steinen. - Haematomma ventomun an Steinen und Felsen.

\section{Fam. Psoromataceae.}

Fam. Gyrophoraceae. Thallus beiderseits berindet, nur in der Mitte (durch einen Nabel) dem Substrat aufsitzend. - Umbilicaria pustulata häufig auf Felsen und Steinen im Gebirge. - Gyrophora, wie vorige.

Fam. Parmeliaceae. Thallus blattartig, beiderseits berindet und mit Haftfasern dem Substrat angeheftet oder strauchig, auch fadenförmig, mit \pm knorpeliger Rindenschicht und Protococcaceae-Gonidien. Apothecien $\overline{\mathrm{dem}}$ Thallus eingesenkt, mit einem Gonidien enthaltenden Rand. - Pur- 
melir physodes, $P$. olivacea, $P$. caperata häufig an Bäumen und Steinen. - Evernia prunastri an Laubholzbäunen; E. vulpina auf Nadelhölzern, hesonders im Hochgebirge. - Cetruria islundica (isländisches Noos) auf trockenen Heideplätzen häufig, namentlich im Hochgebirge; C. glauca auf verschiedenen Unterlagen häufig. - Alectoria ocliroleuca im Hochgebirge zwischen Steingeröll. -- Ramalina fraxinea sehr häufig an Laubholzbäumen; $R$. reticulata, sehr eigenartige Flechte in Californien. Usnee barbata sehr häufig an Bäumen.

Fam. Cladoniaceae. Thallus horizontal, verschwindend, und mit aufrechten, oft trichterförmigen, den Stielen der Apothecien entsprechenden Sprossen. Apothecien an den Spitzen der Podetien oder an deren OberHä̈che hervortretend, schwärzlich, bräunlich oder hochrot. - Cladomic turgida, C. cariosa, C. pyxidata häufig an Wegrändern; C. gracilis, C. degenerans häufig in Nadelwäldern; $C$. digitata, $C$. macilenta auf faulendem Holz, C. uncinuta auf Moorboden, C. furcata auf nackter Erde zwischen Moosen, C.rongiferina (» Renntiermoos»), häufigste Flechte in trockenen Wäldern und auf Heiden.

Fam. Stereocaulaceae. Thallus anfangs krustig oder schnppig, dann mit stranchigen Pseudopodetien, mit knorpeliger Rinde, mit ProtococcaceaeGonidien. - Stereocaulon tomentosum und St. paschale in lichten Nadelwäldern, auf Heideplätzen.

Fam. Theloschistaceae. Thallus krustig, schuppig oder blattartig oder strauchig mit Protococcaceae-Gonidien. Apothecien dem Thallus anfangs eingesenkt, dann weit hervortretend, mit einem durch $K H O$ violett werdenden Excipulum. - Blastenia. - Candellaria concolor im sterilen Zustand sehr verbreitet. - Caloplace vitellina und andere häufig auf Steinen, Bäumen, Holz, Moos. - Placodium saxicolum häufig auf Mauern, auch auf Holz; $\boldsymbol{P l}$. murorum ungemein häufig an Mauern, auf Dächern und auf Steinen. - Theloschistes. - Yanthoria parietina, sehr gemein an Bäumen.

Fam. Physciaceae. Thallus krustig, schuppig oder blattartig oder strauchig, mit Protococcaceae-Gonidien, mit anfangs eingesenkten, dann hervortretenden schwärzlichen oder seltener rotbraunen Apothecien. Buellia parasema gemein an Baumrinden und $\mathrm{Holz}$; B. verruculosa an Felsen. - Plıyscin ciliaris sehr häufig an Laubbäumen; Ph. stellaris, Ph. caesia, Ph. pulvernulenta, Ph. obscura häufig. - Anaptychia (incl. Tornabenia).

4. Unterreihe Pyrenocarpineae. Sphaeriaceales in Symbiose mit Chlorophyceae und Schizophyceae. Fruchtkörper lange geschlossen, zuletzt nit einer rundlichen regelmässigen oder unregelmässigen öffnung. Thallus meist krustig oder schuppig, seltener blattartig oder strauchig.

Fam Moriolaceae. - Fam. Mycoporaceae.

Fam. Verrucariaceae. Thallus heteronıerisch krustig, einförmig (mit Pleurococus-Gonidien). Fruchtkörper einzeln. - Vervucaria. - Theli¿lium. - Polyblastia. - Meist Felsen bewohnend. 
Fam. Pyrenulaceae. Thallus krustig, einförmig, oft unterrindig, mit

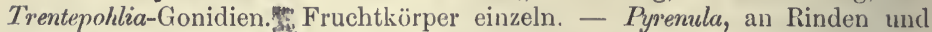
Felsen. - Arthopyrenia, an Rinden.

Farm. Trypethellaceae. Thallus ikrustig, mit Trentepohlia. Gonidien; mehrere Fruchtkörper in ein Pseudostroma vereint, jeder mit eigener und gerader Mündung. - Trypethelium, Melanotheca auf Rinden in den Tropen.

Fam. Pleurotheliaceae.

Fam. Astrotheliaceae. Thallus krustig, mite Trentepohlia-Gonidien; mehrere Fruchtkörper in ein Pseudostroma vereinigt und alle mit einer einzigen gemeinschaftlichen Mündung. - Astrothelium, Parmentaria_an Bäumen in den Tropen.

Fam. Phylloporinaceae.

Fam. Strigulaceae. Thallus kleinrosettig, am Rande effigurirt; $C_{e-}$ phaleuros-Gonidien, mit Zoosporangien. - Strigula complanata auf den lebenden Blättern tropischer Bäume und Sträucher.

Fam. Endopyreniaceae. Thallus laubartig, mit Pleurococcus-Gonidien. - Endocarpon auf Steinen und Felsen im Hochgebirge.

Fam. Dermatocarpaceae.

?Fam. Thamnoliaceae. Thallus strauchig, röhrenförmig, mit Plentrococcus-Gonidien; Fruchtkörper (?) in seitlichen Anschwellungen des Thallus. - Thamnolia vermicularis auf Heiden im Hochgebirge.

Fam. Pyrenothamniaceae. Thallus strauchig. - Pyrenothamnia.

Fam. Pyrenidiaceae. Thallus homoiomerisch, mit Nostoc-Gonidien. - Pyrenidium, auf Felsen.

2. Reihe BASIDIOLICHENES. Basidiomyceten, welche mit Algen in Symbiose leben.

Unterreihe Hymenolichenes. Hymenomyceten, welche mit Algen in Symbiose leben. - Cora Pavonia, Symbiose einer Thelephoracee mit Chroococcus-Gonidien (im tropischen Amerika, besonders in Bergwäldern). - Dictyonema sericeum, Symbiose derselben Theleploracee mit Scytonema-Gonidien unter Vorwiegen der ersteren; Laudatea caespitosa, dieselbe Symbiose unter Vorwiegen des Scytonema. - Rhipidonema ligulatum, ein Hymenomycet in Symbiose mit Seytonema-Gonidien (Borneo).

4. Klasse LABOULBENIOMYCETES. Vegetationskörper zweibis mehrzellig. Geschlechtliche Fortpflanzung durch Antherozoidien, welche ein Carpogon befruchten und die Entwickelung von Schläuchen mit Sporen hervorrufen.

Reihe LABOULBENIALES. Vegetationskörper aus 2 bis vielen Zellen bestehend, welche in mannigfacher Weise reihenweise oder parenchymatisch angeordnet sind. An den Ausgliederungen des Vegetationskörpers entstehen entweder nach Art der Conidien einzelne sich ablösende Befruchtungskörper, »Antherozoiden " oder Antheridien, in welchen Antherozoidien erzeugt werden. Die Fruchtkörper beginnen mit der Bildung eines Procarps, bestehend aus Carpogonzelle, einer darüber liegenden Trichophorzelle und 
einer Trichogynzelle, an welche die Antherozoiden sich ansetzen. Hierauf verschwinden Trichogyn und Trichophor, während die Carpogonzelle sich in 3 Zellen teilt, von denen die untere und obere auch verschwinden, die mittlere aber zum Ascogon wird. Das Procarp ist umschlossen von 9) Zellen, welche den Anfang des Gehäuses bilden, später aber sich so teilen, dass 32 Zellen das aus dem Procarp hervorgehende Gebilde umgeben. Das $\gg$ Ascogon « teilt sich in eine untere und eine obere Zelle, welche sich in 4 Zellen, die eigentlichen Ascogonzellen teilt, aus denen die Schläuche in mehr oder weniger deutlicher Doppelreihe hervorspriessen. Die reifen Schlïuche tremnen sich von den ascogenen Zellen, welche zuletzt frei in der Höhlung liegen und unbegrenzt Schläuche produzieren. In den Schläuchen entstehen meist je 4 lanzettliche, 2-zellige Sporen.

Fam. Laboulbeniaceae. Parasitisch auf Käfern, selten auf anderen Insekten wachsend, viele in Nordamerika und den Tropen. - Stigmatomyces (3) Baerii auf der Stubenfliege. - Jaboulbenia (73).

5. Klasse BASIDIOMYCETES. Mycel vielzellig. Sporenbildung erfolgt an \pm regelmässigen Conidienträgern (Hemibasidien, Basidien) in verschiedener Zahl, und zwar, wie vielfach beobachtet ist, nach vorangegangener Vereinigung zweier kleiner primärer Kerne zu einem grossen secundären Basidienkern und darauf folgender Teilung desselben. Die Basidien sind entweder Stichobasidien, d. h. die Kernspindeln der sich teilenden Kerne liegen alle in der Längsrichtung der Basidien oder sie sind Chiastobasidien, $d . h$. die Spindeln der sich teilenden Kerne kreuzen sich. Andere Conidienbildungen mannigfach.

1. Unterklasse HEMIBASIDII. Conidienträger basidienähnlich, stets aus Chlamydosporen hervorgehend.

\section{Reihe HEMIBASIDIALES.}

1. Unterreihe Ustilaginene. Conidienträger quergeteilt.

Fam. Ustilaginaceae. Conidienträger (Hemibasidien, Promycel) durch Querwände geteilt. Parasitisch auf höheren Gefässpflanzen, zumeist Angiospermen. Mycel an bestimmten Stellen der Nährpflanze, an der Oberseite oder im Innern, häufig unter deutlicher Gallenbildung aus besonderen, dicht gedrängten Nycelzweigen Chlamydosporen erzeugend. - Ustilago (200) Acence auf Hafer, $\boldsymbol{U}$. mudi und $\boldsymbol{U}$. Hordei auf Gerste, $\boldsymbol{U}$. Tritici auf Weizen, früher alle als $\boldsymbol{U}$. segetum (Russbrand) zusammengefasst; U. Panici miliacei auf Hirse; $U$. Caricis auf vielen Cyperaceen; U. Maydis (Maisbrand); U. violacea in den Antheren von Caryophyllaceen.

2. Unterreihe Tilletiineue. Conidienträger ungeteilt.

Fam. Tilletiaceae. Conidientrïger (Promycel) ohne Querwände; Conidien wirtelig an Ende derselben. - Tilletia (30) Tritici (Stinkbrand) auf Triticum vulgare; $T$. laevis auf Sommerweizen; T. Secalis auf Roggen; T. striaeformis auf verschiedenen Gräsern. - Urocystis (25) 
occulta (Roggenstengelbrand) auf Roggen; U. Anemones auf Ranunculaceen; U. Violae in den Blattsticlen und Blattrippen von Viola odorata.

2. Unterklasse EUBASIDII. Conidienträger echte Basidien, entweder aus Chlamydosporen entstehend, oder als Fortsetzung gewöhnlicher Hyphen. In der jungen Basidie 2 kleine primäre Kerne, welche verschmelzen und einen secundären Basidienkern bilden, der zu bedeutender Grösse heranwächst, um nachher durch zweimalige Teilung 4 für die Sporen bestimmte Kerne zu erzeugen.

1. Reihe PROTOBASIDIOMYCETES. Basidien quer oder längs geteilt.

1. Unterreihe (Ordnung) Auricularineae. Basidien quergeteilt. Die Basidien sind Stichobasidien.

Familiengruppe (Unterordnung) Uredinaceales. Basidien a us Chlamydosporen (Teleutosporen) entstehend. - Parasiten auf lebenden Pflanzen. Mycel reich entwickelt, hä ufig mit orangeroten Öltröpfchen, localisirt oder ausgebreitet, in ausdauernden Pflanzenteilen bisweilen perennirend; Hyphenenden unter der Oberhaut der Nährpflanze Chlamydosporen erzeugend, dicht nebeneinander stehend, ein die Oberhaut durchbrechendes Fruchtlager bildend.

Nur ungeschlechtliche Fortpflanzung: A. durch Chlamydosporen von dreierlei Art: 1. Uredosporen, grosse Sporen an kurzen Ästen, in flachen Lagern, sofort nach der Reife keimend und an der Nährpflanze ein neues Lager erzeugend. - 2. Teleutosporen, einzellig oder mehr. zellig, können meist iberwintern und entwickeln aus der Keimpore jeder Zelle eine begrenzte, meist 4zellige Basidie (Promycel), an deren Gliedern je ein Sterigma mit einer Conidie oder Basidiospore (Sporidie) entsteht, welche sofort keimt, oder jede Zelle der Teleutospore teilt sich in meist 4 über einander stehende Zellen, von denen jede ein Sterigma mit Sporidie entwickelt. - 3. Aecidiosporen, in Ketten stehend auf dichtstehenden Hyphenästen, sofort keimend;

B. durch Conidien von zweierlei Art: 1. Spermatien, sehr kleine Conidien, a f dicht stehenden Sterigmen in biruförmigen, meist zugleich mit den Aecidien entstehenden Behaltern. - Sporidien (siehe unter A 2).

Generationswechsel. - Metöcismus und Heteröcismus.

Fam. Endophyllaceae. Teleutosporen durch succesive Abschnürung in längeren, in die Einzelsporen zerfallenden Reihen gebildet. Jede der Teleutosporenzellen entwickelt ein Promycel. - Endophyllıım (3) Sempervivi und $E$. Sedi auf Crassulaceen.

Fam. Schizosporaceae.

Fam. Melampsoraceae. Teleutosporen flache oder polsterförmige Lager oder säulenförmige Körper bildend oder lose im Gewebe der Nährpflanze, ungestielt.

$\S$ Chrysomyxeae. Teleutosporen an denselben Hyphen reihenweise angeordnet, ein polsterförmiges Lager bildend, welches die Epidermis der Nährpflanze durchbricht. -- Chrysomyxa (10) Rhododendri auf Rhododendron; C. Isedi auf Tedum, zu beiden Aecidium rbietinum auf Picea excelsa; C. Abietis auf der Fichte (nur Teleutosporen).

§ Cronartieae. Wie vorige; aber Teleutosporenlager säulen- oder haarförmig. - Cronartium (10) ribncolum auf Ribes-Arten (dazu gehörig Aecidium strobi auf der Weymouth-Kiefer (Pinus strobus)). 
§ Melampsoreae. Teleutosporenlager von der Epidermis bedeckt. Teleutosporen durch frei hervortretende Promycelien keimend. - Melampsor (30) (dazu Caeoma, Aecidien ohne Peridie); M. farinosa u. a, auf Salix, M. Tremulae und $M$. populina auf den Pappeln (dazu Caeoma Laricis auf Larix und $C$. pinitorquum auf Pinns silvestris); $M$. betulina auf der Birke (hierzu ebenfalls Caeoma auf Larix); M. Lini auf Arten von Linum. - Culyptospora (1) Goeppertiana auf der Preisselbeere (hierzu Aecidium colnmnare auf der Edeltanne, daselbst Hexenbesen erzeugend).

Fam. Pucciniaceae. Teleutosporen gestielt, isoliert bleibend oder einzelne von der Nährpflanze abtrennbare Sporenkörper bildend. Jede Teleutosporenzelle entwickelt ein Promycel.

§ Gymnosporangieae. T'eleutosporen von Gallerthüllen umgeben, einen gallertartigen Fruchtkörper bildend. - Gymnosporangium (14) Sabinne auf Juniperus sabina und anderen Arten (hierzu Roestelia cancellata auf dem Birnbaum); G. clavariforme auf Junipenus commnnis (hierzu Roestelia lacerata auf Crataegns); G. juniperinum auf Junipemus communis (hierzu Roestelia cornuta auf Pirus aucuparia).

§ Puccinieae. Teleutosporen nicht in Gallertmassen eingebettet. Spermogonien meist kugelig, eingesenkt; - Aecidien eingesenkt, meist mit Pseudoperidium. Uredo in flachen Lagern. Teleutosporen ein- oder zweizellig. - Hemileia (3) rustatrix auf den Kaffeebäumen, durch die Uredosporen sich verbreitend. - Cromyces (250) Fabae auf Vicieen, U. Betae auf der Runkelrübe, beide metöcisch; $U$. Dactylidis auf Gräsern (hierzu Aecidium Ranunculi auf Ranunculus-Arten); U. Pisi auf Vicieen (hierzu Aecidium Euphorbiae auf Wolfsmilch-Arten); U. scutellatiss auf Euphorbia cyparissias und $\boldsymbol{E}$. esula (nur Teleutosporen und verkümmerte Uredosporen hekannt). - Puccinia (700) Menthae (metöcisch); P. graminis auf Gramineen (hierzu Aecidium Berberidis); P. coromata auf Gramineen (hierzu Aecidium. Rhamni); P. mubigo vera auf Gramineen (hierzu Aecidium Asperifolii); $P$. suaveolens auf Cirsium arvense und $O$. Hieracii auf vielen Compositen (beide metöcisch, Aecidien fehlen); $P$. fusca auf Anemone nemorosa (hierzu Aecidium Anemones; kein Uredo).

§ Phragmidieae. Spermogonien kreisrund, flach, tellerförmig; Aecidien flach ohne Pseudoperidien. Uredosporen einzeln, mit stacheliger Membran; Teleutosporen isoliert, ein- bis vielzellig - Phragnidium (26) violacentm und Pl. Rubi auf Rubus-Arten; Ph. subcorticium auf Rosen; alle inetöcisch.

Zahlreiche Aecidium-Formen, deren Teleutosporen man nicht kennt, z. B. A. punctatum auf Anemone raninculoides, A. elatimum auf den Tannen.

Fam. Coleosporiaceae. Teleutosporen nicht in Längsreihen gebildet. Sporenlager von der Epidermis bedeckt. Jede Teleutosporenzelle wird direct zur Basidie und teilt sich in 4 Tochterzellen, welche Sporidien bilden. - Coleosporium (30) Senecionis (dazu Aecidium auf Pinus silvestris), Tussilaginis, Sonchi, Fuphrasiae, Melampyri, Campanulae etc.

Familiengruppe (Unterordnung) Auriculariaceales. Basidien frei an den Mycelfüden entrtehend. 
Fam. Auriculariaceae. Reich entwickelte und verflochtene Hyphen bilden einen Thallus mit glattem oder aderig gefaltetem Hymenium, das aus den langgestreckten meist vierzelligen Basidien gebildet ist. - Auricularia (40) mesenterica an alten Baumstümpfen und $A$. Auricula Judae an lebenden Stämmen von Sambucus nigra.

Fam. Pilacraceae. Der Fruchtkörper ist geschlossen, kopfförmig, gestielt und sein Inneres durch regellos verteilte Basidien ausgefüllt, welche quergegliedert sind, an den Gliederzellen aber sitzende Basidiosporen tragen. - Pilacre (2) Petersii an Hainbuchen.

2. Unterreihe Tremellineae. Basidien direct am Mycel entstehend, durch zwei Längswände über K reuzgeteilt, seltener reihenweise hinter einander, durch 1 oder 2 schräg stehende Wände in 2 oder 4 Zellen geteilt. Die Basidien sind Chiastobasidien.

Fam. Sirobasidiaceae. Basidien reihenweise hinter einander, durch 1 oder 2 schräg stehende Wände geteilt. - Sirobasidium (3) im tropischen Amerika.

Fam. Tremellaceae. Fruchtkörper offen, gallertartig oder knorpelig. Am Mycel häufig Conidien. - Exidia (10) gelatinosa und Tremella (20) mesenterica an abgefallenen Zweigen. - Tremellodon gelatinosus auf alten Stümpfen von Coniferen. - Ulocolla (2) foliacea an alten Stämmen.

Fam. Hyaioriaceae. Fruchtkörper geschlossen. Basidien in einer Kugelzone am Köpfchen. - Hyaloria (1) in Brasilien.

2. Reihe AUTOBASIDIOMYCETES. Basidien ungeteilt, mehr oder weniger keulig, mit meist 4 , selten 6,8 oder 2 apical gestellten Sterigmen.

1. Unterreihe Dacryomycetineae. Basidien lang keulenförmig, mit $z$ wei langen Sterigmen und grossen Basidiosporen, sie sind Sticho. basidien. Sporen vor der Keimung sich teilend.

Fam. Dacryomycetaceae. Fruchtkörper gallertartig. - Dacryomyees deliquescens auf alten Brettern und Baumstümpfen. - Guepinia peziza auf Eichenstümpfen. - Calocera palmata auf altem Holz, C. viscosa auf Baumstümpfen von Coniferen.

2. Unterreihe Tulasnellineae. Basidien (Chiastobasidien) gerundet, keine Sterigmen bildend, daher die Sporen sitzend, nicht abfallend a u der Basidie keimend und Conidien erzeugend.

Fam. Tulasnellaceae. - Tulasnella, auf altem Holz und Rinden. Muciporus, ebenso.

3. Unterreihe Exobasidiineae. Basidien kurz keulig. Sterigmen um vieles dünnerals die Basidien, welche ein ganz frei stehendes $\mathrm{Hy}$. menium bilden.

Fam. Exobasidiaceae. Mycel im lebenden Gewebe chlorophyllhaltiger Pflanzen. Fruchtkörper eine dünne freiliegende Basidienschicht. - Exobasidium Vaccinii auf Vaccinium-Arten.

4. Unterreihe Hymenomycetineae. Fruchtkörper + differenziert, selten gallertartig, durch Verflechtung vielfach verzweigter Hyphen gebildet. Basidien meist dicht an einander liegend, Chiastobasidien. Das Hymenium zur Zeit der Sporenbildung frei. Conidien selten. 
Fruchtkörper bisweilen mit Milchsaftschläuchen, entweder von Anfang an mit freiem Hymenium (gymocarp) oder Anfangs beschleiert; Teile des Schleiers (velum): Scheide (volva) und Ring (annulus). - Bis. weilen Cystiden. - Selten Chlamydosporen.

Fam. Hypochnaceae. Fruchtlager spinnwebenartig, locker; Basidien mit 2, 4, 6 Sterigmen. Bisweilen Cystiden. - Hypoutınus auf alten Baumstämmen, Laub, Moos etc. - Tomentella.

Fam. Thelephoraceae. Fruchtkörper häutig oder lederartig, flach, muschelförmig, trichterförmig, hutförmig. - Hymenophor glatt oder warzig oder runzelig. - Corticium (32), nit vielen Arten auf abgefallenen Zweigen. - Stereum (20), meist auf Baumstïmpfen. - Thelephora (7) terrestris in Kiefernwäldern. - Cyphella muscigena auf Moosen. - Craterellus (6) cornucopioides (Laubwälder).

\section{An die Thelephoracene schliesson sich die! Hymenolichenes an.}

Fam. Clavariaceae (Keulenschwämme). Fruchtkörper fleischig oder zäh, keulenförmig, einfach oder korallenartig verzweigt. Hymenium glatt, den Fruchtkörper ringsum bekleidend. - Typluula pusilla auf faulenden Blättern von Laubhölzern; $T$ : complanata, namentlich auf alten Weiden- und Pappelblättern (hierzu Sclerotium complanatum). - Claruria (20) botrytis u. a. in Wäldern. - Sparcssis ramosa.

Fam. Hydnaceae (Stachelschwämme). Fruchtkörper fleischig, lederartig oder häntig. Hymenophor frei, mit Warzen, Stacheln oder zahnartigen Platten. - Hydnum (20) coralloides und $H$. repandum, Speisepilze; H. auriscalpium auf Kiefernzapfen. -- Placodon suaveolens und Ph. imbricatus - Sistotrema. - Alle in Wäldern.

Fam. Polyporaceae (Löcherschwämme). Fruchtkörper fleischig, lederartig oder holzig. Hymenophor faltig oder grubig oder röhrig, die Hohlräune von dem Hymeniun überzogen.

§ Merulieae. Hymenophor mit flachen Gruben. Memulius tremellosus an alten Weiden und Pappeln. $\boldsymbol{\Gamma}$. (Serpula) Zrovymans, Hausschwarnm, selten im Wald auf Baumstümpfen, meist in Häusern. - Poria (mit umgewendet angewachsenem Fruchtkörper) vaporaria (PorenHausschwarnm, Lohschwamm).

§ Polyporeae. Hymenophor mit Röhren, welche sich berühren. Fomes (nit holzigem Fruchtkörper) igmiarius (zu Ornamenten verarbeitet) an verschiedenen Laubbäumen, namentlich auf Pflaumenbaum, Apfelbaum, Salix fragilis; $\boldsymbol{F}$. fomentarius, Zuckerschwamm, Feuerschwamm, an alten Buchen und Birken; $F$. annosus an alten Baumstümpfen, auch an Wurzeln der Kiefer und Fichte, forstgefährlich; $F$. pinicola an alten Stümpfen von Kiefern, Fichten und Tannen; $F$. lucidus am Grunde alter Laubbäume. - Polyporus (mit zäh fleischigem Frucbtkörper), $P$. vulgaris, abgefallene Zweige überziehend; $P$. destructor an alten Kieferstämmen und in Häusern; P. squamosus an Nussbäumen etc.; $P$. frondosus in Laubwäldern, Speisepilz; $P$. ovinus Schafeuter, in Nadelwäldern, essbar. Polystictus (mit lederigem oder häutigem Fruchtkörper), P. versicolor 
und $P$. zonatus an alten Baumstümpfen. - Trametes (Substanz zwischen den Poren der Substanz des Hutes gleich); T. Pini an alten Kieferstämmen Schaden anrichtend; $T$. sicaveolens an alten Weidenstämmen. - Daedalea quescina an Eichen und Buchen. - Lensites betulina an Birken und Eichen; L. saepiarir an alten Kiefernstümpfen und Zäunen.

§istulineae. Hymenophor mit gesonderten Röhren. - Fistulina hepatica an Eichen.

$\S$ Boleteae. Fruchtkörper fleischig. Hymenophor eine vom Hut leicht abtrennbare Röhrenschicht. - Boletus scaber, Kuhpilz, Graukappe, in Wäldern, Speisepilz; B. bulbosus ( $=$ B. edulis, Steinpilz) in Wäldern, Speisepilz; $B$. luridus und $B$. satanas, wahrscheinlich giftig; $B$. granulatus und Boletopsis lutea, an Waldrändern, essbar.

Fam. Agaricaceae (Blätterschwämme). Fruchtkörper meist fleischig; Hymenophor mit strahlig angeordneten Leisten oder Lamellen.

\$ Cantharelleae. Lamellen gegen den Rand hin dichotomisch verzweigt. - Cantharellus cibariıs (Rehling, Pfifferling) in Wäldern, beliebter Speisepilz; C. aurantiacus.

§ Paxilleae. Lamellen häutig, spaltbar häufig anastomosierend. Paxillus acherntints in Kellern, Ställen, Bergwerken, auch in Wäldern.

$\S$ Coprineae. Lamellen von verschiedener Iänge, wechselnd, zuletzt zerfliessend. Zwischen den Basidien Paraphysen. - Coprinus domesticus in Gärten, Häusern, Kanälen; C. stercorarius auf Mist; C. atramentarius zwischen Gras.

$\S$ Hygrophoreae. Lamellen von verschiedener Länge, abwechselnd, sehr dick, fleischig. - Gomphidius. - Nyctalis parasitica und $N$. lycoperdoides (mit Chlamydosporen) auf grösseren Agaricaceae. - Hygrophorncs. - Limacium.

$\S$ Russuleae. Fruchtkörper aus zweierlei, dünnen und dickeren (oft Milchsaft führenden) Hyphen; Sporen stark stachelig. - Lactaria volema, Milchreizker und L. deliciosa, Blutreizker, beliebte Speisepilze; L. rufa und L. torminosa, giftig. - Russula emetica, Speiteufel, ohne Milchsaft, mit farblosen Sporen, gefährlich. - Russulina, Täubling (mit gelben Sporen), integra, aluta:ea u. a. in Wäldern, essbar.

$\S$ Schizophylleae. Lamellen mit gespaltener Schneide, zu zweien verbunden. - Schisophyllum alneum, an Baumstämmen, namentlich Linden.

$\S$ Marasmieae. Fruchtkörper zäh, lederartig, vertrocknend. - Lentinus stypticus an Laubholzstämmen in Rasen. -- Mrrosmius androsaceus auf altem Laub, Kiefernadeln etc.; $M$. rotula an abgefallenen Zweigen; M. alliatus, Muscheron, auf Graswurzeln und an alten Baumstämmen.

$\S$ Agariceae. Fruchtkörper fleischig, faulend, mit gleichartigen $\mathrm{Hy}$ phen. Lamellen bisweilen zerfliessend. Basidien dicht.

a. Sporenpulver schwarz: Coprinarius.

b. Sporenpulver dunkelbraun: Psilocybe. - Hypholoma fasciculare an Baumstümpfen. - Psalliota campestris, Champignon, auf 
Triften; auf Pferdemist cultiviert; Ps. arvensis, wilder Champignon, auf Wiesen und in Wäldern.

c. Sporenpulver braun: Derminus Hypni in Wäldern zwischen Moos. - Pholiota squarrosa an Laubholzstämmen; Ph. mutabilis an alten Baumstöcken. - Inocybe geoplyylla in Wäldern. - Cortinrırius cinnamomens in Wäldern, auf Sandboden.

d. Sporenvulver fleischrot oder rostrot: Hyporhodius. - Clitopilus Prumulus, in Wäldern, Speisepilz.

e. Sporenpulver weiss: Russuliopsis laccata in Wäldern. - Agaricus roseus in Lanbwäldern heerdenweise, Speisepilz; $A$. galericulatus, häufig anf Baumstämmen; A. salignus vorzugsweise auf Weiden und Pappeln; $A$. ostreatns auf verschiedenen Laubbäumen, beide essbar; A. graveolens, $A$ gambosus, $A$. borealis (Maipilz) auf Grasplätzen, alle drei essbar: $A$. equestris, Grünling, Grünreizker, in Kieferwäldern. - Ammillaria mellea, Hallimasch (hierzu gehörig Rlizomorpha), an alten Bäumen, diesen schädlich, essbar. - Lepiota procera, Parasolpilz, in trockenen Wiäldern und auf Heideplätzen. - Amrenita muscaria, Fliegenpilz, in Wäldern, sehr giftig; $A$. lnelbosa in Laubwäldern, sehr giftig; A. plualloides in Birkenwäldern, sehr giftig; A. caesarea, Kaiserschwamm, in Südeuropa und Böhmen, essbar.

4. Unterreihe Phallineae. Fruchtkörper vor der Reife kugelig oder eifurmig, aus einer labyrinthisch kammerigen Gleba und einein fast immer pseudoparenchymatischen und gekammerten sehr verschieden. artig gestalteten Körper (Receptaculum) bestehend, welche beide an. fänglich von einer fleischigen Hälle (Volva) umschlossen sind. Spater erfahrt das Receptaculum eine starke Streckung, durchbricht die Volva und tritt weit aus ihr hervor, die Gleba mit sich emporhebend. Letztere zerfliesst zn einer breiigen Masse. Sporen glatt, ellipsoidisch, meist sehr klein.

Fam. Clathraceae. Receptaculum gitterig, lappig oder unregelmässig verzweigt; Sporenmasse resp. Gleba vom Receptaculum umschlossen oder zwischen dessen Ästen liegend. - Clathrus cancellatus (Südeuropa, Amerika, Ostindien). - Andere Gattungen tropisch.

Fan. Phallaceae. Receptaculum hohlröhrig, unverzweigt, am Scheitel mit oder ohne glockenförmigen Hut. Gleba dem Receptaculum aussen aufliegend. - Phallus impudicus, Gichtmorchel, Stinkschwamm, in Gärten und Wäldern. - Mutinus caninus.

5. Unterreihe Hymenogastrineae. Fruchtkörper geschlossen, bis zur Reife fleischig, sich nicht streckend, im Inneren mit unregel. malssigen Kammern, welche vou den Hymenien ausgekleidet sind und hei der Reife im Zusammenhang bleiben. Kein Capillitium.

Fam. Hymenogastraceae. Charakter der Unterreihe. - Hymenoyaster Klotzschii in Gartenerde und in Blumentöpfen. - Rhizopoyon in Wäldern. - Hysterangium.

6. Unterreihe Lycoperdineae. Fruchtkörper anfangs fleischig, später + erhärtend, bis über die Reifezeit der Sporen hinaus geschlossen, aus einer festen, zuletzt regelmässig oder unregelmässig zerreissen. den Hülle (Peridie) und unregelmässigen Kammern bestehend, die an 
den Wänden von dem Hymenium äberzogen sind (Gleba); bei der Reife mit pulveriger Sporenmasse und Capillitium erfüllt.

Fam. Tylostomataceae. Capillitium bei der Sporenreife reichlich. Fruchtkörper a uf gesondertem Stiel. Gleba ohne Kammern und Gänge, von locker verflochtenen Hyphenknäueln erfüllt. Basidien mit vier Sterigmen. - Tylostoma mammosum auf Heideplätzen.

Fam. Lycoperdaceae. Capillitium reichlich. Fruchtkörper abgerundet, zuletzt mit papierartiger Hülle. Peridium doppelt. Gleba aus kleinen Kammern bestehend. Basidien mit $4-8$ Sterigmen. - Lycoperdon piriforme in Wäldern zwischen Moos; I. gemmatrum auf Triften und in Wäldern; $I$. caelatum auf Weideplätzen; alle in der Jugend essbar. - Globaria bovista, Riesenbovist, in Gärten und auf Äckern, jung essbar. - Bovista plumbea, Bovist, auf Triften und Wiesen. - Geaster stellatus, $G$. fimbriatus u. a. in Nadelwäldern.

7. Unterreihe Nidulariineae. Peridie lederartig, im Innern zahlreiche linsenförmige, oft durch einen Gewebestrang mit dem Peridium verbundene Kammern (Sporangiolen) einschliessend, bei der Reife am Scheitel aufspringend und zuletzt becherförmig oder schüssel. förmig. Hymenium die Innenfläche der Sporangiolen flach âber. ziehend.

Fam. Nidulariaceae. Charakter der Unterreihe. Nidularia denudata auf abgefallenen Nadelholzzweigen. - Crucibulum vulgare auf altem Holz etc. - Cyathus striatus auf alten Holzstücken und auf freiem Boden im Wald.

8. Unterreihe Sclerodermatineae. Fruchtkörper rundlich, im Inneren mit gleichmässig verteilten oder knäuelförmige Gruppen bilclen. den Basidien. Eigentliches Capillitium fehlt.

Fam. Sclerodermataceae. Fruchtkörper oft mit stielförmigem Basalteil, mit dicker einfacher Peridie. - Scleroderma vulgave, falsche Trüffel, an Waldwegen, nicht essbar, gefährlich. - Pisolithus crassipes in Wäldern und auf Sandplätzen.

Fam. Sphaerobolaceae. Das Hymenophorum stellt eine kugelige Masse dar. Bei der Reife quillt die mittlere Schicht der Hülle auf, wölbt die innere Schicht hervor und schleudert die Gleba fort. Sporen meist 6-8 am Scheitel der keulenförmigen Basidien. - Sphraerobolus carpobolus auf altem $\mathrm{Holz}$ in Gärten und Wäldern.

\section{Abteilung. E M B R Y O P II Y T A A S IPH O N O G A A (Archegoniatae).}

Seltener thalloidische, meist in Stamm und Blätter gegliederte (kormophytische) Gewächse mit $z$ wei verschiedenen Generationen. Pro embryonale Generation, Geschlechtsgeneration mit Antheridien, in denen die Spermatozoiden entstehen, und mit Archegonien, welche 
die zu befruchtende Eizelle und die vor der Befruchtung verschleimenden Kanalzellen einsehliessen. Nach erfolgter Befruchtung entsteht durch Teilung der Eizelle und weiteres Wachstum die embryonale Generation oder der Embryo, ein Gewebekörper, welcher noch längere Zeit mit cler proembryonalen Generation in Verbindung bleibt und von derselben ernährt wird.

Diese Abteilung schliesst nach unten an die VI. Abt. Chlorophyceae, und zwar an die Klasse Confervales an, nach oben findet sie ihren Fortschritt in Abteilung XIII. Das Charakteristische dieser Abteilung gegenüber der Abt. XIII liegt in dem Modus der Befruchtung, welche erfolgt, wenn die Makrospore sich von der proembryonalen Generation losgelöst hat und darin, dass dann erst in der Makrospore dic embryonale Generation oder das Prothallium entwickelt wird.

\section{Unterabteilung, BRYOPHYTA (Muscineae).}

Die aus den Keimzellen oder Sporen der embryonalen Generation meist durch Vermittelung eines selten flächenförmigen, meist fadenförmigen Vorkeims (Protonema) entstehende proembryonale Generation ist seltener thalloidisch, meist kormophytisch. Die aus der befruchteten Eizelle hervorgehende embryonale Generation, das Sporogonium, ist ohne Gliederung in Axe und Blattorgane eine stiellose oder gestielte Kapsel, welche gleichartige Keimzellen oder Sporen erzeugt; sie ist isospor.

\section{Klasse HEPATICAE (Lebermoose). Protonema meist klein} und vergänglich. Proembryonale Generation meist dorsiventral, thalloidisch oder kormophytisch, aber die Blätter immer ohne Nerven. Das Sporogon bleibt in der Wandung des Archegons eingeschlossen oder durchbricht dasselbe am Scheitel; daher keine dem Sporogon aufsitzende Haube (Calyptra) vorhanden.

1. Reihe MARCHANTIALES. Procmbryonale Generation thalloidisch, dorsiventral, unterseits mit quergestellten schuppigen Isamellen und Hafthaaren, oberseits mit chlorophyllhaltigem Gewele, welches häufig von nach aussen mündenden Lufträumen durchbrochen ist, unterseits mit chlorophyllosem Gewebe. Antheridien und Archegonien auf der Oberseite eingesenkt; sitzend oder auf gestielten Receptakeln. Sporogonien eine kugelige Kapsel oder in kurzen Stiel und Kapsel differenziert.

Fam. Ricciaceae. Lufträume der proembryonalen Generation geschlossen. Antheridien und Archegonien eingesenkt. Sporogon stets im Bauch des Archegoniums eingeschlossen. Columella und Elateren fehlen; die Sporen werden frei durch Resorption der zarten Wand des Sporogons. - Rircir (107) glanca und R. crystallina auf feuchten Ẍckern; R. fliitans in stehenden Gewässern. - Ricciocarpus (1) natans in stehenden Gewässern. - Tesselina (Oxymitra) pyramidata auf feuchtem Borlen in Sïdeuropa. 
Fam. Marchantiaceae. Lufträume der proembryonalen Generation offen; die dichotomischen Zweige des Thallus mit Mittelnerv und unterseits mit zwei Reihen Schuppen. Antheridien höckerartige oder strahlige Stände bildend, welche bisweilen langgestielt sind. Sporogon mit kurzem Fuss, seltener ohne, meist mit vom Grunde aus nach der Peripherie hin ausstrahlenden Schleuderzellen (Elateren); Wandung des Sporogons mit Zähnen oder vier Lappen oder durch Abwerfen eines Deckels sich öffnend.

Unterfam. Corsinioideae. Archegonien gruppenweise in Höhlungen des Thallus eingesenkt. Sporogon mit kurzem Fusse und Elateren oder sterilen Zellen, im Bauch des Archegoniums eingeschlossen; Sporogonien einzeln oler zu mehreren auf der Oberseite des Thallus. - Funicularia Weddellii (Brasilien). - Corsinia marchantioides (Südeuropa).

Unterfam. Targionioideae. Reifes Sporogon einzeln am Rande eines Laubsprosses, nebst den abgestorbenen Archegonien und verkümmerten jungen Sporogonien vcn einer zweiklappigen, gegen die Bauchseite hin geöffneten Hülle eingeschlossen. - Targionia (5) Michelii auf feuchter Erde unter Gesträuch. - Cyathodium (4) in dunkelen Felshöhlen.

Unterfam. Marchantioideae. Sporogonium zu radial gebauten, gestielten Fruclitköpfchen vereint.

§ Astroporae. Archegonien zu mehreren auf einer durch Wucherung des Blütenbodens entstehenden Scheibe emporgehoben, Radialwünde der Porenrandzellen stark verdickt. - Clevea (5) hyalina, in Nordeuropa und den Alpen. - Sauteria (3) alpina, wie vorige.

\& Operculatae. Receptaculum am Ende einer Sprossaxe als directe Fortsetzung des Sprosses. Archegonien akropetal entstehend. Der obere Teil der Kapselwand teils in einem Stück abgeworfen, teils in unregelmässige Platten zerfallend. - Aytonia (20). - Reboulia (2) hemisphaerica an grasigen, sonnigen Berg. abhängen und Hohlwegen, kosmopolitisch. - Grimaldia (7) barbifrons an sonnigen Stellen im Gebirge. - Neesiella rupestris auf Sand- und Kalkfelsen in Mitteleuropa und Nordamerika.

$\S$ Compositae. Thallus deutlich gefeldert, dichotom verzweigt. Sporogonien mit Zähnen sich öffnend. - Conocephalus (Fegatella) (2) conicus häufig an feuchten Hohlwegen, Grabenrändern etc. - Lunulariı cruciata an feuchten Standorten in Südeuropa; auf Blımentöpfen sehr häufig; hier Vermehrung durch Brutknospen. - Dumortiera (6) auf nassen Felsen in wärmeren Gegenden. - Chomiocarpon (2) quadratus (Preissia commutata) wie Conocephahıs, *. - Marchantia (52) polymorpha, häufig an feuchten Standorten, oft massenhaft, über die ganze Erde verbreitet.

2. Reihe ANTHOCEROTALES. Proembryunale Generation thalloidisch, unterseits ohne Schuppen, aber mit Schleimspalten (in denselben bisweilen Nostoc). Geschlechtsorgane monöcisch. Antheridien anfangs in geschlossenen Höhlungen des Thallus. Archegonien eingesenkt. Sporogon über den Thallus hinaustretend, mit Fuss und schotenförmiger, mit zwei Klappen sich öffnender Kapsel, welche ausser den Sporen meist eine Columella und sterile Zellen (Elateren) enthält.

Fam. Anthocerotaceae. Anthoceros (79) punctatus und A. laevis auf feuchten Äckern und Rainen, fast kosmopolitisch. - Notothylas (9). - Dendroceros (15) tropisch.

3. Reihe JUNGERMANNIALES. Proembryonale Generation thalloidisch oder kormophytisch. Sporogonien in Stiel und eine fast immer vierklappige Kapsel gegliedert, stets ohne Columella; aber meist mit Elateren. 
Fam. Jungermanniaceae anacrogynae. Archegonien am Rücken der weiter wachsenden Sprosse, von einem Involuerum geschützt. Keine Blattorgane oder nur einfache einlappige Hüllen der Geschlechtsorgane, nie durch Blattorgane gebildet.

Unterfam. Sphaerocarpoideae. Kapsel leicht aufspringend. Sterile Zellen nicht als Elateren ausgebildet. - Sphaerocarpus (5) Michelii in Süd-und Westeuropa und Nordamerika.

Unterfam. Rielloidece. Proembryonale Generation nicht dorsiventral, mit aufrechtem geflügeltem Spross; Kapsel ohne Elateren, aber mit sterilen Zellen. - Riella (7) helicophylla (auf thonigem Grund von Seen in Algier); R. Reuteri (ehemals im Genfer See).

Unterfam. Metagerioideae. Proembryonale Generation dorsiventral, völlig blattlos, ohne oder mit Mittelrippe. - Riccardia (Aneura) (111) pinguis auf feuchtem Boden; $R$. multifida an Steinen und Holz in Bächen, beide kosmopolitisch. - Metzgeria (36) furcata in dichten, flachen Rasen an Felsen und auf Baumrinden.

\section{Unterfam. Leptothecoidecie.}

Unterfam. Fossombronioidece. Spross blattlos, mit oder ohne Mittelrippe oder mit horizontal stehenden Seitenblättern, bisweilen auch mit schuppenförmigen Unterblättern (Amphigastrien). - Pellia (3) epipliylla an feuchten Gräben etc. * - Blasia pusilla auf feuchtem Lehm- und Sandboden in Europa, Nordamerika, Australien. - Fossombronia (26) pusilla, häufig auf feuchter Erde.

Unterfam. Haplomitrioideae. Spross aufrecht, fast dreireihig bebï̈ttert, mit gleich grossen Blättern. Kapsel lang gestielt, cylindrisch. Haplomitrium Hookeri, auf feuchtem Heide- und Sandboden in Nordeuropa.

Fam. Jungermanniaceae acrogynae. Archegonien das Wachstum der Sprosse beschliessend. Sprosse bilateral, mit zwei Reihen grösserer, anfangs zweilappiger Oberblätter und einer Reihe kleinerer Unterblätter auf der Bauchseite oder ohne solche. Hüllen der Geschlechtsorgane (Involucrum und Perianth) von Blättern gebildet.

Unterfam. Epigoniantheae. Meist ziemlich gross, selten fiederig verzweigt. Blätter unterschlächtig oder quer inseriert; Amphigastrien 0 oder klein. Perianthium cylindrisch oder $3-6$ kantig. Elateren abfällig, beiderseits zugespitzt, 2 spirig. - Gymnomitrizun (18) in Gebirgen auf Felsen, in den Polarländern auf Erde. - Marsupella (Sarcoscyphus) (24), wie vorige; z. B. M. Funckii. - Nardia (44) compressa in Gebirgsbächen in Mittel- und Nordeuropa. - Calypogeia (12) ericetomum auf feuchtem Lehmboden. - Aplogia (20) sphaerocarpa an feuchter Erde. - Lophozia (60) auf feuchter Erde, an Steinen und Felsen. - Plagiochila asplenoides auf schattigem Waldboden in Europa; etwa 460 in den trop. Wäldern. Lophocolen (149) bidentata, sehr häufig auf blosser Erde, kosmopolitisch. - Cliloscyphus (77) polyanthus. - Sarcogyna (Geocalyx) graveolens an feuchten Felsen.

Unterfam. Trigomanthere. Meist beblättert, selten thalloidisch. Blätter oft oberschlächtig, flach oder rinnig, ganz oder verschieden geteilt. 
Blütenstand meist auf einem sehr verkürzten Ventralspross. Perianthien 3 kantig. Elateren wie bei vorigen. - Prionolobus (13). - Cephaloziella (20). - Bazzania (230) meist trop. - Lepidosia (92) reptans bäufig auf Waldboden.

Unterfam. Ptilidioidece. Meist ansehnlich, etwas starr. Blätter unterschlächtig oder quer eingefügt, 2-4 teilig oder zerschlitzt; Amphigastrien ebenso. Perianthium drehrund oder 3-10 faltig. ㅇ Blütenstand end ständig am Stengel oder an Seitenästen. Kapsel und Elateren wie bei vorigen. - Mastigophora (9). - Ptilidium (6) ciliase häufig auf blosser Erde und an Felsen. - Trichocolea (13) tomentella auf feuchtem Waldboden und in Mooren.

Unterfam. Scapanioideae. Blätter gefaltet 2 lappig, mit kleinerem Oberlappen. Amphigastrien 0 oder den Blättern unähnlich. ㅇ Blütenstand terminal. Perianthium flach oder drehrund oder 4- bis mehrfaltig, häufig mit dem Archegonium und den Involucralblättern verwachsen. Kapsel und Elateren wie bei den vorigen. - Diplopliyllum (5) albicans sehr verbreitet auf feuchter Erde, an Felsen und faulem Holz * . Scaparia (37) undulata an Felsen, in Bächen und Quellen *.

Unterfam. Stephaninoideae. Ziemlich grosse, grüne oder gelbgrüne Pfl. Blätter oberschlächtig, gefaltet, 2 lappig, mit kleinerem Unterlappen, an dem sich büschelweise Rhizoiden entwickeln. Amphigastrien 0 . o Blütenstand terminal. Perianth vom Rücken her flachgedrückt, glatt. Kapsel und Elateren wie bei vorigen. - Stephanina (Radula) (72) conplanata in dichten Rasen an Bäumen in Europa.

Unterfam. Pleurozioideae. Meist grosse Pfl. Blätter oherschlichtig, gefaltet 2lappig, mit kleinerem sackartigem, oft durch eine Klappe versehlossenem Unterlappen. Amphigastrien 0. 오 Blütenstand auf kurzen Seitenästen. Perianthium lang und schmal zugespitzt, von der Mitte an 4-10 faltig Kapsel und Elateren wie bei vorigen. - Pleurozia (12) gigantea an Bäumen und auf blosser Erde, palaeotrop.

Unterfam. Bellincinioidece. Stattliche Pfl, grün bis braun. Blätter oberschlächtig, gefaltet 2 lappig, mit kleinem flachem oder an Rande zurückgerolltem Unterlappen. Amphigastrien ansehnlich, an ihrer Basis mit spärlichen Rhizoiden. ㅇ Blütenstand auf lateralen Ästchen. Perianth vom Rücken her zusammengedrückt, ventral mit Kiel oder $3-10$ faltig, zuletzt an der Mündung klaffend. Kapsel mit 4 öfters nicht bis zum Grunde getrennten und unregelmässig gespaltenen Klappen. Elateren wie hei vorigen. - Bellincinia (Madotheca) (77) platyphylla an Stämmen und Felsen häufig; viele Arten trop.

Unterfam. Jubuloideae. Blätter oberschlächtig, gefaltet 2 lappig, mit kleinerem, oft aufgeblasenem oder sackartigem Unterlappen. Amphigastrien ganz oder 2 teilig, bisweilen gezähnt, an der Basis oder in der Mitte mit Büscheln von Rhizoiden. o Blütenstand meist mit nur einem Archegonium. Perianthium fast stets vom Rücken her zusammengedrückt, an der Mündung in ein röhriges Spitzchen zusammengezogen. Kapsel kurz gestielt, von der Spitze bis zu $2 / 34$ klappig. Elateren an den Klappen bleibend, am freien Ende gestutzt bis trompetenartig erweitert, stets einspirig. 
§ Lejeuneeae. \& Blütenstand stets mit nur 1 Archegonium. Tsobulus des Blattes nicht als hohles, helm- oder cylindrisch sackartiges Öhrchen entwickelt. - Eulejeunea (164) serpyllifolia an alten bemoosten Baumstämmen. - Harpalejennea (46) ovata. - Ausserordentlich zahlreich in den Tropen.

Srullanieae. \& Blütenstand mit $2-4$, seltener bis 12 Archegonien. Lobulus des Blattes ein hohles, helmförmiges oder cylindrisch-sackartiges Öhrchen. - Frullania (310) dilatata, häufig an Baumstämmen und Felsen; F. Tamarisci etwas seltener.

2. Klasse MUSCI (Musci frondosi) Laubmoose. (Mit Unterstützung von Prof. Brotherus bearheitet.) Protonema ansehnlich, meist confervenartig, zuweilen ausdauernd. Proembryonale Generation kormophytisch, die Stengel bisweilen schon mit einem Wasser, seltener auch Eiweissstoffe leitenden Centralstrang, die Blätter meist mit Mittelnerv. Bei der Entwickelung des Sporogons wird fast immer die Wan. dung des Archegoniums am Grunde losgelöst und als Haube (Calyptra) in die Höhe gehoben. Im Sporogonium kommt es sehr früh zur Sonderung eines Endotheciums und Amphitheciums.

1. Unterklasse SPHAGNALES. Aus dem Endothecium entsteht nur die Columella, welche die sporenbildende Schicht nicht durchsetzt, sondern von derselben überdacht wird. Sporogon sitzend. Die Archegonwandung wird bei der Reife des Sporogons unregelmässig zerrissen, so dass am Grunde des Sporogons eine Scheide zurückbleibt. Vorkeim prothallium. artig oder seltener cladophoraartig.

Fam. Sphagnaceae. (Torfmoose). Stengel orthotrop. Blätter nervenlos, aus $z$ weierlei Zellen bestehend, aus cylindrischen chlorophyllhaltigen, der Assimilation dienenden, und grösseren chlorophyllosen, mit runden Löchern in der Membran, sowie mit ring- und schraubenförmigen Verdickungen versehenen, der Wasseraufnahme dienenden; aus Zellen letzterer Art besteht auch die Stengelrinde. Archegonien und Antheridien an besonderen Zweigen. Aus dem die Archegonien tragenden Zweige entwickelt sich unterhalb des ein reifes Sporogon einschliessenden Archegoniums als Stiel ein Pseudopodium. Kapsel mit Deckel geöffnet, ohne Peristom. Sphagnum, mit zahlreichen Arten, namentlich in Torfmooren, Sumpfwäldern, auch auf nassen Felsen, oft ausschliesslich Torf bildend. S. cymbifolium, S. fimbriatum, S. cuspidatum häufig in Sümpfen; S. rigiclum S. aculifolium auf Torfmooren und feuchten Heiden; S. squarrosum und S. Girgensolnii an quelligen Stellen in Wäldern.

2. Unterklasse ANDREAEALES. Das Endothecium differenziert sich in Archispor und Columella, welche jenes nicht durchsetzt. Im Amphithecium wird die innerste Schicht zum Sporensack, welche von dem übrigen Wandgewebe durch keinen Intercellularraum getrennt ist. Die Archegoniumwandung sondert sich bei der Reife in Vagina und Haube. Vor der Entwickelung der Vorkeimfäden Bildung eines Vorkeimknöllchens innerhalb der Spore. 
Fam. Andreaeaceae. Polster bildend, mit kurzen, dickbeblätterten Stämmchen. Blätter mit oder ohne Mittelrippe. Psendopodium wie bei vorigen. Kapsel mit 4 bis mehr seitlichen Längsrissen sich öffnend. Andreaea, auf kieselhaltigen Felsen der Gebirge, in der Ebene auf erratischen Blöcken.

3. Unterklasse BRYALES. Sporensack von der Kapselwand durch einen hohlcylindrischen Intercellularraum geschieden. Das Endothecium differenziert sich in Archispor und Columella, welche jene durchsetzt. Sporogon in Kapsel und Stiel (Seta) gegliedert. Die Archegonwandung spaltet sich in eine die Basis der Seta umschliessende Vagina und dic von dem Sporogon in die Höhe gehobene Haube. Vorkeime cladophoraartig oder seltener prothallienartig.

1. Reihe ACROCARPI. Archegonien an Hauptsprossen gipfelständig.

Fam. Archidiaceae. Kapsel lange von der sehr zarten Haube um. hüllt, die zuletzt unregelmässig gesprengt wird. Im Endothecium des sitzenden Sporogons keine Columella, sondern sterile und fertile Zellen durcheinander gemengt. Sporen sehr gross. - Archidium alternifolium auf thonig-sandigem Boden.

Fam. Dicranaceae. Meist rasenbildend. Stengel meist mit deutlichem Centralstrang. Blätter aus breiterer Basis verlängert, pfriemenförmig bis borstenförmig. Kapsel meist unregelmässig und geneigt, trocken oft gekrümmt und längsfaltig. Peristom einfach, selten fehlend; 16 Zähne mit an der Innenfläche radiär stark vorspringenden Querleisten. Haube meist kappenförmig. - Dicranella squarrosa (kalkfeindliches Gebirgsmoos); D. varia (feuchte Erdblössen, Ausstiche); D. subulata und D. heteromalla (Waldränder, Hohlwege); D. cerviculata (nackter Torf). - Aongstroemia (Hochalpen). - Oreas Martiana (Centralalpen). - Cynodontium polycarpum (Mittelgebirge und Alpen). - Dichodontium. - Dicranum undulatum (Waldboden, namentlich auf Sandstein); D. majus (tiefschattige Wälder); D. scoparium (sehr verbreitet); D. montanum (Baumstümpfe, Waldboden). - Campylopus turfaceus (auf bewaldetem Torfboden). Dieranodontium longirostre (torfiger Waldboden, kalkfeindlich). - Pleuridium nitidum (auf feuchtem Thon- und Schlammboden); $P$. subulatum (Waldränder), - Trichodon cylindricus (auf nacktem Waldboden). Ditrichum homomallum (auf feuchtem sandigen Boden). - Ceratodon purpureus (sehr gemein). - Distichium capillaceum (sehr verbreitet auf Kalkfelsen). - Seligeria (meist auf Kalkfelsen). - Blindia acuta (Hochgebirge, oberhalb der Baumgrenze). - Trematodon ambiguus (Grabenwände). - Teucoloma (südl. Hemisphäre). - Brucliia palustris (Wiesengräben).

Fam. Leucobryaceae. Polsterbildend. Stengel ohne Centralstrang. Blätter mit zweierlei Zellen, einer inneren Schicht kleiner, chlorophyllführender und 1-4 Schichten plasmaloser, durchlöcherter Zellen. Kapsel aufrecht und regelmässig oder geneigt und unregelmässig. Peristom meist mit 16 Zähnen. - Leucobryum glaucum (auf feuchtem Wald- und Torfboden, kalkfeindlich); zahlreiche Arten in den Tropen. - Tseucophanes und Octoblepharum tropisch. 
Fanı. Fissidentaceae. Stengel zweizeilig beblättert (mit zweischneidiger Scheitelzelle). Blätter halbstengelunfassend, scheidig-kahnförmig, mit Fortsatz und Dorsalflügel, dicht parenchymatisch. Kapsel aufrecht oder geneigt. Peristom rot, die 16 Zähne bis zur Mitte geteilt. - Fissidens bryoides und $F$. taxifolius (schattige Erdblössen); $F$. osmundoides und $F$. adiantoides (feuchte Torfwiesen); sehr zahlreiche Arten in den Tropen; $F$. julianus (im Wasser an Wehren, Pfeilern, Brunnentrögen).

Fam. Calymperaceae. Schlanke oder kräftige, meist auf Bäunen wachsende Moose. Blătter scheidig, meist mit kräftiger Rippen-Kapsel aufrecht, meist länglichcylindrisch. Peristom einfach, mit 16 lanzettlichen Zähnen. Deckel lang pfriemenförmig. Haube bis zum Grunde der. Kapsel reichend, kappenförmig. - Syrrhopodon und Calymperes (sehr viele in den Tropen).

Fam. Pottiaceae. Rasig. Blätter mit parenchymatischem, meist durchscheinendem Zellgewebe. Kapsel regelmässig, aufrecht, selten etwas geneigt, mit cylindrischen Hals, Peristom mit 16 flachen, kurzen, ungeteilten oder gespaltenen Zähnen oder fehlend. Haube meist kappenförmig.

$\S$ Cinclidoteae. Archegonien meist cladogen. Kapsel ohne Luftraum und ohne Spaltöffnungen. - Cinclidotus fontinaloides an Steinen und $\mathrm{Holz}$ in fliessendem Wasser.

§ Trichostomeae. Archegonien acrogen. Blätter schmal, oben mit kleinen Zellen; Haube meist kappenförmig. - Hymenostomum microstomum (Waldränder, Grabenwände). - Gymnostomum rupestre (Felsen). - Hymenostylium curvirostre (in Hochgebirgen häufig). - Eucladium verticillatum (Kalkfelsen, feuchte Mauern). - Didymodon rubellus (Felsen und Mauern). - Leptodontium flexifolium (torfiger Heideboden). - Trichostomum (meist in Gebirgen). - Tortella tortuosa (besonders auf Kalkboden). Barbula unguiculata (sehr verbreitet); B. convoluta (auf trockenem, sonnigem Boden); B. subulata (erdige Abhänge etc.).

$\$$ Pottieae. Archegonien acrogen. Blätter meist breit, oben mit weiten Zellen; Haube meist kappenförmig. - Acaulon muticum (lehmig. thonige Äcker). - Phascum enspidatum (Äcker und Grasplätze). Pottia minutula (Erdblössen); $P$. truncatula feuchte Stellen); P. Heimii (Salzboden). - Pterygoneumum cavifolium (auf kalkig-thonigem Boden). - Aloina rigida (kalkig lehmige Blössen). - Desmatodon (alpin). Tortula muralis (sehr gemein, auch an Mauern); T. latifolia (am Grunde alter Baumstämme, an altem $\mathrm{Holz}$ etc.); T. papillosa (wie vorige; Brutknospen am Blatt!); $T$. ruralis (an sterilen Orten häufig; auch auf Strohund Schindeldächern).

§ Encalypteae. Archegonien acrogen. Blätter breit, zungenförmig bei spatelförmig, aber mit weiten Zellen; Haube cylindrisch-glockenförmig. Encralypta vulgaris und streptocarpa (Mauern und Kalkfelsen).

Fam. Grimmiaceae. Polster oder Rasen bildend. Blätter mehrreihig, im oberen Teil mit kleinen, rundlichen, chlorophyllreichen Zellen, oft papillös. Kapsel auf kürzerer oder längerer Seta, meist regelmässig, kugelig bis cylindrisch. Peristom einfach, selten fehlend, 16 Peristomzähne, rot oder orange, flach, rissig oder siebartig durchbrochen, nicht selten in $2-3$ fadenförmige Schenkel geteilt Aussenschicht mit leistenartigen Querbalken. Haube kegel- mützen- oder kappenförmig, meist nicht gefaltet. 
§ Sconlerieae. 우 Blüten cladogen. Stengel verlängert, unregelmässig kurz ästig. - Scouleria aquatica (Nordamerika).

$\S$ Orimmieae. of Blüte acrogen, selten cladogen. Stengel meist kurz, mit gleichhohen Innovationen, selten kurzästig. - Schistidium apocarpum (Felsen und Mauern häufig). - Grimmia (meist kalkfeindliche Gebirgsmoose); G. pulvinata (Mauern, Dächer, Planken etc). - Rhacomitrium (meist Gebirgsmoose); $R$. canescens (auf Sandboden verbreitet). - Coscinodon pulvinatus, alpin.

§ Ptychomitrieae. Rasig. Blätter nicht papillös, trocken, kraus. Haube mützenfơrmig, längfaltig, nackt. Ptychomitrium, meist aussereuropäisch. - Campylostelium.

Fam. Orthotrichaceae. Meist polsterförmig. Blätter mit Rippe, papillös oder warzig. Kapsel auf kurzer Seta oder sitzend, trocken meist gefurcht; Peristorn einfach, doppelt oder selten fehlend, ohne vorstehende Querleisten. Haube weit, mützenförmig, längsfaltig, meist behaart. Orthotrichum, zahlreiche Arten an Baumstämmen häufig, wenige an Felsen. Ulota crispa (an Bäumen häufig). - Macromitrium, sehr zahlreich in den Tropen und auf der südlichen Hemisphäre.

Fam. Oedipodiaceae. Fleischige, weiche Pflanzen. Seta fast fehlend. Kapsel fast kugelig mit sehr langem Hals. Peristom fehlend. - Oedipodium Griffithianum.

Fam. Splachnaceae. Dichtrasig, lebhaft grün, mit breiten, grosszelligen Blättern. Kapsel oft sehr lang gestielt, am Grunde meist mit einem veränderlichen, grossen und farbigen Ansatz (Hypophyse), symmetrisch. Peristom einfach, mit 16 oder 32 Zähnen. Haube klein, mützenoder kegelförmig. Vorzugsweise auf tierischen Excrementen im Gebirge.

§ Voitieae. Deckel nicht abgesondert. - Voitia nivalis auf Hochalpentriften an Lagerstellen von Vieh.

§ Taylorieae. Deckel ausgebildet. Kapsel ohne Hypophysen. - Tuyloriı serrata (subalpin und alpin). - Dissodon.

§ Splachneae. Deckel ausgebildet. Kapsel mit Hypophyse. Splachnum luteum (arktisch); S. ampullaceum (auf Rinderexcrementen).

Fam. Disceliaceae Kleine, vereinzelt wachsende Erdmoose mit bleibendem Vorkeim. Pflänzchen knospenförmig. Blätter ohne Rippe. Kapsel auf verlängerter Seta geneigt, fast kugelig. Peristom einfach, 16 zähnig. - Discelium nudum (feuchter Tonboden).

Fam. Funariaceae. Meist einjährig. Blätter wie bei vorigen. Kapsel mit deutlichem Hals, regelmässig oder unsymmetrisch birnförmig.

$\S$ Funarieae. Deckel ausgebildet. Peristom einfach, doppelt oder fehlend. Haube zuletzt meist einseitig. - Funaıia hygrometrica, sehr häufig. - Physcomitrium pyriforme (Äcker, schlammige Gräben). Pyramidula tetragona (Äcker). - Physcomitrella puters auf Teichschlamm.

$\S$ Ephemereae. Deckel nicht abgesondert. Columella in der Mitte des Sporensackes resorbirt. - Ephemerum serrutum auf thonigem Boden, ansgetrockneten Teichen etc.

Fam. Schistostegaceae. Sterile Stengel zweizeilig beblättert mit nervenlosen, am Grunde seitlich verschmelzenden Blättern; fertile Stengel am Grunde zweireihig, oben mehrreihig. Kapsel kugelig, längsstseifig, ohne Peristom. Haube klein, kegelförmig. - Schistostega osmundacea, in Erdlöchern und Felsenhöhlen; Vorkeim (Protonema) das einfallende Licht reflectierend.

Fam. Drepanophyllaceae. Blätter am Grunde umfassend, sichelförmig. - Drepanophyllum fulvum (trop. Amerika). 
Fam. Bryaceae. Rasig. Blätter im oberen Teil mit prosenchymatischen, glatten Zellen. ơ Blüten knospenförmig, mit fadenförmigen Paraphysen. Kapsel meist an langer Seta, mit deutlichem Hals, häufig birnförmig, selten fast kugelig, regelmässig oder unsymmetrisch, oft hängend, selten aufrecht. Peristom meist doppelt, inneres Peristom so lang als das äussere. Haube kappenförmig.

§ Vielichhoferieae. Blüten auf seitenständigen Kurztrieben. Peristom einfach. - Mielichlooferia niticla, alpines Felsmoos.

S Bryear. O Blüten und Sporogone gipfelständig. Peristome doppelt.

Bryum, nehrere Arten auf feuchten, sandigen und lehmigen Plätzen, z. B. B. bimum, B. alpinum, B. caespiticium, B. argenteum, B. capillare etc. - Webera albicans, $W$. annotina ebenso; $W$. nutuns auf trockenem Waldund Torf boden. - Teeptolryum pyriforme auf Torfboden.

Fam. Mniaceae. Blattzellen überall weit parenchymatisch, oben rundlich 6 seitig, glatt. $\sigma^{7}$ Blüten scheibenförmig, mit keuligen Paraphysen. Kapsel, Peristom und Haube wie bei vorigen. - Mnium punctatum, M. cuspidutum, M. affine, $M$. undulatum an feuchten, schattigen Stellen in Wäldern; M. hornum an Wänden von Waldgräben etc.; $M$. stellare auf Waldboden. - Rlizoyonium, aussereuropäisch.

Fam. Meeseaceae. Blattzellen fast überall derb, parenchymatisch, meist glatt. Kapsel auf sehr langer Seta, mit langem Hals, unsymmetrisch, glatt. Peristom doppelt, innen viel länger. - Paludella squarrosa, auf schwammigen Torfsümpfen. - Meesea tristiclu u. a. auf sehr tiefen Torfsümpfen.

Fam. Aulacomniaceae. Rasenbildend. Blätter überall papillös, aus kleinen rundlichen Zellen. Kapsel länglich oder cylindrisch, gestreift, trocken gefurcht. In den Achseln der endständigen Blätter oft fadenförmige, nackte Schosse ınit einem Köpfchen von Brutzellen am Ende. P'eristom wie bei Mniaceae. - Gymnocylve palnstris auf allen Sumpfwiesen. - Aulacomnium androgynum an feuchten, schattigen Orten.

Farn. Timmiaceae. Blätter schmal, am Grunde scheidig, Zellen klein, rundlich, ventralseits mamıillös. Inneres Peristom mit 64 knotig fadenförmigen Wimpern, von denen je 4 mit den Spitzen zusammenhängen. Paraphysen keulenförmig.

Fam. Bartramiaceae. Raseubildend. Blätter schmal, oberseits oder beiderseits papillös. Kapsel unsynımetrisch kugelförmig, gerieft. Peristom doppelt, inneres kürzer. - Plilomotis fontana an quelligen Plätzen; Ph. marclicu auf fenchten Wiesen und in Torfsümpfen; viele aussereuropäische. - Bartramiu. - Glyplıocarpus (Südamerik:ı, Südafrika).

Fam. Polytrichaceae. Rasenbildend. Stengel mit concentrischem Lcitbindel. Blïtter meist derb, oberseits mit Längslamellen, mit parenchymatischen Zellen. Kapsel auf langer Scta, rund oder $4-6$ kantig; Peristom einfach mit 16,32 oder 64 zungenförmigen Zähnen. Haube meist mützenförmig, haarig. - Polytrichum commune (Wiilder, Heiden, Torfnoore); P. juniperinum und P. pilifenum (Heiden); P. gracile (Torfmoore). - Pogonatum urnigerum (Heideland); P. aloides und P. nanum (nackte Heideplätze). - Atrichum undulatım (feuchte, schattige Plätze). - Dawsonia superba in Australien und Neu-Seeland. 
Fam. Georgiaceae. Rasenbildend, klein. Blätter parenchymatisch. Kapsel aufrecht und symmetrisch, nit vierzähnigem Peristom. Haube kegel- bis mützenförmig, gefaltet. - Georgiı (Tetraplis) pellucida (an schattigen, feuchten Orten, besonders an morschen Stämmen), mit eigentümlichen Brutkörperchen; auch mit Flächenvorkeim.

Fam. Buxbaumiaceae. Einzeln wachsend, Stengel sehr kurz. Kapsel gross, schief eiförmig, bauchig; Peristom doppelt, das innere häutig mit 16 oder 32 Längsfalten. Haube klein, glatt. - Buxbuumia aphylla (Nadelwälder). - Diphyscium foliosum (Hohlwege); mit pilzförmigen Vorkeimkörpern.

2. Reihe Pleurocarpi. Archegonien blattachselstandig am Hauptstengel oder an den Ästen.

Fam. Nematocaceae. Allgenähnliche Pflanzen, aus dichotom verzweigten Protonemafäden filzartige Überzüge auf Blättern bildend. Kapsel kurzgestielt, klein, fast aufrecht. Peristom doppelt. Haube kegel-mützenförmig, lang bewimpert. - Ephemeropsis tjilodensis (Java).

Fam. Hypopterygiaceae. Reich verzweigt, am oberen Stengel mit zwei Reihen Blätter, unterwärts mit einer dritten Reihe. Zellen parenchymatisch. Peristom doppelt, das innere mit Wimpern zwischen den Zähnen. Haube mützenförmig. Hypopterygium; viele Arten in tropischen und subtropischen Ländern.

Fam. Hookeriaceae. Lockerrasig. Blätter scheinbar zweireihig, breit, mit oder ohne Papillen, zuweilen ölglänzend, mit parenclyymatischen Zellen. Kapsel mit doppeltem Peristom. Haube kegelförnig. - Pterygophyllum lucens (feuchte, quellige Waldstellen). - Hookeria; zahlreiche Arten in den Tropen. - Callicostella.

Fam. Fontinalaceae. Flutende, weitverzweigte Wassermoose. Blätter mit prosenchymatischen Zellen. Kapsel aufrecht, symmetrisch, mit doppeltem Peristom; das innere eine gitterartige, offene Kuppel darstellend. Haube mützenförmig oder einseitig. - Dichelyma falcatum (Hochgebirge). - Fontinalis antipyretica (fliessende oder stehendè Gewässer).

Fam. Cryphaeaceae. Starre, glanzlose Rinden- oder Felsmoose. Stengel fast kätzchenartig. Blätter meist mit mehreren Längsfurchen; Zellen glatt, gegen die Ränder des Blattgrundes in vielen Schrägzeilen quadratisch und rundlich. Kapsel aufrecht und symmetrisch. Peristom doppelt, selten fehlend. Haube mützen- oder kappenförmig. - Hedwigia ciliaris (auf Felsblöcken). - Leucodon sciuroides (Bäume, Felsen). - Antitrichia curtipendula (alte Baumstämme).

Fam. Neckeraceae. Ziemlich gross, flach polsterförmig. Blätter scheinbar zweireihig, glatt, nie längsfaltig, oben mit rhombischen, unten mit linealischen Zellen. Kapseln aufrecht und symmetrisch, mit doppeltem Peristom. Haube kappen- oder mützenförmig. - Neckera pennata (an Baumstämmen, besonders an Fagus); N. crispa und $N$. complanata (Eichen, Buchen, Felsen); viele in den Tropen. - Homalia trichomanoides (besonders am Grunde von Baumstämmen und auf Steinen). - Pilotrichum, Meteorium, Aerobryum sehr artenreich in den Tropen.

Fam. Fabroniaceae. Zwergig, dichtrasig. Blätter allseitig, ohne Papillen, mit quadratischen Zellen am Blattgrunde. Kapsel gestielt, symmetrisch oder leicht ge- 
krümmt. Peristom einfach oder doppelt, mit 8 oder 16 Zähnen. Haube kappenförmig. - Fabronia (an Bäumen); viele Arten tropisch.

Fam. Leskeaceae. Rasig und Polster bildend. Blätter vielreihig, allscite- oder etwas einseitswendig, papillös oder warzig, mit Rippe, glanzlos; Zellen parenchymatisch. Kapsel aufrecht und symmetrisch oder übergeneigt und unsymmetrisch, mit doppeltem Peristom. Haube kappenförınig. - Lesliea nervosa (Laubholzstämme und Felsen). - Anomodon viticulosus, A. attenuatus (alte Baumstämme, feuchtschattiger Boden). — Pseudoleskiea atrovirens (Gebirge). - Thuidium tamariscinnm (schattige Wälder); Th. delicutulum (Waldboden, Grasplätze); sehr viele in den Tropenländern.

Fam. Pterogoniaceae. Rasig oder polsterförmig. Blätter aın Rícken \pm papillös, mit kurzer bis fehlender Rippe; Zellen der Blattspitze und Blattmitte prosenchymatisch, kurz rhomboidisch, ohne Chlorophyll. Kapsel symmetrisch, mit doppeitem Peristom. Haube kappenförmig. - I'terigynandrum filiforme (Laublıolz. stämme und Felsen in Wäldern). - Pterogonium, tropisch.

Fam. Hypnaceae. Blätter allseitswendig oder zweiseitig oder einseitig, glatt, mit prosenchymatischen bis linealischen Zellen in den Blattflügeln, mit meist übergeneigter Kapsel auf langer Seta, mit meist doppeltem Peristom; dass innere dünnhäutig. Haube kappenförmig.

§ Isothecieae. Kapsel symmetrisch, aufrecht, Peristom meist doppelt, das innere mit sehr schmaler basilärer Haut. Wimpern zwischen den Peristomzähnen rudimentär oder fehlend. - Platygyrium repens (Baumstämme, Dächer, Felsen). - Climacium dendroides (Wiesen, Sümpfe). - Homalothecium sericeum (Laubholzstämme, Felsen, Mauern). Isothecium myurum (Baumwurzeln, Felsen). - Pylaisia polyantha (Obstbäume, Weiden).

$\S$ Hypneae. Kapsel unsymmetrisch, übergeneigt, gekrümmt. Inneres Peristom auf hoher basilärer Haut. Wimpern vollständig, knotig oder mit Anhängseln. - Eurhynchium striatum (Wälder); $\boldsymbol{E}$. murale (feuchte Steine und Mauern); E. piliferum (Waldboden). - Thamnium. - Plagiothecium undulatum; $P$. denticulatum (feuchter Waldboden). - AmWystegium. riparium (feuchtes Holz und Steine); A. serpens (Holz, Steine, Erde). - Camptothecium lutescens (Grasplätze mit mergeliger Unterlage); C. nitens (Moorwiesen). - Brachythecium albicans (trockene, sandige Plätze); B. salebrosum , B. populeum und B. velutinum (Baumwurzeln und Stämme). - IУуриит stellatum (Sumpfwiesen); $H$. cordifolium, $H$. giganteum, H. surmentosum, H. cuspidatum, H. Aluitans etc. (Sümpfe); H. scorpioides (tiefe Torfsümpfe); $H$. purum, H. uncinatum (Grasplätze, in Wäldern); H. molluscum (feuchte Kalkfelsen); H. commututum (nasse Kalkfelsen); H. cupressiforme (Baumstämme, Felsen etc.). - Hylocominm splendens und H. triquetrum in Wäldern am Boden. - Mehrere Gattungen nur tropisch.

\section{Unterabteilung, PTERIDOPHYTA.}

Die aus den Keimzellen oder Sporen der embryonalen Generation unmittelbar entstehende proëmbryonale Generation ist stets thalloidisch (ein Prothallium). Die aus der befruchteten Eizelle hervorgehende 
embryonale Generation ist eine kormophytische Pflanze mit echten, endogen entstehenden Wurzeln, mit Stengeln und Blättern, in denen geschlossene Lcitbündel vorkomınen, und mit Sporenbehältern (Sporangien), welche sich direct auf den Blättern und am Grunde derselhen entwickeln. Die Sporangien tragenden Blätter bilden bisweilen eine gesonderte Sprossformation, die schon als Blüte hezeichnet werden kann.

1. Klasse FILICALES. Die Blätter sind fast immer kräftiger entwickelt als der Stamm, oft sehr ansehnlich und reich gegliedert, in der Jugend meist spiralig eingerollt. Sporangien an gewöhnlichen oder be. sonders gestalteten, aber nicht auf abgeschlossene Sprossregionen oder auf besondere Sprosse beschränkten Blättern, am Rande oder an der Unterseite derselben, meist einzelligen, seltener mehrzelligen Ursprungs, meist in Soris.

Bemerkung. Die lebenden Farne werden nach der Beschaffenheit der Sporangien klassifiziert. Da diese von den zahlreichen fossilen Farnen uur selten bekannt sind, so werden die nur steril bekannten Formen derselben in künstliche, meist auf den Verlauf der Adern gegründete Gruppen untergebracht; die wichtigsten sind:

I. Archaeopterilles. Fiedern der letzten Ordnung nach dem Grunde zu verschmälert, ohne Mittelader, mit mehreren parallelen oder auseinanderstrahlenden, gegabelten Adern. - Meist im Devon. - Adianlites. - Archaeopteris. - Rhicopteris.

II Sphenopterides. Fiedern letzter Ordnung klein oder schmal, am Grunde meist keilförmig, mit \pm deutlicher Mittelader. - Viele im mittleren produktiven Carbon. - Sphenopteris.

III. Pecopterides. Fiedern letzter Ordnung breit ansitzend.

a) mit Mittelader, von der Seitenadern ausgehen: Pecopteris, Zamiopsis, T'hinnfeldia.

b) mit Mittelader, neben welcher aus der Spindel Seitenadern abgehen. Alethopteris, Cycadopteri.s.

c) ohne Mittelader. - Odontopteris, Ctenopteris.

d) mit Maschenadern. - Lonchopteris.

IV. Nenropterides. Fiedern letzter Ordnung oder Wedel \pm zungenförmig, am Grunde stark eingeschnürt bis herzförmig. Aderung \pm parallel. - Neuropteris, Cyclopteris, Taeniopteris, Nilssonia, Linopteris und Glossopteris, letztere mit Maschenaderung und besonders charakteristisch für die den indischen Ocean umgehenden Glossopteris - Facies.

Aphlebia sind Fiedern, welche anders gestaltet sind als die normalen und ausser diesen entweder in grosser Zahl an der Hauptrippe oder am Grunde der Fiedern erster Ordnung oder am Grunde des Blattes stehen.

Die Stammreste sind.:

I. Rhizomopterides. Fossile Farnrhizome.

II. Caulopterides. Stämme mit spiraligen Blattnarben. - Caulopleris, Palaeopteris, Protopteris.

III. Megaphyta. Stämme mit 2 gegenständigen Reihen von Blattnarben. Megaphyton.

IV. grosse Stammreste, umgeben von Adventivwurzeln. - Psuronits.

1. Reihe FILICALES LEPTOSPORANGIATAE. Sporangien aus einzelnen Zellen hervorgehend. Prothallium oberirdisch, in der Regel flach (knollig bei Gymnogramme leptophylla). 
1. Unterreihe Eufilicineae. Sporangiumwand in der Regel mit einer besonders hervortretenden Zellgruppe (Ring, Annulus), inner. halb welcher die Öffnung der Sporangien erfolgt. Sporen alle gleicl und grosse selbständige Prothallien erzeugend, welche mono- oder diklin sein können. Bisweilen Apogamie der Prothallien und Aposporie.

Fam. Hymenophyllaceae. Sorus stets randständig auf nackten Adern (Nerven) endend mit sitzenden oder kurzgestielten Sporangien, an welchen ein vollständiger Ring quer (äquatorial) oder schief hervortritt. $-\mathrm{Kr}$. mit fast stets einschichtigem Mesophyll, ohne Spaltöffnungen. - 200, in feuchten Wäldern, namentlich in den Bergwäldern der Tropen und im südlichen extratropischen Gebiet, nur wenige in Europa. - Hymenophyllum tunbridgense (in der sächsischen Schweiz und Westeuropa), $H$. Wilsoni (Irland und Norwegen). - Trichomanes speciosum (Irland, Südfrankreich, Kanaren).

Fam. Cyatheaceae. Sporangien mit vollständigem und schiefem Ring. - Meist baumartig. - c. 200 trop., subtrop., wenige temp. -

§ Dicksonieae. Sori an der Spitze der Adern, mit einem unterständigen 2 klappigen Indusium. - Balantium (3) culcita (Makaronesien) - Dicksonir (12) antarctica (Austral.). - Cibotium (8) Schiedei (Centralamerika).

§ Thyrsopterideae. Wie vor.; aber Indusium fast kngelig mit Mündung am Scheitel. - Thyrsopteris elegans (Juan Fernandez).

$\S$ Cyatheeae. Sori auf dem Rücken oder in der Gabel der Nerven, Indusium unterständig, becherförmig oder fehlend, Stamm meist hoch. Cyathea (100) medullaris und dealbata (Neu-Seeland). - Alsophila (125) australis (Südaustralien). - Hemilelia (etwa 40) capensis, mit eigenartigen Adventivfiedern.

Fam. Polypodiaceae. Sporangien mit unvollständigem, vertical verlaufendem, an der Basis nicht geschlossenem Ring, sehr selten ohne solchen. - Wenige baumartig, meist Kr. - ca. 2800 trop., subtrop., temp.

$\S$ Woodsieae. Sori terminal oder dorsal. Indusium unterständig, allseits oder extrors sich öffnend, zuweilen verkümmernd. Sporen bilateral. - Woodsia (15 temp., arkt.). - Cystopteris (5) fragilis. Struthiopteris (2) germanica ( * ). - Onoclea sensibilis (Ostas., Nordam.).

§ Aspidieae. Sori meist auf dem Rücken der Nerven, mit oberständigem Indusium, bisweilen ohne solches, Sporen bilateral. Blätter ungegliedert dem Rhizom ansitzend. - Nephrodium (250); N. filix mas, Wurmfarn (nördl. temp.), lief. d. off. Rhizoma Filicis; mehrere andere * und weiter verbreitet, viele trop., - N. plegopteris, Robertianum und dryopteris * ohne Indusium. - Fadyenia prolifera (Westindien) mit Adventivknospen an den Spitzen der Blätter. - Aspidium (50 trop.) - Polystichum (75); P. lonchitis, lobatum, aculeatum (meist temp.). Polybotrya ( $7-8$ trop.), mit sterilen und fertilen Blättern.

\$ Oleandreae. Sori auf den Adern dorsal. Receptaculum schmal. Indusium nierenförmig, schief. Sporen länglich nierenförmig. Blätter gegliedert dem Rhiz.ome angefügt, mit lanzettlicher, paralleladeriger Spreite. - Oleandra (10 trop.).

§ Davallieac. Sori randständig oder nahe am Rande eines Segmentes, mit extrorsem Indusium. Neplerolepis (10 trop., subtrop.), mehrere mit weit kletterndem Rhizom. - Iindsaya (20 trop.) - Odontosoria ferru- 
ginea (Madagaskar) mit mehrere Meter langen kletternden Blättern. Davallia (20); D. canariensis (Südspanien, Portugal, Makaronesien).

$\S$ Aspleneaø. Sori länglich bis linienförmig, einseitig längs des fertilen Nerven mit seitlich an demselben stehenden Indusium. Blattstie] ungegliedert dem Rhizom angefügt.

Blechninae. Sorus auf einer Nerven-Anastomose, welehe mit der Mittelrippe paralle] läuft. - Blechnum (50) spicant *; B. volubile mit windendem Blatt (trop. Am.). - Woodwardia * radicans (subtrop., trop.).

Aspleninue. Sori parallel den Seitennerven. - Asplenum (200) nidus (trop. As.); A. trichomanes fast kosmopolit., A. ruta muraria *, A. bulbiferum (palaeotrop.), A. gemmiferum (trop. Afr.) mit Adventivsprossen auf den Blättern; $A$. ceterach an Mauern, mediterran und in Westeuropa. - Scolopendrium vulgare *, zerstrent, vorzugsweise in der Buchenregion. - Diplazium decussatum (palaeotrop.) mit Adventivsprossen auf der Mittelrippe des Blattes; $D$. esculentum (trop. Asien), als Gemüse gegessen. - Athyrium (25); A. filix femina (* u. andiu) sehr verbreitet in Wäldern, $A$. rhaeticum (* subalpin).

$\S$ Pterideae. Sori meist länglich, terminal oder längs an der fertilen Ader, meist o'nne eigentliches Indusium, oft von dem umgeschlagenen Rand bedeckt.

Gymnogrammineae. Sori die gesamten Nerven einnehmend. Hemionitis (7 trop.). - Gymmogramme (20, viele xerophytisch in Centralamerika) leptoplyylla (trop., subtrop. bis Mittelmeergebiet und Nordamerika), $G$. argentea (Südafr.) mit dichtem weissem oder gelblichem, G. sulphurea (Antillen) mit gelblichem Wachsüberzug an der Unterseite.

Cheilanthinae. Sori den Vorderteil der Adern einnehmend. Pellaea (40) Nothochlaena (30) Marantae (subtrop., mediterr.). - Cryptogramme crispa (in Hochgebirgen). - Allosorus. - Cheilanthes (40), mehrere mit weissem oder gelben Wachsüberzug.

Adiantinae. Sori das Ende der Adern innerhalb der umgeschlagenen Randlappen einnehmend. - Adiantum (80) capillus Veneris (trop., subtrop,, mediterran).

Pteridinae. Sori auf intramarginalem Verbindungsstrang der Adernenden. - Actiniopteris (1 im indoafrik. Steppengebiet). - Pteris (60) cretica (trop., subtrop. mediterran); Pt. sevrulata (Afrika, Asien). - Lonchitis (trop., subtrop.). - Pteridium aquilinum, Adlerfarn (in Heidewäldern und auf offenen Heiden verbreitet, fast kosmopolitisch, subarktisch bis tropisch); das stärkemehlreiche Rhizom dient stellenweise als Nahrungsmittel.

$\S$ Vittarieae. Sori randständig oder auf Adern parallel zur Mittelrippe. Blätter ungegliedert dem Rhizom eingefügt. - Vittaria (20 trop.). - Antropliyum (15 trop.).

$\S$ Polypodieae. Sori meist rundlich und am Ende eines Nerven. Die abgestorbenen Blätter trennen sich vom Rhizom vollständig mit Hinterlassung einer rundlichen Narbe.

Taenitidinae. Sori lineal an einem auf hesonderer Aderanastomose entwickelten Receptaculum. - Drymoglossum (5 trop.). - Taenitis (1 trop. Asien). 
Polypodiinae. Sori rund bis länglich, ohne Receptaculum. - Polyporlium (200, trop. bis temp.); $P$. vulgare (* und Südafr.); P. aurerom (trop. Am.); P. rigidulum (Malesien). - Niplobolus (25 trop.). Lecanopteris (5 Malesien), mit knolligem, fleischigem Rhizom. - Drynaria (10 palaeotrop.), mit Nischenblättern.

$\S$ Acrosticheae. Die Unterseite des ganzen Blattes oder ein Teil desselben ist mit Sporangien bedeckt. Kein Indusium. - Elaphoglossum (SO, trop.). - Polybotrya (trop.). - Acrostichum aureum (Mangrovensümpfe);A. crinitum (Mexiko, Antillen). - Rhipidopteris peltata (trop. Imerika). - Platycerium (8) alcicorne (Ostaustralien).

Fam. Parkeriaceae. Sporangien (bisweilen ohne Ring) einzeln an anastomosierenden Nerven, fast kugelig. Kein eigentliches Indusium, sondern der Rand der Blattsegmente eingerollt und die Sporangien verdeckend. - Ceratopteris thalictroides, trop. Wasserpflanze, heterophyll, mit minimalem Rhizom und mit Adventivsprossen in den Achseln der fertilen Segmente.

Fam. Matoniaceae. Sporangien mit vollstilndigem uud schiefem Ring, zu mehreren an der Basis des Stieles eines schirmförmigen, anfangs mit seinen Rändern der Blattfläche aufsitzenden Indusiums. Rhizom mit dichotomem Blatt, dessen beide Abschnitte einseitig Fiedern tragen. - Malonia (2, Borneo). Fossile im Mesozoicuin.

Fam. Gleicheniaceae. Sporangien mit äquatorialem Ring und Längsriss, meist nur $2-8$ vereinigt, ohne Schleier. Sori unterseits den Adern aufsitzend. Blätter wiederholt dichotomisch. - 30 trop., subtrop., wenige temp., meist auf der südl. Hemisphäre. - Gleichenia glauca (trop., subtrop.), Dickichte bildend; G. bifida (trop. Amer.).

Schizaeaceae. Sporangien sitzend, mit vollständigem Ring am Scheitel, durch Längsriss sich öffnend, einzeln am Blattrand oder in den Achseln ron bracteenartigen Segmenten. - 70, meist im trop. Amer., wenige subtrop. und temp. - Schizaea (20 meist trop; einige auch temp.). - Aneimia phyllitidis (trop. Am.). - Molria (Ostafr., Madagaskar). - Iygodivum (20) mit windenden Blättern; L. japonicum (trop. As., Ostas.); $L$. volubile (trop. Am.); L. palmatum (Nordam.). - Fossil Senftenbergia im mitlercn Obercarbon, Klukia im Jura.

Fam. Osmundaceae. Sporangien sehr kurz und dick gestielt, an der Spitze mit einer einseitigen Gruppe stïrker verdickter Zellen, mit 「ä̈ngsriss sich öffnend - 11 trop. - temp. - Osmundlı regalis **. Todea Larbara (Südafr., Austral., Neuseeland). - Leptopteris hymenophylloides und $L$. superba (Neuseeland).

2. Unterreihe Hydropteridineae. Zweierlei Sporen. Die Makrosporangien enthalten je eine Makrospore, aus der sich das weibliche Prothallium entwickelt; die Mikrosporangien enthalten zahlreiche Mi. krosporen, aus denen das kleine mänliche Prothallium hervorgeht. Sporangien meist zu vielen in Soris, welche in metamorphosirte Blattsegmente oder in indusienartige Hüllen eingeschlossen sind.

Fanı. Marsiliaceae. Das aus der Makrospore hervorgehende $ᄋ$ Prothallium entwickelt nur ein Archegonium, das $\sigma^{7}$ Prothallium besteht aus 
einer vegetativen Zelle und einem zweizelligen Antheridium. Embryonale Generation mit 1-2 Keimblättern und dorsiventralem Stengel mit zwei Reihen Blättern. Zwei bis viele Sori in Blattzipfel eingeschlossen. Sori zweigeschlechtlich. - Marsiliu (32); M. quadrifolia (Eur. und subtrop.); M. Drummondii (Austr.). - Pilularia (3); P. globulifera (Eur.); einc fossil im Tertiär.

Fam. Salviniaceae. Das aus der Makrospore hervorgehende of Prothallium entwickelt einige Archegonien, das aus der Mikrospore entstehende $\delta$ Prothallium besteht aus einer vegetativen Zelle und einem zweizelligen Antheridium. Embryonale Generation mit einem schildförmigen Keimblatt und dorsiventralem Stamm mit drei oder zwei Reihen von Blättern. Sori entweder an besonderen Wasserblättern (Salvinia) oder an den ins Wasser getauchten Lappen der Schwimmbläpter (Azolla). Jeder Sorus von einem dickem Indusium eingeschlossen, eingeschlechtlich. - Salviniı (5); S. natans (Eur.); einige fossil im Tertiär - Azolla (4); A. caroliniana und $A$. filiculoides (Am.).

2. Reihe MARATTIALES. Die Sporangien der einzelnen Sori entwickeln sich als mehrschichtige Zellcomplexe und sind unter sich \pm verwachsen.

Fam. Marattiaceae. Die sehr grossen Blätter der lebenden Arten sind am Grunde mit mächtigen Nebenblättern versehen. - 25 trop., sehr viele fossil in den älteren Formationen.

§ Asterotheceae. Sporangien zu je 4-6 sternförmige Sori bildend, bis zur Hälfte ihrer Höhe einem gemeinsamen Receptaculum angewachsen. - Scolecopteris elegans. - Asterotheca (Carbon bis Keuper).

§ Angiopterideae. Sporangien zu 5-20 einen zweireihigen Sorus bildend; jedes Sporangium mit mehrschichtiger Wand, welche auf dem Scheitel einen rudimentären Ring erkennen lässt, und von hier aus mit einem Iängshiss sich öffnet. - Angiopteris (20-30 palaeotrop.); A. evectu (trop. As., Austral.).

§ Marattieae. Sporangien zu einem mehrfächerigen Sporangium vereiuigt, jedes Fach sich durch einen Längsriss öffnend, die mehrschichtige Wand ohne An deutung eines Ringrudimentes. - Marattia (12 trop.); M. fraxinea (palaeotrop.) Fossil im Rhät und Lias.

§ Kaulfussieae. Synangien kreisrund auf niedrigem Receptaculum. - Kaulfussia aesculifolic (Monsungebiet).

§ Danaeeae. Sporangien zu sehr grossen, auf lang linienförmigem Receptaculum stehenden, vielfächerigen Synangien vereinigt, welche die ganze Fläche des Blattes zwischen Mittelrippe und Rand einnehmen, - Danaea (14 trop. Amer.). Fossil Danaeites (Carbon, Lias).

Die fossilen Farnstämme, welche als Psaronius beschrieben, besonders im Rotliegenden von Sachsen und Böhmen vorkommen, gehören wahrscheinlich zu den Marattiaceen.

3. Reihe OPHIOGLOSSALES (Tuberithallosae). Prothallium ganz oder teilweise unterirdisch, mehrschichtig. Die fruchtbaren Blätter mit 1-2 Auszweigungen, an welche die grossen randständigen Sporangien stehen, die sich als mehrschichtige Zellcomplexe entwickeln.

Fam. Ophioglossaceae. Stamm kurz, senkrecht in der Erde, ein oder wenige Blätter über die Erde entsendend. - Etwa 15 trop. - temp. - 
Ophioglossum (temp. - trop.); O. vulgatum *; Wurzeln Adventivknospen bildend. - Botrychium. - Helminthostachys zeylanica (trop. Asien).

2. Klasse SPHENOPHYLLALES. Blätter im Verhältnis zum deutlich monopodialen Stamm klein, quirlig gestellt, keilförmig, mit gegabelten Adern. Leitbündel axil, dreikantig, geschlossen. Sporangien einzeln oder zı zweien an einem Stiel auf der Blattspreite oder in der Blattachsel, die Sporangien tragenden Blätter zahlreich in langen cylindrischen Blüten. W'ahrscheinlich Makrosporangien und Mikrosporangien.

Fam. Sphenophyllaceae. - Sphenophyllum vom Culm bis an die obere Steinkohle.

3. Klasse EQUJSETALES. Die Blätter sind im Verhältnis zum Stamm klein, quirlig gestellt. Sporangien als Zellcomplexe an besonderen Blättern entstehend.

\section{Reihe EUEQUISETALES. Sporen gleichartig.}

Fam. Equisetaceae. Die unfruchtbaren Blätter der einzelnen Quirle ınit einander $z u$ einer Scheide verwachsen. Die fertilen Blätter stehen continuirlich in zahlreichen Quirlen und bilden am Ende der Stengel und Äste eine cylindrische Blüte. Prothallien oberirdisch, unregelmässig geschlitzt, meist diöcisch. Aussenschicht der Sporen in zwei schraubig aufgerollte Fäden zerschlitzt, welche hygroskopisch sind. - Leitbündel collateral, geschlossen. - Equisetum (etwa 40 trop.-frigid.); fossil namentlich $E$. arenaceum im Keuper, besonders in der Lettenkohle. Die kieselsäurereichen Halme von $\boldsymbol{E}$. hiemale und $\boldsymbol{E}$. arrense dienen zum Poliren von Holz und Metall. - Hierher gerechnet werden auch die fossilen Gattungen Schizoneura (Trias) und Pliyllotheca (Trias und Jura).

2. Reihe CALAMARIALES. Mikrosporen und Makrosporen. Fossile Pflanzen von der Tracht der Equiseten; aber die Blätter superponirt und die Stämme gross und mit Dickenwachsthum der Leitbündel.

Fam. Calamariaceae. Die (selten erhaltenen) Blätter linienförmig, frei oder nur in der Jugend mit einander zu einer kurzen Scheide verbunden. An den Seitenzweigen sind die Blätter eines Quirles entweder getrennt (Asterophylliles') oder zu einer tellerförmigen Platte vereinigt (Annularia). - Die fertilen Blätter bilden Quirle, welche mit Quirlen steriler Blatter alternieren. An einzelnen Blïten wurlen unterwärts fertile Blätter mit Makrosporangien mit einer Makrospore, oberwärts solche mit vielsporigen Mikrosporangien constatirt. Sporangien auf der Unterseite der fertilen Blatter. Nur im Devon und in der Steinkohlenformationen. - Stämme und Steinkerne: Stylocalumiles, Eucalamiles, Calamitina, Archaeoralumites (Carbon und Kohlenkalk). - Laubzweige: Annularia (nur carbonisch) und Asterophyllitis (Devon und Carhon). - Blaten: C'alamostachis, Palaeostachya, Huttonia, Cingularia, - Zusammenhang in einzelnen Fallen beohachtet von Annularia und Calamostachys, von Calamiles, Annularia und Culumostachys, von Calamitina und Cultmnostachys, von Stiloculamiles und Palaeostachya, von Eucalamiles und Calamostachys, von Calamitinut und Asterophyllites.

Fam. Protocalamariaceae, Wie die vorigen, aber die Blätter superponirt, frei uncl gegabelt. - Asterocalamiles, im Culm und unteren produktiven Carbon.

4. Klasse LYCOPODIALES. Blätter im Verhältnis zum Stamm klein, seltener quirlig, meist (9. Sporangien einzeln am Grunde der 
Blattoberseite oder in der Blattachsel. Sporophylle meist endständige Blüten bildend. Wurzeln dichotom.

1. Reihe LYCOPODIALES ELIGULATAE. Blätter ohne Ligula. Sporen gleichartig. Prothallium gross, aus der Spore vollkommen heraustretend.

1. Unterreihe Lycopodiineae. Sporophylle ungeteilt. Sporangien einfächerig.

Fam. Lycopodiaceae. Prothallium knollenförmig, mit Antheridien und Archegonien. Embryonale Generation monopodial, oft scheinbar gabelig verzweigt, mit geschlossenem axilem Leitbündel, dicht beblättert, mit zugespitzten oder schuppigen Blättern. Sporangien einzeln am Blattgrund, fast in der Blattachsel, aus Zellcomplexen entstehend, bei der Reife zweiklappig. - Lycopodium (etwa 100 trop. - temp.); I. selago auf Mooren (temp. frigid.), mit Brutknospen; L. clavatum (oft in Heidewäldern); L. annotinum (in Gewirgswäldern) u. a. geben das Semen Lycopodii. Phylloglossum Drummondii (südöstliches Australien, Neu-Seeland).

2. Unterreihe Psilotineae. Sporophylle zweispaltig. Sporangien 2-3 fächerig.

Fam. Psilotaceae. Embryonale Generation mit rutenförmigen Ästen, mit geschlossenem Leitbündel und ohne Wurzeln; aber mit gabelig verzweigten Rhizomen. - 4 trop., subtrop. - Psilotum nudum (trop., subtrop.), auch ausgezeichnet durch Produktion zahlreicher aus Wurzelhaaren hervorgehender Brutknospen. - Tmesipteris tannensis (Australien, Neu-Seeland).

2. Reihe LYCOPODIALES LIGULATAE. Blätter mit Ligula, Mikrosporen und Makrosporen. Prothallium aus der Spore nur wenig hervortretend, das männliche sehr klein.

1. Unterreihe Selayinellineae. Ohne Dickenwachstum des Stammes.

Fam. Selaginellaceae. Stamm in die Länge wachsend, monopodial, anscheinend gabelig verzweigt, meist dorsiventral, mit kleinen Oberblättern und grösseren Unterblättern. Häufig exogen entstehende Wurzelträger, an denen die Wurzeln endogen sich biden. Sporangien in der Blattachsel. Makrosporangien mit vier (selten zwei oder acht) Makrosporen, Mikrosporangien mit zahlreichen Mikrosporen. Das of Prothallium die Mikrospore nur am Scheitel durchbrechend, mit einem oder mehreren Archegonien. Das $\sigma^{\top}$ Prothallium in der Mikrospore mit einer vegetativen Zelle und einem Antheridium mit zahlreichen Spermatozoiden. Embryo mit zwei Keimb. und Embryoträger. - Selaginella (500, meist tropisch); in den Alpen und nördlich derselben S. selaginoides (spinulosa) und S. helvetica. S. lepidophylla (Kaliforn., Texas, Mexiko) mit schraubelähnlichen Sprossverbänden und sich zu einem Knäuel zusammenrollenden, hygroskopischen Zweigen.

2. Unterreihe Lepidophytineae. Mit Dickenwachstum des Stammes, baumartig. Stammoberfläche mit regelmässig angeordneten Blattnarben und Blattpolstern. 
Fam. Lepidodendraceae. Embryonale Generation baumartig, mit eentralem Leitbündel, selten mit kleinem Mark, mit Diekenwachstum dureh ein Rindenmeristem; Stanm gabelig verzweigt nnd dicht mit (?) gestellten, linealisehen, spitzen Blättern hesetzt; unterirdische, gabelig verzweigte Wurzelträger (Stigmuria); an Stelle der abgefallenen Blätter rhombische Blattfüsse oder Narben. Blüten gross, zapfenăhnlich, unten mit Makrosporangien, oben mit Mikrosporangien. - Vom unteren Devon bis his zmm Obercarbon, besonders im unteren und mittleren Carbon. - Lepidodendron, hierzu Knorria (Steinkern), Lepidophloios, Halonia (Zweige), Lepidostrobus (Blüten).

Fam. Sigillariaceae. Wie die vorigen; aber mit deutlichem Markkörper und Secundärholzring, mit stark hervortretenden Orthostichen der Blattnarben. Bläter lang und schmal, meist nicht auf Blattfüssen. Blüten gestreckt zapfenförmig. Sigillaria im mittleren Carbon; die von den Stammstïmpfen ausgehenden langen dichotomisch verzweigten Wurzelträger wie bei vorigen als Stigmaria bezeichnet.

3. Unterreihe Isoëtineae. Mit Diekenwachstum des knollenartigen Stammes.

Fam. Isoëtaceae. Embryonale Generation mit kurzem, in die Dicke wachsendem Stamm und zahlreichen langen Blättern mit Ligula und Glossopodium oberhalb einer basalen Grube. Sporangien an der Oberseite der Blätter in der Grube, von Trabeculis (sterilen Zellschichten) durchzogen; Makrosporangien mit vielen Makrosporen an den äusseren Blättern; Mikrosporangien mit noch zahlreicheren Mikrosporen an den inneren Blättern. Zwischen den fertilen Blättern je zweier Jahrgänge einige sterile. Entwickelung der Prothallien ähnlich wie bei Selaginella. - Etwa 60 trop. - temp. - Isoëtes lacustris u. I. echinospora auf dem Grunde von Landseeen, andere amphibisch oder auf dem Lande wachsend.

\section{Anhang. CYCADOFILICES.}

Mittelgruppen zwisehen Filicales und Cycadales, mit centripetal und centrifugal sieh entwiekelndem Xylem, mit mehrreihig angeordneten Hoftïpfeln anf den Traeheiden des seeundären Holzes und mit breiten Markstrahlen.

Cladoxyleae. Cladoxylon im Carbon.

Lyginopterideae. Habituell an Farne erinnernd; aber Tracheiden mit gehöften Tïpfeln. - Lyginopteris, Megaloxylon, Calamopitys.

Medulloseae. Säulenförmige Stammreste, mit engspiralig angeordneten Blattfüssen, auf dem Quersehnitt ausgezeichnet durch zahlreiche Sternringe im Mark mit rentralem Xylem und peripherischem Leptom, sowie durch einige an der Peripherie liegende zusammengedrỉckte Plattenringe mit schmalem langgezogenem Querschnitt. -- Medullosu (Carbon bis Perm).

Cycadoxyleae. - Cycadoxylon (Unteres produktives Carbon).

Protopityeae. Stämme ähnlich denen der Coniferen; aber obne Jahresringe. - Protopitys (Carbon).

Arancarioxylu. Besondere Leitbündel mit primärem Xylem in Markkörper.

Weitere Gattungen von zweifelhafter Stellung: Noeggorathia, Calamariopsis, Poroxy. Ion, Dolerophyllum. 


\section{Abteilung. EM B R Y O P H Y T' A SI P H O N O G A A. (Siphonogamen, Phanerogamen, Endoprothalliaten, Samenpflanzen.)}

Kormophytische Gewächse mit in der Samenbildung verdecktem Generationswechsel. Die proëmbryonale Generation ist wie bei den heterosporen Asiphonogamen eingeschlechtlich. Die $\sigma^{\top}$ proëmbryonale Generation entwickelt sich in den Mikrosporen oder "Pollenkörnern"; sie besteht aus einer zum Pollenschlauch auswachsenden vegetativen Zelle, welche die Befruchtung vermittelt und noch einer oder wenigen kleineren Zellen, von denen die eine dem Antheridium der Pteridophyten entspricht und sich in 2 nackte generative Zellen teilt, welche bei den auf der untersten Stufe stehenden Gymnospermen sich in Spermatozoiden umbilden, sonst als Spermakerne fungiren. Die $q$ proëmbryonale Generation entwickelt sich in der Makrospore, hier Embryosack genannt, und enthält einige Archegonien oder nur ein auf 2 Synergiden und eine Eizelle reduciertes; sie ist der wesentlichste Teil der Samenanlage und bei einzelnen Angiospermen ist die letztere auf den Embryosack reduciert. Der aus der befruchteten Eizelle hervorgehende Embryo kommt in der Makrospore zur Entwickelung, während diese noch von denı Makrosporangium (dem Nucellus der Samenanlage) eingeschlossen ist, und während das Makrosporangium noch mit der embryonalen Generation verbunden ist. Mancherlei Modifikationen dieser Verhältnisse bei den Angiospermen (s. d.). Erst nach Ausbildung des Embryo löst sich das Makrosporangium oder der den Embryo umgebende Gewebekörper (nun Same genannt) von der älteren embryonalen Generation los. Mit der Keimung des Samens beginnt die Entwickelung einer neuen embryonalen Generation.

Das Charakteristische dieser Abteilnng, welche sich unmittelbar an die vorhergehende anschliesst, liegt nicht bloss in dem Modus der Befruchtung, sondern auch darin, dass die Befruchtung der in der Makrospore enthaltenen Eizelle erfolgt. während die Makrospore noch mit der proëmbryonalen Generation in Verbindung steht.

\section{Unterabteilung. GYMNOSPERMAE (Nacktsamige, Archispermae,}

\section{erste Samenpflanzen).}

Mikrosporangien oder Pollensäcke stets nur auf der Unterseite der Stb. Frb. nicht zu einem Gehäuse zusammenschliessend (ausser bei Juniperus), daher auch keine Narbe (Stigma). Die Mikrospore oder der Pollen gelangt direct auf die Samenanlage, und zwar zunächst auf den Nucellus, den der Pollenschlauch durchwächst, um zu der Makrospore, dem Embryosack, zu gelangen und die in derselben befindlichen Archegonien zu befruchten. Sa. nackt auf den ausgebreiteten Frb. oder in der directen Verlängerung der Axe liegend. Prothallium (= "Endosperm", später als 
Nährgewebe dienend) vor der Befruchtung die Makrospore (= Em. bryosack) oder weibliche Keimzelle ausfüllend, mit einigen Arche. gonien. Archegonien mit Halszellen, Eizelle und Kanalzelle oder ohne letztere, selten nur mit Eizelle (Tumboa). Die männlichnn Keimzellen, die Mikrosporen oder »Pollenkörner", entwíckeln vor dem Ausstäuben ein wenigzelliges Prothallium mit $1-2$ vegetativen Zellen und die $\sigma$ Sexualzelle oder generative Zelle, welche in selteneren Fällen echte Spermatozoiden, meistens die befruchtenden Spermakerne erzeugt.

1. Klasse CYCADALES. Stamm gar nicht oder nur wenig verzweigt. Gefässe im secundären Holz fehlend. Laubb. nur selten (bei fossilen Gattungen) ungeteilt, in der Regel fiederteilig oder gefiedert, an dem Gipfel des Stammes einen Schopf bildend. Bl. stets endständig diöcisch, nicht zu Blütenständen vereint. Blh. 0 .

Fam. Cycadaceae. $\sigma^{\top} \mathrm{Bl}$. zapfenförmig, die Staubb. mit $\infty$ Sporangieц (= Pollensäcken) auf der Unterseite; of Bl. nicht immer zapfenförmig, mit Frb., welche rechts und links je 1, seltener 2-4 Sa. tragen. Sa. geradläufig, mit 1 Integ. Nucellus der Sa. mit Pollenkammer, Archegonium mit Kanalzelle und Halszellen. Generative Zelle 2 Spermatozoiden erzen. gend, von denen das eine nach Abstreifung des gewimperten Spiralbandes in der durch Verschleimung des oberen Teiles der Embryosackwandung entstehenden Flüssigkeit sich mit dem' Kern der Eizelle vereint. S. steinfruchtartig, mit fleischig-mehligem Nährgewebe. E. an knäuelig aufgewickeltem Suspensor. Keimb. meist 2, oben oder in der Mitte vereinigt. - Verzweigte Schleingänge in der Rinde. - Gegen 90, trop., subtrop., viel zahlreicher von der oberen Steinkohlenformation bis Anfang der Juraformation.

\& Cycadeae. Frb. mit $8-4$, seltener 2 Sa. Stamm die $ᄋ$ Blüte lurchwachsend. Blattfiedern nur mit 1 Mittelnerv. - Cycas (16, trop. Asien, Australien, Polynesien); C. revoluta (südl. Japan) und C. circinalis (Ostindien) liefern Sago. - Fossile Arten vom Rhät an, auch in der Kreide von Grönland. - Cycadospadix (Liassandstein). - Cycadospermum.

§ Zamieae. Frb. stets mit 2 Sa., wie die Stb. angeordnet. Stamm die 우 BI. nicht durchwachsend.

- Stangeriinae. Blattfiedern fiedernervig. - Stangerin paradoxa (Natal).

* Zamiinae. Blattfiedern längsnervig. - Dioon edule (Mexiko) liefert StärkeMehl (Sago). - Encephalartus (Afrika), auch im Tertiär von Griechenland. - Macrozımia (50 Australien) - Zamia (trop. und subtrop. Amerika). - Ceratozamia (Mexiko).

Fossil und von unsicherer Stellung: Pterophyllum (besonders im Keuper), Zamites (Trias bis Kreide), Androstrobus (Kreide).

2. Klasse BENNETTITALES. Stamm mit Dickenwachsthum des Holzringes, bedeckt mit einem Panzer von Blattfüssen, zwischen denselben mit von lineal-lanzettlichen Blattern umgebenem eilänglichen Kolben, gebildet aus zahlreichen stielartigen, von je einem Bündel durchzogenen Gebilden, welche an der Peripherie alle verwachsen sind und je einen mit 2 Integumenten versehenen, einen dikotyledonen Embryo einschliessenden S. tragen.

Fam. Benettitaceae. - Bennettites Gibsonianus in Neocom der Insel Wight. Mantellia. 
3. Klasse CORDAITALES. Stamm verzweigt. Gefässe im secundären Holz fehlend. Blätter lineal bis spatelförmig, meist gross, am Ende der Äste zusammengedrängt. An den Achseln der Blätter Blïtenstände mit eiförmigen Ährchen, welche unter zahlreichen spiralig angeordneten Hochblättern versteckt die nackten Blüten tragen.

Fam. Cordaitaceae. $\sigma^{\top}$ Blüte gestielt mit je 3-4 cylindrischen, nur aus dem Pollensack bestehenden Stb.; \& Blüte ein kurzer fadenförmiger Träger mit einer endständigen, mit 2 Integumenten versehenen Sa. in der Achsel einer Bractee, deren mehrere zu einem Ährchen vereint sind. - Cordaites, hohe Bäume, vom Silur und Devon bis in die permische Formation. - Artisia (Steinkerne von Stämmen). Dadoxylon (Araucarioxylon, Stämme). - Curdaianthus (Blüten). - Stephanospermum, Carriocarpus u. a. (Samen).

4. Klasse GINKGOALES. Stamm verzweigt. Gefässe im secundlären Holz fehlend. Iangtriebe und Kurztriebe vorhanden. Die Laubblätter eingeschnitten, keil- bis fächerförmig, bei ausgestorbenen Gattungen tief eingeschnitten mit schmalen Abschnitten. Bl. eingeschlechtlich, zweihäusig. Stb. der $\sigma^{\top}$ Bl. mit 2 Mikrosporangien (Pollensäcken), Spermatozoiden mit je aus 3 Spiralwindungen bestehendem Kopfe, zahlreichen Cilien und spitzem Schwanzende. Sa. aufrecht 1 oder 2 am Ende der schmal keilförmigen, am Ende oft 2 spartigertan eiser gemeinsamen Axe stehenden Frb. Befruchtung tritt erst in der abgefallenen $\mathrm{Sa}$, ein, nachdem 2 Monate vorher die Bestäubung und von der Pollenkammer aus die Entwicklung eines verzweigten Pollenschlauches erfolgte. Vor der Befruchtung Verschleinung des oberen Teiles der Embryosackwandung und Abstreifung des gewimperten Teiles der Spermatozoiden wie bei den Cyondales.

Fam. Ginkgoaceae - Ginligo biloba (China); zahlreiche nahe verwandte Arten vom Tertiär rückwärts mit Sicherheit bis in die Juraformation. - Baiera (Perm bis Kreide). - Czekanowskia (Rhät bis Kreide). - Rlipidopsis (Jura).

5. Klasse CONIFERAE. Stamm verzweigt. Gefässe im secundären Holz fehlend. Blätter meist schmal, lineal oder lanzettlich. Blüten eingeschlechtlich, stets über die Hochblätter hervortretend. Blh. 0 oder höchstens hochblattartig. Keimb. 2-15, stets frei.

Fam. Taxaceae. Meist nur wenige Frb. in einer ㅇ Blüte oder ein einziges endständiges mit je einer Sa.; S. meist die Frb. überragend, steinfruchtartig. - Mesophyll der B. mit Harzgängen, ausser bei Taxus. c. 70 temp., subtrop.

$\S$ Podocarpeae. Blätter lineal oder lanzettlich. Frb. immer deutlich, mit 1 nach unten gewendeten Sa. Stb. mit 2 Mikrosporangien. Pollen mit Flugblasen. - Microcachrys tetragona (Tasmanien). - Podocurpus (etwa 40, Ostas. u. südl. temp., auch in Gebirgen der Tropen, z. B. P. Mannii auf den Gebirgen Afrikas). - Dacrydium (12, malayisch, Tasmanien, Neu-Seeland).

§ Taxeae. B. lineal oder lanzettlich. Sa. aufrecht, am Grunde des Frb. oder in der Verlängerung der Axe liegend; vollkommen terminal. - 
Pleyllocladus mit Langtrieben und blattartigen Kurztrieben (3, NeuSeeland, Tasmanien, Borneo). - Torreya (4, Ostas., Nordam.) - Truxus (6-8 * temp.); $\boldsymbol{T}$. bucccitu, Eibe (*).

\$ Cephalotaxeae. Frb. in gekreuzten Paaren, mit je 2 Sa. (4 temp. Ostașien).

Frm. Pinaceae. $\sigma^{7} \mathrm{u}$. \& Sexualblätter zu mehreren in einer Blüte. S. zwischen den Frb. versteckt, mit holziger, lederartiger oder knochenharter Schale. - Mesophyll der B. stets mit Harzgängen. - c. 300, meist temp.

§ Araucarieae. Blätter (9). Frb. einfach, in der Mitte mit nur einer umgewendeten Sa. - Ayathis dammara (malay.) liefert Dammaraharz: A. australis, Kaurifichte (Neu-Seeland), liefert Ka uri-Kopal. - Avauctrin $\left(10^{*}\right) ; A$. brasiliana (Brasilien); A. imbricata (Chile); A. excelsa (Norfolk-Ins.) ete; fossile im Jura und Wealden Englands und im Jura Ostindiens.

$\S$ Abietineae. Blätter (Q. Frb. in Deck- und Fruchtschuppe geteilt, erstere meist kleiner als letztere, an der seitlich 2 Sa. sitzen. - (Nach einer anderen Auffassung ist die „Fruchtschuppe ein durch congenitale Verwachsung entstanderer Complex von 2 oder mehr Frb. in der Achsel eines Deckb. und demnach das, was hier als Bl. aufgefasst ist, ein Blütenstand.) a) Langtriebe und Kurztriebe vorhanden: Lavix, Lärche (8); L. Iecidha (Eur.), lief. off. venetian. Terpentin. - Psendolarix Kaempferi, Goldlärche (nördl. u. östl. China). - Cedrus deodara (Himal.); C. ILibani (Libanon, Taurus, Cypern, Atlas); fossile Arten in der Kreide Englands. - Pinus (etwa 70, *, einige calid.). Sect. I. Strobus: $\boldsymbol{P}$. strolus, Weymouthskiefer (Nordam.), lief. Terpentin; P. Lambertiana, Zuckerkiefer (westl. Nordam.), lief. essbares Harz; $\boldsymbol{P}$. cembra, Arve, Zirbel (Alp., Karparth., Sibir.), lief. vorzügliches Schnitzholz und essbare S.; fossile Arten dieser Section schon in den mesozoischen Formationen. - Sect. II. Pinaster: P. taeda, Weihrauchkiefer (atlant. Nordam.) lief. Terpentin; $P$. ponderosa (Neu-Mexiko bis Rocky Mountains); $P$. rigida (atlant. Nordam.); P. pulustris (Carolina bis Florida) lief. das Pich. pine-Holz des Handels; $\boldsymbol{P}$. silvestris, gemeine Kiefer (Eur. nördl. bis $68^{\circ}$, As. nördl. bis $66^{\circ}$ ), lief. Terpentin, Teer, Pech, Waldwolle; P. montanc, Zwergkiefer, Krummholz (Mitteleuropa, subalpin), $P$. pinea, Pinie (medit.), lief. essbare S.; P. nigra, Schwarzkiefer (Sücleuropa, Spanien bis Pontus, nordwärts bis zum Wiener Wald); $\boldsymbol{P}$.pinctster, Seestrandkiefer (Mittelmeergebiet); P. halepensis, Aleppokiefer (Mittel. meergebiet); fossile Arten dieser Section von der cenomanen Kreide an. - P. succinifera im Tertiär des Samlandes, wahrscheinlich Stammpflanze des Bernsteins. - b) Nur Langtriebe vorhanden: Picea, Fichte $(12 *)$; P. excelsı, Fichte, Rottanne (Eur. $42^{\circ}-68^{\circ}$ ) und $P$. obovata (Nordrussland, Sibirien) lief. Harz; $P$. orientalis (Kleinas., Kaukasus); $P$. nigra (östl. Nordam.) lief. »Sprucebeer «; $P$. alba, Schimmelfichte (Kanada bis Carolina); P. Smithiana, Morinda (Himal.); $P$. omorica (Serbien, Sï̈lbosnien); fossile Reste einer sehr nahestehenden Art in quartären $\mathrm{Ak}$ lagerungen des sächsischen Erzgebirges - Tsuga (6 As., Nordam.); Ts. canadensis, Schierlingstanne, Hemlocktanne (atlant. Nordamerika), liefert 
kanadisches Pech. - Pseudotsuga taxifolia (Douglasii), Douglastanne (westl. Nordamerika), lief. Mastbäume. - Abies (20*); A. ciba, Weisstanne, Edeltanne (Mittel- und Südeur.), liefert "Strassburger Terpentin«, Holz zu Resonanzböden etc.; A. Nordmanniana (Krim, westl. Kaukasus); A. pichta (Nordrussl.; Sibirien); A. balsamea (Nordam.) lief. Kanadabalsa m; A.pinsapo (Südspanien). - Keteleeria Fortunei(China).

$\S$ Taxodieae. Blätter (9). Frb. in Deck - und Fruchtschuppe gegliedert oder doch auf der Innenseite mit hervortretender Anschwellung. Sa. 2-8, achselständig und aufrecht oder auf der Fläche der Frb. und dann umgewendet. - Sciadopitys verticillata, Schirmtanne mit Doppelnadeln (Japan). -- Cunninghamia sinensis (südl. China und Cochinchina). - Sequoia gigantea, Mammutbaum (Stämme bis $100 \mathrm{~m}$ hoch und $12 \mathrm{~m}$ dick; Sierra Nevada in Kalif.); S. sempervirens, Red wood (Kalifornien); zahlreiche Arten fossil in der Kreide und dem Tertiär von Eur., As., Nordam. - Arthrotaxis (Tasmanien). - Cryptomeria japonica, japanische Ceder. - Ceratostrobus, fossil in der böhmischen Kreide. Taxodium disticlıum, virginische Sumpfcypresse, mit abfallenden Sprossen (östl. Nordamerika, in der Tertiärperiode auch im westl. Nordam., As. und Eur.). - Glyptostrobus (China); G. europaeus, fossil im 'Tertiär von Eur. und Nordamerika. - Hierher vielleicht auch Voltzia (Trias).

$\S$ Cupressineae. Blätter gegenst. oder quirlst., sehr selten abwechselnd. Häufig Heterophyllie. Sa, aufrecht.

* Actinostrobinae. Zapfen holzig, Frb. klappig. - Actinostrobus (Südwestaustral.). - Callitris (incl. Widdringtonia 15, Nordafr., Südafr., Madag., Austral., Neukaled.); C. quadrivalvis (Atlas und seine Vorberge), liefert Sandarakharz, fossile Arten im Tertiär Südeuropas. Fitzroya patagonica (südl. Chile).

* Thujopsidinae. Zapfen holzig, Frb. dachig. Quirle zweizählig. Thujopsis dolabrata (1 Japan). - Libocedrus (8 Chile, Neuseeland, Nenkaledonien, China, Japan, Kalifornien). - Thuja (4); Th. occidentalis, Lebensbaum (Kanada bis Virginien); Th. orientalis (China, Japan); Verwandte beider Arten im Miocän Europas und Grönlands.

* Cupressinae. Zapfen holzig. Frb. schildfg., klappig an einander gepresst. Quirle zweizählig. - Cupressus (12); C. sempervirens, Cypresse (von Persien aus durch das Mediterrangebiet); C. funebris (ursprünglich in China); $C$. glauca (von Vorderindien aus verbreitet). Chamaecypuris (5); Ch. nutkaënsis (nordwestl. Nordam.); Ch. pisifera (Japan); Ch. sphaeroidea (Kanada, Nordkarolina); Ch. Lau'somirnn (Kalif., Oregongebiet).

* Juniperinae. Zapfen beeren- oder steinfruchtartig. - Juniperus, Wachholder $(30 *)$; . drupacea (Kleinas., Syrien); J. communis (ganze nördl. gem. Zone), liefert die off. Wachholderbeeren; var. nana, Hochgebirgsvar. d. nördl. gem. Zone; J. oxycedrus und $J$. macrocarpa im Mittelmeergebiet; J. sabina, Sadebaum, Sevenbaum (Mittel- und Südeur., Kaukasus, Nordasien), lief. die off. Summitates Sabinae; J. viryiniana, virginische oder rote Ceder (atlant. Nordam.), liefert Holz für Cigarrenkisten und Bleistifteinfassungen, J. procera von Abyssinien bis zum Kingagebirge am Nyassa-See, hoher Waldbaum. 
6. Klasse GNETALES. Stamm einfach oder verzweigt. Gefässe im secundären $\mathrm{Holz}$ vorhanden. Blätter ungeteilt, gegenständig. Blïten eingeschlechtlich oder scheinbar zwittrig, mit Blh., in Blütenständen vereint und \pm von Hochb. bedeckt. O Blüten mit geradläufiger Sa. Befruchtungsapparate ziemlich verschiedenartig. Keimb. 2. - Harzgänge fehlend.

\section{Fam. Gnetaceae.}

Unterfam. Ephedroideae. $\sigma^{7}$ : Blhb. 2; Stb. 2-8, nur aus sitzenden 2 fächerigen A. bestehend. Antheridien zweizellig und gestielt. : Bll. schlauchfg.; Sa. mit einfachem Integument. Archegoniun mit Kanal- und Halszellen. Blh. bei der Reife erhärtend, Hochb. fleischig werdend. Keimling mit zusammengerolltem Suspensor. - t mit schuppenfürmigen decussirten B. - Ephedra (etwa 20 in wärmeren gemässigten Zonen); E. vulgaris (Mediterrangebiet und an wenigen Stellen des südl. Nitteleuropas).

Unterfam. Tumbooideae. $\sigma^{7}$ : Blh. vierblätterig, 6 Stb., unten vereint, mit 3 fächerigeu A.; Antheridien einzellig und sitzend; eine rudimentäre Sa. ᄋ: Blh. schlauchfg. Sa. mit einem Integum. Archegonium auf die Eizelle reduciert. - t mit kurzem, dickem, kegelförmigem, wenig über len Boden tretendem Stamm, zwei grossen, lederartigen, fortwachsenden Laubb. und $\infty$ rispigen Blütenständen. - Tumboa Bainesii (Welwitschia mirabilis) in den Steinwüsten von Damaraland und Benguella.

Unterfam. Gnetoideae. $\sigma^{\text {T: }}$ Blh. röhrenfg., kantig; Stb. 2 mit sitzendem A. 을 Blh. schlauchfg.; Sa. mit 2 Integum. (nach Ansicht einzelner Autoren ist nur 1 Integ. und 1 zweite Blh. vorhanden). Durch Quer- und Längsteilung der Embryosackmutterzellen entwickeln sich mehrere Embryosackanlagen; in derselben entstehen zahlreiche wandständige Kerne, von denen einzelne als Eikerne fungiern. Äusseres Integ. crhärtend, Blh. fleischig werdend. - Meist lianenartige (mit Erzeugung neuer Cambiumringe ausserhalb des ersten Gefässringes), selten aufrechte $\hbar$. Bl. sehr zahlreich in den Achseln je zweier mit einander verwachsenen Hochb., Älıren bildend. Keimling an langem, zusammengerolltem Suspensor und am unteren Ende mit Saugfuss. - Gnetum (etwa 15 trop.).

\section{Unterabteilung, ANGIOSPERMAE (Bedecktsamige, Metaspermae, spätere Samenpflanzen),}

Mikrosporangien oder Pollensäcke meist auf der Vorder- und Rückseite der Stb. und je 2, ein vorderes und ein hinteres eine Theka bildend, bisweilen in kleinere Fächer geteilt. Mikrosporen bisweilen in Tetraden oder zu vielen in Gruppen. Embryosack meist eine die aus derselben Embryosackmutterzelle hervorgegangenen Schwesterzellen verdrängende Zelle. Die Mikrospore (Pollen) gelangt auf die Narbe des weiblichen Apparates (Gynaeceum) und treibt von hier aus den Pollenschlauch, welcher zu der samenanlage und der in derselben eingeschlossenen Keimzelle oder Makro- 
spore (dem Embryosack) gelangt. Eizelle im Embryosack. Samenanlagen von den meist vollständig geschlossenen Fruchtblättern bedeckt. 우 Prothallium (Endosperm) vor der Befruchtung in der Regel kein zusammenhängendes Gewebe (Ausnahme s. bei Verticillatae) bildend, nach der Befruchtung infolge wiederholter Teilung die ganze. Makrospore ausfüllend, sehr häufig von dem sich entwickelnden Embryo schon resorbiert, während dieser noch im Samen eingeschlossen ist, in anderen Fällen ebenso wie das aus dem Nucellus der Sa. hervorgehende Perisperm dem Embryo bei der Keimung als Nährgewebe dienend. Männliches Prothallium in den männlichen Keimzellen (Mikrosporen oder Pollenkörnern) auf eine zum Pollenschlauch auswachsende vegetative Zelle und eine kleinere generative Zelle reduciert, welche 2 in den Pollenschlauch wandernde und durch das aufgeweichte Ende desselben in die Makrospore eindringende Spermakerne erzeugt.

In der Sa. entsteht in der Regel nur eine fertile Makrospore (ausnahmsweise 20 und mehr bei Casuarina oder nur noch einige sterile bei Rosa livida, Cheiranthus cheiri, Isatis tintoria). In der fertilen Makrospore oder dem Embryosack entsteht (ausser bei den Verticillatae, s. d.) vor der Befruchtung: 1. ein rudimentäres Prothallium, welches aus meist drei, bisweilen auch vielen (Lea, Hordeum), meist am Chalazaencle des Embryosackes liegenden Antipoden und einem aus zwei vereinigten Zellkernen entstehenden Zellkern in der Mitte des Embryosackes besteht, nach der Befruchtung aber sich durch Teilung des erwähnten Zellkernes zu einem die Makrospore ausfüllenden Nährgewebe entwickelt; 2. ein aus zwei Synergiden und einer membranlosen Eizelle bestehender Geschlechtsapparat. Der Pollenschlauch wächst von der Narbe in dem Leitungsgewebe des Griffelkanals bis zu der Sa. und gelangt mit seiner Spitze zu dem organisch oberen Ende des Embryosackes, bei den mit Integumenten versehenen Sa. durch die Mikropyle, bei integumentlosen Sa. oder bei Sa. mit freiem Embryosack (Santalales) direct. Dieses häufigste Verhalten ist Acrogamie. Bei einigen Loranthaceae entwickelt sich der Geschlechtsapparat am basalen Ende der Sa. und es findet dann Basig amie statt. Endlich kommt bei einigen Familien (Casuarinaceae, Juglandaceae, Betulaceae) Chalazogamie vor, welche darin sich äussert, dass der Pollenschlauch neben der Mikropyle oder in der Wandung des Gynaeceums zum Chalazaende der Sa. vordringt und von da aus sich verzweigend aufwärts zum Befruchtungsapparat gelangt.

Von den beiden Spermakernen vereinigt sich der eine mit dem Kern der Eizelle, welche sich nun zum Embryo entwickelt, der andere mit dem Embryosackkern, durch dessen Teilung das Endosperm entsteht.

\section{Klasse MONOCOTYLEDONEAE. Embryo mit einem Cotyle-} don. Der Stamm von geschlossenen Fibrovasalsträngen durchzogen. B. vorherrsehend parallelnervig aber auch netznervig. Bl. häufig mit 5 3 gliederigen Quirlen, aber doch auch mit ganz anderen Zahlen-und Stellungsverhältnissen. - Die häufig versuchte Ableitung sämtlicher Monocotyledonenblüten von einem Grundtypus ist durchaus ungerechtfertigt. 
A. Reihen mit vorherrschender Unbestindigkeit in der Zahl der Blütentelle. a. Typisch achlamydelsche (aiso nicht apopetaie) Bl. kommen noch ror.

a) Nacktblüher vorherrschend. Grosse Unbestïndigkeit in der Zahi der Stb. nnd anch der Cp.

1. Reihe PANDANALES. Bl. nackt oder mit homoiochlam. hochblattartiger Blh., $\sigma^{7}$ ㅇ. $\sigma^{7}$ mit $1-\infty$ Sth. o mit $1-\infty \mathrm{Cp}$. S. mit Nährgewcbe. Bl. in zusammengesetzten kugeligen oder kolbenähnlichen Blütenständen. - Sumpfkräuter und Bäume mit linealischen B.

Fam. Typhaceae. Bl. $\sigma^{7}$, nackt. $\sigma^{\top}: 2-5$, selten 1 Stb., oft vereint; Pollentetraden. $\circ: 1 \mathrm{Cp}$. auf cylindrischer, behaarter Axe, mit einer linealischen oder spatelförmigen $N$. und einer herabhängenden Sa. Nüsschen oder Caryopsis. S. mit dünnem Perisperm und fleischigem Endosperm. - Kr. mit Rhizom, 2 zeiligen, linealischen B. und cylindrischen, unten $ᄋ$, oben $\sigma^{\top}$ kolbigen Blütenständen, welche von häutigen Hochb. durchbrochen sind. - Typha, Lieschkolben (9 in Sümpfen, calid., temp.).

Fam. Pandanaceae. Bl. durch Abort $\sigma^{\top}$ 우 nackt, sehr selten mit Spur einer Blh. $\sigma^{7}$ : $\infty$ Stb. an verkürzter oder verlängerter Axe. $ᄋ$ : bisweilen Std., Cp. $(\infty-1)$ mit sitzenden N.; Sa. $\infty-1$. Beeren oder Steinfr. zu Sammelfr. verbunden. S. mit reichlichem Nährgewebe. - $\frac{\hbar}{\mathrm{mit}}$ Stïtzwurzeln oder Klettergewàchse mit 3 zeiligen, parallelnervigen B. Bl. in Kolben, diese terminal oder traubig gehäuft in der Achsel scheidiger Hochb. - 220 trop., von Afrika bis Polynesien, nicht in Amerika. - Freycinetia (kletternd). - Prandamus; die B. dienen zu Flechtwerk, die Fr. und S. vielfach als Nahrungsmittel.

Fam. Sparganiaceae. Bl. $\sigma^{7}$ q, mit Blh., $\oplus$. $\sigma^{7}$ : Blhb. 3-6, Stb. 3-6, Cp. $(1-2)$ mit je einer hängenden Sa., $1-2$ lanzettliche $N$. Steinfr. $\mathrm{S}$. mit mehligem Nährgewebe. - Kr. mit 2 zeiligen $\mathrm{B}$. Bl. in kugeligen Köpfen, untere Köpfe $\$$, obere $\sigma^{\top}$, an Axen 2. und 3. Grades. - Spargrinium (14-20 temp., frigid.).

३) Nacktblïher noch vorhanden: aber in der Reihe treten alle mögIlchen Stnfen von der Achiamydie bis zur Heterochlamydie auf, ebenso Hypogynie und Epigynie. Unbestimmte Zahl der Sexualblätter, sowie bestimmte.

2. Reihe HELOBIAE (Fluviales). B1. cyklisch oder hemicyklisch, achlam. od. haplochlam., diplochlam., homoiochlam., heterochlam., hypogynisch, epigynisch. Stb. $1-\infty$. Cp. $1-\infty$, apocarp-syncarp. Nährgewebe meist 0 oder schwach. - Wasser- oder Sumpfpflanzen.

1. Unterreihe Potamogetonineae. Bläte hypogynisch, achlamy. leisch oder homoiochlamydeisch.

Fam. Potamogetonaceae. Bl. ̧ oder $\sigma^{7}$ ㅇ, mit 1-4 zähligen Quirlen, 申. Blhb. meist 0. Stb. 4-1. Cp. 4-1, jedes mit nur einer vom Scheitel oder der Seite des Faches herabhängenden Sa. Fr. steinfruchtartig oder häutig, mit je einem S. Hypokotyles Stämmchen des E. stark entwickelt. - Kr., untergetaucht oder schwimmend im süssen und salzigen 
2. Unterreihe Alismatineae. Bl. hypogynisch, ine ist heterochlamydeisch; Sa. an der Bauchnaht.

Fam. Alismataceaө. Bl. meist $\Varangle$, meist heterochlamydeisch, $申, 3$ gliedrig. K. 3, P. 3 , Stb. $6-\infty$, Cp. $6-\infty$, mit $1-\infty$ umgewendeten Sa.; Gr. $6-\infty$. Sumpfkraut mit grundst. Laubb. und meist reich verzweigtem Blütenschaft. - Schizogene Milchsaftgänge. - Ca. 50, calid., temp.

$\S$ Sagittarieae. Blütenaxe gewölbt. Stb. u. Cp. mehr als 6. Sagittaria (10): - Echinodoms ranunculoides (Europa, Nordafrika).

§ Alismeae. Blütenaxe flach. Blh. heterochlamydeisch. Stb. 6. Alisma (2). - Elisma.

$\S$ Wiesnerieae. Blütenaxe flach. Blh. homoiochlamydeisch. Reduciert? Wiesneria (Afr., As.).

3. Unterreihe Butomineae. Bl. hypogynisch oder epygynisch, meist heterochlamydeisch; Sa. an der Innenfläche der Cp.

Fam. Butomaceae. Bl. ㅎ, meist heterochlamydeisch, $\oplus, 3$ gliedrig. K. 3, P. 3, Stb. $6+3-\infty$, im letzteren Fall die äusseren steril; Cp. $6-\infty$, (oft am Grunde vereint) mit $\infty$ Sa. an der Innenfläche (Rückenlinie und Ränder ausgenommen). Balgfr. Blütenstand meist doldenähnlich, aus Schraubeln zusammengesetzt. - Sumpfkr. oder schwimmende Pflanzen. - 4 trop.-temp. - Butomus (1 temp. Eur., As.). - Hydrocleis nymphaeoides (trop. Am.).

Fam. Hydrocharitaceae. Bl. selten $\not$, meist $\sigma^{\top} \bigcirc$, meist heterochlamydeisch, $\oplus, 3$ gliedrig. K. 3, P. 3 , Stb. $3+(3+3+3+3)$, die inneren oder äusseren bisweilen Std., die äusseren selten dedoubliert. Cp. in den $\sigma^{\top} \mathrm{Bl}$. bisweilen 0 , sonst $(2-15)$; G. unterst. mit wandst. Plac. und $\infty$ geradläufigen bis umgewendeten Sa. mit 2 Integ. N. häufig tief 2 teilig. Fr. meist unregelmässig zerreissend, mit $\infty$ S. - Untergetauchte, häufig mit den B. hervorragende Wasserpflanzen im stissen und salzigen Wasser, mit (9), zuweilen quirligen oder 2 zeiligen Laubb. Bl. einzeln oder in Trugdolden, anfangs in eine aus $1-2$ Hochb. bestehende Hülle einschlossen.

a. Cp. 6-15. Placenten weit nach innen vorspringend.

Unterfam. Stratiotoideae. Laubb. (9). - Süsswasserbewohner.

$\S$ Ottelieae. Blüte $\sigma^{\pi}$ oder $\delta^{\pi}$. $q$. Blüte in 2lappiger Spatha. Sa. umgewendet, auf der ganzen Fläche der Placenten. Stamm ohne Ausläufer. - Boottia (9). - Ottelia (10), meist trop. Afr.

$\S$ Stratioteae. Bl. $\sigma^{\nearrow}$ ㅇ, 2 häusig. 우 Bl. in der. 2 blättrigen Spatha sitzend. Sa. umgewendet, nur am Grunde der 2 schenkligen Placenten. Stamm mit Ausläufern. Laubb. teilweise untergetaucht. - Stratiotes aloides (Mitteleur., Westsibirien). Von St. Websteri finden sich im Mitteltertiär häufig S. (Folliculites); desgl. in diluvialen Ablagerungen S. der jetzt lebenden Art.

$\S$ Hydrochariteae. Bl. $\sigma^{\top}$ ㅇ. ${ }^{\circ} \mathrm{Bl}$. in der Spatha gestielt. Placenten ungeteilt mit geradläufigen Sa. Stamm mit Ausläufern. Laubb. schwimmend. - Hydromystria stolonifera (trop. Amer.). - Hydrocharis morsus ranae (Eur., Vorderas.). 
Wasser, mit meist 2 zeiligen B., mit Achselschüppchen und Ligula. Bl. meist klein, einzeln oder in Ähren.

a. Bluten in Ähren.

$\S$ Potamogetoneae. Bl. $\Varangle$ in Ähren mit stielrunder Axe. - Potı"moyetom, I aichkraut (50 im süss- und Brackwasser der ganzen Erde). - Ruppia maritima (im Salz- und Brackwasser).

s. Posidonieae. Bl. ఫॄ und $\sigma^{\pi}$ 우 in zusammengesetzten Ähren, die Ihrchen in Achseln laubartiger B. Pollen fadenförmig. - Posidonia (1 im Mittelmeer, 1 an den australischen Küsten).

$\S$ Zostereae. Bl. $\sigma^{\nearrow}$ 으, in flacher dorsiventraler Ähre, welche zur Blütezeit in der Scheide des obersten Laubb. eingeschlossen ist. Pollen fadenförmig. - Zoster $\boldsymbol{a}$ (5 an Meeresküsten); Z. mu als Polstermaterial; Z. nana (heide in Nord- und Ostsee).

b. Bläten einzeln oder in Trugdolden, $\sigma^{\nearrow}$ ㅇ.

§ Cymodoceeae. Blh. 0. Cp. (2), Gr. kurz, N. lang, bandförmig. Pollen fadenförmig. Untergetauchte Bewohner meist wärmerer Meere. Cymodocea ( 7 ); C. nodosa im Mittelmeer.

$\S$ Zannichellieae. Blh. 0 oder kurz, becherförmig, selten getrenntblättrig. Cp. 4-3. - Zannichellia palustris im Süsswasser und Brackwasser. - Althenia (3 im Brackwasser).

Fam. Najadaceae. Bl. $\sigma^{\nearrow} \bigcirc \cdot \sigma^{\top}: 2$ becherförmige Hüllen und 1 endständige A. ㅇ. 1 becherförmige Hülle oder keine. Cp. 1 mit einer umgewendeten Sa. am Grunde. - Untergetauchte $\mathrm{Kr}$. mit centralem Bündel im Stengel und fast ïbereinander fallenden Paaren linealischer, gezähnter B. - Najas major (kosmopolitisch in Teichen); N. minor (Europa).

Fam. Aponogetonaceae. Bl. ㅎ. Blhb. 3-1, corollinisch. Stb. 6 in 2 Quirlen oder mehr in $3-4$ Quirlen. Cp. $3-6$, Gr. $3-6$. Fr. häutig, mit 2 oder $\infty$ S. - Kr. mit knolligem, sympodialem Stamm. B. untergetaucht oder mit schwimmender Spreite, Blütenstand über das Wasser tretend, von einer geschlossenen, dann abfallenden Scheide umhüllt, eine cylindrische Ähre bildend oder von Grund aus in $2-3$ Schenkel geteilt. - Aponogeton (20 Afrika bis Australien); A. fenestralis (Madagaskar) mit Gitterb.; $A$. distachyus (Südafrika) mit Schwimmb.

Fam. Juncaginaceae, Bl. $\Varangle$ oder $\sigma^{7}$ ㅇ, $4-1$ gliederig, mit homoiochlamydeischer, hochblattartiger Blh. oder nackt. Cp. mit $1-2$ umgewendeten Sa. - Sumpfpflanzen mit schmalen Laubb. und endständigem, traubigem oder ährigem Blütenstand.

$\S$ Triglochineae. Bl. $3-4$ gliedrig, $申$. Blhb. $3+3$ oder $2+2$; Stb. $3+3$ oder $2+2$; Cp. $3+3$ oder $4+4$, die äusseren oder inneren oft steril. Sämtliche Bl. eines Blütenstandes gleichartig. - Triglochin (9). - Scheruchzeria $(1 *)$.

§ Llacene. Blüte nackt, am Grunde des ährigen Blütenstandes einige $ᄋ$ Blüten mit $1 \mathrm{Cp}$. und langem $\mathrm{Gr}$., dann nach langen Zwischenräumen $\infty \not ⿱ 乛 ⿻)$ mit $1 \mathrm{Cp}$. und $1 \mathrm{Stb}$, hieran anschliessend zuletzt einige $\sigma^{7}$ mit $1 \mathrm{Stb},-$ Lilaea subulata von Kalifornien bis Chile. 
Unterfam. Thalassioideae. Laubblätter 2zeilig. Blüte $\delta^{7} ㅇ$, diöcisch. Placenten 2schenkelig, nur am Winkel zwischen Aussenwand und Placenta die um. gewendeten Sa. - Meeresbewohner. - Enalus acoroides an den Küsten des indischen und stillen Ocean. - Thalassia (2 ind. Ocean und Antillenmeer).

b. Cp. 3, selten 2, 4, 5. Placenten wenig vorspringend, ungeteilt.

Unterfam. Vullisnerioideae. Blh. heterochlamydeisch. Pollen kugelf. N. kurz. - Süsswasserbewohner.

§ Blyxeae. Blätter (Q). Blüte $\Varangle \sigma^{7}$ ․ St. $3+(3+3) . \sigma^{\top} \mathrm{Bl}$. bis 10 in einer langen Spatha. Sa. umgewendet. - Blyxa (1 Afr., As.).

$\S$ Vallisnerieae. Bl. (9). Bl. $\sigma^{7}$ O , diöc., $\sigma^{\nearrow} \mathrm{Bl} . \infty$ in einer Spatha, sich loslösend und geöffnet an der Oberfläche des Wassers schwimmend. Sa. geradläufig. - Vallisneria (2); V. spiralis (calid., oberital. Seen). - I.agarosiploon (9 Afr.).

$\S$ Hydrilleae. B. in Quirlen, 1 nervig. Bl. $\sigma^{\top}$ 우 oder ㅎ․ $\sigma^{\nearrow} \mathrm{Bl}$. zu $1-3$ in einer Spatha. St. $3+(3+3)$. Sa. geradläufig. - Hydrill verticillata, Grundnessel (Osteur., Sudan, Ostas., Austral.), in Ostindien bei der Zuckersiederei benutzt. - Helodea (Elodea) (5 Am.); H. canadensis, Wasserpest; die o Pfl. in Eur. eingebürgert.

Unterfam. Halophiloideae. Blh. homoiochlamydeisch, einfach. Bl. $\delta^{\nearrow}$ ㅇ. Pollen fadenförmig, N. sehr lang. - Meeresbewohner. - Halophila (5 ind. Ocean).

\section{Reihe TRIURIDALES. Charakter der Familie.}

Fam. Triuridaceae. Blüte $\not \Varangle \sigma^{7} \circ$ ㅇ homoiochlamydeisch. Blhb. 3, 4, 5, 6, 8, corollinisch, klappig. $\delta^{7}: 3,4,6$ Stb. am Grunde der convexen Blütenaxe; Cp. verkümmert oder 0 . $\bigcirc: 2$ Std., $\infty \mathrm{Cp}$. mit je 1 grundst. Sa. mit nur 1 Integ.; $\infty$ Gr.; Fr. mit dickem Pericarp. - Kleine, gelbliche oder rötliche Saprophyten mit Niederb. und kleinen, langgestielten Blüten. - Etwa 10 trop. - Sciaphila (trop. Amer., As.). - Triuris (trop. Amer.).

$\gamma$ ) Nacktblüher vorherrschend. Die Zahl der Stb. nur noch selten unbestimmt.

4. Reihe GLUMIFLORAE. Bl. nackt, seltener mit trichomatischer Blh., ganz selten mit echten Blhb. (Cyperacee Oreobolus), von Hochb. (Spelzen) bedeckt. G. stets einfächerig mit 1 Sa.

Fam. Gramineae. Bl. ఫ్థ, selten $\sigma^{\gamma}$ 우, nackt. Stb. meist 3 , selten $1,2,6-\infty ; \mathrm{Cp}$. mit einer schwach campylotropen, die Mikropyle nach unten kehrenden Sa.; N. 2, 3 oder 1. Caryopsis mit reichlichem Nährgewebe, dessen Vorderseite und Basis der nur vom Pericarp bedeckte E. aussen anliegt, selten Nuss oder Beere. E. mit schildförmiger Erweiterung des Kotyledons (Scutellum), in dessen vorderer Höhlung das Knöspchen und das von einem Hüllgewebe (Coleorrhiza) umgebene Würzelchen liegen. - Meist $\mathrm{Kr}$.. selten $\hbar$ mit knotig gegliederten Stengeln (Halmen) und abwechselnden scheidigen B. mit Ligula. Die kleinen Bl. in der Achsel von Hochb. (Deckspelzen), mit einem der Decksp. gegenüberstehenden meist 2 kieligen Vorb., meist auch noch mit einem über dem Deckb. stehenden, meist bis zum Grunde zweispaltigen, sehr kleinen saftreichen zweiten Vorb. (vordere Schüppchen, Lodiculae), selten auch noch mit einem über dem 2 kieligen Vorb. stehenden dritten ungeteilten Vorb. (hinteres 
Schüppchen) oder mit mehr Vorb. Die Ährchen oder Einzelbl. meist am Grunde mit leeren spelzenartigen Hüllb. in rispen- oder ährenförmigen Blütenständen. - Etwa 3500.

A. Ährchen 1blatig ohne Axenverlängerung über die Blüte hin. aus, selten 2blïtig und dann die untere Blüte unvollkommen, bei ler Reife als Ganzes vom Stiele oder samt gewissen Gliedern der Ïhrenspindel abfallend.

a. Nabel punktförmig. Ährchen vom Rỉcken her zusammenge. drickt oder stielrundlich.

\$ Maydeae. Deckspelze und Vorsp. (kann auch fehlen) zarthäutig, Hüllspelzen derb, die unterste alle anderen umschliessend. Ährchen meist in Trauben oder Ähren, die sich bei der Reife gliedern. $\sigma^{7}$ und 우 Ähr. chen in getrennten Blütenständen oder in getrennten Partieen desselben Blütenstandes. - Euchlaena mexicana, Teosinte (Mexiko), Futterpfl. - Zea mays, Mais (wildwachsend in Mexiko). - Coix lacryma (verbr. in den Tropen).

$\S$ Andropogoneaø. Wie die vorigen; aber Ährchen $\not{q}$ oder $\sigma$ und $\Varangle$ in demselben Blütenstand so gemischt, dass ein $\sigma^{\pi}$ neben einem $\Varangle$ steht. - Andropogon arundinaceus (calid.), Stammpfl. der in Afrika und dem Mittelmeergebiet in $\infty$ Varietäten cult. Getreidepfl. Durrha; die steifen Rispen einer Varietät liefern Material zu den sogen. Reisbesen; A. ischaemon (Mitteleuropa, Asien). - Sacchamum officinarum, Zuckerrohr (trop. Asien), lief. Rohrzucker.

\$Zoysieae. Decksp. u. Vorsp. häutig; die erste Hüllsp. grösser als die folgenden. Ährchen einzeln oder in Gruppen von einer ungegliederten Ährenspindel sich loslösend. - Tragus racemosus (Südeuropa).

§ Tristegineae. Wie vorige, aber die erste Hüllsp, kleiner und schmaler als Jie folgenden. Ährchen einzeln von den Zweigen einer Rispe, sich ablösend. Arundinella (trop.).

§ Paniceae. Decksp. und Vorsp. meist härter als die Hüllsp.; die erste Hüllsp. meist kleiner als die zweite. Ährchen einzeln von den Zweiglein einer Rispe oder ungegliederten Ährenspindel sich loslösend. - Paspalum (calid., in Amer. auch temp.). - Panicum sanguinale und $P$. Crus galli Unkräuter; P. miliaceum, Hirse (Ostind.), Cerealie; $P$. ultissimum, Guineagras (trop. Afr,), Futterpflanze. - Setcria italica, Kolbenhirse, in Asien und Agypten Cerealie (auch in Pfahlbauten der Steinzeit); S. viridis, S. gluuca, Unkräuter. - Pennisetum spicatum, Negerhirse (Afr.), Cerealie; andere Arten Ziergräser. - Spinifex hirsutus (Australien), Dünen befestigend.

b. Nabel lineal, Ährchen von der Seite zusammengedrückt.

§ Oryzeae. Häufig 6 Stb., aber auch weniger bis 1. - Ziaania aquatica, Tuscarora-Reis, Wasserreis (Nordam., nordöstl. Asien), Nahrungsmittel der Indianer, auch in Fischteichen gepflanzt. - Oryะa sativa, Reis, von Ostindien aus seit 2800 v. Chr. als Cerealie in Cultur. Leersia oryzoides (nördl. temp.). - Lygeum spartum, Esparto (Steppen des Mittelmeergebietes).

B. Ährchen 1- bis vielblutig; die 1blatigen oft mit Axenfortsatz ib)er der Blute, ihre Spindel meist oberhalb der Hillspelze geglie. 
dert, so dass diese beim Ausfallen der anderen Spelzen stehen bleibt; wenn 2- bis vielblütig, dann immer mit deutlichen Internodieu zwischen den Blüten.

a. Halm krautig, ljăhrig. Blattspreite stiellos, ohne Gliederung in die Scheide verlaufend.

a) Ährchen auf deutlichen Stielen in Rispen, ährenförmigen Ris. pen oder Trauben.

$\S$ Phalarideae. Ährchen einblütig, mit 4 Hüllsp. und einnerviger Vorsp. - Phalaris canariensis, Kanariengras (Südeuropa). - Anthoxanthum. - Hierochloë.

$\S$ Agrostideae. Ährchen einblütig, mit 2 Hüllsp. und 2 nerviger Vorsp. - Aristida und Stipa, Steppen- und Wüstengräser; St. tenacissima, Esparto Halfa; in Spanien, Algier, Marokko, Charakterpflanze der Steppen und wichtiger Handelsartikel für Papierfabrikation, Flechtwerk etc. - Milium. - Plleum pratense, Timotheus-Gras, und Alopecurus pratensis, Futtergräser. - Coleanthus subtilis, Beispiel für disjuncte Verbreitung in Europa, Amurland, Oregongebiet. - Phippsia algida, arktisch-circumpolar. - Sporobolus (40 subtrop., trop.). - Polypoyon. - Agrostis (100); A. alba, Fioringras. - Calamagrostis (130). - Ammophila arundinacea, Sandrohr, Dünen pflanze, bildet mit Calamagrostis epigeios einen Bastard (A. balticu). - Jagurus (medit.).

§ Aveneae. Ährchen 2- bis vielblütig. Decksp. meist kürzer als die Hüllsp., auf dem Rücken mit einer geknieten Granne, selten aus der Spitze begrannt oder wehrlos, dann immer mit 2 fast gegenst. Blüten ohne Ährchenfortsatz. - Holcus. - Aira. - Deschampsia. - Corynephorus. - Trisetum. - Avena (50 temp.); A. sativa, Hafer, cultiviert in Europa bis 69,5 . - Arrhenatherum. - Danthonia (100 calid., meist Afr., Austral.).

\& Festuceae. Wie vorige, aber Decksp. meist länger als die Hüllsp., unbegrannt oder aus der Spitze begrannt; Granne ohne Knie. - Sesleria. - Gynerium argenteum, Pampasgras (Südbrasilien und Argentinien). Ampelodesmos tenax, Esparto (Mediterrangebiet, besonders Algier), zu Flechtwerk. - Arundo donax, ital. Rohr (Mediterr.), zu Flechtwerk. - Phragmites communis, Schilf (trop., subtrop., temp.). Molinia. - Eragrostis (100); E. abyssinica, Cerealie aus Abyssinien. Koeleria. - Cutabrosa. - Melica. - Brian. - Dactylis. - Cynosurus cristatus, Kammgras (Eur.). - Poc (100); P. pratensis u. a. wichtige Futtergräser. - Glyceria fluitans, Futtergras, gut auf Sumpfwiesen wachsend. Fr. essbar (Schwaden, Manna). - Festucr (80); F. ovina, Schafschwingel, Weidegras auf Sandboden. - Bromus erectus und $B r$. inermis, Trespe, Weidegräser. - Brachypodium.

ß) Ährchen in 2 einander genäherten Reihen, eine einseitige $\ddot{A} h r e$ oder Traube mit ungegliederter Spindel bildend.

§ Chlorideae. Meist aussereuropäisch. - Spartina, Salzgräser. Cynodon Dactylon (subkosmopolitisch), wichtiges Weidegras in Nordamerika; off. das Rhizom. - Chloris (calid.). - Bouteloua (30) Prairiengräser Amerikas. - Eleusine coracana, Korakan, Dagussa, in Ostindien 
und Afrika wichtige Cerealie. - Buchloë dactyloides, Buffalogras der Prairien Nordamerikas.

r) Ährchen in 2 gegenüberstehenden Reihen.

\$ Hordeeae. - Nardus stricta einzige Art dieser Gruppe mit einseitswendiger Ähre. - Lolium perenne, englisches Raygras, und $L$. italicum, italienisches Raygras, Weidegräser; L. temulentum, Taumellolch, häufiges Unkraut auf Äckern, und $\boldsymbol{L}$. remotum, auf Leinfeldern, enthalten das narkotisch wirkende Loliin. - Agropyrum repens, Quecke, liefert das off. Rhizoma graminis. - Secale cereale, Roggen, von dem in Gebirgen Südeuropas und Vorderasiens vorkommenden S. montanum abstammend, in Eur. cult. bis $69^{1} / 2^{0}$, tritt als Culturpfl. erst zur Bronzezeit in Osteuropa auf. - Triticum (incl. Aegilops), T. monococcum, Einkorn (östl. Mediterrangebiet), cult. auf magerem Boden, schon seit der Steinzeit in Cultur (Pfahlbauten der Schweiz, Troja); T. sativum, Weizen, mit $\infty$ Varietäten und Rassen (spelta, Spelz; dicoccum, Emmer; tenax, zäher Weizen, die jetzt am häufigsten cultivierten Varietäten schon in ägyptischen Grabmonumenten, in Norwegen bis $69^{\circ}$ ); $T$. polonicum (Spanien). - Hordeum, Gerste; H. sativum, von dem in Vorderasien vorkommenden $H$. spontaneum abstammend, mit $\infty$ Varietäten (distichum, zweizeilige G.; kexasticluum, sechszeilige G.; vulgare, vierzeilige G.). - Elymus arenavius (nördl. temp.), wichtiges Strandgras.

b. Halm ganz oder ain Grunde holzig. Blattspreite oft mitkurzem Stielchen, zuletzt gliedartig von der Scheide sich loslösend.

§ Bambuseae. - 170 trop., subtrop., in Ostasien auch temp.; 150 in Asien. - Plyyllostachys (Ostasien) liefert das sogenannte Pfefferrohr. Amundinaria (24 Amer., As.). - Clusuruea (Amer.). - Bumbusa arunIinacea, B. balcooa, B. tulda in Vorderindien. - Dendrocalamus. Verwendung der grösseren Arten die ausgedehnteste in der Technik der asiatischen Völker; "Tabaschir" sind Kieselsäure-Concretionen in den Höhlungen der Internodien einiger Arten.

Fam. Cyperaceae. Bl. $\subsetneq$ oder $\sigma^{\top} \circ$, nackt oder selten mit homoiochlamydeischer Blh. Stb. meist 3-1, selten mehr; Cp. (3-2); Gr. 3-2 mit fadenförmigen N. G. mit einer grundst. umgewendeten Sa. Nuss, mit freiem S. E. vom Nährgewebe umschlossen. - Kr. mit meist scharf dreikantigen, selten knotig gegliederten Stengeln und schmalen B. mit geschlossenen Scheiden. Bl. in Ährchen oder ährchenartigen Blütenständen, welche zu ährigen kopfförmigen oder rispigen Blütenständen vereint sind. - 2200 calid. - frigid.

Unterfam. Scirpoideue. Bl. ఫ̧ oder nur einzelne Bl. im Ährchen $\sigma^{7}$ Q. Ährchen ohne Endbl.

Sypolytreae. Bl. mit Vorb. - 41 trop.

\$ Scirpeae. Bl. ohne Vorb.

* Cyperinae. Deckb. des Ährchens zweizeilig. - Cyperus (400 trop., subtrop., wenige temp.); C. papyrus, Papyrusstaude (trop. Afrika, Calabrien, Sicilien); das Mark des Stengels im Altertum zur Papierbereitung verwandt. - C. esculentus (südl. Mittelmeergebiet und trop. Afrika) 
liefert oel- und zuckerreiche Knollen (Erdmandeln, Bulbuli Trasi). Kyllingia.

* Scirpinae. Deckb. des Ährchens spiralig. - Eriophorum. Scirpus (200). - Heleocharis. - Fimbristylis (200 meist trop.).

Unterfam. Caricoideae. Bl. selten 후, meist $\sigma^{\nearrow}$ 우, meist monöcisch, die $\sigma$ und $ᄋ$ Bl. schliessen Axen ungleicher Ordnung ab und stehen in eingeschlechtlichen oder androgynen Scheinährchen.

§ Rhynchosporeae. Scheinährchen wenigblütig, zweigeschlechtlich. Verzweigung aus den letzten B. unterhalb der Endbl. Bl. ఫ̧ oder einzelne 万), Stb. 3-6. - Oreobolus (andin) mit Blh. - Schoenus (60). - Cladium (30). - Rhynchospora (150).

$\S$ Gahnieae. Wie vorige; aber die Endblïten stets $\sigma^{\nearrow}$, die seitlichen $\Varangle, \quad$ Stb. $3-20$. -70 ausschliesslich *.

$\S$ Bisboeckelerieae. Scheinährchen mehrblütig, zweigeschlechtlich; Terminal.

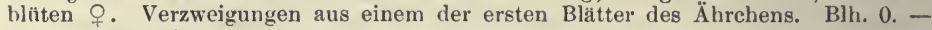
trop. - Mapani\%.

§ Sclerieae. Scheinährchen eingeschlechtlich, seltener androgyne gleichzeitig vorhanden, $q^{1} 1$ blütig, $\sigma^{7}$ mehr- bis vielblütig. Blüte stets eingeschlechtlich. Kein Vorblattutriculus. - Scleria (100 trop.).

$\S$ Cariceae. Scheinährchen zweiblütig, zweigeschlechtlich und dann in eine einfache Ähre angeordnet, oder zweigeschlechtlich, mit einer grundständigen $ᄋ \mathrm{Bl}$. und mehreren $\sigma^{\pi}$, oder durch Abort einblütig; im letzteren Falle die Scheinährchen blütenähnlich zu scheinbar einfachen Ähren vereint (so bei Carex). Blh. 0. 오 Bl. von einem Vorblattutriculus eingeschlossen. - Elyna scirpina (arktisch-alpin). - Kobresia caricina (arktisch-alpin). Uncinia (oceanisch). - Carex (500, meist temp.-frigid, aber auch calid.); von $C$. arencria (Eur.) stammt das off. Rhizoma Caricis.

b. Nacktblüigkeit selten; wenn solche auftritt, danu ist sie meistens secundär, durch Reduction zu erklären und steht in Yerbindung mit Entwicklung von Hochblattscheiden. Fixierung in der Zahl der Stb. und Cp. schon volherrscliend, aber auch mehrfach noch $\infty$ Stb. nnd mehr als $3 \mathrm{Cp}$.

5. Reihe PRINCIPES. Bl. meist cyklisch, homoiochlam., dreigliedrig, hypogynisch, $\phi$, selten schwach $\%$. Stb. meist 6 ; aber auch 3,9 und $\infty$. Cp. 3, meist jedes mit einer der Mitte gegenüberstehenden Sa. Monopodial stammbildend mit strahlig-oder fiederig-nervigen B. und in einfachen oder zusammengesetzten kolbigen Ähren stehenden Bl.

Fam. Palmae. Bl. meist durch Abort $\sigma^{7}$ ㅇ. Blh. hochblattartig oder halbpetaloid, selten $\%$, die äusseren B. oft kleiner als die inneren; Stb. 6 , selten 3 , häufiger $9-\infty$, frei der vereint. Cp. 3 , frei oder meist vereint, im letzteren Falle G. 3-1fächerig, bisweilen mit nur 1 Sa. Beeren oder Steinfr. Nährgewebe reichlich, horn- oder elfenbeinartig, bei den Steinfr. in die Steinschale mit seiner ganzen Oberfläche fest eingewachsen E. klein, seitlich liegend, bei der Keimung mit sich stark verlängerndem Kotyledon. - Stammbildend, oft baumartig; aber ohne ringförmiges Dickenwachstum, selten sich verzweigend, bisweilen mit gestreckten Internodien und kletternd, häufiger mit endstdg. Blattschopf, selten mit endstdg. Blütenstand, meist mit axillären, von Scheidenb. umschlossenen Blütenständen. Abschnitte der fiedrig- oder fächerförmig 
geschlitzten oder geteilten $B$. eingeschlagen $(V)$ oder zurückgeschlagen $(\Lambda)$. - ca. 1100 calid.

A. Blhb. $3+3$, in den $\bigcirc$ Blüten nach der Befruchtung auswachsend.

Unterfam. Coryphoideae. Cp. 3, frei oder locker vereint, jedes zu einer Beere sich entwickelnd. Abschnitte der Fieder-oder Fächerb. V .

§ Phoeniceae. Bl. $\sigma^{\pi}$ ㅇ diöcisch. Kolben von einer oberen Scheide vollständig umhüllt. B. fiederteilig. - Phoenix (11 trop. und subtr. Afr., Vorderind.); Ph. dactylifera, Dattelpalme, von den Canaren durch die Oasen der Sahara bis nach Südwestasien; fossile Arten im Miocän Mitteleuropas.

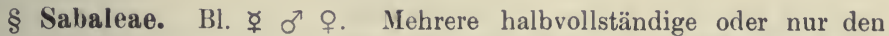
Kolbenstiel bekleidende Scheiden. B. fächerförmig. - Chamaerops humilis (westliches Mediterrangebiet); fossile Arten im Tertiär der Schweiz. - Trachycarpus excelsa (China). - Rhapis flabelliformis (Japan). - Acanthorrliza (trop. Am.). - Corypha, mit terminalem Blütenstand (6 ind.-malay.): liefert Sago und Flechtmaterial. - Livistona (12 ind.-malay.); I. chinensis (China); I. australis (Austral.). - Fritchardia (9 Fidschi-Ins., Sandwich-Inseln). - Wushingtonia (3 Südkalifornien). Sabal (7 Venezuela bis zum südl. atlantischen Nordam., Nordgrenze im Osten bei $36^{\circ}$ ); die nördlichste Art $S$. palmetto; fossile im Tertiär Mitteleuropas. - Copernicia (6 trop. Am.); C. cerifera, Carnaubapalme (Brasil.), liefert vegetabilisches Wachs.

Unterf. Borassoidecie. Cp. (3), jedes befruchtete einen eigenen einsamigen Steinkern ausbildend; S. mit rauher Oberfläche der Innenseite des Steinkernes angewachsen. Bl. von Deckb. umhïllt, die $\sigma^{7}, \mathrm{zu} 1-\infty$ wickelförmig in Gruben der Kolbenäste. B. fächerförmig V .

$\S$ Borasseae. Tropen der alten Welt excl. Australien. - Hyphcene (12 Afr.); $H$. thebaica, Do umpalme (Ïgypten). - Latania (3 Mascarenen). Borassus fabelliformis, Palmýrapalme in Indien, liefert Palm. wein, "Toddy " und Piassave-Fasern (Leitbündel der Blattscheiden), var. Aethiopum, Delebpalme in den Steppen des trop. Afr. Lodoicen Sechellamum (Seychellen) liefert die riesengrossen maldivischen Nüsse.

Unterfam. Lepidocaryoidene. Bl. ఫ્子 oder $\sigma^{7}$ ○. Cp. (3), sich zú einer einsamigen Panzerfrucht entwickelnd. Kolben einmal bis wiederholt zweizeilig verzweigt. $B$. fiederartig oder fächerförmig $\Lambda$.

§ Mauritieae. B. fächerförmig. Bl. diöcisch, dimorph. - Mauritia (9 trop. Am.), M. Alexuosa und M. vinifera, Moriche, gesellig, Wälder und Haine in Uberschwemmungsgebieten bildend, liefern Palmwein etc.

§ Metroxyleae. B. paarig-fiederteilig. Bl. polygamisch-zwitterig oder diklin.

* Raphiinae mit vollständig 3 fächerigem G. - trop. Afr., Madagaskar. - Raphia vinifera, Weinpalme (Westafr. und trop. Am. in den östlichen Küstengebieten); $R$. muffia (Ostafrika); die Blätter aller Arten liefern Raphia-Bast, ihre Scheiden Raphia-Piassave. 
* Calaminae mit unvollständig 3 fächerigem G. - Metroxylon (5 ind.-malay.). $M$. Rumphii und $M$. laeve, Sagopalmen, auf den SundaInseln und Molukken Wälder bildend. - Coelococcus (3 melanesisch und polynesisch); S. als vegetabil. Elfenbein verarbeitet. - Plectocomia (ind.-malay.). - Calamus, Rotangpalmen (200 ind.-malay., 1 trop. Afr.); C. rotang u. a. liefern spanisches Rohr und Stuhlrohr; $C$. draco liefert Drachenblut, geronnenen Saft des Fruchtfleisches.

Unterfam. Ceroxyloideae. Cp. (3), sich zu einer nicht gepanzerten Frucht entwickelnd, G. 3-1 fächerig. Bl. diklin, entweder diöcisch und am Kolben einzeln stehend oder monöcisch und dann in $2-\infty$ blütigen Knäueln mit einer 우 Bl. - B. fiederteilig.

$\S$ Areceae. Meist Beerenfr., die $3 \mathrm{Cp}$. bisweilen nach der Befruchtung sich trennend.

A. G. 3 fächerig mit $3 \mathrm{Sa}$.

* Caryotinae. Beeren 1-3 samig mit gipfelständigen Narbenresten. Blätter unpaarig gefiedert V. - Alle trop. As. - Arenga saccharifera, Sagwirepalme, lief. Palmwein, Palmzucker, Blattgemüse, Fasern etc. - Caryota.

* Geonominae. Beere mit grundst. Narbenresten. Blätter paarig gefiedert $\Lambda$. Blüten tief in Aushöhlungen des fleischig verdickten Kolbens. - Sehr zahlreich im trop. Am., 2 in Westafrika. Nutzen gering.

* Iriartinae. Beere mit gipfelständigen oder grundständigen Narbenresten; $\sigma^{7}$ Blïte schief, 우 Blüte mit dachigen oder sehr schmalen Blhb. - Alle trop. Am. - Iriartea - Ceroxylon andicola, Wachspalme (Anden), u. mehrere andere (Unter. gatt. Klopstockia) lief. reichlich Wachs an der Oberfläche des Stammes.

* Moreniiae. Wie vorige; aber Blütenh. . . ; O mit ganz oder abwärts klappiger Blh. Eine Gattung (Hyophorbe) auf den Maskarenen, die anderen im trop. Am. - Chamaedorea (6, meist centralam.).

* Arecinae. Beere oder Steinfr. einsamig, mit dünnem Endocarp. G. 1 fächerig mit $1 \mathrm{Sa}$. - 44 Gatt. trop., aber nicht im continentalen Afr. - Oreodoxa regia, Palma real der Antillen; O. oleracea, Kohlpalme (Antillen $50 \mathrm{~m}$ hoch). - Euterpe (10 trop. Am.) lief. Gemüse und Palm. wein. - Oenocarpus (trop. Südam.) lief. Öl in ilıren Beeren. - Kentia (10 Molukken bis Neu-Seeland und Chatham-Inseln). - Ptychosperma (13 ind.-malay.); Pt. elegans. - Areca (14 ind.-malay.); A. catechu, Bet elnusspalme (Sunda-Inseln).

$\S$ Cocoeae. Steinfrucht mit meist einsamigem, selten $2-3$ samigem Steinkern, mit soviel Keimlöchern, als S. vorhanden. S. dem Endocarp anhängend.

* Elaeidinae. Bl. in tiefen Gruben der Kolbenäste. Keimlöcher des Steinkernes dem Scheitel genähert. - Elaeis guineensis, Ölpalme (trop. Westafrika und Ostküste von Südamerika), liefert in ihrer Frucht den wichtigsten Handelsartikel Westafrikas, Palmöl.

* Attaleinae. Bl. auf der Oberfläche der Äste in flachen Gruben oder auf vorspringenden Zähnen. Keimlöcher am Grunde des Steinkerns unter Fasern verborgen. - Attalea (24 trop. Amer.); A. fienifer'a (Brasil.), liefert Piassave- oder Piaçava-Fasern; $A$. cohune (Honduras), liefert harte Steinkerne zu Drechselmaterial. - Cocos (30 Südam.), C. nuciferr, Cocosnuss, verbreitet an allen trop. Küsten, namentlich auch auf Koralleninseln; Endosperm als Cocosmilch genossen oder als Copra zur 
Olgewinnung in den Handel gebracht. - Jubaea spectabilis (Chile 31 $\left.-35^{\circ}\right)$.

* Bactridinae. Wie vorige; aber die Keimlöcher des Steinkernes über der Mitte oder nahe am Scheitel. - Alle im trop. Am. - Astrocaryum (29). - Bactris (90).

B. Blh. der $\sigma^{T}$ oder $ㅇ$ Bl. rudimentär. Fr. in dichtgedrängten Kopfständen.

Unterfam. Pliytelephantoidecte. $\sigma^{\top} \mathrm{Bl}$. mit $\infty$ freien Stb. 우 Bl. mit Blh. S. von dünnem, hartem Endocarp umschlossen, mit elfenbeinartigem Nährgewebe. - Phytelephas macrocarpa und Ph. microcarpa (trop. Amer. $8-9^{0}$ s. Br., $70-79^{\circ}$ westl. L.) liefern den wichtigen Handelsartikel: vegetabilisches Elfenbein.

Unterfam. Nipoidece. $\sigma^{7} \mathrm{Bl}$. mit 3 zu einer gemeinsamen Säule verwachsenen Stb. ㅇ Bl. nackt. S. von dickem holzigem Endocarp umschlossen. - Nipa fruticans, vorzugsweise littoral auf Salzboden im ind.malay. Gebiet.

6. Reihe SYNANTHAE. Bl. stets $\sigma^{7}$ 우 $\sigma^{7}$ nackt oder mit dicker, kurz gezähnter Blh. und $6-\infty$ Stb. \& nackt oder mit 4 fleischigen schuppenförmigen B., vor deren jedem ein langes fadenförmiges Std. steht. Cp. (2 oder 4 ) mit 2 oder 4 Placenten, an welchen ringsum $\infty$ Sa. stehen; die G. in die Kolbenaxe eingesenkt und unter einander vereint. - Oft palmenähnliche Gewächse.

Fam. Cyclanthaceae. $\sigma^{7}$ und ${ }^{\circ} \mathrm{Bl}$. in regelmässig abwechselnder Verteilung die ganze Oberfläche eines saftigen unverzweigten Kolbens bedeckend. Sammelbeere, mit $\infty \mathrm{S}$. in den einzelnen Beeren. E. klein, am Grunde des hornig-öligen Nährgewebes. - Grosse $\mathrm{Kr}$. oder Lianen oder mit kurzem holzigem Stamm. B. gefaltet, vielnervig, oft palmblattartig. Kolben von $2-6$ später abfallenden Scheiden umhüllt. - 44 trop. Amer.

§ Carludoviceae. $\delta^{7} \mathrm{Bl}$. in Gruppen zu 4, einzeln gestielt. $ᄋ$ mit 4 selır langen fadenförmigen Std. Blh. rudimentär. - Carludovica (34); C. palmata lief. in ihren jungen noch zusamınengefalteten Blättern das Material zur Herstellung der echten Panamahüte.

$\S$ Cyclantheae. $\sigma^{\top} \mathrm{u}$. ㅇ Bl. in abwechselnden Ringen oder Spiralen. Die Std. kürzer als die Blh. B. zweiteilig. - Cyclanthus.

7. Reihe SPATHIFLORAE. Bl. cyclisch, haplochlam. oder diplochlam., homoiochlam. oder nackt, 3-2 gliedrig, 후 oder $\sigma^{7}$ 우, oft sehr reduciert, schliesslich auf $1 \mathrm{Stb}$. oder $1 \mathrm{Cp}$., stets in einfacher von einem Hochb. (Spatha) 士 umschlossener Ähre (Kolben) ohne Tragb. - Meist sympodial, selten einen aufrechten Stamm bildend.

Fam. Araceae. Bl. $ॄ$ oder $\sigma^{7} \uparrow, 2-3$ gliedrig oder reduciert, bisweilen auf $1 \mathrm{Stb}$. oder $1 \mathrm{Cp}$. Beere, selten saftlose Frucht. S. mit 2 Integ., von denen das äussere fleischig. - Kr., häufig mit knolligem Rhizom, auch strauch- und baumartig oder Lianen. Bl. meist monöcisch, selten diöcisch, meist viele, selten nur $2-3$ in einer Ähre oder einem Kolben. B. von grösster Mannigfaltigkeit. 
Unterfam. Pothoideae. Landpflanzen. Stengel, Blattstiele und Wurzeln ohne Milchsaftschläuche und ohne Spicularzellen. B. zweireihig und (9). Seitennerven II. und III. Grades netzförmig verbunden, șehr selten fast parallel. - Bl. meist $\not{+}$.

a. Bläter in Stiel und Spreite gegliedert. Sa. umgewendet.

$\S$ Pothoëae. S. ohne Nährgewebe. Bl. ఫ̧, mit Blh. oder nackt. - Meist kletternde Sträucher oder Halbsträucher. - Pothos (40 ind.-malay. uud Madagaskar). - Heteropsis (trop. Brasil.).

§ Anthurieae. S. mit Nährgewebe. Blüte $\Varangle$, mit Blh. - Meist Kr , selten strauchartig. Fortsetzungssprosse der Sympodien fast immer mit zwei Niederb., einem gestielten Laubb, und einem Blütenstand. Beisprosse. - Anthurium (308 trop. Am.).

§ Culcasieae. S. mit Nährgewebe. Blüte $\sigma^{\nearrow}$ ㅇ, ohne Blh. - Kletternde Str. mit (Q) Blättern. - Culcasia (trop. Afr.).

\$ Zamioculeaseae. Blïte $\delta$, $\$$, aber mit Rudimenten des anderen Geschlechtes. - Knollengewächse mit gefiederten oder dreifach gefiederten Laubblättern. Blühende Sprosse mit mehreren Niederb. und einem Laubb. - Abgefallene Fiedern zur ungeschlechtlichen Fortpflanzung dienend. - Zamioculcas (Bourbon, Sausibar). Gonatopus (Sansibar).

b. Blätter nicht gegliedert. Sa. geradläufig.

$\S$ Acoreae. Blh. vorhanden. Cp. $(3-2)$; G. drei- bis zweifächerig, mit je 2 oder mehr Sa., selten einfächerig, mit 1 Sa. - Acorus (2 nördl. temp.); A. calamus, Kalmus; off. Rhizoma Calami mit Öl. zellen.

Unterfam. Monsteroidece. Landpflanzen. Fibrovasalstränge ohne Milchsaftschläuche; aber das Grundgewebe, wenigstens der Stengel und B., manchmal auch das der Wurzeln, mit Spicularzellen. Seitennerven III. und IV. Grades oder II., III. und IV. Grades netzförmig verbunden. Bl. ఫ̧, meist nackt. Sa. umgewendet oder amphitrop.

§ Monstereae. Bl. ohne Blh., zweigliedrig. Spatha vor der Reife des Kolbens abfallend. - Meist kletternd, mit adventiven Haft- und Nährwurzeln. Grundgewebe der Stengel und B. reichlich mit Spicularzellen durchsetzt. Häufig durchlöcherte B. - Rhaphidophora (20-30 ind. malay.). - Monstera (15 trop. Am.); M. deliciosa (fälschlich Philodendron pertusum, am Westabhang der mexikanischen Cordilleren), Fruchtstände wie Ananas schmeckend, als Zimmerpflanze viel cultiviert. - Epipremnum mirabile, Tongapfl. (malay.). - Scindapsus (ind.-malay.).

§ Spathiphylleae. Bl. mit Blh., 3-2gliedrig. Spatha nicht abfallend. Halbstr. Grundgewebe der Stengel und Blattstiele sparsam von Spicularzellen durchsetzt. - Spathiphyllum (15 trop. Am., 1 Philippinen und Celebes).

Unterfam. Calloideae. Land-oder Sumpfpflanzen. Fibrovasalstränge mit geraden Milchsaftschläuchen. Bl. meist ఫ̧; B. nie pfeilförmig, meist netznervig, selten parallelnervig. - Alle nördlich temp.

$\S$ Symplocarpeae. Blh. +. Nährgewebe 0. Seitennerven II. und III. Grades netzförmig verbunden. - Symplocarpus foetidus (nordöstl. Asien und nordwestl. Am.). - Orontium aquaticum (atlant. Nordam.), mit langscheidiger Spatha.

$\S$ Callear. Blh. 0. Nährgewebe †. Seitennerven I., II. und III. Grades parallel. - Calla palustris (in Waldsümpfen Europas, Sibiriens und des atlantischen Nordamer.). 
Unterfam. Lrisioidece. Land- und Sumpfpflanzen. Fibrovasalstränge der Blattstiele und Stengel mit geraden Milchsaftschläuchen. Bl. ̧ oder $\sigma^{7}$ ㅇ․ Sa. umgewendet. Nährgewebe meist 0. - B. im Umriss pfeilförmig, oft vielfach geteilt, netznervig.

$\S$ Lasieae. Stamm oberirdisch oder unterirdisch, niemals gerade aufrecht. B. stets deutlich netznervig. Bl. ̧ mit Blh. Sträucher, Stauden und Knollenpflanzen, letztere ohne Nährgewebe im S. - Tasia (ind.-malay.). - Dracontium (6 trop. Amer.) mit einem riesengrossen tief dreiteiligen und vielfach verzweigten $B$.

§ Imorphophalleae. Wie vorige; aher Bl. meist $\sigma^{7}$ ㅇ, ohne Blh. Häufig Kolbenanhang mit rudimentären Blütenanlagen. Nährgewebe 0 . - Knollenpfl. vom Habitus des Iracontium. - Anchomanes (trop. Afr.). - Amorphophallus (15 ind.-malay.); A. cumpanulatus. - Hydrosme (20 trop. Afr. und As.); H. Rivieri (Cochinchina). - Knollen aller dieser stärkereich, gekocht und geröstet genossen.

$\S$ Nephitliytideae. $\delta^{7} 0^{\circ}$ ohne Blh. Nährgewebe 0. - Stauden- oder Kletterpflanzen mit pfeilförmigen Blättern. Blütenstand ohne Anhang. - Trop. Afr.

$\S$ Montrichardieae. $\delta^{T} q$ ohne Blh. - Baumartige Pflanzen mit geradem, starkem Sympodium und grossen pfeilförmigen Blättern; Seitennerven II. Grades zwischen denen I. Grades schief verlaufend und mit denen III. und IV. Grades netzförmig verbunden. - Montrichardia (trop. Am.).

Unterfam. Fhilodendroideae. Land- oder Sumpfpfl. Fibrovasalstränge mit geraden Milchsaftschläuchen. $\mathrm{Bl} . \sigma^{\nwarrow}$ 을, nackt. Nährgewebe meist + . B. fast stets mit parallelen Seitennerven.

s Philodendreae. Strauchig oder kletternd. Stamm \pm oberirdisch. Stb. der $\sigma^{7} \mathrm{Bl}$. frei. Sa. gerade oder umgewendet an langem Funiculus. Nährgewebe +. - Homalomena, Schismatoglottis u. a. (ind.-malay.). Philodendron (170 trop. Am.); bei den meisten Arten der Forsetzungs. spross nur nit 1 Niederb., 1 Laubb. und dem Blütenstand.

$\$$ Anubiadeae. Kriechend. Stb. der $\delta$ Bl. vereint, sonst wie vorige. - Trop. Afr.

$\S$ Aglaonemeae. Stamm aufrecht, oberirdisch. Sth. zu einem Synandrium vereint. Sa. umgewendet, an kurzem Funiculus. Nährgewebe 0 . - Aglaonema (ind.-malay.). - Dieffenbrchia (18 trop. Amer.).

$\S$ Peltandreae. Stamm unterirdisch. Die vereinigten Std, der ㅇ Bl. eine Hülle um das G. bildend. Sa. geradläufig oder fast geradläufig. - Peltundra (2 Nordam.).

Santedeschieae. Wie vorige; aber die Std. getrennt und die Sa. ungewendet an kurzem Funiculus. - Zantedeschia rethiopica (Südafr.), Zimmerpflanze.

Unterfam. Colocasivideae. Land- oder Sumpfpfl. Fibrovasalstränge mit verzweigten Milchsaftschläuchen, selten mit geraden Milchröhren. Bl. $\sigma^{7}$, , ohne Blh.; die Stb. zu Synandrien vereint. Nährgewebe + oder 0 . B. netznervig, die Seitennerven II. Grades einen zwischen den Seitennerven I. Grades verlaufenden Collectivnerven bildend.

$\S$ Colocasieae. Synandrien frei. Nährgewebe + . Sympodium oberirdisch, gerade, oder unterirdisch. - Steudnera (Ostind.). - Alocasia (incl.-malay.); A. macrorrhiza. - Colocasia antiruorum, Eddoas Kalo, Taro (ind.-malay.). - Culudium (trop. Amer.). - Xanthosomen (20 trop. Aner.); $\boldsymbol{X}$. sagittifolium, $\boldsymbol{X}$. violaceum (Westind.). - Alle ge- 
nannten Arten in den Tropen als Gemüsepflanzen cultiviert, die Stämme werden gekocht genossen.

\& Syngonieae. Wie vorige; aber Năhrgewebe 0 und die Sympodien kletternd. - Syngonium (trop. Am).

\& Ariopsideae. Synandrien unter einander vereinigt. Nährgewebe +. - Sympodium unterirdisch, knollig. - Ariopsis (Ostind.).

Unterfam. Aroideae. Land- oder Sumpfpfl. Fibrovasalstränge mit geraden Milchsaftschläuchen. Bl. $\sigma^{x}$ 을 sehr selten mit Blh. Stb. frei oder vereint. Sa. geradläufig oder umgewendet. Nährgewebe +. - Meist Knollengewächse mit netznervigen $\mathrm{B}$.

\$ Stylochitoneae. Bl. mit Blh. Stb. fadenförmig. - Stylochiton (3 Afr.); St. hypogaeus, mit uuterirdischem Blütenstand

8 Staurostigmateae. Bl. selten $\not{q}$, meist $\sigma^{\lambda}+$ mit Rudimenten des andern Geschlechtes. G. meist mehrfächerig, mit 2-1 Sa. in den Fächern. - Knollenpflanzen mit pfeilförmigen oder dreiteiligen Blättern mit fiederspaltigen Abschnitten. - Meist trop. Am. - Taccurum - Staurostigma. - Spathicarpa, Blätenstand vollständig mit der Spatha vereint.

§ Zomicarpeae. Blüte $\sigma^{7}$ 으, ohne Rudimente des andern Geschlechtes. G. aus mehreren $\mathrm{Cp}$. gebildet, einfächerig, mit mehreren umgewendeten Sa. im Centrum. - Meist trop. Am.

$\S$ Areae. Wie vorige; aber G. aus einem Cp. gebildet, einfächerig, mit geradläufigen Sa. - Knollenpfl. oder Wasserpfl.; Blütenstand meist mit Anhang, der von rudimentären Blütenanlagen überzogen ist. - Arum (15 Mediterrangebiet, Mitteleuropa). - Dracunculus vulgaris (medit.). - Helicodiceros muscivor us (Corsica, Sardinien). - Sauromatum (trop. Afr., Himalaya). - Biarum (medit.). - Arisamum vulgare (medit.). - Arisaema (50 trop., subtrop., excl. Südam. u. Austral.), dịöcisch. - Finellia tuberifera (Japan). - Ambrosinia Bassii (Sicilien, Algier). - Lagenandra toxicaria (Ceylon). - Cryptocoryne (20 ind.-malay., Wasserpflanzen). - Alle aufgef ührten Gattungen sehr interessant durch die mannigfache Entwickelung des Kolbenanhanges.

Unterfam. Pistioideae. Schwimmende Wasserptl. Fibrovasalstränge ohne Milchsaftschläuche. $\sigma^{7} \mathrm{Bl}$. mit $2 \mathrm{zu}$ einem Synandrium vereinigten Stb., in einem einzigen Quirl. o Bl. nur 1 mit $\infty$ geradläufigen Sa. Blühende Sprosse mit 1 Niederb., 1 Laubb. und kleinem Blütenstand. Beisprosse in Stolonen auswachsend. - Pistia stratiotes (verbreitet in den Tropen); fossile Arten im Tertiär Nordamerikas und der Kreide Südfrankreichs.

Fam. Lemnaceae. Bl. $\sigma^{\lambda} \uparrow$, nackt, einhäusig. $\sigma^{7}: 1 \mathrm{Stb} .9: 1 \mathrm{Cp}$. mit 1-6 grundst., aufrechten, geradläufigen oder umgewendeten Sa. S. mit dicker, fleischiger, äusserer Hülle und zarter innerer Hülle, mit dünnem Nährgewebe. - Frei schwimmende Wasserpfl. mit mehr oder weniger unterbleibender Ausgliederung der B. Sprosse vom Mutterspross am Grunde umwachsen, mit demselben Sprossverbände bildend oder später von demselben lösgelöst. - Beisprosse neben den gewöhnlichen Fortsetzungssprossen; Luftsprosse, Wassersprosse und Wintersprosse.

Unterfam. Lemnoideae. Sprosse mit Wurzeln. Blütenstand mit Spatha und $2 \sigma^{7} \mathrm{Bl}$. Muttersprosse aus 2 seitlichen, nach rückwärts ge- 
richteten Taschen je einen Tochterspross entwickelnd. - Spirodela polyrrhiza (calid. - temp.). - ILemna.

Unterfam. Wolffioidecie. Sprosse ohue Wurzeln. Blütenstand ohne Spatha und mit nur $1 \delta^{7} \mathrm{Bl}$. Muttersprosse aus einer nach rückwärts gerichteten Grube einen Tochterspross entwickelnd. - Wolffia.

B. Reihen mit typlsch pentacyklischen Bl. Quirle typisch gleichzählig, meist 3 gliedrig, seltener melir- oder 2 gliedrig.

a. Die Bl. sind homoiochlamydeisch bis heterochlamydeisch, änsserst selten nackt. Hochblattartige Ausbildung der Blh. kommt noch vor. Hypogynie und Aktinomorpitie vorherrschend.

8. Reihe FARINOSAE. Bl. cyklisch, homoiochlam. oder heterochlam., 3- oder 2 gliedrig, nach dem Typus T. $3+$ T. 3 , Stb. 3 + Stb. 3, Cp. (3). Ein Kreis Stb. bisweilen ausfallend oder Verkümmerung der Stb. bis auf 1 . Sa. häufig geradläufig, aber auch umgewendet. S. mit mehligem Nährgewebe. - Meist Kr., selten mit kräftigem Stamm.

1. Unterreihe Flagellariineae. Blh. homoiochlamydeisch und bracteoid, hypogyn. Sa. umgewendet.

Fam. Flagellariaceae. Bl. homoiochlam., 3 gliedrig, $̧$ oder $\sigma^{7}$ 우, $\oplus$. Blh. hochblattartig. Cp. (3); N. 3; G. 3 fächerig, jedes Fach mit einer centralwinkelst. umgewendeten Sa. Fr. 3 fächerig oder mit $3-1$ Steinkernen. E. linsenförmig, dem Nährgewebe nahe am Nabel anliegend. - Bisweilen kletternde Pfl. mit langen vielnervigen B. Bl. klein, $\infty$ in vielfach zusammengesetzter endstg. Rispe. - 7 trop. Afr., As, Austral. - Flagellaria indica, mit rankenden Blattspitzen, an den Küsten des trop. Afr. und As.

2. Unterreihe Enantioblastae. Blh. verschieden, hypogyn. Sa. geradläufig.

Fam. Restionaceae. Bl. homoiochlam., 3-2 gliedrig, selten §̧, meist б ㅇ, zweihäusig, $\oplus$. Blh. hochblattartig. Stb. nur 3 oder 2 vor den inneren Blhb. Cp. $(3-1)$; Gr. 3-1, fadenförmig. G. 3-1 fächerig, in jedem Fach mit einer geraden, von oben herabhängenden Sa. Kapsel oder Nuss. E. linsenförmig, mit abgestutatem Cotyledon, dem Nährgewebe anliegend. - Meist $4 \mathrm{Kr}$. mit kriechendem Grundstock, 2 zeilig stehenden Niederb. ain Grunde und abfallenden Schuppenb. am Stengel. Bl. in den Achseln von Hochb., in endständigen oder zu Rispen vereinten Ährchen. Xerophyten und Sumpfpflanzen. - Über 200 ", temp., subtrop.; nur wenige trop.

\$ Diplanthereae. A. dithecisch. -8 in Sudwestaustralien.

\$ Haplanthereae. A. monothecisch. - Restio (100 Austral., Südafr.). Blütenstände zu Trockenbouquets.

Fam. Centrolepidaceae. Bl. ̧ㅜ oder $\delta^{\top} \circ$, von 1-3 haarförmigen Hochb. umgeben oder nackt. Stb, $1-2$. Cp. $(1-\infty)$ (ob wirklich zu einer Blüte gehörig?), mit je einem fădigen Gr. und einer geradlăufigen hängenden Sa. E. wie bei vorigen. - Sehr kleine $\mathrm{Kr}$. mit borstenförmigen B. Blütenstand eine 2 reihige Ähre mit einzeln stehenden Bl. oder nackten wickeligen secundären Blïtenständen in den Achseln der Hochb., oder ein kleines Köpfehen, in welchem zahılreiche Bl. vereint stehen. - Meist Sumpfpfl., 30 - temp, frigid, 1 in Ostas. - Centrolepis tenuior.

Fain. Mayacaceae. Bl. heterochlam., 3 gliedrig. Cp. (3); Gr. 1 mit 3 kurzen N. G. I fächerig, mit 3 wandst. Plac., jede mit einigen geradläufigen Sa. in zwei Reihen. Kapsel 3 klappig: Plac, auf der Mitte der Klappen 
E. linsenformig, an der Spitze des S. - Kleine Sumpfkrăuter mit (9) kurzen linealischen B. Bl. einzeln, auf kurzem Stiel in den Achseln der B. oder doldig geläuft, jeder Blütenstiel mit 2 Vorb. am Grunde. - Mayaca (8); M. Michauxii in Nordam., mehrere in Südam., 1 in SW.-Afr.

Fam. Xyridaceae. Bl. heterochlam., 3 gliederig, ̧․ K. $\cdot$, mit 2 kleineren, seitlichen B. Blkr. sympetal mit Röhre. Die 3 äusseren Stb. zu Std. umgebildet oder 0 ; die 3 inneren Stb. fertil, unten mit der Blkr. vereint. Cp. (3); Gr. 1 . oder oben 3 schenkelig. G. 1 fächerig, mit 3 wandst. oder vom Grunde aus frei aufsteigenden Plac, meist $\infty$ kleinen, geradläıfigen Sa. Kapsel und S. wie hei vorigen. - Meist $4 \mathrm{Kr}$. mit langen, linealischen oder lineal-lanzettlichen B. Blïtenschaft achselständig, mit endständiger Ähre, deren dachziegelig sich deckende Hochb. in ihren Achseln je eine Bl. tragen. - 50 calid., keine in Europa. - Xyris.

Fam. Eriocaulaceae. Bl. sehr klein, heterochlam., 2-3 gliedrig $\sigma^{\top}$ ㅇ, $\phi$ oder $\%$ Blh. trockenhäutig, selten die innere, noch seltener auch die äussere fehlend. Von den. Stb. meist die äusseren fehlend. Cp. $(2-3)$; Gr. $2-3$. G. $2-3$ fächerig, mit je einer geradläufigen, in das Fach hineinhängenden Sa. Kapseln fachspaltig. S. wie bei vorigen. Meist 2 Kr. mit langen, linealischen B. und meist langen Blütenschäften, welche ein mit einem Hüllkelch versehenes Köpfchen tragen. - Meist auf feuchtem, sandigem Boden oder in Sümpfen wachsend. - Etwa 500 calid., wenige temp.

Unterfam. Eriocauloidece. Stb. 4 oder 6. P. innen an der Spitze mit Drïse, frei - Eriocaulon (200 trop, subtrop.); E. septangulare in Nordan, Schottland, Irland und auf den Hebriden. - Mesanthemum (4, trop. Afrika, Madagaskar).

Unterfam. Paepalanthoideae. Stb. 2 oder 3. P. ohne Drüse, häufig vereint. - Paepalanthus (150, Südam. und Westind.). - Syngonanthus (80, meist Südam., selır wenige trop. Afr. und Kapland). - Tonina fluviatilis (im Wasser flutend, trop. Südam., Westind.).

3. Unterreihe Bromeliineae. Blh. heterochlamydeisch, hypogyn bis epigyn. Sa. umgewendet.

Fam. Rapateaceae. Bl. heterochlam., 3 gliederig, $\Varangle, \emptyset$. K. mit häutiger Röhre. P. meist vereint. Stb. 6, meist mit der Blkr. vereint. Cp. (3), Gr. 1; G. 3 facherig, mit je $\infty-2$ centralwinkelst oder $1-2$ grundst., umgewendeten Sa. Kapsel fachspaltig. E. linsenförmig, klein, am Mikropylenende dem Nährgewebe anliegend. $24 \mathrm{Kr}$. mit dickem Grundstock und 2 reihigen breit linealischen oder lanzettlichen B. Blütenschaft am Ende mit 2 grossen Scheidenb., welche ein Köpfehen von Ährchen umschliessen, die aus $\infty$ dachigen Hochb. und einer endst. Bl. bestehen. - Etwa 20 trop. Am. - Rapatea.

Fam. Bromeliaceae. Bl. heterochlam., 3 gliederig, meist ఫ̧千 (Q), selten etwas $\%$ K. krautig oder lederartig, bleibend. P. frei oder vereint. Stb. $3+3$, selten vereint. Cp. (3), Gr. 1; G. oberst. bis unterst., 3 fächerig, mit je $\infty$ umgewendeten Sa. Beere oder Kapsel, mit kleinen S., deren Schale und Funiculus oft in eine falsche Haarkrone zerfasert sind. E. klein, am unteren Ende neben dem Nabel. - Kr., oft epiphytisch, selten baumähnliche Pflanzen, mit (Q), meist grundst., breitscheidigen, oft riemenförmigen, dornig-gezähnten B. Bl. in Ähren oder Rispen, oft mit gefärbten, grossen Hochb. - Schuppenförmige Haare der B. der Wasseraufnahme dienend. - Etwa 1000 trop. Am.

§ Tillandsieae. G. Kapsel. S. mit Haarkrone. B. ganzrandig. Tillandsia (248); T. usneoides (Argentinien bis Carolina), von Bäumen 
in Massen herabhängend, als "Louisiana-Moos zum Polstern dienend. - Vriesea (84 Sïiam.).

§ Puyeae. G. Kapsel. Meist stammbildend mit dornig-gezähnten B. - Puya (44 Peru, Chile). - Hechtia (15 Mexiko). - Dyckia (57 Südam.).

$\S$ Piteairnieae. G. oder halbunterst. Kapsel. B. meist schlaff, lang und schmal. - Pitcuirnin (134, meist Erdbewohner).

$\S$ Bromeliae. G. Beere. B. dornig gezähnt. - Nidularium (15 Brasil.).

Anamas sativus (Westind., Centralamerika, im trop. Afrika und Asien vielfach verwildert) mit syncarpischen, durchwachsenen Fruchtständen; Bastfasern der B. dienen zu den feinsten Geweben. - Billbergia (40). - Aechmea (114).

4. Unterreihe Commelinineae. Blh. heterochlamydeisch. Ein Teil der Stb. häufig staminodial oder ganz fehlend.

Fam. Commelinaceae. Bl. beterochlam., 3 gliederig, $\Varangle, \emptyset$ oder $\%$ Cp. (3-2); Gr. 1; G. 3-2 fächerig, mit je einigen geradläufigen Sa. Kapsel. E. an der Spitze des S., dem Nährgewebe anliegend. - Kr. mit knotigem Stengel, wechselst., scheidigen Laubb. Bl. meist mit blauer oder violetter Blkr, in Wickeln oder Doppelwickeln, in den Achseln von Laubb. 300 calid., wenige temp.

§ Pollieae. Fr. nicht aufspringend. Stb. nackt, selten 6, meist nur die 3 inneren fruchtbar. - Palisota (trop. Afr.).

$\S$ Tradescantieae. Kapsel, 2-3klappig. 6 (selten 5) fruchtbare Sth. - Cyanotis (35). - Dichorisandra (27). - Tradescantia (32 Amer.); T. virginica (Nordam.).

§ Commelineate. Wie vorige; aber nur 3-2 Stb. fruchtbar. Commelina (90 calid.). - Aneilema (60 trop.). - Cochliostema odoratissimum (Ecuador).

5. Unterreihe Pontederiinéae. Blh. homoiochlamydeisch und corollinisch, vereintblättrig.

Fam. Pontederiaceae. Bl. 3 gliederig, $\Varangle, \cdots$ Blh. vereintblättrig, mit langer Röhre. Stb. 6, 3 oder 1, der Röhre der Blh. angewachsen. Cp. (3); Gr. 1; G. 3 fächerig, mit $\infty 2$ reihig stehenden Sa. oder 1 fächerig, mit nur 1 Sa. Kapsel oder Schliessfrucht. E. cylindrisch, wenig kürzer als das Nährgewebe. - Wasserpfl. mit sympodialem Stamm, häufig zweizeiligen B. und meist ährenförmigem Blütenstand. - Etwa 24 calid. - Eichhornia (Südam.), schwimmend. - Pontederia (Am.). Heteranthera (Am.).

6. Unterreihe Philydrineae. Blh. corollinisch, die äusseren B. grösser als die inneren, die beiden hinteren des ausseren Kreises vereint, das hintere des inneren Kreises abortiert.

Fam. Philydraceae. Bl. homoiochlam, 3gliedrig mit starkem Abort, $\not, \cdots \cdots$ Nur 1 vorderes Stb. Cp. (3); Gr. 1; G. 3 ficherig mit centralwinkelst. oder 1 fächerig mit wandst. Plac. mit $\infty$ kleinen, umgewendeten Sa. Kapsel mit $\infty$ S. E. klein, kürzer als das Nährgewebe. - Kr. mit 2 reihig gestellten, scheidigen, schmalen B. und in Ähren stehenden Bl. - 4 ind. Archipel, Austral. - Philydrum lanuginosum (ind.-malay. Sumpfpflanze).

9. Reihe LILIIFLORAE. Wie vorige Reihe; aber die S. init fleischigem orler knorpeligem Nährgewebe; die Sa. meist umgewendet. Ausnahmsweise kommen auch vier- und mehrgliedrige Bl. vor. 
1. Unterreihe Juncineae. Blh. homoiochlamydeisch u. bracteoid. Nährgewebe der S. mit Stärke.

Fam. Juncaceae. Bl. homoiochlam., dreigliedrig, meist $\Varangle, \oplus$. Blh. hochblattartig. Der innere Kreis von Stb. bisweilen nicht entwickelt; Pollentetraden. Cp. (3); Gr. 1 mit 3 fadenförmigen N. G. dreifächerig, mit je 1 oder $\infty$ centralwinkelständigen Sa. Kapsel fachspaltig. E. gerade, in der Axe des stärkereichen Nährgewebes. - Meist $2 \mathrm{Kr}$., selten mit oberirdischem Stamm versehene Pflanzen, mit schmalen B. und mannig. fach zusammengesetzten, meist reichblütigen Blütenständen. - Ltwa 250, meist hygrophil, temp. frigid. - Prionium serratum, Palmiettschilf, mit Stamm (Südafr.). - Juncus (189). - Lu:ula (38).

2. Unterreihe Liliineae. Blh. selten bracteoid, meist corollinisch, sehr selten heterochlamydeisch. Nährgewebe der S. nicht mit Stärke. Der innere Kreis von Stb. ist vorhanden.

Fam. Stemonaceae. Bl. homoiochlam., 2gliedrig, $\Varangle, \emptyset$. Blh. hochblattartig. Cp. (2). G. einfächerig, mit aın Grunde oder am Scheitel stehenden ungewendeten Sa. Kapsel 2 klappig; S. länglich, am Nabelstrang behaart. - $4 \mathrm{Kr}$. mit Grundstock, aufrechtem oder windendem und oft kletterndein Stengel, gestielten, lanzettlichen oder herzförınigen B. und in den Achseln der Stengelh. stehenden Blütenständen. - Trop. As., Ostas., Florida.

Fam. Liliaceae. Blüte meist homoiochlam., selten heterochlam., meist $\Varangle, \emptyset$, sehr selten $\%$ Blh. hochblattartig oder corollinisch, getrenntblätterig oder vereintblätterig. Abort von einzelnen Stb. selten. Gr. getrennt oder vereint. G. meist oberst., selten halbunterst. oder unterst. (Ophiopogonoideae, Aletroideae), meist 3(2-4-5) fächerig, mit centralwinkelständigen Sa., selten einfächerig mit wandst. Sa. Fr. mannigfach. - Etwa 2600 von verschiedenartiger Tracht, calid.-frigid.

Unterfam. Melanthioideae. Rhizom oder Zwiebelknolle mit endständigem Blütenstand. A. extror's und Kapsel septicid oder A. intrors und Kapsel septicid oder A. extrors und Kapsel loculicid, nur selten A. intrors und Kapsel loculicid. Fr. niemals eine Beere.

a. Rhizom, seltener Zwiebel. S. länglich, flach und geflügelt oder kantig.

\$ Tofieldieae. Stb. 6, selten 9; A. intrors. Gr. getrennt oder 0 . Rhizom; B. ungestielt, zweireihig. - Tofieldia. - Narthecium (beide *).

$\S$ Helonieae. Stb. 6; A. bisweilen fast kugelig, mit getrennten Fächern, extrors. Gr. getrennt. - Rhizom; B. gestielt, allseitig abstehend. - Helonias bullata (atlant. Nordamerika).

$\S$ Veratreae. Stb. 6; A fast kugelig, extrors, mit sehr genäherten Fächern, zuletzt schildförmig. Dickes Rhizom oder Zwiebel. Stengel meist beblättert. - Amiantlizum muscitoxicnm (atlant. Nordam.); S. sehr giftig. Sabadilla officinalis (Mexiko bis Venezuela) giebt Semen Sabadillae. - Zygadenus (9 Sibir. bis Nordam.). - Veratrum album und seine Varietäten (Europa, Nordasien) liefert Rhizoma Veratri.

b. Rhizom. S. fast kugelig oder kreisförmig und flach.

§ Uvularieae. A. extrors. - Stengelb. ziemlich gross, sitzend. Bl. endst. oder axillär. - Gloriosa (trop. Afr., As.). - Uvularia (atl. Nordam.). 
c. Zwiebelknolle oder kurzes Rhizom, S. fast kugelig.

§ Anguillarieae. Stengel beblättert. A. extrors. - Medit., Afr., Austral.

§ Colchiceae. B. grundständig. Schaft verkürzt, unterirdisch, mit 1-3 B. A. intrors. Kapsel scheidewandspaltig. - Colchicum (30 Europa und Mediterrangebiet); C. cutımnale, Zeitlose, liefert das off. Semen Colchici. - Bulbocodium (mediterr., Südosteuropa). - Merendera (10 medit.).

Unterfam. Herrerioidece. Knolle, einen windenden Stengel treibend. B. in Bïscheln. Kleinblütige Trauben am Grunde derselben oder am Ende der Zweige in Rispen. Blıb. getrennt. Kapsel scheidewandspaltig. - Herreria (südöstl. Brasil.).

Unterfam. Asphodeloidece. Rhizom mit grundständigen B. oder Stamm mit Schopf oder beblätterter und verzweigter Stengel, noch seltener Knolle oder Zwiebel. Blütenstand meist terminal. A. intrors, bisweilen am Scheitel sich öfinend. Kapsel fachspaltig, sehr selten Beere oder Nüsschen.

a. Rhizom mit grund!̣tändigen B., seltener belaubter oberirdischer Stengel, Knolle oder Zwiebel.

$\S$ Asphodeleae. Blütenstand racemös oder rispig. Blhb. getrennt oder vereint.

* Asphodelinae. Phizom. Blh. trichterförmig oder glockig. Spitze der Stf. einem Grübchen der A. eingesenkt. - Asphodelus (7 mediterr.). - Asphorleline (14 mediterr.). - Paradisea (1 alpin). - Fremurus (18 Vorderas., Centralas.).

* Anthericinae. Wie vorige; aber Blh. radförmig. - Bulbine (23 Afr.). - Anthericum (70, meist Afr., wenige Eur.). - Chloroplytum (70 trop.).

* Eriosperminae. Zwiebel oder Knolle. Stengel am Grunde mit einigen frühzeitig absterbenden $\mathrm{B}$. oder zur Blutezeit ohne solche. Blütenschaft einfach orler verzweigt, mit langen Blütenstielen. A. am Grunde angeheftet, ohne Grübchen. Eriospermum (Afr.) - Bowiea volubilis (Kapland).

* Dianellinae. Rbizom. B. 2 reihig. Rispen. Stf. verdickt oder wollig. - Dianella (11 Ostasien, Polynes., Australien).

$\S$ Hemerocallideae. B. der Blh. unterwärts in eine Röhre vereint. Stb. häufig nach unten gebogen, häufig unterwärts mit der Röhre vereint. IIost (5 Japan, China, entwickeln Nucellarembryonen). - Hemerocallis (5 temp. Eur., As.). - Phormium tenax, neuseeländischer Flachs (Neu-Seeland).

$\S$ Aloineae. B. der Blh. zum grössten Teil unter einander vereint, bisweilen etwas zygomorph. Stb. gar nicht oder nur am Grunde mit der Blh. vereint.

* Kniphofiinae. Blstand. endständig, dichtährig. - Kmiphofia (20-30 Afr., Madagaskar).

* Aloinae. Blstand. axillär, meist lockerblütig, traubig oder rispig. Nicht selten oberirdischer, verzweigter Stamm mit Dickenwachstum. - Alö̈ (über 100 in Steppen und Gebirgen Afrikas); A. Perryi auf Socotra, A. succotrina, A. africana und $A$. ferox im Kapland, A. vera im Mittelmeergebiet und in den Tropen cultiviert, liefern Aloëharz. Gasteria (35 Kapland). - Haworthia (59 Südafr.). 
§ Aphyllantheae. Bl. einzeln in 1-2 endst. Köpfchen von $1-2$ freien und 5 mit einander vereinten Hochb. umschlossen. Fächer des G. mit einer seitlichen Sa. - Aphyllanthes monspeliensis ('westl. mediterr.).

\$ Johnsonieae. Bl. zu mehreren in endst. Köpfchen oder Dolden, zum Teil von den Hochb. bedeckt. Fächer des G. mit 2 bis mehr Sa. -21 nur in Australien.

§ Dasypogoneae. Bl. klein, zu mehreren in endst. Kopf. G. mit 3 aufrechten Sa., manchmal auch nur mit 2-1. Fr. kugelig, einsamige Nuss. Stamm mit Schopf von gezähnelten B. - Dasypogon (2 Sïdwestaustral.).

$\S$ Lomandreae. Blütenköpfchen in Rispen, Ähren oder Köpfen; bisweilen die Köpfchen auf eine von Hochbl. umschlossene Bl. reduciert (Xanthor\%oea) und scheinbar eine einfache thre bildend. Fächer des G. mit $\infty-1$ Sa. Fr. eine fachspaltige Kapsel. - Meist in Austral., 1 auch in Neu-Caledonien. - Jomandra (29). - Xanthorrhoea hastile liefert das gelbe Akaroidharz, Botany-Bay-Gummi, $\boldsymbol{X}$. australe das rote Akaroidharz.

b. Stengel von unten bis oben beblättert.

$\S$ Calectasieae. Bl. ziemlich gross, mit starren Blhb., einzeln oder in einem Köpfchen. A. aufrecht, am Grunde angeheftet. G. 3 fächerig mit je 3 Sa. oder 1 fächerig mit 3 aufrechten Sa. - 3 Westaustralien. - Kingia, baumartig. Calectusia.

Unterfam. Allioideae. Zwiebel oder kurzes Rhizom. Blütenstand eine aus verkürzten Schraubeln zusammengesetzte Scheindolde, von zwei breiten, bisweilen vereinigten Hüllb. umschlossen, seltener von 2 schmalen Hochb. gestützt oder auf einzelne $\mathrm{Bl}$. reduciert.

§ Agapantheae. Rhizom. Blh. vereintblättrig. - Agapanthus umbellatıs (Südafr.).

\& Allieae. Zwiebel oder an Grunde verdickter Stengel. Blh. getrennt- oder vereintblättrig. Stb. radiär. - Gagea (25 temp. Eur., As.). - Allium (250 nördl. temp.); A. sativum (Songarei) var. vulgare, Knoblauch, und var. ophioscorodon, Perlzwiebel; $A$. ampeloprasum, Porree (mediterr.); A. schoenopmasum, Schnittlauch; A. ascalonicum, Schalotte (Kleinasien); A. cepa, Bolle; A. fistulosum, Winterzwiebel (Sibir.). - Brodiaea (30. Amerika).

§ Gilliesieae. Zwiebel. Stb. einseitswendig, meist nur teilweise fruchtbar. -8 in den Anden von Peru und Chile.

Unterfam. Lilioideae. Zwiebel. Blütenstand endst., traubig. Blh. getrennt- oder vereintblättrig. A. stets intrors. Kapsel loculicid (nur bei Calochortus septicid).

§ Tulipeae. Schuppige oder mit häutigen Niederb. versehene Zwiebel. Stengel einige Laubb., selten nur 1 tragend. Bl. nur wenige in den Achseln von Laubb. oder einzeln endst. - Lilium (45 nördl. temp.); L. candidum (Südeuropa); I. bulbifenum (Mitteleuropa) u. a. mit Bulbillen. - Fritillaria (40 nördl. temp.); $F$. imperialis, Kaiserkrone (Persien). - Erythronium (7 nördl. temp.). - Lloydia (alpin!. Tulipa (50 Eur., Asien). - Calochortus (32 westl. Nordam.).

§ Scilleae. Mit häutigen Niederb. versehene Zwiebel. Stengel ohne Laubb. Bl. in den Achseln von Hochb. - Albuca (30 Afr.). - Urginea (24 Afr. und mediterr.); U. maritima, Meerzwiebel (mediterr.); off. Bulbus Scillae. - Scilla (80 Eur., Afr., Asien). - Eucomis (Südafr.). 
- Ornithoyalum (70 Eur., Afr., Vorderasien). - Hyacinthus (30 mediterr., Afr.). - Muscumi (40 mediterr.); M. comosum mit sterilen Bl. am Ende der Traube.

Unterfam. Dracaenoideae. Stamm aufrecht, bisweilen kurz, mit beblättertem Schopf, oder Rhizom mit grundst. B. (Astelia), niemals Zwiebel. B. nie fleischig, aber bisweilen lederartig. B. der Blh. getrennt oder am Grunde vereint. A. intrors. Beere oder Kapsel.

$\S$ Yucceae. Blhb. frei. A. pfeilförmig. S. $\infty$, in jedem Fach der Fr. 2 reihig, schwarz. - Fuccra (20 südl. Nordam. und Centralamerika); Y. flamentosa, niedrig; $Y$. aloifolia, mit hohem Stamm und Dickenwachstum.

§ Nolineae. Blhb. frei. A. herzförmig. S. wenige, kugelig, blass. Nolina (10 Centralamer., Texas, Kaliforn.). - Dasylirion (10 Texas, Mexiko).

§ Dracaeneae. Blhb. am Grunde vereint. - Tropen der alten Welt und * - Cordyline (10). - Dracaence (40); D. draco (Teneriffa); D. Cinnabari (Socotra) liefert "Drachenblut «. - Astelia $(9 *)$. - Samserieria (12 trop. Afr. und Ind.); S. weylanica, S. guineensis und S. cylindrica, wichtige Gespinnstpflanzen.

Unterfam. Aspurrogoideue. Rhizom unterirdisch, in oberirdische hlühende Zweige endigend und sich unter der Erde weiter verzweigend oder unten fortwachsend und seitliche Blütenzweige entwickelnd. Beere.

a. Bl. homoiochlam.

$\S$ Asparageae. Rhizomzweige in oberirdische beblätterte Stengel endigend. Stengelb. klein, schuppenförmig, in ihren Achseln schmale oder breite, blattartige Zweige (Phyllocladien) tragend. - Asparugus (100 meist in den regenarmen Gebieten der alten Welt); A. officinalis, Spargel (nördl. temp. Eur., As.). - Danaë (Vorderas.). - Semele (Kanarien). Ruscus (mediterr.).

§ Polygonateae. Wie vorige; aber die Stengelb. gross, laubig. Smilacina (20 temp. As., Am.). - Majanthemum bifolium (nördl. temp.). - Streptopus (4 nördl. temp.). - Polygonatum (23 nördl. temp.).

\$ Convallarieae. Rhizom fortwachsend. Blütenzweige seitenst.

* Convallariinae. Gr. säulenförmig mit kleiner N. - Convallaria majalis (*).

* Aspidistrinae. Gr. in \pm breite Narbenlappen endigend. - Rhodea (1 Japan). - Aspidistra (3 Himalaya bis Japan); A. elatior (Südjapan). häufig cult. Zimmerpflanze.

b. Bl. heterochlam.

§ Parideae. - Paris (6 temp. Eur., As.); P. quadrifolia, Einbeere. - Trillium (15 extratrop. As., Am.).

Unterfam. Ophiopogonoiderce. Kurzes, bisweilen Ausläufer entwiekelndes Rhizom, mit schmalen oder lanzettl. Grundb. Blhb. frei oder vereint. G. unterst. oder halbunterst. Pericarp der Fr. zerfliessend oder 
aufbrechend mit 1-3 S. mit fleischiger Samenschale. - Liriope graminifolia.(Ostasien). - Opliopogon (Ostasien).

Unterfam. Aletroideae. Kurzes Rhizom mit schmalen oder lanzettl. Grundb. Blhb, vereint. A. halbintrors. G. halbunterst. Fr. trocken, fachspaltig, mit $\infty \mathrm{S}$. - Aletris (8 Ostas., Nordam.); A farinosa (Nordam., Grundstock daselbst off.).

Unterfam. Luzuriagoideae. Sträucher oder Halbsträucher mit aufrechten oder kletternden Zweigen. Blütenzweige am Grunde mit einigen schuppigen Hochb. Bl. homoiochlam. oder heterochlam. Beere mit kugeligen S. - 9 ausschliesslich *. - Geitonoplesium (Austral.). - Luzuriaga (3 Neu-Seeland, Chile). - Philesia buxifolia (südl. Chile). - Iapageria rosea (südl. Chile).

Unterfam. Smilacoideae. Sträucher und Halbsträucher mit kletternden Zweigen und 3-5nervigen, netzartigen B. Bl. klein in achselst. Dolden oder Trauben oder endst. Rispen. Fächer des G. mit 1-2 geradläufigen oder halbumgewendeten Sa. - Smilax (200 trop., subtrop., mediterr., temp. As., Am.); S. china (Ostas.) liefert die off. Tuber Chinae; S. medica (Mexiko), S. officinalis (Orinoko) und S. papyracea (Brasil., Guiana) liefern Radix Sarsaparillae.

Fam. Haemodoraceae. Wie vorige Fam.; aber nur 3 Stb. vor den inneren Abschnitten der Blh. Blh. $\oplus$ oder transversal oder später durch Drehung fast median . . . G. unterst. oder oberst., 3 fächerig, in jedem Fach mit einigen halbumgewendeten Sa. N. kopfförmig. - $4 \mathrm{Kr}$. mit zweizeiligen $\mathrm{B}$. und einfachem oder zusammengesetztem Blütenstand. - 33 meist *, wenige im trop. Am. und weiter nordwärts.

Fam. Amaryllidaceae. Im wesentlichen wie die Liliaceae; Stb. selten teilweise Std., sehr selten mehr als 6; A. meist intrors. Bei mehreren die Stb. mit Stipularbildungen, welche sich zu einer Nebenkrone vereinen. G. unterst., nur selten halboberst., mit meist centralwinkelst. anatropen Sa. in 2 Reihen. Fachspaltige Kapsel oder Beere, neist mit wenigen $\mathrm{S}$. - Tracht verschieden.

Unterfam. Amaryllidoideae. A. intrors. Zwiebel. Schaft blattlos, mit einem von Involucralb. umhüllten doldenartigen Blütenstand oder einer Einzelbl.

§ Amaryllideae. Bl. ohne Nebenkrone.

* Haemanthinae. Fächer des G. mit wenigen Sa. - Meist in Afr., einige in Brasil. - Haemanthus (60 Afr., meist Kapland). - Clivia nobilis (Kapland).

* Galanthinae. Fächer des G. mit $\infty$ Sa. Blh. ohne Röhre, $\oplus$. Galanthus (4 mediterr., 1 mediterr. und Deutschland). - Levcojum (9 mediterr., 2 auch in Mitteleuropa).

* Amaryllidinae. Wie vorige; aber $\mathrm{Bl} . \%$, in reichen Scheindolden. - Nerine (9 Südafr.). - Amaryllis Belladonna (Kapland). - Vallota purpurea (Kapland). - Brunswigia (9 Kapland). - Zierpflanzen.

* Zephyranthinae. Blh. mit Röhre und dieser angewachsenen Stb. Bl. einzeln. - Zephyranthes (30 trop., subtrop. Am.). - Sternbergia (12 meist östl. mediterr.)

* Crininae. Wie vorige; aber Bl. in reichen Scheindolden. - Crinum (60 trop., subtrop.). - Cyrtanthus (15 Südafr.). 
* Ixioliriinae. Mit beblättertem Stengel. - Ixiolirion (Vorderas.).

S Narcisseae. Bl. mit Nebenkrone, bisweilen nur einzelne Schuppen oder ein Ring.

* Euchariciinae. Fächer des G. mit wenigen Sa. B. meist herzförmig oder elliptisch. - Hymenocallis (30 trop. Am.). - Eucharia grandiflora und E. candida (Kolumbien) Zierpflanzen.

* Narcissinae. Fächer des G. mit $\infty$ Sa. Nebenkr. becherförmig, die Stf. innerhalb derselben der Blh.-Röhre eingefügt. - Nar'cissus (35 meist mediterr.).

* Pancratiinae. Wie vorige; aber die Stf. aus dem Rande der becherförmigen Nebenkrone entspringend. - Pancratium (12 mediterr.). - Hippeastrum (50 subtrop., trop. Am.).

* Euslephiinxe. Nebenkrone einen unscheinbaren Ring darstellend. Röhre der Blh. meist kurz. - 11 Südam.

Unterfam. Aguvoideae. A. intrors. Rhizom mit dichter Rosette von fleischigen, grossen B. Blütenstand traubig oder rispig. - Meist Am., 3 Austral. - Polianthes tuberosa, Tuberose (Centralam.). - Agave (50); A. americana (in allen trop. und subtrop. Gebieten acclimatisiert), liefert Pitafaser und das Getränk Pulque, A. rigida den Sisalhanf. - Fourcroya gigantea (Mexiko) mit Adventivknospen im Blütenstand. Laubb.

Unterfam. Hypoxidoideae. A. intrors. Rhizom. Stengel mit gewöhnlichen

$\S$ Alstroemerieae. B. meist um $180^{\circ}$ gedreht, mit der Oberseite nach unten. Scheindolde, meist mit Involucralb. - 100 trop., subtrop. Am. - Alstroemeria (50).

- Bomarea $(50)$.

§ Hypoxideae. B. linealisch. Stiel des Blütenstandes ohne B. Ähre oder Traube. - Curculigo (ind.-inalay.). - Hypoxis (50 trop., subtrop.).

$\S$ Conauthereae. B. linealisch. Stengel beblättert, mit lockerer Traube oder Einzelbl. A. an der Spitze sich öffnend. - 12 Chile.

Unterfam. Campynematoidecie. A. extrors. - Campynema (2 Tasmanien).

Fam. Velloziaceae. Bl. homoiochlam., 3 gliedrig, $\not{q}, \oplus$. Blh. mit Röhre, corollinisch 6 einzelne Stb. oder 6 Bündel von Stb. G. 3 fächerig, die Plac. in Gestalt von Lamellen hervortretend, nach aussen schildförmig verdickt oder verbreitert mit $\infty$ Sa. in regelloser Anordnung. S. zusammengedrückt. $-2 \mathrm{Kr}$. oder $\mathrm{t}$ mit linealischen B. und endst. 1 blïtigen Schäften ohne Vorb. - Vellozia (40 Brasil., Charakterpflanze der Campos). - Barbacenia (30 trop.).

Fam. Taccaceae. Bl. homoiochlam., 3 gliederig, $\Varangle, ~ \oplus$. Blhb. zusammenneigend, gross, halbcorollinisch. Sth. + concav bis kapuzenförmig, mit introrsen A. G. 1 fächerig, mit wandst. \pm vorspringenden Plac. und co umgewendeten Sa. Gr. kurz mit 6 corollinischen Lappen. Kapsel oder Beere. - $4 \mathrm{Kr}$. mit stärkereichen Knollen und grossen, ganzen oder (wie bei Amorplıoplıallus und Dracontium) vielfach geteilten B. Bl. auf blattlosen Stengeln in Scheindolden, mit eigentümlichen fadenförmigen, die Bl. weit überragenden Hochb. - Trecer (9 trop.); T. pinnatifida u. a. cult., liefern in den Knollen Mehl (Arrow-root).

- Fam. Dioscoreaceae. Bl. homoiochlam., 3 gliederig, ㅎ, häufig $\sigma^{\nearrow}$ 우, $\oplus$. Blhb. hochblattartig, meist zu einer kurzen Röhre vereint. Von den 6 Stb. bisweilen die 3 inneren Std. G. 3 -oder 1 fächerig, mit centralwinkelst. oder wandst. Plac., meist mit je 2 umgewendeten Sa. über einander. Gr. 3, bisweilen 2teilig, Kapel oder Beere. - Kletternde oder 
schlingende Kr. mit meist knolligen, stärkereichen Rhizomen (Dickenwachstum), welchselst. oder gegenständigen, nicht selten pfeilförmigen B. und in Trauben stehenden $\mathrm{Bl}$. - 210 meist trop.

§ Stenomerideae. $\mathrm{Bl}$ ఫ̧. . Sa. in jedem Fach $2 \infty .-5$ ind.-malay.

$\S$ Dioscoreae. Bl. $\sigma^{7}$, 오. Sa. in jedem Fach 2. - Borderea pyrenaica (Hochpyrenäen). - Dioscorea (200 meist calid.); D. villosı (atl. Nordam.); D. sativa (Ostas.); D. batatas (Japan), namentlich letztere wichtige Culturpflanze der wärmeren Länder, liefert Yamswurzel, Igname, Brotwurzel; (D. Testudinaria) elephantipes, Hottentottenbrot (Südafr.), mit riesigem knolligem Grundstock und allmählich in polygonale Platten sich spaltendem Periderm. - Trmus communis, beerenfrüchtig (mediterr. und auch subalpin).

3. Unterreihe Iridineae. Wie die vorige Unterreihe; aber der zweite Staubblattkreis abortiert.

Fam. Iridaceae. Bl. homoiochlamydeisch oder heterochlamydeisch, 3 gliederig, ㅎ, oder $\%$. Stb. immer nur 3 des äusseren Kreises, mit extrorsen A. Gr. 3, häufig geteilt und blattartig erweitert. G. 3 fächerig, selten 1 fächerig, mit $\infty$ umgewendeten sa. Kapsel fachspaltig mit rundlichen oder kantigen $\mathrm{S}$. $-2 \mathrm{Kr}$. oder Halbsträucher mit meist reitenden B. und endst. Blütenst. - Besonders in Südafr., Am. und mediterr.

Unterfam. Crocoideae. Bl. einzeln oder mehrere axilläre um eine terminale Endbl. Niedrig, oft mit unterirdischem Blütenstiel. - 120 mediterr. und Südafr. - Crocus (60 meist mediterr.); C. sativus, die N. liefern den Saffran. - Romulea (50 mediterr. bis Südafr.).

Unterfam. Iridoideae. Bl. $\infty$, meist $\oplus, 2$ bis mehr von 1 Tragb. umschlossen, zu zusammengesetzten Blütenständen geordnet. Stengel deutlich entwickelt. B. reitend.

§ Moraeeae. Röhre der Blh. kurz oder 0. Kapsel von dem Tragb. nicht umhüllt. N. auf der Unterseite der verbreiterten Griffeläste. Iris (100*, in wärmeren Gebieten); I. florentina, I. yermanica und I. pallida (mediterr.) lief. Rhizoma Iridis, Veilchenwurzel. Moraea (40 Afr.).

$\S$ Tigridieae. Wie vorige; aber N. an der Spitze der oft geteilten flachen Griffeläste. - Meist Am. - Tigridia pavonia, Tigerlilie (Centralam.); Zwiebel Fiebermittel.

§ Sisyrinchieae. Wie vorige; aber Griffeläste meist stielrundlich. - Libertia (8 - excl. Südafr.); L. formosa (Chile). - Sisyrinchium (50 Amer.).

* Aristeeae. Röhre der Blh. entwickelt. Kapsel stets von der Spatha umhüllt. - Aristea (15 Afr.).

Unterfam. Ixioideae. Wie die vorige Unterfam.; aber stets nur 1 Bl. von einem Tragb. umschlossen. Bl. hfg. $\%$.

$\S$ Ixieae. Äste des Gr. ungeteilt. Bl. $\oplus$ oder wenig $\cdot \mid \cdot-80$ Südafr. Schizostylis coccinea, Zierpfl. -- Ixia (25).

§ Gladioleae. Wie vorige; aber $\mathrm{Bl}$. stark $\%$, oft gekrümmt. 200 Afr., mediterr., einige Mitteleuropa. - Tritonia (18); T. aurea (Natal). - Sparaxis tricolor (Südafr.). - Gladiolus (100, meist Afr.); G. cardinalis und G. psittacinus nebst vielen Hybriden Zierpfl.

§ Watsonieae. Äste des Gr. 2teilig. - 50 Afr. - Lapeyrousia. - Watsonia. 
b. Die BI. sind homoiochlamydelseh bis heterochlamydeisch, im ersteren Falle jedoch ist die Blh. corollinisch. Epigynie und Zygomorphie vorherrschend.

10. Reihe SCITAMINEAE (Arillatae). Bl. cyklisch, homoiochlam. oder heterochlam., 3 gliederig, typisch diplostemon, hfg. mit bedentender Reduction des Androeceums bis auf 1 Stb., meist epigyn, selten $\oplus$, meist \% G. meist 3 fächerig mit grossen Sa. S. meist mit Arillus und mit doppeltem Nährgewebe. - Trop.

Fam. Musaceae. Bl. homoiochlam. oder heterochlam., $\not{q}$ oder $\sigma^{\pi} \not$, $\cdots$ Blh. corollinisch, hfg. vereintb]ättrig. Stb. meist nur 5 fertil, das 6 . meist Std. Gr. 3-6lappig. G. 3 fächerig, mit $1-\infty$ Sa. in jedem Fach. Beere oder Kapsel. S. hfg. mit Arillus. Nährgewebe mehlig $=$ Endo. sperm + Perisperm. E. gerade. - Gr. Kr. mit grossen ovalen oder länglichen fiedernervigen B. Blstand. hfg. zusammengesetzt, mit grossen, oft corollinischen Hochb. - Calid.

Unterfam. Musoideae. B. spiralig. Bl. meist diklinisch reihenweise in den Achseln breiter Hochb. Blh. homoiochlam., 5 Blhb. vereint, das 6 te dorsale frei. Beere. S. ohne Arillus. - Musa, Banane, Plantain, Pisang (trop. As., Austral., Afr.); M. sapientum u. M. paraclisiaca (trop. As.) wegen der essbaren zucker- oder mehlreichen Fr. ïberall in den Tropen cult.; M. textilis (Philippinen) lief. Manilahanf; M. Ensete (Abyssinien), Zierpfl.

Unterfam. Strelit:ioideae. B. zweireihig. Bl. $\sigma^{7}$ in Wickeln in cler Axel einer concaven Bractee. Kelchb. frei.

§ Strelitzieae. Fächer des Frkn. mit mehreren Sa. Loculicide Kapsel. S. mit Arillus. - Ravenala madagascariensis (Madagaskar und Réunion); $R$. guianensis (Guiana, Brasil.). - Strelitzia (4 Südafr.).

$\S$ Heliconieae. Fücher des Frkn. mit 1 Sa. Kapsel in 3 Coccen zerfallend. S. ohne Arillus. - Heliconia (30 trop. Am.) Zierpfl.

Unterfam. Lowioideae. B. 2reihig. Bl. in Rispen, welche dem Rhizom entspringen. Kelch röhrig. - Lowia (Malakka).

Fam. Zingiberaceae. Bl. meist heterochlamydeisch, 후, selten $\sigma^{7}$ 우, \%. (K. 3), (P. 3), unten eine Röhre bildend. Nur 1 Stb. des inneren Kreises fertil; ihm gegenüber das corollinische, von 2 vereinten inneren Std. gebildete Labellum; bisweilen auch noch 2 dem äusseren Kreis angehörige seitliche Std. Gr. sehr dünn, in einer Rinne des fruchtbaren Stb. liegend. $\bar{G}$. 3 fächerig. selten 1 fächerig, mit $\infty$ Sa. Meist Kapsel mit 3 Klappen. S. meist mit Arillus. Nährgewebe mehlig $=$ Endosperm + Perisperm. E. gerade. - $4 \mathrm{Kr}$. mit oft knolligen Rhizomen. B. mit Scheide, Stiel und lanzettfg. Spreite. Blütenstand einfach oder zusammengesetzt. - Ölzellen. - Stärkekörner gross, scheibenfg. mit excentrischem Kern. - 300 vorzugsweise trop. Afr., As.

§ Hedychieae. G. 3 fächerig. Seitenstd. petaloid, von der Beschaffenheit des Iabellums. - Curcuma (30 trop. Afr., As., Austr.); C. longa, Gelbwurzel, Gurgemei (trop. As.) lief. das off. Rhizoma Curcumae, cult.; C. zedoaria, Zittwerwurzel (trop. As.) lief. Rhizoma Zedoariae, cult.; C. angustifolia und C. leucorrliza lief. Arrow-root. - Hedy- 
clium (27), Zierpfl. - Kämpferia (18); K. galanga (Ostind.), Rhizom zur Bereitung von Parfüms.

§ Zingibereae. $\bar{G}$. 3 fächerig. Seitenstd. klein oder 0 . Costus (25 trop.) - Alpinia (40 palaeotrop.); A. officinarum (China, gegenüber der Insel Hainan) lief. d. off. Rhizoma Galangae minoris; $A$. Galanga (Sundainseln) lief. Rhizoma Galangae majoris; Zingiber (20 Maskarenen, trop. As.); $\boldsymbol{Z}$. officinule, Ingwer (trop. As.) lief. Rhizoma Zingiberis, cult.; $Z$. zerumbet (Ostind.); $Z$. cassumunar, gelber Zittwer (Ostind.). - Amomum (50 palaeotrop.); A. melegueta, Melegueta (Pfefferküste, Sierra Leone bis Congo) lief. d. off. Semen Paradisi, Paradieskörner; A. Cardamomum lief. Siam-Cardamomen. - Elettaria cardamomum (westl. Vorderind.) liefert d. Malabar-Cardamomen und Ceylon-Cardamomen (Cardamomum longum).

§ Globbeae. G. 1 făcherig mit 3 wandst. Placenten. Seitenstd, vorhanden. Globba (24 ind. malay.).

Fam. Cannaceae. Bl. heterochlamydeisch, $\Varangle$ unsymmetrisch. K. 3. P. 3, unten vereint. Stb. 1-5, unten mit der Kronenröhre vereint; aber nur das eine innere zur Hälfte fertil, zur Hälfte petaloid, die übrigen petaloide Std. Gr. dick, blattartig, mit schräger N. am oberen Ende. G. 3 fächerig, mit je zwei Reihen umgewendeter Sa. Nährgewebe der S. = Endosperm + Perisperm. - Ölzellen. - Stärkekörner gross, mit excentr. Kern, flach: - $4 \mathrm{Kr}$. mit grossen fiedernervigen B. und ährenfg. oder aus Wickeln zusammengesetzten Bl.-Ständen von ansehnlichen Bl.. - 60 trop. Am. - Canna, Blumenrohr; C. indica u. a. Zierpfl.; C. edulis, wegen des stärkekaltigen Rhizoms cult.

Fam. Marantaceae. Bl. heterochlamydeisch, $\not$, unsymmetrisch. Stb. 4-5; aber nur das eine innere zur Hälfte fertil, zur Hälfte petaloid, die beiden übrigen inneren und 1-2 äusseren ebenfalls petaloid, das eine innere kapuzenförmig. G. 3 fächerig oder durch Hemmung zweier Fächer nur einfächerig, jedes Fach mit $1 \mathrm{Sa}$. Gr. stark, gekrümmt, mit schief hervorgezogener, oft gelappter Spitze. S. mit Arillus. Nährgewebe = Endosperm + Perisperm. E. gekrümmt. $-4 \mathrm{Kr}$. mit zweizeiligen, fiedernervigen, meist ungleichseitigen B., am Ende des Stieles mit einer Anschwellung. - Etwa 270 trop., vorzugsweise Am. und Afr.

§ Phrynieae. G. 3fächerig. - Trachyphrynium (Afr.). - Phrynium (20 trop. Às., Afr.). - Culatheu (60 trop. Am., 2 trop. Afr.).

$\S$ Maranteae. G. 1 fächerig, mit 1 Sa. - Maranta (15 trop. Am.); M. arundinacea (Westind.), lief. Amylum Marantae, Arrow-root. - Thalia dealbata (Nordam.).

11. Reihe MICROSPERMAE. Bl. cyklisch, homoiochlam. oder heterochlam., 3 gliederig, typisch diplostemon, hfg. mit bedeutender Reduction. G. 3 fächerig oder 1 fächerig, mit $\infty$ kleinen Sa. an den Plac. Nährgewebe + oder 0 . gewebe.

1. Unterreihe Burmanniineae. Bl. meist strahlig. S. mit Nähr- 
Fam. Burmanniaceae. Blh. meist vereintblättrig, seltener oberhalb des G. mit ganz freien Abschnitten, die 3 inneren meist kleiner als die äusseren oder ganz schwindend. Stb. 6 oder nur die 3 des inneren Kreises hfg. mit stark verbreitertem Connectiv. G. mit 3 wandstg. oder centralwinkelstg. Plac. Sa. mit 2 Integ. Kapsel mit $\infty$ kleinen S. mit Nährgewebe. - Kr., die 4 mit Rhizom oder Knöllchen, wenig verzweigt, entweder grün mit schmalen B. oder chlorophyllfreie Saprophyten mit schuppigen Niederb. Bl. oft ansehnlich, einzeln oder in Doppelwickeln. - Etwa 60 in trop. Urwäldern und Savannen, wenige Nordam.

§ Thismieae. St.b. 6 mit verbreitertem Connectiv. Blh. ๑. - Thismia (10 trop. Am., As.).

20 trop.).

\$ Fuburmannieae. Stb. 3 mit aufrechten A. Blh. ๑. - Burmannia

§ Corsieae. Stb. 6. Blh. $\mid$. - Corsia (ind. malay.). gewebe.

2. Unterreihe Gynandrae. Bl. stets zygomorph. S. ohne Nahr-

Fam. Orchidaceae. Bl. homoiochlam. oder heterochlam., typisch 3 gliederig, fast immer §̧, $\%$, meist resupinirt. Von den Stb. sind meist nur das unpaare des äusseren Kreises oder die beiden seitlichen des inneren Kreises, sehr selten diese 3 fruchtbar, hfger. das unpaare des äusseren Kreises, bisweilen die beiden seitlichen des inneren Kreises Std., sehr selten sind die anderen auch noch entwickelt. Cp. (3), der hohlen Blütenaxe eingesenkt, diese über die Insertion der Blh. hinaus zu der die Stb. tragenden Säule verlängert. Pollen in Tetraden (Massulae - Pollinien). N. 3, meist auf der Innenfläche der Säule, der unpaare Narbenlappen meist rudimentär oder zu dem Rostellum entwickelt. G. meist 1 fächerig, mit 3 gespaltenen wandst. Plac. und $\infty$ Sa. Kapsel mit $\infty$ sehr kleinen S. ohne Nährgewebe. E. ungegliedert oder wenig gegliedert. - $4 \mathrm{Kr}$. von sehr verschiedener Tracht, etwa 5000 calid. temp.

Unterfam. Pteiandrae (Diundrae). Die beiden paarigen, selten alle Stb. des inneren Kreises fertil, das unpaare des äusseren Kreises Std. oder auch fertil. Die $3 \mathrm{~N}$. ziemlich gleich gestaltet und empfängnisfähig.

$\S$ Apostasieae. Blh. fast $\oplus$. Säule gerade mit endstg. zur Blütenaxe nahezu rechtwinklig ausgebreiteten Narbenflächen. - 7 ind.-malay. - Neuwiedia mit 3 fruchtbaren Stb. - Apostasia.

s Cypripedileae. Blh. $\%$. Säule nach dem schuhfg. Labellum hin übergebogen, die Narbenlappen der Blütenaxe fast parallel. - Cypripedilum 20 *. - Paphiopedilum (30 trop. As., Am.) mit 3 fächerigem G.

Unterfam. Monandrae. Die beiden seitlichen oder alle Stb. des inneren Kreises fehlend oder Std., selten fruchtbar, das unpaare des äusseren Kreises regelmässig fertil. Nur die seitlichen Narbenlappen empfängnis. fähig, der unpaare Narbenlappen rudimentär oder zum Rostellum umgebildet.

a. Busitonae. Pollinien nach der Basis hin Anhängel (Caudiculae) entwickelnd, welche mit den Klebmassen des Rostellums in Verbindung treten. A. niemals abfallend.

$\S$ Ophrydeae. Einzige Gruppe dieser Reihe. - Erdorchideen mit Wurzelknollen. 
* Serapiadinae. Säule kurz. Labellum am Grunde derselben. A. aufrecht. Spiegelnarben. Klebmassen in dem zum Rostellum gehörigen Beutelchen eingeschlossen. - Ophrys (30, meist mediterr.). - Orchis (70 mediterr., temp. Eur., As., wenige Am.); O. morio, O. mrscula, $O$. militaris mit ungeteilten Knollen, O. lutifoliu, O. maculutı mit geteilten Knollen, lief. die off. Tubera Salep. - Serapias (5 mediterr.). - Aceras (mediterr.). - Himantoglossum (mediterr., Mitteleur.). Anacamptis (Eur., Nordafr.).

* Gymnadeniinae. Wie vorige; aber die Klebmassen von den Fortsätzen der A. umschlossen oder nackt. - Herminium (temp. Eur., As.). - Coeloglossum viride (temp. Eur., As.). - Gymnadenir (incl. Nigritella, Eur., As., einige alpin). - Platunther'e (70*, meist Nordam.).

* Habenariinae. Wie vorige; aber die N. als besondere, oft lange Fortsätze hervortretend. - Habenaria (300 calid.).

* Satyriinae. Labellum am Grunde der Säule eingefügt; die A. mit letaterer einen Winkel bildend. - Salyrium (60 Afr., Ostind.) - Disa (60 Afr.).

b. Acrotonae. Pollinien ohne Anhängsel oder solche nach der Spitze hin entwickelnd. Stf. meist dünn und zart, die A. leicht abfallend.

a) Acranthae. Blütenstände an der Spitze der ein Sympodium bildenden Sprosse terminal.

I. Convolutae. B. in der Knospenlage zusammengerollt; die Blattfläche und Blattscheide nicht von einander abgegliedert, Pollen meist weich, körnig, die A. an ihrem Platz welkend.

\section{$\S$ Neottieae.}

* Thelymitrinae, Diuridinae, Pterostylidinae, Caladeniinae (alle in Australien, Neu Seeland, Neu-Caledonien). - Chloraeinae (Südam.). - Pogoniinae (calid.).

* Vanillinae. Labellum von den übrigen Blhb. verschieden, aber ohne Hypochil, die Säule umhüllend. A. das Rostellum überragend, übergeneigt bis aufrecht. - Galeola altissima (Java, Borneo) aus dem Rhizom bis $40 \mathrm{~m}$ lange, kletternde, blassrötliche Stämme treibend, saprophytisch. - V rmilla (20 trop.); V. planifolia (incl. $\boldsymbol{V}$. cromatica) (östl. Mexico, viel in den Trop. cult.), lief. die Vanille des Handels.

* Cephalantheminae. Labellum mit deutlichem, oft gesporntem Hypochil. A. aufrecht. - Cephalantherr (10*). - Epipactis (10*). Limodomu abortivum (mediterı., Saprophyt). - Epipogon aphyllus (temp. Eur., As., Saprophyt ohne Wurzeln).

* Spiranthinae. A. so lang wie das Rostellum und demselben dicht anliegend. B. weich, netzaderig. Pollinien nicht in viele bestimmte Massen abgeteilt. - Spiranthes (40). - Listera (10*). - Neottia nidus avis (Saprophyt mit Wurzeln, welche Mycorr/iza enthalten).

* Physurinae. Wie vorige; aber Pollinien in viele bestimmte Massen abgeteilt. - Meist calid. - Anoectoclitus (8 ind.-malay.). - Goodyer $(25 *)$.

II. Articulatae. B. in der Knospenlage zusammengerollt; aber die Blattfläche von der Blattscheide mit scharfem Riss sich trennend. Pollinien meist wachsartig, die A. bei Entfernung derselben abfallend. 
$\S$ Coelogyneae. Ein einziges Stammglied knollig verdickt. Săule fusslos. 4 wachsartige Pollinien. - Coelogyne (50 ind.-malay.). - Pholidota (20 ind.-malay.).

III. Duplicatae. B. in der Knospenlage gefaltet.

1) Äusserer Kreis der Blh. dem inneren höchstens gleich entwickelt, in der Regel der letztere, namentlich das Labellum, am meisten in die Augen fallend.

S Liparideae. B. meist ungegliedert. 4 wachsartige Pollinien ohne Anhang. - Malaxis paludosa (*). - Micvostylis (70 temp.-trop.). Liparis (70 temp.-trop.). - Calypso borealis (* frigid.). - Coralliorrlei:l innata (*), Saprophyt ohne Wurzel.

§. Laelieae. B. stets gegliedert. Bl. meist gross. 4-8 Pollinien mit Caudicula. - trop. Am. - Epirlendmun (400). - Cattleya (20). - Lueliu (20). - Brassavola (20).

§ Sobralieae. B. stets gegliedert, vielrippig. Pollinien weich, körnig, ohne Anhang. - Am. - Sobralia (30).

2) Äuserer Kreis der Blh. stärker entwickelt als der innere, den letzteren oft ganz verbergend. thallis (400).

$\S$ Pleurothallideae. - Am. calid. - Masdevallia (100). - Stelis (150). - Pleuro-

३) Pleuranthae. Blïtenstände auf besonderen Seitensprossen.

I. Convolutae. B. in der Knospenlage zusammengerollt.

§ Phajeaө. Stamm schlank oder gleichmässig angeschwollen. 4 od. 8 wachsartige Pollinien mit Caudicula, ohne Stipes. - Phajus (12 palaeotrop.). - Calanthe (40 trop.). - Bletia (20 trop. Am.).

$\$$ Cyrtopodieae. Wie vorige; aber 2 oder 4 Pollinien ohne Caudicula, mit kurzem Stipes. - Lissochilus (30 Afr.). - Cyrtopodium (3 Am.).

$\S$ Cataseteae. Wie vorige; aber 2 oder 4 wachsartige Pollinien ohne Caudicula, mit schmalem, oft sehr langem Stipes. - Trop. Am. - Catusetum (30 trop. Am.) mit trimorphen Blüiten (하 Myanthus, ठ Catusetum, o Mourchanthus).

§ Lycasteae. Ein einziges Stammglied zur Luftknolle entwickelt. Pollinien mit deutlichem Stipes. Blütenstand unterhalb des neuen Laubsprosses entspringend. Lippe häntig. - Trop. Am. - Anguloa. - Lycaste (30).

$\S$ Gongoreae. Wie vorige; aber Lippe fleischig, meist mit deutlichem Hypochil. - Trop. Am. - Stanhopea (20).

$\S$ Zygopetaleae. Blütenstand oberhalb des neuen Laubsprosses. Lippe häutig. - Trop. Am. - Zygopetalum.

II. Duplicatae. B. in der Knospenlage zusammengefaltet.

1. Sympodiales. Laubtriebe mit begrenztem Spitzenwachs. tum. Sym podium.

S Dendrobieae. Blütenstände gegen die Spitze der schlanken Stämme oder auf der Luftknolle entspringend. Lippe ohne Hypochil. Pollinien anhanglos oder mit kurzer Caudicula. - Calid. d. alten Welt. - DenMrobium (300, trop. As., Ostas., Austral.). - Eria (80 trop. As.).

§ Bolbophyllene. Blïtenstände unter der einzigen Luftknolle des Sprosses entspringend. Lippe ohne Hypochil. Pollinien meist anhangslos. - Calid. - Bolphyllum (100 trop. As., Afr.).

§ Cymbidieae. Blütenspross höher entspringend als der Laubspross gleicher Ordnung. B. riemenartig. Pollinien mit quergestreckter Caudicula, und breitem Stipes. - Calid. - Cymbidium (30 trop. As.). 
§ Maxillarieae. Blütenspross tiefer entspringend als der Iaubspross gleicher Ordnung. Lippe mit Längsschwielen, wie bei vorigen dem Säulenfuss beweglich angegliedert. Pollinien mit deutlichem Stipes. - Am calid. - Maxillavia (100).

§ Oncidieae. Blütenspross höher entspringend als der Laubspross gleicher Ordnung. Lippe ohne Hypochil, häutig, mit dem Säulenfuss fest verbunden. - Am. cal. -- Trichopilia (18). - Odontoglossum (100).

- Oncidium (300).

2 Monopodiales. Laubtriebe mit unbegrenztem Wachstum.

§ Sarcantheae. Laubb. gegliedert. Blütenstand meist vielblütig. Lippe meist gegliedert oder gespornt. - Calid., wenige Am. - Renanthera (12 ind.-malay.). - Phalaenopsis (35 ind.-malay.). - Sarcanthus (15 ind.malay.). - Saccolabium (20 ind.-malay.). - Vanda (20 ind.-malay.). Angroecum (20 Afr.). - Macroplectrum sesquipedale (Madagaskar) mit $5 \mathrm{dm}$ langem Sporn des Labelluins. - Polyrrhiza funalis (Jamaika), ohne Laubb., nur mit den Wurzeln assimilierend. - Mystacidium (20 trop. Afr.). - Aërides (15 trop. As.).

2. Klasse DICOTYLEDONEAE. Embryo mit zwei, ausnahmsweise mehr Cotyledonen oder in Folge offenen Fibrovasalsträngen durchzogen.

1. Unterklasse Archichlamydeae (Choripetalae und Apetalae). Blütenumhüllung auf niederer Stufe, d. h. 1) entweder ganz fehlend, oder 2) einfach (haplochlamydeisch), dabei entweder hochblattartig (bracteoid) oder blumenkronenartig (petaloid, corollinisch), oder 3) doppelt mit getrennt-blätteriger innerer Hülle, dabei entweder homoiochlamydeisch oder heterochlamydeisch, meist mit petaloider Ausbildung der inneren Hülle, oder 4) doppelt mit verwachsenblättriger innerer Hülle (bei einzelnen Formen, deren nächste Verwandte choripetal sind, oder 5) einfach, in Folge von Abort der inneren Hülle (apopetal).

A. Sa mit vielen (20 und melir) Makresporen; einige derselben wachsen als lange, weite Schläuche nach dem Chalazaende der Sa. nnd lockern daselbst das Gewebe; in anderen entstelit vor der Befruchtung 1) ein aus 20 und mehr Zellkernen bestehendes noch rudimentäres Protliallium, welches nach der Befruclitung sich zu einem mächtigen, die Makrospere ausfüllenden Nährgewebe (Endosperm) entwickelt, 2) eine mit Membran versehene Eizelle, neben welcher bisweilen noch einige unwesentliclie Nachbarzellen auftreten. Der Pollenschlauch wächst in der Wandung des Gynaeceums nach dem aufgelockerten Gewebe des Chalazaendes und wäehst von da ans anfwärts, bis er sieh mit seinem Ende einem.Enbryosack anlegt. Das Weitere ist noch unbekannt.

1. Reihe VERTICILLATAE. Bl. $\sigma^{7}$,, monöcisch. $\sigma^{\nearrow}$ Bl. mit zwei median stehenden hochblattartigen Blhb. und einem centralen Stb. 우 Bl. ohne Blh. Cp. (2 median) mit zwei fadeniörmigen N. G. mit sterilem hinterem und fertilem vorderem $\mathrm{Fach} ; 2-4$ aufsteigende geradläufige Sa. Schliessfr., an der Spitze häutig geflügelt, von den verholzenden klappenartigen Vorb. eingeschlossen. Nährgewebe zuletzt 0 . - $\hbar$ von schachtelhalmartigem Habitus. $\sigma^{7} \mathrm{Bl}$. in kätzchenartigen Ähren am Ende der rutenfg. Zweige; 아 $\mathrm{Bl}$, in kurzen Köpfehen am Ende kleiner Seiten- 
zweige. Zweige mit Längsfurchen, in welchen die Spaltöffnungen versteckt liegen.

Fam. Casuarinaceae. - Einzige Gattung Cusurriul (20, meist in Iustral., einige ind.-malayische); $C$. equisetifolia an den tropischen Küsten ler alten Welt verbr., lief. Eisen holz.

B. Sa. in der Regel nur mit 1 Makrospore; in dieser eine Eizelle mit 2 Synergiden, wio bei den Monocotyledoneae.

a. Reihen, welche nur Pfl. mit nackten BI. oder mit haplochlamyleischer, hochblattartiger Blh. umfassen.

2. Reihe PIPERALES. Bl. achlam. oder homoiochlam., 후 orler $\sigma^{\nearrow} q$. Stb. $1-10$. Cp. $1-4$, frei oder vereint. Bl. sehr klein, in Ähren. B. ungeteilt, mit oder ohne Nebenb.

Fam. Saururaceae. Bl. achlam., ㅎ․ Stb. 6 oder weniger. Cp. $3-4$, frei oder vereinigt, im letzteren Fall mit wandständigen Samenleisten,

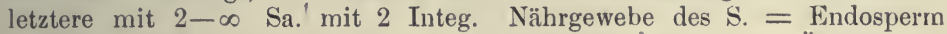
+ Perisperm. - Kr. mit (9) B. und ährig stehenden Bl. - Ölzellen. Saururus cernuus (Sümpfe des atlant. Nordam.). - Houttuynia cordata (Ostasien).

Fam. Piperaceae. Bl. achlam., ఫ̛ oder $\sigma^{\nearrow}$ ㅇ. Stb. $1-10$. Cp. $(1-4)$; G. 1 fächerig mit 1 grundständigem, geradläufigen. Sa. Nährgewebe des $\mathrm{S}$. = Endosperm + Perisperm. - Kr. und $\mathrm{t}$, selten Bäume, mit meist (9) B.; Nebenb. + und 0. - Stets Ölzellen, daher scharfer Geschmack. Gefässbündel zerstreut in 2 oder mehr Kreisen, die des äusseren häufig vereinigt. - Meist tropisch, wenige extratropisch. - Piper (600); P. angustifolium (trop. Am.) liefert Folia Matico; P. cubebu (ind. Archipel), liefert Cubeben (auch off.); $P$. guineense (Westafr.), liefert Aschantipfeffer; P. methysticum (Polynesien), liefert Ava oder Kava; P. Tongum (ind.-malay.), giebt langen Pfeffer (Fruchtähren); P. betle (ind.-malay.) ist Betelpfeffer; $\boldsymbol{P}$. migrum (ind.-malay.), giebt schwarzen und weissen Pfeffer. - Peperomia (400).

Fain. Chloranthaceae. Bl. $\&$ oder $\sigma^{\top}$, achlam. oder mit hochblattartiger Blh. Stb. 1 oder 3 unter einander und mit dem $G$. vereinigt. Cp. 1, mit 1 geradläufigen, am Scheitel hängenden Sa. Perisperm + Endosperm. - $\mathrm{Kr}$ und $\mathrm{t}$ init gegenst. B.; Nebenb. Bl. in Ähren oder Trugdolden. - Ölzellen. Gefässbündel in 1 Kreis. - Trop., sulitrop - Chloranthus (Ostas., Ostind.). - Hedyosmum (trop. Am.).

Fam. Lacistemaceae. Bl. $\not$ mit oder ohne Blh. Bl-Axe concav. 1 Stb. Cp. (2-3); Gr. 1; G. mit 2-3 wandständigen Placenten, an jeder 1-2 lä̈ngende Sa. Fr. eine 1 samige Kapsel. Nährgewebe + . - t mit zweizeiligen, lanzettlichen $B$. ohne Nebeub. - Bl. sehr klein, in den Axeln hreiter schuppiger Deckb. in buschelfg. angeordneten Ähren. - Keine Ölzellen. - Lacistemu (16 trop. Am.).

Zugehörigkeit zu dieser Reihe zweifelhaft.

3. Reihe SALICALES. Bl. achlam., $\sigma^{7}$ 우 , diöcisch, mit becherförmigem oder zu einzelnen zahnartigen Schuppen reducirtem Discus. $\sigma^{\top}$ Bl.: Stb. $2-\infty$. ㅇ Bl.: Cp. (2). G. 1 fächerig init wandst. Placenten und $\infty$ umgewendeten Sa. mit 2 Integ. Kapsel mit $\infty$ S. S. klein, mit basilärem 
Haarschopf, ohne Nährgewebe. - $\hbar$ mit ungeteilten, selten gelappten (9) B. mit Nebenb. und ährigen Blütenständen.

- Fam. Salicaceae. Meist in der nördlich-gem. Zone, wenige trop. Popmulus (18). - Salix, Weide (160); die Rinde von S. pentandra, alba u. a. Cortex Salicis (obs.) enthält Salicin. - Arten beider Gattungen reichlich irn Tertiär.

4. Reihe MYRICALES. Bl. achlamydeisch, $\sigma^{\top}$ ㅇ, monöcisch, bisweilen am Grunde mit Vorb. $\sigma^{7} \mathrm{Bl}$. mit 2-16, meist 4 Stb. ㅇ Bl. mit $\mathrm{Cp}$. (2); G. 1 fächerig mit 1 grùndständigen, geradläufigen Sa. mit 1 Integ. N. 2, fadenfg. Porogam. Steinfr. mit Wachs ausscheidendem Exocarp. Nährgewebe 0 . - $\hbar$, auch halbstrauchig, mit einfachen, selten fiederspaltigen B. und einfachen, seltener zusammengesetzten Ähren.

Fam. Myricaceae. - Myrica (40, meist subtrop.); M. gale in Moor- und Heidegegenden Westeuropas und in den kälteren Teilen der nördlich-gemässigten Zone; M. cerifera (Nordam.) u. a. geben Myrtelwachs.

5. Reihe BALANOPSIDALES. Bl. $\sigma^{\nearrow}$ ᄋ, 2 häusig. $\sigma^{7}$ Bl. haplochlam., ㅇ Bl. nur von $\infty$ schuppigen Hochb. umgeben. Frb. 2, vereint, mit je zwei aufsteigenden Sa. mit 1 Integ. Steinfr. - Holzgewächse mit ungeteilten B. $\sigma^{7} \mathrm{Bl}$. in Aehren, ㅇ Bl. einzeln.

Fam. Balanopsidaceae. - Balanops (7 Neu-Caledonien).

6. Reihe LEITNERIALES. Bl. $\sigma^{\top}$ ㅇ, diöcisch. $\sigma^{\top}$ Bl. achlam., mit 3-12 Stb. $\bigcirc$ Bl. mit einer aus kleinen, schuppenfy., vereinten B. gebildeten Blh. Cp. 1, mit langem Gr. und 1 amphitropen an der Bauchnaht stehenden Sa. mit 2 Integ. Steinfr. Nährgewebe dünn. - † mit (9), ganzrandigen B. und in Ähren stehenden $\mathrm{Bl}$.

Fan. Leitneriaceae. - Leitneriá-(2 im atlant. Nordam.).

7. Reihe JUGLANDALES. Bl. achlam. oder mit haplochlam. Blh., $\sigma^{7}$ 우 , monöcisch. $\sigma^{7} \mathrm{Bl}$. mit $3-40 \mathrm{Stb}$. 우 Bl. mit Cp. (2); G. stets 1 fächerig mit 1 grundständigen, geradläufigen Sa. mit 1 Integ. Chalazogam (ob alle?). Halbfr. steinfruchtartig oder nussartig. Nährgewebe 0 . - † mit (Q), meist gefiederte B. ohne Nebenb. Bl. in Ähren.

Fam. Juglandaceae. $ᄋ \mathrm{Bl}$. mit einer Blh., welche dem Frkn. angewachsen ist, auch mit dem Tragb. und den 2 Vorb. verwachsen. - Reich an Gerbstoff und Harz; aber keine Harzgänge. - Nördl. gemässigte Zone, wenige auch im trop. Ostasien. - Pterocarya fraxinifolia in Transkaukasien. - Juglans regia, Walnuss (Mediterrangebiet bis Himalaya), Bl. off.; J. nigra und J. cinerea in Nordamerika. - Cary $\iota$, Hickory (10 Nordam.).

8. Reihe FAGALES. Bl. cyklisch, homoiochlam., seltener nackt, selten ఫ̧, meist $\sigma^{\gamma}$ ㅇ, monöcisch. Stb. hfg. vor den B. der Blh. Cp. $(2-6)$, mit je 1-2 Sa. G. Halbfr. meist nussartig, mit nur $1 \mathrm{~S}$. ohne Nährgewebe. - \$ mit abwechselnden B. mit Nebenb. Bl. in einfachen oder aus Trugdöldchen zusammengesetzten Ähren. 
Fam. Betulaceae. Bl. $\sigma^{7}$ 오 monöcisch. Blh. hochblattartig, frei oder vereintblätterig oder 0 . $\sigma^{7} \mathrm{Bl}$. dem Tragb. aufgewachsen; 2-10 Stb. mit meist 2 teiligen A. $\quad$ Pl.: (2); 2 Gr.; $\bar{G}$. am Grunde 2 fächerig, mit 2 hängenden, umgewendeten Sa. mit 1 Integ. Chalazogam (ob alle?). Schliessfr. mit 1.S. ohne Nährgewebe. Vorb. der 우 Bl. mit dem Tragb. verwachsen oder eine Hülle bildend. Blütenstände einfache oder zusammengesetzte Ähren. - Nördl.gem. Zone, einige andin.

$\S$ Coryleae. $\sigma^{7} \mathrm{Bl}$. einzeln vor dem Deckb., ohne Blh.; 우 Bl. mit Blhb., die Vorb. der Schliessfr. als Hülle angewachsen. - Carpinus betulus, Hain- oder Weisshuche (Mitteleuropa bis Persien); ausserdem noch 11 Arten. - Ostrya (2). - Corylus (7); C. avellana, Haselnuss (Europa); C. tubulosa, Lambertsnuss (Südeuropa); C. colurna (Südosteuropa, Himalaya), baumartig.

$\S$ Betuleae. of $\mathrm{Bl}$. in Dichasien auf dem Deckb., mit Blh.; 우 Bl. ohne Blh., die Vorb. dem Deckb. angewachsen - Betula (35); B. vermucosc (nordwärts bis $65^{\circ}$ ) und $\boldsymbol{B}$. pubescens (nordwärts bis $71^{\circ}$ ), liefern Birkenteer. - Alnus, Erle (14).

Fam. Fagaceae. Bl. meist $\sigma^{7}$ ㅇ, selten ̧. Blhb. 4-7, hochblattartig, vereint. $\sigma^{7} \mathrm{Bl}$. mit $4-7$ oder $8-14 \mathrm{Stb}$. 우 $\mathrm{Bl}$.: Cp. (3), selten (6); Gr. 3. G. 3 fächerig mit je 2 hängenden Sa. mit 2 Integ. und Fr. einzeln oder gruppenweise von einer becherfg. Axenwucherung (»Fruchtbecher «) umgeben. Schliessfr. mit 1 S. ohne Nährgewebe. - 古 mit ungeteilten bis tief-fiederspaltigen B. mit Nebenb. Temp.-trop.; aber nicht in Afr. südwärts der Sahara.

S Fageae. Bl. in Dichasien in Laubblattachseln. - Nothofagus (12 antarktisch und südl. Anden). - Frıgus (4 nördl. temp.); $\boldsymbol{F}$. silvatica, Rotbuche (Europa, Nordgrenze $60^{\circ}$ ).

$\S$ Castaneeae. $ᄋ$ Bl. in Dichasien oder einzeln in den Achseln von Hochb. - Custaner (30); C. vulgaris, Edelkastanie (mediterran), lief. die Maronen. - Pusania (100 malayisch). - Quercus (200), Fr. essbar, Rinde gerbstoffhaltig; Q. tinctoria (Nordam.), lief. Quercitronrinde; Q. suber und Q. occidentalis (Spanien, Südfrankr., Algier), lief. Kork; Q. vallonea (Kleinasien) und Q. macrolepis (Griechenland), lief. Wallonen (Gerbmaterial); O. infectoria (östl. mediterran), lief. d. off. türkischen oder aleppischen Galläpfel; Q. sessiliflora, Wintereiche (Europa, Nordgrenze $60^{\circ}$ ), lief. deutsche Galläpfel; O.perlun"ulatı, Sommereiche (Europa, Nordgrenze $63^{\circ}$ ), lief. Knoppern; Rinde off. Auf Q. coccifer (mediterran) lebt Chermes Ilicis.

9. Reihe URTICALES. Bl. cyklisch, homoiochlam., selten nackt, meist $2 \cdot$, seltener $2+3$ gliedrig, meist $\oplus$. Stb. vor den B. der Blh. Cp. 2--1. G. mit nur 1 Sa. mit 2 Integ. Steinfr. oder Nüsschen. Bl. meist in trugdoldigen Blütenständen. - Kräuter und 4 mit abwechselnden oder gegenständigen B. mit Nebenb.

Fam. Ulmaceae. Bl, homoiochlan., 후 oder $0^{\pi}$ 오. Blhb. $4-5$ (seltener 3-8). Stb, ebensoviel, vor den Blhb., selten doppelt so viel. Cp. (2 median); Gr. 2. G. meist 1 fächerig, mit 1 vom Scheitel herabhängenden, 
umgewendeten Sa. Nuss oder Steinfr. S. meist ohne Nährgewebe. - t mit zweizeiligen, einfachen, oft ungleichseitigen B. mit Nebenb. Cystolithen. Bl. meist klein in achselst. Trugdolden oder die ㅇ einzeln.

Unterfam. Ulmoideae. Blütenstiele oder Blütenzweiger in den Achseln von Niederb.' Keine Steinfr. E. gerade. - Utmus, Rüster (16 nördl. temp. und trop. As.).

Unterfam. Celtidoideae. Blütenstiele oder Blütenzweige in den Achseln von diesjährigen B. Steinfr. E. gekrümmt. - Celtis (60 temp. trop.); C. australis, Zürgelbaum (mediterr.) und C. occidentalis (Nordam.) lief. vorzügliches Werkholz.

Fam. Moraceae. Bl. homoiochlam. mit bleibender, oft fleischig werdender Blh. oder nackt, $\sigma^{\top}$ ㅇ․ Blhb. meist 4 (selten 2-6). Stb. ebensoviel, vor den Blhb., selten nur 1. Cp. (2). Gr. 2 oder 1. G. 1 fächerig mit 1 vom Scheitel herabhängenden Sa., diese selten grundst. und geradläufig. Nuss oder Steinfr. Nährgewebe + oder 0. E. meist gekrümmt. - 市, selten Kr.; B. mit Nebenb. Bl. klein in trugdoldigen Blütenständen, welche oft Köpfchen oder Ähren bilden oder infolge intercalaren Wachstums der Axen zu Scheiben und Bechern werden. - Milchsaftschläuche im Leptom - Cystolithen hfg.

Unterfam. Moroideae. Sth. einwärts gebogen. Sa. am Scheitel, amphitrop. B. in der Knospenlage gefaltet, mit kleinen Nebenb.

$\S$ Fatoueae. Bl. in lockeren Trugdolden. - Trop.

$\S$ Moreae. Bl. $\sigma^{\top}$ und $q$ in Scheinähren, jeder Blütenstand eingeschlechtlich. - Morus, Maulbeerbaum (10 nördl. temp.); M. nigra (aus Persien stammend); $\boldsymbol{M}$. alba (aus China stammend, seit dem 12. Jahrhundert im Medit. cult.), Hauptnahrung der Seidenraupen.

$\S$ Broussonetieae. $\sigma^{\top} \mathrm{Bl}$. in Scheinähren, Scheintrauben, Scheinköpfchen; $\subsetneq$ Bl. in kugeligen Scheinköpfchen. - Maclura aurantiaca, Osage Orange (Nordam.) lief. essbare Fruchtstände. - Chlorophora tinctoria (trop. Amer.), giebt Gelbholz. - Broussonetia papyrifera und B. Kaempferi (Japan) liefert Rinde zur Papierbereitung.

§ Strebleae. $\sigma^{7} \mathrm{Bl}$. in Scheinähren oder Trauben; 우 Bl. einzeln oder zu 2-4. - Trop. As.

$\S$ Dorstenieae. Bl. monöcisch auf linealischen, kreisel- oder scheibenfg. Receptaculis. - Dorstenia (60 trop.); D. contrajerva (trop. Amer.), lief. Bezoarwurzel, Radix Contrajervae.

Unterfam. Artocarpoideae. Stb. stets gerade. Sa. am Scheitel, amphitrop. B. in der Knospenlage eingerollt. Nebenb. meist stengelumfassend, abfallend.

§ Euartocarpeae. Scheintrauben, Scheinähren, Scheinköpfchen, selten die + Blütenstände mit nur $1 \mathrm{Bl}$. - Treculia africana, Okwabaum im trop. Afr.; Samen zu Mehl verarbeitet. - Artocarpus (40); A. integrifolia, Jack-tree, und A. incisa, Brotfruchtbaum (ursprünglich indischmalayisch), wichtige Nährpflanzen der Tropen.

§ Olmedieae. Kugelige oder scheibenfge. Receptacula, von dachig angeordneten Hochb. umhüllt, 1 geschlechtlich. S. ohne Nährgewebe. E. 
gerade. - Crstilloa elısticu (Mexico, cult. in Westind.), lief. Kaut schuk. - Antirris toxicuria, Upasbaum (ind.-malay.), lief. Pfeilgift.

§ Brosimeap. Receptacula kugelig oder hohl, mit $\infty \delta^{\pi} \mathrm{Bl}$. und 1 o $\mathrm{Bl}$. in der Mitte, sonst wie vorige. - Brosimum alicastrum, Brotnussbaum (Centralam., Westind.), lief. Kautschuk; B. galactoAendron, Milchbaum (Venezuela), lief. geniessbare Milch.

§ Ficeae. Receptacula kugelig oder verkehrt-eiförmig, innen unterhalb der Mündung mit $\infty$ Hochb., $\infty$ Bl. einschliessend. - Ficus (600 trop., wenige extratrop.); F. elustica, Gummibaum (Ostind.), wichtigster Kautschukbaum; $\boldsymbol{F}$. bengalensis, Banyan; $\boldsymbol{F}$. religiosı sowie $\boldsymbol{F}$. Tuccifer (alle in Ostind.) geben Schellak, Gummi Laccae infolge von Insektenstichen; P. sycomorus, Sykomore (Ägypt., Ostafr.), lieferte das $\mathrm{Holz}$ zu den Mumiensärgen; F. carica, Essfeige (Mittelmeergebiet).

Unterfam. Conocephaloidecie. Stb. gerade. Sa. am Grunde oder am Scheitel des Frkn., geradläufig oder etwas gekrümmt. B. wie bei den Artocarpoideae. - Cecvopia (30-40 trop. Amer.), lief. Kautschuk; einzelne myrmekophil.

Unterfam. Canmaboideae. Stb. gerade. Sa. am Scheitel des Frkn. Trockene Schliessfr. S. mit fleischigem Nährgewebe und gekrümmitem Embryo. - Kr. mit opp. oder (9) B. mit freien Nebenb. - Humulus lupulus, Hopfen (nördl. temp.); die Strobili Lupuli enthalten das Lupulin in Drüsen. - Cumnubis sutiva, Hanf, wichtige Ge. spinnstpfl., lief. ausserdem in den Samen Öl; off. d. Herba Cannabis indicae (Haschisch).

Fam. Urticaceae. Bl. selten $\not$, meist $\sigma^{\pi}$ ㅇ. Blhb. 4-5 (selten 2 bis 3). Stb. ebensoviel und vor den B. der Blh., in der Knospenlage nach innen gebogen, später elastisch zurückschnellend. Stets $1 \mathrm{Gr}$. G. 1 fächerig mit 1 grundst., geradläufigen Sa. Nuss oder Steinfr. S. mit Nährgewebe. E. gerade. - Meist Kr., seltener $\hbar$ mit opp. oder (2) B., und Nebenb. Bl. in Trugdolden oder Scheinähren oder Scheinköpfehen. - Kein Milchsaft. Lange Bastfasern. Cystolithen.

A. Mit Brennhaaren.

§ Urereae. Blh. der $q$ Bl. 4 gliedrig. B. (9) oder opp. - Urtica aioir (nördl. temp.), U. cammabina (Persien, Sibirien) und Taporteı crmudensis (Nordam.), Gespinnstpfl.

B. Keine Brennhare.

$\S$ Procrideae. Blh. der $q \mathrm{Bl}$. meist 3 gliederig. N. pinselfg. - Pilea (100 trop.). - Elatostema (60 trop.).

§ Boehmerieae. $\sigma^{7}$ Bl. mit $4-5$ (selten 2-3) Stb. Vorb. nie zu einem Involucrum vereint. - Boehmeria nivea, Ramie (temp. und trop. Ostasien), wichtige Gespinnstpfl. (Nesseltuch). - Maoutia puya (Himalaya), Gespinnstpfl.

§ Parietarieae. Blhb. stets vorhanden. Vorb. hfg. zu einem Involucrum vereint. - Parietaria (7 temp.-trop.). 
$\S$ Forskaoleene. $\sigma^{7} \mathrm{Bl}$. mit nur $1 \mathrm{Stb},-$ Forskaolea.

b. Reiheu, welche vorherrschend Pfl, mit haplochlamydeischer, hochblattartiger oder corollinischer Blh. nmfassen. Heterochlamydie selten.

10. Reihe PROTEALES. Bl. cyklisch, homoiochlarn., meist 2 gliederig, mit den Stb. vor den Blhb., hypogyn., ㅎ oder $\sigma^{\top}$ 우 $\phi$ oder $\%$ Blh. petaloid. Stb. selten ganz frei, meist mit den B. der Blh. vereint, nur die A. frei. Cp. 1. - Meist t nit abwechselnden ungeteilten oder fiederteiligen B. ohne Nebenb. Bl. in Ähren oder Trauben.

Fam. Proteaceae. G. mit $\infty-1$ Sa., mit 2 Integ. an der Bauchnaht. Balgfr. oder Schliessfr. S. ohne Nährgewebe. E. bisweilen mit 3-8 Keimb. - 1000, davon 590 in Australien, 262 in Südafrika, 27 in Neu-Caledonien, 25 in Ostasien, 36 im tropischen Südamerika, wenige im trop. Afrika und in anderen Teilen der südlichen Hemisphäre.

Unterfam. Persoonioidece. Bl. einzeln in den Achseln der 'Tragb. G. meist mit nur 1 Sa. Fr. stets 1 samig.

$\S$ Persoonieae. Blh. $\oplus$, mit freien B. Stf. frei oder nur wenig mit der Blh. vereint. - Personnia (60 Australien).

$\S$ Franklandieae. Blh. $\emptyset$; mit enger Röhre. Stf. mit der Blh, vereint. Franklandia (Austral.).

$\S$ Proteoae. Bl. $\phi$ oder $\uparrow$, mit enger, sich spaltender Röhre. Stf. mit der Blh. vereint; Antheren meist sämmtlich fruchtbar. - Proteci (70 Afrika, insbesondere Kapland). - Levcadendron (70 Kapland); $I$. argenteum. - Ausserdem viele andere im Kapland, weniger in Australien.

$\S$ Conospermeae. Blh. $\cdot$. Stf. oberwärts frei. Von den 4 Antheren 1 dithecisch, 2 monothecisch, 1 steril. - Australien.

Unterfam. Grevilleoidere. Bl. meist paarweise in den Achseln der Tragb. Frkn. mit mehreren oder 2 stets umgewendeten Sa. Fr. init $\infty-1$ S., meist aufspringend.

\$ Grevilleeae. Blütenstand meist ohne Involucrum. G. meist nur mit 2, selten mit 4 Sa. Fr. ohne Scheidewänd zwischen den S. Grevillea (160 Austral.). - Hakea (100 Austral.). - Helicia (25 ind.malay.). - Roupala (trop. Am.).

\& Embotlurieae. Blütenstand meist mit Invol. G. mit wenigstens 4 Sa. und mit Scheidewänden zwischen den S. - Austral., Neu-Caledon., Südamerika.

§ Banksieae. Blütenstand meist mit Invol. G. mit 2 Sa. - Bronksia (46 Austral.). - Dryandra (50 Austral.).

11. Reihe SANTALALES. Bl. cyklisch, homoiochlam. mit den Stb. vor den Blütenhb., seltener heterochlam. und haplostemon oder diplostemon. Cp. ( $\overline{2-3})$, selten nur $1 ; \mathrm{zu}$ jedem Cp. eine vom Scheitel der Fächer oder von einer centralen freien Plac. herabhängende Sa. gehörig oder die Plac. und Sa. nicht ausgegliedert*); bisweilen auch das ganze

*) Die in dlesem Verwandtschaftskreis vorkommenden Modiflkationen in der Lage der Makrosporen oder Embryosäcke nötigen mich zu folgender Erweiterung des Begriffs Placenta: Placenta ist der Teil des Gynöceums, welcher die Makrosporen (Embryosiicke) und damit auch die Samenanlagen einschliesst (ungegliederte Placenta) oder aber \pm frei werdeude, die Makrosporen umschliessende Körper, die typischen Samenanlagen, ausglledert. 
Gynöceum auf einen ungegliederten, die Makrospore einschliessenden Zellkörper reduciert (Balanophora). Sind deutlich hervortretende Sa. vorhanden, dann entbehren dieselben der Integumente oder besitzen nur eines.

1. Unterreihe Santalineae. Sa. aus den Placenten ausgegliedert, hüufig ohne Integ., bei den Olacaceae auch mit 2 und 1 Integ.

Fam. Myzodendraceae. Bl. $\sigma^{\nearrow}$ ㅇ. $\sigma^{7}$ nackt, mit $2-3$ (oder 1) Stb. mit monothecischen A, \& mit einer dem Stempel angewachsenen Blh. (?). Cp. (3); 3 N G. mit centraler Plac., an welcher $3 \mathrm{Sa}$. ohwe Integ. herabhängen. Fr. 3 kantig oder 3 flügelig, mit 3 in den Furchen stehenden, stark verlängerten, federartigen Borsten. - Halbsträucher, wie die Loranthıceae. Halbparasiten, mit (9) B. und sehr kleinen Bl. - Myzodendron (9 Südchile), besonders auf den antarktischen Nothofugus.

Fam. Santalaceae. Bl. $\oplus$, 호 oder $\sigma^{\nearrow}$ 우, monöcisch oder diöcisch; homoiochlam. mit becherfg. Axe. Blhb. 4-5, (selten 3 oder 6), klappig, hochblattartig oder corollinisch, unterwärts vereinigt; Stb. vor den Blhb., mit dithecischen A. Cp. mit den Blhb. abwechselnd. G. einfächerig mit centraler Placenta, von welcher $1-3$ (selten $4-5$ ) integumentlose Sa. mit heraustretendem Embryosack herabhängen. Halbfr. S. nur 1, mit Nährgewebe. - Kr. oder $\frac{\hbar}{\mathrm{b}}$ mit (?) oder gegenst. B. meist chlorophyllhaltige Halbparasiten. Bl. meist klein. - 250 calid., temp.

§ Anthoboleae. Blh. hypogynisch. - Exocurpus (Austral., ocean. Inseln).

$\S$ 0syrideae. Blh, epigynisch, keine Röhre oberhalb des G., oder wenn eine solche vorhanden, dann mit dem Discus bekleidet. - Osyris alba (medit.). - Santalum album, Sandelholzbaum (ind.-malay.).

§ Thesieae. Blh. epigynisch, Röhre oberhalb des G. verlängert, innen nicht mit dem Discus bekleidet. - Thesium (130 meist Eur., As., Afr.).

Fam. Opiliaceae. Bl. ఫ̧, mit undeutlich gesäumtem Kelch. G. mit nur 1 Sa. ohne Integ. - Opilia (palaeotrop.)

Fam. Grubbiaceae. Bl. homoiochlam., diplostemon., $\emptyset$, ̧. . Blhb. hochblattartig, 4 klappig. Stb. $4+4$, mit rudimentären Hinterfächern der Thecae. Cp. (2). Gr.) kurz G. in der Jugend unten 2 fächerig, dann 1 fächerig, mit 2 an centraler Placenta hängenden geradläufigen Sa. mit 1 Integ. Halbfr. steinfruchtartig. S. 1 mit öligem Nährgewebe. - $\hbar$ mit gegenst. lederartigen B. und kleinen Bl. Niemals Halbparasiten. - Grubbia (3 Südafr.).

Fam. Olacaceae. Bl. heterochlam., $\oplus$, meist $\Varangle$. Kelch meist undeutlich, 4 bis $6 z a ̈ h n i g$, bei der Fruchtreife häufig bedeutend vergrössert. P. 4-6, meist klappig. Stb. ebenso viel, oder $2-3 \mathrm{mal}$ so viel. $\mathrm{Cp}$. (2-5). (Gr.). G. nur unten 2-5 fächerig, mit meist freier Plac., von welcher in die Fächer meist je 1 umgewendete Sa. herabhängt, diese meist ohne Integ., seltener mit 1 oder 2. Steinfr. oder Nuss 1 samig. S. mit reichlichem Nährgewebe. - to mit meist (?) ganzrandigen B. und meist kleinen Bl. Niemals Halbparasiten. In den Blättern häufig Zellgruppen mit verkieselten Wandungen. - Calid.

Sa. nackt, geradläufig, den Eıbryosack nach unten kelırend.

Unterfam. Schoepfloideae. Stb. nur vor den Blb. - Kelchsauın nicht deutlich. - Schoepfic (trop).

Unterfam. Olacoideae. Sa. nackt, ungewendet und den Embryosack nach oben kehrend. Kelch bei Fruchtreife \pm vergr. - Olar (palaeotrop). - Dulacia (neotrop).

Unterfam. Dysolacoideae. Sa. mit 1 oder 2 Integ., ungewendet und den Embryosack nach oben kehrend. Kelch nicht selten bei der Fruchtreife vergr. 
\& Heisterieae. Stb. doppelt so viel als Blb. oder ebensoviel und dann mit den Blb. abwechselnd. - Milchsaftschläuche in den B. - Heisteria (trop. Am. Afr.).

\& Couleae. Stb. 4 mal so viel als Blb. - Schizogene Harzbehälter in der Rinde und den B. - Coula edulis in Westafr.

2. Unterreilie Loranthineae. Sa. meist nicht a sgegliedert. Makro. sporen (Embryosäcke) n einem centralen convexen Körper, welcher aus der Basis der Cp. congenital emporgewachsen ist, genau vor den einzelnen Cp. entstehend, oder in den Wänden der Cp. eingeschlossen.

Fam. Loranthaceae. Bl. homoiochlam., meist $\oplus$, selten fast $\%$, oder $\sigma^{\nearrow}$ 우, 2-3 gliederig. Axe \pm becherfg., mit dem G. vollständig vereint, nicht selten um die Basis der Blh. als gekerbter oder gezähnter Rand hervortretend. Blhb. 4-6, hochblattartig oder corollinisch, Stb. so viel als Blhb. und vor denselben, frei oder mit denselben vereint. G. meist ohne Ausgliederung der Plac. und der Sa.; von den Embryosäcken meist nur 1, selten 2-3 fruchtbar, dieselben dem Pollenschlauch entgegen wachsend. Halbfrucht, in welcher die Innenschicht der Bl.-Axe verschleimt und klebrig wird. Nährgewebe \pm . E. mit 2 oder $3-6$ Keimb. - †, selten krautartig, meist auf Bäumen durch Haustorien befestigte, chlorophyllhaltige Halbparasiten, meist mit vollkommen entwickelten Laubb. 550 , vorzugsweise trop.

Unterfam. Loranthoideae. Unterhalb der Blh. 2 damit verwachsene Vorb. oder eine \pm deutliche Wucherung an der Blütenaxe, der „Calyculus«. Halbfr. mit klebriger Mittelschicht (Viscinschicht) ausserhalb der zu den Blhb. führenden Leitbündel.

$\S$ Nuytsieae. Stamm mit Secretgängen. Kein Calyculus; aber die Bl. unten mit den beiden Vorb. verwachsend. Sa. ausgegliedert, ohne Integ., mit einander verwachsend. Halbfr. trocken 3 flügelig, Viscinschicht schwach. - Nicht parasitisch. - Nuytsia (Austral.).

§ Lorantheae. Stamm ohne Secretgänge. Calyculus. Sa. nicht ausgegliedert. Halbfr. beerenartig oder steinfruchtartig. - Struthanthus (40 Südam.), mit Haustorien am windenden Stengel. - Psittacantlus (50 trop. Am.). - Oryctantlus (8 trop. Am.) mit kriechenden Wurzeln, an denen Haustorien entstehen. - Loranthus (220 in den Tropen der alten Welt, wenige extratropisch, wie $I$. europaeus).

Unterfam. Viscoidece. Unterhalb der Blh. keine deutliche Calyculuswucherung. Bl. stets $\sigma^{7}$ 오. Halbfr. mit klebriger Mittelschicht zwischen den zu den Blhb. und den zu den Cp. führenden Leitbündeln.

$\S$ Eremolepideae. Bl. in einfachen Ähren oder Trauben, die Tragb. der $\sigma^{\top}$ Bl. leicht abfallend. - Meist antarktisch und südamerikanisch. - Eremolepis (Südam.).

$\S$ Phoradendreae. Bl. in Gruppen in den Achseln von persistierenden Hochb. oder extraaxillär an den Internodien sitzend. Placenta central. Embryosäcke U-förmig aus der Placenta im Bogen in die Wandung des G. eintretend. - Dendrophthora (Westindien). - Phoradendron (80 Nord- und Südamerika).

§ Arcenthobieae. Embryosäcke in der Placenta eingeschlossen bleibend und in dieser aufsteigend. A. mit cinem Fach. - Arceuthobium (nördl. temp.). - A. Oxycedri (mediterr.). 
\$ Visceae. Bl. einzeln oder in Gruppen in den Achseln von persistierenden Hochb., selten endstg. Placenta basal. A. mit mehr als 4 oder c Fächern. - Viscum album, Mistel, mit unter der Rinde wachsenden Rindensaugsträngen und Senkern, in Europa und Asien; viele Arten in Afr., Am., Austral.

3. Unterreihe Balanophorineae. Placenta central mit hangenden Sa. ohne Integ. und freien Embryosäcken oder die letzteren umschliessend. Chlorophyllose Wurzelparasiten.

Fam. Balanophoraceae. Bl. haplochlam., homoiochlam. oder nackt, meist $\sigma^{x}$ ㅇ. $\sigma^{x}$ : Blhb. 3-4 (selten 2-8), unterwärts vereint. Stb. ebenso viel oder $1-2$, mit 1 -vielfächerigen A. \%: Blh. meist 0 , Cp. (1-2, selten $3-5)$; Gr. $1-2$ oder $(3-5)$. G. mit einer centralen selten freien und hängende nackte Sa. tragenden, häufig mit der Wandung des G. zusammenhängenden Placenta, in welcher in der Regel so viel Embryosäcke liegen, als Gr. vorhanden sind. Nuss oder Steinfr. mit 1 S. Nährgewebe +, ölreich. E. klein ohne Keimb. Bisweilen Apogamie des o Sexualapparates und ein Embryo aus dem oberen Embryosackkern her: vorgehend. - Fleischige Wurzelparasiten, reich an Stärke oder wachsartigem Balanophorin mit knolligem, selten cylindrischem Rhizom, durch knollige Anschwellungen oder kurze Fortsätze den Nährwurzeln aufsitzend; Stengel mit Niederb. meist endogen im Rhizom entstehend und dasselbe durchbrechend; $\mathrm{Bl}$. klein, in einfach kopffg. oder kolbenartigen, seltener verzweigten Blütenständen. - 40 calid.

Unterfam. Mystropetaloideae. Bl. $\sigma^{7}$ ㅇ monöcisch, mit Blh. $\sigma^{7}$ Bl. mit 3lappiger zygomorpher Blh. und 2 Stb. Placenta mit 3 hängenden nackten auf den Embryosack reducierten Sa. - Mystropetalum (2 Südafr.).

Unterfam. Dactylanthoideae. $\sigma^{7} \mathrm{Bl}$. nackt, mit 1-2 Stb. $q$ Bl. mit Blh. Blütenstand verzweigt. - Dactylanthus (1 Neu-Seeland).

Unterfan. Sarcophytoideae. 우 weibliche Bl. nackt. Placenta mit 3 hängenden nackten, auf den Embryosack reducierten Sa.; kein Gir. Rhizom stärkehaltig Blütenstand verzweigt. - Sarcophyte sanguinea (Süd- und Ostafrika).

Unterfam. Lophophytoidecie. \& Bl. nackt. Placenta mit 2 hängenden nackten auf den Embryosack reducierten Sa. or Bl. nackt mit 2 Stb. Rhizom stärkehaltig. - Lophophytum mirabile (hfg. in Brasil.).

Unterfam. Scybalioideae. ㅇ Bl. nackt. G. mit centraler, oben freier, 2 oder mehr Embryosäcke einschliessender Placenta. Gr. 2. Rhizom stärkehaltig. - Scybalium (4 trop. Am.). - Helosis (4 trop. Am.). - Rhopalocnemis (1 Java und Ostind., 2 trop Am.).

Unterfam. Balanophoroidece. Rhizom Balanophorin enthaltend. † Bl. zu einem kegelförmigen, den Embryosack einschliessenden Körper reduciert. - Apogamie und der Embryo aus dem oberen Embryosackkern hervorgehend bei Balanophora (12 trop. Asien und Austral.); aus dem wachsartigen Harz werden Kerzen verfertigt. - Langsdorffic hypogaea im trop. Amerika, zur Kerzenbereitung verw. - Thonningia sanguinea (trop. Afr.).

12. Reihe ARISTOLOCHIALES. Bl. cyklisch, homoiochlam., epigyn., $\oplus$ oder $\%$ Jlh. corollinisch. G. meist unterst., 3-6 fächerig mit centralwinkelst. Plac. oder $1 \mathrm{fächerig} \mathrm{mit} \mathrm{wandst.} \mathrm{Plac.} \mathrm{und} \infty$ Sa. 
Fam. Aristolochiaceae. Bl. meist ఫ⿱一, $\oplus$ oder $\%$. Blh. meist 3 gliederig, vereintblätterig, corollinisch. Stb. $6-36$, selten 5 , frei oder mit Gr. vereint, meist mit extrorsen A. G. meist unterst., 4-6-, selten 5 fächerig, mit $\infty$ umgewendeten Sa. in den Fächern. Sa. mit 2 Integ. Kapsel. $\mathrm{S}$. mit Nährgewebe und kleinem $\mathrm{E}$. - Kr. oder $\mathrm{t}$, letztere windend. B. (Q), meist einfach, ohne Nebenb.

§ Asareae. Bl. Ф. Kr. mit nierenfg. B. G. halbkugelig. - Asamum (13 nördl.-temp.); A. europaeum (Rhizoma Asari).

\$ Apameae. Bl. $\oplus$. † mit länglichen B. G lineal. - 10 ind.-malay.

§ Aristolochieae. Bl. $\%$ - Aristolochia (180 trop.temp.); A. sipho, Pfeifenblume (atlant. Nordam.); A. serpentaria (Nordam.), lief. Rhizoma Serpentariae; $A$. clematitis, Osterluzei (Eur.); $A$. longa und $A$. rotunda (Mittelmeergebiet) lief. Tubera Aristolochiae rotundae und longae.

Fam. Rafflesiaceae. Bl. selten $\not{q}$, meist $\sigma^{\nearrow} \circ$, epigyn., $\oplus$. Blh. 4-5 gliederig. A. $\infty$ an der Unterseite des scheibenfg. Columnarandes, dicht unterhalb der ringfg. N. G. 1 fächerig und mit 4 oder $6-8$ wandst. Plac. oder mit $\infty$ gewundenen Kammern, mit $\infty$ Sa. mit 2 Integ. Beere mit $\infty$ S. E. ungegliedert im Nährgewebe. - Parasiten mit thalloidischem Haftorgan; Sprosse sehr kurz mit Niederb. und 1 endst. Bl. oder Blütentraube.

$\S$ Rafflesieae. 1 Endbl. G. mit $\infty$ unregelmässigen Spalten, deren Wände mit $\infty$ geradläufigen Sa. mit 1 Integ besetzt sind. A. $\infty$ in 1 Kreis. - 10 trop. As. - Rafflesia Arnoldii in Sumatra, die grösste Bl. der Erde mit $1 \mathrm{~m}$ Durchmesser; R. patma auf Java; beide auf Wurzeln von Cissus-Arten.

$\S$ Apodantheae. 1 Endbl. G. 1 fächerig mit wandst. sitzenden Sa. mit 2 Integ. A. in 2 oder 3 Kreisen. Stammparasiten. - Apodanthes (2 Brasil. auf Flacourtiaceae). - Pilostyles (8 Amer., Afr., Syr., auf Leguminosen).

§ Cytineae. Traube. A. in einem Kreis. G. mit verzweigten Plac. - Cytinus hypocistis auf den Wurzeln von Cistus im Mediterrangebiet; eine zweite Art' in der Kapkolonie auf der Composite Erioceplaalus racemosus; eine dritte in Madagaskar auf dem Stamm der Hamamelidacee Dicoryplee. - Scytantlus (4 Mexiko).

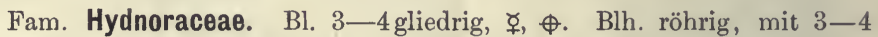
fleischigen, klappigen Abschnitten. Stb. 3-4 an der Innenseite der Röhre, seitlich mit einander verwachsen, mit $\infty$ linienfg., parallelen Pollenfächern, bisweilen auch noch 3 tiefer stehende Std. G. 1 fächerig, mit 3 Gruppen wandst., plattenfg. Plac., mit $\infty$ geradläufigen Sa. mit 1 Integ. Beere mit fast holziger Schale, quer aufspringend. Nährgewebe aus Perisperm und Endosperm bestehend, mit kleinem, kugeligem oder eiförnigem E. Hydnora (7 Afr.). - Prosopanche Burmeisteri (Argentinien).

13. Reihe POLYGONALES. Bl. homoiochlam. oder heterochlam., $\oplus$. G. 1 fächerig mit 1 aufrechten, nur selten umgewendeten Sa. nit 2 Integ. $\bar{B}$. meist mit Ochrea. 
Fam. Polygonaceae. Bl. cyklisch oder teilweise (9, homoiochlam. oder heterochlam., ̧ oder $\sigma^{7}$ ㅇ, $\oplus$. Blhb. 3-6. Stb. 6-9, seltener weniger oder mehr, teilweise verdoppelt. Cp. (3) oder (2), selten (4) mit 3, 2, $4 \mathrm{Gr}$. G. 1 fächerig mit 1 aufrechten, bisweilen umgewendeten Sa. Nuss. S. mit reichlichem, mehligem Nährgewebe. E. gerade oder gekrümmt. $\mathrm{Kr}$., seltener Sträucher oder $t$, mit meist (Q), selten gelappten oder gespaltenen B., meist mit stengelumfassender, häutiger oder fleischiger Ochrea. B1. meist klein in zusainmengesetzten Blütenst. - Etwa 600.

Unterfam. Rumicoideae. Bl. cyklisch. Nährgewebe der S. "nicht zerklüftet.

\$ Eriogoneae. Laubb. meist ohne Ochrea.

* Koenigiinae. Teilblütenstände ohne Involucrum. - Koenigia islandica, circum. polar. - Pterostegia (1 Kalif.).

* Eriogoninae. Teilblütenstände mit Involucrum. - Chorizanthe (34 Kalif., Chile). Eriogonum (120 westl. Nordam. und Mexiko).

§ Rumiceae. Laubb. mit Ochrea. - Rumex (etwa 100, grösstenteils *); R. acetosa, P. patientia, Gem üsepfl. - Oxyria (arktisch und alpin). - Rheum, Rhabarber (20 von Sibirien bis zum Himalaya und Palästina), Wurzel und Rhizom enthalten Chrysophansäure; Rh. palme tum, var. tanguticum (Westchina) lief. d. off. Kron-Rhabarber (Radix Rhei moscovitici); Rh. officinale (Tibet, Westchina) lief. d. off. Canton-Rhabarber; $R h$. rhaponticum, Rh. undulatum u. a. Gemüsepfl.

Unterfam. Polygonoideae. Bl. meist (9. Nährgewebe nicht zerklüftet.

S Atraphaxideae. Sträucher. - Atruphaxis (17). - Calligonum (20). - Alle in Steppen d. östl. Medit. und Centralas.

§ Polygoneae. Kr., selten Halbsträucher. - Polygonum (150 meist temp.); $P$. tinctorium (China) lief. chinesischen Indigo; $P$. bistorta, Natterwurzel (*), Futterpfl. - Fagopyrum, Buchweizen; F. esculentum (Mittel- und Ostasien; auf Oedland cult.) lief. die Heidegrütze, ausserdem Bienenfutterpfl., desgl. $F$. tataricum.

Unterfam. Coccoloboidece. Bl. (9, Nährgewebe zerklüftet.

$\S$ Coccolobeae. Bl. ̧ oder $\sigma^{\top}$ 우, vielehig. - Mühlenbeckia $(15$ *); M. platyclada (Salomonsinseln) mit Flachsprossen. - Coccoloba (125 Amer. calid.); C. uvifera in Warmhäusern.

§ Triplarideae. Bl. $\delta^{\top}$ q, zweihäusig, oder wenn $̧$, dann nur 3 Stb. vor den inneren Blhb. - Nur Südam.

c. Reihe mit haplochlam., hochblattartiger oder corollinischer Blh. Heterochlamydie auch schon mehrfach auftretend.

14. Reihe CENTROSPERMAE. Bl. () oder cyklisch, homoiochlam, oder heteruchlam. Stb. hfg. so viel wie Blhb. und vor diesen, aber auch $\infty-1$. Cp. $1-\infty$, meist vereint. G. meist oberst., seltener unterst., selten mehrfächerig, meist einfächerig mit $1-\infty$ krummläufigen (campylotropen) Sa. meist mit 2 Integ. (ausgenommen Cynocrambac.). Nährgewebe Perisperm. E. gekrümmt. Meist $\mathrm{Kr}$.

1. Unterreihe Chenopodiineae. Blh. stets homoiochlain., bracteoid, nicht uber 5 Blhb. Stb. meist vor diesen. G. meist mit 1 Sa. 
Fam. Chenopodiaceae. Bl. (9), homoiochlam., ఫ̧ oder $\sigma^{\top}$ \%, meist $\oplus$. Blhb. 5, 3, 2 (selten 4, 1,0), dachig. Stb. so viel oder weniger als Blhb. und vor diesen, in der Knospe einwärts gebogen. Cp. (2), seltener (3-5), mit meist ebensovielen Griffelschenkeln. G 1 fächerig mit 1 grundst. Sa. Nuss oder mit Deckel sich öffnende Fr., von der bleibenden Blh. umgeben. E. gekrümmt, der Samenschale anliegend. Nährgewebe Perisperm. Meist Kr., selten $\hbar$, mit meist (9, kahlen oder behaarten, oft fleischigen, ganzrandigen oder unregelmässig gezähnten B. ohne Nebenb. und sehr kleinen, unscheinbaren Bl. in meist knäueligen, trugdoldigen, racemös vereinigten Partialinflorescenzen. - Etwas über 500, meist Bewohner der Steppen und Wüsten, insbesondere auf Salzboden, ein Teil weitverbreitete Ruderalpfl. fassend.

A. Cyclolobeae. E. ringfg. oder hufeisenfg., das Nährgewebe um-

a. Wurzel und Stamm mit normalem Dickenwachsthum der primären Bündel.

§ Polyenemeae. Kr. oder Halbstr. mit ఫ̧ Einzelbl. in den Achseln der Tragb. - Polycnemum (5 medit., Eur.).

b. Wurzeln oder auch bei längerem Dickenwachsthum der Stamm mit extrafascialem Cambium.

a. Fr. nach der Reife oder bei der Keimung mit Deckel sich öfnend.

$\S$ Beteae. - Hablitzia tamnoides, Kletterpfl. (Kaukasus). - Betı vulgaris, Mangold, rote Rübe, Futterrübe (Küsten Südeuropas); d. Var. rapa, Zuckerrübe, lief. durchschnittlich $12-14 \%$ Zucker.

३. Fr. meist geschlossen oder un regelmässig zerreissend.

I. Bl. in knäueligen, seltener ährigen Inflorescenzen. Griffelschenkel ringsum papillös.

1. Fr. bis zur Reife von der Blh. oder von Vorb. umhüllt.

$\S$ Chenopodieae. Bl. meist $\not{+}$, proterogyn. Stb. 1-5. Blhb, meist krautig, frei oder höchstens bis zur Mitte vereint. Meist Blasenhaare. Chenopodium (etwa 50, meist temp.); Ch. quinoa (Anden von Peru), S. dort Nahrungsmittel; Ch. ambrosioides' (Mexiko), Theesurrogat.

$\S$ Atripliceae. Bl. meist $\sigma^{\top}$ ㅇ. $\sigma^{\top}$ mit Blh. und ohne Vorb. ㅇ ohne Blh. und mit Vorb. Blasenhaare oder Sternhaare. - Atriplex (100 temp., subtrop.). - Spinacia (4 Orient); S. oleracea, Spinat, Gemüsepfl.

§ Champliorosmeae. Bl. ̧ ohne Vorb. Stb. 4-5. Blh. häutig, höchstens bis zur Mitte frei. B. seidenhaarig. - Camphorosina (5 Südeur., As.).

2. Fr. bei der Reife nackt.

§ Corispermeae. - Corispermum (8 Südeur., As., westl. Nordam.).

II. Bl. in keuligen oder zapfenahnlichen Inflorescenzen oder in Höhlungen scheinbar blattloser Zweige.

$\S$ Salicornieae. - Salicornia (8 auf Salzboden). - Art/rocnemum (7 As., Afr., Austral.). 
B. Spirolobeae. E. spiralig aufgerollt, das Nährgewebe fehlend oder durch den E. in 2 gesonderte Massen geschieden.

a. Bl. ohne Vorb., die $\sigma^{\top}$ nackt in ahriger Inflorescenz, die zeln, axillär.

§ Sarcobatideae. Sarcobalus (1 Strauch, Nordam.).

b. Bl. mit Vorb., $\Varangle$ und $\sigma^{\top}$ 우, in Knäueln in den Achseln der Tragb. oder von gegenst. Scheidenb.

§ Suaedeae. Vorb. klein. Griffelschenkel ringsum papillös. B. fleischig, kahl. - Suaeda (40 an Meeresküsten und in Salzwästen).

$\S$ Salsoleae. Vorb. so gross oder grösser als die Blhb. Griffelschenkel nur innen papillös. B. meist mit Fadenhaaren. - Traganum (2 Nordafr., Arab., Kanar.). - Haloxylon (10 Südeur., As.); H. ammodendron, Saxaul, Baum in den Steppen Vorderasiens. - Salsola (40); S. kali (*), S. soda (medit.) u. a. liefert Soda. - Anabasis (15 medit., As.).

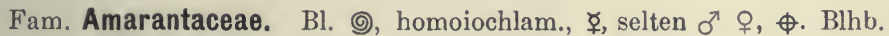
$4-5$, meist häutig, frei oder zusammenhängend. Stb. 1-5, hypogyn., vor den Blhb., \pm am Grunde vereint. Cp. $(2-3)$, mit einfachem oder $2-3$ spaltigem $\mathrm{Gr}$. G $1 \mathrm{fächerig} \mathrm{mit} \infty-1$ aufrechten oder an langem Funiculus hängenden Sa. Nuss, selten Beere. S. linienfg. oder nierenfg., zusammengedrückt oder geschwollen, mit meist glänzender Schale und mehligem Nährgewebe. E. ringfg. peripherisch, mit dünnen Keimb. Kr. oder Sträucher, selten $\hbar$, mit gegenst. oder wechselst., ganzrandigen B. ohne Nebenb. Bl. klein, oft zum Teil steril, in Trugdöldchen, welche $\mathrm{zu}$ ährigen und rispigen Blütenständen vereint sind. - Etwa 500 calid. - temp.

$\S$ Celosiear. G. mit $2-\infty$ S. Theken der A. 2 fächerig. B. abwechselnd. - Celosia (30 calid.); C. cristata Hahnenkamm (Ostind.).

$\S$ Amaranteae. G. mit 1 Sa. Theken der A. 2 fächerig. (45 calid.). Amarantinae. Sa. aufrecht, an kurzem Funiculus. - Amarantus

* Achyranthinae. Sa, an langem Funiculus hängend. - Aerua $(10 \mathrm{As.}$, Afr. calid.). - Achyranthes (12 calid.).

§ Gomphreneae. G. mit 1 Sa. an langem Funiculus. Theken der A. zuletzt 1 fieherig. - Alternanthera (16 calid.). - Gomphrena (70 calid.). - Iresine (18 Am. calid.).

2. Unterreihe Phytolaccineae. Blh. homoiochlam. bis heterochlam. mit Neigung zur cyklischen Anordnung. Stb. bisweilen in grösserer Zabl. Cp bisweilen nur wenig vereint.

Fam. Nyctaginaceae. Bl. homoiochlam., 후 oder $\sigma^{7}$ 우, $\oplus$. Blhb. (5) corollinisch, bei der Reife der untere Teil um das G. meist als Anthocarp persistierend. Stb. $1-30 . \quad$ Cp. $1 . \quad \underline{G}$ mit 1 grundst., umgewendeten oder campylotrop. S. Dünnwandige Schliessfr. E. im Perisperm-Nährgewebe. - Kr. und $\mathrm{t}$ mit meist gegenst. B. und in Trugdolden stehenden Bl. Hochb. am Grunde der Bl. frei oder vereint, bisweilen petaloid, oft eine kelchähnliche Hülle bildend. - Rhaphidenschläuche. Dickenwachstum des Stengels und der Wurzel wie bei folgenden. - 160 calid., meist Am. 
$\S$ Mirabileae. Bl. meist ఫ̧. E. hakig gekrümmt. Kr. bis Halbsträucher. - Mirabilis jalapa, Wunderblume (Mexiko), lief. die falsche Jalapa; M. longiflora. - Boerhavia (20 trop.). - Bougainvillea (7 Südam.); B. spectabilis (Bras.).

§ Pisonieae. Bl. meist $\sigma^{\top}$ ․ E gerade. \$. - Pisonia (40 trop.) - Neeu theifera (Bras.), theïnhaltig

Fam. Batidaceae. Bl. homoiochlam. (?), $\sigma^{7}$ ㅇ, diöcisch. $\sigma^{\pi}$ in den Achseln von 4 reihig angeordneten, schuppenfg. Hochb., mit becherfg. Blh. 4 Stb. und ebensoviel spatelfg. Staminodien (?). $O$ Bl. nackt, mit 4 fächerigem G., in jedem Fach mit einer aufrechten, umgewendeten Sa.; alle 우 Bl. einer Ähre unter einander verwachsen. S. leicht gekrümmt, ohne Nährgewebe. - Küstenstrauch mit gegenst., fleischigen, linealen oder lineal-länglichen B. und in Rispen stehenden Blütenähren. - Butis maritima an den Küsten des trop. und subtrop. Amerikas und der Sandwich-Inseln.

Fam. Cynocrambaceae. Bl. homoiochlam., $\sigma^{\top}$ ㅇ. $\sigma^{\top}$ mit 2-3teiliger Blh. und 10-30 Stb. auf concaver Axe, im oberen Teile des Stengels, den B. gegentiberstehend. ㅇ Bl. mit kleiner, keulig-röhriger, verwachsenblätteriger, 3-4 zähniger $\mathrm{Blh}$. $\mathrm{Cp} 1$ mit grundst. Gr. und 1 Sa mit 1 Integ. Steinfr. S. mit gekrümmtem E. und knorpe. ligem Nährgewebe. $O \mathrm{Bl}$, in 3 blütigen Trugdöldchen in den Blattachseln. - Einjähriges Kraut, sympodial, mit unterwärts gegenst., fleischigen, eifg. B. und laăutigen, zerschlitzten Nebenb. - Cynocrambe prostrata (medit.), die einzige Art.

Fam. Phytolaccaceae. Bl. cyklisch, meist homoiochlam., selten heterochlam., 후 oder $\delta^{7}$ 우, $\oplus$. Blhb. meist $4-5$. Stb. $4-5$ oder $\infty$. Cp. $1-\infty$, frei oder vereint. Gr. $1-\infty$. $\underline{G}$, selten $\bar{G}$, jedes Cp. mit nur 1 amphitropen oder camptotropen Sa. an der Bauchnaht. Schliessfrucht oder fachspaltige Kapsel. Mehliges Perisperm. E. gekrüımt. $\mathrm{Kr}$. oder $\hbar$ mit ungeteilten $\mathrm{B}$. und unscheinbaren $\mathrm{Bl}$. in Trauben oder Trugdolden. - Im Blattgewebe hfg. Raphidenschläuche. Ausserhalb des ursprünglichen Gefässbündelringes werden successive neue Gefässbündel angelegt, welche nicht in die Dicke wachsen. - Etwa 82 calid.

\& Phytolacceae. Cp. 5-10, frei oder vereint. Blhb. 4-5, frei oder unterwärts wenig vereint. - Phytolacca (11 trop., subtrop.); P. decandra (Nordam.), lief. in den Beeren schwarzroten Farbstoff zum Färben von Weinen etc.; $P$. dioica (Südam.) mit dickem Stamm.

\$ Stegnospermateae. Cp. $(3-5)$; Gr. 3-5. Kapsel.

\$ Limeae. Cp. (2); Gr. 2. Blhb. getrennt Kapsel oder Spaltfr. - Limeun

§ Rivineae. Cp. 1. Blhb. meist frei. Schliessfr. - Seguieria (Südam.) besitzen kalireiches Holz. - Rivina (trop. Am.).

§ Gyrostemoneae. Cp. $(2-\infty)$. Gr. frei. Bllıb. bis zur Mitte oder darüber vereint. - Austral.

§ Agdestideae. Cp. (4), unterst. (Gr.). Blhb. 4, corollinisch. Stb. $\infty$. Sclıliessfr. mit $1 \mathrm{~S}$. - Agdestis (Centralamerika).

Fam. Aizoaceae. Bl. cyklisch, homoiochlam. od. heterochlam., ㅎ, $\oplus$. Blhb. 4-5, frei oder vereint, hochblattartig. Stb. $5(-3)$ oder $\infty$ (durch Spaltung?), die äusseren in petaloide Std. umgewandelt. Cp. $(2-\infty)$, meist mit $\infty$ umgewendeten oder campylotrop. Sa. $\underline{G}$ oder $\bar{G}, 2-\infty$ fächerig, selten $1 \mathrm{fächerig.} \mathrm{Kapsel} \mathrm{verschieden.} \mathrm{E.} \mathrm{das} \mathrm{mehlige} \mathrm{Perisperm-Nähr-}$ gewebe umschliessend. $-\odot$ oder $24 \mathrm{Kr}$. oder Halbstr. mit fadenfg. oder fleischigen B. Nebenb. 0 oder trockenhäutig. Bl. cymös. - In den primären Bündeln erlischt das Cambium früh, 1 oder mehr neue Cambiumschichten ausserhalb der ersten gebildet. - 420 meist afrik. 
Unterfam. Molluyinoideae. Blhb. nur wenig vereint. Petaloide Std. + oder 0. G. - 60 calid., meist Steppen- und Wiistenpfl.

Unterfam. Ficoideae. Blh. mit längerer oder kürzerer Röhre.

Sesuvieae. $G$; Kapsel mit Deckel. Std. 0. - Sesuvium am Strande der calid.

§ Alzoëae. G; Kapsel fachspaltig. Std.0. - Aizoon (medit. und Wüstenpfl.).

s Mesembrianthemeae. G. Std. 0 oder +. - Tetragomia expansa, Neuseeländischer Spinat (Ostas., Polynes.), Blattgemüse. - Mesem anthemum (300 Afr. medit., meist Südafr.).

3. Unterreihe Portulacineae. Blh. heterochlam., $2 \mathrm{~K}$. und 4-5 P.

Fam. Portulacaceae. Bl. cyklisch, heterochlam., ㅎ, $\oplus$. K. meist '2, P. $4-5$, hinfällig. Stb. 5 vor den $P$. oder weniger oder $5+5$ oder $\infty$ (durch Spaltung). Cp. (3-5); Gr. $3-5$. $\bar{G} 1 \mathrm{fächerig,} \mathrm{mit} 2-\infty$ Sa. an der grundst. Placenta. Kapsel. E. gekrümmt, das Nährgewebe umschliessend. - Kr. oder Halbstr. mit fleischigen B. und trockenhäutigen Nebenb. Bl. meist unscheinbar. - 114 meist Am. - Calandrinia (60). Claytonia (20). - Montia fontana (weit verbr.). - Portulaca (20); P. olercrea. - Lewisia rediviva (Kalif.), sehr widerstandsfähig gegen Austrocknung.

Fam. Basellaceae. BI. (9), heterochlam., §, 申. K. 2, P. 5, unterwärts vereint. Stb. 5 vor den Blhb. Cp. (3), meist mit $3 \mathrm{Gr}$. G ein. fächerig, mit 1 grundst. an kurzem Funiculus sitzenden aufrechten Sa. Nuss. S. mit ringförmig gebogenem E. und meist sparsamem Nährgewebe. - Rechts windende Kr. - Etwa 14, meist Am., wenige As. und Afr.

$\S$ Eubaselleae. Stf. in der Knospe aufrecht. - Basella rubra (Ost. indien) Gemüsepfl.

$\S$ Boussingaultieae. Stf. in der Knospe gekrümmt. - Boussingaultia (10 trop. Am.).

4. Unterreihe Caryophyllinece. Blh. homoiochlam, bis heterochlam., im letzteren Fallebensoviel K. wie P. Bl. vollkommen cyklisch, bisweilen apetal.

Fam. Caryophyllaceae. Bl. cyklisch, heterochlam. oder apetal, 5(selten 4-)gliederig, diplostemon, seltener haplostemon, meist ซ⿱宀, $\oplus$. Cp. (5-2); Gr. meist 5-2; G meist 1 fächerig, mit $1-\infty$ umgewendeten oder campylotropen Sa. auf grundst. Centralplac., oder Sa. centralwinkelständig. Kapsel oder Beere. Sa. mit Nährgewebe und gekrümmtem E. - Kr. oder Halbsträucher mit ungeteilten, meist schmalen, gegenst., seltener abwech. selnden B., bisweilen mit Nebenb. Bl. meist in trugdoldigen, zu Rispen vereinigten BI.-Ständen. - Etwa 1300, meist temp.

Unterfam. Alsinoidecie. K. frei. Stb. hfg. perigyn. Gr. frei oder vereint.

a. Kapsel, mit Zähnen sich öffnend.

§ Alsineae. Gr. frei. B. ohne Nebenb. -- Stellaria (80). - Cerastium (100?). - Holostenm. - Sagiur (20). - Alsine (60 *). - Arenuria (70). - Moehringia (20).

§ Sperguleae. Gr. frei. B. mit Nebenb. - Spergula arrensis, Spergel (Eur.), Futterpfl. - Spergularia (20, viele halophil). 
$\S$ Polycarpeae. Gr. unterwärts vereint. - Viele trop., subtrop., auch

*. - Polycarpon.

b. Schliessfr.

§ Paronychieae. Bl. alle ఫ̧. Nebenb. 1-4 Sa. - Corrigiola (6). - Paronychia (40). - Herniaria (15). - Illecebrum (1 medit. und Eur.). - Meist Sand- und Steppenpfl.

§ Sclerantheae. Bl. alle ఫ్ధ. Nebenb. 0. 1-2 Sa. - Scleranthus. $\S$ Pterantheae. Bl. zu je 3 vereint, die seitlichen verkümmernd, die mittlere ఫ̧. Sa. einzeln. - Medit. Steppen- und Wüstenpfl.

Unterfam. Silenoideae. K. vereint. E. u. Stb. hypogyn., hfg. auf Gynophor. Gr. frei.

$\S$ Lychnideae. Kelch mit Commissuralrippen. P. in der Knospe wechselwendig. - Agrostemma githago, Kornrade (medit.), überall im Getreide. - Viscaria (5). - Silene (300 * und Afr.). - Iychnis (10 Eur., Sibir.). - Melandryum (60 * und Kapland). - Drypis (1 östl. medit.). - Cucubalus (1 Eur., As.).

§ Diantheae. Kelch ohne Commissuralrippen. P. in der Knospe gedreht. - Gypsophila (50 Eur., As.). - Tunica (20 meist östl. medit.). - Dianthus (230 Eur., As., Afr., meist medit.); D. caryophyllus, Nelke (medit.). - Saponaria (20 Eur., As., meist medit. u. alp.); S. officinalis (Eur., As.).

d. Reihen mit vorherrsehend heterochlamydeischen Familien.

a) Apoearpie und Iypogynie vorherrschend, Perigynie und Epigynie bei den Lauraceae und Hernandiaceae.

15. Reihe RANALES. Bl. (9, spirocyklisch oder cyklisch, homoiochlam. bis heterochlam., epigyn. bis hypogyn., $\oplus$ oder $\%$, meist mit $\infty$ Stb. Cp. $\infty-1$, meist frei, seltener vereint. - Kräuter und Holzgewächse.

1. Unterreihe Nymphaeineae. Bl, mannigfach mit vorherrschend (a) Anordnung. Sa. bei grösserer Zahl an der Innenfläche der Carpelle; aber bisweilen nur 1 am Scheitel (Ceratophyllaceae).

Fam. Nymphaeaceae. Bl. (9, spirocyklisch oder cyklisch, homoiochlam. oder heterochlam., $\Varangle, \emptyset$. Blütenaxe convex oder becherfg. und im letzteren Falle mit dem G. vereint. Blhb. $6-\infty$; Stb. $6-\infty$; Cp. $3-\infty$, getrennt oder vereint, jedes mit $1-\infty$ Sa. an der Innenfläche, hfg. mit der Blh. und den Stb. vereint. Sa. mit 2 Integ., hfg. mit Arillus. Nährgewebe + oder 0. E. mit dicken Keimb. - Wasser- oder Sumpfpfl. mit untergetauchten und schwimmenden B. Bl. stets einzeln.

Unterfam. Nelumbonoideae. Nährgewebe 0. Bl. (9), homoiochlamydeisch. Blütenaxe kreiselfg.; Cp. frei mit. 1 Sa. Wasserpfl. mit schildfg. B. und langgestielten Bl. - Nelumbo lutea (atlant. Nordam.); N. nucifera (trop. As., Ostasien); die S. und die Rhizome essbar.

Unterfam. Cabomboideae. Nährgewebe $+(=$ Endosperm + Perisperm). Bl. cyklisch oder spirocyklisch. K. 3, P. 3, Stb. 3-18, Cp. 3-18. Wasserpfl. mit schildf. Schwimmb. - Cabomba (4 Am.). Brasenia. 
Unterfam. Nymphacoidene. Nährgewebe wie bei vorigen. Bl. spirocyklisch. Cp. $\infty$, mit $\infty$ Sa. an den ganzen Scheidewänden.

§ Nuphareae. K. 6-12. P. $\infty$, Stb. frei. G. vielfächerig. Fr. beerenartig. - Nuphur.

§ Barclayeae. K. 5, frei. P. untereinander und mit den Stto. sowie mit dem G. vereint. - Barclaya (trop. As.).

$\S$ Tetrasepaleae. K. 4, P. $\infty$. S. mit Arillus. B. mit intraaxillären Nebenb.

* Nymphaeinae. Nur die P. und die Stb. mit den Cp. vereint. Nymphriea (32 calid., temp.); N. lotus (Afr. und Ungarn); N. coemilea, blater Lotos (nordöstl. Afrika).

* Euryalinae. K., P. und Stb. mit den Cp. vereint. - Euryale ferox (Ostas.). - Victoria regia (Gebiet des Amazonenstroms).

Fam. Ceratophyllaceae. Bl. acyklisch, homoiochlam., $\sigma^{\nearrow}$ ㅇ, monöcisch, $\oplus$. $\sigma^{7}$ Bl.: Blhb. etwa 12, Stb. 12-16. 우 Bl.: Blhb. etwa 9-10; Cp. 1 mit geradläufiger, vom Scheitel herabhängender Sa. mit 1 Integ. Gr. lang, pfriemenfg. Nuss. S. mit dünnem Nährgewebe. - Untergetauchte Wasserpfl. mit vielgliederigen Quirlen von durchscheinenden, später knorpeligen, doppelt oder mehrfach gabeligen $\mathrm{B}$. Bl. ohne Vorb. einzeln in den Blattachseln. - Ceratophyllum (3 in stehenden und langsam fliessenden Gewässern).

2. Unterreihe Trochodendrineae. Bl, nackt, spirocyklisch. Sa. an der Bauchnaht. Keine Ölzellen.

Fam. Trochodendraceae. Bl. $\not$ oder $\sigma^{\nearrow}$ 오, diöcisch. Stb. $\infty$ (9). Cp. $2-\infty$ getrennt, cyklisch, mit $\infty-1 \mathrm{Sa}$. Balgfr oder Schliessfr. Nährgewebe reichlich. † mit wechselständigen oder gegenständigen, drüsig gezahnnten B. Bl, einzeln oder in Trauben in den Achseln der Knospenschuppen (6 Ostasien). - Cercidiphyllum (2 Japan). - Trochodendron (1 Japan).

3. Unterreihe Ranunculineae. Bl. behüllt, (2) bis cyklisch. Sa. an der Bauchnaht. Keine Ölzellen.

Fam. Ranunculaceae. Bl. (9), spirocyklisch, selten vollkommen cyklisch, homoiochlam. oder heterochlam., im ersteren Falle mit petaloider Blh., hfg. mit Honigb. zwischen dieser und den Stb., meist $\Varangle$, $\oplus$, seltener $\cdot$. Stb. meist $\infty$, frei. Cp. $\infty-1$, selten vereint, mit $\infty-1$ Sa. mit 1-2 Integ. Meist Balgfr. oder Schliessfr., selten Beere. Nährgewebe reichlich, ölig, mit kleinem $\mathrm{E}$. $-\odot$ und $\mathrm{t} \mathrm{Kr}$., hfg. mit verzweigten B. - Meist scharf, mehrere Alkaloide enthaltend, - Etwa 1200 temp. - frigid.

A. Sa. zu beiden Seiten der Bauchnaht der Cp., selten einzeln. Balgfr. mit $\infty-1$ S., selten Beere oder Kapsel, nur bei Calli. anthemum 1 samige Schliessfr.

$\S$ Paeonieae. Bl. fast stets einzeln, ohne Honigb. Wandung des G. fleischig. S. mit mächtigem äusseren Integ., welches das innere weit überragt. - Plıeonia (15 temp. As., Eur., medit.). -- Hydrastis canculensis (Wälder des atlant. Nordam.) besser bei den Berberidaceae stehend; das off. Rhizom enthält das Alkaloid Hydrastin.

$\S$ Helleboreae. Bl. einzeln oder zu mehreren. Wandung des G. selten fleischig. Das äussere Integ. der S. nicht länger als das innere. - 
Caltha (16). - Trollius (12). - Callianthemum (3 alp., centralas.). Helleborus (15 medit., subalp.); H. niger (alp.) und $H$. orientalis (Kaukasus), Nieswurz, früher off. - Eranthis hiemalis (Südeur.). Nigella sativa, Schwarzkümmel (Eur.); Samen als Gewürz. - Isopyrum (17, meist As.). - Coptis (8 subarkt., arkt.); C. trifolia (Nordam.), in Am. off.; C. teeta (Himalaya) als Mamira-, Mishmee-Bitter im Handel. Xanthorrhiza apiífolia (atlant. Nordam.). - Actıea (incl. Cimicifuga 13 *). - Aquilegia (50 *). - Delphinium (120); D. Staphisagria, die alkaloidhaltigen S. als Stephanskörner früher off. (medit.). - Aconitum (60 *); A. napellus, A. variegatum und A. Stoerckianum, Eisenhut (Eur., As., alp.), lief. die off. Tubera Aconiti.

B. Sa. einzeln am Grunde der Bauchnaht, oft noch rudimentäre an den Seiten derselben. Schliessfr. 1 samig.

$\S$ Anemoneae. - Anemone (incl. Pulsatilla, 90 temp.); $\boldsymbol{A}$. mratensis, Küchenschelle (Eur., As.), lief. die off. Herba Pulsatilla e. Clematis (170). - Myosurus (5). - Ranunculus (250). - Thalictrum (76). - Adonis (20 Eur., As.).

Fam. Lardizabalaceae. Bl. cyklisch, homoiochlam., 3 gliederig, 후 $\sigma^{\gamma}$ 우 $\phi$. Meist 2 Kreise Blhb., 2 Kreise Honigb., 2 Kreise Stb. mit extrorsen A., 1 Kreis Cp. (selten 2-3 Kreise) mit $\infty$ umgewendeten Sa. an den Seitenwänden. Beere Nährgewebe +; E. klein, gerade. - Meist schlingende $\hbar$ mit handfg. zusammengesetzten oder gefiederten B. und einzeln oder in Trauben stehenden Bl. - 11 Himalaya, Ostas., Chile. - Akebia quinata (Japan).

Fam. Berberidaceae. Bl. cyklisch, selten hemicyklisch, homoiochlam. oder heterochlam., 3-2 gliederig, ㅎ, $\oplus$. Meist 2-4 Kreise Blhb., oft 2 Kreise Honigb., 2 Kreise Stb., A. mit Klappen oder Spalten, meist 1, selten mehrere $\mathrm{Cp}$. mit $\infty-1 \mathrm{Sa}$. an der Bauchnaht oder 1 am Grunde, mit 2 Integ. Beere. Nährgewebe +; E. klein, gerade. $-4 \mathrm{Kr}$. oder t mit einfachen oder zusammengesetzten B.; Bl. einzeln oder in Trauben. - 135 temp. - Folgende Einteilung teilweise nach Tischler.

Unterfam. Hydrastidoideae. Mehrere Cp. mit wenigen Sa. A. mit Längsspaltan. - Hydrastis canadensis im atlant. Nordam., mit bitterem Wurzelstock, Hydrastin enthaltend, eine andere Art in Japan.

Unterfam. Podophylloidece. $1 \mathrm{Cp}$. mit vielen oder wenigen Sa. A. mit Klappen. Keine Honigb. Kr. mit sympodialem Rhizom und endständigen Inflorescenzen, B. nie gefiedert. - Diphylleia (2 Nordam., Ostas.). Podophyllum (Nordam., temper. Ostas.); P. peltatum (Nordam.) mit essbaren Fr., May-Apple, und giftigen, Podophyllin enthaltenden Stengeln und Wurzeln; P. Emodi (Himalaya).

Unterfam. Berberidoideae. $1 \mathrm{Cp}$. mit vielen oder wenigen Sa. A. mit Klappen oder Längsspalten. Honigb. B. gefiedert oder auf die Endfieder reduciert.

§ Berberideae. Inflorescenzen am Sympodialglied seitlich. Holzpfl. A. mit Klappen. - Berberis $(70 *$ und andin); B. lycium (Himalaya), lief. Extract Rusot. - Mrhonia (37 \#, besonders Mexiko); M. aquifolium (pacif. Nordam.). 
§ Epimedieae. Inflorescenzen am Sympodialglied endständig. Meist Stauden. A. mit Klappen oder Längsspalten. - Nandina domestica (Ostas.); Wurzeln enthalten das Alkaloid Nandinin. - Epimedium (11 Südeur., Tibet, Ostas.). - Teontice (12 Südeur., Westas., Nordam.). Jeffersonia (2 Nordam.).

Fam. Menispermaceae. Bl. cyklisch, homoiochlam. oder heterochlam., 3-2 gliederig, fast stets $\sigma^{7}$ \%, diöcisch, $\oplus$. Meist je 2 Kreise K., P. und Stb., die P. meist kleiner. Cp. 3 (-1), frei, mit je 1 an der Bauchnaht hängenden, halbumgewendeten Sa. (2 Integ. und Mikropyle nach oben). Steinfr., deren Spitze hfg. der Basis dicht genähert. Nährgewebe + oder 0 ; E. gekrümmt. - Meist schlingende $\hbar$ mit ungeteilten oder gelappten, handfg. genervten B. und kleinen, in achselst. Trauben stehenden Bl. Im Stamm und der Wurzel mancher Arten eigentümlicher Dickenzuwachs aus secundären Cambiumbündeln, welche sich in der Rinde bilden. Wurzeln bitter. Früchte scharf narkotisch, viele giftig. - Etwa 250 calid., wenige temp.

$\S$ Cocculeae. Kotyledonen aufeinander liegend. Nährgewebe + . Griffelansatz der Basis der $\mathrm{Fr}$. dicht genähert.

* Menisperminae. Nährgewebe nicht zerklüftet. Fr. nierenfg. Cp. 3. Stf. wenigstens oberwärts frei. $ᄋ \mathrm{Bl}$. mit Std. - Menispermum canadense (atlant. Nordam.)! - Cocculus (30 palaeotrop.); C. Tecieba (Steppen Nordafrikas und des Pundjab), aus den Fr. bereiten die Araber das Getränk Chamr el madjnune.

* Cissampelinae. Wie vor.; aber nur $1 \mathrm{Cp}$. Stf. vereint. 우 $\mathrm{Bl}$. ohne Std. - Cissampelos pareiva (trop.) lief. die falsche Radix Pareirae bravae.

* Tiliacorinae Nährgewebe zerklüftet. Fr. länglich oder verkehrt-eifg. ㅇ Bl. mit Std. - Abuta (trop. Am.); einige Arten lief. Pareira-Wurzeln.

§ Tinosporeae. Kotyledonen nur am Grunde aufeinander liegend. Nährgewebe + oder 0. Ansatz des Gr. der Basis gegenüberliegend. Iatrorrhisa palmata (Mozambique) lief. die Radix Colombo. Anamirta cocculus (ind.-malay.) lief. die Fructus Cocculi, Kokkelskörner, welche das giftige Picrotoxin enthalten.

§ Pachygoneae. Kotyledonen neben einander liegend. Nährgewebe 0. - Chondrodendron tomentosum (Brasil., Peru), lief. die echte Radix Pareirae bravae.

4. Unterreihe Magnoliineae. Bl. behüllt, (-) bis cyklisch. Sa. an ler Bauchnaht. Olzellen.

Fam. Magnoliaceae. Bl. (2) oder spirocyklisch, meist heterochlam., §̧ oder $\sigma^{\pi} \uparrow, \oplus$. Cp. meist $\infty$, frei, selten vereint, jedes mit umgewendeten Sa. an der Bauchnaht. Nährgewebe reichlich, nicht zerklüftet, mit kleinem E. - t mit (9) ungeteilten, selten gelappten B. und meist einzeln stehenden Bl. - Olzellen. - Etwa 70 Am., As., meist subcalid. u. temp.

\$ Magnolieae. B. Init Scheiden, welche in der Knospe ringsum geschlossen sind. Bl. ఫ̧ mit verlängerter Axe. - Magnolia (21 trop. As., Ostas., atlant. Nordam.), Zierbäume; während der Kreide und Tertiär- 
periode zahlreiche Arten in Europa, Grönland etc. - Michelia champaca (Java); Bl. zur Bereitung von Parfums. - Liriodendron tulipifera, Tulpenbaum (atlant. Nordam.), Zierbaum; in der Tertiärperiode existierten nahe Verwandte in Europa und Grönland.

§ Illicieae. B. ohne Nebenb. Bl.-Axe kurz. Immergrüne Sträucher. - Illicium (7 atlant. Nordam., Ostas.); I. verum (China), lief. allein das Gewürz Sternanis, Anisum stellatum; I. anisutum $\boldsymbol{L}_{\text {. }}(=I$. religiosum Sieb. et Zucc. in Japan), lief. zu Weihrauch verwendete Rinde; die Fr. enthalten das giftige Sikimin. - Drimys (10 vorzugsweise *); D. Winteri (von Mexiko bis Feuerland).

§ Schizandreae. B. ohne Scheiden oder Nebenb. Bl.-Axe convex, oft später verlängert. $\mathrm{Bl} . \sigma^{\gamma}$ ㅇ. Stamm windend. -14 Ostas., atlant. Nordam.

Fam. Calycanthaceae. Bl. acyklisch, homoiochlan., $ॄ$, mit becherfg. Axe. Blhb. $\infty$, corollinisch. Stb. 10-30. Cp. etwa 20, getrennt, im Grunde der hohlen Blütenaxe mit je 2 umgewendeten Sa., mit 2 Integ. Schliessfr. S. fast ohne Nährgewebe, mit grossem E., mit (Q)-gerollten Keimb. - Sträucher mit gegenst., ungeteilten B. - Ölzellen. - 4 temp. Ostas., atlant. Nordam. - Calycanthus floridus, sehr wohlriechend, Rinde medicinisch verw.

Fam. Lactoridaceae. Bl. cyklisch, homoiochlam., 3 gliederig. Blhb. 3. Stb. $3+3$. Cp. 3. - † Lactoris (1 Juan Fernandez).

Fam. Anonaceae. Bl. spirocyklisch, meist heterochlam., meist $\Varangle, \oplus$. Blhb. meist in drei 3 gliederigen Quirlen. Stb. $\infty$ (Q). Cp. $\infty$, meist frei; die Sa. an der Bauchnaht oder grundst., mit 2 Integ. Meist Beerenfr. S. mit zerklüftetem Nährgewebe. - $\hbar$ mit ungeteilten B. ohne Nebenb. und meist ansehnlichen Bl. - Ölzellen. - Etwa 800, neeist trop.

Unterfam. Uvarioidene. Blütenaxe convex oder flach. Blh. + . Bast in mehreren Śchichten mit Leptom abwechselnd.

§ Uvarieae. Cp. spiralig. P. ungegliedert oder genagelt und dann der Nagel den Stb. anliegend. - Uvaria (incl. Asimina 100 trop.), $U$. triloba (Nordam.) mit essbaren Fr. - Unona (40 trop. As., Afr.). - Cananga odorata, Ilang-Ilang (ind.-malay.), lief. Macassar-Öl, welches aus den Bl. dargestellt wird. - Polyalthia ('70 palaeotrop.).

$\S$ Miliuseae. Cp. spiralig. P. klappig, meist ungleich, wenn genagelt, der Nagel von den Stb. abstehend.

$\S$ Hexalobea. Cp. spiralig. P. gleich gross, in der Knospe mit Querfalten. - Hexalobus (trop. Afr.).

§ Xylopieae. Wie vor.; aber die P. am Grunde hohl, darüber \pm eingeschnürt und wieder ausgebreitet oder seitlich zusammengedrückt. Xylopia (60 trop.); $\boldsymbol{X}$. aethiopica Mohrenpfeffer (trop. Afr.); Fr. als Gewürz und Geld; $\boldsymbol{X}$. aromatica (Guinea, Antillen), lief. Neger-und Guineapfeffer. - Artabotrys intermedia (Java), lief. wohlriechendes Öl. Anona (60 trop. Am., einige auch im trop. Afr. und As.), lief. geschätzte essuare Fr. "Corossol «; $A$. squamosa, Caneel-Appel, Sugar-Apple überall cult., ferner $A$. reticulata und $A$. muricata.

\& Monodoreae. Cp. cyklisch in einem 1 fächerigen G. mit wandst. Sa. vereint. - Monodora myristica (trop. Afr.); die Sa. wie Muskatnüsse verwendet. 
Unterfam. Eupomatioideae, Blütenaxe beclıerförmig. Blh. 0. Stb. $\infty$, perigyn. Cp. dicht gedrängt. Bast unregelıässig zerstreut. Traclıeiden mit gehöften Tüpfeln. - Eupomatia (? Nordostaustral.).

Fam. Myristicaceae. Bl. cyklisch, homoiochlam., meist 3 gliederig, $\sigma^{7}$ 우, $\oplus$. Blh. 3 lappig. Stb. 3-18 mit verwachsenen Stf. und extrorsen A. Cp. 1, mit einer fast grundst., umgewendeten Sa. mit 2 Integ. Beere an der Rücken - und Bauchnaht aufspringend. S. mit fleischigem Arillus, mit zerklüftetem Nährgewebe und kleinem $\mathrm{E}$. - $\hbar$ mit ungeteilten immergrünen B. und in den Blattachseln stehenden Trauben. - Ölzellen. - 255 trop., davon 38 in Sïdam., 11 im trop. Afr., 179 im trop. Asien. - Eng anschliessend an Anonaceae. - Myristica fragrans (Molukken, cult. in Trop.); die S., Muskatnüsse, bekanntes Gewürz, geben auch Muskatbalsam; der Arillus als Macis, Muskatblüte im Handel; wichtig auch $M$. argentea vom westl. Neu-Guinea, $M$. succedanea, $M$. speciosa von Batjang, M. Schefferi vom westl. Neu-Guinea.

Fam. Gomortegaceae. Bl. homoiochlam., spirocyklisch, ఫ̧. Blhb. 7, Stb. 2-3. Cp. (2-3), in jedem Fach mit 1 hängenden Sa, mit 2 Integ. Steinfr. 3-1 fächerig. S. mit reichlichem Nährgewebe und grossem E. - t mit gegenständigen immergrünen B. und in Trauben stehenden Bl. - 1 (Chile). - Gomortega.

Fam. Monimiaceae. Bl. hemicyklisch, homoiochlam. oder heterochlam., ̧ㅜ oder hfg. $\sigma^{7}$ 으, $\oplus$ bis … Blütenaxe sehr mannigfach, oft scheiben-oder becherfg. und dann die Insertion der Blh. perigyn. oder epigyn. Blhb. klein, die inneren oft corollinisch. Stb. $\infty$, bisweilen wenige in 2 Kreisen. Cp. $\infty$, frei, nit je 1 grundst., aufrechten oder hängenden, anatropen Sa., mit 2 Integ. Schliessfr. von der anschwellenden Axencupula hfg eingeschlossen. S. mit fleischigem Nährgewebe. E. klein mit eifg., flachen Keimb. - \$ mit meist gegenst. B. ohne Nebenb. Bl, einzeln oder in trugdoldigen Blütenständen. - Ölzellen. - 300 calid.

Unterfam. Monimioideae. Fächer der A. mit Langsspalte oder die ganze A. mit Kreisspalte sich öffnend. - Peumus boldus (Chile), lief. Folia Boldo.

Unterfam. Atherospermoideae. Fächer der A. mit Klappen sich öffnend. - Siparuna (60 trop. Am.).

Fam. Lauraceae. Bl. cyklisch, homoiochlam., meist 3 gliederig, 후 oder $\sigma^{7}$ 우 $\oplus$. Blütenaxe becherfg. oder schüsselfg. Blhb. klein in zwei Kreisen. Stb. in 3-4 Kreisen, davon einzelne bisweilen Std.; die A mit Klappen sich öffnend, intrors, die des dritten Kreises, selten alle, extrors. Cp. frei, 1 fächerig, mit 1 hängenden, umgewendeten Sa., mit 2 Integ. Fr. später von der fleischig werdenden Blütenaxe eingeschlossen. S. ohne Nährgewebe mit dünner Schale; E. mit grossen, flachen Keimb. - \$ mit meist lederartigen und wechselst. B. ohne Nebenb. - Schleim. und Öl. zellen in den B. und der Rinde. - 1000 calid.

Unterfam. Perseoidecue. A. 4 fächerig, mit 4 Klappen.

$\S$ Cinnamomeae. Die Stb. des 3. Kreises mit extrorsen A. - Cinnamonum (54 trop. As., Ostas., Austral.); C. seylanicum lief. d. off. Cortex Cinnamomi acuti und Zimmt; C. cassia lief. Cortex Cinnamomi Cassiae; C. camphora, Kampferbaum (Japan bis Formosa), lief. d. off. Stearopten Camphora. C. polymorphum u. a. fossil in miocenen Schichten Europas und Nordamerikas. - Perser gratissima (trop. Am., viel cult.), lief. die $1 d m$ langen A vocato-Birnen. - Phoebe (50). 
- Ocotea (200 trop., subtrop.). die Fabae Pichurim (Keimb.).

§ Litseeae. Alle Stb. mit introrsen A. - Sassafras officinale (temp. atlant. Nordam.) lief. d. off. Lignum Sassafras. - Iitsea (100 ind.-malay.).

Unterfam. Lamroideae. A. 2 fächerig, mit 2 Klappen.

$\S$ Cryptocaryeac. t. Stb. des 3. Kreises mit extrorsen A. - Cryptocarya (40 ind.-malay., trop. Am.); C. moschata (Brasilien), lief. d. amerikanischen Muskatnüsse.

§ Laureae. t. Alle Stb. mit introrsen A. - Iindera (60). Laums nobilis, Iorbeer (medit.), lief. die off. Folia und Baccae Lauri.

$\S$ Cassytheae. Blattlose, schlingende Parasiten. - Cassytha (16); C. filiformis (trop.).

Fam. Hernandiaceae. Bl. cyklisch, homoiochlamydeisch, 호 od. $\sigma^{\nearrow}$ 오, $\phi$. Blhb. 4-10. 1 Kreis Stb. vor den äusseren Blhb. G. unterst., 1 fächerig, mit I hängenden umgewendeten Sa, mit 2 Integ. Fr. geflügelt. S. ohne Nährgewebe. E. gerade, mit grossen, runzeligen, gefalteten Keimb. - t mit abwechselnden B. olne Nebenb. - Ölzellen und Cystolithen. - 24 trop. - Gyrocarpus. - Hernandia.

ß) Syncarpie und Hypogynie vorherrschend.

16. Reihe RHOEADALES. Bl. cyklisch (das Androeceum nicht immer), heterochlam., selten apetal oder homoiochlam. (Moringaceae), hypogynisch, $\oplus$ u. \% Cp. $(\infty-2)$. Sa. mit 2 Integ. - Meist Kr., seltener t. Bl. hfg. in Trauben.

1. Unterreihe Rhoeadineae. Bl. heterochlam. Meist nur $2 \mathrm{Kelchb}$.

Fam. Papaveraceae. Bl. ఫ̧, $\emptyset$ oder $\%$ K. 2 (selten 3). P. 4 (selten 6 oder mehr oder 0 ). Stb. $\infty$ oder nur 4 oder 2 , im letzteren Fall von Grund aus verzweigt. Cp. $(2-16)$. $\quad \underline{\text { mit }} 2-16$ wandst. Plac. und $\infty$ Sa. oder mit 1 grundst. Sa. Sa. umgewendet oder campylotrop. Kapsel, seltener Schliessfr. Nährgewebe ölhaltig. E. klein. Meist Kr., mit meist wechselst. B., hfg. mit Milchsaft. - Milchsaftschläuche gegliedert, bisweilen 0 . - 80 meist *, temp., subcalid.

Unterfam. Hypecoideae. P. $2+2$ ungespornt, zuweilen 3 teilig, Stb. $2+2$ vor den P. Cp. (2). - Kein Milchsaft. - Hypecoum (12 medit., Centralas.).

Unterfam. Papaveroideae. P. ohne Sporn, bisweilen 0 . Stb. Cp. $(2-\infty)$.

§ Eschscholtzieae. Gr. so viele als $\mathrm{Cp}$., frei oder nur wenig vereint, mit den Plac. abwechselnd, zuweilen 3 lappig oder von ähnlichen über den Plac. stehenden begleitet. - Eschscholtzia (10 pacif. Nordam.).

\$ Chelidonieae. Gr. in 2 mit den Plac. abwechselnde, ungeteilte Äste endigend, welche innen und am Rande die N. tragen. - Sanguinaria canadensis (atlant. Nordam.); Rhizom daselbst off. - Chelidonium majus, Schöllkıaut (*). - Macleya cordata (Ostas.).

§ Papavereae. N. nur über den Placenten liegend. - Glaucium (11 medit.). - Roemeria (medit.). - Meconopsis (10 * zerstreut). - Argemone mexicana (Am.). - Papaver (40 Eur., As., temp.); P.somniferum 
(medit.); der eingedickte Saft der Kapsel lief. das Opium (Morphin, Thebain, Narcotin enthaltend), die S. als Gewürz und Mohnöl gebend.

Unterfam. Fumarioideae. Bl. meist transversal zygomorph. 1 oder 2 äussere P. mit Aussackung oder Sporen. Stb. vor diesen stehend, dreiteilig, die seitlichen Abschnitte monothecisch. - Dicentra (15*). - Adlumia fungosa (atlant. Nordam.) - Corydalis (90 temp. Eur., As.). - Fumaria (40 meist medit.). mehr.

2. Unterreihe Capparidineae. B I. heterochlam. 4 Kelchb. oder

Fam. Capparidaceae. Bl. જ̧, $\oplus$ und $\%$. Blütenaxe ring- oder schuppenfg. oder seltener zu einem röhrenfg. Gebilde innerhalb der Blh. entwickelt, unterhalb der Stb. bisweilen, unterhalb der Cp. fast immer stielartig verlängert (Gynophor). K. 4, P. 4 (meist), Stb. $\infty-6-4$. Cp. (2-mehr); G. 1 fächerig oder mehrfächerig. Sa. $\infty$, campylotrop. Kapsel, Beere, Steinfr. S. nierenfg., ohne Nährgewebe. E. gekrümmt, mit zusammengewickelten oder gefalteten oder gedrehten Keimb. Kr. oder t, mit abwechselnden, einfachen oder gefingerten B., hfg. mit Nebenb. Bl. in Trauben mit Tragb. - 300 calid.

A. Kr., meist $\odot$, niemals mit Schuppen bekleidet. Schote mit bleibendem Replum.

Unterfam. Cleomoideae. - Cleome (70). - Polanisia (30).

B. $\hbar$, mit Sternharen oder Schuppen bekleidet. Fr. ohne bleibendes Replum.

Unterfam. Dipterygioideae. Fr. 1 samiges Nüsschen. - Dipterygium (Sahara).

Unterfam. Capparidoideae. Fr. beerenartig. - Crataeva (10 trop.). - Capparis (150); C. spinosa (medit.) lief. die Kappern. - Cadaba mit einseitiger, röhriger Discuseffiguration (14 Afr., Ostind.). - Maemua (20 Afr., Vorderind.).

Unterfam. Roydsioideae. Steinfr.

Unterfam. Emblingioideae mit nur 2 verwachsenen $P$.

Fam. Crucifera $\theta^{*}$ ). Bl. mit mehreren 2 gliederigen und 1 viergliederigen Quirl, ㅎ, ๑. K. $2+2$, P. 4 diagonal, Stb. 2 (kurz) $+2 \times 2$ (lang), Cp. (2). G. mit nahtst. Plac., meist mit Scheidewand. Sa. anatrop oder campylotrop. Fr. meist Schote, seltener Schliessfr., Teilfr. oder Gliederfr. Nährgewebe meist 0. Lage der Keimb. $O$ () (notorrhiz), $O$ » (orthoploc), $\bigcirc \bigcirc$ (pleurorrhiz). Kr., $\odot$ oder $\hbar$, mit wechselst. B., meist mit einzelligen einfachen oder verzweigten Haaren. Bl. ohne Tragb. und Vorb. in Trauben - 1200 temp. - frigid, meist *.

A. Haare unverzweigt oder 0 , nie Drüsenhare.

§ Thelypodieae. N. ringsum gleich entwickelt auf ungeteiltem oder über den Medianen der Cp. verlängertem oder zurückgeschlagenem Gr.

*) Die Cruciferae sehe ich als von den Capparidaceae abstammend an, nicht umgekehrt, wie es meist geschieht. 
* Stanleyinae. Keimb. Oo. - Pringlea antiscorbutica, Kerguelenkohl (Kerguelen), antiscorbutisch.

*Heliophilinae. Keimb. spíralig gerollt oder zweimal_quer gefaltet. - Heliophila $(60$ Südafr.).

$\S$ Sinapeae. N. über den Plac. stärker entwickelt auf gestutztem oder 2 lappigem Gr.

a. Keimb. hinter der Krämmung des E. entspringend.

* Iepidiinae. Bl. perigyn oder mit seitlichen und medianen Honigdrüsen. Schötchen oder Schliessfr. - Subularia aquatica (* zerstreut). Teesdalea (Eur., medit.). - Lepidium (100 temp.--calid.); L. sutivum, Kresse. - Coronopus (12 calid., temp.). - Biscutella (12 med., alp.).

b. Keimb. an der Krümmung des E. entspringend.

a. Nur seitliche Honigdrüsen. Meist Schötchen oder Schliessfr.

$\S$ Cochleariinae. Keimb. nicht gefaltet. - Iberis (30 medit.). Aethionema (50 medit., alp.). - Thlaspi (60 medit., Eur., As.). Cochlenria $(15 *)$; C. officinalis (Eur.) auf Salzboden, off. Herba Cochleariae; C. armoracia, Meerrettig.

ß. Meist sejtliche und mediane Honigdrüsen. Meist Schote, seltener Schötchen, oder quergegliedert oder Schliessfr.

I. Gr. gestutzt, nicht eingezogen.

* Alliariinae. Schote oder 1 samige Schliessfr. Mediane Honigdrüsen vorhanden. - Alliaria officinalis (Eur., As.).

II. Gr. 2lappig oder eingezogen.

* Sisymbriinae. Keimb. $O()$; sehr selten 0 . Mediane Honigdrüsen vorhanden. - Sisymbrium (50). - Cakile maritima (Littoralpflanze in Eur.). - Isatis (50 östl. medit.); I. tinctoria, Waid, lief. Indigo.

*Vellinae. Keim. O». Mediane Honigdrüsen +. Schötchen oder 2 fächerige Schliessfr. - Nur medit., viele Wüstenpflanzen.

* Brassicinae. Keimb. $\odot$ ». Mediane Honigdrüsen +. Schote, zuweilen quer gegliedert. Gemüsepfl. und Oelpfl. - Eruca sativa (medit.). - Sinapis (5 medit., Eur.), S. alba, weisser Senf. Diplotaxis (20 medit., Eur.). - Brassica (50 medit., Eur., As.); B. nigra, schwarzer Senf, off. Semen Sinapis; B. oleracen, Kohl (Küste des Mittelmeers und d. Nordsee); var. acephala, Blätterkohl; var. gongylodes, Kohlrübe; var. gemmifera, Rosenkohl; var. sabauda, Wirsing, Welschkohl; var. capitata, Kopfkohl; var. botrytis, Blumenkohl; B. campestris (=B. Rapa, medit.), Rübsen; var. апnиa, Sommerrübsen und var. oleifera, Winterrübsen und Ölfr.; var. rapifera, weisse Rübe, Teltower Rübe; B. nripus, Raps (medit.); var. annua, Sommerraps, var. oleifera, Winterraps; var. napobrassica, Kohlrübe. - Rhaphanus sativus, Rettig (medit.?) und var. radicula, Radieschen. - Crambe (20). - Morisia hypogaea (Sardinien, Corsica).

* Cardamininae. Keimb. O O. Mediane Honigdrüsen + oder 0. Fr. stets 2 klappig. - Barbaraea (14). - Nasturtium (50), N. officinale, Brunnenkresse (*).-Cardamine (50); C. chenopodiifolia (Brasil., Argent.), amphicarp. - Dentaria (15*). - Lunaria (2 Eur.). 
B. Haare sämtlich oder teilweise verzweigt, nur selten gänzlich fehlend; zuweilen ausserdem Drüsenhare.

§ Schizopetaleae. N. ringsum gleich entwickelt auf ungeteiltem oder über den Mediamen der Cp. verlängertem oder zurückgeschlagenem Gr. - Lesquerella (33 Am.).

$\S$ Hesperideae. $\quad$ N. über den Plac. stärker entwickelt, auf ungeteiltem oder über den Plac. in kürzere oder längere Lappen verlängertem Gr.

a. Oberhatzellen der Scheidewand nicht der Quere nach geteilt.

a. Oberhatzellen der Scheidewand ohne zahlreiche parallele Teilungswände.

* Capsellinae. Nur seitliche Honigdrüsen. Fr. meist kurz. S. nie 1 reihig. - Hutschinsia. - Capsella. - Camelina. - Neslea. INabu (150 alp., arkt.). - Aubrietia (12 medit.).

* Turritinae. Seitliche Honigdrüsen mit je 1 medianen zu einem Ring vereint. Fr. lang. - Stenophragma (10). - Turritis (5). - Arubis (100 *, Südam.).

* Erysiminae. Seitliche und je 2 mediane Honigdrüsen. Fr. lang. Erysimum (80 Eur., As.). - Cheiranthus (10).

$\beta$. Oberhatzellen der Scheidewand mit zahlreichen paral. lelen Teilungswänden.

* Alyssinae. Alyssum (100 mediterr., Mitteleuropa). - Berteroa.

b. Oberhautzellen der Scheidewand der Quere nach geteilt.

* Malcolmiinae. Keine Drüsenhaare oder Drüsenhöcker. - Anastatica hierochuntica, Rose von Jericho (östl. medit.). - Malcolmia (30 medit.).

* Hesperidinae. Drüsenhaare oder Drüsenhöcker. - Hesperis (24 östl. medit.). - Mratthiola (50); M. incana, Levkoje (medit.). Bumias.

* Moricandiinae. Behaarung fehlt vollständig. Keimb. gewölbt bis gefaltet. - Conringia (östl. medit.).

Fam. Tovariaceae. Bl. 8 gliederig, ఫ, 4 . K. 8, P. 8 , Stb. 8 , Cp. (6). Placenten bis in die Mitte rückend und nach aussen umbiegend mit $\infty$ Sa. Beere. Nährgewebe spärlich. - Kr. mit gedreiten B. und endständigen Trauben. - Tovaria (2 trop. Am.).

3. Unterreihe Resedineae. Bl. spirocyklisch, heterochlamydeisch.

Fam. Resedaceae. Bl. spirocyklisch, $\Varangle, \%$ Blütenaxe in ein Gynophor ausgehend, welches sich unterhalb der Stb. zu einem excentrischen oder halbmondfg. Discus erweitert. K. 4-8, P. $0-8$, Stb. 3-10, Cp. (2-6); aber G oben offen und 1 fächerig, mit $1-\infty$ sa. Nährgewebe 0 . E. gekrümmt. - Kr., mit wechselst., einfachen oder geteilten B. mit Nebenb. Bl. in Trauben. - 60 Afr., Eur., Kalif., meist medit. - Reseda (50); R. luteola, IVau (Eur.), liefert Luteolin; $\boldsymbol{R}$. odoratu (medit.). - Oclıradenus, IVüstenstrauch.

4. Unterreihe Moringineae. Bl. cyklisch, homoiochlamydeisch.

Fam. Moringaceae. Bl. cyklisch, homoiochlam., 5 gliederig, ̧ㅗ . \% . Blütenaxe schüsselfg. K. 5, P. 5, Stu. 5 + Stb. 5 mit zuletzt 1 fücherigen A., Cp. (3) auf 
kurzem Gynophor, mit parietalen Plac. und $\infty$ Sa. Lange Kapsel, zuletzt 3 klappig, die Plac. auf der Mitte der Klappen. S. gross, 3 flügelig. Nührgewebe $0 . \mathrm{E}$. gerade, mit dicken Keimb. - Bäume mit 2-3fach gefiederten B. ohne Nebenb. und in Rispen stehenden Bl. - Lysigene Gummigänge. - Moringa (3 Afr., Vorderind.), M. arabica lief. das Ben-Öl.

17. Reihe SARRACENIALES. Bl. spirocyklisch bis cyklisch, homoiochlam. oder heterochlam., hypogynisch, $\oplus$. Cp. $(3-5)$, syncarp mit pariet. oder centralwinkelst. Plac. und $\infty$ Sa. S. klein mit Nährgewebe. Alle $\mathrm{Kr}$. meist mit (a) ungeteilten, insektenfangenden B.

Fam. Sarraceniaceae. Bl. spirocyklisch, heterochlam. oder homoiochlam.; ㅎ, ఉ. K. $8-5$, 9); P. 5 ; Stb. $\infty$; Cp. (5-3). Gr. 1. G. 5-3fächerig mit $\infty$ umgewendeten, mit 1 Integ. versehenen Sa. an den centralwinkelständigen, zurückspringenden Plac. Kapsel fachspaltig. S. $\infty$, klein, mit dünner Schale und fleischigem Nährgewebe. E. klein. $-4 \mathrm{Kr}$. mit (9) Schlauchb. Bl. einzeln oder in lockerer Traube an axillarem Schaft. - Schläuche Schleim und Honig absondernd, insektenfangend (ob verdauend?). - 8 Sumpfpfl. Amerikas. - Heliamplora (1 Guiana). Sarracenia (6 atlant. Nordam.); S. purpurea enthält Alkaloid Sarracenin. - Darlingtonia (1 Kalif.).

Fam. Nepenthaceae. Bl. cyklisch, homoiochlam., $\sigma^{\nearrow}$ ㅇ, $\oplus$. Blhb. $2+2$. $\sigma^{\top}:(4-16$ Stb.). o: (Cp. 4). G. 4 fächerig mit $\infty$ centralwinkelst. Sa. Kapsel fachspaltig. S. langgestreckt-spindelfg, mit langen Endflügeln, sehr klein. E. gerade im Nährgewebe. - Kletterpfl. mit (9) B., die unteren mit bedeckelten Schläuchen, die oberen in Ranken endend. Bl. in Trauben oder Rispen. - Schläuche innen mit Wachs ausscheidender Zone, darunter mit Drüsen tragender Zone. Drüsen schleimiges, schwach säuerliches Secret ausscheidend. Insekten werden gefangen und verdaut. - 40, meist ind.-malay., 1 Seychellen, 1 Madagascar. - Nepenthes destillatoria (Ceylon) u. a.

Fam. Droseraceae. Bl. eyklisch, heterochlam., 5-4 gliederig, ఫ, ๑. K. 5-4. P. 5-4. Stb. $5(+5-\infty)$, meist mit Pollentetraden. Cp. $(2-5)$. Gr. 1; N. einfach bis wiederholt gabelig. G. einfächerig oder $2-5$ fächerig, mit $3-\infty$ Sa. Kapsel meit 1 fächerig, carpellspaltig. S. $3-\infty$ mit Nährgewebe und kleinem E. am Grunde. - Kr. mit (9), selten quirlst. B. B. in der Knospe nach innen gerollt, mit Digestionsdrüsen. Bl. hfg. in Wickeln; aber auch einzeln oder in Trauben. - 106 temp.- subcalid. - G. 1 fächerig; Dionaea muscipula, Venus-Fliegenfalle (Carolina). - Aldrovandia vesiculosa (Eur., As. in Sümpfen und Teichen schwimmend). - Drosophyllum lusitanicum (Portugal, Südspan., Marokko). - Drosera (90). - G. 2-3 fächerig: Byblis (2 Austr.). - Roridula (2 Kapland).

r) Apocarpie und Hypogynie noch anftretend, aber Perigynie wird häufiger; durch Bergung des Gynäcenms in die hohle Blütenaxe kommt es auch zu Syncarpie und epigynischer Insertion der Blb. und Stb.

18. Reihe ROSALES. Bl. cyklisch, selten spirocyklisch (RosaceaeRosoideae), heterochlam. oder apetal, hypogynisch bis epigynisch, $\oplus$ oder $\%$. 
Cp. hfg. frei; aber auch hfg. vereint, bisweilen mit dicken, $\infty$ Sa. tragenden Placenten. - Grenzen zwischen den meisten hierher gehörigen Fam. schwach.

1. Unterreihe Podostemonineae. Untergetauchte Wasserpfl., unter dem Wasser blthhend, nur durch die Placenten an die Saxifragaceae erinnernd, durch Anpassung an eigenartige Lebensbedingungen voll. ständig deformirt.

Fam. Podostemonaceae. Bl. haplochlam., $\infty$ cyklisch oder $1-2$ einseitig. Cp. (2-3). Gr. 2-3. G mit dicker, centralwinkelst. Plac. und $\infty$ umgewendeten Sa. Kapsel meist scheidewandspaltig. S. sehr klein, ohne Nährgewebe, mit dickem E. - Meist kleine Kr. in stark strömenden Gewässern der calid.; an Steinen und Felsen, seltener an Holzstämmen, meist mit dorsiventralem, thallusartigem Stengel und 2 zeiligen, am Grunde scheidigen B. Wurzeln plagiotrop, dorsiventral und der Assimilation dienend, hfg. mit zahlreichen Adventivsprossen. Bl. terminal in dichasialen Sprosssystemen. Einzelverhältnisse sehr compliciert. - 150, meist trop. Am., einige trop. Afr. oder As.

Fam. Hydrostachyaceae. Bl. nackt, $\sigma^{7}$ 우, diöcisch. $\sigma^{7}: 1$ Stb. 오: Cp. (2), mit medianen Placenten mit $\infty$ Sa. mit 1 Integ. Gr. 2. Kapsel an den Bauchseiten der Cp. sich offnend. - Grosse Pfl. mit knollenförmigem Stamm und einfachen oder 1-3 mal fiederförmig geteilten B., welche von $\infty$ schuppenförmigen Fmergenzen besetzt sind. Bl. in Ähren. - Etwa 12, auf dem Grunde stehender Gewässer in Madagaskar und Südafr.

2. Unterreihe Saxifragineae. Cp. ebensoviel als Blb. oder weniger. Nahrgewebe der S. meist reichlich, nur bei den Crassulaceae und $\mathrm{Ha}$ mamelidaceae $\mathrm{sch}$ ach.

Fanı. Crassulaceae. B. cyklisch, heterochlam., 3-30gliederig, haplostemon oder obdiplostemon, meist ఢ̧, ๑. P. frei oder (P.). Cp. frei oder wenig vereint, hinten am Grunde mit drüsigen Schüppchen. Sa. mit 2 Integ., $\infty$, meist in 2 Reihen an der Bauchnaht, selten wenig. Meist Balgfr. S. klein, länglich, mit schwachem Nährgewebe. - Succulente Kr. oder Halbsträucher ohne Nebenb. Bl. meist cymös. - 450 temp. - calid. viele Felsenpfl., aber wenige echte Xerophyten. - Serlum (140, meist *). - Sempervivum (50, meist medit. und alp.). - Cotyledon (90). - Bryophyllum calycinum (trop.), mit Adventivsprossen in den Kerben der B. - Crassula (120, meist Südafr.).

Fam. Cephalotaceae. Bl. cyklisch, haplochlam., 6 gliederig, ㅎ, $\oplus$. Cp. frei mit 1-2 grundst., umgewendeten Sa. Balgfr. S. mit fleischigem Nährgewebe und kleinem E. - $4 \mathrm{Kr}$. mit (9), lanzettlichen und bedeckelten Schlauchb. Bl. in Rispen an endst. Schaft. - Nur Cephalotus follicularis in Sümpfen Westaustraliens.

Fam. Saxifragaceae. Bl. cyklisch, meist heterochlam., bisweilen haplochlam.-apetal, meist 5 gliederig, aber G. meist oligomer, meist ㅎ und $\oplus$, selten $\%$ Blütenaxe convex, flach oder concav, dann unterwärts, hfger. der ganzen Länge nach mit dem G. vereint. Stb. hfg. obdiplostemon; aber auch haplostemon, seltener $\infty$. Cp. selten frei und den P. gleichzählig, meist weniger. Gr. meist frei. G. 1 fächerig oder hfger. 2, selten 
5 fächerig, mit angeschwollenen Plac. und meist $\infty$ Sa. in mehreren Reihen. S. klein, mit reichlichem Nährgewebe und kleinem E. - Meist $\mathrm{Kr}$., aber auch $t$ mit meist (2) B., diese bisweilen mit nebenblattartigen Auswüchsen an der Scheide. Bl. klein oder mittelgross, meist $\infty$ in verschiedenartigen Blütenständen. - Etwa 600 calid. - frigid.

Unterfam. Saxifragoideae. Kr. mit (2) B. Bl. meist 5 gliederig. Cp. 2, selten $3-4$, frei oner unterwärts vereint. Sa. mit 2 Integ.

a. Stb. hypogynisch, perigynisch oder epigynisch, aber dann von den Gr. getrennt. verschieden.

§ Saxifrageae. Cp. selten frei, bei Vereinigung die Gr. frei. Plac.

* Astilbinae. Cp. bisweilen frei. $24 \mathrm{Kr}$. mit doppelt bis dreifach 3 teiligen oder gefingerten B. - Astilbe (* exclus. Eur.), Habitus der Rosacee Amuncus.

* Saxifraginae. Cp. \pm vereint. Blütenaxe flach oder becherfg. Bergenia (Centralas.). - Saxifraga (100, meist in den Hochgebirgen *, wenige andin). - Heuchera (24 Am.), bisweilen \%. - Tolmiea Menziesi乞 (pacif. Nordam.), $\%$ und mit Adventivsprossen an den B. - Chrysosplenium $(40 *$ und andin).

$\S$ Parnassieae. Cp. $(3-4)$; kein oder 1 kurzer Gr. Kapsel mit wandst. Plac., 3-4 klappig. - Parnassia (19 *).

b. Stb. epigynisch, dicht neben den Gr.

\$ Donatieae. - Donatia $(2 *)$.

Unterfam. Francoideae. $4 \mathrm{Kr}$. mit grundst. B. und einer Traube oder Ähre am Ende eines nackten Schaftes. Bl. 4 gliederig. G 4 oder 2 fächerig. Francoa (2 Chile).

Unterfam. Hydrangeoideae. th mit einfachen meist gegenst. B. ohne Nebenb. Stb. meist epigynisch. G. halbunterst. oder unterst., meist $3-5$ fächerig. Sa. mit 1 Integ.

§ Philadelpheae. Bl. alle gleich. Stb. meist flach. Fr. scheidewandspaltig, die einzelnen Cp. nach innen fachspaltig. - Philadelphus (13 *). - Deutzia (10 Himalaya, Ostas., Nordam.).

§ Hydrangeeae. Die peripherischen $\mathrm{Bl}$. hfg. steril, mit grösseren Kelchb. Stb. fadenfg. oder pfriemenfg. Kapsel oder Beere. - Hydrangea (30 temp. As., Am.); H. hortensia, Hortensie (China, Japan), Zierpfl.; H. radiata (Nordam.).

Unterfam. Pterostemonoideae. † mit (9) B. mit kleinen Nebenb. Stb. 10. G. 5 fácherig, mit 4-6 Sa. an den centralwinkelst. Plac. - Pterostemon (Mexiko).

Unterfam. Escallonioideae. to mit () einfachen B. ohne Nebenb. Stb. 5. G. bis $\bar{G}$., meist mit $\infty$ mehrreihig stehenden Sa. mit 1 Integ. - Brexia (Madag.) - Itea (temp. As., Am.). - Escallonia (50 Südam.).

Unterfam. Ribesioideae. t mit (9) einfachen B. ohne Nebenb. Sth. 5. G. 1 fächerig, mit 2 wandst. Plac. Halbfr. eine Beere. Bl. in Trauben. - Ribes (50* und andin, temp.); R. Mubrum, Johannisbeere, und R. grossularia, Stachelbeere. 
Unterfam. Baueroideae. to mit gegenst. 3 teiligen $B$. ohne Nebenb. G. halbunterst. mit 2 wandst. Plac. mit $\infty$ Sa. Fachspaltige Kapsel. Bl. einzeln, achselst. - Bauera (2 Ostaustral.).

Fam. Pittosporaceae. Wie die Saxifragaceae-Escallonioideae, soweit dieselben hypogynische Insertion zeigen. Cp. (2) oder (3-5); G. 1 fächerig oder 3-5 fächerig; Sa. mit 1 Integ., 2 reihig. Gr. einfach mit kopffg. oder gelappter $\mathrm{N}$. - t , oft windend, mit (9) B. - Schizogene Harzgänge an der Aussenseite des Leptoms.

$\S$ Pittosporeae. Kapsel. - Pittospormm (70 calid. Afr., As., Austr.).

$\S$ Billardiereae. Beere. - 17 Austral.

Fam. Brunelliaceae. B1. haplochlam., $\sigma^{7}$ ㅇ, 4-5 oder 7 gliedrig, diplostemon. Blhb. in der Knospe klappig. Cp. 5-2, frei, mit je 2 an der Bauchnaht hăngenden Sa. Balgkapseln mit sich ablösendem Endocarp, 1-2 samig. Nährgewebe mehlig. t) mit gegenständigen oder in Quirlen stehenden B. Bl. klein, in zusammengesetzten Rispen. - 10 auf den Anden von Mexiko bis Peru. - Brunellia.

Fam. Cunoniaceae. Wie die Saxifrag; aber in den Cp. die Sa. 2 reihig. - t mit gegenst, oder quirlst. B. mit Nebenb. Bl. klein in traubenähnlichen Blütenständen oder zusammengesetzten Rispen. - subcalid., temp. - Weinmannia (70).

Fam. Myrothamnaceae. Bl. achlain., $\sigma^{\nearrow}$ 우, $\oplus$. $\sigma^{\top}: 4-8$ Stb. 우 Cp. $(4-3)$; Gr. 4-3, mit grossen, länglichen $\mathbf{N}$. Kapsel septicid, die einzelnen Cp. balgfruchtartig. S. mit reichlichem Nährgewebe. - Kleine Sträucher mit gegenst., facherartig gefalteten B. Bl. in endst. Ähren. - Harzzellen. - 2 Madag. und Afrika. Myrothamnus.

Fam. Bruniaceae. Bl. cyklisch, heterochlam., 5 gliederig, ̧ㅗ, $\oplus$, selten $\cdot 1 \cdot$, meist perigyn. P. meist genagelt. Stb, haplostemon. Cp. (3-2), mit je 3, selten 4 Sa. oder Cp. 1 mit 1 Sa. mit 1 Integ. Gr. 3-1. 2 samige Kapsel oder 1 samiges Nïsschen S. mit Arillus, mit reichlichem Nährgewebe; E. sehr klein. - Halbstralucher, mit (?) schmalen B. ohne Nebenb., von heidekrautartigem Habitus. Bl. klein, in zusammengesetzten Ähren, Trauben oder Köpfchen. - 12 Gatt. mit etwa 50 Arten, nur im Kapland.

Fam. Hamamelidaceae. Bl. cyklisch, heterochlam. oder apetal oder nackt, $\Varangle, \sigma^{\top}$ ㅇ, $\oplus$, hypo-epigyn. K., P., Stb. 4-5, Stb. wechselnd. Cp. (2), mit $1-\infty$ hängenden Sa. Kapsel 2 fächerig, fach-oder zugleich noch wandspaltig. S. mit dünnem Nährgewebe und geradem E. - t, meist mit (9) B. mit Nebenb. Bl. meist unansehnlich, in Ähren oder Köpfchen, welche von Hochb. umhüllt sind. Gegen 50 calid.

Unterfam. Bucklandioiderıe. Cp. mit $\infty$ Sa. - Krystalldrusen im Blattparenchym.

\& Bucklandieae. P. vorhanden. Laubb. mit Spicularzellen. Keine Balsamgänge. - Bucklandia populnea (Himalaya).

$\S$ Altingieae. P. 0. Laubb. ohne Spicularzellen. Balsangänge. Liquirlambar orientale (Kleinasien), L. formosanum (Formosa) und L. styraciflumm (Centralam., atl. Nordam.) lief. Storax, die erstere d. off. Storax liquidus; $L$. europaeum in der Tertiärperiode in Eur. Altingia excelsa, Rasamalabaum (ind.-malay.), bis $60 \mathrm{~m}$ hoch.

Unterfam. Hamcimelidoidecte. Cp. mit je 1 Sa. - Einzelkrystalle im Blattparenchym.

$\S$ Parrotieae. Stb. lang, fadenfg. Bl. in Ähren. - Parrotia persica (Nordpersien). - Fothergilla (Afghanistan bis Nordam.). - Corylopsis (6 Ostas.). 
$\S$ Hamamelideae. Stf. kurz. Bl. in Köpfchen - Hamamelis (3 Japan, Nordam.); H. virginica (Nordam.), Rinde daselbst off. - Trichocladus (2 Afr.).

3. Unterreihe Rosineae. Cp. $\infty-1$. Sa. mit 2 Integ. Nährgewebe der S. schwach oder gänzlich fehlend.

Fam. Platanaceae. Bl. cyklisch, heterochlam., 3-8 gliederig, $\sigma^{\top}$ ㅇ, $\oplus$. Bl. typisch isomer: K., P., St., Cp. in Alternation; aber vielfach Störungen durch Abort. Stb. mit kurzen Stf. und keulenfg. A., deren Connectiv in ein dachfg. Schildchen erweitert ist. Cp. frei, mit $1-2$ fast geradläufigen Sa. mit 2 Integ. S. mit schwachem Nährgewebe. $-\frac{\hbar}{\mathrm{m}}$ mit (9) 3---5lappigen $\mathrm{B}$. und grossen verwachsenen Nebenb. $\mathrm{Bl}$. in kugeligen Köpfchen. - Platanus orientalis (Ital. bis Himalaya); P.occidentalis (Mexiko bis Canada); in Am. noch 2 Arten; zahlreiche $P$. fossil in Europa und Grönland von der Kreide bis ins Tertiär.

Fam. Crossosomataceae. Wie die Rosaceae-Spiraeoideae, aber S. nierenförmig, mit reichlichem Nährgewebe und Arillus. - Sträucher mit kleinen graugrünen starren B. und weissen am Ende von Kurztrieben einzeln stehenden Bl. - Crossosoma (2 Neumexiko und Südkalifornien).

Fam. Rosaceae. Bl. cyklisch, heterochlam., selten haplochlam., meist 5-, selten 3-, 4, 6-, 8- und mehrgliederig, $\oplus$, seltener $\%$. Blütenaxe flach, schüsselfg. oder becherfg., in der Mitte bisweilen convex. K., P. und Stb. am Rande der Blütenaxe perigynisch oder epigynisch. Stb. meist $2-4$ mal so viel als $K$. od. $\infty$, selten nur $1-5$, in der Knospe einwärts gekrümmt. Cp. so viel als $\mathrm{K}$. oder $2-3$ mal so viel oder $\infty$, seltener nur $1-4$, frei oder mit.der Innenwand der hohlen Blütenaxe vereint, 1 fächerig, meist mit 2 (selten mehr oder 1) umgewendeten Sa.; Gr. am Scheitel oder an der Bauchseite der Cp. Fr. Balgkapseln oder Schliessfr. oder Steinfr. oder bei Vereinigung mit der vergrösserten Blütenaxe Halbfr. bildend. Nährgewebe der S. spärlich oder 0 . Keimb. meist fleischig, planconvex. - Kr. und t mit meist (9) B. Nebenb. dem Blattstiel angewachsen, selten 0. - Etwa 2000.

Unterfam. Spiraeoideae. Cp. 12-1, meist 5-2, quirlig, weder in die Axe eingesenkt, noch auf besonderem Gynophor, mit je $2-\infty$ Sa. Fr. meist Balgfr. Stf. aus breiterer Basis nach oben verschmälert.

$\S$ Spiraeeae. $\hbar$, selten $4 \mathrm{Kr}$. Balgkapseln mit ungeflügelten $\mathrm{S}$. Physocarpus (3 Nordam., Ostas.). - Spiraea (40*); viele Ziersträucher; hierher nicht die früher als $S p$. bezeichneten Stauden unserer Wiesen. - Aruncus silvester ( $\sigma^{\top} \circ$, *). - Gillenia (2 Nordam.).

§ Quillajeae. ち. Balgkapseln mit geflügelten S. - Quillajı saponaria, Seifenbaum (Chile); Rinde enthält Saponin, zum Waschen verwendet, auch off.

\$ Holodisceae. $\hbar$. Schliessfr. - Holodiscus discolor (pacif. Nordam.).

Unterfam. Pomoideae. Cp. 5-2, mit der Innenwand der hohlen Axe, meist auch unter einander vereint. Axe und unterer Teil des zuletzt fleischigen K. mit der Fr. eine Halbfr. bildend. Nebenb. deutlich. Meist * und andin, wenige trop. As. - Cotoneaster $(20-30 *)$. - 
Cydonia (3 Eur., As.); C. vulgaris, Quitte (Südeur.); off. Semen Cydoniae, Samenschale lief. Bassorin; $C$. japonica, Scharlachquitte (Japan). - Pirus (50-60 *); Untergatt. Piroploorum mit getrennten Gr.: P. communis, Birnbaum (Stammformen der Kulturbirnen: $P$. achras in Centralas., $P$. persica in Syrien und Persien, $P$. cordata im Medit., P. elaeagnifolia im Or. - Bastarde!) - Untergatt. Malus mit am Grunde vereinten Gr.: $\boldsymbol{P}$. malus, Apfelbaum (Stammformen: $P$. pumila im Kaukasus und Altai, $P$. dasypluylla im Orient, $P$. prunifolia in Sibirien); P. sylvestris, Holzapfel (Mitteleur.). - Untergatt. Hahnia mit P. torminalis (Eur., Vorderas.). - Untergatt. Sorbus mit P. domestica (medit.), $\boldsymbol{P}$. ancuparia, Eberesche (Eur., As.), P. aria (Eur.); auch Bastarde mit den Arten anderer Untergatt. - Eviobotrya japonica, japanische Mispel (Japan; cult. in calid.). - Photinia (Ostas., Am.). - Amelanchier (1 subalp., 1 Am. u. a.). - Mespilus (incl. Crataegus 30-40 *); $\boldsymbol{M}$. germanicr, Mispel (östl. medit.).

Unterfam. Rosoideae. Cp. $\infty$ auf gewölbtem oder kegeligem Gynophor, selten wenige, nicht eingeschlossen oder $1-\infty$ in die hohle, bleibende Blütenaxe eingeschlossen, jedes mit $1-2$ Sa. Stets Schliessfr.

§ Kerrieae. Blütenaxe flach oder gewölbt, keine Halbfr. bildend. Cp. wenige, quirlig. Stb. $\infty$, ans breiterer Basis nach oben verschmälert. - Rhodotypus kerrioides (Japan). - Kerria japonica (China). nophor.

Sotentilleae. Wie vorige; aber $\mathrm{Cp}$. meist $\infty$ auf convexem Gy.

* Rubinae. Cp. mit 2 Sa. Kein Nebenblattkelch. Steinfr. - Rubus (200); $R$. chamaemomus, Moltebeere; $R$. arcticus (* subarkt.), Fr. sehr geschätzt; R. idaens, Himbeere (* temp.).

* Potentillinae. Cp. mit 1 hängenden Sa. Schliessfr. ohne Gr. Aussenkelch. - Fraguria, Erdbeere (8 * und andin); F. vesca, Walderdbeere; $F$. virginiana $\times$ chiloënsis, Ananaserdbeere. - Potentillı $(200 *$, andin und *).

* Dryadinae. Cp. mit 1 aufrechten Sa. Schliessfr. mit meist bleibendem Gr. Aussenkelch. - Geum (36 *, andin und *). - Dryus $(2 *)$.

§ Cercocarpeae. Blätenaxe röhrig, $1 \mathrm{Cp}$. einschliessend, mit der Schliessfr. eine Halbfr. bildend. Nebenb. schwach. - Cercocarpus (6) u. a. im pacif. Nordam.

§ Ulmarieae. Blütenaxe flach oder schwach concav. Stf. fast keulenfg., bald abfallend. - Clmecria (8-9 *).

\$ Sangnisorbeae. Blütenaxe krugfg.; 2 oder mehr Schliessfr. einschliessend, meist erhärtend. - Alchimill (häufig Parthenogenesis). - Agrimomia (10). - Hagenia abyssinica (Abyssinien bis Kilimandscharo) lief. die off. Flores Koso. - Srmguisorba $(30 *)$. Cliffortia (40 Südafr.).

\$ Roseae. Blütenaxe krugf. oder röhrig, zahlreiche Cp. einschliessend,

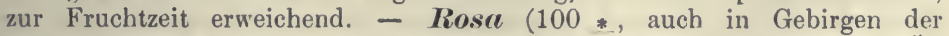
calid.); Stammpflanzen der Edelrosen sind einerseits für Provinzrosen, Ölrosen, Centifolien, Monatsrosen, Moosrosen; R. gallica (Eur., Orient) und $R$. moschata (Nordafr. bis Nordind.); andererseits für Bengalrosen, Thee- 
rosen, Remontanten: $R$. indica u. $R$. moschata. Wichtiger Handelsartikel: Rosenöl.

Unterfam. Neuradoideae. Cp. 5-10, unter einander und mit der Innenwand der hohlen, bei der Reife trockenen Blütenaxe verwachsen. Kr. - Neuradu und Grielum, afrik. Wüstenpfl.

Unterfam. Prunoideae. Cp. 1, selten $1-5$, frei, mit endst. Gr. mit 1 hängenden Sa. Steinfr. - t mit einfachen B. und deutlichen Nebenb. - Prunus (75 *, wenige Am. calid.); Untergatt. Prunopliora: P. armeniacr, Aprikose (Turkestan, Mongolei); P. insititia, Kriechenpflaume (Eur., Vorderas.), P. cerasifera, Kirschpflaume (Turkestan, Südwestsibir.) und $\boldsymbol{P}$. domestica, Stammpflanzen der cultiv. Pflaumen; $\boldsymbol{P}$. spinosa, Schlehdorn. - Untergatt. Amygdalus: P. amygdalus, Mandelbaum (Turkestan, Centralas.) mit den Var. bittere und süsse Mandel, Bittermandelwasser, 0,1\% Blausäure enthaltend; $\boldsymbol{P}$. persicu, Pfirsichbaum (aus Nordchina stammend?) mit der Var. Nektarine. - Untergatt. Chamaeamygdalus: P. nana (Donausteppen bis Ostsibirien). - Untergatt. Cerasus: P. avium, Süsskirsche (Eur. bis Norwegen); P. cerasus, Sauerkirsche (Kleinas.); P. malualeb, (Südeur., Vorderas.) lief. Weichselrohr. - Untergatt. Padus: P. padues, Ahlkirsche, Faulbaum (Eur., As.); P. Zaurocerasus, Kirschlorbeer (medit.) zur Bereitung von Kirschlorbeerwasser.

Unterfam. Chrysobalunoideae. Cp. 2-5, frei, mit grundst. Gr. und 2 grundst. aufrechten Sa. Sonst wie vorige. Alle sehr gerbstoffreich.

* Chrysobalaninae. Bl. fast $\oplus$. - Chrysobalanns icaco (trop. Am., Westafr.) lief. die essbaren Icacopflaumen. - Iicaria (36 Südam.) lief. schwarze Farbe.

* Hirtellinae. Bl. + - Hivtella (40 Am.); H. silicea lief. verbrannt Kieselsäure für Töpferei. - Parinarium (viele trop.); $P$. macrophyllum, Ingwerpflaume (Westafr.); P. excelsum, grosse Pflaume (Westafr.), mit essbaren Fr.

Fam. Connaraceae. Bl. cyklisch, heterochlam., 5 gliederig, meist diplostemon, hypogynisch, ̧ㅜ, selten $\sigma^{\top}$ ㅇ, $\oplus$. K. meist bleibend und bei der Reife die Basis der Frucht umhüllend. P. bisweilen leicht verwachsen. Stb. vor den P. meist kürzer als die anderen oder steril. Cp. meist 5, seltener 4 oder 1 , mit je 2 geradläufigen Sa. am Grunde. Meist nur 1 Kapsel, mit nur 1 S., an der Bauchseite sich öffnend. Nährgewebe + oder 0. Arillus. - Meist kletternde $\hbar$, selten Bäume, mit (2) unpaarig gefiederten B. ohne Nebenb. und in Rispen stehenden Bl. - Etwa 160 trop. (40 trop.).

\& Conuareae. K. dachig. Nährgewebe 0. - Connarus (50 trop.). - Rourea

$\S$ Cnestideae. K. klappig. Nährgewebe + oder $0 .-$ Cnestis (9 trop. Afr.).

Fam. Leguminosae. Bl. cyklisch, heterochlam., 5 gliederig, meist diplostemon, aber auch pleiostemon, hypogynisch, 후, selten $\sigma^{\top}+$, $\oplus$ oder häufig $\%$ Cp. meist nur 1 , seltener 2 , sehr selten $5-15$, mit $\infty$, seltener $1 \mathrm{Sa}$. an der nach hinten gekehrten Bauchnaht, gewöhnlich an 2 abwechselnden Zeilen. Sa. umgewendet oder amphitrop. Gr. endst. Fr. häufig 2 klappig (Hülse), bisweilen Balgfr. oder nicht aufspringend, meist Nähr- 
gewebe spärlich oder 0 . - - t und Kr., meist mit (a) B. mit Nebenb. und meist in Trauben stehenden $\mathrm{Bl}$. -7000 frigid. bis trop.

Unterfam. Mimosoideae. Bl. ๑. P. in der Knospe klappig.

A. K. in der Kंnospe klappig.

a. Stb. $\infty$ oder mehr als 10.

§ Ingeae. Stf. \pm verwachsen. Bisweilen mehr als $1 \mathrm{Cp}$. - Inga (140 trop. Am.); I. Feuillei (Peru) und I. edulis (Brasil.) mit süssen Fr. - Pitlecolobium (110 trop.); P. avaremotemo (Brasil.); bittere Rinde medizinisch gebraucht. - Albiasia (50 palaeotrop.); A. lebbek (trop. Afr., As.) lief. Gerbrinde und Gummi.

$\S$ Acacieae. Stf. frei, seltener die inneren unten vereint. Stets nur 1 Cp. - Acacia (450 calid., davon etwa 280 Plyyllodineae in Austral. und auf ocean. Inseln). Das beste Gummi arabicum lief. namentlich $\boldsymbol{A}$. sencegal (Nordafrika), A. glaucoplylla und A. abyssinica (Abyssinien); bräunliches Gummi lief. A. Eilirenbergiana und $A$. stenocarpa (Nubien, Abyssin.), A. seyal und A. arabica (trop. Afr.); Kapgummi lief. $A$. horrida (Südafr.); australisches Gummi lief. mehrere australische Arten. A. cutechu (Vorderind., Ostafr.) lief. das aus dem Holz durch Kochen gewonnene Catechu.

b. Stb. ebenso viel oder doppelt so viel als P. (5 oder 10 ).

§ Eumimoseae. A. ohne Drüse am Ende. - Mimosa (300 trop., meist Am.); $\boldsymbol{M}$. pudica (ursprüngl. Brasil.) mit besonders auffallender Reizbarkeit der B.

§ Adenanthereae. A. in der Knospe mit Enddruise. S. mit Nährgewebe. Neplunia oleracea (trop. Wasserpfl.). - Prosopis (25 calid.), mit sehr hartem Holz; $P$. julifora, Mesquitobaum (Texas bis Kalif.); lief. Mesquite-oder Sunora-Gummi. - Adenanthera pavonina (trop. Asien) lief. die roten Korallenerbsen.

\$ Piptadenieae. Wie vor.; aber S. ohne Nährgewebe. - Entrula (11 trop.); $\boldsymbol{E}$. scandens (trop.) mit $1 \mathrm{~m}$ langen Gliederhülsen; die S. durch den Golfstrom weit verbreitet.

B. K. in der Knospe dachig.

§ Parkieae. Parkia (19 trop.).

Unterfam. Caesalpinioideree. Bl. . . P. in der Knospe dachig, mit aufsteigender Deckung.

§ Dimorphandreae. B. doppelt gefiedert, selten einfach gefiedert. K. in der Knospe zusammenhängend. - Erythrophloeum guineeuse, Red-water-tree (trop. Afr.) nit stark giftiger Rinde.

\$ Cynometreae. B. einfach gefiedert, paarig. K. frei. P. 0, 1, 3, 5. G. frei, meist mit $1-2 \mathrm{Sa}$ - Copcrifera (16 trop. Am.); mehrere lief. Balsamum Copaivae, z. B. C. officinalis (Guiana bis Columbien), C. Langsslorffii und C. coviacer in Brasilien.

§ Inherstieae. B. einfach gefiedert. K. frei. G. rückwärts dem Receptaculum angewachsen. - Trachylobium verrucosum (Madagaskar, Ostafrika) lief. den ostafrikanischen Copal. - Hymenrea (8 trop. Am.), $\boldsymbol{H}$. courbaril, Lokustbaum u. a. Arten lief. amerikanischen Copal oder Courbaril. - Afzelia (10 trop. As., Afr.); A. bijuga 
(Seychell. bis Polynes.) lief. Eisenholz (für Möbel). - Tamarindus indica (trop. Afr.); Fr. sehr geschätzt, das Fruchtmus (Pulpa Tamarind.) vorzügliches Purgiermittel.

$\S$ Bauhinieae. B. nicht gefiedert, einfach, 2 lappig oder bis zum Grunde geteilt. Stb. 10 oder weniger. K. zusammenhängend. - Bauhinia (150 trop.); Stämme der kletternden Arten oft flach und mit zerklüftetem Holzkörper. - Cercis (4 Südeur., Ostas., Nordam.); C. siliquastmum (mediterr.); C. canadensis (atlant. Nordam.).

§ Cassieae. B. einfach gefiedert. K. frei. Vordere P. entwickelt, abortiert oder reduciert, aber nicht $\mathrm{zu}$ fleischigen Drüsen umgebildet. Thecae der A. mit endstdg. Porus. - Cassia (400 calid.); C. acutifolia (trop. Afr.) lief. die off. Folia Sennae Alexandrinae; C. Mngustifolia (Ostafr., Arab., cult. in Ostind.), lief. die Folia Sennae Tinnevelly; C. fistula (trop. Afr.) enthält in den cylindrischen Fr. purgierendes Mark. - Ceratonia siliqua, Johannisbrotbaum, apopetal (Arab., cult. und subspontan im Mediterrangeb.), lief. essbare Fr.

§ Kramerieae. B. einfach. K. frei. Vordere 2 P. zu grossen, fleischigen, schuppenartigen Drüsen ausgebildet. Thecae der A. mit endst. Poren. - Krameria (früher zu den Polygalaceae gerechnet; 12 Amer. calid.); K. triandra (Anden von Bolivia und Peru) lief. die off. Radix Ratanhiae.

§ Eucaesalpinieae. B. doppelt gefiedert. K. frei. Vordere P. entwickelt, abortiert oder reduciert. - Caesalpinia (38 calid.); mehrere lief. Farbhölzer, so C. brasiliensis (Antillen) und C. echinata (Brasil.) Fernambukholz, C. sappan (trop. As.) das Sappanholz. - Haemcetoxylon campechianum (Centralam., cult. in Westind.) lief. Blauholz. - Gymnocladus canadensis (Bl. ๑; atlant. Nordam.). - Gleditsr.hia (11 Westas., Ostas., Nordam., Südam., trop. Afr.). - Poinciana (3 Ostafr., Mascar., Vorderind.).

\& Sclerolobieae. B. einfach unpaarig gefiedert. K. frei. P. 3 oder 5. A.

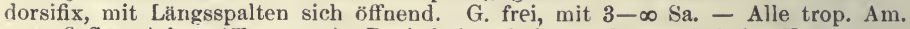

\$ Swartzieae (Tounaleeae). B. einfach gefiedert, seltener einfach. K. zusammenhängend. Stb. meist $\infty$, seltener 9-13. - Swartzia (60, davon 1 trop. Afr., die anderen trop. Am.).

Unterfam. Papilionutae. BI. + . P. in der Knospe dachig, mit absteigender Deckung. - Wurzeln in Symbiose mit Bacillus radicicola (s. S. 4).

§ Sophoreae. 10 oder mehr Stb. frei. $\hbar$ oder Sträucher mit gefiederten B. - Sophora (22 calid.); S. japonica (Japan). - Cladrastis tinctoria (atlant. Nordam.). - Myroxylon toluifera (Venezuela, Net1Granada) lief. d. off. Balsamum tolutanum; M. pereirae (Centralam.) lief. das off. Balsamum peruvianum.

$\S$ Podalyrieae. 10 Stb., frei. Meist Sträucher mit einfachen oder gefingerten B. - Anagyris (2 medit.). - Thermopsis (12 Himal., Ostsibir., Nordam.). - Baptisia (14 Nordam.). - Podalyria (17 Südafr.). - Oxylobium (27), Chorizema (15), Pultenaea (75) u. a. in Australien.

§ Genisteae. $10 \mathrm{Stb}$, meist vereint, seltener 1 frei und 9 vereint. Sträucher oder $\mathrm{Kr}$. mit einfachen oder gefingerten B. und ganzrandigen 
Blättchen. - Viele Austral. und Südafr. - Lotononis (Afr. medit.). Aspalathus (150 Südafr.). - Crotalaria (200 calid.); C. juncea (Ostind.) lief. Bast. - Lupinus (80 meist Am., einige medit.); J. luteus (medit.); L. angustifolius (medit.); J. allus (medit.), Futterpfl. - Argyrolobium (42 medit., Ostind., Südafr.). - Lraburnum vulgare, Goldregen (medit.), mit giftigen Samen. - Calycotome (4 medit.). - Genista (70 medit., Eur. und Westas.). - Spartium junceum (medit.). - Ulex (12 Westeur. und 2 medit.); $U$. europaeus auch als Pferde- und Wildfutterpfl. auf sandigem Boden cult. - Cytisus (38 medit., Eur., Westas.); C. scoparius, Besenginster.

\$ Trifolieae. 10 Stb., selten alle vereint, meist 1 frei und 9 vereint. Kr. mit selten gefiederten, meist gefingerten B. und am Rande gezähnelten Blättchen. - Ononis (60 medit., Eur. und Westas.); O. spinosa lief. die Radix Ononidis. - Parochetus communis (Gebirge von trop. As. und Afr.). - Trigonella (50 meist medit.); T. foenum graecum lief. die off. Semen Foenu graeci. - Medicago (40 medit., Eur., Westas.); M. sativa, Iuzerne. - Melilotus (10 temp., subtrop. Eur., As., Afr.); M. officinalis, Honigklee, lief. d. off. Herba Meliloti. - Trifolium (280 temp., subtrop.); T. pratense, T. hybridum, T. repens und T. incarnatum Futterpfl.

\& Loteae. 10 Stb., selten alle vereint, meist 1 frei und 9 vereint. $\mathrm{Kr}$. mit gedreiten, seltener gefiederten B. und ganzrandigen Blättchen. Anthyllis (20 medit. und Eur.); A. vulneraria, Wundklee, Futterpfl. Lotus, Hornklee (100 temp.).

§ Galegeae. $10 \mathrm{Stb}$, selten alle vereint, meist 1 frei und 9 vereint. Kr., Sträucher oder $\hbar$ mit meist gefiederten B. Bl. meist in Trauben. Hülse 2 klappig. - Psoralea (100 meist subcalid.). - Amorpha (8 Nordam.). - Inaligofera (220 calid.); I. tinctoria (Senegamb.) und I. anil (trop. Am.?, cult. in den Trop.) lief. Indigo. - Galega (3 Südeur., Westas.). - Tephrosia (90 calid.). - Wistaria sinensis (Ostas.), kletternder Zierstrauch. - Robinia (6 Nordam.); R. psendacucia in Eur. eingebürgert. - Carmichaelia (9 Neuseeland). - Colutea (7 Südeur. und As.); C. arborescens, Blasenstrauch (Südeur.). - Halimodendron argenterm (Salzsteppen Russlands). - Caragana (15 Centralas.); C. arborescens (Altai, Songarei), Wurzel und Rinde früher off. - Astragalus $\left(600^{*}\right.$ und andin); A. adscendens (Sïdwestpersien), A. gummifer (Syrien, Kleinasien), A. microcephalus (Armenien), A. cylleneus (Peloponnes) u. a. Arten lief. Traganthgummi. - Oxytropis $\left(100^{*}\right)$. - Bisermula pelecinus (medit.). Glycyrhian (12 * und Südam.); G. glalrre (von Ungarn bis Afghanistan) lief. d. off. Radix Liquiritiae, Süssholz.

$\S$ Hedysareae. $10 \mathrm{Stb}$., selten alle vereint, meist 1 frei und 9 verbunden. B. gedreit oder gefiedert. Gliederhülsen oder Bruchfr. - Or $\boldsymbol{n}$ ithopus (7 temp., subcalid.); O. sctivers, Serradella (Portugal), Futterpfl. auf Sandboden. - Coronilla (20 medit. und Nachbarländer). - Hippocrepis (12 medit. und Nachbarländer). - Hedysamum (50*). - Onobiychis (50 medit., As.); O. sativa (Eur.), Futterpfl. - Alhagi (6 Wüstenpflanzen von Griechenland bis Ägypten und zum Himalaya). Amicia (trop. Anden); A. zygomeris mit auffallender Tag- und Nacht- 
stellung der B. - Aeschynomene (50 calid.) elcphroxylon, Am. batsch (im Nilgebiet von $3-8^{\circ} \mathrm{n}$. Br.), berühmt wegen des leichten Holzes. - Adesmia (110 Südam.). - Stylosanthes (15 calid.). - Arachis hypoyaea, Erdpistazie, Erdnuss (trop. Am.), in d. Trop. cult. wegen der ölreichen, unter der Erde reifenden Samen. - Desmodium (125 calid.); D. gyrans, Telegraphenpt. (Ostind.), ausgezeichnet durch selbständige Bewegung der kleinen Seitenblättchen; D. penduliflorum (Japan), Zierpfl. - Iespedeza (25 temp. Ostas., Nordam.).

\$ Dalbergieae. Stb. 10, alle vereint oder 1 frei und 9 verbunden. B. meist gefiedert. Fr. nicht aufspringend. - Dalbergia (64 trop.). Machaerium (60 trop. Am.). - Pterocarpus (15 trop.); Pt. santalinus (Ostind.) giebt das rote Caliaturholz; Pt. marsupium (Ostind.) und Pt. indicus, Korallenholz (Ostind.), lief. rotes Gummi, das ostind. Kino. Andira (17 trop. Am.); A. araroba (Südam.) lief. das Chrysarabin. Dipteryx (8 trop. Am.); D. odorata (Surinam) lief. die Tonkabohnen, Fabae de Tonca.

$\S$ Vicieae. Stb. 10 , selten alle vereint, meist 1 frei. B. gefiedert, ohne Endblättchen, statt dessen mit feiner Spitze oder Ranke. Meist Kr. Keimb. dickfleischig, im S. verbleibend. - Abrus (5 calid.); A. precatorius, Paternostererbse (trop.), mit roten S. - Cicer (medit., As. calid.); C.arietinum, Kichererbse (medit.), wird cult. - Vicia (180 * und andin); $V$. sativa und andere Futterpflanzen; $V$. amplicarpa (medit.) mit oberirdischen und unterirdischen Bl. und Fr.; $\boldsymbol{V}$. fab $\boldsymbol{a}$, Pferdebohne (am kaspischen Meer), cult. - Léns (8 medit.); L. esculenta, Linse, cult. - Lathyrus (100 * und Südam.); L. sativus (medit.), $\Gamma_{\text {. }}$ cicera u. a. im Medit. cult. - Pisum sativum, Erbse (medit.) und P. arrense, graue Erbse, cult.

$\S$ Phaseoleae. Bl. und Fr. wie bei vorigen; aber windende $\mathrm{Kr}$. oder Sträucher, selten $\hbar$ mit gedreiten oder gefingerten B. - Clitoria (27 calid.). - Glycine (12 palaeotrop); G. soja (Ostas.) lief. d. wohlschmeckende Soja, cult. - Erythrina (25 trop.). - Apios tuberosa (atl. Nordam.), mit knolligem essbarem Rhizom. - Mucuna (22 calid.); $M$. pruriens u. a. mit Jucken erregenden Haaren. - Butea frondosa (Ostind.) lief. das Butea Kino. - Canavalia (12 calid.); C. ensiformis und C. gladiata in d. Trop. cult. wegen der essbaren S. - Physostigma venenosum (trop. Westafr.) lief. d. das giftige Physostigmin enthaltenden Calabarbohnen, Gottesurteilbohnen. - Phaseolus (60 calid.); Pl.vulgaris und Ph. multiflor us (Südam.) vorzugsweise in Eur. cult.; in den Trop. auch Ph. mungo (Ostind.); Ph. lunatus (Ostind., Afr.) u. a. - Vigna (30 calid.); V. sinensis (trop. As., Afr.), Hülsengemüse. - Voandzeia subterranea (trop.), Hülsengemüse mit unterirdischen Fr. aus apopetalen Bl. - Pachyr r $/$ izus bulbosus (trop. Am., trop. As.) mit kopfgrossen, rübenfg., als Nahrungsmittel dienenden Wurzeln; cult. - Dolichos (20 calid.); D. lablab Hülsengemüse in Ostafr. und Ostind. - Cajanus indicus (trop. As., Afr.), beliebtes Hülsengemüse in d. Trop. - Rhynchosia (75 calid.).

ઈ) Die Bl. zeigen vorherrschend 5 oder 4 Cyklen. Apocarpie und Isomerie treten noch auf, aber Syncarpie und Oligomerie des Gyniceums herrschen vor, Pleiomerie desselben selten. 
19. Reihe GERANIALES. Bl. cyklisch, heterochlam. oder apetal, selten ganz nackt, meist 5 gliederig. Androeceum wechselnd. G. Cp. $(5-2)$, selten mehr, quirlig, bei der Reife hfg. wieder von einander getrennt, seltener mit $\infty$, meist mit 2-1 Sa. Sa. epitrop mit ventraler Rhaphe und der Mikropyle nach oben, oder wenn mehr als $1 \mathrm{Sa}$. vorhanden, einzelne bisweilen mit dorsaler Rhaphe und der Mikropyle nach unten.

1 Unterreihe Geraniineae. Bl. heterochlam., selten apetal, meist $\oplus$, bisweilen $\cdots$; meist obdiplostemon (d.h. Stb. doppelt so viel als P. und die $C_{p}$. bei Gleichzähligkeit vor den P.), seltener haplostemon, in .. Bl. hfg. A bort einzelner Stb.; A. mit Länggspalten sich öfnend. G. isomer oder oligomer.

A. Keine Secretzellen oder Secretlücken.

Fam. Geraniaceae. Bl: 5 gliederig, $\not$, meist $\oplus$. Kein eigentlicher Discus. Stb. 10 oder 15 , bisweilen nur 5 fertil. Cp. meist mit $1-2$. seltener mit $2-\infty$ Sa., mit 2 Integ. Kapsel oder Fr. in 5 geschnäbelte Teilfr. zerfallend. Nährgewebe +. - Meist Kr. mit gelappten oder geteilten B. Nebenb. + oder 0. - 350 temp.-subcalid.

A. K. frei oder wenig vereint. Andin.

$\S$ Wendtieae. Fr. ohne sich zurückrollende Grannen. Cp. mit $\infty-2$ Sa. -

§ Biebersteinieae. Wie vorige; aber Cp. mit 1 Sa. - Biebersteinia (östl. medit.).

\$ Geranieae. Fr. mit elastisch sich zurückrollenden Grannen. Geranium (160 temp.). - Monsonia (Afr., Westas.). - Sarcocaulon (Xerophyt., Südafr.). - Erodium (50 temp.). - Pelurgonium (180 Syrien bis Südafr.).

B. K. zu einer Röhre oder Glocke vereint.

\& Vivianieae. Kapsel. - Südan.

Fam. Oxalidaceae. Bl. 5 gliederig, ㅎ, $\oplus$. Kein Discus. Stb. 10, unten vereint. G. isomer. Cp. mit $\infty-1$ Sa., mit 2 Integ. Kapsel oder Beere. Nährgewebe fleischig. - Meist $4 \mathrm{Kr}$., selten $\hbar$ mit meist zusammengesetzten B. (Schlafstellung derselben). Nebenb. + oder 0. 250 temp. bis calid. - Oxalis (220); O. ucetosella, Sauerklee (*) u. a. lief. Kaliumoxalat; Trimorphismus der Bl. - Biophytum (trop.). - Arerhore carambola und A. bilimbi, th (trop.), mit essbaren Fr.

Fam. Tropaeolaceae. Bl. 5 gliederig, ఫ્, $\%$ Blütenaxe hinten in einen Sporn übergehend. Stb. 8, G. 3 mer. Cp. mit 1 Sa., mit 2 Integ. Fr. in drei 1 samige Teilfr. zerfallend. Nährgewebe 0 . - Oft kletternde Kr. mit rankendem Blattstiel und einfachen B. Nebenb. + oder 0. Tropueolum (35 andin); T. mojus, Kapuzinerkresse.

Fam. Linaceae. Bl. 5-4 gliederig, ̧ㅜ $\oplus$. Kein eigentlicher Discus. Stb. 5-20, am Grunde vereint. G. isomer oder oligomer, völlig syncarp. Cp. mit 1-2 Sa., mit 2 Integ. Kapsel oder Steinfr. Nährgewebe + . - Kr. oder $t$ mit (9), ungeteilten B. Nebenb. + oder 0. -150 temp.-calid.

§ Eulineae. Meist Kr. 1 Kreis Stb. Kapsel. - Ralliola multiflora (temp. Eur., As., Gebirge in $\mathbf{A f r}$.). - Limum (90 temp., subtrop.); $\boldsymbol{L}$. 
usitatissimum, Lein, Flachs, cult. seit 4-5000 Jahren in Vorderas. und Ägypt., durch die Arier in Eur. eingeführt; L. angustifolium (medit.), zur Zeit der Schweizer Pfahlbauten cult. in Eur.

$\S$ Hugonieae. †. 2-4 Kreise Stb. Kapsel oder Schliessfr. - trop.

Fam. Humiriaceae. Bl. 5 gliederig, ఫ્ఛ, $\oplus$. Becherfg. Discus um das G. Stb. $10-\infty$. G. isomer., völlig syncarp. Cp. mit 1-2 Sa. Steinfr. Nährgewebe +. t mit (9), ungeteilten B. Nebenb. +. -18 trop. Am., 1 Afr.

Fam. Erythroxylaceae. Bl. 5 gliederig, ㅎ, $\oplus$. Kein Discus. P. an der Innenseite mit Anhängsel oder Schwiele. 10 Stb. am Grunde zu einer Röhre vereint. G. 3-4 mer, aber meist nur $1 \mathrm{Cp}$. mit $1-2 \mathrm{Sa}$, mit 2 Integ. Steinfr. Nährgewebe + - t mit (9, ungeteilten B. Nebenb. +. - 100 calid. - Erythroxylon (90 calid.); E. coca (Peru) lief. Cocain.

Fam. Zygophyllaceae. Bl. 5-4 gliederig, ఫ̧, $€$. Discus bisweilen ringfg. oder Gynophor. Stb. $10-8$, selten 15, am Grunde hfg. mit Nebenb., welche vereint ein innenseitiges Anhängsel bilden. G. isomer oder

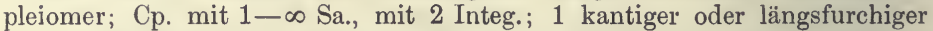
Gr. Meist Kapsel oder Teilfr,, selten Beere oder Steinfr. Nährgewebe + oder 0. - Selten $\odot$, meist Halbsträucher oder Sträucher mit gegenst., seltener (Q), hfg. paariggefiederten B.; Nebenb. Bl. einzeln in Wickeln oder in zusammengesetzten Inflorescenzen. - Etwa 140 calid., viele Xerophyten.

A. Kapseln oder Fr. in Teilfr. zerfallend, selten Beere.

Unterfam. Zygophylloideae. B. gegenst. oder durch Abort eines B. der Blattpaare wechselst., einfach oder gedreit oder paarig gefiedert. Cp. (5).

§ Zygophylleae. S. mit Nährgewebe.

* Fagoniinae. B. gedreit oder mit 1 Blättchen. - Fagonia (18 medit., Afr., Kalif., Chile).

* Zygophyllinae. B. ungeteilt oder paarig gefiedert. - Zygophyllum (60 in der alten Welt). - Guajacum (4 Am. calid.); G. officinale und G. sanctum lief. das off. Guajakholz oder Pockholz mit Guajakharz. - Porlieria hygrometrica (Peru, Chile), mit sich zusammenlegenden Blättchen. - Bulnesia (6 Argentinien), mit dauerhaftem Holz. (calid.).

§ Tribuleae. S. ohne Nährgewebe. - Tribulus (12); T. terrester

Unterfam. Augeoideae. B. keulenfg, mit kurzen Nebenb. (Cp. 10), - Augea (Südafr.).

Unterfam. Chitonioideae. B. (9), einfach oder unpaarig gefiedert. - Mexiko.

Unterfam. Peganoideae. B. (9), vielspaltig. Kapsel oder Beere. Peganum Tarmala (Steppen des Medit. und der angrenzenden Länder); Samen enthalten Harmalin zur Darstellung des türkischen Rot.

Unterfam. Tetradiclidoideae. B. fiederschnittig. Fächer des G. durch Ausbuchtung der Seitenwände mit 3 kleinen, communicierenden Kammern. - Tetradiclis (1 Salzsteppen von Ägypten bis Vorderasien). 
B. Steinfr. mit hartem, 1 samigem steinkern.

Unterfam. Nitrarioidece. B. einfach, (9). Wüstensträucher. Nitraria retusa (Salzwüsten von Nordafr. bis Palästina), zur Bereitung von Soda.

Unterfam. Balınitoidece. B. einpaarig, abwechselnd. - Balanites (1) aegyptiaca (Steppen von Senegambien bis Birma).

B. Wie A.; aber Secretzellen, Secretlücken oder Secretgange vorhanden, bei den hierher gestellten Simarubaceae nur bisweilen im Mark und in der'Rinde.

Fam. Cneoraceae. Bl. 3-, selten 4 gliederig, જ, $\oplus$. Discus säulenfg. oder polsterfg. Stb. 3 oder 4. G. isomer, gelappt; Cp. mit 2 Sa., mit 2 Integ.; 1 Gr. Steinfr. in 3-4 von einem Mittelsäulchen sich loslösende Teilfr. zerfallend, diese mit zwei 1 samigen Fächern. - Sträucher mit (Q), lederartigen, schmalen B. Nebenb. 0. Bl. einzeln oder in Trugdolden. - Ölzellen. - Cneorum (12 medit.).

Fam. Rutaceae. Bl. 5-4 gliederig, 후, selten $\sigma^{7}$ 우, $\oplus$ und $\cdots$ Discus ringfg. oder polsterfg., bisweilen becherfg. Stb. obdiplostemon oder haplostemon, bisweilen durch Abort 3-2, selten $\infty$ (durch Spaltung?). Cp. 5-4, selten $3-1$ oder $\infty$, oft unten frei und nur oben vereint, mit $\infty-2$ Sa., mit 2 Integ. Fr. und S. verschieden (s. unten). - Selten Kr., meist $t$ oder Sträucher mit (a) oder gegenst., einfachen oder zusammengesetzten B. Nebenb. 0. - I ysigene Öldrüsen, selten mehrzellige Öldrüsen in Rinde und B., diese daher durchsichtig punktiert.

Unterfam. Rutoiderie. Cp. meist 4-5 (sehr selten mehr oder nur 3-1), hfg. nur durch die Gr. vereint und unten frei, bei der Reife 士 getrennt, nach innen fachspaltig sich öffnend, in der Regel mit sich ablösendem Endocarp, sehr selten 4-1 fleischige Steinfr.

A. B. und Rinde mit lysigenen öldrüsen.

$\S$ Xanthoxyleae. $\hbar$, meist mit kleinen, grünlichen oder grünlichweissen, seltener grossen und leuchtend weissen, stets $\oplus$, nicht selten eingeschlechtlichen Bl. Cp. nur selten mit mehr als 2 Sa. E. meist mit flachen Keimb. im Nährgewebe. - Xanthoxylum (9 temp. Ostas., Nordam.); X. fraxineum (atlant. Nordam.). - Fagara (130 trop.); Rinde vieler Arten schweisstreibend. - Evodia (45 trop. As., Malegassien). - Orixa japonica (Japan.). - Choisya ternata (Mexiko).

§ Ruteae. Kr. oder Halbsträucher, seltener Sträucher mit mittelgrossen, stets $\Varangle \mathrm{Bl}$., die bisweilen schwach $\%$ sind. Cp. in der Regel mit mehr als $2 \mathrm{Sa}$. Die S. mit Nährgewebe. - Ruta (40 medit. bis Ostsibirien); R. graveolens, Raute, off. - Boenninghansenia (1 Japan). Dictammus albus, Diptam (Eur., As.).

$\S$ Boronieae. Meist Halbsträucher und Sträucher. Bl. stets $\oplus$, meist ̧. S. mit fleischigem Nährgewebe, sonst wie vorige. - 180 Austral. - Beronia. - Eriostemon. - Correa, mit sympetaler Corolle.

§ Diosmeae. Meist Halbsträucher und Sträucher, selten Bäume, mit einfachen B. S. ohne Nährgewebe. E. meist gerade mit fleischigen 
Keimb. - 180 Kapland. - Coleonema. - Agathosma. - Barosma. Calodendron.

$\S$ Cusparieae. Sträucher und Bäume. Bl. $\phi$ oder $\%$ S. mit wenig oder ohne Nährgewebe. E. gekrümmt, mit dem Stämmchen zwischen den Keimb. - 100 Am. calid.

* Pilocarpinae. Bl. 申. - Pilocarpus pennatifolius u. P. Sellormus (Brasil.) geben die off. Folia Jaborandi. - Esenbeckia (10). Metrodorea.

* Cuspariinae. Bl. + - Cusparia trifoliata (Neu-Granada) giebt Cortex Angosturae. - Galipea (Brasil). - Erythrochiton (trop. Am.).

B. B. nit mehrzelligen, aber nicht lysigenen Drüsen.

$\S$ Dictyolomeae. Bl. $\oplus$, haplostemon. Stb. am.Grunde mit Schüppchen. CP. mit $\infty$ Sa., nur am Grunde vereint. Bäumchen mit doppelt gefiederten B. Dictyoloma ('? Südam.).

Unterfam. Flindersioideae. Cp. (5-3), mit je 28 ? reihig stehenden Sa. Kapsel fachspaltig od. septicid, mit bleibendem Endocarp. S. geflügelt, ohne Nälırgewebe. - $\hbar$ mit lysigenen Öldrüsen. - Flindersia (ind.-malayisch).

Unterfam. Spathelioideae. Cp. (3), mit je 2 hängenden Sa. Steinfr. geflügelt. Secretzellen und lysigene Öldrüsen (an den Blatträndern). - Spatheliu (Westind.).

Unterfam. Toddalioideae. Cp. $(5-2)$ oder nur 1, mit je 2-1 Sa. Steinfr. oder trockene Flügelfr. Nährgewebe + oder 0 . - B. und Rinde. mit lysigenen Öldrüsen.

§ Toddalieae. 60 temp.-calid. - Todilalia (palaeotrop.). - I'teleu trifoliata (Nordam.). - Skimmia japonica (Japan).

Unterfan. Aurantioidece. Beere, hfg. mit Periderm und mit einer aus saftreichen Emergenzen der Cp. hervorgehenden Pulpa. S. ohne Nährgewebe. B. und Rinde mit lysigenen Öldrüsen. - palaeotrop.

\section{$\S$ Aurantieae.}

* Iimoniinae. Cp. mit 2 oder 1 Sa. - Murraya (4 ind. malay.). Iimonia (7 Ostind., trop. Afr.). - Triphasia aurantiola (Vorderind. und cult.).

* Citrinae. Cp. mit $\infty$ Sa. - Aegle sepiaria (Japan); A. Marmelos (Ostind.) mit wohlschmeckenden Fr. - Feronia elephantum (Ostind.) u. a. Arten dieser Gruppe magenstärkend und stimulierend. - Citmis (trop. As.); alle lief. ätherische Öle und essbare Fr.; C. Iecumunu, Pompelmus (China, Cochinchina); C. medica, Citrone, Limone (Vorderind.); C. aurantium mit der Var. bigaradia, Pomeranze (südl. Himalaya) und der Var. dulcis, Apfelsine; C. nobilis, Mandarine (Cochinchina). Nucellarembryonen bei $C$. aurantium.

Fam. Simarubaceae. Bl. 5- 4 gliederig, selten $\not{q}$, meist $\sigma$ Discus hfg. wie bei vorigen. Stb. 10 oder 5 , selten $\infty$. Cp. 5 oder weniger. Sa. mit 2 Integ. Fr. und S. mannigfach. - to mit bitterer Rinde, (9) oder gegenst., selten einfachen, meist gefiederten B.; Nebenb. 0. - Niemals Öldrüsen; bisweilen schizogene Ölgänge im Mark. - Etwa 120 calid.

Unterfam. Sırianoileae. Cp. mit je $2 \mathrm{Sa}$, frei. Stb. ohne Ligularschuppe. - Suriana maritima (trop. littoral). 
Unterfam. Simamboideae, Cp. mit je $1 \mathrm{Sa}$.

S Simarubeae. Stf. mit Ligularschuppe. - Quassia amara (trop. Am.) lief. Quassiaholz, Lignum Quassiae surinamense. - Simaruba amara (Bras., Guiana) giebt Cortex Simarubae. - Samen von Sime cedron (trop. Neu-Granada) gegen Schlangenbiss.

§ Picrasmateae. Stf. ohne Ligularschuppe. Cp. unten frei, aber die Gr. unten vereint. - Picrasma excelsa (Antill.) lief. Lignum Quassiae jamaicense. - Ailanthms glandulosa, Götterbaum (China), durch $\infty$ Wurzelschösslinge sich ausbreitend, cult.

Unterfam. Picramnioilene. Cp. (2-3) mit je 2 hängenden Sa. - Picramnia (trop. Am.).

Fam. Burseraceae. Bl. 5-4 gliederig, obdiplostemon oder haplostemon, selten $\not$, meist $\sigma^{\nearrow}$ ㅇ, $\phi$. Discus $\mathrm{hfg}$. wie bei vorigen. Cp. $(5-3)$, mit je 2 collateralen, selten nur 1 Sa., mit 2 Integ.; $1 \mathrm{Gr}$. Steinfr. mit 2-5 Steinkernen oder klappig aufspringende Fr., bisweilen scheidewandspaltig. S. ohne Nährgewebe. E. oft mit gefalteten Keimb. - t mit (Q), gedreiten oder unpaarig-gefiederten, selten einfachen B. und kleinen B1. - I ysigene und schizogene Balsamgänge. - 320 trop. - Commiphor (= Balsamodendron, 63, meist in den Steppen von Afr., einige auch in Arab. und Vorderind.); C. abyssinica (Südarab., Nordabyssin.) lief. die echte arabische Myrha; C. Playfairii (Somaliland) lief. wahrscheinlich das Myrrhenharz Molmol. - Bosuellic (10 Somaliland, Socotra, Vorderind.); B. Carteri (Somaliland und Hadramaut in Arabien) lief. Olibanum, Weihrauch. - Bursera (40 trop. Am.); B. gummifera (Antillen) u. a. lief. einen grossen Teil des a merik. Elemi. - Protium (50 Am. calid.); $P$. aracouchini (trop. Südam.) lief. A racouch in ibalsam. Tetragastris balsamifera (Antill.) lief. Schweinshalsam. - Canarium (80 trop. As., Afr.); C. commune lief. das Canarienharz für Fackeln; hierzu dient auch das Harz von Dacryodes hexandra auf den Antillen.

Fam. Meliaceae. Bl. 5-, seltener 4-7 gliederig, meist obdiplostemon, seltener haplostemon, meist $\not{q}, \phi$. Blütenaxe planconvex oder in mannigfache Effigurationen auswachsend. K. oft, P. bisweilen vereinigt. Stb. meist in eine Röhre vereint. G. isomer oder oligomer, völlig syncarp, mit 1 Gr., die Cp. mit meist $1-2$, selten $4-\infty$ Sa., mit 2 Integ. Fr. mannigfach. Nährgewebe + oder 0 . - $\hbar$, selten $\mathrm{Kr}$., meist mit gefiederten B. ohne Nebenb. Bl. in Trugdolden, zu Rispen vereint. Meist Secretzellen. - 400 calid. - Wertvolle Nutzhölzer und Fieberrinde.

Unterfam. Cedreloileae. Stb. frei.

$\S$ Cedreleae. Cp. $(4-5)$. S. lang geflügelt. - Toom $(7-8$ trop. As.); $\boldsymbol{T}$. febrifutgr (ind.-malay.); Rinde Fiebermittel. - Cedrel odorata (Antillen) lief. das Zuckerkistenholz.

$\S$ Ptaeroxyleae. Cp. (2). S. nach oben geflügelt. - Ptaeroxylon obliquum (Kapland) Niesholz, kapens. Mahagoni.

Unterfam. Swietenioidene. Stb. in eine Röhre vereint. S. geflügclt. 
\$ Swietenieae. Cp. mit $\infty-4$ Sa. - Swietenia (3) mahagoni, Mahagonibaum (Antill.). - Khaya senegalensis lief. das Gambia-Mahagoni. - Soymida febrifuga (Ostind., Ceylon) lief. Nutzholz und Fieberrinde.

Unterfam. Melioidece. Stb. in eine Röhre vereint. S. nicht geflügelt.

\& Carapeae. Cp. mit je 2-8 Sa. S. gross mit holziger Schale. Carapa (trop. Afr. Am.); C. procera (trop. Afr.) und C. guianensis (trop. Am.) geben in ihren S. Carapäol. - Xylocarpus (2 palaeotrop., littoral).

§ Melieae. Cp. mit 2 Sa. S. mit wenig Nährgewebe. - Meliv azedarach (calid.).

§ Azadirachteae. Cp. mit je 2 od. 1 Sa. Fr. 1 samig. Nährgewebe 0. Blättchen gesägt. - Azadirachta indica (Ostind.) lief. Margosa.Öl und Fieberrinde.

§ Trichilieae. Cp. mit 2-1 Sa. Nährgewebe 0. Blättchen ganzrandig. - Trichilia (150 trop. Am., Afr.). - Guarea (80 trop. Am., Afr.).

2. Unterreihe Malpighiineae. Wie die Geraniineae; aber die Bl. wenigstens im G. schräg zygomorph; B. hfg. gegenst.

Fam. Malpighiaceae. Bl. 5 gliederig, obdiplostemon, meist ఫ̧. Blütenaxe convex oder eben, bisweilen ein Gynophor bildend. K. hfg. mit Nektarien. P. meist genagelt. Von den Stb. hfg. einzelne abortiert. Cp. meist (3), selten (2) (4) (5), mit je 1 Sa., mit 2 Integ. Spaltfr. mit am Rücken aufspringenden Teilfr., selten Nuss oder Steinfr. Nährgewebe 0 . - \$, meist Lianen, mit unregelmässig gefurchten Holzkörper. B. meist gegenst., hfg. mit Drüsen; Nebenb. +. Blütenstand zusammengesetzt, traubig. - 500 trop., besonders Am. - Banisteria (60 trop. Am.). Malpighia (20 trop. Am.). - Hiraea (50 trop. Am.).

Fam. Trigoniaceae. Bl. typisch 5 gliederig, ఫ્ł, schräg zygomorph. K. am Gruude vereint. P. 5-3, oft sehr ungleich. Stb. 5, 6 oder $10(11-12)$, am Grunde + in eine gespaltene Röhre vereint. Cp. (3), mit je $\infty-2$ Sa. Fr. 3 klappige septicide Kapsel, selten Flügelfr. Nährgewebe + oder 0 . - - $\mathfrak{t}$, oft kletternd, mit (Q) oder gegenst. B. Nebenb. + oder 0. -27 trop. Am., 1 trop. As.

Fam Vochysiaceae. Bl. typisch 5 gliederig, ఫ્+, schräg zygomorph. K. am Grunde vereint, das eine oft gespornt, abfällig; $\mathrm{P}$. selten 5 , meist $3-1$, perigynisch oder epigynisch; 1 fruchtbares Stb. und einige Std. Cp. (3), mit je $\infty-2$ Sa., mit 2 Integ. Fr. nicht aufspringend oder eine fachspaltige Kapsel. Nährgewebe 0 - $t$, selten Kr., mit gegenst. oder quirlst., einfachen B.; Nebenb. + oder 0. -80 trop. Am.

3. Unterreihe Polygalineae. Bl. $\oplus$ oder $\because$, mit 2 Kreisen Stb. Die A. mit Poren sich öffnend. Cp. (2), median.

Fam. Tremandraceae. B1. 4-, 5-, selten 3 gliederig, ఫ̧, 申. K. frei, P. klappig. Stb. doppelt so viel als P. Cp. mit $1-2$ Sa., mit 2 Integ. Fr. eine zusammengedrückte Kapsel, an den Rändern fachspaltig. Nährgewebe +. Kleiner E. - Kleine Sträucher mit ganzrandigen oder gezähnten B. und einzelnen achselst. Bl. - 23 Austral.

Fain. Polygalaceae. Bl. typisch 5 gliederig, ఫ્子, $\%$. Von den $5 \mathrm{~K}$. sind 2 petaloid, flügelfg. P. nur 3 in der Stellung $\frac{2}{1}$. Stb. $8(44)$. Cp. mit 1, selten 2-4 Sa., mit 2 Integ. Kapsel oder Steinfr. Nährgewebe + oder 0. - Kr. oder $\hbar$, mit meist (Q), einfachen, ganzrandigen B. ohne 
Nebenb. Bl. einzeln oder traubig, selten in Rispen. - 400 temp., calid. - Polygala (200); P. senega (Nordam.) lief. d. off. Radix Senegae. - Muraltia (50 Südafr.). - Securidaca (25 trop.), Iianen:

4. Unterreihe Dichapetalineae. Bl. 申 oder $\cdots$, mit nur 1 Kreis Stb. Die P. frei oder vereint. S. bisweilen mit Caruncula.

Fam. Dichapetalaceae. Bl. typisch 5 gliederig, 후, oder $\sigma^{\top}$ ㅇ, $\oplus$, bisweilen Blittenaxe in Schuppen oder in einen becherförmigen Discus auswachsend. $K$. frei oder vereint. $\mathrm{P}$ häufig $\mathbf{2}$ spaltig, gleich oder ungleich, frei oder in eine Röhre vereint. Stb. 5, frei oder mit den P. vereint. Cp. $(z-3)$ mit je $2 \mathrm{Sa} .$, mit 1 Integ. Steinfr. mit 1-2fächerigem Kern. Nährgewebe 0 . - t mit ganzrandigen B., mit Nebenb. Pl. klein, in achselst. Scheindolden. -- Dichapetalum (80 trop., meist Afr.).

5. Unterreihe Tricoccae. B]. $\oplus$, stets $\sigma^{\top}$, , oft sehr reduciert. Cp. meist (3), mit je 2-1 Sa., mit 2 Integ.

Fam. Euphorbiaceae. Stb. eben so viel als K. oder doppelt so viel, $\infty$ oder wenige bis 1 . Cp. (3), seltener $(2-4$ oder $\infty)$. S. meist mit einer Caruncula üher der Mikropyle. Fr. meist eine in 3 Teilfr. (Cocen) sich spaltende Kapsel, seltener Beere oder Steinfr. Nährgewebe reichlich. E. central, gerade oder gekrümmt. - Kr. oder t , meist mit (9) B., häufig mit Nebenb. Bl. meist in zusammengesetzten Blütenständen. Hfg. (nicht imrner) Milchsaft in gegliederten oder ungegliederten Röhren. Bisweilen markständiges Leptom. - Etwa 4000 temp.-calid.

A. Platylobeae. Keimb. vielmal breiter als das Stammchen des E.

Unterfam. Plyllanthoidece. Jedes Cp. mit 2 Sa. Nie Milchröhren und nie markst. Phloëm.

§ Phyllantheae. E. gross, wenig kürzer als das Nährgewebe. K. der ơ Bl. dachig. - Plyllanthus (400 calid.); PH. emblive (Maskaren., trop. As.) lief. die Myrobalanen; Ph. nimuri, $\odot$; PH. speciosus mit Phyllocladien (trop. Am.).

$\S$ Bridelieae. Wie vorige; aber K. der б’ Bl. klappig. - Bridelia (30 palaeotrop.).

Unterfam. Crotonoidecue. Jedes Cp. mit 1 Sa. Milchröhren vorhanden oder fehlend. Markst. Leptom vorhanden oder fehlend.

a. Blätenstände kein Cyathium darstellend.

a) Stf. in der Knospe $\mathrm{nach}$ innen gebogen.

$\S$ Crotoneae. $\sigma^{\top} \mathrm{Bl}$. meist mit P. Bl. in endst. Ähren oder Trauben. - Inneres Phloëm mit Siebröhren. Lang gestreckte (anfangs gegliederte) Milchsaftschläuche. - Crotom (600); C. eluteria (Bahama-Inseln) und $\boldsymbol{C}$. cascarilla (ebenda und Florida) lief. d. off. Cascarilla-Rinde; C. tiglium (trop. As.) lief. Semen Tiglii, Purgirkörner und Crotonöl.

§) Stf. in der Knospe nicht nach innen gebogen.

§ Acalypheae. $\sigma$ Bl. meist ohne P. K. klappig. Bl. in Trauben, Ähren, Rispen. - Keine Milchröhren; aber Gerbstoffschläuche. Inneres Phloëm +. - Chrozophora tinctoria (medit.) lief. d. Farbstoff für Tournesol. - Mercurirlis (7). - Mallotus philippinensis (Rottlesa, ind.mal.) lief. d. off. Kamala-Drüsen zum Rotfürben. - Alchomea ilicifolia 
(Südost-austral.) entwickelt Nucellarembryonen. - Acalypha (220 trop.). - Tragia (50 trop.), mit Brennhaaren. - Dalechampia (60 trop.) mit interessantem zusammengesetztem Blütenstand. - Ricinus communis (Afr.) liefert Oleum Ricini (Samen mit deutlichen Proteinkrystalloiden in den Aleuronkörnern!).

§ Jatropheae. $\sigma^{7} \mathrm{Bl}$. mit oder ohne P. Bl. in dichasial gebauten Rispen. - Gegliederte Milchschläuche. Inneres Leptom +. - Aleurites molucanna (trop.) lief. Speiseöl. - Jatropha (70); J. curcas (trop. Am.) lief. Oleum infernale; J. multifida (trop.) lief. Purgiernüsse und Oleum Pinhoën. - Hevea (10 trop. Am.); H. guianensis und H. brasiliensis lief. Kautschuk.

§ Manihoteae. $\sigma^{\top}$ Bl. stets ohne P. Bl. in Ähren oder Trauben. - Gegliederte Milchschläuche. Inneres Leptom +. - Manihot (80 trop. Am.); M. Glasiovii (Bras.) lief. Ceara-Rubber, Kautschuk; M. Utilissima, Maniok oder Cassavestrauch (Brasil.), wichtige Nährpflanze der Trop., liefert Stärkemehl.

§ Cluytieae. $\sigma^{\top} \mathrm{Bl}$. stets mit P. K. der $\sigma^{\lambda} \mathrm{Bl}$. dachig. $\sigma^{\lambda} \mathrm{Bl}$. in Knäueln, welche entweder axillär sind oder in ährigen bis rispigen Blütenst. stehen. - Cluytia (30 Afr.). - Codiaeum variegatım (ind. Archip.) mit zahllosen Blattvarietäten ("Croton" der Gärtner).

§ Geloniene. $\sigma^{7} \mathrm{Bl}$. ohne P. K. der $\sigma^{7} \mathrm{Bl}$. dachig. - Gegliederte Milchsaftschläuche.

$\S$ Hippomaneae. $\sigma^{\nearrow} \mathrm{Bl}$. ohne P. K. der $\sigma^{\top} \mathrm{Bl}$. dachig. - Milchsaftschläuche ungegliedert. - Mabea piriri (Guiana) lief. Kautschuk. Excoecaria (30 palaeotrop.); E. agallocha (trop. As.); d. Milchsaft erzeugt starke Augenentzündung. - Stillingia silvatica (südl. Nordam.). Sapium sebiferum, Talgbaum (trop. As.) lief. Fett (an der Oberfläche der S.) zur Herstellung von Lichtern und Seife. - Hippomane mancinella, Manschinellapfel (Centralam., Antillen) lief. Pfeilgift. - Hura crepitans mit 5-20 Cp., Sandbüchsenbaum (trop. Am.), giftig.

b. Partialblütenstände Cyathien.

$\S$ Euphorbieae. Bl. ohne P., meist auch ohne K. $\sigma^{\text {T }} \mathrm{Bl}$. mit nur 1 Stb. - Milchsaftschläuche ungegliedert. - Anthostema (3 Afr.). Euphorbia (600); E. pulchesrima, Poinsettie (Mexiko, Centralam.); E. resinifera (Marokko) lief. d. off. Gummiharz Euphorbium. Pedilanthus (15 trop. Am.), mit giftigem Milchsaft.

B. Stenolobeae. Keimb. etwa sq breit als das Stämmchen des E.

Unterfam. Porantheroideae. Cp. mit je 2 Sa. - Keine Milchröhren. - 17 Austral.

Unterfam. Ricinocarpoideae. Cp. mit je 1 Sa. - 45 Austral.

Von unsicherer Stellung, vorläufig noch hier untergebracht:

Fam. Callitrichaceae. Bl. nackt. $\sigma^{\top} \mathrm{Bl}$. mit terminalem Stb. ㅇ Bl. mit 2 transversal stehenden $\mathrm{Cp}$., welche durch eine Längswand in 2 Klausen geteilt sind, mit je 2 Sa. 2 Gr. Sa. mit 1 Integ. Fr. in 4 Steinfrüchtchen zerfallend. S. mit Nährgewebe und centralem E. - 
Kr., oft untergetaucht, mit (-) zusammengedrängten, schmalen B. und kleinen axillären monöeischen $\mathrm{Bl}$. - Callitriche (25).

20. Reihe SAPINDALES (Celastrales). Wie die vorige Reihe; aber die Sa. in entgegengesetzter Stellung, entweder hängend mit dorsaler Raphe und der Mikropyle nach oben oder aufsteigend mit ventraler Raphe und mit der Mikropyle nach unten. - Vorzugsweise $\mathbf{t} ;$; aber auch Kr.

1. Unterreihe Buxineae. Blh. haplochlamydeisch. Sa. mit 2 Integ.

Fam. Buxaceae. Bl. $\sigma^{\top}$ 우 , bisweilen mit Rudimenten der abortierten Sexualb., $\oplus$. Stb. $4-\infty$. Cp. (3) oder $(2-4)$, mit je $2-1$ Sa. Gr. getrennt. Fachspaltige Kapsel oder Steinfr. Nährgewebe + - - t mit meist ganzrandigen, immergrünen B. ohne Nebenb.; Bl. einzeln oder in Trauben. - 30 temp., subtrop. - Buxus (19); B. sempervirens, Buxbaum (West- und Südeur.) lief. das beste Holz zu Holzschnitzereien. - Paclysandra procumbens (atl. Nordam.).

2. Unterreihe Empetrineae. Blh. heterochlam. Cp. mit je 1 anf. stcigenden Sa, mit 1 Integument, bis zur Reife vereint. Sträucher.

Fam. Empetraceae. Bl. $\sigma^{7}$ 오, mit Rudimenten der abortierten Sexualbl., ๑. K., P., Stb. 2-3. Cp. (2-9). Steinfr. S. ohne Caruncula. - Kleine ericoide Sträucher mit linealen, unterseits tief gefurchten B. ohne Nebenb. Bl. klein in Köpfchen. - 4 frigid., temp. Empetrum nigrum, Rauschbeere, Krähenbeere (* arkt. bis subalp.); Beeren geniessbar.

3. Unterreihe Coriariineae. Blh. heterochlam. Cp. mit je 1 hängenden Sa. mit 2 Integ, zuletzt frei. Sträucher.

Fam. Coriariaceae. Bl. 후 und $\sigma^{\pi}$ 우, 5 gliederig, diplostemon, $\oplus$. Cp. 5-8. Fr. in Coccen zerfallend. S. mit dünnem Nährgewebe. - 万 mit gegenst. oder quirligen, ganzrandigen B. ohne Nebenb.; Bl. axillär oder tranbig. - 5 temp. - Coriaria myrtifolia (medit.).

4. Unterreihe Limnanthineae. Blh. heterochlam. Cp. mit je 1 anfsteigenden Sa. mit 1 Integ., zuletzt frei. Kräuter.

Fam. Limnanthaceae. Bl. ̧ㅜ, 5- oder 3 gliederig, diplostemon, $\oplus$. Blütenaxe flach. Cp. (5 oder 3), mit centralem Gr., hei der Reife von einander sich loslösend, nicht aufspringend. S. ohne Nährgewebe. E. mit dickfleischigen Keiml, $-\odot$ mit (9) zerschlitzten B. ohne Nebenb. Bl. einzeln, achselst. - 4 (Nordam.). - Limnanthes Douglasii (Kalif.).

5. Unterreihe Anacardiineae. Pl. heterochlam., bisweilen apetal, stets $\oplus$. G. selten isomer, zur Oligomerie neigend, - th mit Harzgängen.

Fam. Anacardiaceae. Bl. diplostemon oder haplostemon, selten mit weniger oder mehr Stb. Blütenaxe variabel, daher $\mathrm{Bl}$. hypogynisch bis epigynisch. Cp. selten (5), meist $(3-1)$, mit je 1 hängenden oder aufsteigenden umgewendeten Sa. mit 2 Integ. Fr. meist Steinfr., mit harzreichem Nesocarp. Nährgewehe 0 . E. hfg. gekrïmmt, mit flachen oder planconvexen Keimb. - t mit (Q), selten quirligen, einfachen oder un. 
paarig-gefiederten oder gedreiten B., mit $\infty$ kleinen Bl. in Rispen. Reichlich Gerbstoff. Stets schizogene Harzgänge. - 500 calid., temp.

$\S$ Mangifereae. Cp. 5-1 frei, oft mit seitlich am Grunde stehenden Gr. Oft Gynophor. Stb. in 1 bis mehreren Kreisen oder nur $1-4$. B. immer einfach. - Buchanania, mit 5 Cp. (20 ind.-malay.). - Die anderen mit nur 1 Cp.: Mangifera (27 trop. As., Afr.); M. indicr, Mango, wichtige Obstpfl. d. Trop. - Auccardium (8 trop. Am.); A. occidentale, Acajou (cult. in den Trop.), Fruchtstiel und ölhaltige S. werden genossen; der Stamm lief. A cajou-Gummi. - Melanorrhoea (6 ind.-malay.); M. usitata (Ostind.) lief. Firniss.

§ Spondieae. Cp. (5-4), selten mehr oder (3), mit je 1 hängenden Sa. B. hfg. gefiedert. - Spondias (6 trop.); Sp. purpurea, Mombinpflaume (trop. Am.); Sp. lutea, gelbe Mombinpflaume (trop.); Sp. dulcis (Polynes.) u. a. als Obstbäume cult.

$\S$ Rhoideae. Cp. (3); aber G. nur mit 1 fertilen Fach. Fr. frei. B. verschieden. - Pistacia (*); die S. aller geben Öl; P. vera (mediterr.), S. als Gewürz; $\boldsymbol{P}$. terelinthus (mediterr.) lief. gerbstoffreiche Gallen; P. lentiscus (mediterr.) lief. d. Mastixharz. - Sclinus (12 Südam.); Sch. molle, Pfefferstrauch (cult. in calid.), giebt arnerikanischen Mastix. - Cotinus coggygria, Perrückenstrauch (südl. temp.**). - Comocladia (Antill.); Fr. zum Schwarzfärben. - Metopium (Antill.). - Rhas.s (120 temp., subcalid.); viele Gerbst off liefernd; Rh. coriaria (mediterr.), Rinde zum Gerben, Wurzeln und Fr. zum Färben; Rh.typhina, Essighaum und $\boldsymbol{R} \boldsymbol{h}$. glabra (atlant. Nordam.) lief. auch Gerbmaterial; $\boldsymbol{I} \boldsymbol{h} \boldsymbol{h}$. rernicifera und Rh. succedanea (Japan) lief. japanischen Firniss; Rh. venenata (atl. Nordam.) lief. auch Firniss; die Fr. von $\boldsymbol{R} \boldsymbol{h}$. succedanea geben Cera japonica; R. toxicodendron (Nordostas. und Nordam.), sehr giftig. - Astronium (9 Südam.). - Schinopsis (5 Südam.); Sch. Lorentzii, Quebracho colorado (Argentinien), ausgezeichnetes Nutzholz.

§ Semecarpeae. Cp. (3); aher G. mit nur 1 fertilen Fach, der becherfg. oder röhrigen Blütenaxe eingesenkt. B. einfach. - Semec(ı)pus (40 ind.-mal.); S. Anacardium, Tintenbaum (Ostind.) lief. Firniss u. d. ostind. Elephantenläuse (Fructus Anacardii orientalis).

§ Dobineeae. Cp. 1. Q Bl. nackt. B. einfach, gesägt, gegenständig. - Dobinea (2 Himalaya).

6. Unterreihe Celastrineae. Bl. heterochlam., stets $\varphi$, diplostemon oder haplostemon. G. selten isomer, zur Oligomerie neigend.

Fam. Cyrillaceae. Bl. ఫ̧, 5 gliederig diplostemon, ๑. K. und P. bisweilen unten zusammenhängend. Cp. (5-2), mit je 1 Sa. mit 2 Integ. Fr. klein, 2-4 teilig. Nährgewebe +. - † mit imnergrünen ganzrandigen B. an der Spitze der Zweige. Bl. klein, in Trauben. - 8 Am., temp. calid. - Cyrilla.

Far. Pentaphylacaceae. Bl. ㅎ, 5 gliederig, haplostemon, $\phi$, durchweg isomer. Cp. (5), mit je 2 hängenden Sa. Fr. eine 5 kantige Kapsel. Nährgewebe sparsam. E. hufeisenförmig gekrümmt. - $\hbar$ mit abwechselnden, lederartigen B. Bl. klein unterhalb der Laubb. in Trauben. - Pentaphylax (1 Hongkong).

Fam. Corynocarpaceae. Bl. જ્ઞ, diplostemon; aber mit Umwandlung der inneren Stb. in Std. Cp. (2); aber nur 1 fruchtbar, mit 1 vom Scheitel herabhängenden Sa. mit 2 Integ. Steinfi. mit fleischigem Exocarp, zusaınmengedrückt. Năhrgewebe 0. - ち mit abwechselnden, fleischig-lederigen, glänzenden, länglich verkehrt-eiförmigen B.; Bl. ziemlich klein, in endständiger Rispe. - Corynocarpus (1 Neuseeland). 
Fam. Aquifoliaceae. Bl. 4-6 gliederig, $\sigma^{\gamma}$ 우, diöcisch 申. P. hfg. am Grunde und mit den gleichzähligen Stb. vereint. Cp. $(4-6)$, selten (7-8) mit je $1-2$ hängenden Sa. mit 1 Integ. Steinfr. $4-8$ kernig. 古 mit abwechselnden, meist immergrünen, einfachen B. Nebenb. sehr klein oder 0. Bl. klein, trugdoldig. - Ilex (150 temp., calid.); I. aquifolium, "Stechpalme" (Süd- und Westeur.); I. theesans, I. amara, I. paraguariensis u. a. in Südbrasil. liefern eine Sorte Mate-Thee.

Fam. Celastraceae. Bl. 4-5 gliederig, meist $\not$, $\oplus$. P. dachig. Stb. $3-5$ (selten 2 oder 10 ) am Rande des Discus. Cp. $(3-5)$, mit je $\infty-1$, meist je vom Grunde aus aufsteigenden Sa. Kapsel oder Beere. S. hfg. mit Arillus. Nährgewebe + oder $0 .-\hbar$ mit stets einfachen gegenst. oder wechselstg. B.; Nebenb. bisweilen + , aber abfällig. Bl. klein, hfg. grünlich, meist in Trugdolden. - 320 temp., calid. - Evonymus (60 temp.). - Catha edulis (Arab., Abyss., Ostafr.) lief. den Kat-Thee. - Celastrus (27 calid.). - Maytenus (70 Am.).

Fam. Hippocrateaceae. Bl. 5 gliederig, mit weniger Stb. und Cp., જ્, థ. Stb. 3 (selten 5, davon 3 oder $\approx$ steril). Cp. (3), mit je $\infty-2$ Sa. mit 2 Integ. Beere oder dreiflügelige Fr. Nährgewebe 0 . - $\downarrow$ oft kletternd, mit gegenst. oder () einfachen B. Nebenb. klein oder 0. Bl. klein, grünlich, in Trugdolden. - Hippocratea (60 trop.). - Salacia (60-70 calid.).

Fam. Stackhousiaceae. Bl. 5 gliederig, haplostemon, mit schüsselfg. Axe. Cp. $(2-5)$, mit je 1 aufsteigenden Sa. Fr. in 2-5 nicht aufspringende Teilfr. zerfallend. Nihrgewebe t. - t mit (a) lineal, oder spatelfg. B, oline Nebenb. Bl. in Ähren oder Knäueln. - 20 Austral., Neuseeland, Philippinen.

Fam. Staphyleaceae. Bl. 5 gliederig, haplostemon. 5 Stb. ausserhalb des Discus. Cp. $(2-3)$, oben frei, mit $\infty$-wenigen an der Bauchnaht hängenden Sa. mit 2 Integ. Fr. $2-3$ fächerig, meist 1 -wenigsamig. Nährgewebe +, fleischig. - † mit gegenständigen, gefingerten oder gefiederten B. Bl. in Rispen oder Trauben; -20 * und trop. Staphylea (7) pinnata (pont. Gebiet); S. trifoliata (atlant. Nordam.).

7. Unterreihe Icacinineae. Bl. heterochlam., stets $\oplus$, haplostemon. Stb. vor den Kb. G. meist auf 1 fertiles Cp. reduciert. Sa. mit 1 Integ. Fr. 1 samig.

Fanu. Icacinaceae. Bl. 5-4 gliederig, haplostemon, ̧ㅜ oder $\delta^{7} \circ, \oplus$. Blütenaxe convex oder becherfg. das G. umgebend. Cp. (3), mit 1 Gr., selten alle, meist nur 1 mit je 2 hängenden Sa. Steinfr. 1 fächerig, 1 samig. Nährgewebe.$+-\hbar$, einige kletterud, meist mit (Q) B. ohne Nebenb. Bl. meist klein. - 110 calid. - Villaresia (10*); V. congonha (Südbrasil.) lief. eine Sorte Mate-Thee, Congonha. - Phytocrene (7 trop. As.) und Chlamydocarya (trop. Afr.) Lianen.

8. Unterreihe Sapindineae. Bl. heterochlam., typisch diplostemon, aber mit Abort einiger Stb. und Cp., $\oplus$ oder schräg zygomorph. Sa. mit 2 Integ.

Fam. Aceraceae. Bl. ㅎ, $\sigma^{\nearrow} \uparrow, \oplus$, mit scheibenfg. oder concaver Axe. K. u. P. 4-10. Stb. 4-10, meist 8 . Cp. (2), selten $(3-5)$, je mit 2 fast geradläufigen Sa. Fr. mit geflügelten, 1-, selten 2 samigen Fächern. Nährgewebe 0. - t mit gegenst. einfachen oder gelappten oder gefiederten B. ohne Nebenb. Bl. klein, in Ähren, Trauben, Rispen oder Dolden. 111 *, wenige trop. As. - Acer (incl. Negundo), Ahorn; A. saccharum. (atlant. Nordam.) lief. A hornzucker. - Viele im 'Tertiär. 
Fam. Hippocastanaceae. Bl. $\Varangle \quad శ$ ㅇ. schräg zygomorph. K. 5, P. 4 bis 5, Stb. 5-8. Cp. (3), mit je 2 Sa. Kapsel 3-1 fächerig, mit meist $1 \mathrm{~S}$. ohne Nährgewebe. E. mit dicken Keimb. - t mit gegenst. 5- bis 9 fingerigen B. ohne Nebenb. Bl. ansehnlich in Rispen. - 16 temp., calid., Nordgriechenland, As., Am. - Aesculus (incl. Pavia).

Fam. Sapindaceae. Bl. 후 $\sigma^{\pi}$ 우, typisch 5 gliederig, selten $\oplus$, meist schräg zygomorph, mit extrastaminalem, hfg. einseitigem Discus. P. 5-3 oder 0 , hfg. mit Schuppen. Stb. meist 8 , seltener 10,5 oder $\infty$. Cp. (3-2) mit meist je 1, seltener mehr oder 2 Sa. Fr. kapselartig, nussartig, steinfruchtartig oder Spaltfr. S. häufig mit zuckerreichem Arillus. Nährgewebe 0. - E. gekrümmt. - Meist $\hbar$ mit (9) ungeteilten oder gefiederten B. Hfg. Secretzellen. - Etwa 1050 calid., wenige trop.

A. Eusapindaceae. Cp. mit je $1 \mathrm{Sa}$.

a. Nomophyllae. B. mit völlig entwickeltem Ende. Das innere Keimb, bisweilen auch das äussere quer 2 faltig.

§ Paullinieae. Kletterpfl. mit rankenden Zweigen, meist mit Nebenb. - Serjania (172 Am. calid.). - Paullinia (125 Am. calid., 1 Afr. Madag.); P. cupana (=P. sorbilis) (Südam.) lief. d. Guarana, welche aus den Samen bereitet wird; wichtiges Genussmittel. - Cardiospermum (11 calid.).

§ Thoninieae. 古 ohne Ranken und ohne Nebenb. - Allophylus (94 calid.).

b. Anomophyllae. E. einfach oder mit reduciertem Ende. Keimb. gekrümmt, selten gefaltet.

a) Fr. nicht oder wie Balgfr. aufspringend.

I. Ohne Arillus.

§ Sapindeae. Fr. in Teilfr. zerfallend, welche bisweilen geflügelt sind. - Sapindus (11 Am., As.); S. saponaria (trop. Am.), die zerquetschten Fr. stark schäumend.

II. Mit A rillus.

§ Schleichereae. Fr. nicht gelappt. - Schleichera trijuga (Ostind.) mit adstringierender Rinde.

$\S$ Nephelieae. Fr. \pm gelappt, bisweilen wie Balgfr. aufspringend. - Litchi chinensis (China, Philippinen und cult.), Zwillingspflaume, mit sehr wohlschmeckenden Fr. - Nephelium (22 ind.-malay.), auch mit wohlschmeckenden Fr.

ß) Fr. fachspaltig - klappig.

§ Cupanieae. Cupania (32 Am. calid.); C. tomentosa (Antill.), mit adstringierender Rinde und B. - Blighia sapida (trop. Westafr. und cult.); Früchte und Arillus beliebte Speise in den Trop.

B. Dyssapindaceae. Cp. mit je 2 oder mehr Sa., selten mit nur 1 epitropen. 古ohne Ranken und ohne Nebenb.

a. Nomophyllae. B. mit völlig entwickeltem Ende. Keimb. + eingerollt. 
§ Koelreuterieae. Kapsel aufgeblasen, häutig. - Koelreuteria paniculata (temp., China).

$\S$ Dodonaeeae. Kapsel gefurcht oder gelappt, bisweilen geflügelt. - Dodonaea (42, meist Austral.); D. visiosa (calid.).

b. Anomophyllae. B. meist mit reduciertem Ende. Keimb. ge$\mathrm{kr} u ̈ \mathrm{mmt}$.

$\S$ Doratoxyleae. Bl. $\oplus$. Fr. nicht anfspringend. - Hippobromus (Kapland).

$\S$ Harpullieae. Bl. $\oplus$ oder + . Fr. anfspringend. - Xanthoceras (Nordehina). - Ungnadia speciosa (Texas) mit essbaren Fr. - Harpullia (18 ind.-malay., Polynes.).

9. Unterreihe Sabiineae. Bl. heterochlam. Stb. vor den Blb.

Fam. Sabiaceae. Bl. ఫ̧ oder $\Varangle \sigma^{7}$ ㅇ. K. 2-5. P. 4-5. Stb. 5 vor den P., bisweilen 4 steril. Cp. $(2-3)$, mit 2 hängenden oder horizontalen Sa. Fr. meist 1 fächerig mit $1 \mathrm{~S}$. Nährgewebe 0 . E. mit grossem gebogenem oder gewundenem Hypokotyl und gefalteten Keimb. - $\frac{\hbar}{\text { oder }}$ Kletterpflanzen mit abwechselnden einfachen oder gefiederten B. Bl. klein in Trauben oder Doldentrauben. - Etwa 70 trop. - Sabia (Ostas.). Meliosma (trop.).

10. Unterreihe Melianthineae. Bl. heterochlam., $\cdots$, haplostemon, seltener diplostemon, mit freien A.

Fam. Melianthaceae. Bl. ఫ. $\quad$ K. 5. P. 5. Stb. 5-4, selten (10), ungleich oder teilweise vereint. Cp. $(4-5)$, mit je $\infty-1$ Sa. Kapsel, mit 1 samigen Fächern, fachspaltig. S. mit oder ohne Arillus. Nährgewebe + . - $t$ mit (9), meist unpaarig gefiederten $B$. mit oder ohne Nebenb.; Bl. ansehnlich in Trauben. - 17 Afr. calid. - Meliant/us major (Kapland). - Greyia Sutherlandii (Kapland).

11. Unterreihe Balsaminineae. Bl. heterochlam, $\%$, haplostemon, mit vereinten $\mathrm{A}$.

Fam. Balsaminaceae. Bl. ఫ̧. Kb. 3 (die 2 vorderen nicht entwickelt). P. 5, doch je 2 seitliche vereint. Stb. (5). Cp. (5), mit je $\infty$ Sa. Kapsel meist elastisch aufspringend, mit $\infty \mathrm{Sa}$. ohne Nährgewebe. E. gerade. Impatiens (220, meist trop. Afr., As., wenige *); I. balsamina (Ostind.), Zierpfl.; I. noli tangere (* temp.); I. parviflora (im südl. Sibirien heimisch, in Eur. verwildert).

21. Reihe RHAMNALES. Bl. cyklisch, diplochlam., bisweilen apetal, haplostemon mit den Stb. vor den P., $\oplus$. Cp. $(5-2)$ mit je $1-2$ aufsteigenden Sa. mit dorsaler, seitlicher oder ventraler Raphe und 2 Integ.

Fam. Rhamnaceae. Bl. 5-4 gliederig, perigyn oder epigyn. P. klein orler $0 . \quad$ Cp. $(5-2)$. Steinfr. oder Trockenfr. mit 1 samigen Fächern. S. meist mit Nährgewebe. E. gerade, gross. - $\hbar$, selten Kr., oft kletternd, mit einfachen, hfg. $3-5$ nervigen B., mit kleinen Nebenb. Bl. klein, grünlich oder gelblich, oft in axillären trugdoldigen Blütenständen. Etwa 380 temp. - trop.

§ Ventilagineae. Fr. 1 făcherig, 1 samig, mit grossem flügelförınigem Anhang und Rest des Gr. an dessen Spitze. S. ohne Nährgewebe. - Kletternde Sträncher ohne Dornen. - Ventilago (10 palaeotrop.). 
Zizypheae. Fr. mit 1-4 fächerigem hartem Steinkern. - Oft dornige Sträucher. - Paliurus australis (medit.). - Zi:yphus (40 trop.); Z. vulgaris (medit.), Z. lotus (Nordafr.), Z. jujuba (Ostind., China) mit essbaren Fr., Jujuben.

§ Rhamneae. G. oberst. oder unterst. Steinfr. mit 3 dünnwandigen Steinkernen oder in Teilfr. zerfallende Trockenfr., selten Schłiessfr. Seriale Beisprosse nicht vorhanden. - Rhamnus (70); Rh. catharticu, Kreuzdorn, lief. d. off. purgierenden Baccae spinae cervinae; IRh. frangula, Faulbaum, lief. d. off. Cortex Rhamni frangulae; aus den Steinfr. von Rh. cuthartica, Rh. infectoria (Südeur.), Rh. tinctoria (Ungarn) u. a. wird gelbe Farbe bereitet. - Hovenia dulcis (Japan, Nepal) mit birnfg., als Obst genossenen Blütenständen, - Ceanothus (36 Am.). - Phylica (65 Südafr., Madagaskar, Tristan d'Acunha).

\$ Colletieae. Fr. teilweise mit der Axe vereint, 2-3 teilig oder 3-1 fächerige Steinfr. S. mit derber Schale. Seriale Beisprosse vorhanden. B. gegenst. $-34 \%$ - Colletia, fast blattlose Sträucher mit gekreuzten Dorneu (Südam.).

\& Gouanieae. Halbfr. vom Kelchsaum gekrönt, lederartig, 3-4 teilig, oft 3 flügelig oder 3 kantig. - Sträucher mit (Q) breiten B. - Trop. - Gouania (30 trop), oft mit rankender Blütenstandaxe.

Fam. Vitaceae. Wie vorige; aber Beerenfrucht. P. klappig, hfg. oben vereint und zusammen abfallend. Cp. $(2-6)$ oberst. S. mit harter Schale und knorpeligem Nährgewebe. E. kurz am Grunde des Nährgewebes. - Kletternde Sträucher mit den B. gegenüberstehenden Panken (entsprechen den Inflorescenzen). - 300 calid.

Unterfam. Vitoideae. Stb. frei. Cp. (2), in jedem Fach mit 2 Sa. - Vitis (28, meist *); $\boldsymbol{V}$. vinifera (wild am Rhein, im östlichen und centralen Frankreich, in den Donauländern und dem Mediterrangebiet bis nach Centralasien hinein), V. labrusca (atlant. Nordam., wie vorige mit $\infty$ Culturrassen), V. aestivalis (atlant. Nordam., mit $\infty$ Culturvarietäten), $V$. rotundifolia (südlich atlant. Nordam. und Mexiko; ebenfalls cult.) sind die wichtigsten Wein liefernden Arten. - Ampelocissus (60 trop., meist Afr., As.). - Pterisanthes (12 trop. As.) mit sehr eigenartigem Blütenstand. - Parthenocissus (10 temp. As. und Nordam.); $\boldsymbol{P}$. quinquefolia (Nordam.; cult. in Eur., eine Var. mit polsterförmigen an Mauern sich ansetzenden Haftscheiben). - Cissus (250 trop., subtrop., succulente Arten in Südwestafr.).

Unterfam. Leeoideae. Stb. unten vereint. Cp. $(3-8)$, in jedem Fach mit $1 \mathrm{Sa}$ - t . - Leea (45 palaeotrop).

22. Reihe MALVALES. Bl. cyklisch (im Andröceum nicht immer), heterochlam., selten apetal, $\not$, seltener $\sigma^{7}$ ㅇ, $\oplus$, seltener $\%$. K. und P. meist 5 gliederig. K. meist klappig. Stb. $\infty$ oder in 2 Kreisen, davon die inneren gespalten. Cp. $(2-\infty)$ mit je $1-\infty$ umgewendeten Sa. mit 2 Integ.

1. Unterreihe Elaeocarpineae. Kb. \pm frei. A. dithecisch, mit Poren. Schleimschläuche fehlen.

Fam. Elaeocarpaceae. K. und P. 5-4 gliederig, Bl. meist ł. K. klappig oder dachig, nie gedreht. Stb. auf gewölbter Blütenaxe. Cp. $(2-\infty)$ mit meist $\infty$ Sa.; 
1 Gr. G. 2 - $\infty$ fächerig, selten 1 facherig mit wandst. Plac. Kapsel, selten Steinfr. S. bisweilen mit Arillus, mit wenig Nahrgewebe und geradem E. - to mit ungeteilten B. und Nebenb. - Schleimselläuche fehlen. - 120 trop. und temp. (44 trop.).

§ Elaeocarpeae. P. klappig oder 0. - Elaeocurpus (60 ind.-malay.). - Sloanea

$\$$ Aristotelieae. P. dachig. - Aristotelia (7 ).

2. Unterreihe Chlaenineae. Kb. frei, dachig. Stb. eingeschlussen vol einem Becher (aus Std. gebildet oder Discus?). A dithecisch mit Spalten. Schleimschläuche oft vorhanden.

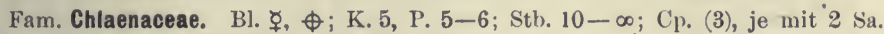
Kapsel 3 klappig oder 1 fächerig. S. mit Nährgewebe. - $t$ mit abwechselnden, ganzrandigen B.; Nebenb. +; Bl. einzeln oder zu 2 in einem Involuer, eingeschlossen. in Trugdolden oder Rispen. - 8 nur auf Madagaskar.

3. Unterreihe Malvineae. Kb. frei, selten dachig, neist klappig. Schleimschläuche vorhanden.

Fam. Gonystilaceae. Bl. ఫ్+, $申$, K. 5-4; P. 5, 2 teilig oder in viele Fäden gespalten; Sth. $\infty$, A. dithecisch. Cr. $(5-3)$, je mit 1 hängenden Sa. am Scheitel. Beere 5-3 facherig $S$. einzeln in den Fächern, ohne Nährgewebe. - t , mit abwechselnden, lederartigen, ganzrandigen B ohne Nebenb.; Bl. in cymösen, bisweilen ahrenartigen Rispen. - 7 im indisch-malayischen Gebiet. - Gonystilus.

Fam. Tiliaceae. Bl. meist ̧․ K. und P. 5 gliederig. K. klappig. P. bisweilen 0 . Stb. $\infty$, seltener bis 10 , frei oder 5-10 Bündel bildend, mit dithecischen A., bisweilen teilweise Std. Cp. $(2-\infty)$, mit je $1-\infty$ Sa.; 1 Gr. G. $2-\infty$ fächerig. Fr. $2-\infty$ fächerig oder durch Abort 1 fächerig. Nährgewebe meist + . E. mit meist blattartigen Keimb. Meist $\mathrm{t}$, seltener Kr., mit meist (9), ganzen oder gelappten B. und Nebenb. - Schleimschläuche in Mark und Rinde. - Etwa 270, meist calid., wenige temp.

A. K. vereint, an der Spitze frei. The cae der A. zuletzt zusammenfliessend.

§ Brownlowieae. - 12 trop.

B. K. frei. Thecae der A. nicht zusammenfliessend.

§ Apeibeae. Kein Androgynophor. Cp. $(6-\infty)$. Stb. an der Spitze mit läutigen Anhängen. - Apeibn (5 trop. Am.).

$\S$ Tilieae. Kein Androgynophor. Cp. (2-5). Stb. olnne Anhänge. - Tilia $(10 *) ; \boldsymbol{T}$. Mlmifolia, Winterlinde und T. platyphyllos, Sommerlinde (beide Eur.) lief. die off. Lindenblüten und technisch verwendbaren Bast. - Corchorus (30 trop.); C. olitorius (cult. in den Trop.) und $\boldsymbol{C}$. copsularis (Ostind., cult. in den Trop.) lief. die Jutefasern.

§ Grewieae. Androgynophor +. P. am Grunde mit Driisenfeld. - Grewia (90 palaeotrop., fossil im Tertiär von Eur.). - Triumfetta (60 trop.).

Fam. Malvaceae. Bl. meist ఫ̧. K. und P. 5 gliederig. P. in der Knospe gedreht. Stb. sehr selten 5, meist $\infty$ in 2 Kreisen, die vor den K. stehenden oft Std., die Stb. vor den P. vielfach gespalten, alle zusammen in ein Bündel vereint; A. monothecisch, mit grossen, bestachelten Pollenkörnern. Cp. $(5-\infty)$ mit je $1-\infty$ Sa.; Gr. ebensoviel oder doppelt soviel. Kapsel oder Fr. in Teilfr. ozerfallend. E. mit gefalteten, blattartigen Keimb., vom Nährgewebe umgeben. - $\mathrm{Kr}$, und $\mathrm{t}$ mit einfachen 
oder gelappten B. mit Nebenb. Bl. meist ansehnlich, einzeln oder in aus Wickeln zusammengesetzten Blütenständen. Hfg. Aussenkelch. - Schleimschläuche. - Etwa 800 calid., temp.

A. Cp. auf convexer Axe stehend, in 5 vor den P. liegenden Feldern.

\$ Malopeae. $\odot$ oder $4 \mathrm{Kr}$. Cp. mit $1 \mathrm{Sa}$. - Malope (3 medit.). - Kitaibelia (1 Donauländer).

B. Cp. in einer Ebene kreisfg.

§ Malveae. Fr. in Teilfr. zerfallend. Griffeläste so viel als $\mathrm{Cp}$.

* Abutilinae. Sa. $\infty-2$ in den einzelnen Cp. - Abutilon (80 trop.).

* Malvinae. Sa. einzeln in jedem Cp., aufsteigend. - Tavatera $(20$, meist medit.). - Althaea (15 temp. Eur., As.); A. rosea, Pappelrose, Stockrose (Balkanländer, Kreta); A. officinalis, Eibisch (auf Salzboden in Eur., Sibir.), lief. die off. Folia und Radix Althaeae. Malva (30); M. silvestris lief. die off. Flores und Folia Malvae. - Napaea dioica (Nordam.), Gespinnstpflanze. (70 calid.).

* Sidinae. Sa. einzeln, in jedem Cp. hängend. Kein Aussenkelch. - Sidu

§ Ureneae. Fr. in Teilfr. zerfallend. Griffeläste doppelt soviel als Cp. - Urena lobata (trop.), Gespinnstpfl.

\$ Hibisceae. Fr. eine fachspaltige Kapsel. - Hibiscus (150 calid.). - Abelmoschus esculentus, Gombo (Ostind.) mit essbaren, jungen Fr. Gossypium, Baumwolle; G. burbadense (trop. Am.) giebt die Peru-, Kidney- und Brasilbaumwolle; G. arboreum (Westafr., cult. in Agypt., Arb.); G. herbaceum (Ostind., Arab.; cult. in As., Afr., Am.).

Fam. Bombacaceae. Wie vorige Fam.; aber die A. mit 1, 2, oft auch mehr Fächern, aufliegend oder angewachsen, zuweilen gekrümmt oder nach dem Verblühen schneckenfg. eingerollt, mit glattem, niemals stacheligem Pollen; bisweilen Std. Cp. (2-5), bei Isomerie die Cp. vor den P., mit $2-\infty$ Sa. S. kahl; aber bisweilen von dem Pericarp angehörender Wolle umschlossen, zuweilen mit Arillus. Nährgewebe dünn oder 0 , Keimb. meist gefaltet. - $\quad$ t mit ganzen oder fingerfg. B. mit abfälligen Nebenb. Bl. oft gross. - Sternhaare oder Schuppen. Schleimgänge. 72 trop.

$\S$ Adansonieae. B. gefingert. Keimb. gefaltet oder um das Würzelchen gerollt. Kein Aussenkelch. Sternhare. - Adansonia (1 Afr., 1 Madagaskar, 1 Austral.); A. digitcta, Affenbrotbaum, Baobab (Savannenbaum Afrikas), liefert Bast zu Stricken und Papier. - Bombax (50, meist trop. Am.). - Ceiba (9 trop.); C. pentandra, Baumwollenbaum (trop.) u. a. lief. Wolle für Polster.

\$ Matisieae. B. einfach, handnervig oder am Grunde 3 nervig. Keimb. wie bei vor. Sternhaare, selten weiche Schuppen. - Ochroma (Antillen).

§ Durioneae. B. fiedernervig. Keimb. dickfleischig oder blattartig flach. Aussenkelch. Starre Schuppen an den Bl. und Fr. - Durio (13 ind.-malay.); D. wibethinus mit grossen, essbaren Fr.

Fam. Sterculiaceae. Bl. ఫॄ oder $\sigma^{\pi} \uparrow$. K. vereint. P. in der Knospenlage rechts oder links gedreht. Stb. in 2 Kreisen, die vor den K. stehenden Std., die vor den P, stehenden hfg. gespalten, alle 士 vereint; A, dithecisch. 
Hfg. Androgynophor. Cp. meist (5) vor den P., mit je 2-s Sa. Fr. oft in Teilfr. zerfallend. - $\hbar$ und $\mathrm{Kr}$., mit meist einfachen, ganzen oder gelappten oder gefingerten B. Nebenb. abfallend. Bl. meist in complicierten Blütenständen. - Etwa 660 calid.

A. Bl. ఫ̧.

a. Kein Androgynophor.

S Eriolaeneae. Stb.röhre lang. P. vorhanden. -8 Ostind.

Fremontieae. Stb.röhre lang. P. 0. - 2 Centralam, Kalif.

Dombeyeae. Stb.röhre kurz. P. gross, flach, zuletzt welkend, aber bleibend. (1). vor den K. - Melhania (20 Afr., Ostind.), - Dombeya (40 Afr., Madagaskar).

§ Hermannieae. Wie vorige; aber P. abfällig. Cp. vor den K. oder P. - Melochia (60 trop.). - Waltheria (30 trop. Am.). - Hermannia (120, meist Afr.).

§ Büttnerieae. Stb.röhre kurz. P. gross, kappenfg. - Büttneria (30 Am. calid.). - Theobroma cacao (trop. Am.; cult. in trop.).

§ Iasiopetaleae. Stb.röhre kurz. P. sehr klein, schuppenfy. oder 0. 67 Austral.

b. Androgynophor entwickelt.

§ Helictereae. P. flach. Bl. bisweilen . . - Helicteres (40 trop.).

B. Bl. $0^{7}$ 우.

s Stereulieae. P. 0. - t - Sterculia (90 trop.). - Bracheycliton, Flaschenbaum (Austral.). - Cola (10 trop. Afr.); C. vera, Kolanusshaum (Westafr.; cult. in Westind.); S. anregend, wichtiger Handelsartikel. - Heritiera (2 ind.-malay.); H. littoralis (Strandwälder).

4. Unterreihe Scytopetalineae. Kb. in einen schüsselförmigen $\mathrm{K}$. vereint.

Fam. Scytopetalacene. K. schn̈sselförmig; P. $3-7$, klappig; Stb. $\infty ; \mathrm{Cp}$. (4-6), mit je 2-6 hängenden Sa. Fr. holzig od. steinfruchtartig, 1 samig. - 24 mit abwechselnden, lederartigen, länglichen B. Bl. langgestielt in Büscheln od. Trauben. - 2 (trop. Westafr.)

ع) Die Bl. sind spirocyklisch oder zeigen 5-4 Cykleu; die Apocarpie tritt aber nur noch auf der ersten Stufe auf, die Syncarpic wird die Regel, ebenso zeigt sich schon melırfach eine Versenknng des Gynäceums in die Blütenaxe.

23. Reihe PARIETALES. Bl. spirocyklisch oder cyklisch, hfg. mit $\infty$ St.b. und $\infty \mathrm{Cp}$., heterochlam., selten apetal, hypogynisch bis epigynisch. Cp. \pm vereint, hfg. mit wandst. Plac., die aber auch in der Mitte zusammentreffen können, sehr selten mit grundständiger Sa.

Jie Unterreihen dieser Reihe dïrften phylogenetisch zu einigen der früheren Reihen, insbesondere den Ranales und Rhoeadales in Bezielinng stehen; auch flnden sich Anklinge der Cucurbitaceae (Reihe 8 der Metachlamydeae) an die 6. Unterreihe der Parietales.

1. Unterreihe Theineae. Gynaceum frei a uf convexer oder flacher Axe. Năhrgewebe der S. Öl und Proteinkörner enthaltend.

Fam. Dillenlaceae. Bl. ̧, , selten $\sigma^{\top}$ ᄋ, $\oplus$, bisweilen $\cdots$, hfg. noch teilweise $($ ). K. $3-\infty$, P. $5-3$, St. $\infty$, selten 10 oder weniger, Cp. $1-\infty$, mit je $1-\infty$ auf. steigenden Sa., mit 2 od. 1 Integ.; Gr. getrennt. Fr. am Rücken sich offnend oder geschlossen mit 1 oder wenigen S.; Arillus; Nährgewebe mit kleinem E. - $t$, bisweilen kletternd, selten Kr.; B. meist (2) und ganzrandig, immergran; Nebenb. + 
oder 0. Bl. gelb oder weiss. - 200 calid., sehr zahlreich in Australien. - Hibbertiu (Austral.). - Curatella (trop. Am.).

Fam. Eucryphlaceae. Bl. teilweise (9), ․․ ๑. K. 4, P. 4, St. $\infty$, Cp. (5-18), jedes mit $\infty$ hängenden Sa. mit 2 Integ., bei der Reife frei werdend, durch 2 Stränge mit dem Mittelsäulchen zusammenhängend, aufspringend. S. geflügelt, mit Nährgewebe. - $\hbar$ mit immergrüuen, gegenst., ungeteilten oder gefied. B.; Nebenb. + . Bl. einzeln, achselständig, weiss. - 4 Chile und Austral.

Fam. Ochnaceae. Bl. meist 5 gliederig, mitunter auch teilweise (9), ఫ્, $\phi$, bisweilen $\cdots$ Blütenaxe nach dem Abblühen häufig vergrössert; K. 4-10; P.5 (selten $4-10)$; Stb. 10 oder $\infty$, bisweilen Std., Cp. $2-5-10$, häufig unterwärts frei, aber $1 \mathrm{Gr}$.; Cp. mit $\infty-1$ aufsteigenden oder hängenden Sa., mit 2 oder 1 Integ. Fr. und S. verschieden. Nährgewebe + oder $0 .-\hbar$ oder Halbsträucher mit immergrünen, meist glänzenden, einfachen, selten gefied. B., meist mit parallelen Seitennerven; Nebenb. + . Bl. ansehnlich, gelb, meist in Rispen. - 160 calid.

A. Ohne Nährgewebe.

$\S$ Ourateeae. Cp. 3-10, nur die Gr. vereint, mit je $1 \mathrm{Sa}$. Mehrere Steinfr. - Ouratea (90 trop. Am.). - Ochna (30 Afr., As.).

§ Elvasieae. Cp. (2-5) mit je 1 Sa. Kapsel oder Beere. - Elvasia (4 trop. Am.). Lophira.

$\S$ Lophireae. Cp. (2). G. 1 fächerig, mit 10-20 aufsteigenden Sa. Stb. $\infty-$

B. Mit Nährgewebe.

§ Luxemburgieae. Cp. (3-5) mit je $\infty$ Sa. G. 3-5 fächerig oder 1 fächerig. Kapsel. - Luxemburgia (7 Bras.). Sauvagesia (10, meist Am.).

§ Enthemideae. Cp (5) mit je 2 Sa. Steinfr. - Euthemis (ind.-malay.).

Fam. Caryocaraceae. Bl. ఫ̧, $\oplus ;$ K. und P. $5(-6)$, letztere zusammenhängend; Stb. $\infty$; Cp. $(4-8-20)$, selten $(1-3)$ mit je 1 hängenden Sa., mit 2 Integ.; Gr. getrennt; Fr. hfg. in die einzelnen Cp. zerfallend, bei Caryocar mit ölreichem Mesocarp; S. mit dünnem Nährgewebe oder ohne solches. E. gekrümmt mit grossem Stämmchen und kleinen Keimb. - I mit 3-fingerigen, immergrünen B.; Nebenb. am Grunde des B.stiels und der Blättchenstielchen. Bl. in endständigen Trauben. - 14 trop. Am. - Caryocar nuciferum, C. glabrum und C. amygdaliferum lief. in ihren grossen Teilfr. die Souari-Nüsse mit essbarem $\mathrm{S}$.

Fam. Marcgraviaceae. Bl. ఫ̧, 申; K. 4-5; P. 4-5, + zusammen-

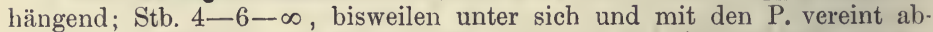
fallend; Cp. (5) oder $(2-8-\infty)$, mit $\infty$ Sa. an anfangs parietalen, später im Centrum sich berührenden Plac. Kapsel geschlossen oder fachspaltig; S. ohne Nährgewebe. - $\hbar$, oft kletternd und epiphyt., mit einfachen, bisweilen heteromorphen B. ohne Nebenb.; Bl. traubig; Tragb. hfg. mit den Blütenstielen vereint, ihre Spreite in lebhaft gefärbte, meist hohle Nektarienträger umgebildet. - 30 trop. Am. - Marcgravia. - Norantea.

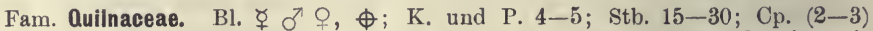
oder (7) mit je 2 centralwinkelst. Sa.; Gr. getrennt. Beere, zuletzt klappig, mit filzigen S.; E. mit kurzem Stämmchen. - † mit glänzenden, einfachen oder fiederspaltigen, immergrünen B.; Nebenb. +; Bl, klein, in Trauben oder Rispen. - Bisweilen lysigene Gummigänge. - 16 trop. Am. - Quiina.

Fam. Theaceae (Ternstroemiaceae z. Teil). Bl. hfg. noch teilweise (9), ఫ, $\oplus$; K. $5-7$; P. $5-9$, bisweilen am Grunde vereinigt; Stb. $\infty-5$, bisweilen in Gruppen vereinigt; Cp. $(3-5)$, auch $(2-\infty)$, mit $\infty-1$ Sa. 
an centralwinkelst. Plac., mit 2 Integ. Kapseln septicid oder loculicid oder nicht aufspringend. S. klein oder gross; Nährgewebe + oder 0 . t) mit einfachen, meist abwechselnden, hfg. immergr. B.; Nebenb. 0; Bl. oft ansehnlich. - 200 trop., subtrop. - Visnea mocanera auf den makaronesischen Ins. - Eurya (Ostasien). - Ther japonica, Kamellie (Japan); Thea chinensis (Theestrauch, vielleicht wild im oberen Assam und in der Provinz Cachar, seit Alters her cult. in Ostind. und China).

Fam. Guttiferae. Bl. hfg. noch teilweise (9), ఫ oder $\sigma^{\pi}$ \&, $\oplus$. K. und P. der Zahl und Stellung nach sehr verschieden; Stb. $\infty-4$, oft teilweise Std. und in Gruppen vereinigt; Cp. $(3-5)$, auch $(1-15)$ mit $\infty-1$ Sa., mit 2 Integ. S. ohne Nährgewebe. - t, seltener $\mathrm{Kr}$., mit einfachen, meist gegenst., hfg. immergr. B.; Nebenb. selten. Bl. oft ansehnlich. - Stets schizogene Secretlücken (Harzgänge oder Öldrüsen). 450 calid.-temp.

Unterfam. Kielmeyeroideue. B. abwechselnd oder gegenst.; Bl. meist ్; Stb. $\infty$; 1 Gr.; Frkn. 3-5 fächerig. - Kielmeyera (15 Brasil.).

Unterfam. Hypericoideae. B. meist gegenst.; Bl. ఫ̧; Stb. meist $\infty$ in 2-8 Bündeln, selten weniger als 10; Gr. meist getrennt. Kapsel, Beere, Steinfr. Keimb. nicht dicker als das Stämmchen.

§ Hypericeae. G. 1 fächerig oder unvollkommen $3-5$ fächerig. Kapsel septicid. - Hypericum (160 calid.-temp.).

§ Cratoxyleae. (i. 3 fächerig. Kapsel loculicid oder zugleich septicid. Cratoxylon (12 trop. As.). und Afr.).

\$ Vismieae. G. 5 fächerig. Beere oder Steinfr. - 'Vismia (15 trop. Am.

Unterfam. Endodesmioideae. B. gegenst.; Bl. ̧; Stb. $\infty$, alle vereinigt; G. 1 mit 1 Sa. Steinfr. Keimb. sehr dick, Stämmchen fast 0. - Endodesmia (trop. Afr.).

Unterfam. Calophylloideae. B. gegenst.; Bl. ఫ̧ oder $\sigma^{7}$ 우 Stb. $\infty$, frei oder am Grunde vereint; Cp. 2-4 mit je 2-1 Sa. G. gef ächert oder $1 \mathrm{fächerig.} \mathrm{Fr.} \mathrm{meist} \mathrm{nicht} \mathrm{aufspringend.} \mathrm{Keimb.} \mathrm{sehr} \mathrm{dick,} \mathrm{zusammen.}$ hängend; Stämmchen klein. - M Iammea americana (Westind.; cult. in den Trop.) lief. die Mammeyäpfel. - Mesur ferrea (Ostind.) lief. ceylan. Eisenholz. - Caloply yllum calaba (Westind.) lief. Calababalsam; $C$. inoplıyllum (Ostafr. bis Polynesien) lief. Balsamum Mariae, Takamahak; C. tacamahaca (Maskarenen) lief. bourbonisches Takamahak.

Unterfam. Clusioidecue. B. gegenst.; Bl. ̧ㅜ oder $\sigma^{7}$ 우. Stb. meist $\infty$, frei oder in Gruppen. Fr. mannigfach. E. mit sehr dickem Stämm. chen und ganz kleinen Keimb.

§ Clusieae. Stb. nie in Gruppen; N. getrennt. Kapsel zuletzt septicid. - Clusia (70 trop. Am.), vielfach epiphyt. und Baumwürger, lief. purgierende Harze. S. mit Arillus.

§ Garcinieae. Stb. meist in Gruppen; eine N. Beere (meist gross und wohlschmeckend). - Allcublaclicia (4 trop. Afr.); A. Stullmannii, Fettbaum, mit riesigen Fr. (Ostafr.). - Rheedia (trop. Am.). - Garcinia (trop. Afr. und As.); G. mangostana, Mangostane (Malakka); 
G. morella (Ostind. bis Cochinchina) und einige Verwandte geben Gummigutt. - Xanthoohymus.

\$ Moronobeeae. Stb. in 5 Gruppen. Gr. lang mit getrennten $\mathbf{N}$. Beere. - Pentadesma butyraceum, Butterbaum (Sierra Leone) enthält butterartigen Saft in den Fr. - Platonia. - Syinphonia.

Fam. Dipterocarpaceae. Bl. ఫ̧, $\oplus$. K. 5, bei der Reife hfg. $2-3$ zu Flügeln verlängert. P. 5, frei oder unten vereint. Stb. co oder 15,10 , 5 ; Cp. $(3-1)$ mit je $\infty-2$ Sa. mit 2 Integ. Fr. meist nicht aufspringend und 1samig. Nährgewebe 0 . E. verschieden. - t mit abwechselnden, immergr. B. Nebenb. +. Bl. in Rispen. - Stets Harzgänge. - 313 trop. As., 1 trop. Afr. - Dryobalanops (4) camphora (Sumatra und Borneo) lief. den Baroskampfer. - Dipterocarpus (65) turbinatus u. a. in Ostindien geben Harz. - Vateria indica giebt Harz. - Shorea (87); mehrere geben Kopal und in den S. Fett. - Vatica (44); mehrere geben Kopal.

2. Unterreihe Tamaricineae. Gynäceum frei auf flacher Axe. Nährgewebe der S. stärkehaltig oder fehlend. P. frei. Stb. in Quirlen oder, wenn $\infty$, in Bündeln.

Fam. Elatinaceae. Bl. cyklisch, haplostemon oder diplostemon, $2-5$ gliederig, ㅎ, $\oplus$. Cp. mit $\infty$ centralwinkelst. Sa. mit 2 Integ. Kapsel septicid; Nährgewebe der S. dünn oder 0 . - Halbsträucher oder Kr.; oft Wasserpflanzen mit gegenst. oder quirlst. B.; Nebenb. +; Bl. klein, einzeln achselst. oder cymös. - 20 temp., subtrop., trop. - Elatine.

Fam. Frankeniaceae. Bl. 4-6 gliederig, ఫ, $\oplus . \quad$ K. vereintb., P. mit Jigularbildung; Stb. bisweilen $\infty$, frei oder am Grunde etwas vereint; Cp. $(4-2)$, mit $\infty$ aufsteigenden Sa. mit 2 Integ. an pariet. Plac. und getrennten Gr. Kapsel zwischen den Plac. aufspringend; S. mit Nährgewebe. - Halbsträucher oder $4 \mathrm{Kr}$. mit kleinen gegenst. B. ohne Nebenb.; Bl. endst. oder in Wickeln. - 15 Strand- und Wüstenpfl. - Frankenia.

Fam. Tamaricaceae. Bl. 4-5-, selten 6 gliederig, meist $\not$, $\emptyset$. Stb. so viel als P. oder doppelt so viel oder $\infty$ in Gruppen. Cp. $(5-2)$, mit $\infty$ aufsteigenden Sa. an basalen oder frei aufsteigenden Plac. mit 2 Integ.; Gr. getrennt. Kapsel; S. ringsum oder am oberen Ende lang behaart. $\mathfrak{t}$ oder $4 \mathrm{Kr}$, mit abwechselnden kleinen ganzrandigen B. - 40 temp., subtrop., Salz- und Gebirgspfl.

A. P. frei oder nur am Grunde etwas vereint.

§ Reaumurieae. S. ringsum behaart, mit dünnem Nährgewebe. Bl. einzeln. - Reaumuria (Steppen und Wüsten des Mittelmeergebietes und Centralasiens).

$\S$ Tamariceat. S. am Scheitel behaart, ohne Nährgewebe; Bl. traubig. - Tamarix gallica (medit.), adstringierend. - Myricaria germanica, subalpin.

3. Unterreihe Fouquierineae. Gynäceum frei auf flacher Axe. Nährgewebe der S. ölhaltig. P. ver'eint.

Fam. Fouquieraceae. Bl. 5 gliederig', ఫ్., $\emptyset \quad$ P. (5); Stb, 10-15; Cp. (3), mit je 4-6 Sa. an Placenten in der Mitte der Bauchseite. Fr. kugelig, 3 fächerig; S. 
lang behaart oder getlügelt. - Striucher mit abfalligem Laub, verdornenden Mittel. rippen der B. und Zweiglein; Bl. ansehnlich, $\infty$, in endständigen Rispen oder Trauben. - Fouquiera (3-5 Mexiko).

4. Unterreihe Cistineae. Gynäceum frei auf flacher oder con. vexer Axe. Nährgewebe der S, stärkehaltig. P. frei. Stb. $\infty$, nicht in Bändeln.

Fam. Cistaceae. Bl. ㅎ, $\oplus$. K. $5-3$, P. $5-3-0$, Sth. $\infty$, Cp. $(5$ bis 10) mit $\infty$ oder $2 \pm$ geradläufigen Sa. mit 2 Integ. an wandst. oder weit einspringenden Plac. Kapsel zwischen den Plac. aufspringend; S. mit Nährgewebe und gekrümmtem E. - Kr. und Sträucher mit meist gegenst. B. - Sternhaare und Drüsenhaare, letztere mit ätherischem Öl. - 160 temp., vorzugsweise medit. - Cistus creticus und C. Zadamiferus geben Ladanum. - Helianthemum (meist medit., einige Mitteleuropa).

Fam. Bixaceae. Bl. ㅎ, 申. P. 5, P. 5, Stb. $\infty$, Cp. (2) mit je $\infty$ umgewendeten Sa. mit 2 Integ. an wandst. Plac.; (Gr.). Kapsel zwischen den Plac. in Klappen aufspringend, mit häutigem, sich loslösendem Endocarp und $\infty$ S., diese mit roten, fleischigen Papillen. - $\hbar$, mit (9) handnervigen, ungeteilten B. und ansehnlichen in Rispen stehenden BI. Bixcl orellana, Orleansbaum (trop. Am. und cult.); die fleischige rote Samenschale (terra Orleana) Handelsartikel, zum Orangegelbfärben von Wolle und Seide.

5. Unterreihe Cochlospermineae. Wie vorige, aber Nährgewebe der nierenförmigen S. ölhaltig.

Fam. Cochlospermaceae. Bl. ఫ̧, $\oplus$, bisweilen schwach $\cdot 1$ K. $4-5$, P. 4-5, Stb. $\infty$, Cp. $(3-5)$ nit je $\infty$ Sa. mit 1 Integ. an wandständigen oder fast centralwinkelständigen Plac.; (Ğr.). Kapsel. S. $\infty$ mit gekrümmitem E. und reichlichen Nährgewebe. - $\hbar$, bisweilen mit kurzem unterirdischem Stamm, meist mit handförmig gelappten oder gefingerten B. Bl. ansehnlich, in T'rauben oder Rispen. Etwa 18 trop. - Cochlospermum (13 trop. xerophytisch).

Fam. Koeberliniaceae. Bl. ̧, 申. K. 4, P. 4, Stb. 8, Cp. (2) mit $\infty$ Sa. mit 2 Integ. an der Scheidewand; (Gr.). Beere 2-1 samig. S. und E. stark gekrümınt, mit dünnem Nilhrgewebe. Blattloser Strauch mit starren, grünen Zweigen. Bl. zieinlich klein in Trauben. - Koeberlinia (1 Texas, Mexiko).

6. Unterreihe Flacourtineae. Gynaceum frei auf convexer oder in röhriger Axe, selten seitlich angewachsen. Nährgewebe der S. reichlich, Öl und Proteinkörner enthaltend.

Fam. Canellaceae. Bl. ̧, $\oplus$. K. $4-5$, P. 4-5 oder 0, Stb. 20 oder weniger in eine Röhre vereint, Cp. $(2-5)$, mit $2-\infty$ Sa. mit 2 Integ. an parietalen Plac. Beere mit $2-\infty \mathrm{S}$. - Ölreiches Nährgewebe. - $\mathrm{b}$ mit abwechselnden ganzrandigen B.; Nebenb. 0. Bl. in Trugdolden. - 4 trop. Am., 1 trop. Afr., 1 Madagask. - Canella alba (Antillen) giebt die zimmetartig riechende Canellrinde, Cortex Canellae albae. - Cinnamodendron.

Fam. Violaceae. Bl. 5 gliederig (mit Ausnahme des G.), haplostemon, $\not{q}, \oplus$ oder $\%$ P. bisweilen vereinigt. Cp. (3) mit je $1-\infty$ umgewendeten Sa. mit 2 Integ. an wandst. Plac. Fachspaltige Kapsel oder Beere. S. mit Nährgewebe. E. gerade. - Kr. oder t mit abwechselnden B.; Nebenb. - 250 trop., subtrop., temp. 
$\S$ Rinoreae (Alsodeieae). Krone $\oplus$ oder schwach $\%$ Vordere Stb.

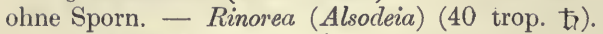

$\S$ Violeae. Krone $\%$ Vordere 2 Stb. mit Sporn. - Viola (150 temp.); off. V.tvicolor, Stiefmütterchen. - Jonidium (40 calid); J. ipecacuanha (Brasil.) lief. d. Radix Ipecacuanhae albae.

Fam. Flacourtiaceae. Bl. $\Varangle$ oder $\delta^{\nearrow}$, h hfg. noch teilweise (9), $\oplus$. K. $2-15$, P. $10-0$, Stb. meist $\infty$, Cp. $(2-10)$, meist mit $\infty$ umgewendeten Sa. mit 2 Integ. an wandst. Plac. Beere oder Kapse]. S. hfg. mit Arillus und Nährgewebe. - Meist $\hbar$ mit meist (9), selten gegenst. oder quirlst. einfachen, ganzrandigen oder gesägten B., mit kleinen Nebenb. Bl. oft klein. - Etwa 300 trop.

Diese Fam. steht mit den drei folgenden in der innigsten verwandtschaftlichen Beziehung.

§ Oncobeae. Bl. ఫ̧. K. 3-5, P. 4-10 grösser, dachig, Stb. $\infty$ hypogyn., mit linealischen A. Cp. $(3-10)$ mit je $\infty$ Sa.; Gr. frei oder vereint. Fr. nicht oder spät aufspringend. - Oncoba (7 trop. Afr.). - Mayna (7 trop. Am.).

$\S$ Pangieae. Bl. $\delta^{\lambda}$, diöcisch. K. 2-5, P. 5-8, am Grunde mit Schüpp. chen, Stb. $\infty-5$, Cp. (2-6) mit je $\infty-1$ Sa. Beere. - Pangium edule (Sundainseln); Samen frisch giftig, geben Samaunöl.

$\$$ Flacourtieae. K. 4-6, dachig, P. meist 0, Stb. $\infty$, hypogyn, mit kurzen A.; Cp. $(2-6)$ mit je $\infty-1$ Sa.; Gr. frei oder vereint. Beere oder Kapsel. - Laetia (10 trop. Am.). - Flacourtia (12 palaeotrop.). - Xylosma (25 trop.).

$\S$ Azareae. K. 4-6, fast klappig, P. klein oder 0, Stb. $\infty$ perigyn, mit kurzen A. Cp. (3-6) mit je $\infty$ Sa.; Gr. frei oder vereint. G. einfächerig oder mehrfächerig. - Azara (12 Chile). - Prockia (trop. Am.) - Banara (12 trop. Am.).

§ Paropsieae. K. 5. Axe schwach röhrig, in einen Discuskranz, bisweilen anch in ein kurzes Gynophor ausgehend. P. 5, Stb. $\propto-20$ oder $9-5$ perigyn oder am Grunde des Gynophors; Stf. bisweilen zu einer Röhre vereint. Cp. (3-5), meist (3), mit meist $\propto$ Sa. - palaeotrop., meist trop. Afr.

§ Samydeae. K. 4-5, dachig, P. 0, Stb. $\infty$ oder in beschränkter Zahl, bisweilen Std., perigyn.; Cp. (2-6), meist (3), mit je $\infty-2$ Sa. - Casearia (80 trop.).

\$ Abatieae. K. 4, klappig, P. 0, Stb. $\infty-8$, Std. 0, perigyn ; Cp. (2-4), mit je $\infty \mathrm{Sa}$. B. gegenst. - Abatia (7 trop. Am).

$\S$ Homalieae. K. $4-15$, P. 4-15, Stb. $4-15$ vor den P. oder $\infty$ in Bündeln vor den P., perigyn. oder epigyn. B. (9), seltener gepaart. - Homalium (30 trop.).

Fam. Stachyuraceae. Bl. 후 oder $\not \sigma^{7}$ 우, $\oplus$. K. 4, P. 4, Stb. 8, Cp. (4) mit $\infty$ 2 reilig an den Placenten stehenden $\mathrm{Sa}$. mit 2 Integ. $\mathrm{Fr}$. beerenartig, 4 fächerig. S. $\infty$, klein mit Arillus und fleischigem Nährgewebe. - Kleine $\hbar$, kahl, mit ab. wechselnden, gesägten, nach den Bläten auftretenden B. Bl. klein, in kurzen achselständigen Trauben. - Stachyurus (2 Japan, Himalaya).

Fam. Turneraceae. Bl. 5 gliederig, haplostemon, ఫ̧, $\oplus$, mit röhriger Axe. Cp. (3), mit je $3-\infty$ Sa. mit 2 Integ. an parietalen Plac. Gr. getrennt. Kapsel 1 fächerig, 3 klappig; S. mit Arillus und Nährgewebe. $\odot$ und $24 \mathrm{Kr}$. oder $\hbar$. mit (9), gezähnten oder geteilten B.; Nebenb. + oder 0 . Bl. axillär, einzeln oder traubig oder cymös. - 83 subtrop., trop., grösstenteils Amer. - Turnera aphrodisiaca (Mexiko) und T. diffusa (Mexiko und Antillen) liefern die als anregendes Mittel geschätzte Damiana.

Fam. Malesherbiaceae. Bl. ̧, $\oplus$, mit röhriger $A x e$, die in einen extrastaninalen Discuskranz und ein Gynophor ausgeht, 5 gliederig, haplostemon, Stb. dem Gynophor eingefilgt. Cp. (3) mit $\infty$ Sa. mit 2 Integ. an parietal. Plac.; Gr. 3 oder 4 unter der Spitze des Frkn. eingefügt. Kapsel hfg. in den K. eingeschlossen. S. ohne Arillus. - Kr. oder Halbsträucher mit alternierenden, meist stark behaarten, einfachen, oft tief eingeschnittenen B.; Nebenb. 0. Bl. traubig oder cymös. -16 in Peru und Chile. 
Fam. Passifloraceae. Bl. $\Varangle$ oder $\sigma^{\top} \uparrow, \oplus$, mit mannigfach gestalteter, hfg. mehr oder weniger, röhriger und rielfach in Effigurationen ausgehender Axe. K. meist 5 , seltener $4-8$, P. $5(3-8)$ selten 0 . Stb. seltener $\infty$, meist 5 oder $4-8$, dem cylindrischen Axenteil eingefügt. Cp. $(3-5)$, meist mit $\infty$ Sa. mit 2 Integ. an wandst. Plac. Kapsel oder Beere; S. zusammengedrückt, meist mit Arillus und Nährgewebe. - Kr. oder $\hbar \mathrm{hfg}$. kletternd, mit ungeteilten, meist gelappten, selten gefiederten B. Nebenb. + oder 0. Hfg. Nektarien an den B. Bl. einzeln oder traubig oder cymös. Die Ranken entsprechen nach ihrer Stellung Inflorescenzen. Holzprosenchym meist mit Hoftüpfeln. - 250 calid., meist Afr. und Am. Prıssiflor'c (über 250); $P$. edulis, $P$. quadrangularis, $P$. coerulea und $P$. laurifolia (Am.) lief. wohlschmeckende Fr., Grenadillas.

Fam. Achariaceae. Bl. $\sigma^{7}$ ㅇ, 3-5 gliederig, $\oplus$, monöcisch. P. (3-5), Stb. ebensoviel mit dem Grunde der Blkr. vereint. Cp. wie bei vorigen. Kapsel 3-5klappig. S. mit reichlichem Nährgewebe, - Kr. oder Halbsträucher, mit einfachen od. gelappten B. Bl. einzeln oder zu wenigen axillär. Holzprosenchym einfach getïpfelt. -3 Südafr.

7. Unterreihe Papayineae. Gynäceum frei in röhriger oder glockiger Axe. Năhrgewebe der S. Öl und Proteinkörner enthaltend. Reich verzweigtes Milchröhrensystem in allen Teilen der Pfl.

Fam. Caricaceae. Bl. 5 gliederig, diplostemon, $\sigma^{\top}$, $\oplus$, mit röhriger oder glockiger Axe. P. in den $\sigma^{7} \mathrm{Bl}$. zu einer langen, in den 우 Bl. zu kurzer Röhre vereint. Cp. $(\hat{5}-5)$, mit $\infty$ Sa. mit 2 Integ. an parietalen Plac. und freien Gr. Beere. S. $\infty$, mit Näbrgewebe. - $t$ mit einfachen oder handfg. oder gefingerten B. ohne Nebenb. und mit achselständigen Nebenb. - Reich verzweigtes und gegliedertes Milchröhrensystem. - 28 trop. Am., 1 Afr. - Carica papaya, Melonenbaum, u. a. liefern essbare Fr. Der Milchsaft enthält das Ferment Papayna, welches Eiweiss peptonisirt und frisches Fleisch schnell weich macht, auch frische Milch gerinnen macht.

8. Unterreihe Loasineae. Gynäceum in die Axe eingesenkt und mit lerselben vereint. Nährgewebe der S. Öl und Proteinkörner enthaltend orler selten fehlend.

Fam. Loasaceae. Bl. ఫ̧, mit röhriger kreiselförmiger oder kegeliger Axe. K. 5 (selten 4, 6, 7), P. ebensoviel, sehr selten vereinigt, häufig concav, Stb. $\infty$, vor den K. bisweilen nur 2 oder 5 , die vor den K. stehenden hfg. in Std. oder Nektarienschüppchen umgewandelt; Cp. (3-7), mit je $1-\infty$ Sa. mit 1 Integ. am Scheitel des G. oder an parietalen Plac. Kapsel gerade oder spiralig gedreht, meist 5-7 klappig. S. mit Nährgewebe. - Kr., selten Sträucher, bisweilen windend, mit abwechselnden oder gegenst., ganzrandigen oder gelappten oder fiederspaltigen B. ohne Nebenb. - Meist mit Häkchen versehene Haare, vielfach Brennhaare. 200 im subtrop. und temp. Amerika. - Loasa. - Mentzelia. - Blumenbachia. - Cajophora lateritia Zierpflanze. - Kissenia als Ausnahme in Afr.

9. Unterreihe Datiscineae. Gynäceum in die Axe eingesenkt und mit derselben vereint. Nahrgewebe sehr sparsan. E. Öl und Protein. stoffe enthaltend. Bl. in Trauben.

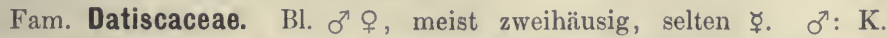
$3-9$, P. 0 oder 8 , Stb. $4-25$. 市 und $\Varangle$ : Blhb. $3-8$, Cp. $(3-8)$ unterst.; 
Gr. frei; G. mit wandst. Plac. Sa. mit 2 Integ. Kapsel mit $\infty$ kleinen S. Nährgewebe sparsam. - Kr. oder $\hbar$ mit einfachen oder gefiederten $B$. ohne Nebenb.; Bl. klein, traubig. - 4 calid., temp. - Datisca cannabina im Orient.

10. Unterreihe Begoniineae. Wie vorige; aber Nährgewebe fehlend. Bl. in Dichasien od. Wickeln.

Fam. Begoniaceae. Bl. unsymmetrisch, $\sigma^{\top}$ 우, einhäusig. $\sigma^{\top}$ : Nur selten K. 5, P. 5, häufig K. 2, P. 2-6 oder 0. Stb. $\infty$. ㅇ: Blhb. 5-2 (bisweilen $3+3$ oder 8). Cp. meist (3), selten $(4-5)$, unterständig; Gr. frei. G. mit wandst. oder eingebogenen und von der Mitte an wieder zurückgebogenen Plac., mit $\infty$ Sa. mit 2 Integ. Kapsel, selten Beere; S. klein; Nährgewebe 0. - Kr. oder Halbsträucher, auch Knollengewächse, mit (9) schiefen, hfg. gelappten, bisweilen gefingerten B.; Nebenb. †. Bl. in Dichasien oder Wickeln. - 350 calid., ausgenommen Austral. -

\section{Begonia.}

11. Unterreihe Ancistrocladineae. Gynäceum in die Axe eingesenkt und mit derselben vereint, einfächerig mit einer grundständigen Sa. Nährgewebe der S. zerklüftet, stärkehaltig.

Fam. Ancistrocladaceae. Bl. $\Varangle, \emptyset$, epigynisch. K. 5, P. 5 am Grunde etwas vereint, Stb. 5-10, Cp. (3?); nur 1 Fach mit 1 grundstïndigen Sa. mit 2 Integ. Nuss mit 1 kugeligem S. - Kletternde Lianen mit lanzettlichen ganzrandigen $B$. und kleinen in Trauben od. Rispen stehenden Bl., die Blütenstäude häufig mit Ranken. - Ancistrocladus (8 trop. Westafr., trop. Asien).

24. Reihe OPUNTIALES. Bl. hemicyklisch, heterochlam., mit $\infty$ (2) K., P., Stb. an röhriger Axe und $4-\infty$, ein unterständiges G. bildenden Cp. - Succulente Gewächse.

Der Ausicht Schumanns, dass diese Reihe plylogenetisch zu den Azioaceae (Reihe 14, Centrospermae) in Bezielnung stehe, schliesse ich mich an.

Fam. Cactaceae. Bl. ఫ્,, $\oplus$, bisweilen etwas $\%$, mit oft langer, röhriger Axe. K. und P. $\infty$, ineinander übergehend. Stb. $\infty$. Cp. $(4-\infty)$; (Gr.); G. meist 1 fächerig, mit $\infty$ Sa., mit 2 Integ. an wandst. Plac. Halbfr. Beere mit $\infty$ S. Nährgewebe sparsam oder 0 . — E. gerade oder gekrümmt mit bisweilen sehr kleinen Keimb. - Meist succulente Pf., selten mit flachen oder cylindr. B., in der Regel mit fleischigem Stamm, mit rippenartig hervortretenden Orthostichen oder höckerförmig vorspringenden Blattpolstern; B. selbst frühzeitig abfallend; Blattpolster oft filzig und mit Dornen (umgebildeten Blättern der Achselsprosse) besetzt. Bl. meist den Blattpolstern aufsitzend. - 900 temp., calid. Am., 1 auch in Afr.

Unterfam. Peireskioideae. B. flach, bleibend. Dornen ohne Widerhäkchen. Sa. an kurzem Funiculus. - Peireskia.

Unterfam. Opuntioideae. Stamm häufig gegliedert mit flachen Gliedern. B. klein, in der Jugend abfallend. Dornen mit Widerhäkchen. Sa. an langem Funiculus. - Opuntia ficus indica, Feigencactus, in der alten Welt, besonders im Mediterrangebiet eingebürgert; Fr. essbar; auch wird auf ihr Coccus cacti gezogen. 
Unterfam. Cereoideae. B. sehr klein, schüppchenförmig, bald abfallend; Dornen ohne Widerhäkchen. Sa. an langem Funiculus.

A. B1.-Axe langröhrig.

\$ Echinocacteat. Bl. in den Areolen oder am Scheitel der Höcker. Cerenis (200). - Epiphyllum (3). - Melocactus (30). - Echinocartus (200).

$\S$ Mamillarieae. Bl. am Grunde der Höcker. - Mamillaria.

B. Bl.-Axe kurz.

§ Rhipsalideae. Stongel stielrund oder verbreitert und gekerbt, mit kleinen schuppenfg. B. und seitlichen kleinen Bl. Beere erbsenfg. Rhipsalis (30).

Ђ) Dle Bl. sind cyklisch und die Versenkung des Gynäcenms in die hohle Bliitenaxe ist allgemein; die Verwachsung desselben mit der Blïtenaxe oder dem Receptaculum wird vorherrschend.

25. Reihe MYRTIFLORAE. Bl. cyklisch, heterochlam., selten apopetal, haplostemon oder diplostemon (bisweilen verbunden mit Spaltung), selten $\%$, mit \pm concaver Axe und $2-\infty$ zu einem selten freien oder meist mit der Axe (Receptaculum) zusammenhängenden G. vereinten $\mathrm{Cp}$., seltener mit 1 freien $\mathrm{Cp}$. - Kr. und $\mathrm{t}$, hfg. mit bicollateralen Bündeln.

1. Unterreihe Thymelaeineae. Bl. mit schässelförmiger röhriger Axe (wenigstens in den $\gamma$ und $q$ Bl.) und $2-4$ zu einem freien G. ver. einigten Cp., $\oplus$. Meist th, selten Kr. mit ungeteilten B.

F:um. Geissolomataceae. Bl. ఫ̧, 4 gliederig, mit flach schïsselförmiger Axe. K. dachig, P 0, Stb. ₹, Cp. (4) mit je ¿ von der Spitze des Faches herabhängenden Sa. (Gr.). Kapsel 4 fächerig, in jedem Fach mit $1 \mathrm{~s}$ oder überhaupt mit nur is. Nährgewehe + , fleischig. F. cylindrisch. - Kleiner Strauch mit gegenständigen, immergrünen, gauzrandigen B. und in deren Achseln stehenden Einzelbl. - Geissoloma (1 sildwestl. Kapland).

Fam. Penaeaceae. Bl. mit becherfg. Axe, haplochlam., haplostemon, 4 gliederig, ఫ̧. Blhb. klappig. Stb. mit den Blhb. abwechselnd. Cp (4), mit je 2-4 auf. steigenden Sa. mit 1 Integ. (Gr.). Kapsel fachspaltig, mit 1 samigen Fächern. Nährgewebe 0. E. dickfleischig, kurz 2lappig. - Sträncher mit kleinen, leclerartigen, ganzrandigen, gegenst. B, und in den oberen Blattachseln sitzenden Bl. -20 in der Kapkolonie.

Fam. Oliniaceae. Bl. જ̧, 4-̄̄gliederig, mit eylindrischer Axe. K. corollinisch, P. kleiner, klappig, behaart; Stb. in einem Kreise vor den P.; Cp. $(3-5)$, mit je 2-3 centralwinkelständigen Sa., mit 2 Integ. (Gr.) kurz. Steinfr., nit 5-1 1 samigen Steinkernen. Näırgewebe 0. E. mit gefalteten Keimb. - Kleine $t$ mit gegenst., ganzrandigen, lederartigen B. und kleinen Bl. in Trugdolden am Endle der Zweige. - Olinia (6 von Abyssinien bis zum Kapland).

Fam. Thymelaeaceae. Bl. mit becherfg. oder röhriger 'Axe, heteroehlam., oder apopetal. diplostemon oder haplostemon, 5-4 gliederig. Cp. (2) oder 1 mit je 1 hängenden Sa.; (Gr.). Nährgewebe + oder 0 . E. gerade, mit fleischigen Keimb. - $\hbar$ oder Bäume, selten Kr. mit festem, netzartigem Bast, ganzrandigen (2) oder gegenst. B. ohne Nebenb. und einzelnen oder in Ähren und Trauben stehenden Bl. - 360 temp., calid.

Unterfam. Aquilarioirleare. Bl. diplostemon oder haplostemon, mit schuppenfg. P. Cp. (2), mit je 1 Sa. 2 fächerige Kapsel loculicid. - 
Aquilaria agallochum (Ostind., China), lief. das zum Räuchern verwendete Adlerholz, Lignum Aloës.

Unterfam. Phalerioideae. Bl. diplostemon, mit schuppenfg. P. oder apetal. Cp. (2) mit je $1 \mathrm{Sa}$. Steinfr. mit 2 (oder 1) Kernen. - Trop. Afr., As.

Unterfam. Thymelaeoideae. Bl. diplostemon oder haplostemon, selten hemistemon mit schuppenfg. P. oder apetal. Cp. 1 mit 1 Sa. Halbfr. nuss- oder steinfruchtartig. - Pimelea (80 Austral., Timor, NeuSeeland). - Daphne (36 Eur., As.); D. meaereum, Kellerhals, Seidelbast (temp. Eur., As.) lief. die früher off. Cortex Mezerei. - Lagetta linteuria (Westind.) mit zartem, spitzenähnlichem Bastgewebe. - Gnidia (50 Afr.). - Thymelaea (20 medit.).

Unterfam. Drapetoideae. P. 0, Cp. 1, Stb 4 zwischen den Kb. und 4-8 vor denselben. - Winzige moosartige Pflänzchen. Drapetes 5 *, antarktisch.

Fam. Elaeagnaceae. Bl. mit becherfg. oder in $\sigma^{\top} \mathrm{Bl}$. mit flacher Axe, haplochlam., haplostemon oder diplostemon, meist 4 gliederig, §̧ oder $\sigma^{7}$ ㅇ. Cp. 1 mit 1 vom Grunde aus aufsteigenden Sa. Nuss von der fleischigen Blütenaxe eingeschlossen. Nährgewebe schwach oder 0 . E. gerade, mit dickfleischigen Keimb. - $\hbar$ mit (Q) oder gegenst. ganzrandigen B. und einzeln oder in Trauben und Ähren stehenden Bl. 16 temp., calid. - Elaergnus (12 *). - Hippophä̈ rhamnoides, diöcisch (Eur., As.). - Shepherdia (3 Nordam.).

2. Unterreihe Myrtineae. Bl. mit röhriger Axe und $2-\infty$ zu einem selten freien, meist mit der Axe zusammenhängenden $G$. vereinten Cp. Sa. mit 2 Integ. - Kr. t mit (a) oder häufiger init gegenst. oder quirlst. B.

Fam. Lythraceae. Bl. heterochlam. oder apopetal, 3-16-, meist 4- bis 6 gliederig, ఫ̧, $\oplus$ oder $\%$. Bl.-Axe schüsselfg, bis langröhrig. K. klappig, mit Nebenb. zwischen sich; P. am Rande der hohlen Axe, bisweilen 0 . Stb. doppelt so viel als P. oder $1-\infty$, etwas tiefer als die P. Cp. (2-6), mit je $\infty-2$ Sa.; G. frei, meist $2-6$-, selten 1 fächerig mit 1 wandst. Plac. (Gr.). Kapsel. S. ohne Nährgewebe. - Kr. und to mit ungeteilten, ganzrandigen B.; Nebenb. kiein; Bl. in Trauben oder Dichasien oder Rispen. - Narkständiges Leptom. - 250 temp., calid., zahlreich in $\mathrm{Am}$.

§ Lythreae. Scheidewände des G. oberwärts unvollständig. - Ammannia (30 calid.). - Peplis (3 *). -- Lythrum (25). - Cuphere mit $\%$ Bl. (160 Am. calid.).

§ Nesaeeae. Scheidewände des G. vollständig. - Heimia (Am., Afr.). - Lagerstroemia indica (As. calid.). - Lausonia inermis (Nordafr. bis Ostind.) liefert die Henna.

Fam. Sonneratiaceae. Bl, heterochlam. oder apetal, $\not$ oder $\sigma^{7}$ ㅇ, $\oplus$. Bl.-Axe glockig. K. 4-8. I', 4-8 oder 0. Sth. $\infty$. Cp. $(4-15)$, mit der hohlen Axe vereint. (Gr.). G. gefäch. mit $\infty$ Sa. Halbfr. kapsel- und beerenartig; S. $\infty$, ohne Nährgewebe. - $\hbar$ mit gegenst. ganzrandigen B. ohne Nebenb. Bl. meist ansehnlich. - 12 trop. Afr., As. - Sonneratia caseolaris in Mangrovewäldern mit aufrechten Atmungswurzeln.

Fam. Punicaceae. Bl. heterochlam., ఫ્, 申. Bl.-Axe kreiself. K. 5-7, P. $5-7$, Stb. $\infty$, Cp. $(\infty)$ mit $\infty$ Sa. in 2 Reihen ühereinander, mit der 
Axe völlig vereint. (Gr.). Halbfr. beerenartig, mit vielsamigen Fächern. S. gross, kantig, mit saftreicher Schale, ohne Nährgewebe. - t mit ganzrandigen B. Bl. achselständig, ansehnlich. - Markständiges Leptom. 2 Medit., Ostind., Socotra. - Punica gr'murtum, Granatapfel (medit.); off. die gerbstoffreiche Wurzelrinde.

Fam. Lecythidaceae. Bl. heterochlam., selten apopetal, ‘̧. Blütenaxe becherfg. K. meist $4-6$, selten $2-3$. P. 4-6, selten mehr oder 0 , dachig. Stb. $\infty$ in mehreren Kreisen, hfg. teilweise steril, in der Knospe einwärts gebogen, am Grunde \pm vereint. Cp. $(2-6$, selten mohr) mit der Axe vereint, mit je $\infty-1$ umgewendeten Sa. (Gr.). Halbfr. fleischig oder holzig. S. ohne Nährgewebe. - † mit abwechselnden ganzrandigen B. ohne Nebenb. - Keine Secretzellen oder Secretlücken. Kein markständiges Leptom. Rindenständige Gefässbündel. - 130 trop.

Unterfam. Foetidioideae. P. 0. Stf. sehr schwach vereint. - Foetidia (3 malagassisch).

Unterfam Planchonioidece. P. + . Stf. alle bis zu derselben Höhe vereint. Beere ohne Deckel. - Palaeotrop. - Barringtonia (30).

Unterfam Napoleonoideae. P. 0. Die äusseren Stb. als Std. entwickelt und untereinander vereint. Beere ohne Deckel. - Napoleona (7 trop. Afr.).

Unterfam. Lecythidoideae. P. +. Stb. vereint. Beere mit deutlichem Deckel oder eine Deckelkapsel. - Lecythis (30 südam.), mehrere mit mandelartig schmeckenden S.; $J$. ollaria mit topfartigen Fr. Bertholletir (2 trop. Südam.); B. excelsa und B. nobilis lief. ölreiche, essbare S. (Paranüsse des Handels).

Fam. Rhizophoraceae. Bl. heterochlam., selten apopetal, meist $\not{q}, \oplus$. K. $3-16$, meist $4-8$, klappig. P. ebensoviel, selten 0 . Stb. $8-\infty$, meist alle fertil. Cp. meist $(2-5)$, selten (3) oder (6), meist mit der becherfg. $\Lambda x$ vereint, miit meist je 2 , seltener $4-\infty$ herabhängenden, centralwinkelst. Sa. G. selten 1 fächerig. Halbfr. $1-5$ fächerig, meist mit $1 \mathrm{~S}$. in jedem Fach. E. klein oder gross, bisweilen mit mächtigem, hypokotylem Stämmchen, welches den Scheitel der Halbfr. durchwächst und von der hängenbleibenden Halbfr. und den Keimb. sich lostrennend in den Schlamm heruntergefallen fortwächst. - t mit gegenst. B. und hinfälligen Nebenb., seltener zerstreut und ohne Nebenb. Bl. klein oder mittelgross, einzeln oder in trugdoldigen Blütenständen. - 50 trop.

Unterfam. Rhi:ophoroideae. Bl. epigynisch oder perigynisch. Gr. 1. S. mit Nährgewebe. B. gegenst. Beere, selten Kapsel.

§ Gynotrocheae. Bl. epigynisch. Placenten in den Gr. übergehend. Sa. ohne Anhängsel. - Ceriops (2 palaeotrop., an Küsten). - Rhi:olohorre mangle in den amerikanischen Mangroven; $R$. mucronata und $R$. conjugata in den Mangroven des trop. As., erstere auch im trop. Afr. Bruguiera (5 trop. As. bis Ostafr.); B. gymnorrhiza.

Unterfam. Anisophylleoideae. Bl. epigynisch. - Gr. 3-4. S. ohne Nährgewebe. Steinfr. oder Schliessfr. B. wechselst. ohne Nebenb. - Anisophyllea (5 palaeotrop.).

Fam. Combretaceae. Bl. heterochlam. oder apopetal, ̧ㅜ, oder $\sigma^{\top}$ 우, $\oplus$, mit eifg. oder röhriger Axe. K. $4-5$ (selten 6-8); P. 4-5 (selten 
6-8) oder 0; Stb. 4-5-8-10, selten $\propto ;$ (Cp.); (Gr.); G. 1 fächerig mit 2-6 vom Scheitel herabhängenden Sa. an meist langem Funiculus. Halbfr. lederartig oder steinfr.artig, hfg. 4-5 flügelig, 1 samig. Nährgewebe 0. E. mit kleinem Stämmchen. - $\hbar$, oft kletternd, mit gegenst. ganzrandigen B. ohne Nehenb. Bl. in Trauben. - Markständiges Leptom. - 240 trop. - Lumnitzera (5). - Laguncularia (1) in trop. Strandwäldern. - Terminalia (90 trop.); T. catappa in Ostind.; lief. wohlschmeckende S.; T. clebnla (Ostind. u. a.) lief. die früher als Myrobalani gebräuchlichen Fr. - Combretum. - Quisqualis (3 trop. Afr., As.); Q. indica, prächtige Liane (Ostind.).

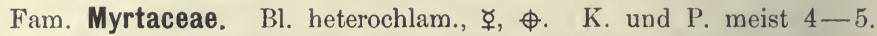
Sth. $\infty$, bisweilen in Gruppen vereint, selten in begrenzter Zahl. Cp. $(2-5-\infty)$, mit der Axe vereint, mit je $\infty-1$ Sa. (Gr.). Fr. verschieden. S. meist ohne Nährgewebe. - t mit abwechselnden oder gegenst. B. ohne Nebenb. - Stets Secretlücken. Markständiges Leptom. - 1700 calid.

Unterfam. Myrtoideae. B. gegenst. Halbfr. beeren- oder steinfr.artig. - Psidium guajava (trop. Am.), Ps. jambosa u. a. lief. angenehm schmeckende Fr. - Myrtus communis (medit.). - Pimentu officinalis (Antillen) lief. den Nelkenpfeffer oder das englische Gewürz (unreife Fr.). - Eugenia (600); E. caryophyllata (Molukken) ist die Stammpflanze der Gewürznelken (Blütenknospen).

Unterfam. Leptospermoideae. B. gegenst. oder (Q). Kapsel.

$\S$ Leptospermeae. G. $2-5-\infty$ fächerig. Halbfr. kapselartig, meist am Scheitel fachspaltig. Austral., Ostind. - Leptospermum (25). Callistemon (12). - Melaleuca (100); M. leucadendrom (ind.malay.) lief. das Kajeputöl (aus B. und Fr. destilliert). - Metrosideros. - Eucalyptus (160); E. resinifera (Austral.) lief. das Gunmiharz Kino australe; $\boldsymbol{E}$. globulus (südöstl. Austral.), über $100 \mathrm{~m}$ hoch, ist der in allen subtropischen Gebieten angepflanzte "Fieberbaum «.

§ Chamaelaucieae. G. 1 fächerig. Fr. meist 1 samig, Sträucher mit kleinen B. - Nur in Austral., mit den vorigen wesentlicher Bestandteil der Scrubs. - Etwa 140.

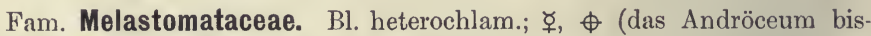

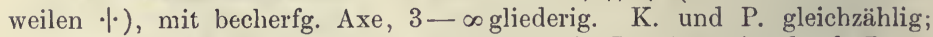
Stl. meist etwas mehr als doppelt soviel wie P.; A. meist durch Poren sich öffnend; (Cp.) frei oder \pm mit der Axe vereint; (Gr.); G. meist gefächert mit $\infty$ Sa., selten einfächerig. Kapsel, Beere oder Halbfr. S. klein, ohne Nährgewebe. $-\mathrm{Kr}$. oder $\hbar$ mit gegenst. oder quirlst., oft $3-9$ nervigen B. ohne Nebenb. Bl. hfg. ansehnlich. - Markständiges Leptom. 1800 calid., besonders Am.

Unterfam. Melastomatoideae. G. $2-\infty$ fächerig, mit $\infty$ Sa. an centralwinkelst. Plac.; Fr. vielsamig; E. klein. - Centradenia (3 Centralam.). - Sonerila (53 Ostind.). -- Medinilla (50 trop. As.); mehrere Arten dieser Gattungen in Warmhäusern. 
Unterfam. Astronioideae. G. 2-5fächerig, mit $\infty$ Sa. an basilären oder parietalen Plac.; Fr. vielsamig; E. klein. - Nur im ind. Archipel (42).

Unterfam. Memecyloidecıe. G. 1 fächerig, mit $6-\infty$ Sa. an freier Plac. oder 2-5 fächerig mit je 2 Sa. Beere 1-2 samig. E. gross. -130 .

Fam. Oenotheraceae. Bl. heterochlam., meist $\Varangle$, und $\oplus$, seltener $\%$. Axe röhrig. K. $2-4$ (selten $5-6$ ); P. 2-4, selten 0; Stb. 4-8 (selten $1,2,6,12)$, bisweilen teilweise Std.; Cp. meist (4) mit der Bl.axe vereint, selten $(1-6)$, mit je $1-\infty$ Sa.; (Gr.). Halbfr. verschieden, meist mit vielen S. Nährgewebe wenig oder 0 . - Meist $\mathrm{Kr}$. mit gegenst. oder wechselst. B. ohne Nebenb. Bl. achselst. oder traubig. - Meist markst. Leptom. - 300 temp., subtrop., wenige trop.

$\S$ Trapeae. G. nur halbunterst., 2 fächerig. Halbfr. 2-4 dornig. Tropa nutuns (Wassernuss) mit essbaren $\mathrm{S}$.

\$ Oenothereae. G. unterst., 4-1 fächerig. - Epilobium (100). - Jussiaer (30 trop.). - Oenothera (100 Am.). - Fuchsir (50 Am., Neu-Seeland). - Lopesia coroncta (Mexiko) mit 1 Stb. und 1 Std., ausgezeichnet proterandrisch. - Circaea (2*).

3. Unterreihe Halorrhagidineae. Bl. stets epigyn. Cp. nur mit 1 Sa, diese mit nur 1 Integument.

Fam. Halorrhagidaceae. Bl. heterochlam. oder hfg. apetal, $\not$ oder $\delta^{7}$ 우 $\oplus, 4-$, seltener 3-, 2-, 1 gliederig; Stb. doppelt soviel als K. oder weniger, bisweilen nur 1; Cp. (4), bisweilen nur 1, mit der becherfg. Axe vereint, mit je 1 hängenden Sa.; Gr. getrennt. Halbfr. nuss- oder steinfr. artig. S. mit Nährgewebe. - Kr. von durchaus verschiedener Tracht; Bl. unansehnlich. - Kein markst. Leptom. - 94 temp., subtrop.

$\$$ Halorrhagidear. P. $2-4$ oder 0 . Cp. $(2-4)$ mit je 1 Sa. Serpicula (2-4 calid.). - Myriophyllum (15 calid. - frigid.). - Halorrhagis (40, meist *). - Proserpinaca (2 Am.).

$\S$ Gunnerear. P. 0 . Cp. (2) mit 2 Gr. und zusammen mit nur 1 Sa. - Gummera (11 zerstreut, meist *); G. chilensis in Eur. cult.

$\S$ Hippureae. P. 0. Cp. 1 mit 1 Gr. und 1 Sa. - Iiplmris rulgaris (* und Südain.).

4. Untcreihe Cynomorimeae. Bl. epigyn. mit nur 1 Stb. Cp. 1 mit 1 Sa., diese mit 1 Integument. Wurzelparasiten.

Fam. Cynomoriaceae. Bl. $\Varangle, \sigma^{\top} 11 . ~ q$ mit Blb. $\Varangle$ mit 1 epigyn. stehendem Stb. G. mit 1 hängenden Sa. - Rhizom stärkehaltig. Cymomorium coccineum, Hundskolhen, Malteserschwamm (auf Halo. phyten in dem littoralen Mittelmeergebiet und den Salzgebieten Westasiens).

26. Peihe UMBELLIFLORAE. Bl. cyklisch, heterochlam., meist haplostemon, epigynisch, $5-4 \cdot$, seltener $\infty$ gliederig, meist $\Varangle, \oplus$. Cp. $(5-1)$

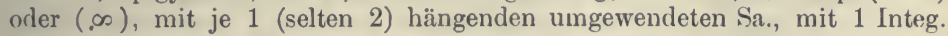
S. mit reichlichem Nährgewebe; Bl. meist in Dolden.

Fam. Araliaceae. Bl. meist 5-, seltener $3-\infty$ gliederig, hisweilen mit undeutlichem K. Stb. selten mehr als P. Cp. $(1-\infty)$. Halbfr. beeren- 
artig oder steinfruchtartig mit $1-\infty$ getrennten Steinkernen. - $\hbar$, selten $\mathrm{Kr}$., mit (Q), selten gegenst., ungeteilten oder handfg. oder fiederig geteilten oder zusammengesetzten B., hfg. mit Nebenb. Bl. selten einzeln, meist in Köpfchen, Dolden oder Ähren, welche zu Trauben oder Rispen vereint sind. Ölgänge in Stengeln und anderen Teilen. - 400 meist calid.

§ Schefflereae. P. klappig. Nährgewebe der S. gleichartig, bisweilen zerklüftet. - Fatsiajaponica (Japan), Zimmerpflanze. - Tetrapanax papyrifer (Formosa); aus dem Mark wird das chinesische » Reispapier « hergestellt. - Schefflera (etwa 80 trop.). - Oreopanax (40 trop. Am.). Hedera (Eur., As.); H. helix, Epheu, bitter aromatisch. - Acantlopanax (12 Ostas.). - Cussonia (23 trop., subtrop. Afr.).

§ Aralieae. P. \pm dachig, mit breiter Basis sitzend. - Arctir (30 *). - Panax; $\bar{P}$. ginseng (Mandschurei, Korea, cult. in Japan), Stammpflanze der in China als Universalheilmittel hochgeschätzten Gin sengWurzel; P. quinquefolius (nordöstl. Am.) weniger geschätzt.

§ Mackinlayeae. P. kurz genagelt, klappig. - Austral.

Fam. Umbelliferae. Bl. 5 gliederig, haplostemon, mit oft undeutlichem K. und 2 medianen Cp., meist $\not{q}, \phi$, bisweilen $\%$. Epigynischer Discus am Grunde der 2 Gr. Halbfr. eine Spaltfr; die Teilfr. am Carpophor hängend; jede mit 5 Hauptrippen (3 dorsale, 2 seitliche; Carinalrippen, Commissuralrippen) und bisweilen noch 4. Nebenrippen; zwischen den Rippen die Thälchen. Meist Ölstriemen in den Thälchen oder Nebenrippen und je 2 oder mehr an der Fugenseite. E. klein, oben im hornartigen ölreichen Nährgewebe. $-\odot$ und $4 \mathrm{Kr}$. mit Pfahlwurzel oder Rhizom, hohlem Stengel und (9) B., meist mit grosser Blattscheide und mehrfach geteilter Spreite. - Bl. klein, meist in einfachen oder zusammengesetzten Dolden. Ölgänge in Stengel und Wurzeln. - 1300 temp., besonders *.

Unterfam. Hydrocotyloideae. Halbfr. mit holzigem Endocarp aus Faserzellen, ohne freies Carpophor. Ölstriemen fehlend od. in den Hauptrippen eingesenkt, keine in den Riefen.

§ Hydrocotyleae. Halbfr. mit schmaler Fugenfläche und weit vorspringender Rückenkante in 2 von der Seite stark abgeflachte Teilfr. zerfallend. - Hydrocotyle (78, meist*).-Azorella (35*); A. Gilliesii (auf den peruanischen Anden) lief. Bolaxharz.

§ Mulineae. Teilfr. mit abgeflachtem od. abgerundetem Rücken, gegen die Fugenfläche hin breiter. - Fast alle * - Bowlesia (12, davon 1 bis Mexiko, 1 auf den Canaren).

Unterfam. Saniculoideae. Teilfr. mit weich parenchymatischem Endocarp; Exocarp selten glatt. Gr. lang mit kopfförmigen N., von einem ringförmigen Discus (Stylopodium) umwallt. Ölstriemen verschieden.

$\S$ Saniculeae. Frkn. 2 fächerig. Halbfr. 2 samig mit breiter Fugenfläche. Ölstriemen vorhanden. - Eryngium (150 calid. und temp.) - Astrantia (5 Eur., As.). - Hacquetia (1 Südeur.). - Sanicula (10). § Lagoecieae. Frkn. $1 \mathrm{fächerig,} \mathrm{mit} 1 \mathrm{Sa}$., seltener schief $2 \mathrm{fächerig.}$ Halbfr. stets 1 samig. Ölstriemen undeutlich. - Lagoecia cuminoides (medit.). - Petagnia sicula mit interessanter Inflorescenz.

Unterfam. Apioidecue. Teilfr. mit weich parenchymatischem Endo. carp, zuweilen durch subepidermale Holzschichten nussartig verhärtet, Gr. 
auf der Spitze des Stilopodiums stehend. Ölstriemen in den jungen Riefen angelegt, später verschiedenartig ausgestaltet.

A. Hauptrippen + vorspringende Leisten bildend, die seitenstandigen ebenfalls leistenförmig oder flïgelartig verbreitert; Riefen nur durch ölstriemen ausgezeichnet (Haplozygieae).

a. Die Doldenstrahlen tragen je 1 bis wenige sitzende $ᄋ \mathrm{Bl}$. und um dieselben herum einen Kranz von $\sigma^{T} \mathrm{Bl}$.

Echinophoreae. Gr. lang. Halbfr. von den erhärteten Stielen der $\sigma^{7}$ Bl. umhüllt. Von den Cp. 1 steril. - Echinophora (8 medit.).

b. Bl. alle ఫ̧ oder unregelmässig polygamisch.

a) S. an der Fugenfläche durch die Raphewucherung tief gefurcht oder hohl.

$\S$ Scandicineae. Parenchym in der Umgebung des Carpophors mit Krystalldrusen.

* Scandicinae. Halbfr. lang cylindrisch und geschnäbelt, glatt oder kurzstachelig. - Myrrhis odorata (Eur.). - Chrerophyllum (30*); Ch. temulum (Eur.) giftig; Ch. Bulbosum (Eur., As.), dem Schierling ähnlich, mit knolligen, essbaren Wurzeln. - Anthriscus (10); A. cerefolium, Kerbel (medit.), Küchengewürz. - Scandix (15 medit.). Molopospermum (1 subalp.).

* Cancalinae. Halbfr. eiförmig-abgeflacht kugelförmig, über den Riefen mit zusammenhängenden Stachel- und Borstenleisten. - Caucalis (incl. Turgenia 5, Mittel- und Südeuropa, Orient). - Torilis (23 medit., Afr.).

$\$$ Coriandreat. Parenchym in der Umgebung des Carpophors ohne Krystalldrusen. Halbfr. kugelig-eiförmig, selten länglich, nussartig, mit holzigen Schichten unter der anfangs glatten Epidermis. - Coriandrum srativum Koriander (medit.), Gewürz. - Bifora (4 medit., subtrop.); $B$. testiculata und B. radians, Halbfr. ebenfalls Gewürz.

$\S$ Smyrnieae. Halbfr. mit 2 an schmaler Fugenfläche zusammenlıängenden Teilfr., nach aussen eirund-gewölbt. - Smyminum (7 medit.). - Conium marulatum, Schierling (*), giftig. - Mrangos (36 mediterran-oriental.), mit sehr grossen Teilfr., desgl. Cachrys; beide gewürzhaft.

3) S. an der Fugenfläche geradlinig abgeflacht, oft mit etwas gegen das Carpophor vorspringender Raphe.

$\S$ I mmineae. Die Randrippen und 3 rückenständigen Rippen gleichartig. S. im Querschnitt halbkreisförmig, mit breit entwickeltem Nährgewebe.

* Carinae. Rippen schwach vorspringend, Teilfr. mit schmaler Fugenfläche. - Bupleurum (90 meist Eur., As., Nordafr.). - Cuminum cyminum (ostmedit.); S. lief. ein off. ätherisches Öl. - Apium (14); A. graveolens, Sellerie (auf Salzboden wild). - Petroselinum sativum, Petersilic (medit.), Küchenkrant. - Cicutu virosı, Wasserschierling, giftig. - Ammi (2 medit.). - Falcaria (1 Eur.). - Cиюиm crrri, Kümmel (Eur.), lief. d. off. Fructus Carvi; C. bulbocastanum mit 1 Keimb. - Aegopodium (1 Eur., As.). - Pimpinella (70); 
P. anisum (östl.-medit.) lief. Fruct. Anisi vulgaris und die off. Radix Pimpinellae. - Sium (4).

* Seselinae. Rippen stärker und zuweilen flügelartig, die randständigen Rippen verbreitern die Fugenfläche beider Teilfr. - Athamanta (Eur., As.). - Seseli $\left(60_{*}^{*}\right)$. - Foeniculum (3 medit.); F. vulgare, Fenchel, d. junge Kraut als Gemüse genossen, off. die Fructus Foeniculi, lief. Fenchelöl. - Oenanthe $(35 *)$. - Aethusa cynapium, Hundsdolde (Eur., Sibir.), giftig, oft mit Petersilie verwechselt. - Meum athamanticun (subalpin) mit gewürzhafter Wurzel. - Tigusticum mutellina, Hochgebirgspfl. von Eur., gute Futterpfl.

\& Peucedaneae. Randrippen viel breiter als die oft nur schwachen 3 rückenständigen Rippen, an beiden Teilfr. Randflügel bildend. S. im Querschnitt schmal.

* Angelicinae. Randflügel getrennt: klaffend. - Levisticum officinale, Liebstöckel (Südam.); off. d. Radix Levistici. - Angelica (18 * Neu-Seeland). - Archangelica (5*); A. officinalis (Eur.) lief. die scharf aromatische Radix Angelicae sativae.

* Ferulinae. Halbfr. durch die fest auf einander gefügten Randrippen doppelt flügelförmig berandet. - Femula (60 medit. und Centralas.); F. narthex und $\boldsymbol{F}$. asa foetida (Ostpers., Afghanistan) lief. Stinkasand, Asa foetida; F. mubricaulis (Südpersien) lief. das Gummi Galbanum. - Dorema ammoniacum (Nordpersien) lief. das Gummi Ammoniacum. - Peucedanum (100); $P$. ostruthium, Meisterwurz (eur. Gebirge), lief. d. off. Radix Imperatoriae; P.graveolens, Dill (medit.), Gewürzpfl.; P. sativum, Pastinak (Eur.).

* Tordyliinae. Halbfr. mit verhärteten, gemeinsam verdickten Flügelrändern. - Heracleum (70*). - Tordylium (12*).

B. Nebenrippen über den Ölstriemen zu den Hauptrippen gleich. artigen oder sie an Grösse übertreffenden Leisten und Flügeln entwickelt (Diplozygieae).

\& Laserpitieae. Nebenrippen sehr hervortretend und oft in breite ungeteilte oder nur gewellte Flügel erweitert. - Laserpitium (20*). Siler (Eur., As.). - Thapsia (4 medit.).

\$ Dauceae. Nebenrippen mit freien Stacheln oder Stachelleisten. Daucus (50 *); D. carota, Möhre (Eur.).

Fam. Cornaceae. Bl. 4-5- $\infty$ gliederig, meist haplostemon, seltener diplostemon bis tetraplostemon, bisweilen $\sigma^{\top}$.. Cp. (4-1) mit epigynischem Discus, mit je 1, sehr selten $2 \mathrm{Sa}$. Halbfr. 1-4 fächerig, mit 1-4 S. - † oder kleine Sträucher mit gegenst. oder (9) ganzrandigen, selten gelappten B. ohne Nebenb. und kleinen in Trugdolden, Rispen oder Köpfchen stehenden $\mathrm{Bl}$. -100 , meist $*$.

Unterfam. Garryoideae. $\overline{\text { G. }} 1 \mathrm{fächerig} \mathrm{mit} 2$ die Mikropyle nach aussen und nach der parietalen Placenta kehrenden Sa. $\mathrm{Bl} . \sigma^{\top}$, , in kätzchenähnlichen Rispen. - Garrya (12 atlant. Nordam., Mexiko).

Unterfam. Nyssoideae. G. meist 1 fächerig mit $1 \mathrm{Sa} . \mathrm{Bl} . \sigma^{\top}$ \% in gedrängten Trauben, Dolden oder Köpfchen. - Nyssa (6 Himal., Ostas., atlant, Nordam.). 
Unterfam. Duvidioidere. G. 6-10facherig, mit je $1 \mathrm{Sa}$. $\sigma^{7} \mathrm{Bl}$. ohne Blh.,

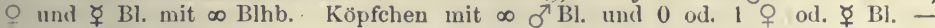
Davidia (China).

Unterfam. Alangioideae. G. 1-2 fächerig, mit je 1 Sa. P. 4-10. Bl. ̧․ Alangium (15 palaeotrop.).

Unterfan. Mastixioideae. G. 1 fächerig, mit 1 Sa. Bl. ̧. . Steinkern mit tiefer Längsfurche. - Mastixia (12 trop. As.).

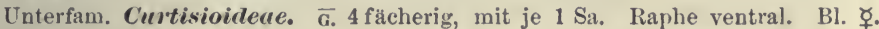
- Curtisia (1 Suidafr).

Unterfam. Comnoiderte. $\bar{G} .1-5$ fächerig, mit je 1 Sa. Raphe (lorsal. Bl. ఫ̧ od. $\sigma^{\top}$ 우. - Cornus (30 * und andin); C. mus, Cornelkirsche (unittl. und südl. Eur.). - Auculbu (Himal., China, Japan); A. juporice. - Heleingic (2 Himal., China, Japan); H. rusciflor, mit auf der Mitte der Blattnerven sitzenden Bl.

2. Unterklasse METACHLAMYDEAE oder SYMPETALAE (fälschlich Monopetalae). Blütenumhüllung auf vorgeschrittener Stufe, stets der Anlage nach doppelt und die innere Hülle verwachsemblätterig (bei einzelnen Formen jedoch im Gegensatz zur grossen Mehrzahl ihrer nächsten Verwandten getrenntblätterig oder fehlend).

a. Veben sympetalen Blkr. kommen anch noch bisweilen getrenntblatterige Blkr. vor. 2 Staubblattquirle oder nur eimer. Iypogynie vorheri'schend, seltener Epigynie.

1. Reihe ERICALES. Bl. 5-4 gliederig, obdiplostemon oder die vor (len P. stehenden Stb. nicht entwickelt, ㅎ, meist $\oplus$. P. frei oder (P.). Stb. hypogyn oder epigyn, seltener am Grunde mit den (P.) vereint. Cp. $2-\infty$, bei Gleichzähligkeit meist vor den P. G. bis $\bar{G}$. Sa. mit 1 Integ. - to und Kr. mit einfachen B.

Fam. Clethraceae. Bl. 5 gliederig, obdiplostemon, 오, $€$. P. frei. Stb. lyypogyn. Cp. (3) mit je $\infty$ umgewendeten Sa. - Gr. lang mit 3 N. Kapsel 3 klappig, die Seheidewăncle auf der Mitte der Klappen von der Mittelsäule abgelöst. S. mit sackartig lockerer Aussenschale und fleischigem Näbrgewebe um den cylindrischen E. - t mit (9) B. und in Trauben stehenden Bl. - Clethra (25 Kanaren, Nordam., Ostas.).

Fam. Pirolaceae. Bl. 5-4 gliederig, obdiplostemon, ఫ, $申$. P. frei oder vereint. Stb. hypogyn. Cp. (5-4), mit je $\infty$ sehr kleinen Sa. an dickfleischigen Plac. Kapsel fachspaltig. S. mit lockerer, sackartiger Aussenschale und fleischigem Nährgewebe. E. wenigzellig, ohne Keimb. 4 immergrüne oder chlorophylllose $\mathrm{Kl}$. mit (9) B. und endst. Trauben oder Finzelbl.

Unterfam. Piroloidecte. A. vor der Blütezeit zurückgebogen, dann aufrecht mit 2 Poren aufspringend. Pollentetraden. P. getrennt. - Chimoplicil (4*). - Pirolı (15*).

Unterfam. Monotropoidece. A. auf der Spitze der Stb. aufrecht, mit einer ring. oder hufeisenfg. Spalte oder mit 2 Längsspalten. Pollen einfach.

$\S$ Monotropeae. G. unten 4-5fächerig, oben 1 fächerig. -- Monotropr (3*); $\boldsymbol{M}$. Iypopitys, Fichtenspargel (*). - Andere Gattungen in Nordam. 
\$ Pleuricosporeae. G. 1 fächerig mit 1 wandst., in 2 Lamellen umgebogenen Plac. - 3 Himalaya und pacif. Nordam.

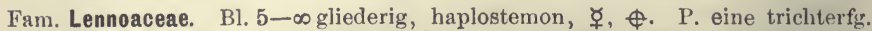
Röhre bildend, die Stb. erst am Schlund der Röhre frei; A. mit Längsspalten. Pollen einzeln. Cp. (6-14) mit je 2 Sa, jedes Cp. mit einer falschen Scheidewand. Steinfr. mit 12-28 1 samigen Steinkernen. Nährgewehe reichlich... E. kugelig. Wurzelparasiten ohne Chlorophyll, bräunlich, mit $\infty$ Bl, in einer Ähre oder Rispe mit wickelfg. Ästen oder in einem Becher. - 4 Südkalif., Mexiko.

Fam. Ericaceae. Bl. 5-4 gliederig, obdiplostemon, §̧. P. selten frei, meist vereint und Stb. am Aussenrand einer hypogynen oder epigynen, zwischen den Kelchzipfeln ausgebreiteten Scheibe. Thecae der A. frei und oben oft spreizend. Pollentetraden. (Cp.) mit je $1-\infty$ umgewendeten oder amphitropen Sa. an den centralwinkelst. Plac. (Gr.) mit kopffg. N. Beere, Steinfr., Kapsel. S. mit sackartiger Aussenschale und reichlichem Nährgewebe. E. oft sehr kurz. - $\mathbf{t}$, meist Halbsträucher oder Sträucher mit (9), gegenst. oder quirlst., meist immergrünen B. und einzeln oder in Trauben stehenden Bl. - Etwa 1350 frigid.-calid.

A. Scheidewandspaltige Kapsel. P. frei oder (P.). Stb. mit aufrechten oder lang angewachsenen A. ohne borstige Anhängsel. S. mit lockerer Schale.

\section{Unterfam. Rhododendroideae.}

§ Ledene. P. frei. S. lang geflügelt. - Befaria (15 Am., meist andin). - Ledum (2*); L. palustre, Sumpfporst.

$\S$ Rhododendreat. (P.) trichterfg. oder glockig, schwach $\%$. S. flach, von den Flügeln breit umsäumt. E. cylindrisch. - RhorloAendron (incl. Azalea 200, frigid.-calid., excl. Afr.). - Menziesia (7 Ostas., Nordam.).

§ Phyllodoceae. (P.), selten P. frei. S. rundlich oder 3 kantig. E. cylindrisch. - Loiseleuria procumbens (circumpolar-alpin). - Rhodothamnus (1 alp.). - Kalmia (6 Nordam.). - Phyllodoce (6 Nordam., 1 circumpolar). - Bryanthus (1 Nordwestas.). - Daboecia (1 atlant. Eur.).

B. Beere oder fachspaltige Kapsel. (P.). A. mit borstenfg. Anhängseln oder in lange Röhren vorgezogen. S. dreieckig. rundlich, eifg.

Unterfam. Arbutoideae. G. frei.

$\S$ Andromedeae. Trockene fachspaltige Kapsel. - Cassiope (* frigid.). - Leucothoë (32, meist Am.). - Andromeda (5*). - Lyonia (16 *); I. calyculata vom nordöstl. Deutschland bis Nordam. - Epigaea (2 atlant. Nordam.).

§ Gaultherieae. Beere oder Kapsel, von dem fleischig auswachsenden K. umhüllt. A. oberhalb der Poren stumpf oder in 2 kurze, aufrecht grannenartige Fortsätze auslaufend. - Gaultheria $(90-100 *$ und Ostas., Nordam.). - Pernettya (26, meist * und andin).

§ Arbuteae. Beere oder Steinfr. A. mit 2 langen, abgegliederten und herabgebogenen Anhängseln. - Arbutus (20 * subcalid.); A. unedo und A. andrachne, Charakterbäume der Macchien im Medit. - Arctostaphylos (18*); A. uva ursi lief. d. off. Folia Uvae ursi. 
Unterfam. Taccinioidecie. G.

§ Vaccinieae. (P.) krugfg., glockig oder radig. Stb. getrennt. $\overline{\text { G. }}$ vom Blütenstiel scharf abgesetzt. - Gaylussaccia (40 Am.). - Vaccinium, (100); V.myrtillus, Heidelbeere und V.vitis idnen, Preisselbeere; V.oxycoccus, (alle *); V.macrocarpum (Nordam. und Westeur.).

§ Thibaudieae. (P.) aus bauchigem Grunde röhrig oder lang cylindrisch. lederig fleischig. Stl. getrenut oder zu einer Säule verwachsen. G. voin Blittenstiel selten abgegliedert. - 162 meist in Gebirgen der Trop.

C. Kapsel scheidewandspaltig oder fachspaltig oder Nuss. S. rundlich, ungeflügelt. (P.), nach dem Blähen trockenliäutig, bleibend. Thecae spreizend, oben mit Löchern aufspringend, hfg. mit sclıwanzfg. Anhängseln an der Rückenseite der Connective.

Unterfam. Evicoideae.

\$ Ericeae. Cp. mit os Sa.; Kapsel vielsamig. - Culluna vulyaris, Heidekraut (Eur. und Küsten von Nordam.). - Erica (420, zum grössten Teil in der Kapkolonie, wenige medit. und im westl. Eur.). Südwestafr.

§ Salaxideae. Cp. mit je 1 Sa. oder G. Ifácherig mit 1 Sa. - 96 nur in

Fam. Epacridaceae. Bl. 5-4 gliederig, haplostemon, ఫ̧, ๑. (P.). Stb. mit der Röhre der Blkr. vereint oder am Rande des hypogynen Discus; Thecae mit gemeinsamem Längsspalt. Cp. meist (5), mit je $1-\infty$ Sa. an centralwinkelst. Plac. (Gr.) mit kopffg. N. 5 klappige Kapsel oder Steinfr. mit 1-5 samigen Kernen. E. cylindrisch im Nährgewebe. Sträucher oder Halbsträucher mit (?) starren, ganzrandigen, sitzenden B. und meist in Trauben stehenden Bl. - Etwa $320^{*}$, zumeist in Austral.

§ Prionoteae. Cp. mit $\infty$ Sa. Fachspaltige Kapsel. Stb. hypogyn. - Lebetanthus (Feuerland).

§ Epacrideae. Wie vorige, aber Stb. mit der Blkr. vereint. - Dracophyllum (20 Neu-Seeland. Nen-Caledon., Austral). - Epacris (30 wie vorige).

\$ Styphelieae. Cp. mit je $1 \mathrm{Sa}$. Fr. geschlossen. - Styphelia (172 Austral.).

Fam. Diapensiaceae. Bl. 5 gliederig, obdiplostemon oder haplostemon, 후, $\emptyset$. (P.). Stb. am Schlunde oder Grunde der Blkr.röhre, 5 unfruchtbare von den P. oder fehlend. Cp. (3) mit je $\infty$ umgewendeten Sa. an centralwinkelst. Plac. (Gr.). Kapsel 3 fächerig, fachspaltig. E. cylindrisch im Nährgewebe. - Niedere Halbsträucher oder $4 \mathrm{Kr} .9$ *

\$ Galaceae. 5 Stb. und 5 Std. - Schizocodon (2 Japan). - Galax (1 atlant. Nordam.). - Shortia (1 Japan, 1 atlant. Nordam.).

\$ Diapensieae. $5 \mathrm{Stb}$, - Diapensin lapponic", cireumpolar.

2. Reihe PRIMULALES. Bl. 5 gliederig (selten 4-8gliederig), typisch diplostemon, doch meist haplostemon mit epipetalen Stb., ̧ㅜ oder $\delta^{\top} 0, \oplus$, selten $\%$. P. sehr selten frei, meist (P.). G. bis $\bar{G}$., 1 fächerig mit $\infty-1$ Sa. an der basilären oder freien Plac., mit $\overline{2}$ Integ.

Fam. Theophrastaceae. Bl. $\subsetneq$ oder $\sigma^{\top}$ ㅇ, $\oplus$. (P.). Ausser den 5 Stb. noch $5 \mathrm{Std}$. G. 1 fächerig mit $\infty \mathrm{Sa}$. an der meist freien, selten basilären Plac. Fr. steinfruchtartig, mit $\infty-2 \mathrm{~S}$. Nährgewebe + . - t mit (9), hfg. an der Spitze des Stammes oder der Zweige zusammengedrängten lanzettlichen B. ohne Nebenb. - Etwa 40 trop. Am. und Sandwichinseln. - Theophrasta. - Clavija; Wurzeln emetisch.

Fam. Myrsinaceae. Bl. $\not$ oder $\sigma^{\top} q, \oplus$. (P.). Ausser den 5 Stb. nur selten noch Std. G. bis $\bar{G}$., 1 fächerig mit $\infty$ Sa. an der basilären oder freien Plac. (Gr.). Fr. meist steinfruchtartig, mit 1 bis wenigen $\mathrm{S}$. 
E. von fleischigem oder hornigem Nährgewebe umhüllt. - t mit (9), hfg. immergrünen, ungeteilten B. ohne Nebenb. - Schizogene Harzgänge. Etwa 1000 calid.

Unterfam. Maesoirleae. $\overline{\mathrm{G} .}$ oder halbunterst. Fr. vielsamig. - Maesa (102 palaeotrop).

Unterfam. Myrsinioideae. G. Std. 0. Fr. 1 samig. - Myrsine (80 trop. As., Afr.).

$\S$ Ardisieae. Sa in mebreren Reihen. - Ardisia (240 trop.); A. crenulaı mit aus der Beere herauswachsenden Embryonen. - Aegireras majus an den trop. Meereskiisten der alten Welt, mit aus der Fr. herauswachsendem Embryo und quergefächerten $\mathrm{A}$

$\S$ Myrsineae. Sa. in einer Reihe wenige. - Embelia (90 palaeotrop.). - Myr. sine (4 palaeotrop.). - Rapanea (136 trop.).

Fam. Primulaceae. Bl. ఫॄ, $\emptyset$, selten $\%$ Ausser den 5 epipetalen Stb. selten noch 5 episepale Std. G., selten halbunterst., 1 fächerig mit $\infty$ quirlig oder spiralig stehenden $\overline{\mathrm{Sa}}$. an der freien Plac. Kapsel mit zusammengedrückt-kantigen S. E. im fleischigen Nährgewebe. - Kr. mit meist (a) B. ohne Nebenb. - Etwa 350 temp.-frigid., wenige calid.

A. Bl. $\oplus$. K. nicht stachelig.

a Abschnitte der (P.) aufrecht oder abstehend.

§ Primuleat. Knospenlage der P. quincuncial. G. - Primula (etwa 300 , zumeist * in Gebirgen). - Aretia (12 alp., arkt.). - A $\boldsymbol{\text { - }}$ Arosace $(70 *)$. - Cortusa (Alp. bis Himalaya). - Soldanella (4 Eur. alp.). - Hottonia palustris (Eur., Sibir.).

Samoleae. Knospenlage der P. quincuncial. G. halbunterst. - Samolus $(8$, meist $*)$.

\$ Lysimachieae. P. in der Knospe gedreht. - Lysimachia (60 temp.). - Naumburgia thyrsiflora (*). - Trientalis ( 2 *). Glaux maritima (SalzpH. *). - Anayallis (12). - Centunculus (3).

b. Abschnitte der (P.) zurückgeschlagen.

$\S$ Cyclamineae. - Cyclamen (10 alpin und medit.). - Dodecatheon ( 5 Nordostas. und Am.).

B. Bl. $\%$ K. stachelig.

$\S$ Coridene. - Coris monspeliensis (medit.).

Fam. Plumbaginaceae. Bl. haplostemon, ఫ̧. P. frei oder (P.). Cp. (5) mit $5 \mathrm{Gr}$. G. mit 1 umgewendeten Sa. an langem Funiculus. E. in mehligem Nährgewebe. - Sträucher oder Halbstr. oder $4 \mathrm{Kr}$. mit ungeteilten ganzrandigen B. und meist zusammengesetztem Blütenstand. Oberhaut hfg. mit Wasser oder Kalk absondernden Drüsen. - Etwa 260.

§ Plumbagineae. Blütenstand meist einfach, ährig bis traubig. Stb frei. Gr. nur oben frei. Meist $4 \mathrm{Kr}$. oder Sträucher. - Plumbago (10 calid).

\$ Staticeaө. Blütenstand aus Wickeln zusammengesetzt. Stb. mit den (P.) vereint. Gr. nur am Grunde vereint. - Acantholimon (80 östl. medit.). - Armeria (50 * und andin). - Statice (120, meist an Küsten und in Salzsteppen).

b. Nnr Sympetalie; aber dio Zahl der Stb. bisweilen sehr gross: häufig 3 und 2 Quirle derselben, seltener nur einer. Hypogynie vorrherrschend.

3. Reihe EBENALES. Bl. diplostemon oder triplostemon oder durch Abort haplostemon, selten mit $\infty$ Stb. (P.). G. gefächert mit centralwinkelst. Plac. mit 1 bis wenigen Sa. in den Fächern. - t mit einfachen $B$. 
1. Unterreihe Sapotineae. G. oberständig, vollkommen gefächert, in den Fuchern mit je 1 aufsteigenden Sa., mit 1 Integ.

Fam. Sapotaceae. Bl. meist ఫ̧. K. 4-8, selten mehr, in 2 Quirlen. P. ebensoviel als $\mathrm{K}$. in einem Quirl oder doppelt soviel in 2 Quirlen, bisweilen mit seitlichen Auszweigungen oder mit rückenst. Anhängseln. Stb. in 2 oder 3 Quirlen, entweder alle fertil oder die äusseren zwischen den P. stehenden blumenblattartige Std. oder ganz fehlschlagend. (Cp.) ebensoviel oder doppelt soviel als in einem Kreis Stb., mit je 1 am Grunde oder an Centralwinkel stehenden umgewendeten aufsteigenden Sa. (Gr.) nit unscheinbarer N. Beere. S. mit mehr oder weniger erweiterter Ansatzfläche am Grunde oder an der Innenseite, im übrigen mit glatter, glänzender Schale. Ölreiches Nährgewebe + oder 0 . - t mit (2) einfachen, meist ganzrandigen, fiedernervigen B. Zahlreiche in geraden Reihen angeordnete Secretschläuche in Pinde, Mark und B. - Etwa 370 trop.; ausgezeichnete Nutzpflanzen.

§ Palaquieae. (P.) ohne rückenständige Anhängsel.

* Illippinae. Stb. in 2 oder 3 Kreisen, im letzteren Fall die äusseren Std. - Hierher volzügliches Guttapercha liefernde Arten: Puyena (16 ind.-malay.); P. Leevii. - Paluruium (50 ind.-malay.); P. olllongifolium (Malakka bis Sumatra), P. guttu (Singapore, ausgerottet), P. borneense (Borneo), P. Treubii (Banka). - Tllippe (30 ind.malay.) mit Öl liefernden S., besonders I. butyracea; die Bl. von I. latifolia Nahrungsmittel. - Omplıalocarpum (Westafr.).

* Sideroxylinue. Stb. in 2 Kreisen, aber nur die epipetalen fertil. - Acheres sapote, Breiapfel, Sapotillbaum (trop. Am., cult.). - Butyrospermum Purkii (trop. Afr.) liefert die Sheabutter. - Vitellaria (15 trop. Am.); mehrere Arten lief. essbare Fr., besonders V. mammosa. - Sideroxylon (80 calid. Afr., As.). - Argania sideroxylon (Marokko) lief. Eisenholz und Öl.

* Chrysophyllinae. Stb. in 1 Kreis. - Chrysophyllum (60 trop., meist Am.); C. cainito, Sternapfelbaum (Antill.); C. monopyrenum u. a. Ol)stbäume der Tropen.

§ Mimusopeae. (I’) am Rücken mit 2 einfachen oder vielfach geteilten Anhängseln. - Mimusops (35); M. bulatı (Guiana) lief. Guttapercha; andere Arten geben öl.

2. Unterreihe Diospyrineae. G. oberständig oder halbunterständig, oben nicht gefüchert. Sa, mit 2 Integ.

Fam. Ebenaceae. Bl. 3-mehrgliederig, meist $\sigma^{\pi} \circ$, seltener $\xi . \mathrm{K}$. bleibend, nach der Blütezeil oft vergrössert. (P.) mit gedrehter, selten klappiger Knospenlage. Stb. in den $\not{q}$ und $\sigma^{7}$ soviel als P. oder doppelt soviel oder inehr, am Grunde der Blh. frei oder zu 2 bis inehreren unter sich vereint; in den $q \mathrm{Bl}$. meist Std. Cp. $(2-16)$, init je $1-2 \mathrm{um}$. gewendeten hängenden Sa.; Gr. ganz frei oder unten vereint. Neist Beere mit 1 bis wenigen S. S. mit reichlichem, häufig zerklüftetem Nährgewebe und axilem E. - t mit (9), selten gegenst., ganzrandigen B. ohne Nebenb. und einzelnen achselst. Bl. oder armblütigen Trugdolden. - Schr hartes und schweres Kernholz. - 283 calid. - Royena (13 Südafr.). - 


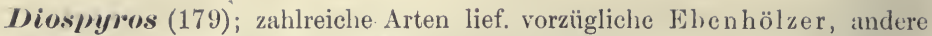
essbare Fr., namentlich I. kuki (Japan, China).

Fam. Symplocaceae. Blïte meist 5 gliederig, meist ఫ̧. P. soviel als K. oder doppelt soviel, \pm vereint: Stb. in 1-3 Quirlen, in den $\not+$ alle fertil und mit den (P.) vereint. Cp. (5-2), mit je 2-4 umgewendeten hängenden Sa. G. oder halboberst. (Gr.). Steinfr. mit 2-5 fächerigem Steinkern mit 1 samigen Fächern. E. in Nährgewebe. - Symplocos (etwa 150 calid., trop).

Fam. Styracaceae, Bl. 5-4 gliederig, ఫ̧. (K.), (P.). Stb. doppelt soviel als P., nur am Grunde oder selten ganz zu einer Röhre vereint. Cp. $(5-3)$, mit je 1 oder einigen Sa. G., selten halbunterst, unten 3 bis 5 fächerig; (Gr.). Steinfr. oder Schliessfr., seltener geflügelt, mit 1 bis wenigen S. E. meist gerade im Nährgewebe. - $\hbar$ mit (9) ganzrandigen oder gesägten B. und kleinen oder mittelgrossen Bl. - Stern- oder Schuppenhaare. - Etwa 73 trop. und temp. Am., Ostas., 1 medit. Halesia hispida (Japan); H. tetraptera (atlant. Nordam.). - Styıux officinalis (östl. medit.) giebt d. off. Harz Storax; St. ben:oin (Sundainseln) lief. Benzoëharz.

c. Sympetalie herrschend, ganz ausnahmsweise noch Choripetalie oder Apetalie. Stets nur 1 Staubblattkreis. Die Vereinigung der Carpelle bisweilen gering, meist Hypogynie.

4. Reihe CONTORTAE. Bl. meist 5 gliederig, seltener $2-6$ gliederig, meist sympetal, seltener choripetal oder apetal, mit gleichzähligen, seltener minderzähligen Stb. und $\mathrm{Cp}$. (2). Stb. selten hypogyn, meist am Grunde mit den (P.) vereint. P. in der Knospe meist gedreht, bisweilen klappig. B. meist gegenst., meist ungeteilt und ohne Nebenb. - t und Kr.

1. Unterreihe Oleineae. Bl. mit nur $2 \mathrm{Stb}$. Sa. mit 1 Integ.

Fam. Oleaceae. Bl. 2-6gliederig, meist sympetal, seltener choripetal oder apetal, ఫ̧ oder $\sigma^{\top}$ 우 $申$. P. 0 oder $4,5,6$, frei oder vereint, in der Knospe dachig oder eingefaltet bis klappig. Stb. 2, selten 4, am Grunde mit den P. vereint oder hypogyn, mit kurzen Stf. und grossen A. Cp. (2), mit je 2 , seltener 1 oder $4-8$ umgewendeten an der Scheidewand stehenden Sa. Fachspaltige 2 klappige Kapsel oder Beerenfr. oder Steinfr., mit 2-4 oder häufiger $1 \mathrm{~S}$. Nährgewebe + oder 0 . E. gerade. - t , bisweilen kletternd, selten Kr. mit gegenst. oder quirlst., einfachen oder gefiederten B. ohne Nebenb. und mit zusammengesetzten, traubigen oder cymösen Blütenständen. - Etwa 300, meist subcalid.

Unterfam. Oleoilleıe. Sa. vom Scheitel der Fächer herabhängend.

$\S$ Fraxineae. P. frei oder nur am Grunde verhunden, bisweilig 0 . Flügelfr. - Fraxinus $(30 *) ; \boldsymbol{F}$. ormus, Mannaesche (medit.) lief. das off. Manna. -- Fontanesia (1 östl. medit.).

§ Syringeae. (P.). Fr. fachspaltig mit geflügelten S. - Forsythir (2 Ostas.) ; $F$. suspensa. - Syminga (6 Eur., As.).

$\S$ 0leeae. P. 4 oder (P.). Steinfr. oder Beere, meist 1 samig. Phillyrea (4 medit.). - Chionanthus (Ostas., Nordam.); Ch. virginiana. Olea (35 medit., Afr., Neu-Seeland); Oter emropaer, Ölbaum (medit.). - Ligustrum (25 Eur., As., Austral.). 
Unterfam. Jusminoidece. Sa. am Grunde der Fächer sitzend, aufsteigend. Fr. 2 lappig oder 2 teilig. - Jasmiumm (120 As., Afr., Austral., medit.); J. srmmbre (Ostind.) und .J. officinale (Ostind.; cult. in Medit.) lief. Jasminöl. - Nyctanthes arbor tristis (Ostind.).

2. Unterreihe Salvadorineae. Stb. so viel als P. G. 1-2fächerig, mit 1-2 aufrechten Sa. mit 2 Integ. in jedem Fach.

Fam. Salvadoraceae. Bl. 4-5 gliederig, meist sympetal, $\Varangle$ oder $\sigma^{7}$ ㅇ diöcisch, ๑. Stb. 4-5; Cp. $(2)$, mit $1-2$ grundst. umgewendeten Sa. Beere oler Steinfr, mit häutigem orler pappartigem Endocarp, meist 1 samig. S. ohne Nährgewebe.

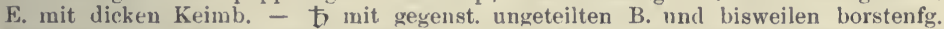
Nebenb.; Bl. in Rispen oder Büscheln. -- 9 Afr., As., calid, meist Steppensträucher. - Salvadora persicr (Afr., Westas.) mit scharf aromatischen Fr.

3. Unterreihe Gentianineae. Stb. so viel als P. G. 1-2fächerig meist mit $\infty$ Sa. mit 1 Integ. an wandständigen Placenten.

Fam. Loganiaceae. Bl. meist 4-5 gliederig, sympetal, ̧ㅜ oder $\delta^{\top}$ 우, $\oplus$. K. meist dachig. P. $(4-5-\infty)$, in der Knospe klappig oder dachig oder gedreht. Blkr. meist trichterfg. oder krugfg. Stb. so viel als P., selten nur 1, in der Röhre oder am Schlunde frei werdend. Cp. (2), selten $(3-5)$, mit $\infty-1$ Sa. an den scheidewandst. oder centralwinkelst. Plac. (Gr.) 2--4 spaltig oder 2 Gr. Kapsel septicid in 2 Carpelle oder Klappen zerfallend oder Beere oder Steinfr. S. mit fleischigem oder knorpeligem Nährgewebe; E. gerade oder gekrümmt. - $\hbar$, seltener $\mathrm{Kr}$., mit gegenst. oder quirlst., ganzrandigen oder gezähnten B., welche durch eine schmale querverlaufende Leiste verbunden sind oder mit Öhrchen am Grunde oder mit sehr kleinen Nebenb. Bl. in trugdoldigen Inflorescenzen. - Etwa 350 calid., wenige temp., keine in Eur.

Unterfam. Loyın ioidecie. Keine Drüsenhaare. Intraxyläres Leptom vorhanden.

§ Gelsemieae. Kapsel. P. in der Knospe dachig. Gr. 2 spaltig, mit wiederum 2spaltigen Schenkeln. - Gelsemium sempervirens (atlant. Nordam.), windend, narkotisch; Grundstock in Am. off.

\$ Loganieae. Wie vor.; aber Gr. einfach. - Austr., ocean. Inseln.

Spigelieae. Kapsel. P. in der Knospe klappig. - Spigelia (30 Am.); Sp. merylandica (südl. Nordam.) und Sp. anthelmia (trop. Am.) narkotisch giftig; anthelmintisch.

§ Strychueae. Beere oder Steinfr. P. in der Knospe klappig. Strychnos (65 trop.); Str. nux vomica, Brechnussbaum (Ostind.); die S. "Nuces vomicae (Krähenaugen)\&, sehr giftig, lief. Strychnin, St. colubrina (Ostind.) lief. das echte Schlangenholz (Lignum colubrinum), Mittel gegen Schlangenbisse; St. potatomum (Ostind.); S. zur Klärung des Wassers verwendet.

\$ Fagraeeae. Beere. P. in der Knospe gedreht, - Fagraea (30 ind.-malay.).

Unterfam. Buddleioideae. Drüsenhaare. Kein intraxyläres Leptom. - Nuxia (14 Afr., Mascarenen). - Buddleia (70 calid., einige temp.).

Von unsicherer Stellung: Desfontainea (1 Anden).

Fam. Gentianaceae. Bl. meist 4-5-, seltener 6-12 gliederig, sympetal, $\underset{+}{ }$, selten $\delta^{\top}$ ㅇ, $\oplus$, selten $\cdots$. K. frei oder vereint. (P.) in der Knospe 
meist gedreht, seltener dachig oder klappig. Stb. soviel als P., selten einzelne abortierend, in der Röhre oder am Schlunde der (P.) frei werdend, bisweilen einige sterile. Cp. (2), mit meist $\infty$ umgewendeten oder amphitropen Sa. G. meist 1 fächerig, mit 2 einfachen oder geteilten wandst. Plac., oder 2 fächerig mit scheidewandst. Plac. Gr. einfach oder 2 spaltig. Kapsel an den Nähten '2 klappig aufspringend, selten Fr. nicht aufspringend. Nährgewebe +. E. klein. - $\odot$ und $4 \mathrm{Kr}$., seltener Sträucher, meist kahl, meist mit gegenst., ganzrandigen B. ohne Nehenb. und mit cymösen Blütenständen. - Etwa 650, meist temp.

Unterfam. Gentianoideae. B. gegenst. (P.) gedreht oder dachig. Einzelpollen oder Tetradenpollen. Das Einzelkorn nie seitlich zusammengedrückt. - Inneres Leptom.

§ Gentianeae. Einzelpollen, kugelig oder länglich, mit 3 Iängsspalten, in deren Mitte die Keimporen liegen.

* Lxacinae. Pollen winzig. G. 2fächerig. N. nicht oder schwach gelappt. Exacum (30 palaeotrop.).

* Enythraeinae Pollen mittelgross. G. 1 fächerig. - Erythraer (30 meist temp.); E. centaurium, Tausendgüldenkraut (Eur.) lief. die off. Summitates Centaurii minoris. - Chlora (2 medit. und Eur.).

* Chironinae. Pollen sehr cross. G. 1 fächerig. (P.) fast radförmig. Holzkörper mit Leptominseln. - Chironia (15 Afr.).

* Gentianinae. Pollen gross mit feinhöckeriger Exine. G. $1 \mathrm{fächerig.}$ - Gentiana (300 temp.); G. lutea, G. purpurea, G. pammonicr. (alp.) lief. die off. Radix Gentianae. - Suevtir (70 Eur., As., Afr.). - Halenia (25 Nordas., Nordam., Anden) mit gespornten Bl.

* Tachïnae. Pollen gross. Exine mit sehr deutlich netzartig verlaufenden Leisten. G. 1 fächerig. - Lisianthus (10 trop. Am.).

$\S$ Rusbyantheae. Einzelpollen gross, ohne Keimfurchen. G. 2fächerig. Rusbyanthus (1 Bolivia). trop. Afi.

$\S$ Helieae. Tetradenpollen. - Mehrere Gattungen, meist trop. Am., nur wenige

\$ Voyrieae. Einzelpollen schwach gebogen, mit 2 polaren Spalten. Saprophyten mit knolligem Rhizom und grossen Bl. - Voyvia (3 trop. Am.).

$\S$ Leiphaenteae. Einzelpollen eiförmig, mit 1 apicalen Keimporus. Saprophyten mit dünnem Rhizom. Kapsel laternenartig aufspringend. Jeiphaemos (18 trop. Am., 2 trop. Afr.).

Unterfam. Menyanthoideae. B. abrechselnd. (P.) induplicatvalvat. Einzelpollen, von einer Seite her zusammengedrückt, von oben gesehen 3 eckig, in jeder Ecke mit 1 Keimporus. G. 1 fächerig, mit parietalen Plac. - Kein inneres Leptom. - Menyunthes trifoliatr, Bitterklee (*) lief. d. off. Herba Trifolii febrini. - Limnanthemum (24 temp.-calid.); I. nymphaeoides (Eur.).

Fam. Apocynaceae. Bl. 5-4 gliederig, sympetal, ఫ̧, $\bullet$. P. in der Knospe gedreht, selten klappig. Stb. in der Röhre der Blkr. frei werdend; A. länglich-lineal oder pfeilfg. mit an der Spitze nach innen gebogenem oder zugespitztem Connectiv. Cp. selten mehr als 2, meist mit $\infty$ amphitropen hängenden Sa., unten getrennt und durch die Gr. vereint oder völlig vereint; G. dann 2 fächerig oder 1 fächerig. Gr. meist vereint und 
oben in eiuen Narbenkopf verdickt. Fr. sehr verschieden. Nährgewebe dünn oder 0 . E. gerade, fast so lang wie der S., mit flachen, seltener gefalteten Keimb. - 古 oder $4 \mathrm{Kr}$. mit cinfachen, meist gegenst. ganzrandigen B. und trugdoldigen Blütenständen. - Stets Milchsaftschläuche und inneres Leptom. - Etwa 1000 calid., wenige temp.

Unterfam. Plumerioidene. Stb. frei oder nur locker dem Narbenkopf anhängend. Theken meist ungeschwänzt. S. meist ohne Haarschopf.

§ Arduineae. Cp. (2). Gr. am Grunde nicht gespalten. - Arduina (20 palaeotrop.); A. carandas (Carissa edulis, palaeotrop.) mit essbaren Fr. - Allamanda (12 trop. Am.). - Landolphia (Vahea) (16 trop. Afr., Madagaskar); L. (comorensis var. florida (trop. Afr.), L. owariensis (IVestafr.), L. Kirl:ii (Ostafr.) u. a. Lianen, lief. reichlich Kautschuk. - Carpodinus (Westafr.). - Hancornia speciosa in Südbrasilien, lief. Mangabeira-Kautschuk.

§leícarpea. Cp. 3-5, frei. - Palaeotrop.

$\S$ Plumeriere. Cp. 2, unterhalb der Gr. getrennt.

* Tahernaemontaninae. Cp. mit $\infty$ Sa. K. innen mit zahlreichen Drüsen oder anl Grunde mit Haarring. Fr. saftig. - Tabernuemontana (110 trop.).

* Alstoniinae. Cp. mit $\infty$ Sa. K. innen ohne Drüsen. Fr. trocken. - Aspidosperma (45 trop. Am.); A. quebracho blanco (Argentin.) lief. die sehr tanninhaltige Quel,rachorinde zum Gerben. - Amsonia (Nordam., Japan) und Rhazya (1 Arab., Westas.) mit (Q) B. - Vinca (5). - Lochnera (3 trop.) rosea. - Alstonia (30 trop. As., Austral. und Pacif.); A. scholaris (ind.-mal.), Rinde in Ostind. off.

* Rauwolfinae. Cp. mit 2, selten 4 oder 6 Sa. an dünnen Placenten. - Ranwolfia (45 trop.).

* Cerberinae. Cp. mit 2 oder 4 schildfg. ansitzenden Sa. an dicken Placenten. Steinfr. oder Beeren. - Thevetia (5 trop. Am.). - Cerbera (5 trop. As.). - Tanghinia venenifera (Madag.). - Alle sehr giftig; die S. geben Brennöl.

Unterfam. Echitoideae. Sth. mit dem Narbenkopf fest verbunden. Theken stets geschwänzt. S. meist mit Schopf haaren.

\$ Echitifleae. A. in der Röhre eingeschlossen. - Fehites (40 trop.

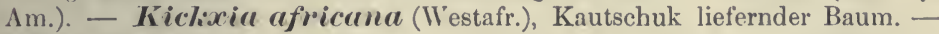
Muscurenhasia elastica in Ostafrika lief. Mgoa-Kautschuk. Adenium (5 in Steppen u. Wüsten Afrikas). - Apocymum (5*); $\boldsymbol{A}$. cannubinum (Nordam.) lief. Gespinnstfasern (Indian hemp) und d. in Am. off. Radix Apocyni; Blïten von A. androstemifolium (Nordam.) Fliegen fangend. - Nerium (2-3 medit. bis Ostas.); N. olerender, Oleander. - Strophanthus (25 As., Afr.); Str. hispidus und Str. kombe (trop. Afr.) lief. d. off. Semen Strophanthi.

§ Parsousieae. A. niber die Röhre der Blkr. hinausragend.

Fam. Asclepiadaceae. Bl. 5 gliederig, sympetal, ఫ̧, $\oplus$. K. wenig vereint. (P.) in der Knospe gedreht, selten klappig, bisweilen mit Anhängseln, welche eine Nebenkrone bilden. Stb. frei oder häufiger am Grunde vereint, häufig am Rücken oder hinten seitwärts mit corollinischen, ebenfalls eine Nehenkrone bildenden Anhängseln; Pollen selten in Tetraden und körnig, meist wachsartig, in Pollinien; diese letzteren durch hornartige 
Körperchen (Translatoren), welche hfg. in Klemmkörper und Arm gegliedert sind, mit dem Narbenkopf verbunden. Cp. 2 getrennt, von der Stb.röhre eingeschlossen, mit $\infty$ hängenden, umgewendeten Sa., oben vermöge eines schildfg. Griffelkopfes zusammengehalten; N. am Scheitel. Fr. 2 Balgfr. mit $\infty$ zusammengedrückten S., mit einem Schopf langer weisser Haare. E. mit flachen Keimb., so lang wie das Nährgewebe. -- 4 .Kr., Halbsträucher oder Sträucher, oft windend, andere succulent. B. gegenst. oder quirlst., selten (9), ohne Nebenb. Bl. einzeln oder in 'Trugdolden. - Stets Milchsaftschläuche und inneres Leptom. - Etwa 1500 meist calid., sehr zahlreich in Afr.

Unterfam. Periplocoideae. Pollen körnig, in Tetraden. Stf. an der Spitze oder vom Grunde an frei; die 4 fächerigen A. mit ihrer Spitze über der N. zusammenneigend; Translatoren löffelförmig ohne Klemmkörper, am Grunde mit Klebscheibe; meist an der Rückseite der Stf. sterile Anhängsel (Nebenkrone), seltener keine. - Alle in der alten Welt. Periploca (12 medit. und Afr.).

Unterfam. Cynanchoidece. Pollen in wachsartigen Massen. Stf. in eine meist kurze Röhre vereint. A. selten 4 fächerig, meist 2 fächerig; Translatoren mit Klemmkörper.

§ Asclepiadeae. Pollinien im Grundkörper der A. an den Translatorenarmen hängend; Theken durch Poren oder Spalten geöffnet. - Calotropis (3 As., Afr. calid.); C. procera, Oschur, in der Sahara. - Asclepias (80 meist Am.); A. Cornuti, von Bienen stark besucht. - Cynanchum (incl. Vincetoxicum über 100). - Sarcostemma (8 palıeotrop.), blattlose Wüstensträucher.

§ Secamoneae. Pollinien paarweise im Endkörper jeder Theka an den Translatorenarmen aufrecht, bisweilen wagerecht, sehr selten hängend. - Secamone (50 palaeotrop.).

§ Tylophoreae. Wie vorige; aber Pollinien einzeln in der längsaufspringenden Theka, fast stets aufrecht.

* Marsdeniinae. A. mit Endanhängsel. - Marsdeniu (60 calid.); M. condurango (Ecuador) lief. d. off. Condurangorinde. - Stephanotis (15 palaeotrop.). - Hoya, Wachsblume (50 palaeotrop.). - Dischidin (24 ind.-malay.), einzelne mit Schlauchb., in welche Adventivwurzeln hineinwachsen.

* Ceropegiinae. A. ohne Endanhängsel. - Leptadenia (15), oft blattlose Wüstensträucher. - Ceropegia (80 palaeotrop.). - Boucerosia (medit., Ostind.). - Stapelia (Südafr.).

$\S$ Gonolobeae. Wie vor.; aber Pollinien in den fast quer aufspringenden Theken horizontal. - Nur Am. - Gonolobiss (70).

d. Sympetalie ausschliesslich. Stets nur 1 Staubblattkreis. Die Vereinigung der (meist 2) Carpelle stets vollständig. Häufig Zygomorphiø.

a) Insertion der Blh. hypogyn.

5. Reihe TUBIFLORAE. Bl. typisch mit 4 gleichzähligen Quirlen oder häufiger mit minderzähligem $G$. oder, wenn $\%$, auch mit minderzähligen Stb. Stb. mit den (P.) vereint. Sa. mit 1 Integ. - Vorzugsweise $\mathrm{Kr}$; ; aber auch $\hbar$. 
1. Unterreihe Convolvulineue. Bl. meist $\oplus$. Carpelle mit wenigen his je $2 \mathrm{Sa}$. mit nach unten gekehrter Mikropyle. Fr. sehr selten in 4 Klausen zerfallend. B. meist (9).

Fam. Convolvulaceae. Bl. 5-4 gliederig, meist $\varnothing$ und $\Varangle$. (P.) in (ler Knospe meist induplicat-valvat. Stb. meist am Grunde der.(P.). Cp. (2), selten (3-5), mit je 2 grundst., aufrechten Sa. mit 1 Integ. (Gr.) oder 2 Gr. Kapsel, sehr selten 4 Klausen. \$. kugelig, eifg. bis 3 kantig. Nährgewelıe t. - Meist Kr., oft links windend, seltener $\mathbf{t}$, Sträucher oder Bäume, meist mit ansehnlicher Bl. - Hfg. gegliederte Milchsaftschläuche. - Etwa 1100, meist calid.

Unterfam. Convolruloideae. Autobiotisch mit Iaubb. (P.) ohne Schuppen unter den Stb. E. gerade oder gekrümmt mit gefalteten Keinb.

A. Streifen der Blkr. selten scharf abgegrenzt; Blkr. meist von unten nach oben gleichmässig erweitert. Pollen glatt.

a. K b. verwachsen.

§ Dichondreae. - Dichondra (5 calid.); D. repens (verbreitet). - Falkia (4 Afr.).

b. Kb. frei.

a) Fr. a ufspringend, oder klein, dünn ohne Klappen.

§ Dicranostileae. $2 \mathrm{Gr}$. Bl. in Dichasien oder einzeln. Kapsel aufspringend. (i. mit 4 Sa. - Cressa retica (medit.). - Evolvulus $(80$ calid.). - Seddera - Hildebrandtia (Afr.).

§ Convolvuleae. 1 Gr., sonst wie vor. - Calystegia (7 temp. subtrop.). - Conıolvulus (200 calid. - temp.); C. sccmmonia (Kleinas.); aus dem dickfleischigen Rhizom fliesst das Harz Ścam monium.

$\S$ Poraneae. Bl. in Rispen oder Trauben. Kapsel dünn, häutig, 1 samig. $3-5 \mathrm{~Kb}$, später vergrössert. - Porana (10 trop. As.).

३) Fr. nicht aufspringend, beerenartig oder hart. Gr. ungeteilt.

§ Erycibeae. Erycibe (11 trop. As.).

B. Streifen der Blkr. seitlich durch 2 Nerven scharf algegrenzt. Blkr. un regelmässig erweitert. Pollen stachelig.

§ Ipomoeeae. Fr. 4 klappig oder klappenlos, pergamentartig. Calonyction speciosum (trop. Am.), Zierpfl. - Quamoclit (10 trop.); Q. coccinea (trop. Am., As.). - Exogonium (15 trop. Am.); E. Murga (Mexiko) lief. die Jalapenwurzel mit Resina Jalapae. - Ipomoer (300 calir.); I. britutrs (Centralam.), wichtige Culturpfl., lief. die Bataten oder süssen Kartoffeln. - Plarbitis (60 trop.).

§ Argyreieae. Fr. nicht aufspringend, holzig, mehlig oder fleischig. - Aryyreia 25 palaeotrop.).

Unterfam. Cuscutoidene. Parasiten mit fadenfg. Stengeln und Haustorien. (P.) meist mit Schuppen unter den Stb. 2 Gr. getrennt oder vereint. E. kreisfg. oder spiralig eingerollt, ohne Keimb. oder mit rudimentären Keimb. - Cuscuta (90 calid.-temp.); sehr schädlich; C. epilinum auf Lein; C. Trifolii auf Klee.

Fam. Polemoniaceae. Bl. 5 gliederig, ఫ̧, $\oplus$, zuweilen $\cdots$ (P.) in der Knospe meist rechts gedreht. Cp. (3), selten (2) oder (5), mit je $\infty-1$ 
aufsteigenden, umgewendeten Sa. 1 Gr. an der Spitze +3 spaltig. Kapsel meist fachspaltig. E. gerade, im Nährgewebe. - Meist $\odot$ und $4 \mathrm{Kr}$. mit (9) oder gegenst. B. - Etwa 200, insbesondere in Westam.

$\$$ Cobaeeae. Blattranken. Bl. sehr gross. K. laubig. Kapsel wandspaltig. - Cobaea (6 trop. Am.); C. scandens (Mexiko), Zierpfl.

\$ Cantueae. Kapsel fachspaltig. S. breit geflügelt. - Cantua (7 andin).

$\$$ Polemonieae. Kapsel fachspaltig. S. nicht oder schmal geflügelt. - Plilox (30 Nordam., 1 Sibir.). - Collomia (18 pacif. Nordam., Chile). - Gilia (70 temp. und subtrop. Am.). - Polemonium (10*).

2. Unterreihe Borraginineue. Wie vorige; aber die Sa, mit nach oben gekehrter Mikropyle. Fr. Kapsel od. Steinfr. od. in Klausen zer. fallend.

Fam. Hydrophyllaceae. Bl. meist 5 gliederig, ఫॄ, 申. (P.) in der Knospe meist dachig, seltener gedreht. Stb. 5, selten 4 oder mehr. Cp. (2), mit je $\infty-2$ sitzenden odor hängenden, umgewendeten oder amphitropen Sa. Gr. 2 oder 1. Kapsel meist fachspaltig. E. klein, axil im Nährgewebe. - Etwa 170, besonders in Nordam. - Meist $\odot$ und $4 \mathrm{Kr}$. mit (Q), selten gegenst. B.; Bl. in Wickeln.

$\S$ Hydrophylleae. Gr. einfach oder \pm 2 teilig. Plac. breit. Kapsel 1 fächerig. - Hydrophyllum (6 Nordam.). - Nemophila (11 Nordam.).

\$ Phacelieae. Gr. einfach oder \pm 2 teilig. Plac. schmal. Kapsel $1-2$ fächerig. fuchspaltig. - Phacelia (70-80, meist westl. Nordam., 4 Mexiko, wenige Chile, Peru), - Romanzoffia (2 subarkt. Ostas. und Nordam.). - Codon (Südafr.)

§ Nameae. Gr. 2. Plac. geteilt, durch oft halbe Scheidewände nit den Frucht klappen verbunden. - Nama (27 westl. Nordam.). - Wigundia (6 in den Gebirgen (les trop. Am.); W. caracusana (Mexiko), Zierpfl.

§ Hydroleeae. Gr. 2. Plac. gross, schwammig, zuletzt vereint. - Hydrolen (12 trop.); H. spinosa in Gewässern.

Fam. Borraginaceae. Bl. 5. (selten $6-\infty$ ) gliederig, meist $\not{q}, \oplus$, zurreilen $\%$. (P.) in der Knospe quincuncial oder rechts gedreht, hfg. mit Hohlschuppen (Ligulargebilde). Cp. (2) mit je 2 umgewendeten Sa. G. ungelappt, 2 fächerig mit endst. Gr. oder durch falsche Scheidewände 4 fächerig oder vollkommen 4 lappig, mit einem zwischen den Lappen gelegenen Gr. Gr. einfach oder 2 schenkelig oder zweinal 2 schenkelig. Fr. steinfruchtartig oder in Klausen zerteilt. Nährgewebe + bis 0. E. gerade oder gekrümmt. - $\mathrm{Kr}$. oder $\mathrm{t}$, oft rauhhaarig oder borstig, selten mit gegenst., meist mit (Q), ungeteilten B. und wickeligen Blütenständen. Etwa 1200.

Unterfam. Cordioideae. G. nicht gelappt. Gr. endst., zweimal 2 spaltig. Steinfr. mit meist 4 fächerigem Kern. Keimb. gefaltet. Nährgewebe 0. - t. - Cordia (180 trop.); C. myxa (Ostind., Ägypt.) lief. Rosenholz.

Unterfam. Ehretioideae. G. nicht gelappt oder an der Seite 4 furehig. Gr. endst, einfach oder 2 schenkelig oder $2 \mathrm{Gr}$. Steinfr. mit zwei 2 samigen oder vier 1 samigen Steinkernen oder in 4 Teile geteilt. Keimb. flach. Nährgewebe + oder 0 . - t oder Sträucher. - Ehretia (50 trop.).

Unterfam. Heliotropioideae. Wie vorige, aber Gr. kurz und unter der kegelfg oder 2 spaltigen Spitze mit einem breiten Haarring. - Tournefortin (100 calid.). Heliolropium (150 calid.-temp.). 
Unterfam. Borrrginoidece. G. tief, 4-oder 2 lappig. Gr. zwischen den Lappen des G., einfach oder 2 spaltig. Fr. 4 oder weniger 1 samige Klausen, sehr selten mehr. Nährgewebe 0 .

\$ Cynoglossear. Klausen mit flacher Areole der Gynobasis ansitzend, ihre Spitzen über die Insertionsstelle nicht hinausragend. - $\mathrm{Om}$ plualodes $(15 *)$. - Cynoglossum (68 temp.--calid.); C. offuinale.

$\S$ Eritrichieat. Klausen mit ihren Spitzen über die schmale Insertionsstelle hinausragend. - Echinospermum (50). - Eritrichium (70, meist *). - Asperngo (1 Eur., As.).

$\S$ Ancliuseae. Klausen mit concaver Areole. - a. Mit Hohlschuppen an den (P.): Symphytum (17*); S. officinale, S. peregriniom und $S$. aspervimum (nördl. Kaukasus), gute Winter-Futterpfl. - Borrago officinalis, Boretsch (medit.), Küchenpfl. - Anchusa (30 Eur., As., medit). - Iyjcopsis arvensis, Ackerunkraut. - b. Ohne Hohlschuppen: Pulmonaria (6 Eur., As.). - Alkanna (40 medit.); A. tinctoria (medit., Ungarn), Wurzel lief. Farbstoff.

\$ Lithospermeae. Klausen aufrecht mit flacher oder kleiner Areole. - Myosotis (40 temp., excl. Am.). - Lithospermum (40, meist *). - Onosma (70 medit., Centralas.). - Cerinthe (10 Eur. und medit.). $\S$ Echieae. Wie vor.; aber Bl. \pm \% - Echinm (50 Eur., As., Afr.).

3. Unterreihe Verbenineae. Bl. meist $\cdots$ C C. mit je 2 , selten nur $1 \mathrm{Sa}$. B. meist gegenst. oder quirlst. Steinfr. oder steinfruchtartigé oder nusschenartige Klausen.

Fam. Verbenaceae. BI. 5-4-(seltener 6-8-)gliederig, meist ఫ్ , selten $\oplus$, meist $\%$ (K.). (P.) mit oft langer, cylindrischer, nicht selten gekrümmter Röhre und hfg. 2 lippigem Saum. Stb. selten den P. gleichzählig, meist 4 didynamisch oder 2 und $2-3 \mathrm{Std}$. Cp. (2), selten $(4-5)$, mit je $2 \mathrm{Sa}$. mit nach unten gekehrter Mikropyle. G. zuletzt meist in Folge secundärer Scheidewandbildung 4 fächerig. Gr. endst., einfach. Meist Steinfr. mit 2-4 Fächern oder septicid in 2 fächerige oder 1 fächerige Teilfr. zerfallend. E. gerade. - $\mathrm{Kr}$. oder $\hbar$ mit meist gegenst. oder quirligen, ganzrandigen bis vielspaltigen $\mathrm{B}$. und ährigen oder trugdoldigen Inflorescenzen. - 700 calid. und temp. *, wenige in temp. *.

A. Blintenstand meist ahrig oder traubig.

\$ Verbeneae. G. mit ungeteilten oder geteilten Fächern. S. ohne Nährgewebe. Meist Kr. - Lantana (50 trop.), Zierpfl. - Lippir (90, meist Am.); L. citriodora mit Citronengeruch, cult. - Verbena (80, meist Am.). - Cutharexylum (Am. calid.) lief. Eisenholz. - Duranta (Am. calid.); D. ellisia mit essharen Fr.

§ stilbeae. S. mit Nährgewebe. G. 2 fücherig. - Schmalblätterige Strüucher. - Nur Südafr.

B. Blütenstand trugdoldig.

a. Sa. seitenständig, halbumgewendet.

a) S. mit Nahrgewebe.

\$ Chloantheae. G. 2 fácherig mit je $2-1$ Sa. P. $(4-8)-$ Austral. und ocean. Insehn.

B) S. ohne Nuhrgewebe. 
§ Viticeae. G. mit halbierten Fächern. Steinfr. t. - Callicarpa (30 calid.). - Tectona (3 trop. As.); T. grandis, Teakholzbaum (Ostind.); das kieselsäurehaltige Teakholz ist das beste für Schiffsbauten; die B. geben rote Farbe. - Vitex (60 calid.); V. agnus castus (medit.). Clerodendron (70 trop.), mehrere Zierpfl.

\$ Caryopterideae. G. mit halbierten Fächern. Fr. kapselartig. - Ostas.

b. Sa. hängend, geradläufig, gi felständig.

$\S$ Symphoremeae. G. zuletzt mit halbierten Fächern. Fr. 1 samig. - Kletter. sträıcher. - Ind.-malay.

\$ Avicennieae. G. mit halbierten Fächern. Fr. 2 klappige Kapsel mit 1 S., dessen E. vor dem Abfall der Fr. keimt. - t. - Avicennia (3-4 in tropischen Strandwäldern), mit Atmungswurzeln.

Fam. Labiatae. Bl. 5 gliederig, mit Reduction im Androeceum und Zweigliederigkeit im Gynaeceum, meist ㅎ, $\%$ (K.). (P.) mit Röhre und meist 2 lippigem Saum. Stb. 4 didynamisch oder 2 und 2 Std., selten noch ein 5. Std. oder nur 2 Stb. Cp. (2) mit je 2 aufrechten umgewendeten Sa., zwischen denselben \pm eingefaltet. $\mathrm{Fr}$. in 4 Klausen geteilt oder bei

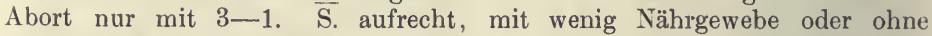
solches. E. mit fleischigem flachen oder flach-convexen Keimb. - $\mathrm{Kr}$. oder Sträucher, selten $\hbar$ mit gegenst. oder quirlst. B. und Zweigen und trugdoldigen, oft in Scheinquirle zusammmengezogenen Inflorescenzen. Etwa 2600, meist calid. und temp., wenige frigid.

Unterfam. Ajugoidene. (K.) 10-11 rippig. (P.) 1- oder 2 lippig, selten fast $\oplus$. Stb. 4 , selten 2. G. kurz 4 teilig oder bis $\mathrm{zu} 1 / 3^{3}$ seiner Höhe geteilt. Klausen verkehrt-eifg., mit trockenem Pericarp. S. fast ohne Nährgewebe, gerade, mit geradem E.

$\S$ Ajugeae. (K.) 10 rippig. (P.) selten fast $\oplus$ oder (bei unseren Gattungen) mit abwärts zurückgebogenen Lappen. Stb. 4 oder 2 mit zweifächerigen A. Klausen 士 warzig. - Ajuga (45 temp.). - Teucrium (100 temp.).

$\S$ Rosmarineae. (K.) 11 rippig. (P.) 2 lippig. Stb. 2 mit 1 fächerigen A. Klausen glatt. - Rosmarinus officinalis (medit.), lief. d. off. Herba Rosmarini.

Unterfam. Prostantheroideae. (K.) 10-13 rippig. (P.) mit teller-oder becherförmig ausgebreitetem Saum, breiter, etwas convexer oder fast flacher Oberlippe. Stb. 4 . G. bis zu $1 / 3$ oder $1 / 2$ seiner Höhe geteilt. Klausen verkelırt-eifg. S. meist mit Nährgewebe, gerade mit geradem E. - 90 Austral.

Unterfam. Prasioidene. (K.) 5-10rippig. (P.) 2lippig mit concaver Oberlippe. Stb. 4. G. bis zum Grunde 4 teilig. Klausen verkehrt eifg. oder \pm tetraëdrisch, mit dickem, fleischigem oder \pm saftigem Pericarp nnd kleiner basilärer Ansatzflache. s. meist ohne Nährgewebe, gerade. - Etwa 50 trop. As. und Sandwichinseln, nur 1, Prasium majus, medit.

Unterfam. Scutellarioideae. (K.) 2 lippig. (P.) 2 lippig mit helmfg. Oberlippe. Stb. 4. G. 4 teilig. Klausen \pm kugelfg., mit trockenem Pericarp, dem als Gynophor ausgebildeten Torus mit einer kleinen basilären Ansatzfläche ansitzend. S. transversal, ohne Nährgewehe, mit gekrümmtem E. - Scutellaria (180). 
Unterfam. Lavauduloiderte. (I'.) 2 lippig. Sth. verborgen. Discuslappen den Klausen superponiert. - Luvandula (26 medit., Abyss., Ostind.); L. rera (medit.) lief. d. off. Flores Lavandulae.

Unterfam. Stachyoideae. (K.) 5-15 rippig. (P.) fast $\phi$ oder 2 lippig. Stb. 4 oder 2. G. 4 teilig. Klausen eifg., verkehrt eifg. oder tetraëdrisch, mit trockenem Pericarp, mit kleiner basilärer Ansatzfläche. $\mathrm{S}$. gerade mit geradem $\mathrm{E}$.

§ Marrubieae. (K.) glockig oder röhrenfg., 5-10 zähnig. (P.) in schlunde des K. verborgen oder nur wenig hervorragend. Stb. in der (P.) verborgen. - Marrubium (30 temp. Eur., As., Afr.). - Sideritis (50 medit.).

§ Perilomieae. (K.) 2 lippig, mit ganzrandigen Lippen. Oberlippe ler (P.) nicht helmfg. Stb. 4, unter der Oberlippe parallel, die vorderen länger und mit nur einem fertilen Fach. - Perilomia (8 andin).

$\S$ Nepeteae. K. meist parallel 15 rippig. (P.) 2 lippig. Stb. 4, die linteren länger oder allein ausgebildet. - Cedronella (4 Makarones.). Dracocephalum (40 Eur., As.). - Nepeta (incl. Glechoma 150 *).

S Stachyeae. (K.) 5-10 rippig. Oberlippe der (P.) concav oder helmfg. Stb. 4, unter der Oberlippe parallel aufsteigend.

Brunellinae. (K.) 2 lippig, Unterlippe nach der Anthese gegen die Oberlippe sich neigend und den Schlund abschliessend. Oberlippe der (P.) helinfg. - Brunella (5 temp.).

* Melittinae. (K.) grossglockig. (P.) von unten an breit oder nur im oberen Teil erweitert. Die A. mit eifg., vollständig ausgebildeten Fächern. - Fhysostegia (3 Nordam.). - Melittis melissophyllum (Eur.). * Lamïnae. (K.) 5-10 rippig. (P) mit helmfg. oder concaver Oberlippe. Stb. aus der Röhre der (P.) herausragend. - Eremostackys (40 Westas.). - Plilomis (65 medit. und temp. As.). - Lerucas (60 trop.). Molucella (2 medit.). - Lamium (40 Eur., As., Afr., extratrop.). Galeopsis (7 Eur., As.). - Leonurus (8 Eur., As.). - Ballota (25 medit.), - Stuchys (200 meist temp.); St. Iffinis (Japan), als Wurzelgemüse cult.

S Salvieae. (K.) + glockig oder röhrig. (P.) 2 lippig, mit sichelfg. oder helmfg. Oberlippe. Nur die vorderen 2 Stb. fertil, mit linear-fä̀lichem Connectiv und meist nur einer fertilen Theka. - Salvia (500 temp., calid.); S. officinalis (medit.), lief. d. off. Folia Salviae.

$\S$ Meriandreae. (K.) \pm glockig, 2 lippig. (P.) mit gleichen und ungleichen kleinen Lappen. Nur die vorderen 2 Stb. fertil, mit erweitertem Connectiv. Meriandro (Abyssinien bis Himalaya).

\$ Monardeae. (K.) 5 zähnig oder 2 lippig. (P.) 2 lippig, mit sichelfg. Oberlippe. Nur die vorderen 2 Stb. fertil. - Monurda (7 Nordam.).

§ Hormineae. (K.) glocken- bis röhrenfg., 2 lippig. (P.) 2 lippig. Stb. 4 mit linienfg. Thecis. - Horminum pyrenaicum (Pyrenäen bis Tyrol). -- Sphacele (20 An. und Sandwichinseln).

\$ Glechoneae. (K.) gleich 5 zälınig oder 2 lippig. (P.) mit sichelfg. oder helmfg. Oherlippe. Stb. 4 mit eifg. Thecis. - Glechon (Brasil.). - Acanthominthe (Kalif.).

§ Saturejeae. (K.) 5 zähnig oder 2 lippig. (P.) mit flachen Lappen entweder fast $\$$ oder 2 lippig. - Stb. 4 oder '2, gleich lang oder die vorderen länger; Thecae eifg. oder kugelig. 
* Melissinae. (P.) deutlich 2 lippig. Stb. an der Basis unter der Oberlippe aufsteigend, nach oben gerade vorgestreckt und spreizend. Ziziphora (8 medit. und temp. As.). - Melissa officinulis (medit.) lief. d. off. Folia Melissae. - Calamintha (auch mit Melissa vereinigt, 40 *). - Hedeoma (12 Am.). - Micromeria (60).

* Hyssopinae. K. 15 nervig. (P.) 2 lippig. Stb. gerade vorgestreckt, spreizend. - Hyssopus officinalis (medit., Centralas.).

* Thyminae. (P.) deutlich 2 lippig. Stb. gerade vorgestreckt, spreizend. - Satureja (14 medit. und Florida); S. hortensis, Pfefferkrant, Küchenkraut. - Origanum (25 meist medit.); O. major(m) Mairan. Küchenkraut. - Bystropogon (14 Canaren, Anden). - Thymus (35 medit., Abyssinien); Th. vulgaris (medit.) liefert d. off. Herba Thymi; Th. serpyllum, Quendel (mit $\infty$ Variet. *) lief. d. off. Herba Serpylli.

* Menthinae. (P.) fast $\oplus$. Stb. gerade vorgestreckt, spreizend. Lycopus (7 *). - Preslia cervina (medit.). - Mentha (15, meist temp.); M. piperita (Westeur., Nordam.), Pfeffermünze, lief. die off. Folia Menthae piperitae; M. silvestris var. crispa (nur in Kultur) lief. d. off. Folia Menthae crispae.

* Perillinae. (P.) fast $\oplus$ und +2 lippig. Stb. gerade ausgestreckt, fast gleich. - Perilla (Ostind., China). - Collinsonia (6 Nordam.).

$\$$ Pogostemoneae. (K.) 5 -10 rippig. (P.) fast $\oplus$, mit kurzer Rohre. Stb. 4, gerade vorgestreckt, mit an der Spitze verwachsenden Thecis. - Elsholtzia (18 As., 1 auch in Eur.). - Pogostemon (30 As. calid.); 1 . patchouly (China) lief. das auch off. Parfum Patchouly.

Unterfam. Ocimoideae. (K.) verschieden. (P.) 2 lippig; aber meist die Oberlippe mit 4, die Unterlippe mit 1 Lappen. Stb. 4, selten 2, mit + kugelfg., zuletzt (durch Verwachsen der Thecae an der Spitze) ein. fächerigen A. G. bis zum Grunde 4 teilig. Klausen mit trockenem Pericarp. S. ohne Nährgewebe, gerade, mit geradem E.

§ Ocimeae.

* Hyptidinae. Vorderer Lappen der (P.) scharf abgebogen, an der Basis meist contrahiert. - Hyptis (3nก trop., meist Am.).

* Plectranthinae. Vorderer Lappen der (P.) lang, concav oder kahnfg. Coleus (90 palaeotrop.) Zierpfl. - Plectranthus (90 palaeotrop. und Ostas.).

* Moschosminae. Vorderer Lappen der (P.) kaum länger, aber schmäler als die übrigen. - Moschosma (6 trop.). - Ocimum (60 trop.).

Unterfam. Catopherioideae. (K.) 2 lippig. (P.) 2 lippig, Unterlippe mit 1 Lappen. Stb. weit hervorragend. Klausen mit trockenem Pericarp. S. geralle mit gehogenem E. - Catopheria (trop. Am.)

4. Unterreihe Solanineae. Bl. $\oplus$ oder hfger. $\cdot \cdot$, typisch 5 gliederig. Stb. 5 oder 4 oder 2 . Cp. selten (5), meist (2), mit meist $\infty$, seltener nur 2-1 Sa. Seltener Beere oder Steinfr., meist Kapsel, letztere nie bis zum Grunde fachspaltig.

a. Fr. in 5 oder viele Klatsen zerfallend.

Fam. Nolanaceae. Bl. 5 gliellerig, tudinale Einschnnürungen in 5-10 in einer Reihe stehende Klansen geteilt oder durch quere Einschnürungen in $10-302-3$ reihige Klausen geteilt. Klausen $1-7$ samig. S. mit Nährgewebe und gekrümmtem E. $-\odot$ oder $24 \mathrm{Kr}$. oder kleine Sträucher mit (a) B. und einzeln stelıenden, mitunter zu einer Traube vereinten Bl. -40 in Chile und Peru, meist Meerstrandpfl. - Nolana. 
b. Fr. 2-, selten 5- 5 fächerig oder 1 fächerig.

a. Leitbündel bicollateral.

Fam. Solanaceae. Bl. meist 5 gliederig, $\not{+}, \oplus$ oder seltell $\%$ (P.) in der Knospe meist gefaltet. Stb. 5, in $\%$ Bl. bisweilen 1 Std. Cp. (2), sehräg gegen die Mediane, mit je $\infty-1$ umgewendeten oder amphitropen Sa. an scheidewandst. Plac. G. selten $3-5$ fächerig durch secundär auftretende Scheidewände. (Gr.) mit 2 lappiger oder 2 teiliger $\mathrm{N}$. Beere oder Kapsel. E. im Nährgewebe, gerade oder gekrümmt. - Kr. oder Sträucher mit (9) B. Bl. endst., einzeln oder in trugdoldigen Blütenständen. - Markständiges Leptom. Alkaloide. - Etwa 1300 calid.-temp.

A. E. deutlich gekrammt. Alle $5 \mathrm{Stb}$ fertil, nur wenig verschieden.

$\S$ Nicandreae. G. $3-5$ fächerig (durch falsche Scheidewände). Nicandra physaloides (Peru).

Solaneae. G. 2 fächerig, selten vielfächerig (Solanum lycopersicum).

a. Stf. am unteren Ende des schmalen Connectivs der A. an. sitzend.

* Iyciinae. (P.) röhrig oder schmalglockig. Beeren. - Iyciım (70 calid.); I. europaenum (medit.); I. vulgare (Mittel- und Südeuropa). Atropk (2 Eur., As.); A. belladomna (Eur. bis Persien), Tollkirsche lief. d. off. Folia Belladonnae u. d. Atropin.

Hyoscyaminae. (P.) trichterig oder glockig. Kapseln. - Scopolia (4 Eur., As.). - Hyoscyamus (11 Eur., Nordafr., As.); H. niger lief. d. off. Herba et Semen Hyoscyami.

* Solaninae. (P.) radfg. oder glockig. Beeren. - Withania (5 palaeotrop.); $W$. coagulans (Ostind. bis Beludschistan) dient zur Käsebereitung. - Prysalis (45 calid., meist Am.). - Capsicum (30 Am.); C. апииим und C. longum lief. scharf schmeckende Fr., spanischen Pfeffer oder Paprika. - Solanum (900, meist calid.); viele mit giftigen Beeren; S. melongena, Eierfrucht, cult. in Trop.; S. lycopersicum (Peru), Liebesapfel. Tomate, mit essbaren Fr.; S. tuberosum (Chile), Kartoffel; S. nigrmm und $\boldsymbol{S}$. dulcumrm (Eur., As.) mit giftigen Beeren; letzteres lief. d. off. Stipites Dulcamarae.

b. Stf. a m Räcken der A.'ansitzend oder am Grunde des breiten Connectivs.

* Mandragorinae. - Mandragora (4 medit. und Himal.); M. officinamum, Alraunwurzel.

§ Daturear. G. durch secundäre Scheidewände 4 fächerig. - Dutura (15 calid.); D. strumonium (*), Stechapfel; die off. B. und S. enthalten Atropin; D. arborea (Chile, Peru).

B. E. gerade oder nur schwach gekrümmt.

\$ Cestreae. Alle 5 Stb. fertil.

* Cestrinae. Fr. eine Beere. S. mit Nährgewebe. - t. - Cestrum (140 trop. Am.).

* Nicotianinae. Fr. eine septicide Kapsel. S. mit Nihrgewebe. Meist Kr: - Fubiana (14 Südam.). - Nicotiana (40 Am. und *); N. tabucum (Südam.), virginischer Tabak; N. mestica (Südam.), Bauerntabak. s Salpiglossideae. Meist nur 2-4 Stb. fertil. Alle * - Salpiglossis (8 Südam.). - Petmia (14 Südam.); P. nyctaginiflora und I'. violacea 
Zierpfl. - Schizanthus (11 Chile). - Duboisin (2 Austral., Neukaledon.); D. myoporoides enthält das Duboisin, D. Hopwoodii das Piturin.

F. Leitbündel collateral.

I. G 2 fächerig mit $\propto$-wenigen Sa.

Fam. Scrophulariaceae. Bl. 5 gliederig, $\lcm{+}, \pm \%$ Stb. selten 5 , meist 4 oder 2 . Cp. (2), median, mit je $\infty$-wenigen umgewendeten oder amphitropen Sa. a. d. scheidewandst. Plac. (Gr.). Kapsel oder Beere. E. gerade oder schwach gebogen im Nährgewebe. - Kr., Halbsträucher oder $\mathrm{t}$ mit (9) oder gegenst. oder quirligen B. Bl. niemals endst., in einfachen oder zusammengesetzten Trauben oder Ähren oder Trugdolden etc. - Kein markständiges Leptom. - Etwa 2000 trop.-frigid.

Unterfam. Pseudosolaneae. Die 2 rückwärtigen $\mathrm{P}$. oder die Oberlippe decken in der Knospe die seitlichen P. B. meist (9). 5 Stb.

§ Verbasceae. (P.) ohne Röhre oder mit sehr kurzer Röhrc. Verbascum (160 Eur. und medit.); V.phlomoides und $\boldsymbol{V}$. thapsiforme lief. d. off. Flores Verbasci. - Celsia (40 medit., Afr., Ostind.).

§ Aptosimeae. (P.) mit verlängerter Röhre. - Afr., Arab., Ostind.

Unterfam. Antirrhinoidene. Deckung der P. wie bei vorigen. Wenigstens die unteren B. opp. Das hintere 5. Stb. ein Std. oder fehlend.

\$ Hemimerideae. (P.) $\mid$, ohne Röhre, gespornt. - Alonsoa (6 andines Am.).

$\$$ Calceolarieae. (P.) $\%$ mit blasig aufgetriebenen, concaven lippen. - Calceolaria (134 meist Südam., einige Centralam., Neuseeland).

$\S$ Antirrhineae. (P.) $\%$, mit flachen oder convexen Lippen, gespornt oder am Grunde sackartig, mit Röhre. - Elatinoides (23 medit. und Eur.). - Linaria (95); L. vulgaris (Eur., Sibir.) off. - Anthir»inum (32 *). - Maurandia (6 Mexiko).

$\S$ Cheloneae. (P.) $*$, ohne Sporn. Blütenstand cymös. - Halleria (8 Afr.). - Scrophularia (114 * temp.). - Pentastemon (82 Nordam., einige Nordostas.). - Paulownia tomentosa (Japan).

§ Mannleeae. (P.) $\%$, ohne Sporn, Blätenstand nicht cymös, meist einfach. A. zuletzt 1 fächerig. - Afr. Arab., Ostind.

§ Gratioleae. Wie vorige; aber A. zuletzt 2 fächerig. - Mimulus (59, meist andin. Am.). - Gratiola (24 temp.); G. officincelis (Eur., As.) lief. d. off. herba Gratiolae. - Limosella aquatica (temp., subcalid.), - Torenia (20 trop.). - Lindernia (26 trop.-temp.).

\& Selagineae. Einsamige Steinfr. oder eine nicht aufspringende wenigsamige Kapsel. - 120, ausschliesslich Südafrika, Madag. und afrikanische Gebirge. - Hebenstreitia dentata (afrikanische Gebirge).

Unterfam. Rhinanthoidece. Die 2 rückwärtigen P. oder die Oberlippe werden in der Knospe von einem oder beiden Seitenzipfeln gedeckt.

a. Zipfel der (P.) alle flach.

$\S$ Digitaleae. Die Fächer der A. zuletzt an der Spitze vereint. - Nicht Parasiten. - Sibthorpia (6); S. europaea (Westeur.). - Veronicu (200, meist * und Neu.Seeland, Austral.). - Wulfenia (3 Kärnthen, Syrien, Himalaya). - Digitalis (22 Eur., Westas.); D. pmrpurea (Westeur.) lief, d, off. Folia Digitalis, - Eninus (1 alp.). 
§ Gerardieae. Die Fächer der A. immer getrennt, manchmal 1 Fach reduciert. - Parasiten und Halbparasiten. - Gerardia (30 Am.). - Sopubia (11 Afr.). - Buchnera (30 calid.). - Striga (18 palaeotrop.). - Hyobanche (2 Sïdafr.).

b. Die 2 oberen Zipfel der (P) bilden eine helmartige Oberlippe.

§ Rhinantheae. Parasiten und Halbparasiten. - Euphresiu (50 temp. * und *). - Odontites (20 medit. und Eur.). - Rhinanthus (9 Eur.). - Pedirularis (250* und andin). - Melampymum (25 *). - Tozzia (1 Eur.). - Lathraea (3 Eur., 1 Jap.).

Fam. Bignoniaceaө. Bl. 5 gliederig, ㅎ, $\%$ Stb. 4 oder 2 , ausserdem bisweilen $1-3$ Std. Cp. (2) median, mit $\infty$ Sa. G. 2 fächerig mit je 2 an der Scheidewand stehenden Plac. oder 1 fächerig mit 2 wandst., 2 spaltigen Plac. (Gr.) mit 2 lappiger $\mathrm{N}$. Fr. eine fachspaltige oder septifrage, 2 klappige Kapsel oder fleischig und nicht aufspringend. S. I zusammengedrückt, oft häutig geflügelt. Nährgewebe 0 . E. flach, mit flachen oder zusammengefalteten Keimb. - t , seltener $\mathrm{Kr}$. mit gegenst., bisweilen (9, hfg. zusammengesetzten B. und meist ansehnlichen Bl. in einfachen oder rispigen oder trugdoldigen Blütenständen. - Hfg. eigentümliche Zerklüftung des Holzkörpers. Viele giftig. - Etwa 450 calid., wenige temp.

§ Bignonieae. G. vollkommen 2 fácherig. Kapsel septifrag, die beiden Klappen und die Scheidewand abfallend, nur ein fadenfg. Rand zurückbleibend. S. meist geflügelt. Meist Kletterpfl, seltener Bäume, hfg. init Blattranken. - Bignonia (120 Am.); B. leucoxylon (Jamaika) lief. vorzïgliches Schiffsbauholz. - Calosanthes indica (Ostind.), Rinde und Wurzel daselbst off.

s Tecomeae. G. vollkommen 2 fächerig. Kapsel fachspaltig, die beiden Klappen und die Scheidewand abfallend. S. hfg. geflügelt. t, seltener Kr., niemals mit Blattranken. - Catalpa syringifolia (atlant. Nordam.). - Tecoma radicans (atlant. Nordam.); T. stans (Westind.). Incarvillea (China, Turkestan).

§ Eccremocarpeae. G. vollkommen 2 fächerig, mit zuletzt verschwindender Scheidewand. Kapsel 2 klappig. - Eccremocarpus (3 westl. Südam.). - Jacaranda obtusifolia (Sïdam.) lief. das Palixanderholz.

§ Crescentieae. G. 1 fächerig, init 2 parietalen, nur am Grunde vereinten Plac. Fr. nicht aufspringend, mit ungeflügelten, der faserig pulpösen Plac. eingebetteten S. - t ohne Ranken. - Crescentia (15 trop). Im.); C. cujete, Kalabassenbaum (trop. Am.), die Fr. dienen als Gefässe. - Kigelire pinnata (trop. Afr.) mit grossen leberwurstähnlichen Fr.

Fam. Pedaliaceae. Bl. 5 gliederig, $\not{\psi} \%$ Stb. 4 oder 2 mit paarweise zusammenneigenden A. Cp. (2), selten (3-4) mit je $\infty$ Sa. G. $2-4$ fächerig mit quergefächerten Fächern. Sa. in jedem Fach $1-\infty$, centralwinkelständig. Kapsel oder Nuss, meist mit erhärtetem Endocarp. S. mit dünnein Nährgewebe. - $\odot$ und $4 \mathrm{Kr}$. mit Schleimdrüsenhaaren. mit gegenst. oder oberwärts (9), ganzrandigen bis fiederspaltigen $\mathrm{B}$. Bl. axillär oder in Trauben.

§ Pedalieae. Thecae getrennt, fast lıängend. G. 2 fächerig. Bl. axillär. Ifr., Ostind. - Pedalium. - Harpagophytum (Südafr.) mit vielhakiger Fr.

§ Sesameae. Thecae der A. dorsifix. G. 2 fächerig, zuletzt 4 fächerig. Bl. axillär. - Sesumum (16 Afr., Ostind.); S. inflicum, Sesam (Ostind.), wichtige Ölpfl. 
§ Pretreeae. Thecae der A. dorsifix. G. 1-4 fücherig, oft noch durch Querfächerung 2-8 fächerig. - Preirea (Ostafr.).

II. G. 1 fächerig, mit \pm wandständigen Placenten und $\infty \mathrm{Sa}$.

Fam. Martyniaceae. Wie vorige; aber Thecae der A. gespreizt. G. mit 2 einspringenden, parietalen, 2 spaltigen Plac. Kapsel, zuletzt 4 kammerig. Bl. in Trauben. - 12 Am. - Martynia (Reizbarkeit der Narben beachtenswert).

Fam. Orobanchaceae. Bl. 5 gliederig, ㅎ․ $*$. (P.) deutlich 2 lippig. Stb. 4, didynamisch. Cp. (2) median, selten (3), jedes Cp. mit 2 wandst., getrennten oder in der Mitte des Faches vereinten Plac. mit $\infty$ umgewendeten Sa. Gr. 1, N. 2-4 lappig. Fachspaltige Kapsel. E. wenigzellig. kugelig, im fetthaltigen Nährgewebe. - $\odot$ und 24 parasitische $\mathrm{Kr}$. mit schuppenfg. B. und einzelnen Endbl, oder Trauben. - Etwa 150, meist temp. *, wenige trop. und *. - Orobanche (83); O. ramosa (Eur. und Medit.), besonders auf Hanf und Tabak, O. minor (Medit., Westeur.), besonders auf Klee.

Fam. Gesneraceae. Bl. 5 gliederig, ఫ̧, $\cdots$ (P.) \pm 2 lippig. Stb. 4 oder 2, ausserdem bisweilen 1-3 Std.; die A. paarweise oder alle zusammenneigend. Cp. (2) median. G. bis $\bar{G}$., 1 fächerig mit 2 wandst., oft 2 spaltigen Plac. mit $\infty$ kleinen Sa. (Gr.) mit breiter, kopffg. oder 2 lappiger N. Kapsel oder Beere mit $\infty$ kleinen S. Nährgewebe † oder 0 . E. gerade, fast stielrund, mit kleinen Keimb. - Kr. oder I mit gegenst., ganzrandigen oder gezähnten B. und ansehnlichen, einzeln oder in Trugdolden stehenden Bl. - Etwa 800 calid., wenige temp.

Unterfam. Cyrtandroidece. G. frei.

$\S$ Ramondieae. (P.) fast $\oplus$ bis $\%$ Stb. 5, 4, 2. Kapsel länglich. septicid 2 klappig. - 4 Kr. mit grundständiger Blattrosette. - Ramondia (3 Pyren. und Serbien). - Haberlea (1 Rhodopegebirge). - Saintpaulia (1 Usambara).

$\S$ Roettlereae. (P.) $\oplus$ bis $\%$ Stb. 5, 4 oder $2 . \quad$ Kapsel länglich, fachspaltig. - Roettlera (100 ind.-malay. und Madag.).

$\S$ Championieae.

$\$$ Streptocarpeae. (P.) glockig oder trichterförmig, $\%$; Stb. 2; Kapsel 2-4 klappig, mit gedrehten Klappen. - Boea (15 trop. As.). - Streptocarpus (40 Afr., Madag.); St. polyanthus u. a. mit 1 grossen ausdauernden Keimb.

§ Trichosporeae. (P.) $\%$, Stb. 4, Kapsel lineal. S. mit haarförmigen Anhängseln. - Trichosporum (70 trop. As.).

§ Klugieae. Kapsel kurz, im K. eingeschlossen, fachspaltig, 2 klappig. Klugia (4 trop. Am.).

§ Hemiboeeae, § Auctantheae.

$\S$ Beslerieae. Stb. 4. Beere, selten quer aufreissende Kapsel, - Kr. oder Sträucher. - Besleria (50 trop. Am.).

§ Coronanthereae. Stb. 4. Fr. verschieden. - Oft kletternde Sträucher mit gegenst, kleinen B. - Alle *

$\S$ Cyrtandreae. Nur die 2 vorderen Stb. fruchtbar. Fr. niemals aufspringend, eiförmig. Sträucher oder Halbstr., auch kleine Bäuıne. Cyrtandra (180 meist auf den Inseln des ind. und stillen Oceans). 
$\S$ Columneeae. (P.) verschieden. Von allen vorigen durch den in Drissen zerteilten Discus verschieden, eine Drüse an der Hinterseite der Bl. gross. - Columnea (70 trop. Am.).

\section{Unterfam. Gesmeroidene. $\bar{G}$. Kapsel. - Alle trop. Am.}

$\S$ Bellonieae. (P.) radfg. oder glockig. Kein Discus. - Nicht knollig. Antillen, trop. And.

§ Gloxinieae. Röhre der Blkr. cylindrisch bis glockig. Discus ringfg. oder gelappt. - Nicht knollig. - Trop. Am. - Gloxinia (6 Brasil. bis Mexiko). - Achimenes (25 Brasil. bis Mexiko). - Smithiantha (6 Mexiko).

\section{$\S$ Kohlerieae. § Solenophoreae.}

$\S$ Sinningieae. (P.) meist mit längerer Röhre. - Kr. mit knolligen Rhizomen und gegenst. oder quirligen B. - Corytholoma (50 meist Südam.).

§ Gesnereae. Röhre der (P.) cylindrisch bis glockig. Discus ringfg. - Knollengewächse oder Sträucher. - Gesnera (35, meist Westind.) mit wechselständ. B.

Fam. Columelliaceae. Bl. 5-8 gliederig, ఫ̧, fast $€$. Stb 2 , mit langem, gefaltetem, ungeteiltem Fach der A. Cp. (2) median, mit $\infty$ Sa. G. mit 2 wandst., 2 spaltigen, in der Mitte des Faches sich fast berührenden Plac. Kapsel 4 klappig. s. mit Nährgewebe und kleinem E. - $\hbar$ mit gegenst., ganzrandigen B. und in Trugdolden stehenden Bl. - Columellia (2 andin. Südam.).

III Frkn. nur noch selten 2fächerig, meist 1 facherig, mit centralständiger Plac. und $\infty \mathrm{Sa}$.

Fam. Lentibulariaceae. Bl. 5 gliederig, $\Varangle$, selten $\phi$, meist $\%$ (P.) meist deutlich 2 lippig. Stb. selten 5, meist 2 an der Basis der Blkr. frei werdend. Cp. (2) median. G. mit scheidewandständiger, häufiger nit freier mittelst. Plac., mit $\infty$ umgewendeten Sa. Kapsel mit 2 bis 4 Klappen und $\infty$ samig oder geschlossen und 1 samig. S. ohne Nährgewebe. - Kr., meist im Wasser oder zwischen Moos epiphytisch wachsend, oder auf feuchtem Boden, häufig ohne Wurzel. - Etwa 250 calid.-temp.

Byllidoidece. Bl. $\oplus$, ohne Sporn. Stb. 5. G. 2 fächerig. Byblis (2 Austral.).

Utricularioideae. Bl. $\%$, mit Sporn. Stb. 2. G. 1 fächerig mit freier, mittelständiger Placenta.

\$ Utricularieae. Blkr. mit deutlichem Sporn. Sa. $\infty$. Wasser- und Landpf. - Pinguicula (30). - Genlisea (10 trop.). - Utricularia, mit sehr verschieden gestalteten $B$., vielfach mit insektenfangenden Schläuchen (250 trop.-temp.).

$\S$ Biovularieae. Blkr. mit abgerundeter spornartiger Aussackung. Sa. 2. Wasserpfl. - Biovularin (Westind.).

IV. Frkn. 2- oder 1 fächerig, in jedem Fach oder aber. haupt mit 1 hängenden Sa.

Fam. Globulariaceae. Bl. 5 gliederig, ̧ㅗ, $\%$ Stb. 4 oder 2 mit zu. letzt 1 fächerigen A. Cp. (2), mit je 1 oder im Ganzen nur mit 1 Sa. (Gr.). Fr. je 2 Coccen teilbar oder 1 fächerig und 1 samig. E. fast stielrund, vom" Nährgewebe umgeben. - $4 \mathrm{Kr}$. mit verkehrt-eifg. oder länglichen Grundb. und in kugeligen Köpfchen oder Ähren stehenden Bl. 
- 20 temp. Eur., Makarones., Socotra. - Globularia (17 medit. und alp.).

5. Unterreihe Acanthineae. Bl. meist $\cdots$, typisch 5gliederig. Stb. 4 oder 2. Cp. (2), mit meist $\infty$ Sa. Kapsel bis zum Grunde fachspaltig.

Fam. Acanthaceae. Bl. 5 gliederig, meist $\not{\leftarrow}, \cdots$ K. frei oder vereint. (P.) $\oplus$ oder $\cdots, 2$ lippig. Stb. 4 oder 2 , bisweilen noch $1-3$ Std. Pollen sehr mannigfach. Cp. (2) median, mit je $\infty-22$ reihig oder 1 reihig stehenden, umgewendeten oder amphitropen Sa. Kapsel von der Spitze bis zum Grunde fachspaltig, mit zurïckgekrïmmten, in der Mitte die halben Scheidewände tragenden Klappen; ausnahmsweise Steinfr. S. meist ohne Nährgewebe, hfg. durch hakenförmige Auswüchse des Funiculus (Jaculatoren) gestützt. - Kr. oder Sträucher, selten kleine Bäume mit gegenst. B. und in einfachen oder aus Trugdolden zusammengesetzten Ähren oder Trauben stehenden Bl. - Bisweilen inneres Phloëm. Mannigfache Cystolithen - Etwa 1500 calid.

Unterfarn. Nelsonioialeae. Sa. $\infty$. Jaculatoren papillenförmig. Spaltenpollen mit Porus. - Nelsonia (1 calid.).

Unterfam. Mendoncioideae. Sa. 4, stets höchstens 2 S. Fr. steinfruchtartig. Jaculatoren 0. Glatter runder Pollen. - Mendoncia (20 trop. Am.).

Unterfam. Thumbergioideae. Sa. 4. Kapsel. Jaculatoren papillenförmig. Furchenpollen. - Thunbergia (72 palaeotrop.); Th. alata (Ostafr.) Zierpfl.

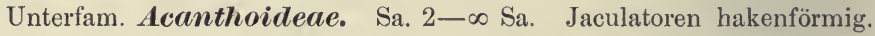
dachig.

A. Contortae. P. gedreht, selten anders, niemals aufsteigend

\& Trichanthereae, Lontheridieae, Hygrophileae, Petalidieae, Strobilantheae, alle mit Rippenpollen, letztere mit stielrunder Kapsel, - Hierher Strobilanthes (120 As. calid.).

$\S$ Ruellieae. Wabenpollen. Cp. mit $\infty-2$ Sa. - Ruellia (200 calid.). - Eranthemum (17 trop. As.).

$\S$ Barlerieae. Wabenpollen. Cp. mit 2 Sa. Stf. frei, nicht genähert. - Barleria (100 trop. Steppen).

B. Imbricatae. P. aufsteigend dachig gedeckt. Oberlippe bis. weilen fehlend.

\& Acantheae. Stb. 4. Spaltenpollen. Oberlippe fehlend oder (P.) hinten tief gespalten. - Blepharis (40 palaeotrop., medit.). - Acanthus (20 medit., palaeotrop.).

§ Aphelandreae. Wie vor.; aber Oberlippe. - Aphelandra (60 trop. Am.).

$\S$ Andrographideae (Daubenpollen), § Asystasieae, Graptophylleae (Rahmenpollen), § Pseuderanthemeae, Spangenpollen und glatter Pollen, § Odontenemeae (nur Spangenpollen).

§ Isoglosseae. Gürtel- und Stachelpollen. Stb. 2.

§ Justicieae. Knötchenpollen. Stb. 2. - Justicia (incl. Adhatoda 250 trop.); J. adhatoda (indisch-malayisch). 
6. Unterreihe Myoporineae. Bl. 5gliederig, 申 oder ... Cp. (2) wit je 2-4-8 Sa. oder Cp. (2- - ) mit je 1 hăngenden, die Mikropyle nach oben kehrenden Sa. Steinfr. mit gefächerten Endocarp oder $2-\infty$ Steinkernen.

Fam. Myoporaceae. Bl.5gliederig, $\oplus$ oder $\cdot$ Stb. 5 oder 4. Das 2 fächerige G. durch nachtriagliche scheidewandbildung oft 4 facherig; in anderen Fällen das G. 2- $\infty$ fächerig. (Gr.). Steinfr. mit gefächertem Endocarp oder mit 2-10 samigen Steinkernen. Nahrgewebe dinn oder (). E. mit halbstielrunden Keimb. - t mit (Q) oder gegenst., ganzrandigen oder gezähnten, durchsichtig punktierten B. und cinzeln oder in Büscheln stehenden Bl. - Ölzellen - Etwa 80 Ostas, Austral. und oceanische Inseln. - Myoporum (20), - Eremophila (40 Austral.).

7. Unterreihe Phrymineae. Bl. $\cdot \mid \cdot 1 \mathrm{Cp}$. mit 1 geradläufigen nach oben gekehrten Sa.

Fam. Phrymaceae. Aufrechtes Kr. mit gegenständigen, dünnen B. Bl. klein, in den Achseln sehr reducierter Tragb., kurz gestielt. - Phryma (1 Ostas., Nordam.).

6. Reihe PLANTAgInales. Bl. 4 gliederig, his auf die $\mathrm{Cp}$. gleichzïhlig, ఫ̧ und $\sigma^{\top}$ ㅇ, $\oplus$. B. meist (Q). - Meist Kr., seltener mit holzigem Stanm.

Fam. Plantaginaceae. K. 4. (P. 4), trockenhäutig. Stb. 4, gleich unten mit der (P.) vereint. Cp. (2 oder 1), bisweilen nochmals gefächert, mit einigen bis 1 umgewendeten Sa. G. $4-1$ fächerig. Kapsel quer aufspringend oder Nuss. S. mit Nährgewebe. E. gerade. - Kr., selten Halbsträucher mit (9), selten gegenst., meist ungeteilten B. und in Ähren stehenden Bl. - Plantago (200, meist temp.); P. psyllium (medit.) giebt "Flohsamen", Semen Psyllii; ähnlich $P$. cynops (medit.) und P. arenaria (Eur.). - Litorell lacustris (in Landseen).

\section{Insertion der Blh. epygynisch.}

\section{Stb. frei.}

7. Reihe RUBIALES. Bl. typisch 5-4 gliederig, mit gleichzähligen oder minderzähligen Stb. oder Cp., $\oplus$ oder $\uparrow$ od. unregelmässig. $\overline{\mathrm{G}}$. gefächert od. 1 fächerig, in jedem Fach mit $\infty-1$ umgewendeten Sa. - t und $\mathrm{Kr}$. mit gegenständigen, meist ungeteilten, seltener geteilten $\mathrm{B}$.

A. Stb. in gleicher Anzahl mit den Abschnitten der Blkr.

Fam. Rubiaceae. Bl. 4-5., selten mehrgliederig, mit isomerem oder meist oligomerem $\bar{G}$., $\not{\gamma}$, selten $\sigma$ o , $\oplus$, selten $\%$. K. meist ohne Deckung. (P.) in der Knospe klappig, dachig oder linksgedreht. Cp. meist (2), seltener $(1-\infty)$, mit je $1-\infty$ umgewendeten Sa. (Gr.) mit kopfigem oder verzweigtem Ende. Halbfr. verschieden, selten $1 \mathrm{fächerig.} \mathrm{-} \mathrm{Kr.}$ oder $\mathrm{t}$ mit kreuzgegenst. und ganzrandigen B. und Nebenb., welche bisweilen wie die Hauptspreiten entwickelt sind. Bl. meist in Rispen oder Cymen, letztere nicht selten zu Köpfen vereint. - Etwa 4500 calid. bis frigid.

Unterfam. Cinchomoideae. Cp. mit $\infty$ Sa.

A. Halbfr. trocken.

a. Bl. einzeln oder in decussierten Rispen.

$\S$ Condanineae. Bl. $\oplus$. (P.) klappig. Sa. horizontal. Sa. mngefluggelt. Nelıenb. ganz orler zweiteilig. - 古 mit ansehnlichen Bl. - Meist trop. Am. 
§ Oldenlandieae. Wie vor.; aber mit vertical gestellten Sa. und oft borstig zerschlitzten Nebenb. - Meist Kr. Init kleinen Bl. - Oldenlandia (170 trop.).

$\S$ Rondeletieae. Bl. $\oplus$. (P.) dachig oder gedreht. S. ungeflügelt. - Sickingia (14 trop. Am.); melirere geben d. off. Arariba-Rinden.

$\S$ Henriquezieae. Bl. $\cdot$. S Sth. ungleich hoch in der Röhre der (P.). S. ungeflügelt. - Henriquezia (Amazonenstrom).

$\S$ Cinchoneae. Bl. $\oplus$. Sa. aufsteigend. Halbfr. kapselartig, fachoder wandspaltig. S. geflügelt. Meist $\hbar$ mit interpetiolaren Nebenb. Cinchona $\left(30-40\right.$ trop. Am., Ostabhang der Anden $10^{0}$ n. Br. bis $19^{\circ}$ s. Br.. $1600-2400 \mathrm{~m}$; cult. in trop. As.); C. calisaya var. Lealgeriana lief. d. off. Cortex Chinae regius; C. succivulra lief. Cortex Chinae ruber. - Ladenbergia (31 trop. Am.); I. hexandra lief. Quina do Rio; L. pedunculata lief. China cuprea. - Remija (14 trop. Am.); R. fermginea (Südbras.) lief. Quina do Serra. - Bouvardia (30 Centralam.); inehrere Zierpfl. - Exostema (20 Westind.); Rinden ehemals Fiehermittel. - Coutarea hexandra (trop. Am.) lief. die Quina do Pernambuco.

b. Bl. in $\mathrm{Kopfchen.}$

§ Naucleeae. - Ourouparia (Uncaria, 30 meist trop. As.); $\boldsymbol{O}$. gambir (ind.-malay.); die B. geben off. Catechu. - Nauclea (30 trop. As.). - Cephalanthus (4 Am., 1 Afr., 1 As.); C. occidentalis (Nordam.).

B. Halbfr. saftig.

§ Mussaendeae. (P.) klappig. - Mussaenda (30 palaeotrop.) mit 1 stark vergrösserten corollinischen Kelchblatt.

§ Gardenieae. (P.) dachig oder gedreht. - Randia (100 trop.). - Gardenia (60 palaeotrop.); G. Alorida (China; cult. in Warmhäusern) lief. die Gelbschoten des Handels.

Unterfam. Coffeoidece. Cp. mit je 1 Sa.

A. Mikropyle der hängenden Sa. nach oben.

§ Vanguerieae. Stb. am Schlunde oder am Saum der Blkr.röhre frei werdend. Steinfr. S. mit Nährgewebe. - †. - Vangueria (30 meist trop. Afr.); V. edulis (trop). Afr.) mit wohlschmeckenden Fr.

§ Guettardeae. Wie vorige; aber S. ohne Nährgewebe. Cp. $(2-\infty)$. - Gueltarda (40 trop. Am).

§ Chiococceae. Stb. am Grunde der Blkr.röhre frei werdend. Cp. $(2-\infty)$. S. mit Nährgewebe. - Chiococca anguifuga (Südam.); Wurzel gegen Schlangenbiss gebraucht.

B. Mikropyle der aufstrebenden Sa. nach unten.

a. (P.) gedreht.

§ Ixoreae. - Coffer (25 palaeotrop., meist Afr.); C. (urctbicu, Kaffeebaum (Abyssinien, Mozambique, Angola; cult. in Trop., besonders Brasil.); C. Tiberice (Westafrika). - lwora (100 trop.).

b. (P.) klappig.

$\alpha$. Sa. am Grunde des G.

I. G. $2-\infty$ fächerig, mit dicker Scheidewand.

$\S$ Psychotrieae. Stb. am Schlunde der (P.) frei werdend. Äste des Gr. kurz. Steinfr. - t. - Psychotria (etwa 350 trop.). - Uragogy (150 trop., meist Brasil. = Cephaëlis); U. ipecacurnha (Westbrasil.) lief. d. off. Radix Ipecacuanha. - Hydnophytum (30 ind.-malay.) und 
Myrmecolia (18 ind.-malay.) interessante epiphytische Ameisenpfl. mit Knollen.

§ Paederieae. Wie vorige; aber Äste des Gr. lang. Trockene Fr.

Anthospermeae. Sth. am Grunde der (P.) frei werdend. Bl. diöcisch. - Plylis nobla (Canaren). - Anthospermum (25 Afr.). - Serissa foetida (Ostas.). - Nertera $(6 *) ; N$. depressa, Zierpfl. - Coprosma (40 *). - Mitctella (2 Nordam., Japan). - Plocama pendula (Canaren).

II. G. 1-2 fächerig mit dünner Scheidewand.

s Coussareeae. - 140 trop. Am.

(3) Sa. an der Scheidewand des G.

$\S$ Morindeae. $\hbar$ mit ungeteilten und nicht laubigen Nebenb. - Morinda (40 trop ). - M. citrifolia (cult. in Ostind.); B. u. Fr. dort im Gebrauch.

§ Spermacoceae. Kr. und Halbstrulucher mit zerschlitzten Nebenb. - Richardsunia $(4 \mathrm{Am}$.). - Burreria (80 calid.).

Galieae. Kr. mit laubigen Nebenb. - Sherardia (Eur., As.). Cruciunella (meist medit.). - Asperula (80 medit., Ostas., Austral.); 1. odoruta, Waldmeister (Eur., Westas., Nordafr.). - Galium (250). - IBubia (7); R. cordifolia (Kapland) und R. tinctomum (medit.) als Krapp liefernde Pfl. cult.

Fam. Caprifoliaceae. Bl. meist 5 gliederig, mit isomerem oder oligo-

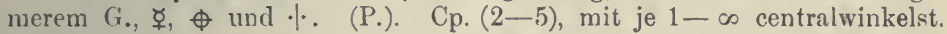
hängenden Sa. Gr. getrennt oder (Gr.). Halbfr. beeren- oder steinfr.artig, selten Kapsel. S. mit fleischigem Nährgewebe und kleinem E. - Meist to mit gegenst. B., selten mit Nebenb. - Etwa $270 *$ und andin.

§ Sambuceae. B. fiederschnittig. Steinfr. A. nach aussen aufspringend. - Sambucus (20, keine in Afr.); S. nigra, schwarzer Hollunder, d. Bl. off.

§ Viburneae. B. ungeteilt oder nur gelappt, Cp. (1-5) mit je $1 \mathrm{Sa}$. Beere oder Steinfr. A. nach innen aufspringend. - Vibumum (63 * und andin).

\$ Linnaeeae. B. ungeteilt. Cp. $(2-5-8), 2$ mit $\infty$ Sa., $1-2$ mit 1 Sa. - Symphovicarpus (8 Nordam.). - Linnaea (20, incl. Abelia); L. Horealis (boreal-circumpolar).

\$ Lonicereae. B. meist ungeteilt. Cp. $(2-5-8)$; alle mit $\infty$ Sa. - Ionicere $(100 *)$; T. caprifolium, Gaisblatt (Eur.). - Dievvilla (5 Ostas., Nordam.); D. florida (China), Zierstrauch. - Jeycesteria (3 Himal.).

Fam. Adoxaceae. Bl. ఫ్ , ๑. K. $(2-3)$, selten K. (4-5). P. $(4-6)$. Stb. 4-6, gespalten. Cp. $(3-5)$, mit je 1 hängenden Sa. Steinfr. mit 1-3 Kernen. E. klein, im Nährgewebe. - t Kr. mit Rhizom. Stengel mit 2 gegenst. Laubb. u. 5-7 blütigem Knäuel. - Einzige Art: Adoxa moschatellina (* temp.).

B. Stb. in geringerer Zahl als Abschnitte der Blkr. $\overline{\text { G. }}$ stets mit nur 1 fruchtbarem Fach und 1 hängenden Sa.

Fam. Valerianaceae. Bl. ఫ̧ oder $\sigma^{\nearrow}$ ㅇ, unregelmässig. K. zur Blütezeit wenig deutlich, später vergrössert, als Haarkrone entwickelt. P. (5) oder (3 his 4), am Grunde oft 1 Höcker oder Sporn. Stb. 1-4. Cp. (3), aber 
nur 1 mit 1 hängenden, umgewendeten Sa. (Gr.), mit $1-3 \mathrm{~N}$. Nährgewebe 0 . - Kr. mit gegenst. B. ohne Nebenb. und in entwickelten oder verkürzten Trugdolden stehenden Bl. Valeriansäure. - Etwa 224 * und andin. - Patrinia (13 Central- und Ostas.). - Nardostachys (2 Himal.). -Valevianella (41 meist inedit.); V.olitoria, Rapunzelchen. - Fedia (1 medit.). - Valeriana (150 * und andin); $\boldsymbol{V}$. officinalis (Eur., As.) lief. d. off. Baldrianwurzel; V. celtiru Speik (alp.). - Centronthus (12 medit.).

Fam. Dipsacaceae. Bl. ్, meist $\%$ Stb. 4 oder weniger. Cp. (2); aber das G. 1 fächerig, mit nur 1 hängenden Sa. (Gr.) mit $1-2 \mathrm{~N}$. Nährgewebe + . $-\mathrm{Kr}$. oder Halbsträucher mit gegenst. B. ohne Nebenb. und in Köpfchen oder Trugdolden stehenden Bl., letztere mit einem aus Vorb. gebildeten Aussenkelch. - Etwa 146, meist medit. - Cephalaria (30, meist östl. medit.). - Dipsacus (12 Eur., medit. und Ostind.); D. fullonum (Südwesteur.), Weberkarde. - Succisa (2-4 medit., Eur.). - Knantia (13 Eur., medit.). - Scabiosa (53 Eur., As., meist medit.).

\section{Stb. zusammenneigend oder teilweise vereint.}

8. Reihe CAMPANULATAE. Bl. typisch 5 gliederig, mit gleichzähligen Stb. und meist minderzähligen $\mathrm{Cp}$. Die A. der Stb. zusammenneigend und hfg. mit einander sämtlich oder teilweise vereint. $\overline{\text { G. }}$ mehrfächerig mit $\infty-1$ Sa. in den Fächern oder 1 fächerig mit $1 \mathrm{Sa}$. - Meist Kr., seltener $t$.

1. Unterreihe Cucurbitineae. A. mit zwei 1 fächerigen Thecis, ent. weder 5 frei oder je 2 vereinigt oder alle 5 in ein centrales Syundrium verbunden.

Fam. Cucurbitaceae. Bl. selten $\not{x}$, meist $\sigma^{\nearrow}$ 우, $\phi$. Blütenaxe becherförmig. Stb. 5, 2 fächerig, am Rande der becherförmigen Axe, je 2 vereinigt oder alle 5 in ein centrales Synandrium verbunden. Cp. meist (3), mit je 2 meist nach aussen zurückgebogenen Plac. mit meist $\infty$ ungewendeten Sa. $\bar{G}$. meist 3 fächerig. (Gr.) mit 3 commissuralen gegabelten N. Halbfr. meist beerenartig. Nährgewebe 0 . E. mit grossen, breiten ölreichen Keimb. - Meist $\odot$ Kr., selten Halbsträucher, kletternd vermöge der neben den B. stehenden (Sprossanlagen entsprechenden) Ranken, mit (9) rundlichen bis vielfach zerteilten, meist gelappten B. - Markst. Leptom. - Etwa 650 calid.

A. Pollenfächer nicht zu einem kreisförmigen Ring vereinigt.

a. Stb. 5, nur am Grunde vereint, sonst frei.

$\S$ Fevilleeae. - Fevillen (6 trop. Am.). - Thladiantha (8 Ostas.); T. dubia (China). b. Stb. 5 , meist je 2 vereint.

$\S$ Melothrieae. A. mit geraden oder wenig gebogenen Pollenfächern.

* Melothriinae. A. mit je 2 Pollenfächern. Sa horizontal. Discus am Grunde des Gr. - Melothria (60 calid.).

* Anguriinae. Wie vorige; aber kein Discus. - Anguria (17 trop. Am.). - Gurania (49 trop. Am.).

* Telfairinae. A. mit je 4 Fächern. - Telfaivia pedata (Ostafr.) mit $1 \mathrm{~m}$ langen Fr, deren S. wertvolles Speiseöl liefern. 
\$ Cucurbiteae. A. mit $\boldsymbol{c}$ - oder U-fg. gewundenen Fächerı.

* Cucumerinae. Sa. $\infty$, horizontal. Blkr. radfg. mit ganzen P. Acanthosicyos horrida Naraspflanze (Südwestafr.). - Momordica (25 trop. Afr., As.). - Luffa (7 trop.); L. cylinalrica (trop. Afr., As.) lief. die Luffaschwämme; Fr. esshar. - Bryonia (8 medit.); B. alba, Zaunrübe (Eur., W'estas.). - Ecballium (1 medit.). - Citrullus (4 Afr.); C. Mulgaris, Wassermelone (Südafr.), C. colocynthis (Afr., Ostind., medit.) d. off. Fruct. Colocynthidis. - Cucumis (26 calid.); C. melo, Melone (trop. As., Afr.); C. sativus, Gurke (Ostind.). - Benincasa hispida (trop. As.); Fr. mit Wachsüberzug. -- Lagenaria vulgaris, Flaschenkürbis (palaeotrop.).

* Trichosanthinue. Wie vorige; aber P. vielfach zerschlitzt. - Trichosanthes (42 ind.-malay.).

* Cucurbitinae. Sa. $\infty$, horizontal. Blkr. glockig. - Cucurbitu (10 trop. Am.); C. maxima und C. pepo, Kürbis.

§ Sicyoideae. Sämtliche $5 \mathrm{Stb}$. zu einem Synandrium vereint. Serhium edule (trop. Am.); der S. keimt schon in der Fr. - Sicyos (30 Am., pacif. Inseln und Austral.).

B. Pollenfächer zu einem kreisfg. Ringe vereint.

s Cyclanthereae. Cyclanthera (30 Am.).

2. Unterreihe Campanulineae. A.5, seltener nur 2 mit zwei 2 fäche. rigen Thecis.

Fam. Campanulaceae. Bl. meist 5 gliederig, seltener $6-10$ - oder $3-4$ gliederig, meist $\lcm{+}, \oplus$ oder $\%$. P. selten frei, meist vereint. Stb. unter sich frei oder vereint, mit introrsen $\mathrm{A}$. Cp. meist $(2-5)$, mit $\infty$ umgewendeten Sa. (Gr.) oft mit Sammelapparat für Pollen. G. gefächert mit centralwinkelst., selten hängenden oder aufsteigenden Plac., selten 1 fächerig. Halbfr. kapsel-, selten beerenartig. Nährgewebe fleischig. E. gerade. - Kr., Halbsträucher oder $\mathrm{t}$, meist mit (9) $\mathrm{B}$. und häufig ansehnlichen Bl. - Meist gegliederte Milchsaftschläuche. Bisweilen inneres Leptom. - Etwa 1000, vorzugsweise temp., subtrop.

Unterfam. Campamuloidene. Bl. $\oplus$, selten etwas $\%$ A. meist frei. S Campanuleae. (P.) in der Knospe klappig. Bl. symmetrisch.

A. In isomeren Bl. die Cp. vor den K. und Stb.

* Campanulinae. Halbfr. kapselartig, sich seitlich öffnend oder geschlossen bleibend, seltener eine Beere. G. stets unterst. - Сатрапиla (230 *, meist medit.). - Adenophora (10 Eur., As.). - Specularia (10 *). - Michauxia (Orient) mit 7-10gliederigen Bl. - Phyteuma (40 medit., alp., Europa). - Canarina (1 Canaren, 1 Ostafr.).

* Wahlenbergiinae. Halbfr. kapselartig, am Scheitel sich offnend oder beerenartig. G. unterst. bis oberst. - Wahlenbergia (70 meist *). - Hedraeanthus (11 medit. Gebirge). - Jasione (5 Eur., medit.).

B. In isomeren Bl. die Cp. vor den P.

* Plutycodinae. G. unterst. oder halbunterst. - Platycodon (Ostas.). - Musschia (2 Madeira).

$\S$ Pentaphrngmateae. (P.) in der Knospe klappig. B. asymmetrisch. Bl. in ilursiventralen Wickeln. - P'entuphruymu (4 ind -malay.). 
* Splienocleeae. (P.) in der Knospe dachig. Gr. ohne Sanımelhaare. - Sphenoclea zeylanica (trop.).

Unterfam. Cyphioidece. Bl. ·. Stf. zuweilen vereint, die A. aber frei. Cyphia (20 Afr., meist Südafr.).

Unterfam. Lobelioideae. Bl. $\%$ und resupiniert. A. verwachsen. - Centropogon (80-90 Südam.). - Siphocampylus (100 trop. Am.). Dialypetalum (1 Madagaskar) mit freien P. - Lobelia (200 calid.); I. influtu (Nordam.), das Kraut off.; I. dortmanna (Eur., Nordam.), Wasserpfl. - Pratia (16*).

Fam. Goodeniaceae. Bl. 5 gliederig, ㅎ, meist $\cdot \mid \cdot$. Stb. frei oder mit den P. vereint. Cp. (2) mit je $\infty$ Sa. Meist G., selten F., $2-1$ fächerig. Gr. dicht unterhalb der N. mit napfförmigem oder zweilippigem Pollenbecher. Hallofr. kapsel-, selten steinfr.- oder nussartig. E. gerade. - Kr., Halbsträncher oder Sträucher, mit meist ungeteilten B. - Kein Milchsaft. - 203 Austral.

Unterfam. Goodenioideae. Bl. einzeln oder in lockeren Inflorescenzen. (P.) in der Knospe gefaltet. G. mit $2-\infty$, selten mit 1 Sa., halb oder ganz unterständig. S. mit Nährgewebe. - Goodenia (50) Austral.). - Selliera (2); S. radicans (*) - Scaevola (60, meist Austral.), Sr. Koenigii (trop. Küsten).

Unterfam. Brunonioideae. Bl. in Köpfchen. (P.) in der Knospe klappig. G. oberst., mit 1 grundst. Sa. Kein Nährgewebe. -- Brunonin (1 Austral.).

Fam. Candolleaceae (Stylidiaceae). Bl. typisch 5 gliederig, ̧ㅜ oder $\overbrace{}^{\nearrow}$, selten $\phi$, meist $\%$ (P.) in der Knospe dachig. Stb. 2, mit dem Gr. vereint und mit extrorsen A. Cp. (2). G. 2 fächerig oder 1 fächerig, Halbfr. scheidewandspaltig oder geschlossen bleibend. E. in fleischigem Nährgewebe. - Kr., seltener Halbsträucher mit ungeteilten B. - Etwa 100.meist Austr. - Candollea (85); C. adnata, mit reizbarem Gynostemium.

Fam. Calyceraceae. Bl. 4-6 gliederig, $\Varangle$ oder $\sigma^{7}$ ㅇ, $\oplus$ oder $*$ K. 5. Stf. vereint; aber A. frei, intrors. G. 1 fächerig, mit 1 umgewendeten, hängenden Sa. G. einfach, mit kopffg. N. S. mit wenig Nährgewebe und geradem E. - Kr. oder Stauden'mit (Q) B. Köpfchen von einer aus Hochb. gebildeten Hülle umgeben. 23 andin. Südam.

Fam. Compositae. Bl. 5 gliederig, 후 oder $\delta^{\nearrow}$ 우, $\oplus$ oder $\cdots$ Kelchb. selten deutlich entwickelt, an Stelle derselben zahlreiche Haare, Borsten und Schüppchen einen sogenannten Pappus bildend. (P.) $\oplus$ oder $\%$, 2 lippig oder $\%$ zungenfg. Stb. am Grunde mit der Röhre der (P.) vereint; die Stf. meist frei, die A. meist in eine Röhre vereint, nach innen sich öffnend. Cp. (2) median; aber G. 1 fächerig mit 1 umgewendeten aufsteigenden Sa. Gr. in den fertilen Bl. an der Spitze 2 spaltig; die Schenkel an der Innenseite die N. tragend, aussen oder unter der Spitze mit Sammelhaaren. 1 samiges Achänium. S. ohne Nährgewebe. E. gerade, mit flachen oder halbcylindrischen, zuweilen eingerollten Keimb. - $\mathrm{Kr}$., Sträucher und seltener $\hbar$ mit meist (Q), seltener gegenst. B. und meist in Köpfchen oder verkürzten Ähren stehenden Bl. Köpfchen mit Involucrum von Hochb.; die Tragb. der Bl. als „Spreuschuppen entwickelt oder fehlend; Blütenboden sonst nackt oder mit Trichomen besetzt. Bisweilen inneres Leptom. - Etwa 11000.

A. Tubuliflorae. Keine Milchsaftschläuche. Hänfig schizogene Harzgänge. (P.) der Scheibenbl. nicht zungenfg. 
§ Vernouieae. Kobpfchen meist homogam (d. h. alle Bl. ఫ̧). (P.) 申, nie gelb. A. am Grunde pfeilfg., spitz, seltener geschwänzt, mit loch ïber dem Grunde eingefïgten Stf. - Nicht in Eur. - Vernonia (450).

§ Eupatorieae. Köpfehen hoinogam. (P.) $\oplus$, niemals rein gelb. A. am Grunde stumpf, mit am Grunde eingefïgten Stf.

* Agerutinae. Achaenium 3-5 rippig. - Ageratum (30); A. conyzoides (trop.). Fupatorium (400 meist Am.). - Mikania (120-150 meist Brasil.); M. scandens (trop.).

* Adenostylinae. Achaenium 8-10 rippig. - Adenostyles (5 Gebirge von Eur., As.).

S Astereae. Köpfchen heterogam oder homogam. (P.) aller Bl. oder ler Scheibenbl. $\oplus$. A. am Grunde stumpf, mit am Grunde eingefügten Stf.

* Solidagininae. Köpfchen mit zungenfg. Strahlenbl. von der Farbe der Scheihenbl. oder homogam. - Solidago (80 meist Nordam.).

* Bellidinae. Köpfchen mit zungenfg. Strahlenb. von anderer Farbe als die Scheibenbl., seltener homogam. Pappus verkümmert oder 0 . Bellis (10 Eur. und medit.).

* Asterinae. Wie vorige; aber Pappus entwickelt. - Callisteplıus chinensis, Gartenaster (China, Japau). - Aster (200, zur Hälfte Am.). - Evigeron (150, zur Hälfte Nordam.). - Olearia (90*), viele t.

* Conyzinae. Köpfchen mit fadenfy. oder kurz zungenfg., selten apetalen ㅇ Randbl., selten homogam. Pappus mit $\infty$ Borsten. - Conyza (50 trop.).

* Baccharidinae. Köpfehen diöcisch oder polygamisch-diöcisch. - Baccharis (300 Am.).

§ Inuleae. Köpfchen heterogam oder homogam. (P.) aller oder der Scheibenbl. $\oplus$, mit $4-5$ teiligem Saum. A. am Grunde geschwänzt.

a. Zweihäusig. 古 oder Sträucher.

* Tarchonanthinae. - Tarchonanthus camphoratus (Afr.).

b. Köpfchen heterogam.

* Plucheinae. (P.) der $\mathrm{O}_{\mathrm{Bl}} \mathrm{Bl}$ fadenfg. Blütenboden ohne Spreub. Gr. der ఫ̧ Bl. mit fadenfy. spitzen, aussen mit Fegehaaren besetzten Schenkeln. - Blumea (60 trop).

* Filagininae. (P.) der ㅇ Bl. fadenfg. Blütenboden mit Spreub. Micropus (5 medit. und Nordam.). - Evax (15 medit. und Nordam.). Filrigo $(12 *)$.

* Gnaphaliinae. (P.) der 우 Bl. fadenfg. Blütenboden ohne Spreub. Gr. der ఫ̧ Bl. mit abgestutzten, am Ende einen Kranz von Fegehaaren tragenden Schenkeln. - Antenmaria (15 temp., arkt.); A. alpina parthenogenetisch. - Leontopodiam (2-4 * und andin) Edelweiss. - Phagnalon (20 medit. und Centralas.). - Gnaphalium (120). - Raoulia (18 Austral., Neu-Seeland). - Helipterum (48 Austral., Südafr.). -- Helichrysum (300 excl. Am.). - Ammobium (2 Austral.). - Humea (4 Austral.).

* Inulinae. (P.) der 오 Bl. zungenfg. Schenkel der Gr. stumpf. Blütenboden ohne Spreub. - Inula (90 Eur., As., Afr.); I. helenimm, Alant (Mittelmeer bis Persien), lief. d. off. Radix Helenii. - Pulicaria (30 meist medit.).

* Buplthalminae. (P.) der $ᄋ$ Bl. zungenfg. Blütenboden mit Spreub. orler langen Borsten. - Buplıthalmurn (7 Eur., Westas.). - Odontospermum (12 meist medit.); O. pygmaeum, die "Rose von Jericho" (Sahara).

\$ Heliantheae. Schenkel der Gr. oberhalb der Teilungsstelle mit einem Kranz von längeren Fegehaaren. A. meist am Grunde alggerundet, 
mit am Grunde eingefügten Stf. (P.) der Scheibenbl. †. Pappus nicht haarfg. Hüllb. ohne trockenhäutigen Saum. Blütenboden spreublätterig.

* Melampodinie. Blütenboden durchweg spreublätterig. $\quad$ Bl. fehlend oder, wenn vorhanden, dann mit vollkommen entwickelter (P.). Scheibenbl unfruchthar. - Espeletia (11 andin), bisweilen $\mathrm{t}$. - Melampodium (25 Am.). - Silphium (12 Am.).

- Parthenum (9 Am.).

* Ambrosiinae. Blütenboden durchweg spreublätterig. of $\mathrm{Bl}$. ohne oder mit stark verkümmerter (P.). A. bisweilen ganz frei. - Ambrosia (15, meist Am., 1 medit.). — Xanthium (4); X. spinosum (Südam.?; jetzt weit verbreitet).

* Zinniinae Blütenboden durchweg spreublätterig. Die Randbl, mit dem Achaenium abfallend. - Zinnia (12 Nordam.); Z elegans, Zierpfl.

* Verbesininae. Blütenboden durchweg spreublätterig. Die (P.) der Randbl. vor der Reife abfallend. Scheibenbl. fruchtbar. Pappus fehlend oder aus Grannen oder aus rückwärts rauhen Borsten oder kleinen Schüppchen bestehend. Achänien nicht oder von der Seite her zusammengedrückt. Siegesbeckia orientalis (calid.). - Eclipta alba (calid.). - Rudbeckia (30 Nordam.). - Helianthus (55 Am.); H. (mnuus, Sonnenblume (Mexiko) lief. Öl; H. tuberosus, Topinambur (Nordam.), Futterpfl. - Spilanthes (20 meist Am.); Sp. urens, Sp. alba gegen Scorbut; Sp. Acmella und Sp. oleracea gegen Zahnschmerzen.

* Coreopsidinae. Wie vorige; aber die Achänien + vom Rücken her zusammengedrückt. - Guizotia abyssinica lief. Ramtilla-Öl. Coreopsis (70, meist Am.). - Dahlia (9 Mexiko); D. vavirbilis und D. coccinea (Georgine), Zierpfl. - Bidens (60).

* Galinsoginae. Blütenboden durchweg spreublätterig. Die (P.) der Randbl. vor der Reife abfallend. Pappus der Scheibenbl. aus grösseren Schuppen oder kammartig gefiederten Borsten bestehend. - Gulinsogu pariflora (Mexiko), Unkraut, auch in Eur.

* Madiinae. Nur in der Mitte des Köpfchens ein Kreis von Spreub., welche Strahlbl. und Scheibenbl, von einander trennen. - Mradir (1'2 Nordam. und Chile); M. sativa lief. das Madi-Öl.

$\S$ Helenieae. Wie vorige Gruppe; aber der Blütenboden ohne Spreub. - Meist Mexiko und pacif. Nordam.

* Heleniinae. B. ohne Öldrüsen. - Helenium (30 Nordam.).

* Tagetinae. B. mit Öldrüsen. - Tagetes (20 Argentin. bis Arizona); T. erec/us und $T$. patulus Zierpfl.

$\S$ Anthemideae. Gr. wie bei d. Heliantheae; aber Hüllb. mit trockenhäutigem Saum. Pappus 0 oder verkümmert.

* Anthemidinae. Blütenboden mit Spreub. - Santolina (8, meist medit.); S. chamaecyparissus, Cypressenkraut, off. - Anthemis (100 Eur. und medit.); A. nobilis, römische Kamille (Westeur.), lief. d. off. Flores Chamomillae romanae; A. Cotula, Hundskamille (*). - Aruacyclus (12 medit.); A. pyrethrum lief. d. off. Radix Pyrethri romani; $\boldsymbol{A}$. officinarum lief. d. Rarlix Pyrethri germanici. - Achillea (80*); A. millefolium, Schafgarbe (*) und A. nolbilis (Südeur.), off.; $\boldsymbol{A}$. moschata (alp.) zur Bereitung des Ivabitter.

* Chrysantheminae. Blütenboden ohne Spreub. - Matricaria (50, meist Eur., Afr.); M. chrmomilla (*) Kamille, lief. d. off. Flores Chamomillae vulgaris; $\boldsymbol{M}$. inodora, hfg. Unkraut. - Chrysunthe- 
mum (140*); Chr. segetum (Eur., medit.) Wucherblume, Unkraut; Chr. bulsamita (Orient), B. als Gewürz; Chr. roseum und Chr. Murscllullii (Kaukasus, Armenien, Nordpersien) lief. das persische Insektenpulver; Chr. cinerariifolium (Dalm.) lief. das dalmati n ische Insektenpulver; CHr. indicmm und Chr. simense (beide in China und Japan) in zabllosen Varietäten Zierpfl. - Artem isia (200. meist *); A. Arecumculus (Russland, Mongolei), Estragon, als Gewürz und Zusatz zu Essig; A. cina (Turkestan) lief. d. off. Zittwersamen, Flores Cinae; A. rbsinthium (Eur., As.), Wermuth, Absinth; off. Herba Absinthii.

§ Senecioneae. Gr. wie bei d. Heliantheae; aber Pappus haarfg. Tussilugo furfuro, Huflattich (*), d. Kraut off. - Petasites (12*). - Homogyme (3 Gebirge Eur.). - Avnica $(10 *)$; A. montuma, Wohlverleih (Eur.), off. Flores Arnicae. - Doronicum (12 Eur., As. temp.). - Cineraria (25, meist Südafr.). - Senccio (900, incl. Pericallis, I.ignlaria, Cacalia, Kleinia).

§ Calenduleae. Köpfchen mit $\odot$ Randbl. und meist sterilen $\oplus$ Scheihenbl. mit ungeteiltem Gr.; A. am Grunde zugespitzt. Blütenboden ohne Spreub. Kein Pappus. - Dimorphothecr (20 Südafr.); D. IIurialis, schliesst die Bl. bei Regenwetter. - Crelenclulr (20 medit.).

§. Iretotideae. Köpfchen mit zungenfg. ㅇ oder sterilen Randbl.; A. am Grunde spitz. Gr. unterhalb oder an der Teilungsstelle verdickt oder mit einem Kranz von Feghaaren. - Meist Südafr. - Venidium (18). - Gaznnia (24).

§ Cynareae. Köpfchen homogam oder mit ungeschlechtlichen, selten ㅇ, nicht zungenfg. Bl. A. meist geschwänzt. Gr. wie bei vorigen, Blütenboden meist borstig.

* Echinopsinae. Köpfchen 1 blütig in Köpfen. - Echinops (70 Eur., As., Afr.).

* Carlininae. Köpfchen $\infty$ blütig. Achänien mit gerader Ansatzfläche, seidenhaarig. Pappus schuppig oder mit 1 reihigen Borsten. - Yeranthemı

* Carduinae. Köpfchen so blütig. Achänien mit gerader Ansatzfläche, meist kahl. Pappus meist mit mehrreihigen Borsten. - Arctium, Klette (Iappa, 6 Eur., As.). - Cousinia (126 Centralas., Westas.). C'ureluus (60 Eur., As., Nordafr.). - Cnicus (incl. Cirsium, 200 *, meist Eur., As.); C. benedictus, Mariendistel (östl. medit.), off. Herba Cardui benedicti. - Onoporlon (12 Eur. und medit.). - Cymare (6 medit.); C. scolymm,s, Artischocke, die Blütenköpfe Gemüse. Silybum marirnmum (medit.). - Saussurea $(60 *)$. - Jurinea (40 Eur., As.).

* Centanreinae. Köpfchen $\infty$ blütig. Achänien mit schiefer Ansatzfliiche, kahl oder behaart. - Pappus mit mehrreihigen Borsten. - Serratula (30 Eur., As., Nordafr.); S. tinctoria lief. Farbstoff. - Centurrea (400, meist *, nanentlich medit.); C. cyunus, Kornblume (aus Südeur.). - Curthremus (20 medit., Centralas.); C tinctorius, Safflor (östl. Medit.), die Bl. lief. gelben und roten Farbstoff.

§ Mutisieae. Köpfchen homogam oder heterogam. Randbl. 2 lippig oder fehlend, selten zungenfg.; Scheibenbl. $\oplus$ mit tief gespaltenem Saum 
oder +2 lippig. - Mutisia (36 Südam.). - Gerbera (20 Afr., As. calid.). - Perezia (50 Am.). - Moscharia (1 Chile).

B. Liguliflorae. (P.) aller Bl. zungenfg. Pfl. mit anastomosierenden gegliederten Milchsaftschläuchen. Harzgänge sehr selten.

\section{\$ Cichorieae.}

* Scolyminne. B. und Hüllb. der Köpfchen dornig. Achänien vom Rücken her zusammengedrïckt, von den Spreuschuppen umschlossen. - Scolymus (3 medit.).

* Dendroseridinae. $\hbar$. Hüllb. \pm vereint. - Dendroseris (7 Juan Fernandez).

* Hyoseridinae. Achänien abgestutzt, mit schuppigem Pappus. Cichorium (3 Eur., As., temp. und medit.); C. intybus, Cichorie (Eur., As. temp.), die Wurzel Kaffeesurogat; C. endivia (medit.), Salatpfl.

* Tapsaninae. Hüllb. fast gleich. Achänien stumpf oder abgerundet, ohne Pappus. - Lapsana $(4 *)$.

* Rhagadiolinıe. Hüllb. fast gleich. Achänien spitz oder geschnäbelt, selten abgerundet und mit Pappus. - Neist medit. und Centralas.

* Crepidinae. Nur die inneren Hüllb. fast gleich. Achänien mit borstigem Pappus von einfachen Haaren, selten ohne Pappus. Weder Sternhaare noch Wollhaare an den B. -- Picris (24 Eur. und medit.). Crepis $(130 *)$.

* Hieraciz̈nae. Nur die inneren Hüllb. gleich. Achänien am Scheitel abgerundet, mit borstigem Pappus von einfachen Haaren. Sternhaare oder Wollhaare hfg. an den B. - Hieracium (* und andin).

* Hypochaeridinae. Hüllb. alle darhziegelartig, die inneren nach dem Blühen kielig verdickt. Achänien mit federhaarigem oder einfach borstigem Pappus. - Hypochaeris (40 temp.). - Leontodon (40, meist Eur., Centralas. und medit.). - Taraxacum (20 temp. - frigid.); T. officincle (*), off. Radix Taraxaci.

* Lactucinae. Innere Hüllb. gleich und nach dem Blühen unverändert. Achänien oben meist spitz oder geschnäbelt mit zahlreichen, einfachen Pappushaaren. - Chondrilla (15 Eur., As., medit.). - Lactur'ı (meist *); L. sativa, Lattich; die Var. capitata als Kopfsalat cult.; L. virosa (Eur.), giftig, der Milchsaft giebt das off. Lactucarium. Mulgedium (Eur., As. temp.). - Prenanthes (15 *). - Sonchus (24).

* Scorzonerinae. Achänien in einer breiten Grube sitzend, meist spitz oder geschnäbelt. Pappus mit einfachen oder federigen Borsten. Tragopogon (130 Eur., As.. Afr.). - Scomonera (100 Eur., medit. und Centralas.); Sc. hispanica, Schwarzwurzel (Eur.), als Wurzelgemüse cult. 


\section{A n h a $n$ g.}

\section{Übersicht über die Florenreiche und Florengebiete der Erde.}

I. Nördliches extratropisches oder boreales Florenreich.

\section{A. Arktisches Gebiet.}

Herrschend das arktisch-nivale Element, hier und da sparsam vertreten das arkto-tertiäre Element.

\section{Arktische Provinz.}

Unterprovinzen: Arktisches Eurasien. - Spitzhergen. - BärenInsel. - Novaya Semlya. - Tschuktschenland. - Aleuten. Arktisches Nordamerika. - Grönland. - Jan Mayen.

\section{B. Subarktisches oder Coniferen-Gebiet.}

Herrschend das arkto-tertiäre und das arkto-nivale Element, das erstere in den Waldformationen, das letztere auf Wiesen- und MoorFormationen, daher diese allmählich in die Tundren-Formationen des arktischen Gebietes übergehend.

\section{Provinz Subarktisches Europa.}

Unterprovinzen (Zonen): Island. - Far-Öer. - Skandinavien ausser Schonen und Blekinge. - Kola und Finnland. - Westliches Russland. - Ostrussische Waldzone und Ural.

\section{Provinz Subarktisches Asien oder Sibirien.}

Unterprovinzen (Zonen): Westsibirien mit den Bezirken: Nördliches Westsibirien, Baraba, Altai. - Ostsibirien mit den Bezirken: Nördliches Ostsibirien, Baikalien, Nordostsibirien mit Kamtschatka.

Provinz Subarktisches Amerika.

Unterprovinzen (Zonen): Alaska. - Peace und Athabasca-RiverZone. - Nördliches Ontario. - Quebec und Labrador.

\section{Mitteleuropäisches Gebiet.}

Arktotertiäres Floren-Element und die boreale, vorzugsweise aus dikotyledonen Gehölzen bestehende Laubwaldflora herrschend, wenn dieselhe nicht hinter dem Steppen-Element zurücktritt; auf den Hochgebirgen alpin-nivales Element mit dem arktisch-nivalen. 
Atlantische Provinz.

Unterprovinzen (Zonen): Island. - England und Schottland. Südwestliches französisches Tiefland. - Nordfranzösisches und belgisches Tiefland. - Niederrheinisches Tiefland.

\section{Subatlantische Provinz.}

Unterprovinzen: Niedersachsen (einschl. Niederlande). - Jütische Halbinsel, benachbarte Inseln und südwestliches Schweden. Mecklenburg, Pommern, Rügen und nordwestliches Westpreussen.

\section{Sarmatische Provinz.}

Unterprovinzen (Zonen): Mittleres Schweden. - Oeland. - Gotland. - Östliche Ostseeländer mit den Bezirken: Russische Ostseeländer, Ostpreussen und östliches Westpreussen. - Mitteldeutsches Tiefland mit den Bezirken: Westlicher Bezirk (ungefähr bis zur Oder), östlicher Bezirk (ungefähr östlich der Oder und des Bober). - Mittel-Russland.

\section{Provinz der enropäischen Mittelgebirge.}

Unterprovinzen (Zonen): Centralfranzösisches Bergland. - Rheinland mit den Bezirken: Vogesen und Schwarzwald, Mittelrheinisches Bergland. - Jurassisches Bergland ınit den Bezirken: Französischer und Schweizer Jura. - Deutscher Jura. - Hercynisches Bergland. - Böhmisch-mährisches Bergland. - Sudeten. - Nördliches Karpathen-Vorland.

\section{Pontische Provinz.}

Unterprovinzen (Zonen): Danubische Zone. - Russische Steppenzone mit den Bezirken: Tschernosem- oder Wiesensteppe, südrussische Grassteppe, Nordkaspische Steppe.

\section{Provinz der Pyrenaien.}

Unterprovinzen (Zonen): Ostpyrenäen. - Centralpyrenäen. Asturisch-Cantabrisches Gebirge.

\section{Provinz der Alpenländer.}

Unterprovinzen (Zonen): Nördliches Alpen-Vorland. - Nördliche Kalkalpen mit den Bezirken: Österreichische und Eisenerzer Ka., Salzburger Ka., Mittelbairische und Nordtiroler Ka., Westliche Ka. vom Algäu bis zur Westschweiz, Waadtländer und Savoier Alpen, anschliessend südlicher Schweizer und französischer Jura. Centralalpen und Südwestalpen mit den Bezirken: Norische Alpen und niedere Tauern, hohe Tauern (einschl. Zillerthaler A.), Mitteltiroler und ostrhätische Centralalpen, westrhätische A., Walliser oder Penninische A., Grajische A., Cottische A., Seealpen. Siidliche Kalkalpen mit den Bezirken: Insubrische A., Bergamasker A., Judicarien, Trientinisch-veroneser A., Südtiroler Dolomiten, Mittelgebirge des Etschthales in Südtirol, Karnisch-venetianische A., Südöstliche Dolomiten und Kalkalpen, Karst und Karniolischillyrisches Übergangsgebiet. - Östliches Alpenvorland. 
Provinz der Apenninen.

Unterprovinzen (Zonen): Nördlicher Apennin und die Apuanischen Alpen. - Mittlerer Apennin mit den Abruzzen.

Provinz der Karpathen.

Unterprovinzen (Zonen): Westkarpathen mit den Bezirken: Sandsteinbezirk, nördlicher Innenbezirk, südlicher Innenbezirk, Trachytgebirge. - Waldkarpathen. - Siebenbürgen mit den Bezirken: Nord- und Ostrand, Südrand, Westrand, Centrales Hochland.

Provinz der westpontischen Gebirgslinder.

Unterprovinzen (Zonen): Illyrische Gebirge. - Serbisch-bulgarische Gebirge. - Albanesische Gebirge.

\section{Provinz des Balkan.}

Provinz des Jaila - Gebirges.

Provinz des Kankasus.

Unterprovinzen (Zonen): Westlicher Kaukasus. - Daghestan. Kleiner Kaukasus. - Alburs.

\section{Makaronesisches Übergangsgebiet.}

Neben dem mediterranen Element herrscht auch das palaeotropische, afrikanische, schwach vertreten ist das boreale und auch in noch geringerem Grade das neotropische Element.

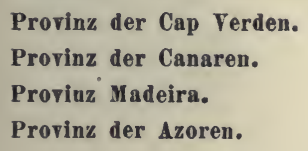

\section{E. Mediterrangebiet.}

Die bekannten immergrünen Formen dieses Gebietes sind nicht mehr dem arktotertiären Element angehörig, da sie in den tertiären Ablagerungen des heutigen arktischen Gebietes nicht fossil gefunden werden, doch existierten mehrere in dem Gebiet, in welchem jetzt die boreale Flora herrscht, sodass wir das die Mittelmeer-Flora auszeichnende Element auch tertiär-boreal nennen können. Es ist aber schliesslich nicht verschieden von dem palaeotropischen. Festzuhalten ist, dass der Charakter der Mediterran-Flora von seiner ursprünglichen Beschaffenheit durch die fortschreitende Zunahme des xerophytischen Areals verloren haben muss. Im südwestlichen Teil des Mittelmeer-Gebiets finden wir noch mehr von dem ursprünglichen Charakter erhalten, im Osten aber hat das SteppenElement der Mediterran-Flora, welches in gewissem Grade schon lange Zeit vorhanden gewesen sein muss und auch mit dem afrikanischen Steppen-Element mehr oder weniger verwandt ist, so die Oberhand gewonnen, dass die Vegetationsdecke habituell immer mehr der der centralasiatischen und südlichen Steppenländer ähnlich geworden ist. Auf den Hochgebirgen tritt die arktisch-nivale Flora fast ganz zurück. 
Südwestliche Mediterranproviuz.

Iberisehe Provinz.

Unterprovinzen (Zonen): Centrales Iberien. - Östliches Iberien. - Südatlantisches Iberien. - Westatlantisches Iberien.

\section{Ligurisch-tyrrhenische Provinz.}

Unterprovinzen (Zonen): Corsica und Sardinien. - Unteritalien und Sicilien.

Mittlere Mediterranprovinz.

Unterprovinzen (Zonen): Adriatische Zone. - Thracien und Rumelien. - Mittel- und Süd-Griechenland. - Euxinische oder ostpontische Zone. - Kleinasiatische Zone. - Syrien.

Armenisch-iranische Mediterranprovinz.

Südliche Mediterranprovinz (Algier bis Ägypten).

\section{F. Centralasiatisches Gebiet.}

Ausser dem Steppen-Element sind vertreten das mediterrane, das subarktische und arktisch-nivale; das boreale Element ist nur schwach entwickelt.

Turanische oder aralo-caspisclie Provinz (incl. des westlichen Turkestan).

Provinz des turkestanischen Gebirgslandes.

Provinz der Han-hai.

Provinz der tibetanischen Hochwiiste.

Provinz des extratropischen Himalaya.

Provinz des Yünuan.

Provlnz Kansa.

\section{G. Temperirtes 0stasien.}

Neben dem borealen, subarktischen und arktisch-nivalen Element ist auch das subtropische Element etwas vertreten, d. h. im subtropischen Gebiet herrschende Typen haben hier mehr als in Europa Gelegenheit gefunden, sich in dem gegenwärtig extratropischen Gebiet durch solche Formen zu erhalten, welche eine geringe Wärmemenge beanspruchen.

Provinz des nördlichen China und Koreas.

Provinz des mittleren und nördlichen Japan.

Provinz Amurland und Sachalin.

Provinz des sïdwestlichen Kamtschatka mit den Kurilen und Aleuten.

\section{H. Gebiet des pacifischen Nordamerika.}

\section{Provinz der paciflschen Conlferen.}

Unterprovinzen (Zonen): Nördliche Zone mit den Bezirken des nördlichen Küstenwaldes und dem ciskaskadischen Waldes mit dem Kaskadengebirge. - Südliche Zone mit dem Bezirk des kalifornischen Küstenwaldes und dem des westlichen NevadaWaldes mit der Sierra Nevada. 
Provinz der Rocky Monntains.

Unterprovinzen (Zonen): Nördliche Zone. - Südliche Zone und Übergang zu der Chaparal-Sonora-Provinz des centralamerikanischen Xerophytengebietes.

Westamerikanische Wïsten- und Steppen-Provinz.

Unterprovinzen (Zonen): Übergang aus der Chaparal-Sonora-Provinz in die Gila- und Mohave-Wüste. - Zone des Great Basin. Innerkalifornische Zone.

\section{Gebiet des atlantischen Nordamerika.}

Zeigt vielfach starke Verwandtschaft mit G.

Seeenprovinz.

Unterprovinzen (Zonen): Zone der Pinus strobus. - Östliche Ǔbergangszone der sommergrünen Laubwälder.

Provinz des sommergrïnen Mississlppi- und Alleghany-Waldes mit den Alleghanies.

Unterprovinzen (Zonen): Missisippi-Ohio-Tennessee-Zone. - Alleghany-Zone. - Zone der Pinebarrens.

Immergrüue Provinz der südatlantischen Staaten.

Unterprovinzen (Zonen): Küstenzone der Sumpfkiefer. - Zonen des Mischwaldes. - Prairie-Wald-Zone. - Nördliche KiefernwaldZone.

Prairienprovinz.

Unterprovinzen (Zonen): Nördliche Zone. - Mittlere Zone. Südliche Zone.

\section{Palaeotropisches Florenreich.}

Herrschend das palaeotropische Floren-Element, auf den Gebirgen in höheren Regionen das boreale Element, das auch hier und da auf dem Kulturland, sowie in den trocknen Distrikten sich eingesprengt findet. Das subarktische und arktisch-nivale Element finden sich nur in dem nördlichen Grenzgebiet der indischen und chinesischen Hochgebirge, deren obere Regionen an das centralatlantische Gebiet angeschlossen werden können. In einzelnen Gebieten kommt das australe und austral-antarktische Floren-Element schon ziemlich stark zur Geltung.

\section{A. Nordafrikanisch-indisches Wüstengebiet.}

Das palaeotropische Xerophyten-Element herrschend, daneben auch Vertreter des mediterranen Xerophyten-Elementes.

\section{B. Afrikanisches Wald- und Steppengebiet.}

Das palaeotropische Hygrophyten-Element reichlich, dazwischen einige Vertreter des neotropischen Hygrophyten-Elements; in den Steppen und Wüsten palaeotropische Xerophyten, in den Hochgebirgen Vertreter des australen und borealen Elements. 
Nordafrikanische Steppenprovinz.

Unterprovinzen (Zonen): Darfur mit Kordofan und Sennar. Etbai. - Abessinisches Hochland und Yemen. - Hadramaut. - Somali-Land. - Socotra.

\section{Westafrikanische Waldprovinz.}

Ostafrikanische und südafrikanische Steppenprovinz.

Unterprovinzen (Zonen): Sambesi-Zone. — Süd-Angola und Benguella. - Südafrikanische Küstenzone. - Kalahari und Damara. Namaqua-Zone.

\section{Gebiet des südwestlichen Kaplandes.}

Das australe Element tritt in ganz besonders reicher Entwicklung auf, daneben aber auch das afrikanische Xerophyten-Element und sehr sparsam das boreale Element.

\section{Gebiet der südatlantischen Inseln.}

Provinz Ascension.

Provinz St. Helena.

\section{E. Malagassisches Gebiet.}

Das palaeotropische Hygrophyten-Element herrschend, daneben das palaeotropische Xerophyten.Element und auch in geringerem Grade das australe Florenelement.

Provinz Madagaskar und Comoren.

Provinz der Mascarenen.

Provinz der Seychellen.

\section{F. Yorderindisches Gebiet.}

Im grössten Teil des Gebiets das palaeotropische Xerophyten-Element herrschend, im Westen palaeotropische Hygrophyten, im Westen solche vom malayischen Typus, in den Hochgebirgen einige boreale himalayensischostasiatische Typen.

Hindostanische Provinz.

Provinz des westllehen Ceylon und Travancore.

Provinz der Lakadiven und Malediven.

\section{G. Monsungebiet.}

Palaeotropisches Hygrophyten-Element des malayischen Typus herrschend, im Himalaya und auf anderen Gebirgen das boreale Element hervortretend, im Süden das australe (altoceanische) Element eindringend. Provinz des tropisehen Himalaya.

Westmalayische Provinz.

Unterprovinzen (Zonen): Pegu mit den Bezirken Pegu, Andamanen,

Nikobaren. - Malakka. - Sumatra. - Java. - Borneo.

Centromalayische Provinz (Celebes, Molukken).

Austromalayische Provinz (Timor und das tropische Nordaustralien). 
Papuanische Provinz (Neu-Guinea, Aru- und Key Inseln, Bismarck-Archipel, Salomon-

Inseln).

Arancarien-Provinz.

Unterprovinzen (Zonen): Ostaustralien. - Lord Howe-, NorfolkInsel und Kermadec-Inseln. - Neu-Caledonien. - Nördliches Neu Seeland und Chatham-Inseln.

Hinterindisch-ostasiatische Provinz (Birma, Siarn, Cochinchina, Annam, Tongking, Hainan, südliches chinesisches Küstenland bis Hongkong).

Provinz der Philippinen und Siid-Formosa.

Melanesische Provinz (Neue Hebriden, Fidschi-Inseln, Samoa-Inseln, Tonga-Inseln, Gesellschafts-Inseln).

Polynesiselie Provinz.

\section{H. Gebiet der Sandwich-Inseln.}

Neben dem palaeotropischen Floren-Element und dem sparsam vertretenen austral-antarktischen Element machen sich das neotropische und boreale Element geltend.

III. Das central- und südamerikanische Florenreich.

Herrschend das neotropische Floren-Element, in den Gebirgen und den südlicheren sowie den nördlicheren weniger warmen Gehieten teils geringere Wärmesummen erfordernde Verwandte der neotropischen Typen, teils boreale und subarktische, teils australe und austral-arktische Typen.

\section{A. Mittelamerikanisches Xerophyten-Gebiet.}

Chaparal-Provinzen (Texas und Neu-Mexiko).

Sonora-Provinz (Sonora, Teil von Neu-Mexiko, grösster Teil der kalifornischen Halbinsel).

Provinz des mexikanischen Hochlandes.

\section{B. Gebiet des tropischen Amerika.}

Provinz des tropischen Central-Amerika und Süd-Kalifornien.

Unterprovinzen (Zonen): Kalifornische Zone. - Mexikanische Zone. - Yucatan-Zone. - Guatemala-Zone.

Westindische Provinz.

Unterprovinzen (Zonen): Süd-Florida mit Bahama-Inseln und Bermudas. - Cuba. - Jamaika. - San Domingo. - Porto Rico. - Kleine Antillen.

Subaiquatoriale andine Provinz.

Unterprovinzen (Zonen): Nicaragua-Costarica-Zone. - Columbische Zone.

Cisåquatoriale Savannenprovinz (nichtandines Venezuela mit dem Hochland von Guyana und Trinidad).

Provinz des Amazonenstromes oder Hylaea.

Südbrasilianische Provinz.

Unterprovinzen ('Zonen): Ostbrasilianische Tropenwaldzone. Catingas-Zone. - Campos-Zone. - Südbrasilianische AraucarienZone. - Insel Süi-Trinidad. 


\section{Andines Gebiet.}

Das neotropische Element erscheint meist in subtropischen Formen, das boreale Element tritt sehr stark hervor, und zwar ganz besonders mit Typen des pacifischen Nordamerika. Selbst einzelne Vertreter des arktischnivalen Elementes finden sich in den höchsten Regionen und im südlichen Teil des Gebiets. Die fremden Elemente treten aber nirgends so stark hervor, dass die Regionen nach ihnen bezeichnet werden könnten.

Nördliche und mittiere hochandine Provinz.

Unterprovinzen (Zonen): Nördliche Anden-Zone. - Tucuman-Zone. - Mittlere Anden-Zone.

Argentinische Provinz.

Unterprovinzen (Zonen): Zone des Gran-Chaco. - Zone des Espinale. - Pampas.Zone.

Andin-patagonische Provinz.

Chilenische Übergangsprovinz.

D. Gebiet der Galapagos-Inseln.

E. Gebiet von Juan Fernandez und Masofuera.

IV. Das australe (altoceanische) Florenreich.

Herrschend das austral-antarktische Floren-Element.

A. Austral-antarktisches Gebiet Süd-Amerikas.

Westliche Waid provinz.

Waidlose Inselprovinz.

B. Gebiet der Kerguelen.

C. Neuseeländisches Gebiet.

Provinz Neuseeland.

Provinz Anckland- und Campbell-Inseln.

Provinz Macquarie-Inseln.

D. Australisches Gebiet.

Ostanstralische Provin\%.

Provinz Tasmauien.

Westanstralische Provinz.

E. Gebiet von Tristan da Cunha, St. Paul und Amsterdam-Inseln.

V. Oceanisches Florenreich.

Herrschend die gewöhnlich als Algen zusammengefassten Rhodophyceen, Phaeophyceen, Chlorophyceen, Bacillariaceen, Dinoflagellaten und wenige Helobiae.
A. Boreales Gebiet.
B. Tropisches Gebiet.
C. Australes (rebiet. 


\section{R E G I S T E R.}

(Die cursiv gedruckten Namen sind Synonyma)

\section{A.}

Abatia 164 .

Abelmoschus 158.

Abies 74 .

Abrus 142.

Abuta 125.

Abutilon 158.

Acacia 139.

Acalypha 150.

Acanthaceae 196.

Acanthinae 196.

Acantholimon 178.

Acanthomintha 189.

Acanthopanax 172.

Acanthorrhiza 85.

Acanthosicyos 201.

Acanthus 196.

Acaulon 57.

Acer 153.

Aceraceae 153.

Aceras 103.

Acetabularia 15.

Achariaceae 165.

Achillea 204.

Achimenes 195.

Achlya 27.

Achnanthes 10 .

Achras 179.

Achyranthes 119.

Aconitum 124.

Acorns 88.

Acrasiales 1.

Acrocarpi 56.

Acrostichum 65.

Acrotylaceae 21 .

Actaea 124.

Actiniopteris 64 .

Actinomyces 5.

Actinostrobus 74 .

Adansonia 158.

Adenanthera 139.

Adenium 183.

Adenophora 201.
Adenostyles 203 .

Adesmia 142.

Adhatodn 196.

Adiantites 62.

Adiantum 64.

Adlumia 129.

Adonis 124.

Adoxa 199.

Adoxaceae 199.

Aechmea 93.

Aecidium 45.

Aecidium 44, 45.

Aegiceras 178.

Aegilops 83.

Aegle 146.

Aegopodium 173.

Aërides 106.

Aerobryum 60.

Aerua 112.

Aeschynomene 142.

Aesculus 154.

Aethionema 130.

Aethusa 174.

Afzelia 139.

Agapanthus 96.

Agricaceae 48.

Agarieus 49.

Agathis 73 .

Agathosma 146.

Agave 99.

Agdestis 120.

Ageratum 203.

Aglaonema 89.

Agrimonia 137.

Agropyrum 83.

Agrostemma 122.

Agrostis 82.

Agyrium 37.

Ailanthus 147.

Aira 82.

Ajuga 188.

Aizoaceae 120 .

Aizoon 121.
Akebia 124.

Alangium 175.

Alaria 17.

Albizzia 139.

Albuca 96.

Albuginaceae 28.

Albugo 28.

Alchemilla 137.

Alchornea 149.

Aldrovandia 132.

Alectoria 41.

Alethopteris 62 .

Aletris 98.

Alenrites 150 .

Alhagi 141

Alisma 74.

Alismataceae 79.

Alismatineae 79 .

Alkanna 187.

Allamanda 183.

Allanblackia 161.

Alliaria 130.

Allium 96.

Allophylus 154.

Allosorus 64 .

Alnus 109.

Alocasia 89.

Aloë 95

Aloina 57

Alonsoa 192.

Alopecurus 82.

Alpinia 102.

Alsidium 23.

Alsine 121

Alsodeia 164.

Alsophila 63.

Alstonia 183.

Alstroemeria 99.

Alternanthera 119.

Althaea 158.

Althenia 78.

Altingia 135.

Alyssum 131.
Amanita 49.

Amarantaceae 119.

Amarantus 119.

Amaryllidaceae 98.

Amaryllis 98.

Amblystegium 61 .

Ambrosia 204.

Ambrosinia 90.

Amelanchier 137.

Amianthium 94.

Anicia 141.

Ammannia 168.

Ammi 1.73.

Ammobium 203 .

Ammophila 8\%.

Amoinum 102.

Amorpha 141.

Amorphophallus 89.

Ampelocissus 156 .

Ampelodesmos 82.

Amphimonadaceae 7.

Amphisphaeria 35.

Amphisphaeriaceae

35.

Anuphora 10.

Amsonia 183.

Anabaena 6

Anabasis 119.

Anacamptis 103.

Anacarliaceae 151.

Anacardiineae 151.

Anacardium 152.

Anacyclus 204.

Anagallis 178 .

Anagy ris 140.

Anamirta 125.

Ananas 93.

Anaptychia 41.

Anastatica 131.

Anchomanes 89.

Anchusa 187. 
Ancistrocladaceae 166.

Ancistrocladineae 166.

Ancistrocladus 166.

Ancylistaceae 27.

Ancylistes 27.

Ancylistineae 27.

Andira 142.

Andreaea 56.

Andreaeaceae 56 .

Andreaeales 56.

Andrographis 196.

Andromeda 176.

Andropogon 81.

Androsace 178.

Androstrobus 71.

Aneilema 93.

Aneimia 65.

Anemone 124.

Aneura 53.

Angelica 174.

Angiopteridium 62 .

Angiopteris 66.

Angiospermae 75 .

Angraecum 106.

Anguillaria 89.

Anguloa 105.

Anguria 200.

Anisonema 8.

Anisophyllea 169 .

Annularia 67.

Anoectochilus 104.

Anomodon 61 .

Anona 126.

Anonaceae 126.

Antennaria 203.

Anthemis 204.

Anthericum 95.

Anthoceros 52.

Anthocerotaceae 52 .

Anthocerotales 52 .

Anthospernum 199.

Anthostema 150 .

Anthostoma 35.

Anthoxanthum 82.

Anthriscus 173.

Anthurium 88.

Anthyllis 141.

Antiaris 111.

Antirrhinum 192.

Antitrichia 60 .

Antrophyum 64 .

Anubias 83.

Aongstroemia 56.

Apaniea 108.

A peiba 157.

Apetalae 106.

Aphanizomenon 6 .

A phanomyces 27.
Aphanothece 6 .

Aphelandra 196.

Aphlebia 62.

Aphyllanthes 96 .

Apios 142.

Apiosporium 33.

Apium 173.

Aplogia 53.

Apocynaceae 182.

Apocynum 183.

Apodanthes 116.

A ponogeton 78 .

A ponogetonaceae 78.

Apostasia 103.

Aptosimum 182.

Aquifoliaceae 153.

Aquilaria 168.

Aquilegia 124.

Arabis 131.

Araceae 87.

Arachis 142.

Aralia 172.

Araliaceae 171.

Araucaria 73.

Araucarioxylon 72.

Arbutus 176.

Arceuthobium 114.

Archaeocalamites67.

Archaeopterides 62

Archaeopteris 62.

Archangelica 174.

Archegoniatae 50.

Archichlamydeae 106.

Archidiaceae 55.

Archidium 52.

Archispermae 66 .

Arctium 205.

Arctostaphylos 176.

Arcyria 2.

Ardisia 178.

Arduina 183.

Areca 86

Arenaria 121.

Arenga 86.

Aretia 178.

Argania 179.

Argemone 118.

Argyreia 185.

Argyrolobium 141.

Arillatae 101.

Ariopsis 90.

Arisaema 90.

Arisarum 90.

Aristea 100.

Aristida 82.

Aristolochia 116.

Aristolochiaceae116.

A ristolochiales 115.

Aristotelia 157.
Armeria 178.

Armillaria 49.

Arnica 205.

Arrhenatherum 82.

Artabotrys 126.

Artemisia 205.

Arthonia 31, 39.

Arthopyrenia 42.

Arthotelium 31.

Arthrocnemum 118.

Arthrospira 5.

Arthrotaxis 74 .

Artisia 72.

Artocarpus 110.

Arrhenatherum 82.

Arum 90.

Aruncus 134, 136.

Arundinaria 83 .

Arundinella 81.

Arundo 82.

Asarum 116.

Asclepiadaceae 183.

Asclepias 184.

Ascobolaceae 30 .

Ascobolus 30 .

Ascochyta 36 .

Ascocorticiaceae 29.

Ascocorticium 29.

Ascocyclus 16.

Ascoidea 35.

Ascoideaceae 35.

Ascolichenes 38.

Ascophyllum 17.

Ascospora 35.

Asimina 126.

Aspalathus 141.

Asparagus 97.

Aspergillaceae 32.

Aspergillus 32.

Asperugo 187.

Asperula 199.

Asphodeline 95.

Asphodelus 95

Aspidistra 97.

Aspidium 63.

Aspidosperma 183.

Asplenum 64.

Astasia 8.

Astasiaceae 8.

Astelia 97.

Aster 203.

Asterocalamites 67.

Asterophyllites 67 .

Asterotheca 66.

Astilbe 134.

Astragalus 141.

Astrantia 172.

Astrocaryum 87.

Astronium 152.

Astrotheliaceae 42.
Astrothelium 42.

Asystasia 186.

Athamanta 174.

Athyrium 64.

Atraphaxis 117.

Atrichum 59.

Atriplex 118.

Atropa 191.

Attalea 86.

Aubrietia 131.

Aucuba 175.

Augea 144

Aulacodiscus 9 .

Aulacomniaceae 59.

Aulacomnium 59.

Auliscus 9

Auricularia 46.

Auriculariaceae 46 .

Auriculariaceales 45.

Auriculariineae 44.

A utobasidiomycetes 46.

Avena 8?.

Averrhoa 143.

Avicennia 188.

Aytonia 52.

Azadirachta 148.

Azulea 176.

Azara 164

Azolla 66.

Azorella 172.

B.

Baccharis 203.

Bacidia 39.

Bacillaria 10.

Bacillariaceae 9.

Bacillariales 9 .

Bacillus 4.

Bacteria 3.

Bacteriaceae 3 .

Bacteriastrum 9 .

Bacterium 4.

Bactris 87.

Baeomyces 40 .

Baeomycetaceae 39 .

Baiera 72.

Balanites 145 .

Balanophora 115.

Balanophoraceae

115.

Balanophorineae 115.

Balanops 108.

Balanopsidaceae 108.

Balanopsidales 108.

Balantium 63.

Balbiania 20 . 
Ballota 189.

Balsamia 32.

Balsamiaceae 32 .

Balsaminacere 155 .

Balsaminineae 155 .

Balsamodendron 147.

Bambusa 83.

Banara 164.

Bangia 19.

Bangiaceae 18.

Bangiales 18.

Banisteria 148.

Banksia 112.

Baptisia 140.

Barbacenia 99.

Barbarea 130 .

Barbula 57.

Barclaya 123.

Barleria 196.

Barosma 146.

Barringtonia 169.

Bartramia 59.

Bartramiaceae 59.

Basella 121.

Basellaceae 121.

Basidiobolus 26.

Basidiolichenes 42 .

Basidiomycetes 43 .

Batidaceae 120.

Batis 120.

Batrachospermum 20.

Bauera 135.

Bauhinia 140.

Bazzania 54.

Befaria 176.

Beggiatoa 5.

Beggiatoaceae 5.

Begonia 166.

Begoniaceae 166.

Begoniineae 166.

Bellincinia 54.

Bellis 203.

Bellonia 185.

Benincasa 201.

Bennettitaceae 71.

Bennettitales 71 .

Bennettites 71 .

Berberidaceae 124.

Berberis 124.

Bergenia 134.

Berteroa 131.

Bertholletia 169

Bertia 34.

Besleria 194.

Beta 118.

Betula 109.

Betulaceae 109

Biarum 90.

Biatorella 31 .
Biatoridium 31, 39.

Biatorina 39.

Bicoecaceae 7.

Bidens 204.

Biebersteinia 143.

Bifora 173.

Bignonia 193.

Bignoniaceae 193.

Bilimbia 39.

Billardiera 135 .

Billbergia 93.

Biophytum 143.

Biovularia 195.

Biscutella 130.

Biserrula 141.

Bixa 163.

Bixaceae 163.

Blasia 53.

Blastenia 41.

Blechnum 64.

Blepharis 196.

Bletia 105.

Blighia 154.

Blindia 56.

Blumea 203.

Blumenbachia 165.

Blyxa 80.

Bodo ?.

Bodonaceae 7.

Boea 194.

Boehmeria 111.

Boenninghausenia 145.

Boerhavia 120.

Bolbophyllum 105.

Boletopsis 48.

Boletus 48.

Bomarea 99.

Bombacaceae 158.

Bombax 158.

Bonnemaisonia 22.

Bonnemaisoniaceae 22.

Boottia 79.

Borassus 85 .

Borderea 100.

Boronia 145.

Boraginaceae 186.

Borraginineae 186.

Borrago 187.

Borreria 199.

Bostrychia 20.

Boswellia 147.

Botrychium 67.

Botrydiaceae 14.

Botrydium 14.

Botryosphaeria 35.

Botrytis 30, 37.

Boucerosia 184.

Rougainvillea 120 .
Boussingaultia 121.

Bouteloua 82.

Bouvardia 198.

Bovista 50.

Bowiea 95.

Bowlesia 172.

Brachychiton 159 .

Brachypodium 82 .

Brachythecium 61 .

Brasenia 122.

Brassavola 105.

Brassica 130.

Brefeldiaceae 2.

Bremia 28.

Brexia 134.

Bridelia 149.

Briza 82.

Brodiaea 96.

Bromeliaceae 9 ?.

Bromeliineae 92.

Bromus 82.

Brosimum 111.

Broussonetia 110.

Brownlowia 157.

Bruchia 56.

Bruguiera 169.

Brunella 189.

Brunellia 135.

Brunelliaceae 135.

Bruniaceae 135.

Brunonia 202.

Brunswigia 98.

Bryaceae 59.

Bryales 56.

Bryanthus 176.

Bryonia 201.

Bryophyllum 133.

Bryophyta 51 .

Bryopsidaceae 14.

Bryopsis 14.

Bryum 59.

Buchanania 152.

Buchloë 83.

Buchnera 193.

Bucklandia 135.

Buddleia 181.

Buellia 31, 41.

Büttneria 159.

Bulbine 95.

Bulbochrete 13.

Bulbocodium 95.

Bulgaria 31.

B̧ulnesia 144.

Bunias 131.

Buphthalmum 203.

Bupleurum 173.

Bursera 147.

Burseraceae 147.

Burmannia 103.

Burmanniaceae 103.
Burmanniineae 102.

Butea 142.

Butomaceae 79.

Butomineae 79.

Butomus 79.

Buty rospermum 179.

Buxaceae 151.

Buxbanmia 60.

Buxbaumiaceae 60 .

Buxineae 151.

Buxus 151.

Byblis 132, 195.

Byssocaulaceae 39 .

Bystropogon 190.

C.

Cabomba 123.

Cacalia $\simeq 05$.

Cachry8 173.

Cactaceae 157.

Cadaba 129.

Caeoma 45.

Caesalpinia 140.

Cajanus 14\%.

Cajophora 165.

Cakile 130.

Caladium 89.

Calamagrostis 82 .

Calamariaceae 67.

Calamariales 67.

Calamariopsis 69 .

Calamintha 190.

Calamites 67.

Calumitina 67.

Calamopitys 69.

Calamostachys 67.

Calamus 86.

Calandrinia 121.

Calanthe 105.

Calathea 202.

Calceolaria 192.

Calectasia 96.

Calendula 205

Caliciaceae 31, 38.

Caliciopsis 31 .

Calicinm 38.

Calla 88.

Callianthemum 124

Callicarpa 188.

Callicostella 60 .

Calligonum 117.

Callistemon 170.

Callistephus 203.

Callithamnion 23.

Callitrichaceae 150 .

Callitriche 151.

Callitris 74.

Calloria 30.

Callophyllis 21. 
Calluna 177.

Calocera 46.

Calochortus 96.

Calodendron 146.

Caloglossa 20.

Calonyetion 185.

Calophyllum 161.

Caloplaca 41.

Calosanthes 193.

Calosphaeria 35.

Calothrix 6.

Calotropis 184.

Caltha 1:4

Calycanthaceae 126 .

Calycanthus 126.

Calyceraceae 202.

Calycotome 141.

Calymperaceae 57.

Calymperes 57 .

Calypogeia 53.

Calypso 105.

Calyptospora 45 .

Calystegia 185 .

Camelina 131.

Campanula 201.

Campanulaceae 201.

Campanulatae 200.

Campanulineae 2(1)1.

Camphorosma 118.

Camptopteris 59.

Camptothecium 61 .

Campylodiscus 10.

Campylopus 56.

Campylostelium 58.

Campynema 99.

Cananga 126.

Canarina 201 .

Canarium 147.

Canavalia 142.

Candellaria 41.

Candollea 202.

Candolleaceae 202.

Canella 163.

Canellaceae 163.

Canna 10:.

Cannabis 111.

Cannaceae 102.

Cantharellus 48 .

Cantua 186.

Capparidaceae 129.

Capparidineae 129.

Capparis 129.

Caprifoliaceae 199.

Capsella 131.

Capsicum 191.

Caragana 141.

Carapa 148.

Cardamine 130.
Cardiocarpus 72.

Cardiospermum 154.

Carduus 205.

Carex 84.

Carica 165.

Caricaceae 165.

Corissu 183.

Carlina 2115.

Carludovica 87.

Carmichaelia 141.

Carpinus 109.

Carpodinus 183.

Carthamus 205.

Carum 173.

Carya 108.

Caryocar 160.

Caryocaraceae 160.

Caryophyllaceae121.

Caryophyllineae 121.

Caryopteris 178.

Caryota 86.

Casearia 164.

Cassia 140.

Cassiope 167.

Cassytha 128.

Castanea 109.

Castilloa 111.

Casuorina 107.

Casuarinaceae 107.

Catabrosa 8:.

Catalpa 193.

Catasetum 105.

Catha 153

Catillaria 39.

Catopheria 190.

Cattleya 105.

Cancalis 173 .

Caulerpa 14.

Caulerpaceae 14.

Caulopterides 62 .

Caulopteris 62.

Ceanothus 156.

Cecropia 111.

Cedrela 147.

Cedronella 189.

Cedrus 73.

Ceiba 158.

Celastraceae 153.

Celastrales 151.

Celastrineae 152.

Celastrus 144.

Celidiaceae 30 .

Celidium 31.

Celosia 119.

Celsia 192.

Celtis 110 .

Cenangiaceae 31 .

Cenangium 31.

Centaurea 205.

Centradenia 170.
Centranthus 200.

Chamaerops 85.

Centrolepis 91 .

Centropogon 202.

Centrospermae 117.

Centunculus 178.

Cephaëlis 198.

Cephalanthera 104

Cephalanthus 198.

Cephalaria 190.

Cephaleuros 42 .

Cephalotaceae 133.

Cephalotaxus 73.

Cephalotus 133.

Cephaloziella 54.

Ceramium 23.

Ceramiaceae 23.

Cerastium 121.

Ceratium 18.

Ceratiomyxa 2.

Ceratiomyxaceae 2.

Ceratodon 56 .

Ceratonia 140.

Ceratophyllaceae 123.

Ceratophyllum 123.

Ceratopteris 65 .

Ceratosphaeria 34 .

Ceratostomataceae 34.

Ceratostomella 34.

Ceratostrobus 74 .

Ceratozamia 71.

Cerbera 183.

Cercidiphyllum 123.

Cercis 140.

Cercospora 37.

Cercocarpus 137.

Cereus 167

Cerinthe 187.

Ceriops 160.

Ceropegia 184.

Ceroxylon 86.

Cestrum 191.

Cetraria 41.

Chaerophyllum 173.

Chaetangiaceae 21 .

Chaetangium 21.

Chaetoceras 9.

Chaetocladiaceae 26

Chaetocladium 26.

Chaetomiaceae 34.

Chaetomium 34.

Chatomorpha 13.

Chaetophora 12.

Chaetophoraceae 12.

Chaetopteris 16 .

Chamaecyparis 74 .

Chamaedorea 86.

Chamaelancium 161 .
Chamaesiphon 6 .

Chamaesiphonaceae 6.

Championia 194.

Chantrasia 20.

Chara 3, 15.

Characeae 15.

Characium 12.

Charales 15.

Cheilanthes 64 .

Cheiranthus 131.

Chelidonium 128.

Chenopodiaceae 118.

Chenopodiineae 117.

Chenopodium 118.

Chiloscyphus 53.

Chimophila 175.

Chiococea 198.

Chionanthus 180.

Chironia 182.

Chitonia 144.

Chlaenaceae 157.

Chlaenineae 157.

Chlamydobacteriaceae 4.

Chamydocarya 153.

Chlamydomonas 11 .

Chloanthes 187.

Chlora 182.

Chloranthaceat 107.

Chloramoeba 7.

Chloranthus 107.

Chloris 82.

Chlorochytrium 12.

Chlorococcum 12,44.

Chloromonadaceae7.

Chloromonadales 7.

Chlorophora 110.

Chlorophyceae 11, $38,41,51$.

Chlorophytum 95.

Chlorosphaera 11.

Chlorosphaeraceae 11.

Chlorosplenium 30 .

Choanephora 26.

Choanephoraceae?6.

Choiromyces 33.

Choisya 145.

Chomiocarpon 52.

Chondrilla 206.

Chondrioderma 2.

Chondrodendron 125.

Chondrus 21.

Choranthaceae 101.

Chorda 16.

Chordaria 17.

Choripetalae 106. 
Chorizantlie 117. Chorizena 140 . Chromatium 5. Chromosporium 37. Chromulina 7. Chromulinaceae 7 . Chroococcaceae $\mathbf{6}$, 40.

Chroococcus 6, 42 .

Chrozophora 149.

Chrysamueba 7 .

Chrysanthemum 204.

Chrysobalanus 138. Chrysomonadales 7 . Chrysonyxa 44.

Chrysophyllum 179. Chrysopyxis 7 .

Chrysosplenium 134. Chrysot richaceae 39 . Chrysymenia 22.

Chusquea 83.

Chylocladia 2:?.

Chytridiinae 26.

Chytridium 27.

Cibotium 63.

Cicer 142.

Ciclıorium 206.

Cicuta 173.

Cilioflagellata 8.

Cinchoua 198.

Cinclidotus 57.

Cineraria 205.

Cingularia 67.

Cinnamodendron 163.

Cinnamomum 127.

Circaea 171.

Cirsium 205̄.

Cissus 156.

Cissampelos 125.

Cistaceae 163.

Cistineae 163.

Cistus 163.

Citharexylum 187.

Citrullus 201.

Citrus 146.

Cladium 84.

Cladochytriacene 27.

Cladochytrium 27.

Cladonia 41 .

Cladoniaceae 41 .

Cladophora 13, 39.

Cladophoraceae 13.

Cladosporium 37.

('ladostephus 16.

Cladoxvlon 69.

Cladrastis 140 .

Clathraceae 49 .

Clathrocystis 6 .
Clatlıroptychiaceae 2.

Clathrus 49 .

Clavaria 47.

Clavariacene 47 .

Claviceps 34.

Clavija 177.

Claytonia 121.

Clematis 124.

Cleome 129.

Clerodendron 188.

Clethra 175.

Clethraceae 175.

Clevea 5?.

Cliffortia 137.

Climacium 61.

Clitopilus 49 .

Clitoria 142.

Clivia 98.

Closterium 10, 27.

C\%ostridium 14

Clusia 161.

Cluytia 150.

Clypeusphaeriaceae 35.

Cneoraceae 145.

Cneorum 145.

Cnestis 138.

Cnicus 205.

Cobaea 186.

Coccaceae 5.

Coccoloba 117.

Cocconeris 10.

Cocrulus 125.

Cochlearia 130.

Cochliostema 93.

Cochlospermaceae 163.

Cochlospermineae $16 \ddot{s}$.

Cochlospermum 163.

Cocos 86 .

Codiaceae 14.

Codiaeum 150.

Codiolum 14.

Codium 14

Codon 186.

Coelococcus 86.

Coeloglossum 104.

Coelogyne 105.

Coelosphaerium 6 .

Coenogoniaceae 39.

Coenogonium 39.

Coffea 198.

Coix 75.

Cola 159.

Colchicum 95.

Coleanthus 82 .
Coleachaetaceae 13. Cordaitales 72.

Coleochaete 13.

Coleonema 146.

Coleosporiacene 45

Coleosporium 45.

Coleus 190.

Collema 4u.

Collemataceae 40.

Colletia 156.

Collinsonia 190.

Collomia 186.

Colocasia 89.

Columellia 195.

Columelliaceae 195 .

Columnea 195.

Colutea 141.

Combretaceat 169.

Combretum 170.

Commelina 93.

Commelinaceae 93.

Commelinineae 93 .

Commiphora 147.

Comocladia 152.

Compositae 202.

Compsogonaceae 19.

Condaminea 197.

Conferva 1:2.

Confervales 12, 51 .

Coniferae 72.

Coniocarpineae 31 , 38.

Coniocybe 35 .

Coniophyllaceae 38 .

Conjugatae 10.

Coniam 173.

Conanthera 93.

Connaraceae 138.

Connarus 138

Conocephalus 52.

Conospermum 112.

Conringia 131.

Contortae 180.

Convallaria 97.

Convolvulaceae 185.

Convolvulienae $\mathbf{1 8 5}$.

Convolvulus 185.

Conyza 203.

Copaifera 139.

Copernicia 8.

Coprinarius 48 .

Coprinus 48.

Coprosma 199.

Coptis 124.

Cora 49.

Corallina 24.

Corallinaceae 94.

Coralliorrhiza 105.

Corchorus 157.

Cordaianthus 72

Cordaitaceae 72.
Cordaites 72 .

Cordia 187.

Cordieritidaceae 31 .

Cordyceps 34.

Cordyline 97.

Coreopsis 204.

Coriandrum 173.

Coriaria 151.

Coriariacene 151.

Coriariineae 151.

Coris 178.

Dorispermum 118.

Cornaceae 174.

Cornus 175.

Corouanthera 194.

Coronilla 141.

Coronopus 130.

Correa 145.

Corrigiola 122.

Corsia 103.

Corsinia 52.

Corticium 47.

Cortinarius 49.

Cortusa 178.

Corydalis 129.

Corylopsis 135.

Corylus 109.

Coryne 30.

Coryneum 36.

Coryneliaceae 35 .

Corynephorus 82 .

Corynocarpaceae 152.

Corynocarpus 152.

Corypha 84.

Corytholoma 195.

Coscinodiscus 9.

Coscinodon 58.

Cosnarium 10.

Costa 7 .

Costiopsis 7 .

Costus 10?.

Cotinus 152.

Cotoneaster 136.

Cotyledon 133.

Coula 114.

Cousinia 205.

Coussarea 199.

Coutarea 198.

Crambe 130.

Craspedomonadaceae 7.

Crassula 133.

Crassulaceae 133.

Crataeva 129.

Craterellus 47.

Cratoxylon 161.

Crenothrix 4.

Crepis 206. 
Crescentia 193.

Cressa 185.

Cribraria 2.

Cribrariaceae 2.

Crinum 98.

Crocus 100.

Cronartium 44.

Crossosoma 136.

Crossosomataceae 136.

Crotalaria 141.

Croton 149.

Cryphaeaceae 60.

Cryptocarya 128.

Crytocoryne 90.

Cryptogramme 64 .

Cryptomeria 74.

Cryptomonadaceae 7.

Cryptomonadales 7 .

Cryptomonas 7.

Cryptonemiales 20.

Cryptospora 35.

Crucianella 199.

Cruciferae 129.

Crucibulum 50 .

Cruoria 34.

Ctenopteris 62.

Cucubalus 122.

Cueurbita 201.

Cuenrbitaceae 200.

Cucurbitaria 34 .

Cucurbitariaceae 34 .

Cucurbitineae 200.

Cucumis 201.

Culcasia 88.

Cuminum 173.

Cunninghamia 74.

Cunoniaceae 135.

Cupania 154.

Cuphea 168.

Cupressus 74 .

Curatella 160.

Curculigo 99.

Curcuma 101.

Curtisia 175.

Cuscuta 185.

Cusparia 146.

Cussonia 172.

Cutleria 17.

Cutleriaceae 17.

Cyanophyceae 5.

Cyanotis 93.

Cyathea 63.

Cyatheaceae 63 .

Cyathodium 52.

Cyathus 50.

Cycadaceae 71 .

Cycadales 71 .

Cycadofilices 69 .
Cycadopteris 62.

Cycadospadix 71 .

Cycadospermum 71

Cycadoxylon 69 .

Cycas 71

Cyclamen 178.

Cyclanthaceae 87 .

Cyclanthera 201.

Cyclanthus 87.

Cyclopteris 62 .

Cyclosporeae 17.

Cydonia 137.

Cylindrocapsa 13.

Cylindrocapsaceae 13.

Cylindrospermum 6.

Cymbella 10.

Cymbidium 105.

Cymodocea 78.

Cynanchum 184.

Cynara 205.

Cynocrambaceae 120

Cyuocrambe 120 .

Cynodon 82.

Cynodontium 56

Cynoglossum 187.

Cynomoriaceae 171.

Cynomoriineae 171.

Cynomorium 171.

Cynosurus 82.

Cyperaceae 83 .

Cyperus 83.

Cyphella 47.

Cyphelium 38.

Cyphia 202.

Cypripedilum 103.

Cyrilla 152.

Cyrillaceae 152.

Cyrtandra 194.

Cyrtanthus 98.

Cyrtopodium 105.

Cystoclonium 21.

Cystopteris 63 .

Cystoseira 18.

Cytinus 116.

Cytisus 141.

Cyttariaceae 31.

Czekanowskia 78.

$$
\text { D. }
$$

Daboecia 176.

Dacrydium 72.

Dacryodes 147.

Daryomyces 46.

Dacryomycetaceae 46.

Dacryomycetineae 46.
Dactylanthus 115.

Dactylis 82.

Dadoxylon 72 .

Daedalea 48.

Dahlia 204.

Dalbergia 142.

Dilechampia 150.

Danaë. 97.

Danaea 66.

Danaeites 62 .

Danthonia 82.

Daphne 168.

Darlingtonia 132.

Dasya 23.

Dasycladaceae 14.

Dasylirion 97.

Dasypogon 96.

Dasyscypha 30.

Datisea 166.

Datiscaceae 165.

Datiscineae 165.

Datura 191.

Daucus 174.

Davallia 64.

Davidia 175.

Dawsonia 59

Delesseria 22.

1)elesseriaceae 2:.

Delphinium 124.

Dematiaceae 37.

Dendrobium 105.

Dendrocalaınus 83 .

Dendroceros 52.

Dendrophthora 114.

Dendroseris 206.

Dentaria 130.

Dermatocarpaceae 42.

Derminus 49.

Deschampsia 82.

Desfontainea 181.

Desmarestia 17.

Desmatodon 57.

Desmidiaceae 10.

Desmidium 10.

Desmodium 142.

Desmotrichium 16.

Deutzia 134.

Dialypetalum 202 .

Dianella 95.

Dianthus 122.

Diapensia 177.

Diapensiaceae 177.

Diaporthe 35.

Diatoma 10.

Diatrypaceae 35.

Diatrype 35.

Diatrypella 35.

Dicentra 129.

Dichaenaceae 32.
Dichapetalaceae 149.

Dichapetalum 149.

Dichapetalineae 149.

Dichelyma 60.

Dichodontium 56.

Dichondra 185.

Dichorisandra 93

Dicksonia 63.

Dicotyledoneae 106.

Dicranaceae 56 .

Dicranella 56.

)icranodontium 56.

Dicranum 56.

Dictamnus 14j.

Dictyoloma 146.

Dictyonema 43.

Dictyosiphon 17

Dictyosteliaceae 1.

Dictyostelium 1.

Dictyota 18.

I ictyotaceae 18.

Dictyotales 18 .

Didlymiaceae 1, 2.

Diclymium 2.

Didyınodon 57.

Didymosphaeria

Dieffenbachia 89. 35.

Diervilla 199.

Digitalis 192.

Dilleniacere 159.

Dimorphotheca 205.

Dinobryon 7.

Dinoflagellatae 8.

Dionaea 13?.

Dioon 71.

Dioscorea 100.

Dioscoreaceae 99.

Diospyrineae 179.

Diospyros 180.

)iphyscium 60.

Diplacium 64.

Diplanthera 85.

Diplochistaceae 39.

Diplodia 36.

Diplophyllum 54.

Diplosiga 7.

Diplotaxis 130 .

Dipsacaceae 200.

Dipsacus 200.

Dipterocarpaceae 162.

Dipterocarpus 162.

Dipterygium 129.

Dipteryx 142.

Dirina 31.

Dirinaceae 39.

Disa 104.

Disceliaceae 58. 
Discelium 58.

Dischidia 184.

Discocarpineae 31, 39.

Dissodon 58.

Distichium 56.

Distigma 8.

Distomataceae 7.

Distomatinales 7.

Ditrichum 56.

Dobinea 152.

Dodecatheon 178.

Dodonaea 155.

Dolerophyllum 69 .

Dolichos 142.

Dombeya 159.

Donatia 134.

Dorema 174.

Doronicum 205.

Dorstenia 110.

Dotlidea 34.

Dothideaceae 34.

Dothideaceales 34 .

Draba 131.

Dracaena 97.

Dracocephalum 189.

Dracontium 89.

Dracophyllum 177

Dracunculus $y 0$

Draparnaldia 12.

Drapetes 168 .

Drepanophyllaceae 58.

Drepanophyllum 58.

Drimys 126.

Drosera 13:.

Droseraceae 132.

Drosophylluin 132.

Dryandra 112.

Dryas 137.

Drymoglossum 64 .

Drynaria 65.

Dryobalanops 162.

Drypis 12:.

Duboisia 192.

Dudresnaya 23.

Dulacia 113.

Dumontia 24.

Dumontiaceae 23.

Dumortiera 52.

Duranta 187.

Durio 158.

Dyckia 93.

$$
\text { E. }
$$

Ebenaceae 179.

Ebenales 178.

Ecballium 201.

Eccremocarpus 193.

Echinocactus 167.
Echinodorus 79.

Echinophora 173.

Echinops 205.

Echinospermum 187.

Echites 183.

Echium 187.

Eclipta 204.

Ectocarpus 16.

Ectocarpaceae 16.

Ectosporeae 1, 2.

Ectrogella 26.

Ehretia 186.

Eichhornia 93.

Elnchista 16.

Elaeagnaceae 168.

Elaeagnus 168.

Elaeis 86.

Elaeocarpaceae 157.

Elaecocarpineae 156.

Elaeocarpus 157.

Elaphoglossum 65.

Elaphomyces 33, 34.

Elaphonycetaceae 33.

Elatinaceae 162.

Elatine 16 ?.

Elatinoides 192.

Elatostema 111.

Elettaria $10 \%$.

Eleusine 82.

Elisma 79.

Elodea 80.

Elsholtzia 190.

Elvasia 160.

Elymus 83.

Elyna 84.

Embelia 178.

Emblingia 129.

Embothrium 112.

Embryophyta siphonogama 70.

Embryophyta asiphonogama 50.

Enericella 33.

Empetraceae 151.

Empetrineae 151.

Empetrum 151.

Empusa 26.

Enalus 80.

Enantioblastae 91.

Encalypta 57.

Encephalartos 71 .

Encoelium 16.

Endocarpon 42.

Endodesinia 161.

Endogone 23.

Endomyces 29.

Endomycetaceae 29.

Endophyllaceae 44.

Endophyllum 44.
Endopy:eniaceae 42.

Endosporeae 2.

Entada 139.

Enteromorpha 12.

Entoderma 12.

Entomophthora 26.

Entomophthoraceae 26.

Entomophthorineae 26.

Epacriclaceae 177.

Epacris 177.

Ephebaceae 40.

Ephelse 40.

Ephedra 75.

Ephemeropsis 60.

Ephemerum 58.

Epichloë 34.

Epicladia 12.

Epidendrum 105.

Epigaea 176.

Epilobium 171.

Epimedium 125.

Epipactis 104.

Epiphyllum 167.

Epipogou 104.

Epipremnum 88.

Epipyxis 7.

Epithemia 10.

Equisetaceae 67.

Equisetales 67.

Equisetum 67.

Eragrostis 8:.

Eranthemin 196.

Eranthis 123.

Eremascus 29.

Eremolepis 114.

Eremophila 197.

Eremosphaera 12.

Eremostachys 189.

Eremurus 95.

Eria 105.

Erica 177.

Ericaceae 176.

Ericales 166.

Erigeron 203.

Erinus 192.

Eriobotrya 137.

Eriocaulaceae 92.

Eriocaulon 92.

Eriogonum 117.

Eriolaena 159.

Eriophorum 84

Eriospermum 95.

Eriostemon 145.

Eritrichium 187.

Erodium 143.

Eruca 130.

Erycibe 185.

Eryngium 172.
Erysibaceae 33.

Erysibe 33.

Erysimum 131.

Erythraea 182.

Erythrina 142.

Erythrochiton 146.

Erythronium 96.

Erythrophloeum 159.

Erythroxylacea 144.

Erythroxylon 144.

Escallonia 134.

Eschscholtzia 128.

Esenbeckia 146.

Espeletia 204.

Euascales 29.

Euasconiycetes 28.

Euastrum 10.

Eubacteria 3.

Eubasidii 44.

Eucalamites 67.

Eucalyptus 170.

Eucharis 99.

Eucheuma 21.

Euchlaena 81.

Eucladium 57.

Eucomis 96.

Eucryphiaceae 160.

Eudorina 11.

Eugenia 170.

Euglena 8.

Euglenaceae 8.

Euglenales 7.

Euglenopsis 8.

Eulejeunea 55.

Eumycetes 1, 25.

Eunotia 10.

Eupatorium 203.

Euphorbia 150.

Euphorbiaceae 149.

Euplırasia 193.

Eupomatia 197.

Eurhynchium 61 .

Eurya 161.

Euryale 123.

Eustephia 99.

Euterpe 86.

Euthemis 160 .

Eutuberaceae 32.

Evax 203.

Evernia 41.

Evorlia 145.

Evolvulus $18 j$.

Evonymus 153.

Exacum 182.

Excipulaceae 36.

Excoecaria 150.

Exidia 46.

Exoascaceae 29. 
Exoascus 29

Exobasidiaceae 46 .

Exobasidiineae 46 .

Exobasidium 46.

Exocarpus 113.

Exogonium 185.

Exostema 198.

Exuviaella 8.

\section{F.}

Fabiana 191.

Fabronia 61 .

Fabroniaceae 60 .

Fadyenia 63

Fagaceae 109.

Fagales 108.

Fagara 145.

Fagonia 144.

Fagopyrum 117.

Fagraea 181.

Fagus 109.

Falearia 173.

Falkia 184.

Farinosae 91 .

Fatsia 172.

Fedia 200.

Fegatella 52.

Feronia 146

Ferula 174.

Festuca 82.

Fevillea 190

Ficus 111.

Filago 203.

Filicales 62.

Filicales Leptospo. rangiatae 62 .

Fimbristylis 84 .

Fissidens 57.

Fissidentaceae 57.

Fistulina 48.

Fitzroya 74.

Flacourtia 164.

Flacourtiaceae 164.

Flacourtiineae 163.

Flagellaria 91.

Flagellariaceae 91.

Flagellariineae 91 .

Flagellatae 6 .

Flindersia 146.

Florideae 19.

F/uviales 77.

Foeniculum 174.

Foetidia 169.

Folliculites 79.

Fomes 47.

Fontanesia 180.

Fontinalis 60 .

Fontinalaceae 60 .

Forsythia 180.

Forskaolea 112.
Fossombrouia 53.

Fothergilla 135.

Fouquiera $16: 3$.

Fouquieraceae 162 .

Fonquierineae 16\%.

Fourcroya 99.

Fragaria 137.

Francoa 134.

Frankenia 16:.

Frankeniaceae 162 .

Franklandia 112.

Fraxinus 180.

Fremontia 159.

Freycinetia 77.

Fritillaria 46 .

Frullania 55.

Fucaceae 17.

Fuchsia 171.

Fucus 18.

Fuligo 2.

Fumaria 129.

Funaria 54 .

Funariaceae 58.

Fungi 25.

Fungi imperfecti 36 .

Funicularia 52.

Fusarium 37.

Fusicladium 37.

Gagea 96 .

Gahnia 84.

Galanthus 98.

Galax 177.

Galaxaura 21.

Galega 141.

Galeola 104.

Galeopsis' 189.

Galinsoga 204.

Galipea 146.

Galium 199.

Garcinia 161.

Gardenia 198.

Garrya 174.

Gasteria 95.

Gaultheria 176.

Gaylussaccia 177.

Gazania 205.

Geaster 50.

Geissoloma 167.

Geissolomaceae 167.

Geitonoplesium 98.

Gelidiaceae 20.

Gelidium 21.

Gelonium 150.

Gelsemium 181.

Genea 32.

Genista 141.

Genlisea 195 .

Gentiana 182.
Gentianaceae 181. Gentianineae 181. Geocalyx 53.

Georgia 60.

Georgiaceae 60.

Geoglossaceae 29.

Geoglossum 29.

Geraniacene 143.

Geraniales 143.

Geraniineae 143.

Geraniumm 143.

Gerardia 193.

Gerbera 206.

Gesnera 195.

Gesneraceae 194.

Geum 137.

Gibberella 34 .

Gigartina 21.

Gigartinaceae 21.

Gigartinales 21.

Gilia 186.

Gillenia 136.

Gilliesia 96.

Ginkgo 72.

Gingkoaceae 72 .

Gingkoales 72.

Girandia 16.

Gladiolus 100

Glaucium 128.

Glaux 178.

Glechoma 189.

Glechon 189.

Gleditschia 140.

Gleichenia $6 \mathbf{5}$.

Gleicheniaceae 65 .

Globaria 50.

Globba 10?.

Globularia 196.

Globulariaceae 195.

Gloeocapsa 6.

Gloeosporium 36 .

Gloeothece 6 .

Gloiopeltis 23 .

Gloiosiphonia 23.

Gloiosiphoniaceae 23.

Gloriosa 94.

Glossopteris 62 .

Gloxinia 195.

Glomiflorae 80.

Glycine 142 .

Glyceria 82.

Glycyrrhiza 141.

Glyphocarpus 59.

Glyptostrobus 74.

Gnaphalium 203.

Gnetaceae 75 .

Gnetales 75.

Gnetum 75.

Gnidia 168.
Gnomonia 35

Gnomoniaceae 35.

Gomontia 13.

Gomontiaceae 13.

Gomortega 127.

Gomortegaceae 127.

Gomphidius 48.

Gomphonema 10.

Gomphrena 119.

Gonatopus 88.

Gonium 11.

Gonolobus 184.

Gonystylaceae 1507.

Gonystylus 157.

Goodenia 202.

Goodeniaceae 202.

Goodyera 104.

Gossypium 158.

Gouania 156.

Gracilaria 22.

Gramineae 80.

Grammatophora 10.

Graphidaceae 31, 32, 3!)

Graphidineae 31, 39.

Graphis 32, 39.

Graptophyllum 196.

Grateloupia 24.

Grateloupiaceae 23.

Gratiola 192.

Grevillea 112.

Grewia 157.

Greyia 155.

Grieluin 138.

Griffithia 23.

Grimaldia 52.

Grimmia 58.

Grimmiaceae 57.

Grubbia 113.

Grubbiaceae 113.

Gnajacum 144.

Guarea 148.

Guepinia 46

Guettarda 198.

Guizotia 204.

Gunnera 171.

Gurania 200.

Guttiferae 161 .

Guttulinaceae 1.

Gyalecta 39.

Gyalectareae 39.

Gymnadenia 104.

Gymnoascaceae 32.

Gymnoascus 32.

Gymnocladus 140 .

Gymnocybe 59 .

Gymnodiniaceae 8.

Gymnogramme 62, 
Gymnomitrium 53

Gymnospermae 70 .

Gymnosporangium 45.

Gymnostomum 57. Gynandrae 103.

Gynerium 8:.

Gypsophila 123.

Gyrocarpus 128.

Gyromitra 29.

Gyrophora 40.

Gyrophoraceae 40.

Gyrostemon 120 .

\section{II.}

Habenaria 104.

Haberlea 194.

Hablitzia 118.

Hacquetia 172.

Haemanthus 98.

Haematomma 40.

Haematoxylon 140.

Haemodoraceae 98.

Hagenia 137.

Hakea 112.

Halenia 182.

Halesia 180.

Halimeda 14.

Halimodendron 141

Halleria 192.

Halonia 69

Halophila 80 .

Halorrhagidaceae 171.

Halorrhagidineae 171.

Halorrhagis 171.

Haloxylon 119.

Halymenia 24.

Hamamelidaceae 135.

Hamamelis 136.

Hancornia 183.

Hapalosiphon 6.

Haplomitrium 53.

Harpagophytum 193.

Harpalejeunea 55.

Harpullia 155.

Huworthia 95.

Hebenstreitia 192.

Hechtia 93.

Hedeoma 190.

Hedera 172.

Hedraeanthus 201.

Hedwigia 60.

Hedychium 101.

Hedyosmum 107.

Hedysarum 141.

Heimia 168.
Heisteria 114.

Helenium 204.

Heleocharis 84.

Helia 182.

Heliamphora 132.

Helianthemum 163.

Helianthus 204.

Helichrysum 203.

Helicia 112.

Helicodiceros 90 .

Heliconia 101.

Helicteres 159

Heliophila 130.

Heliotropium 186.

Helipternm 203.

Helleborus 124.

Helminthocladiaceae 20.

Helminthosporium 37.

Helminthostachys 67.

Helobiae 77.

Helodea 80

Helonias 94.

Helosis 115.

Helotiaceae 30.

Helotiun 30.

Helvella 29.

Helvellaceae 29

Helvelliveae 29.

Helwingia 175.

Hemerocallis 95 .

Hemiascales 28.

Hemiascomycetes 28.

Hemiaulus 9.

Hemibasidiales 43

Hemibasidii 43.

Hemiboea 194.

Hemileia 45.

Hemionitis 64 .

Hemitelia 63.

Henriquezia 198.

Hepaticae 51.

Heracleum 174.

Heritiera 159.

Hermannia 159.

Herminium 104.

Hernandia 128.

Hernandiaceae 128.

Herniaria 122.

Herpotrichia 34 .

Herreria 94.

Hesperis 131.

Heteranthera 93.

Heteronema 8.

Heteropsis 88.

Heuchera 134.

Hevea 150.
Hexalobus 126.

Hibbertia 160.

Hibiscus 158.

Hieracium 206.

IHierochloë 82 .

Hildebrandtia 185.

Hildenbrandia 20, 25.

Himantlıalia 17.

Himantoglossum 104.

Hippeastrum 99.

Hippobromus 155.

Hippocastanaceae 154.

Hippocratea 153.

Hippocrateaceae 153.

Hippocrepis 141.

Hippomane 150.

Hippophaë 168.

Hippuris 171.

Hiraea 148.

Hirtella 138.

Holcus 82.

Holodiscus 136.

Holomastigacere 7 .

Holosteum 121.

Homalia 60.

Homalium 164

Homalomena 89.

Homalothecium 61 .

Homogyne 205.

Hookeria 60.

Hookeriaceae 60.

Hordeum 83.

Hormidium 12.

Horminum 189.

Hosta 95.

Hottonia 178.

Houttuynia 107.

Hovenia 156.

Hoya 184.

Hugonia 135.

Humea 203.

Humiriaceae 144.

Humulus 111.

Hura 150.

Hutschinsia 131.

Huttonia 67.

Hyacinthus 97.

Hyaloria 46.

Hyaloriaceae 46 .

Hyalotheca 10.

Hydnaceae 47.

Hydnophytum 198.

Hydnora 116.

Hydnoraceae 116

Hydnuin 47.

Hydrangea 134.

Hydrastis 123, 124
Hydrilla 80 .

Hydrocharis 79 .

Hydrocharitaceae

79.

Hydrocleis 79 .

Hydrocotyle 172.

Hydrodictyaceae 12.

Hydrodictyon 12, 26.

Hydrolea 186.

Hydromystria 79 .

Hydrophyllaceae

186.

Hydrophyllum 186.

Hydropteridineae 65.

Hydrosme 89.

Hydrostachydaceae 133.

Hydrurus 7.

Hygrophila 186.

Hygrophorus 48 .

Hylocomium 61

Hymenaen 139.

Hymenocallis 99 .

Hymenogaster 49.

Hymenogastraceae 49.

Hymenogastrineae 49.

Hymenolichenes 42, 47.

Hymenomonada. ceae 7 .

Hymenomycetineae 46.

Hynenophyllaceae 63.

Hymenophyllum 63 .

Hymenostomum 57.

Hymenostylium 57.

Hyobanche 193.

Hyophorbe 86.

Hyoscyamus 191 .

Hypecoum 128.

Hypericum 161.

Hyphaene 85.

Hyphochytriaceae 27.

Hypholoma 48

Hyphomycetes 36 .

Hypnaceae 61.

Hypnum 61 .

Hypochaeris 206.

Hypochnaceae 47.

Hypochnus 47.

Hypocrea 34.

Hypocreaceae 34 .

Hypocreaceales 33 .

Hypoderina 31. 
Hypodermataceae 31.

Hypolytrum 83.

Hypomyces 34 .

Hypopterygiaceae 60.

Hypopterygium 60 .

Hyporhodius 49.

Hypoxis 99.

Hypoxylon 35.

Hyptis 190.

Hyssopus 190.

Hysterangium 49.

Hysteriaceae 32 .

Hysteriineae 31, 39.

Hysterium 32.

\section{J.}

Jacaranda 193.

Jasione ?01.

Jasminum 181.

Jatropha 150.

Iatrorrhiza 125.

Iberis 130 .

lcacinaceae 153.

Icacinineae 153.

Icmadophila 39.

Jeffersonia 125.

Ilex 153.

Illecebrum 122.

Illicium 126.

Illipe 179.

Illosporium 37.

Impatiens 155.

Incarvillea 193.

Indigofera 141.

-Inga 139.

Inocybe 49.

Inuli 203.

Johnsonia 96.

Jonidium 164.

Ipomoea 185.

Iresine 119.

Iriartea 86.

Iridaceae 100.

Iridineae 100.

Iris 100.

Isaria 37.

Isatis 130.

Isoëtaceae 69 .

Isoëtes 69 .

Isoetineae 69 .

Isoglossa 196.

Isopyrum 124.

Isothecium 61 .

Itea 134.

Jubaea 87.

Juglandaceae 108.

Juglandales 108.
Juglans 108

Juncaceae 94.

Juncaginaceae 78.

Juncineae 94.

Juncus 94.

Jungermanniaceae acrogynae 53.

Jnngerıanniaceae anacrogynae 53.

Jungermanniales 52.

Juniperus 74 .

Jurinea 205.

Jussiaea 171.

Justicia 196.

Ixia 100.

Ixiolirion 99.

Ixora 198.

\section{K.}

Kämpferia 102 .

Kalmia 176.

Karschia 31.

Kaulfussia $b 6$.

Kentia 86.

Kerria 137.

Keteleeria 74.

Khaya 148.

Kickxia 183.

Kielmeyera 161 .

Kigelia 193.

Kingia 96.

Kissenia 165.

Kitaibelia 158.

Kleinia 205.

Klugia 194.

Knautia 200.

Kniphofia 95.

Knorria 69.

Kobresia 84.

Koeberlinia 163.

Koeberliniaceae 163.

Koeleria 82.

Koelreuteria 155.

Koenigia 117.

Kohleria 185.

Krameria 140.

Kyllingia 84 .

\section{I.}

Labiatae 188.

Laboulbenia 43 .

Laboulbeniaceae 43.

Iaboulbeniales 42 .

Laboulbeniomycetes 42.

Laburnum 141.

Lachnea 30.

Lachnum 30.

Lacistema 107.

Lacistemaceae 107.
Lactaria 48.

Lactoridaceae 126.

Lactoris 126.

Lactuca 206.

Ladenbergia 198.

Laelia 105.

Laetia 164.

Lagarosiphon 80 .

Lagenandra 90.

Lagenaria 201.

Lagenidiaceae 27.

Lagenidium 27.

Lagerstroemia 168.

Lagetta 168.

Lagoecia 17?.

Laguncularia 170.

Lagurus 82.

Laminaria 17.

Laminariaceae 17.

Lamium 189.

Lamprocystis 15.

Landolphia 183.

Langsdorffia 115

Lantana 187.

Lapageria 98.

Lapeyrousia 100.

Laportea 111.

Lappa 205.

Lapsana 206.

Lardizabalaceae 124.

Larix 73.

Laserpitium 174.

Lasia 89.

Lasiosphaeria 34 .

Lasiopetalum 159.

Latania 85.

Lathraea 193.

Latyrus 142.

Laudatea 42.

Lauraceae 127.

Laurencia 23.

Laurus 128

Lavandula 189.

Lavatera 158.

Lawsonia 168.

Lebetanthus 17\%.

Lecanactidaceae 39 .

Lecanopteris 65 .

Lecanora 40.

Lecanoruceae 40.

Lecidea 31, 39.

Lecideaceae $31,39$.

Lecythidaceae 169.

Lecythis 169.

Ledum 176.

Leea 156.

Leersia 81.

Leguminosae 138.

Lejolisia 23.

Leiphaemos 182.
Leitneria 108.

Leitneriaceae 108.

Leitneriales 108.

Lemanea 20.

Lemaneaceae 20.

Lemna 91.

Lemnaceae 90.

Lennoaceae 176.

Lens 142.

Lentibulariaceae 195.

Lentinus 48.

Lenzites 48.

Leocarpus 2.

Leontice 125.

Leontodon 206.

Leontopodium 203.

Leonurus 189.

Leotia 29.

Lepidium 130.

Lepidodendraceae 69.

Lepidodendron 69.

Lepidopbloios 69 .

Lepidophytineae 68 .

Lepidosia 54.

Lepidostrobus 69 .

Lepiota 49.

Leptadenia 184.

Leptobryum 59.

Leptodontium 57.

Leptogium 40.

Leptomitaceae 27.

Leptomitus 27.

Leptopteris 65.

Leptosphaeria 35.

Leptospermum 170.

Leptostromataceae 36.

Leskea 61.

Leskeaceae 61 .

Lespedeza 142.

Lesquerella 131.

Lessonia 17.

Leucadendron 112.

Leucas 189.

Leucobryaceae 56.

Leucobryum 56.

Leucodon 60.

Leucojum 98.

Leucoloma 56.

Leuconostoc 5.

Leucophanes 56 .

Leucothoë 176.

Levisticum 174.

Lewisia 121.

Leycesteria 199.

Liagora 20.

Libertia 100.

Libocedrus 74. 
Licania 138. Liceaceae 2.

Lichenes 38 .

Lichina 40.

Ligularia 205.

Ligusticum 174.

Ligustrum 180.

Lilaea 78.

Liliaceae 94.

Iiliiflorae 9:3.

Liliineae 94.

Lilium 96.

Limacium 48.

Limeum 120.

Limodorum 104.

Limonia 146.

Limosella 192.

Limnanthaceae 151 .

Limnanthemum 182 .

Limnanthes 151.

Limnanthineae 151.

Linaceae 143.

Linaria 192.

Lindera 128.

Lindernia 192.

Lindsaya 63.

Linnaea 199.

Linopteris 62.

Linum 143.

Liparis 105.

Lippia 187.

Liquidambar 135.

Liriodendron 126.

Liriope 98.

Lisianthus 182.

Lissochilus 105.

Listera 104.

Litchi 154.

Lithoderma 16.

Tithospermum 187.

Lathothamnion 25 .

Lithorella $19 \%$.

Litsea 128.

Livistona 84 .

Lloydia 96.

Loasa 16.5 .

Loasaceae 16 .

Loasineae 165.

Lobaria 40.

Lobelia 202.

Juchnera 183.

Lodoicea 85.

Logania 181.

Loganiaceae 181.

Loiseleuria 176.

Iolium 8.3.

Lomandra 96.

Lomentaria 22.

Jonchitis 64.

Lonchopteris 62.
Louicera 199.

Lophiostoma 35.

Lophiostomataceae 35

Lophira 160.

Lophocolea 53.

Lophodermium 39.

Lophophytum 115.

Lophozia う̌3.

Lopezia 171.

Loranthaceae 114.

Loranthineae 114.

Loranthus 114 .

Lotononis 141 .

Lotus 141.

Lontheridia 196.

Lowia 101.

Luffa 201.

Lumnitzera 170.

Lunaria 130.

Lunularia 52 .

Lupinus 141.

Luxemburgia 160.

Luzula 94.

Luzuriaga 98.

Lycaste 105.

Lychnis 122 .

Lycium 191.

Lycogala 2.

Lycoperdaceae 50 .

Lycoperdineae 49 .

Lycoperdon 50 .

Lycopodiaceae 68.

Lycopodiales 67.

- eligulatae 68 .

- ligulatae 68.

Lycopodiineae 68 .

Lycopodium 68.

Lycopsis 187.

Lycopus 190.

Lygeum 81.

Lyginopteris 69.

Lygodium 65.

Lyngbyaceae כ̃.

Lyonia 176.

Lysimachia 178.

Lythraceae 168.

Iythrum 168.

M.

Mabea 150.

Machaerium 142 .

Mackinlaya 172.

Macleya 128.

Maclura 110.

Macrocystis 17 .

Macromitrium 58.

Macroplectrum 106.

Macrosporium 37.

Macrozamia 71 .
Madia 204.

Madotheca 54 .

Maerua 129.

Maesa 178.

Magnolia 125.

Magnoliaceae 125.

Magnoliineae 125.

Mahonia 124.

Majantheinum 97.

Malaxis 105.

Malcolmia 1:31.

Malesherbiaceae 164.

Mallotium 40 .

Mallotus 149.

Mallope 158 .

Malpighia 148.

Malpighiaceae 148 .

Malpighiineae 148 .

Malva 158 .

Malvaceae 157 .

Malvales 156.

Malvineae $15 \%$.

Mamillaria $16 \%$.

Mammea 161.

Mandragora 191.

Mangifera 152.

Manihot 150 .

Mantellia 71 .

Manulea 192.

Maontia 111.

Mapania 84.

Maranta 102.

Marantaceae 102.

Marasmius 48 .

Marattia 66.

Marattiaceae 66.

Marattiales 66 .

Marcgravia 160.

Marcgraviaceae 160 .

Marchantia 52 .

Marchantiaceae 52 .

Marchantiales 51 .

Marrubium 189.

Marsdenia 184.

Marsilia 66.

Marsiliaceae 65.

Marssonia 36.

Marsupella 53.

Martynia 194.

Martyniaceae 194.

Mascarenhasia 184.

Masdevallia 105.

Massaria 35.

Massariaceae 35.

Mastigamoeba 7.

Mastigophora 54 .

Mastixia 175.

Matonia 6 .̃.

Matoniaceae 65 .
Matricaria 204.

Matthiola 131 .

Maurandia 192.

Mauritia 85.

Maxillaria 106.

Mayaca 92.

Mayacaceae 91.

Mayna 164.

Maytenus 153.

Meconopsis 128.

Medicayo 141.

Medinilla 170.

Medullosa 69 .

Meesea 59.

Meeseaceae 59 .

Megaloxylon 69 .

Megaphyta 62.

Megaphyton 62.

Megastoma 7.

Melaleuca 170 .

Melampodium 204.

Melampsora $4 \tilde{5}$.

Melampsoraceae 44 .

Melampyrum 193.

Melanconiaceae 36 .

Melanconiales 36 .

Melanconidaceae 35 .

Melanconis 35.

Melanconium 36.

Melandryum 122.

Melanomma 34.

Melanorrhoea 152 .

Melanospora 34 .

Melanotheca 42 .

Melastomataceae 170.

Melhania 159.

Melia 148.

Meliaceae 147.

Melianthaceae 155.

Melianthineae 155.

Melianthus 155.

Melica 82.

Melilotus 141.

Meliosma 15̄.

Melissa 190.

Melittis 189.

Melobesia 24.

Melocactus $16 \%$.

Melochia 159.

Melogramma 35.

Melogrammataceae 35.

Melosira 9.

Melothria 200.

Memecylon 161.

Mendoncia 196.

Menisperıaceae125.

Menispermum 125.

Mentha 190. 
Mentzelia 156.

Menyanthes 182.

Menziesia 176.

Mercurialis 149.

Merendera 95.

Meriandra 189.

Merismopedia 6 .

Merulius 47.

Mesanthemum 92.

Mesembrianthemum 121.

Mesocarpaceae 10.

Mespilus $13 \%$.

Mesua 161.

Metachlamydeae 175 .

Meteorium 60.

Metopium 152.

Metrodorea 146.

Metrosideros 170.

Metroxylon 86.

Metzgeria 53.

Meum 174.

Michauxia 201.

Michelia 126.

Microcachrys 72.

Micrococcus 5.

Microcoleus 5.

Micromeria 190.

Micropus 203.

Microspermae 102.

Microspira 4.

Microstylis 105 .

Microthyriaceae 33.

Mielichhoferia 59 .

Mikania 203.

Milium 82.

Mimosa 139.

Mimulus 192.

Mimusops 179.

Mirabilis 120 .

Mitchella 199.

Mniaceae 59.

Mnium 59.

Moehringia 121.

Mohria 65.

Mollisia 30.

Mollisiaceae 30.

Mollugo 121.

Molinia 82.

Molopospermum 173.

Molucella 189.

Momordica 201.

Monuchanthus 105.

Monadaceae 7 .

Monarda 189.

Monas $\%$.

Monascaceae 28.

Monascus 28.
Monilia 38.

Monimiaceae $12 \%$.

Monoblepharidaceae $2 \%$.

Monoblepharis 27.

Monocotyledoneae 76.

Monodora 126.

Monopetolae 175.

Monostroma 12.

Monotropa 175.

Monsonia 143.

Monstera 88.

Montia 121.

Montrichardia 89.

Moraceae 110.

Moraea 100.

Morchella 29.

Morinda 199.

Moringa 132.

Moringaceae 131.

Moringineae 131.

Moriolaceae 41.

Morisia 130 .

Mortierella 26.

Mortierellaceae 26.

Morus 110

Moscharia 206.

Moschosma 190.

Mougeotia 10.

Mucedinaceae 36.

Muciporus 46.

Mucor 25, 26.

Mucoraceae 25.

Mucorineae 25.

Mucuna 142.

Mühlenbeckia 117.

Mulgedium 206.

Multicilia $\%$.

Muraltia 149.

Murraya 146.

Musa 101.

Musaceae 101.

Muscari 97.

Musci 55.

Musci frondosi 55.

Muscineae 51.

Mussaenda 198.

Musschia 201.

Mutinus 49.

Mutisia 206.

Myanthus 105.

Mycarthonia 31 .

Mycetozoa 1.

Mycocalicium 31.

Mycoconiocybe 31 .

Mycoidea 12.

Mycoideaceae 12.

Mycoporaceae 41.

Mycorrhiza 38.
Mycosphaerella 35 .

Mycosphaerellaceae 35.

Myoporaceae 197.

Myoporineae 197.

Myoporum 197.

Myosotis 187.

Myosurus 124.

Myriangiaceae 33 .

Myrica 108.

Myricaceae 108.

Myricales 108.

Myricaria 162.

Myrionema 16.

Myriophyllum 171 .

Myriotrichia 16 .

Myristica 127.

Myristicaceae 127.

Myrmecodia 199.

Myroxylon 140.

Myrothamnaceae

135.

Myrothamnus 135.

Myrrhis 173 .

Myrsinaceae $17 \%$.

Myrsine 178.

Myrtaceae 170 .

Myrthiflorae $16 \%$.

Myrtineae 168.

Myrtus 170.

Mystacidium 106.

Mystropetalon 115 .

Myxogasteres 1.

Myxomycetes 1.

Myxothallophyta 1.

Myxotrichum 32.

Myzodendraceae

113.

Myzodendron 113.

\section{$\mathbf{N}$.}

Najadaceae 78.

Najas 78.

Nama 186.

Nandina 125.

Napaea 158.

Napoleona 169.

Narcissus 99.

Nardia 53.

Nardostachys 200.

Nardus 83.

Narthecium 94.

Nasturtium 130.

Nauclea 198.

Naumburgia 178.

Navicula 10.

Neckera 60.

Neckeraceae 60.

Nectandra 128.
Nectria 34.

Nectrioidaceae 36 .

Neea 120.

Neesiella 52.

Nequndo 153.

Nelumbo 122.

Nelsonia 196.

Nemalion 20.

Nemalionales 20 .

Nemastomaceae 24.

Nematocaceae 60.

Nemophila 186.

Neottia 104.

Nepenthaceae 1:32.

Nepenthes 132.

Nepeta 189.

Nephelium 154.

Nephrodium 63.

Nephrolepis 63.

Nephroma 40.

Nephtytis 89.

Neptunia 139.

Nerine 98.

Nerium 183.

Nertera 199.

Neslea 131.

Neurada 138.

Neuropterides 62.

Neuropteris 62.

Neuwiedia 103.

Nicandra 191.

Nicotiana 191.

Nidularia 50.

Nidulariaceae 50 .

Nidulariineae 50 .

Nidularium 93.

Nigella 124.

Nigritellı 103.

Nilssonia 62.

Nipa 87.

Niphobolus 65.

Nitella 15.

Nitophyllum 22.

Nitraria 145.

Nitschkia 34.

Nitschia 10.

Nodularia 6.

Noeggerathia 69.

Nolana 190.

Nolanaceae 190.

Nolina 97.

Noranthea 160.

Nostoc 6, 40.

Nostocaceae 6 .

Nothochlaena 64.

Nothofagus 109.

Notothylas 52.

Nummularia 35.

Nuphar 123.

Nuxia 181. 
Nuytsia 114.

Nyctalis 48.

Nyctanthes 181.

Nymphaea 123.

Nymphaeaceae 122.

Nymphaeineae 122.

Nyctaginaceae 119.

Nyssa 174.

\section{D.}

Ochna 160.

Ochnaceae 160.

Ochradenus 131.

Ochrolechia 40.

Ochroma 158.

Ochromonadaceae 7.

Ocimum 190.

Ocotea 128.

Octoblepharum 56.

Odontites 193.

Odontoglossum 106.

Odontonema 196.

Odontopteris 62 .

Odontosoria 6:3.

Odontospermum $20: 3$.

Oedipodiaceae 58 .

Oedipodium 58 .

Oedogoniaceae 13.

Oedogonium 13, 26.

Oenanthe 174 .

Oenocarpus 86.

Oenothera 171.

Oenotheraceae 171.

Oicomonadaceae $\%$.

Oidium 33.

Olacaceae 113.

Olax 113.

Oldenlandia 198.

Olea 180.

Oleaceae 180.

Oleandra 63.

Olearia 203.

Oleineae 180.

Olinia 167.

Oliniaceae 167.

Olpidiaceae 26.

Olpidium 26.

Omphalaria 40 .

Omphalocarpum 179.

Omphalodes 187.

Oncidium 106.

Oncoba 164.

Onobrychis 141.

Onoclea 63.

Ononis 141.
Onopordon 205.

Onosma $18 \%$.

Onygena 33.

Onygenaceae 33 .

Oochytriaceae 27.

Oomycetes 26 .

Oospora 37.

Opegrapha 32, 39.

Ophiocladium 37.

Ophioglossaceae 66.

Ophioglossales 66 .

Ophioglossum 67.

Ophiopogon 98.

Ophrys 104.

Opilia 113.

Opuntia 166.

Opuntiales 166 .

Orbilia 80.

Orchidaceae 103.

Orchis 104.

Oreas 56.

Oreobolus 80, 84 .

Oreodoxa 86.

Oreopanax 172.

Origanum 190.

Orixa 145 .

Ornithogalum 97.

Ornithopus 141.

Orobanchaceae 194.

Orobanche 194.

Orontium 88.

Orthotricliaceae 58 .

Orthotrichum 58 .

Oryctanthus 114.

Oryza 81.

Oscillatoria 5.

Oscillatoriaceae 5 .

Osmunda 65 .

Osmundaceae 65.

Ostropaceae 32.

Ostrya 109.

Osyris 163.

Otidea 30 .

Ottelia 79.

Ouratea 160.

Ourouparia 198.

Ovularia 37.

Oxalidaceae 143.

Oxalis 143 .

Oxylobium 140.

Oxymitra $\lesssim 1$.

Oxyria 117.

Oxytropis 141.

\section{I.}

Pachyrrhizus 142.

Pachysandra 151.

Padina 18.

Paederia 199.

Paeonia 123.
Paepalanthus 92.

Palaeopteris 62 .

Palaeostachya 67.

Palaquium 179.

Palisota 93.

Paliurus 156.

Paludella 5\%.

Palmae 84.

Panax 172.

Pancratium 99.

Pandanaceae 7\%.

Pandanales 77.

Pandanus 77.

Pandorina 11.

Pangium 164.

Panicum 81.

Pannaria 40.

Pannariaceae 40.

Pantostomatinales 7.

Papaver 128.

Papaveraceae 128.

Papayineae 165.

Paphiopedilum 103.

Paradisea 95.

Paranema 8.

Paranemataceae 8 .

Parietales 159.

Parietaria 111.

Parinarium 138.

Paris 97.

Parkeriaceae 65.

Parkia 139.

Parmelia $\mathbf{4 0}$.

Parmeliaceae 40.

Parmentaria 42.

Parnassia 134.

Parochetus 141.

Paronychra 122.

Parrotia $13 j$.

Parsonsia 183

Parthenium 204.

Parthenocissus 156 .

Pasania 109.

Paspalum 81.

Passiflora 165.

Passifloraceae 165.

Patellaria 31.

Patellariaceae 31 , 39.

Patellea 31.

Patinella 31.

Patrinia 200.

Paullinia 154 .

Paulownia 152.

Puvia 154.

Paxillus 48 .

Payena 179.

Pecopterides 62.

Pecopteris 62.

Pedaliaceae 193.
Pedalium 193.

Pediastrum 12.

Pedicularis 193.

Pedilanthus 150.

Peganum 144.

Peireskia 166.

Pelargonium 143.

Pellaea 64.

Pellia 53.

Peltandra 89.

Peltigera 40 .

Peltigeraceae 40 .

Penaeaceae 167.

Penicillium 32.

Penicillus 14.

Penium 10.

Pennisetum 81.

Pentadesma 162.

Pentaphragma 201.

Pentaphylacaceae 152.

Pentaphylax 152.

Pentastemon 192.

Peperomia $10 \%$.

Peplis 168.

Peranema 8.

Peranemataceae 8 .

Perezia 206.

Pericallis 205.

Perichaena 2.

Peridineae 8.

Peridiniaceae 8.

Peridinales 8.

Peridinium 8.

Perilla 190.

Perilomia 189.

Periploca 184.

Perisporiaceae :33.

Perisporiaceales 33 .

Pernettya 176.

Peronospora 28.

Peronosporaceae 28.

Peronosporineae 27.

Persea 127.

Persoonia 112.

Pertusaria 40 .

Pertusariaceae 40 .

Pestalozzia :36.

Petagnia 172.

Petalidium 196.

Petasites 20.5.

Petrea 194.

Petroselinum 17:.

Petunia 191.

Pencedanum 174.

Peumus 127.

Peyssonellia 24.

Peziza 30.

Perizaceae 30.

Pezizineae 30. 
Phacelia 186.

Phacidiaceae 31 .

Phacidiineae 31.

Phacidium 31 .

Phacus 8.

Phaeodon 47.

Phaeophyceae 15.

Phaeosporeae 16.

Phagnalon 203.

Phajus 105.

Phalaenopsis 106.

Phalansteriaceae 7.

Phalaris 82.

Phaleria 168.

Phallaceae 49.

Phallineae 49.

Phallus 49 .

Phanerogamae 70.

Pharbitis 185.

Pharcidia 35.

Phascum 5\%.

Phaseolus 142

Philadelphus 134.

Philesia 98.

Phillyrea 180.

Philodendron 88, 89.

Philonotis 59.

Philydraceae 93.

Philydrineae 93.

Philydrum 93.

Phippsia 82.

Phleum 82.

Phlomis 189.

Phlox 186.

Phlyetis 40.

Phlyetochytrium $2 \%$.

Phoebe $12 \%$.

Phoenix 85.

Pholidota 105.

Pholiota 49.

Phoma 36.

Phoradendron 114.

Phormidium 5.

Phormium 95.

Photinia $13 \%$.

Phragmidiothrix 4.

Phragmidium 45.

Phragmites 82.

Phryma 197.

Phrymaceae $19 \%$.

Phrymineae 197.

Phrynium 102.

Phycochromaceae 5, 40.

Phycomyces 25.

Phycomycetes 25.

Phycopeltis 12.

Phylica 156.

Phyllachora 34.
Phyllactinia 33.

Phyllanthus 149.

Phyllis 199.

Phyllitis 16.

Phyllocladus 73.

Phyllodoce 176.

Phylloglossum 68.

Phyllophora 21.

Phylloporinaceae 42.

Phyllosiphon 14.

Phyllosiphonaceae 14.

Phyllostachys 83.

Phyllosticta 36.

Phyllotheca 67.

Physalis 191.

Physaraceae 1.

Physaraceae 2.

Physarum 2.

Physcia 41.

Physciaceae 31, 41.

Physcomitrella 58.

Physcomitrium 58.

Physma 40.

Physocarpus 136.

Physoderma 27.

Physostegia 189.

Physostigma 142.

Phytelephas $8 \%$.

Phyteuma 201.

Phytocrene 153.

Phytolacca 120.

Phytolaccaceae 120.

Phytolaccineae 119.

Phytophtora 27.

Phytosarcodina 1.

Picea 73.

Picramnia 147.

Picrasma 147.

Picris 206.

Pilacraceae 46.

Pilacre 46.

Pilea 111.

l'ilobolus 26.

Pilocarpaceae 39.

Pilocarpus 146.

Pilostyles 116.

Pilotrichum 60.

Pilularia 66.

Pimelea 168.

Pimenta 170.

Pimpinella 173.

Pinaceae 73.

J'inellia 90.

Pinguicula 195.

Pinnularia 10.

Pinus 73.

Piper 107.

Piperaceae $10 \%$.
Piperales 107.

Piptocephalidaceae 26.

Piptocephalis 26.

Pirola 175.

Pirolaceae 175.

Pirus 137.

Pisolithus 50.

Pisonia 120.

Pistacia 152.

l'istia 90.

Pisum 142.

Pitcairnia 93.

Pithecolobium 139.

Pittosporaceae 135.

Pittosporum 135.

Placodium 41.

Placographa 31.

Plagiochila 53.

Plagiothecium 61 .

Planococeus 5.

Planosarcina 5.

Plantaginaceae 197.

Plantaginales 197 .

Plantago 197.

Plasmodiophora 1.

Plasmodiophoraceae 1.

Plasmodiophorales 1.

Plasmopara 28.

Platanaceae 136.

P'latanthera 104.

Platanus 136.

Platonia 162.

I'latycerium 65.

Platycodon 201.

l'latygrapha 31.

Platygyrium 61 .

Plectascineae 32.

Plectocomia 86.

Plectranthus 190.

Pleiocarpa 183.

Pleospora 35.

Pleosporaceae 35.

Pleuricospora 176.

Pleuridium 56.

Pleurocarpi 60.

Pleurocladia 16.

Pleurococcaceae 11, 38, 39.

Pleurococcus 11, 39, 41, 42.

Pleurosigma 10.

Pleurothallis 105.

Pleurotheliaceae 42.

Pleurozia 54.

Plocama 199.

Plocamium 22.

Plumaria 23.
Plumbaginaceae 178.

Plumbago 178.

Poa 82.

Podalyria 140.

Podocarpus 72.

Podophyllum 124.

Podostemonaceae 133.

Podostemonineae 133.

Pogonatum 59.

Pogostemon 190.

Poinciana 140.

Polanisia 129.

Polemoniaceae 185.

Polemonium 186.

Polianthes 99.

Polyalthia 126.

Polyblastia 41.

Polybotrya 6:3, 65 .

Polycarpon 122.

Polyenemum 118.

Polygala 148.

Polygalaceae 148.

Polygalineae 148.

Polygonaceae 117.

Polygonales 116.

Polygonatum 97 .

Polygonum 117.

Polyides 24.

Polyphagus $2 \%$.

Polypodiaceae 63.

l'olypodium 65 .

Polypogon 82.

Polyporaceae 47 .

Polyporus 47 .

P'olyrrhiza 106.

Polysiphonia 23.

Polystichum 63 .

Polystictus 47 .

Polystigma 34 .

Polytrichaceae 59.

Polytrichum 59.

Pontederia 93.

Pontederiaceae 93.

Pontederiineae 93.

l'opulus 108.

Porana 185.

Poranthera 150.

Poria 47

Jorlieria 144.

Porocyphus 40.

Poronia 35.

Porphyra 19.

Portulaca 121.

Portulacaceae 121.

Portulacineae 121.

Posidonia 78.

Potamogeton 78. 
Potamogetonacea $\theta$ 77.

Potamogetonineae r7.

Potentilla 137.

Pottia 57.

Pottiaceae 57.

Pothos 88.

Prangos 173.

Prasiola 12.

Prasium 188.

Pratia 202.

Preissia 52.

Prenanthes 206.

Preslia 190.

Primula 178.

Primulaceae 178.

Primulales 177.

Principes 84.

Pringlea 130.

Prionium 94.

Prionolobus 54.

Pritchardia 85.

I'rockia 164.

Prorocentraceae 8.

Prorocentrum 8.

Proserpinaca 171.

Prosopanche 116.

Prosopis 139.

Prostanthera 188.

Protea 112.

Proteaceae 112.

Proteales 112.

Protium 147.

Protoascineae 29.

Protobasidiomycetes 44.

Protocalamariaceae 67.

Protocaliciaceae 31 , 38.

Protocaliciineae 31.

I'rotococcaceae 12, $38,40,41$.

Protococcales 11.

Protodiscineae 29.

Protomastigales 7 .

Protomyces 28.

Protomycetaceae 28.

Protopitys 69.

Protopteris 62.

Protospongia 7 .

Protoxylon 69.

Prunus 138.

Psalliota 48.

Psaronius 66.

Pseuderanthemum 196.
Pseudolarix 78. Pseudoleskea 61. Pseudomonas 4 . Pseudopeziza 30. Pseudotsuga 74.

Psidium 170.

Psilocybe 48 .

Psilotaceae 68.

Psilotineae 68.

Psilotum 68.

Psittacanthus 114.

Psora 39.

Psoraceae 39.

Psoralea 141.

Psoromataceae 40.

Psorotrichia 40 .

Psychotria 198.

Ptaeroxylon $14 \%$.

P'telea 146.

Pteranthus 122.

Pteridium 64.

Pteridophyta 61.

Pterigynandrum 61.

Pteris 64.

Pterisanthes 156.

I'terocarpus 142.

Pterocarya 108.

Pterogoniaceae 61 .

Pterogonium 61.

Pterophyllum 71.

Pterostegia $11 \%$.

l'terostemon 134.

Pterygoneurum 57.

Pterygophyllum 60.

Ptilidium 54.

P'tilota 23.

Ptychodiscus 8.

Ptychomitrium 58 .

Ptychosperma 86.

I'uccinia 45.

Pucciniaceae 45.

I'ulicaria 203.

Pulmonaria 187.

Pulsatilla 124.

Pultenaea 140.

Punica 169.

Punicaceae 168.

Punctaria 16.

l'uya 93.

Pycnochytrium 26.

Pylaisia 61.

Pylayella 16.

Pyramidula 58.

Pyrenidiaceae 42 .

Pyrenidium 42.

I'yrenocarpineae 36 , 41.

Pyrenomycetineae 33.

Pyrenopsidaceae 40 .
Pyrenothamnia 42. Pyrenothamniaceae 42.

Pyrenula 42.

Pyrenulaceae 42.

Pyrocystis 8.

Pyronema 30.

Pyronemataceae 30.

Pyrophacus 8.

Pythiaceae $2 \%$.

Pythium 2\%.

\section{(.)}

Quamoclit 185.

Quassia 147.

Quercus 109.

Quiina 160.

Quiinaceae 160 .

Quillaja 136.

Quisqualis 170.

\section{IR.}

Radiola 143.

Radula 54.

Rafflesia 116.

Rafflesiaceae 116.

Ralfsia 16.

Ramalina 41 .

Ramondia 194.

Ranales 122.

Randia 198.

Ranunculaceae 123.

Ranunculineae 12:3.

Ranunculus 124.

Raoulia 203.

Rapanea 178.

Rapatea 92.

Rapateaceae 92.

Raphanus 130.

Raphia 85.

Raphidomonas 8 .

Rauwolfia 183.

Ravenala 111.

Reaumuria 162.

Reboulia 52.

Remija 198.

Reseda 131.

Resedaceae 131.

Resedineae 131.

Restio 91.

Restionaceae 91.

Reticulariaceae 2.

Rhacomitrium 58.

Rhacopteris 62.

Rhagadiolus 206.

Rhamnaceae $\mathbf{1 5 5}$.

Rhamnales 155 .

Rhamnus 156.
Rhaphidomonas 7 .

Rhaphidophora 88 .

Rhapis 85.

Rhazya 183.

Rheedia 161.

Rhenanthera 106.

Rheum 117.

Rhinanthus 193.

Rhipidonema 42.

Rhipidopsis 72.

Rhipidopteris 65 .

Rhipsalis 167.

Rhizidiaceae 27 .

Rhizina 29.

Rhizinaceae 29.

Rhizobiun 4.

Rhizocarpon 39.

Rhizogonium 59.

Rhizomastigaceae 7 .

Rhizomopterides 62 .

Rhizomorpha 49.

Rhizophidium 27

Rhizophyllidaceae 24.

Rhizophora 169.

Rhizophoraceae 169.

Rhizopogon 49.

Rhizosolenia 9.

Rhodea 97.

Rhodobacteriaceae j.

Rhodochaetaceae 19.

Rhododendron 176.

Rhodomela 23.

Rhodomelaceae 22.

Rhodophyceae 18.

Rhodophyllidaceae 21.

Rhodophyllis 21 .

Rhodothamnus 176 .

Rhodotypus 137.

Rhodymenia 22.

Rhodymeniaceae 22.

Rhodymeniales 21.

Rhoeadales 128.

Rhoeadineae 128.

Rhopalocnemis 115.

Rhopographus 34 .

Rhus 152.

Rhynchosia 142.

Rhynchospora 84.

Rhytisma 31.

Ribes 134.

Ricasolia 40.

Riccardia 53.

Riccia 51.

Ricciaceae 51.

Ricciocarpus 51 .

Richardsonia 199. 
Ricinocarpus 150. Ricinus 150.

Riella 5:3.

Rinorea 164.

Rivina 120.

Rivularia 6, 40.

Rivulariaceae 6 .

Robinia" 141.

Roccella 31, 39.

Roccellaceae 39.

Roemeria 128.

Roestelia 45.

Roettlera 194.

Romanzoffia 186.

Romulea 100.

Roridula 132.

Rosa 137 .

Rosaceae 136.

Rosales 132.

Rosellinia' 34 .

Rosineae 136.

Rosmarinus 188.

Rotulaceae 39.

Roupala 112.

Rourea 138.

Roydsia 129.

Royena 179 .

Rubia 199.

Rubiaceae 197.

Rubiales 197.

Rubus 137 .

Rudbeckia 204.

Ruellia 196.

Rumex 117.

Ruppia 78.

Rusbyanthus 182.

Ruscus 797.

Russula 48.

Russulina 48.

Russuliopsis 49 .

Ruta 145.

Rutaceae 145.

Rytiphloea 23.

\section{s.}

Sabadilla 94.

Sabal 84.

Sabia 155.

Sabiaeeae 155.

Sabiineae 15\%.

Saccharomyces 28.

Saccharomycetaceae 28.

Saccharum 81.

Saccolabium 106.

Sachria 37.

Sagittaria 73.

Sagina 121.

Saintpalia 194.

Salacia 153.
Salicaceae 108.

Salicales $10 \%$.

Salicornia 118.

Salix 108.

Salpiglossis 191.

Salsola 119.

Salvadora 181.

Salvadoraceae 181 .

Salvadorineae 181 .

Salvia 189.

Salvinia 66.

Salviniaceae 66 .

Sambucus 199.

Samolus 178 .

Sanicula 172.

Sanguinaria 128.

Sanguisorba $13 \%$.

Sanseviera 97.

Santalaceae 113.

Santalales 112.

Santalineae 113.

Santalum 113.

Santolina 204.

Sapindaceae 154 .

Sapindales 151.

Sapindineae 153.

Sapindus 154.

Sapium 150.

Saponaria 122.

Sapotaceae 179.

Sapotineae 179.

Saprolegnia 27.

Saprolegniaceae 27.

Saprolegniineae $2 \%$.

Sarcanthus 106.

Sarcina 5 .

Sarcinomyees 37.

Sarcobatus 119.

Sarcocaulon 143.

Sarcogyna 53.

Sarcophyte 115.

Sarcoscypha 30.

Sarcoscyphus 53.

Sarcostemma 184.

Sargassum 18.

Sarracenia 132.

Sarraceniaceae 132.

Sarraceniales 132.

Sassafras 128.

Satureja 190.

Satyrium 104.

Sauromatum 90.

Saururaceae 107.

Saururus 107.

Saussurea 205.

Sauteria 52.

Sauvagesia 160 .

Saxifraga 134.

Saxifragaceae 133.

Saxifragineae 133.
Scabiosa 200.

Scaevola 202.

Scandix 173.

Scapania 54.

Sceletonema 9.

Scenedesmus 12.

Schefflera 172.

Scheuchzeria 78.

Schinopsis 152.

Schinus 152.

Schismatoglottis 89 .

Schistidium 58 .

Schistostega 58.

Schistostegaceae 58 .

Schizaea 6.̃.

Schizaeaceae 65.

Schizandra 126.

Schizanthus 192.

Schizocodon $17 \%$.

Schizomycetes 1,3 .

Schizonema 10

Schizoneura 67.

Schizophyceae 5, 38, $39,41$.

Schizophyllum 48.

Schizophyta 3.

Schizosaccharomyces 28.

Schizosporaceae 44.

Schizostylis 100 .

Schizymenia 24.

Schleichera 154.

Schoenus 84.

Schoepfia 113.

Sciadopitys 74 .

Sciaphila 80.

Scinaia 21.

Scindapsus 88 .

Scilla 96.

Scirpus 84.

Scitamineae 101.

Scleranthus 122.

Scleria 84.

Scleroderma 50.

Sclerodermataceae 50.

sclerodermatineae 50.

Sclerolobium 140.

Sclerotinia 30.

Sclerotium 34, 47.

Scolecopteris 66.

Scolopendrium 64.

Scolymus 206.

Scopolia 191.

Scorzonera 206.

Scrophularia 192.

Scrophulariaceae 192.

Scouleria 58.
Scutellaria 188.

Scybalium 11 .

Scytanthus 116.

Scytonema 6, 42.

Scytonemataceae 5.

Scytopetalaceae 159.

Scytopetalineae 159.

Scytosiphon 16.

Secale 83.

Secamone 184.

Sechium 201.

Secoliga 39.

Securidaca 149 .

Seddera 185.

Sedum 133.

Seguieria 120.

Selaginella 68 .

Selaginellaceae 68 .

Selaginellineae 68 .

Seligeria 56.

Selliera 202.

Semecarpus 152 .

Semele 97.

Sempervivum 133.

Senecio 205.

Senftenbergia 65 .

Septogloeum 36.

Septoria 36.

Sequoia 74.

Serapias 104.

Serjania 154.

Serissa 199.

Serpicula 171.

Serpula 47.

Serratula 205.

Sesamum 193.

Seseli 174.

Sesleria 82.

Sesuvium 121.

Setaria 81.

Shepherdia 168.

Sherardia 199.

Shorea 162.

Shortia 177.

Sibthorpia 192.

Sickingia 198.

Sicyos 201.

Sida 158.

Sideritis 189 .

Sideroxylon 179.

Siegesbeckia 204.

Sigillaria 69 .

Sigillariaceae 69 .

Silene 122.

Siler 174.

Silphium 204.

Silybum 205.

Simaba 147.

Simaruba 147.

Simarubaceae 146. 
Sinapis 130 .

Siparuna 127.

Siphycampylus 202.

Siphoneae 13.

Siphulastracene 40.

Sirobasidiaceae 46 .

Sirobasidium 46.

Sirasiphonaceae 6.

Sistrotema 47.

Sisymbrium 130 .

Sisyrinchium 100 .

Sium 174 .

Skimmia 146 .

Sloanea 157.

Smilacina 97.

Smilax 98.

Smithiantha 195

Smyrnium 17:3.

Sobralia 105.

Solanaceae 191.

Solanineae 190.

Solanum 191.

Soldanella 178.

Solenophora 195.

Solidago 202.

Solorina 40.

Sonchus 206.

Sonerila 171 .

Sonneratia 168 .

Sonneratiaceae 168 .

Sophora 140.

Sopubia 193.

Sordaria 34.

Sordariaceae 34.

Soymida 148 .

Sparassis 47.

Sparaxis 100.

Sparganium 77.

Sparganiaceae 77 .

Spartium 141.

Spartina 82.

Spathelia 146.

Spathicarpa 90.

Spathiflorae 87 .

Spathiphyllum 88.

Specularia 201.

Spergula 121.

Spergularia 121.

Sphacelaria 16.

Sphacelarieae 16.

Sphacele 189.

Sphrocelia 34.

Sphaerella 11.

Sphaeriaceae 34 .

Sphaeriaceales 34 , $36,41$.

Sphaerioideaceae 36.

Sphaerobolaceae 50.

Sphaerobolus 50.

Sphaerocarpus 53.
Sphaerococcaceae22. Stelis 105.

Sphaerococcus 22.

Sphaerophoraceate 39.

Sphaerophorus 39.

Sphaeroplea 13.

Sphareopleaceae 13.

Sphaeropsidales 36 .

Sphaeropsis 36.

Sphaerotheca 33.

Sphaerotilus 5.

Sphagnaceae 55.

Sphagnales 55.

Sphagnum 55.

Sphenoclea 202.

Sphenophyllaceae 67.

Sphenophyllales 67 .

Sphenophyllum 67 .

Sphenopterides 62.

Sphenopteris 62.

Sphinetrina 38.

Sphyridium 39.

Spigelia 181.

Spilanthes 204.

Spinacia 118.

Spinifex 81.

Spiraea 136.

Spiranthes 104 .

Spirillaceae 4.

Spirillum 4.

Spirochaete 4 .

Spirodela 91 .

Spirogyra 10.

Spirosoma 5 .

Spirulina 5.

Splachnaceae 58.

Splachnum 58.

Spondias 152.

Sporobolus 82 .

Sporodinia 25.

Sporormia 34.

Sporotrichum 37.

Spumaria 2.

Spumariaceae 1, 2.

Squamaria 24.

Squamariaceae 24 .

Stachys 189.

Stachyuraceae 164.

Stachyurus 164 .

Stackhousiaceae 153 .

Stangeria 71 .

Stanhopea 10.)

Stapelia 184

Staphylea 153.

Staphyleaceae 153.

Statice 178.

Staurastrum 10.

Staurostigma 90.

Stegnosperma 120.
Stellaria 121.

Stemonaceae 94.

Stemonitaceae 2.

Stemonitis 2.

Stenomeris 100 .

Stenophragma 131.

Stephanina 54.

Stephanospermum 72.

Stephanosphaera 11.

Stephanotis 184.

Sterculia 159.

Sterculiaceae 158 .

Stereum 47.

Stereocaulon 41 .

Stereocaulaceae 41 .

Sternbergia 98.

Steudnera 89.

Sticta 40.

Stictaceae 40 .

Stictidaceae 31, 39.

Stictis 31.

Stigeoclonium 12.

Stigmaria 69.

Stigmatea 35.

Stigmatomyces 43 .

Stigonema 6.

Stigonemataceae 6 .

Stilbaceae 37.

Stilbe 188.

Stilbella 37 .

Stillingia 150.

Stilocalamites 67 .

Stilophor: 17.

Stipa 82.

Stratiotes 79.

Strelitzia 101.

Streptocarpus 194.

Streptococcus 5.

Streptopus 97.

Striaria 16.

Striga 19:3.

Strigula 42.

Strigulaceae 42.

Strobilanthes 196.

Strophanthus 183.

Struthanthus 114.

Struthiopteris 63.

Strychnos 181.

Stylidiaceae 202.

Stylocalamites 67 .

Stylochiton 90.

Stylosanthes 142.

Styphelia $17 \%$.

Styracaceae 180.

Styrax 180.

Suaeda 119.

Subularia 130.

Succisa 200.
Suriana 146.

Surirella 10 .

Swartzia 140 .

Swertia 182.

Swietenia 148.

Sympetalae 175.

Symphonia 162.

Symphorema 188.

symphoricarpus 199.

Symphytum 187.

Symplocaceae 180.

Symplocarpus 88 .

Symplocos 180.

Synalissa 40 .

Synanthae 87 .

Synchytriaceae 26.

Synchytrium 26 .

Synedra 10 .

Syngonanthus 92 .

Syngonium 90.

Synura 7.

Syringa 180.

Syrrhopodon 57 .

T.

Tabellaria 10 .

Tabernaemontana 183.

Tacca 99.

Taccaceae 99.

Taccarum 90.

Taenitis 64 .

Taeniopteris 62 .

Tagetes 204.

Tamaricineae 162.

Tamaricaceate 162.

Tamarindus 140 .

Tamarix 162.

Tanıus 100.

Tanghinia 183.

Taphria 29.

Taraxacum 206.

Tarchonanthus 203.

Targionia 52.

Taxaceae 72.

Taxodium 74 .

Taxus 73.

Tayloria 58 .

Tecoma 193.

Tectona 188.

Teesdalea 130 .

Telfairia 200.

Thephrosia 141 .

Terfezia 33 .

Terfeziaceae 33.

Terminalia 170 .

Ternstroemiaceae 160.

Tesselina 51.

'Testudinaria 100. 
Tetradiclis 144.

Tetragastris 147 .

Tetragonia 121.

Tetramitaceae 7.

Tetramitus 7.

Tetrapanax 172.

Tetrophis 60.

Tetraspora 11.

Tetrasporaceae 11.

Teucrium 188.

Thalassia 80 .

Thalictrum 124.

Thalia 102.

Thallophyta 3.

Thamnidium 25.

Thamnium 61 .

Thamnolia 42.

Thamnoliaceae 42 .

Thapsia 174.

Thea 161.

Theaceae "160.

Theineae 159.

Thelidium 41.

Thelephora $4 \%$.

Thelephoraceae 42, 47.

Theloschistaceae 41 .

Theloschistes 41 .

Thelotremataceae 39.

Theobroma 159.

Theophrasta 177 .

Theophrastaceae 177.

Thermopsis 140 .

Thesium 113.

Thevetia 183.

Thibaudia $17 \%$.

Thinnfeldia 62 .

Thiobacteria 5 .

Thiothrix 5.

Thismia 103.

Thladiantha 200 .

Thlaspi 130.

Thonningia 115 .

Thorea 20.

Thoreaceae 20.

Thuja 74.

Thuidium 61 .

Thujopsis 74 .

Thunbergia 196.

Thylophoraceae 38 .

Thymelaea 168 .

Thymelaeaceae 167 .

Thymelaeineae $16 \%$.

Thymus 190.

Thyrsopteris 63 .

Tichothecium 35.

Tigridia 100.

Tilia $15 \%$.
Tiliaceae $15 \%$.

Tillandsia 92.

Tilletia 43.

Tilletiaceae 43 .

Tilletiineae 43 .

Tilopteridaceae 17.

Timmiaceae 59.

Tmesipteris 68 .

Toddalia 146.

Todea 65.

Tofieldia 94.

Tolmiea 134.

Tolypella 15 .

Tolypothrix 6 .

Tomentella 47 .

Tonina 92.

Toninia 39.

Toona 147.

Tordylium 174.

Torenia 192.

Torilis 173 .

Tornabenia 41.

Torreya 73.

Tortella 57.

Tortula $5 \%$.

Torula 5, 37 .

Tournefortia 186.

Tovaria 131.

Tovariaceae 131.

Tozzia 193.

Trachelomonas 8

Trachycarpus 85 .

Trachylobium 139.

Trachyphrynium 102

Tradescantia 93.

Traganum 119.

Tragia 150.

Tragopogon 206.

Tragus 81.

Trametes 48 .

Trapa 171.

Treculia 110.

Tremandraceae 148 .

Trematodon 56.

Trematosphaeria 35.

Tremella 46.

Tremellaceae 46 .

Tremellineae 46 .

Tremellodon 46.

Trentepohlia 12, 38, $39,42$.

Tribulus 144.

Triceratium 9.

Trichanthera 196.

Trichia 2.

Trichiaceae 2.

Trichilia 148.

Trichocolea 54.

Trichocoma 33.

Trichocomaceae 33. Tylostomataceae 50.

Trifolium 141.
Trichocladus 136.

Trichodon 56 .

Txichomanes 63 .

Trichopilia 106.

Trichosanthes 201 .

Trichosphaeria 34.

Trichosporium 37.

Trichosporum 194.

Trichostomum $5 \%$.

Trichothamnion 23.

Tricoccae 149.

Trientalis 178 .

Triglochin 78.

Trigonella 141.

Trigoniaceae 148.

Trillium 97.

Trimastigaceae $\%$.

Triphasia 146.

Triplaris $11 \%$.

Trisetum 82.

Triticum 83.

Tritonia 100.

Triumfetta $15 \%$.

Triuridaceae 80 .

Triuridales 80 .

Triuris 80 .

Trochodendraceae 123.

Trochodendrineae $12: 3$.

Trochodendron 123.

Trollius 124.

Tropaeolaceae 143.

Tropaeolum 143.

Tryblidiaceae 31 .

Trypetheliaceae 42 .

Trypethelium 42.

Tsuga 73.

Tuber 32, 33.

Tubercularia 37 .

Tuberculariaceae $3 \%$.

Tuberineae 32.

Tuberithallosae 66.

Tubiflorae 184.

Tulasnella 46 .

Tulasnellaceae 46 .

Tulasnellineae 46 .

Tnlipa 96.

Tumboa 71, 75.

Tunica 122

Tuomeya 20.

Turgenia 173.

Turritis 131.

Turnera 164.

Turneraceae 164 .

Tussilago 205.

Tylophoraceae 38.

Tylostoma 50.

Typha $7 \%$

Typhaceae 77.

Typhula 47.

U.

Ulex 141

Ulmaceae 109.

Ulmaria 137.

Ulmus 110.

Ulocolla 46.

Ulota 58.

Ulothrix 12.

Ulotrichaceae 12.

Ulva 12.

Ulvaceae 12.

Umbelliferae 172.

Umbelliflorae 171 .

Umbilicaria 40 .

Uncaria 198.

Uncinia 84.

Uncinula 33.

Ungnadia 15 อ̆.

Unona 126.

Uragoga 198.

Uredinaceales 44 .

Urena 158.

Urginea 96.

Urocystis 43.

Uroglena 8.

Uromyces 45.

Urophlyctis 27.

Urtica 111.

Urticaceae 111.

Urticales 109.

Usnea 41.

Ustilaginaceae 43 .

Ustilagineae 43 .

Ustilago 43.

Ustulina 35.

Utricularia 195.

Uvaria 126.

Uvularia 94.

\section{v.}

Vaccinium $17 \%$

Vacuolaria 7.

Valeriana 200.

Valerianaceae 199.

Valerianella 200.

Vallisneria 80.

Vallota 98.

Valonia 14.

Valoniaceae 14.

Valsa 35.

Valsaceae 35.

Vanda 106.

Vangueria 198.

Vanilla 104.

Vateria 162. 
Vatica 162.

Vaucheria 14.

Vaucheriaceae 14.

Vella 130.

Vellozia 99.

Velloziaceae 99.

Venidium 205.

Ventilago 155.

Venturia 35.

Veratrum 94.

Verbascum 192.

Verbena 187.

Verbenaceae $18 \%$.

Verbenineae $18 \%$.

Vernonia 203.

Veronica 192.

Verpa 29.

Verrucaria 41.

Verrucariaceae 41.

Verticillatie 106.

Verticillium 37.

Vibrio 4.

Viburnum 199.

Vicia 142.

Victoria 123.

Vigna 142.

Villaresia 153.

Vinca 183.

Vincetoxicum 184.

Viola 164.
Violaceae 163.

Viscaria 122.

Viscum 115.

Vismia 161.

Visnea 161.

Vitaceae 156.

Vitellaria 179.

Vitex 188.

Vitis 156.

Vittaria 64.

Voandzeia 142.

Vochysiaceae 148.

Voitia 58.

Voltzia 74.

Volvocaceae 11.

Volvox 11.

Voyria 182.

Vriesea 93.

\section{W.}

Wahlenbergia 201.

Waltheria 159 .

Washingtonia 85.

Watsonia 108.

Webera 59.

Weinmannia 135.

Welwitschia 75

Wendtia 143.

Wiesneria 79.

Wigandia 186.
Wistaria 141.

Withania 191.

Wolffia 91.

Woodsia 63.

Woodwardia 64.

Wrangelia 20.

Wulfenia 192.

\section{x.}

Xanthium 204.

Xanthoceras 155.

Xanthochymus 162.

Xanthoria 41.

Xanthorrhiza 124.

Xanthorrhoea 96.

Xanthosoma 89.

Xanthoxylum 145.

Xeranthemum 205.

Ximenia 114.

Xvlaria 35.

Xylariaceae 35.

Xylocarpus 148 .

Xylographa 39.

Xylographaceae 31, 39.

Xylopia 126.

Xylosma 164.

Xyridaceae 92 .

Xyris 92.
Yucea 97.

z.

Zamia 71.

Zamiopsis 62 .

Zamioculeas 88.

Zamites 71.

Zanardinia 17.

Zannichellia 78.

Zantedeschia 89.

Zeal 81.

Zephyranthes 98.

Zingiber 102.

Zingiberaceae 101.

Zinnia 204.

Zizania 81.

Ziziphora 190.

Zizyphus 156.

Zomicarpa 90.

Zostera 78.

Zygadenus 94.

Zygnema 11.

Zygnemataceae 10 .

Zygogonium 10.

Zygomycetes 25.

Zygopetalum 105.

Zygophyceae 8.

Zygophyllaceae 144 .

Zygophyllum 144. 





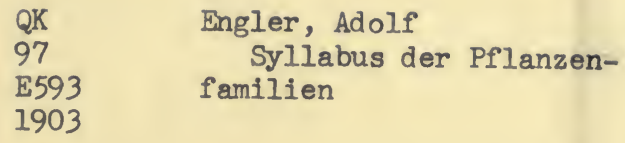

Biological

\& Medical

PLEASE DO NOT REMOVE CARDS OR SLIPS FROM THIS POCKET 
